Florida International University FIU Digital Commons

6-21-2012

\title{
A Comprehensive Study of Bankruptcy Prediction: Accounting Ratios, Market Variables, and Microstructure
}

Giovanni Fernandez

Florida International University, gfern001@fiu.edu

DOI: $10.25148 /$ etd.FI12080805

Follow this and additional works at: https://digitalcommons.fiu.edu/etd

\section{Recommended Citation}

Fernandez, Giovanni, "A Comprehensive Study of Bankruptcy Prediction: Accounting Ratios, Market Variables, and Microstructure" (2012). FIU Electronic Theses and Dissertations. 712.

https://digitalcommons.fiu.edu/etd/712 


\title{
FLORIDA INTERNATIONAL UNIVERSITY
}

Miami, Florida

\section{A COMPREHENSIVE STUDY OF BANKRUPTCY PREDICTION: ACCOUNTING RATIOS, MARKET VARIABLES, AND MICROSTRUCTURE}

\author{
A dissertation submitted in partial fulfillment of the \\ requirements for the degree of \\ DOCTOR OF PHILOSOPHY \\ in \\ BUSINESS ADMINISTRATION \\ by
}

Giovanni Fernandez

2012 
To: Dean Joyce Elam

College of Business Administration

This dissertation, written by Giovanni Fernandez, and entitled A Comprehensive Study of Bankruptcy Prediction: Accounting Ratios, Market Variables, and Microstructure, having been approved in respect to style and intellectual content, is referred to you for judgment.

We have read this dissertation and recommend that it be approved.

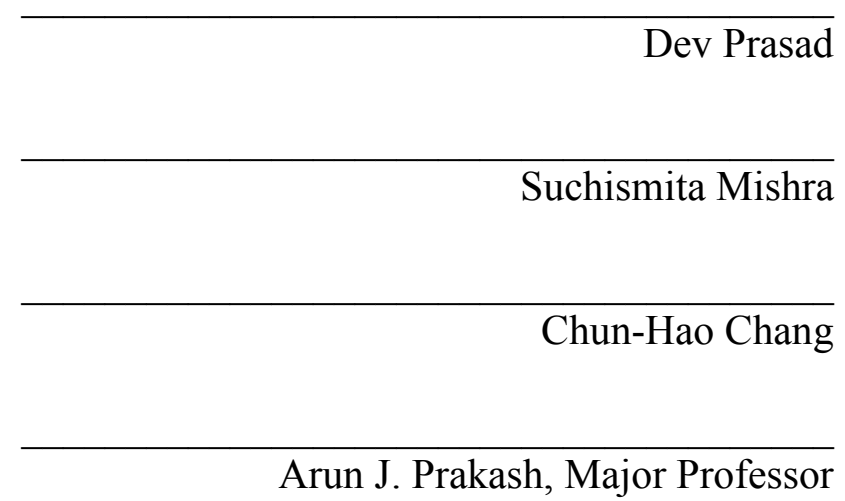

Date of Defense: June 21, 2012

The dissertation of Giovanni Fernandez is approved.

Dean Joyce Elam

College of Business Administration

Dean Lakshmi N. Reddi

University Graduate School

Florida International University, 2012 
(C) Copyright 2012 by Giovanni Fernandez

All rights reserved. 


\section{ACKNOWLEDGMENTS}

First and foremost, I would like to thank Dr. Arun J. Prakash, my major professor for his assistance, guidance, support, and direction. Without his kind support and encouragement, this dissertation would not have been possible.

I am grateful to my doctoral committee members, Dr. Chun-Hao Chang, Dr. Suchismita Mishra, and Dr. Dev Prasad for their support and guidance. I am also grateful to the faculty and staff of the Department of Finance and Real Estate for their support and encouragement throughout my Ph.D. studies.

Last, but not least, I wish to acknowledge my family and friends for all their support, patience, understanding, and love. I am very grateful to my parents, who shared with me the pains and pleasures of my doctoral studies at Florida International University. Without their support, I would have never taken the leap needed to begin and persevere through my doctoral studies. I am also forever thankful to my classmates/friends, who took this journey with me. Without each other, we would not have made it this far. 
ABSTRACT OF THE DISSERTATION

A COMPREHENSIVE STUDY OF BANKRUPTCY PREDICTION: ACCOUNTING

RATIOS, MARKET VARIABLES, AND MICROSTRUCTURE

by

Giovanni Fernandez

Florida International University, 2012

Miami, Florida

Professor Arun J. Prakash, Major Professor

Bankruptcy prediction has been a fruitful area of research. Univariate analysis and discriminant analysis were the first methodologies used. While they perform relatively well at correctly classifying bankrupt and nonbankrupt firms, their predictive ability has come into question over time. Univariate analysis lacks the big picture that financial distress entails. Multivariate discriminant analysis requires stringent assumptions that are violated when dealing with accounting ratios and market variables. This has led to the use of more complex models such as neural networks.

While the accuracy of the predictions has improved with the use of more technical models, there is still an important point missing. Accounting ratios are the usual discriminating variables used in bankruptcy prediction. However, accounting ratios are backward-looking variables. At best, they are a current snapshot of the firm. Market variables are forward-looking variables. They are determined by discounting future outcomes. Microstructure variables, such as the bid-ask spread, also contain important information. Insiders are privy to more information that the retail investor, so if any financial distress is looming, the insiders should know before the general public. 
Therefore, any model in bankruptcy prediction should include market and microstructure variables. This is the focus of this dissertation. The traditional models and the newer, more technical models were tested and compared to the previous literature by employing accounting ratios, market variables, and microstructure variables. Our findings suggest that the more technical models are preferable, and that a mix of accounting and market variables are best at correctly classifying and predicting bankrupt firms. Multilayer perceptron appears to be the most accurate model following the results. The set of best discriminating variables includes price, standard deviation of price, the bid-ask spread, net income to sale, working capital to total assets, and current liabilities to total assets. 


\section{TABLE OF CONTENTS}

CHAPTER

PAGE

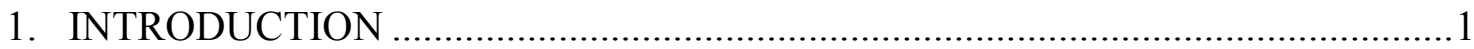

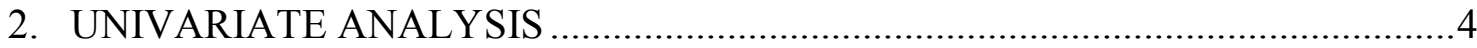

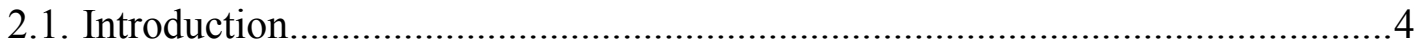

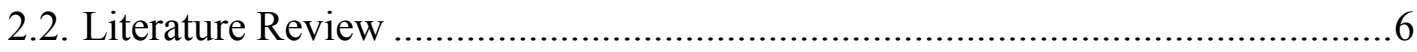

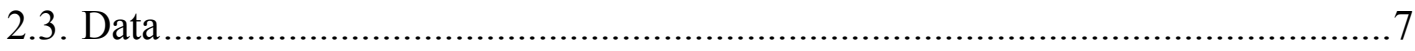

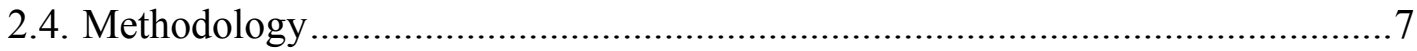

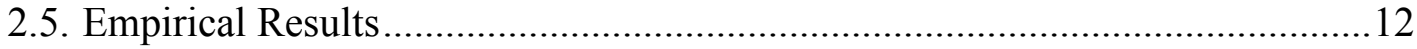

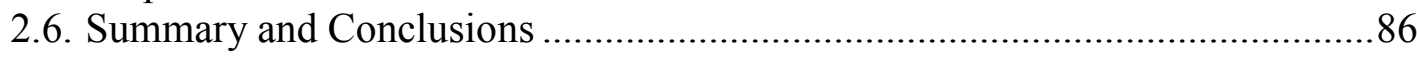

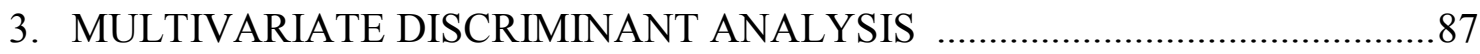

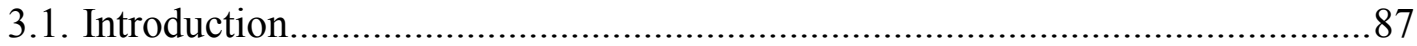

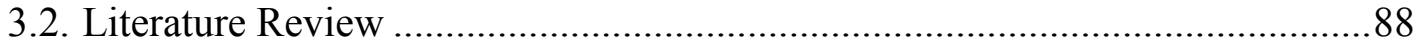

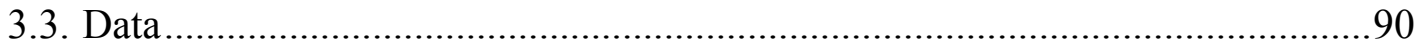

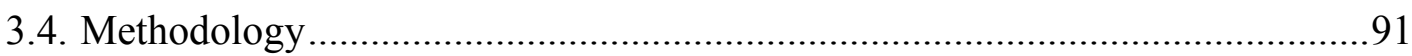

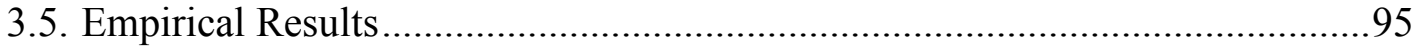

3.6. Summary and Conclusions …………………….........................................264

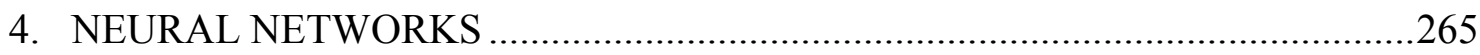

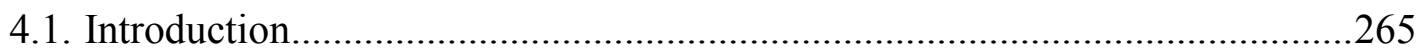

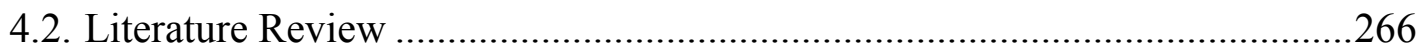

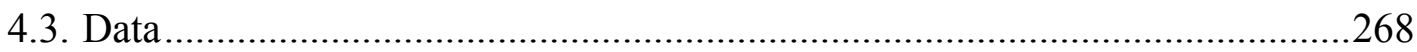

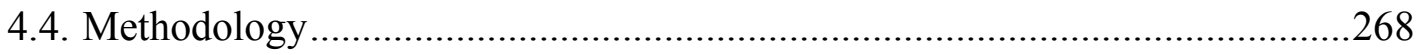

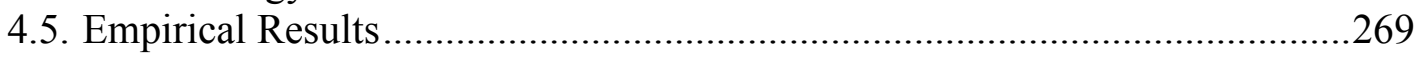

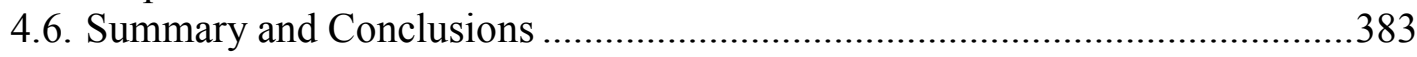

5. EVALUATION, COMPARISON OF MODELS, AND CONCLUSION ...............384

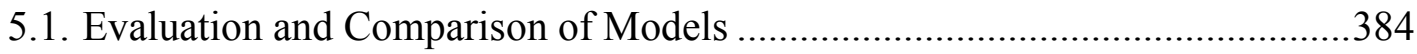

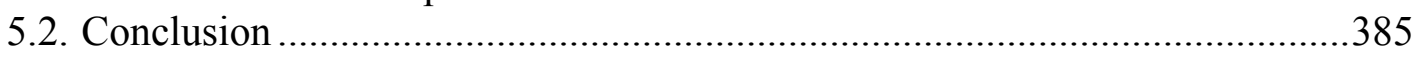

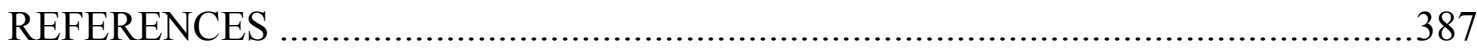

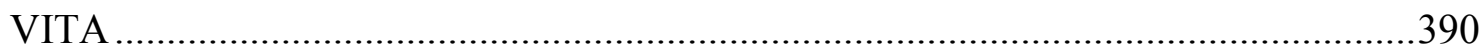




\section{LIST OF TABLES}

TABLE

PAGE

1. Summary of Accounting Ratios, Market Variables and Microstructure Variables .....8

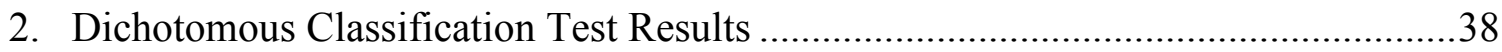

3. Contingency Table Results for Classification Tests ............................................51

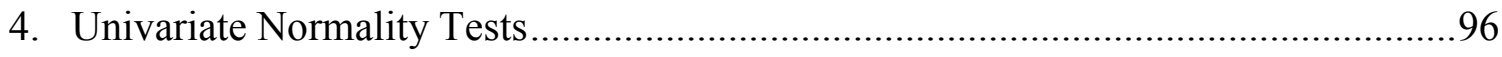

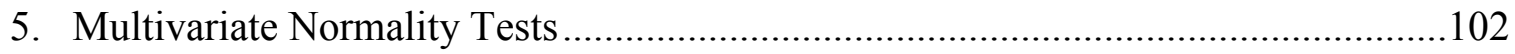

6. Results of Box's M Test for Equality of Variance-Covariance Matrix ....................107

7. Linear Multivariate Discriminant Analysis Results...........................................113

8. Quadratic Multivariate Discriminant Analysis Results ......................................160

9. Nonparametric Multivariate Discriminant Analysis Results ................................207

10. Out-of-Sample Nonparametric Multivariate Discriminant Analysis Results ............246

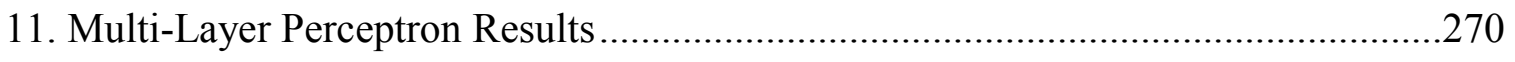

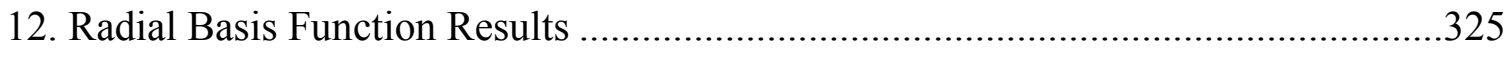

13. Out-of-Sample Multi-Layer Perceptron Results ................................................379 


\section{CHAPTER 1: INTRODUCTION}

Bankruptcy prediction has been extensively studied over the past five decades. Beaver (1966) and Altman's (1968) studies are the seminal works that began a plethora of research done on a very important topic. From academics to corporate directors to investors, the financial distress, and the path taken to get there, is a very important topic. While the research is rich in techniques and answers, many questions are still left unanswered. The models used and the variables selected have been a huge topic in themselves, and that is what is studied in this dissertation.

Beaver (1966) begins the conversation employing univariate analysis. Analyzing the intertemporal behavior of numerous accounting ratios, he concludes that there is a clear difference between the accounting ratios of bankrupt and nonbankrupt firms. Hence, accounting ratios have been used as the main discriminating variables in bankruptcy prediction studies since then. Following this finding, Altman (1968) employs multivariate discriminant analysis to determine which set of accounting ratios are best at discriminating between bankrupt and nonbankrupt firms. This is the famous Altman's Zscore model. The model performs well and has withstood time. However, as with many traditional, parametric models, this model has stringent underlying assumptions that have come into question over time. Prakash and Karels (1987) demonstrate that the multivariate normality assumption needed to use the linear multivariate discriminant model is violated when dealing with accounting ratios. This has led to the use of more complex models, such as neural networks, which are less limited by distributional assumptions. 
Furthermore, as stated above, most research is centered on using accounting ratios as the input or discriminatory variables in bankruptcy prediction models. While these ratios have performed well over time, there is still space for improvement. An important limitation of these ratios is the fact that these ratios are backward-looking variables. When a company publishes its' accounting numbers, it is months after these numbers were created; at best, it is a current picture of the firm. Therefore, as an input variable in a prediction model, a backward-looking or current-looking variable is not ideal. Ideally, a forward-looking variable is best suited in a predictive framework. This has led to the use of market variables.

Market variables are theoretically good predictors. For example, the price of a company's stock is not only reflective of the current situation of the firm, but also on its' future potential cash flows and risks. While the accuracy of this price may not be exact, over time, the markets' sentiment (mixed with insiders and retail investors) is correct. Forward-looking variables, such as price and volume, should provide better predictive power.

Furthermore, microstructure is a growing field. The behavior of insiders and information only found on the trading floor has been shown to contain information not found in other variables. Since insiders are privy to more information than the general public, they are more educated about the current and future prospects of their firm. If a firm is in financial distress or is headed in that direction, insiders should be able to see it coming before the market. Consequently, any bankruptcy prediction model should be improved by the inclusion of microstructure variables. 
This dissertation is a comprehensive study that tries to answer all of the above mentioned questions. Different models are used in testing the classification accuracy as well as the predictive ability of the models. Accounting ratios, market variables and microstructure variables are used each by themselves and in conjunction with each other to test whether each model is can be improved than previously found in the research.

In chapter 2, we study the univariate time-series behavior of each of the variables prior to bankruptcy and see which variables change significantly prior to bankruptcy. Discriminant analysis will is employed in chapter 3. Chapter 4 focuses on neural networks. We evaluate, compare the models, and conclude with chapter 5. 


\section{CHAPTER 2: UNIVARIATE ANALYSIS}

\subsection{Introduction}

While the behavior of individual accounting ratios prior to bankruptcy [Beaver (1966)] and the multivariate time-series of accounting ratios [Gonedes(1973)] have been studied, a comprehensive examination of the behavior of accounting, market, and microstructure variables prior to bankruptcy has not been done. It has been demonstrated throughout the literature that accounting ratios and market variables have predictive power; however, some important aspects have been neglected. First, the intertemporal behavior of market variables has been a very fruitful area of research. From volume to price levels, the time-series patterns are well documented. However, the behavior of those variables specifically for future bankrupt firms has not been studied. Second, microstructure variables have not been fully implemented in terms of bankruptcy. Frino, Jones, and Wong (2007) examine the behavior of stock prices on the Australian Stock Exchange leading up to bankruptcy and document significant negative abnormal returns leading up to bankruptcy along with a widening of the bid-ask spread up to 7 months before bankruptcy. To understand the predictive ability of the bid-ask spread, it is important to test whether the variable deteriorates before or after other market variables and the accounting ratios. The purpose of this chapter is to dissect each of the above mentioned components. To the best of our knowledge, this is the first study to investigate the behavior of all three types of variables: accounting ratios, market variables, and microstructure variables.

To understand why it is important to include market and microstructure variables in the analysis, we need to explain their main difference with accounting ratios. Any firm 
that is in financial distress will eventually show deteriorating accounting ratios; the ratios are basically a measure of the financial health of a firm. The issue is with the timing. Companies report their accounting numbers after the fact; the balance sheet of a company is a snapshot of the company at the time it is created. Therefore, these ratios are backward-looking, or at best, current. Market variables, such as price, are very different. In determining a stock's price, analysts use estimates of future cash flows. While the accuracy of the market variables at any time can be called into question, over the longrun they must be correct in an efficient market. This allows the stock price to be a forward-looking variable.

Hence, as predictive tools, we want to focus more on forward-looking variables than backward-looking variables. To do so, it is important to understand the behaviors of these variables, comparing those of bankrupt and non-bankrupt firms, while also comparing accounting and market variables.

The most important finding is that market and microstructure variables are best at correctly classifying bankrupt firms. Furthermore, the Type I errors for these variables are much smaller relative to Type II errors when compared to other variables in the prior literature. The best predictors are price, standard deviation, and bid-ask spread. These variables display the lowest misclassification rates.

With the accounting ratios, cash flow plays a less important role than found in previous studies. Ratios that include net income, current liabilities, and working capital perform much better than other ratios. Therefore, any multivariate bankruptcy prediction model should include price, standard deviation, bid-ask spread, along with the accounting 
ratios. That will be the starting point for the coming chapters. This should lead to more powerful and accurate models.

This study attempts to describe and distinguish these two groups. The remainder of this paper is organized as follows: Section 1.2 reviews the previous literature associated with bankruptcy univariate analysis. Section 1.3 discusses the data used in this study. Section 1.4 describes the methodology. Section 1.5 discusses the results, and Section 1.6 summarizes and concludes.

\subsection{Literature Review}

Most of the literature focuses on multivariate analysis since the deterioration of a company is multi-faceted, and one variable alone cannot describe the entire picture. However, before the entire picture is seen, the pieces must be understood.

The study of bankruptcy prediction through ratio analysis truly began through univariate analysis. Beaver (1966) set the field in a new direction. As a means of showing the usefulness of financial ratios, Beaver chooses corporate failure. He finds that while the time-series of the ratios of nonfailed firms are relatively stable, that of failed firms significantly deteriorates as bankruptcy looms.

The distributions of certain ratios overlap substantially five years before failure, but the overlap is very small a year before failure. Cash-flow to total-debt classifies failed and nonfailed firms correctly and better than random up to at least five years before failure. However, not all ratios perform as well. Most ratios are much more useful in correctly classifying nonfailed firms than they are at classifying failed firms.

Furthermore, Beaver (1968) finds that changes in stock market prices are also indicative of financial distress. 
However, Casey and Bartczak (1984) find that none of the variables studied, mostly cash flow variables, can accurately discriminate between bankrupt and nonbankrupt firms. They conclude that this method of classification is faulty because of the fact that many healthy firms go through periods of low operating cash flow.

Lin and Piesse (2001) also find that the ratios of failed and non-failed firms are significantly different. Furthermore, the market-to-book ratio, which takes into account forward-looking market prices, also is significantly different between failed and nonfailed firms. Nonetheless, the t-statistics are still highest for profitability and liquidity ratios.

Neophytou et al. (2001) also document deterioration in accounting and cash-flow variables. They find that the financial leverage ratios provide the highest classification accuracy. Profitability and cash-flow ratios also perform very well.

\subsection{Data}

The list of bankrupt firms was obtained from bankruptcydata.com. The list includes companies the filed for bankruptcy from January 1995 to December 2010. The subsample of non-bankrupt firms comes from the entire database of Compustat, consisting of firms that did not file for bankruptcy during our sample period. The accounting ratios for all firms, bankrupt and non-bankrupt, are obtained from Compustat. The market variables for these firms were obtained from CRSP.

\subsection{Methodology}

As is common in the bankruptcy prediction literature, the non-bankrupt firms are selected in such a way so that firm size does not severely affect the results. Ex-ante, successful firms are expected to be larger than failing firms. Furthermore, firm success 
rates are highly influenced by their industry. For example, when the tech bubble was growing, any firm with a dotcom in its name benefited heavily. To mitigate this issue, it

Table 1

Summary_Br_Nbr_Ratio_data Bankrupt

\begin{tabular}{|c|c|c|c|c|c|}
\hline Variable & $\mathrm{N}$ & Mean & Std Dev & Minimum & Maximum \\
\hline SHROUT & 4624 & & 86169.89 & 42 & 1571700 \\
\hline BIDLO & 4530 & 11.12 & 13.21 & -72.25 & 113.85 \\
\hline ASKHI & 4530 & 13.25 & 15.69 & -52.25 & 207.44 \\
\hline PRC & 4512 & 12.10 & 14.44 & -72.25 & 130.00 \\
\hline VOL & 4530 & 86025.86 & 260903.62 & 0.00 & 4141655.00 \\
\hline BID & 4249 & 12.65 & 13.92 & 0.03 & 130.00 \\
\hline ASK & 4249 & 12.83 & 13.95 & 0.06 & 131.00 \\
\hline SPREAD & 240 & 0.38 & 0.38 & 0.03 & 2.50 \\
\hline CEQQ & 4541 & 452.38 & 1505.16 & -2887.00 & 25789.00 \\
\hline CSHOQ & 4513 & 48.67 & 91.09 & 0.01 & 1500.14 \\
\hline TXTQ & 4573 & 6.82 & 47.83 & -770.13 & 2076.00 \\
\hline REQ & 4447 & -17.15 & 1088.36 & -13603.00 & 8450.15 \\
\hline REVTQ & 4585 & 337.19 & 1182.21 & 0.00 & 36882.00 \\
\hline NETINCOMETOSALES & 4431 & -3.10 & 52.42 & -2629.00 & 32.35 \\
\hline NETINCOMETOTOTALASSETS & 4556 & -0.05 & 0.79 & -51.10 & 1.14 \\
\hline TOTALDEBT & 4483 & 928.70 & 3242.33 & 0.00 & 44267.00 \\
\hline NETINCOMETOTOTALDEBT & 4466 & -0.46 & 19.63 & -1307.00 & 2.10 \\
\hline CURLIABTOTOTASSET & 4545 & 0.28 & 0.22 & 0.00 & 3.43 \\
\hline LTLIABTOTOTASSET & 4483 & 0.29 & 0.58 & 0.00 & 22.68 \\
\hline TOTDEBTTOTOTASSET & 4483 & 0.58 & 0.62 & 0.00 & 23.52 \\
\hline TOTDEBTPLUSPREFTOTOTASSET & 4450 & 0.60 & 0.68 & 0.00 & 23.52 \\
\hline CASHTOTOTALASSETS & 905 & 0.14 & 0.16 & 0.00 & 0.97 \\
\hline QUICKASSETS & 4504 & 313.91 & 966.05 & 0.06 & 11579.00 \\
\hline QUICKASSETSTOTOTALASSTS & 4504 & 0.36 & 0.24 & 0.01 & 1.00 \\
\hline WORKINGCAPITAL & 4543 & 88.34 & 507.56 & -4499.00 & 4907.00 \\
\hline WCTOTOTALASSETS & 4543 & 0.19 & 0.30 & -3.24 & 0.97 \\
\hline CASHTOCURLIABILITIES & 904 & 0.98 & 1.86 & 0.00 & 24.94 \\
\hline QASSETSTOCURLIABILITIES & 4503 & 2.90 & 39.98 & 0.02 & 2663.00 \\
\hline CURRENTRATIO & 4543 & 3.40 & 42.23 & 0.02 & 2828.00 \\
\hline CASHTOSALES & 878 & 1.72 & 17.96 & 0.00 & 516.90 \\
\hline INVENTORYTOSALES & 4361 & 0.90 & 12.73 & 0.00 & 650.14 \\
\hline QUICKASSETSTOSALES & 4334 & 10.63 & 224.58 & 0.05 & 13986.00 \\
\hline CURRENTASSETSTOSALES & 4374 & 12.49 & 236.64 & 0.11 & 13986.00 \\
\hline WORKINGCAPITALTOSALES & 4373 & 8.04 & 188.37 & -606.07 & 11605.00 \\
\hline TOTALASSETSTOSALES & 4403 & 19.90 & 266.90 & 0.63 & 14453.00 \\
\hline
\end{tabular}




\begin{tabular}{|c|c|c|c|c|c|}
\hline BIDASKSPREAD & 4249 & 0.18 & 0.23 & -0.81 & 3.50 \\
\hline HILOBIDASKSPREAD & 4530 & 2.13 & 6.31 & -101.13 & 153.94 \\
\hline \multicolumn{6}{|c|}{ Summary_Br_Nbr_Ratio_data Nonbankrupt } \\
\hline Variable & $\mathrm{N}$ & Mean & Std Dev & Minimum & Maximum \\
\hline SHROUT & 4250 & 113515.58 & 436934.97 & 35.00 & 6064759.00 \\
\hline BIDLO & 4226 & 18.11 & 17.65 & -25.53 & 119.86 \\
\hline ASKHI & 4226 & 20.89 & 19.91 & -34.88 & 161.39 \\
\hline PRC & 4222 & 19.43 & 18.90 & -38.50 & 153.29 \\
\hline VOL & 4226 & 130886.25 & 454724.84 & 2.00 & 8280692.00 \\
\hline BID & 3989 & 19.25 & 17.93 & 0.10 & 153.00 \\
\hline ASK & 3989 & 19.44 & 17.99 & 0.11 & 153.37 \\
\hline SPREAD & 101 & 0.33 & 0.26 & 0.02 & 1.50 \\
\hline CEQQ & 4188 & 1541.63 & 6982.92 & -424.48 & 115367.00 \\
\hline CSHOQ & 4124 & 120.95 & 452.41 & 1.09 & 6043.55 \\
\hline TXTQ & 4195 & 24.29 & 168.28 & -6573.00 & 2863.00 \\
\hline REQ & 3955 & 596.50 & 2846.65 & -7586.00 & 35863.00 \\
\hline REVTQ & 4211 & 666.70 & 2264.68 & -0.13 & 31581.00 \\
\hline NETINCOMETOSALES & 4167 & -0.84 & 11.08 & -480.98 & 36.60 \\
\hline NETINCOMETOTOTALASSETS & 4184 & -0.01 & 0.23 & -10.76 & 0.34 \\
\hline TOTALDEBT & 4030 & 2378.79 & 11350.47 & 0.26 & 172571.00 \\
\hline NETINCOMETOTOTALDEBT & 4028 & -0.04 & 0.45 & -11.38 & 2.87 \\
\hline CURLIABTOTOTASSET & 4093 & 0.24 & 0.21 & 0.00 & 6.01 \\
\hline LTLIABTOTOTASSET & 4030 & 0.23 & 0.23 & 0.00 & 2.58 \\
\hline TOTDEBTTOTOTASSET & 4030 & 0.48 & 0.31 & 0.01 & 7.22 \\
\hline TOTDEBTPLUSPREFTOTOTASSE & 4028 & 0.49 & 0.33 & 0.01 & 7.84 \\
\hline CASHTOTOTALASSETS & 1222 & 0.14 & 0.17 & 0.00 & 0.95 \\
\hline QUICKASSETS & 4061 & 615.11 & 1820.24 & 0.01 & 23567.00 \\
\hline QUICKASSETSTOTOTALASSTS & 4061 & 0.38 & 0.23 & 0.00 & 0.98 \\
\hline WORKINGCAPITAL & 4091 & 98.53 & 1311.37 & -21893.00 & 8960.48 \\
\hline WCTOTOTALASSETS & 4091 & 0.27 & 0.30 & -5.96 & 0.96 \\
\hline CASHTOCURLIABILITIES & 1199 & 0.90 & 1.55 & 0.00 & 14.55 \\
\hline QASSETSTOCURLIABILITIES & 4061 & 2.37 & 3.87 & 0.00 & 63.24 \\
\hline CURRENTRATIO & 4091 & 2.98 & 3.89 & 0.00 & 64.71 \\
\hline CASHTOSALES & 1212 & 5.38 & 55.11 & 0.00 & 1276.84 \\
\hline INVENTORYTOSALES & 4072 & 0.53 & 1.12 & -2.68 & 31.33 \\
\hline QUICKASSETSTOSALES & 4015 & 5.88 & 54.46 & -505.26 & 2340.64 \\
\hline CURRENTASSETSTOSALES & 4045 & 6.37 & 54.31 & -507.94 & 2341.76 \\
\hline WORKINGCAPITALTOSALES & 4045 & 4.74 & 49.04 & -494.21 & 2093.38 \\
\hline TOTALASSETSTOSALES & 4143 & 14.29 & 113.44 & -603.91 & 3802.83 \\
\hline BIDASKSPREAD & 3989 & 0.19 & 0.28 & -0.50 & 4.50 \\
\hline HILOBIDASKSPREAD & 4226 & 2.77 & 4.99 & -65.25 & 75.31 \\
\hline
\end{tabular}


is common to select firms in such a way that size and industry factors do not distort the results.

The procedure is two-fold. First, a bankrupt firm is selected. Second, a nonbankrupt firm within the same industry with asset size closest to the bankrupt firm is selected. These two firms (the one bankrupt and the one non-bankrupt) are then stored and removed from the continuing procedure. A second bankrupt firm is selected, and the selection process is done with the remaining non-bankrupt firms. This is done for each bankrupt firm, so that in the end there are an equal number of bankrupt and non-bankrupt firms.

To clearly understand the difference in behavior between the two subsamples, a graphical demonstration is a great place to begin. To do so, the annual mean value of each ratio is calculated from one year before failure to five years before failure. The same is done for non-bankrupt firms, but the cutoff date is just matched to that of the bankrupt firm. Furthermore, since the behavior of the ratios in the two subsamples should differ over time, especially as bankruptcy approaches, a test of autocorrelation is applied. This will demonstrate the trends of the ratios in each subsample.

To further demonstrate the behavior of the variables, especially the downward (or upward spiral) for bankrupt firms as bankruptcy looms, tests of autocorrelation are run. There should be a clear trend during the quarters nearest bankruptcy. For brevity, I run the autocorrelations from the last quarter, three years before bankruptcy, up until the quarter right before bankruptcy. This is performed also on the nonbankrupt sample. 
While the trend analysis and autocorrelations provide explanations of the trends and comparisons of the ratios of each subsample, this is not a predictive test.

A useful predictive test employed to test the power of each ratio in distinguishing between bankrupt and non-bankrupt firms is a dichotomous test. The ratios for bankrupt and non-bankrupt firms are each ranked from lowest to highest, and a cutoff point is chosen to minimize the misclassification between failed and non-failed. This is synonymous to the decision-making process of a practitioner; the ratios of a firm are analyzed, and if they are above or below a certain level, then the firm is believed to be healthy or under distress. This is procedure one.

The problem with this procedure is that the cutoff point is derived from the entire sample, so it is not purely a predictive test. To avoid this issue, the entire sample is further randomly divided into two subsamples. A cutoff point is then derived in each subsample, but then that cutoff point is used to classify firms in the other subsample. This is procedure 2 .

One important problem with the preceding predictive test is that Type I (misclassifying a failed firm) and Type II (misclassifying a non-failed firm) errors are treated equally. However, the severity of committing these errors is very different. A lender who wrongfully lends to a firm that eventually fails will suffer deeper consequences than a lender who denies a loan to an eventually proven healthy firm. In order to distinguish between these errors, contingency tables are employed. The contingency tables are made for each ratio, one to five years before failure. The rows of the table signify the predicted outcome (failed or non-failed), and the columns demonstrates the actual outcome (failed or non-failed). 


\subsection{Empirical Results}

While each variable does not tell the whole story, it is important to understand how the different variables and types of variables behave prior to bankruptcy, and how the behaviors of the ratios of failing and non-failing firms differ. The individual ratios are studied through dichotomous tests, contingency tables, and likelihood ratios.

While the levels of the different ratios (accounting, market, or microstructure) for the bankrupt and non-bankrupt firms are clearly different, the differences do not change as much in magnitude as has been documented in the previous literature. Market turmoil clearly has an effect on all firms, whether under distress or not. The magnitude may differ, but the market as whole was effected. This will make the multivariate analysis in the coming chapters that much more important.

Focusing on market and microstructure variables, volume for bankrupt firms is substantially lower than that of non-bankrupt firms, but there is no trend. The market might be able to notice financial distress farther than five years out. The spread stays in a tight range, again indicating that the market made up its' mind long before five years before bankruptcy. However, the high-loww bid-ask spread does show an upward trend for bankrupt firms.

While the prices of all securities show a downward trend (due to the financial crisis), the stock prices of bankrupt firms decline by $40 \%$, while those of non-bankrupt firms decline by only $25 \%$. Furthermore, there is an upward trend in prices one year before the cutoff period for non-bankrupt firms. Since this sample time-period includes the financial crisis, most stock prices trend downward. However, one year before either bankruptcy or the cutoff, the market is able to distinguish between firms in distress and 
those not. Hence, the prices of bankrupt firms continue the downward spiral, while those of nonbankrupt firms show a spike. Returns turn negative for bankrupt firms, while those of non-bankrupt firms stay relatively flat; moreover, returns for nonbankrupt firms are mean-reverting, as commonly found in the overall market, while those for bankrupt firms display a downward trend. This is a substantial difference. Clearly, market determined prices are leading indicators of financial distress. The standard deviation of the returns are mostly higher for bankrupt firms. This is due to the uncertainty surrounding firms in distress. While the entire market has a substantially higher level of systematic risk during this sample period, the unsystematic risk is higher for deteriorating firms. Relative systematic risk is upward trending for bankrupt firms, while the opposite is true for nonbankrupt firms.

Figure 1

The figure present the market variables, accounting ratios, and the microstructure variables for the bankrupt and nonbankrupt firms from one year before bankruptcy (year 1) to five years before bankrupt (year 5).

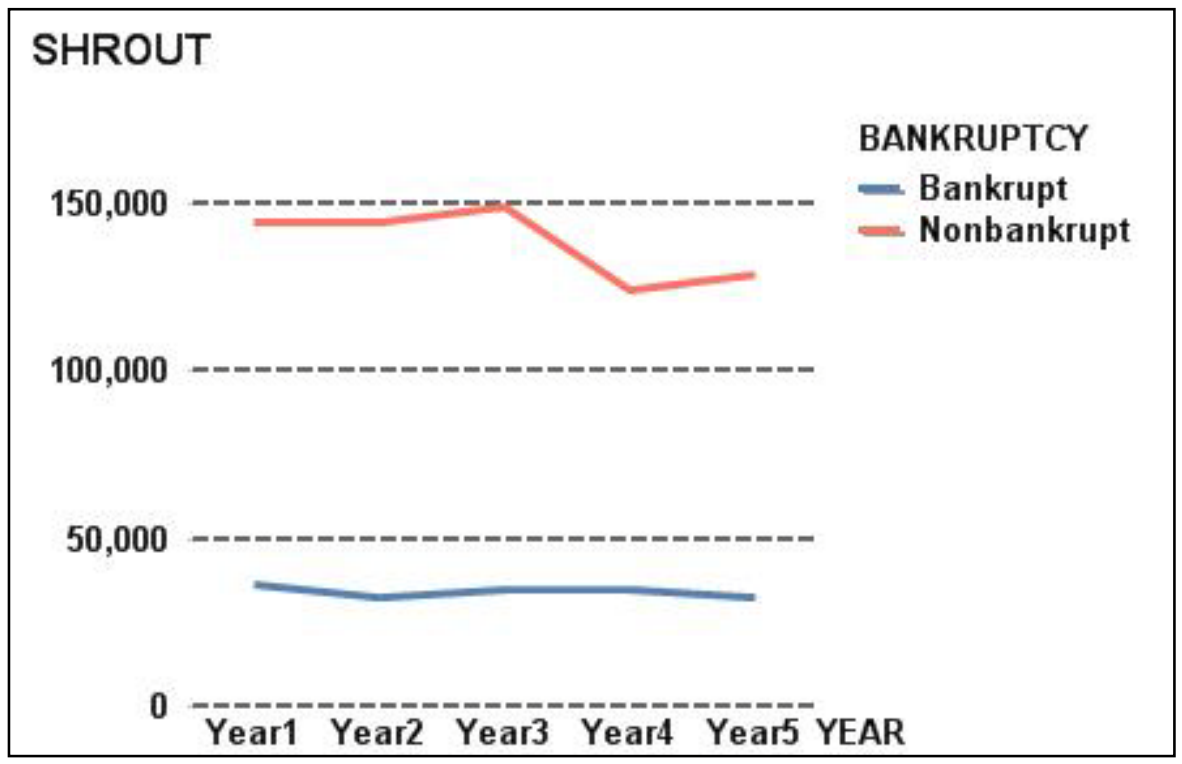



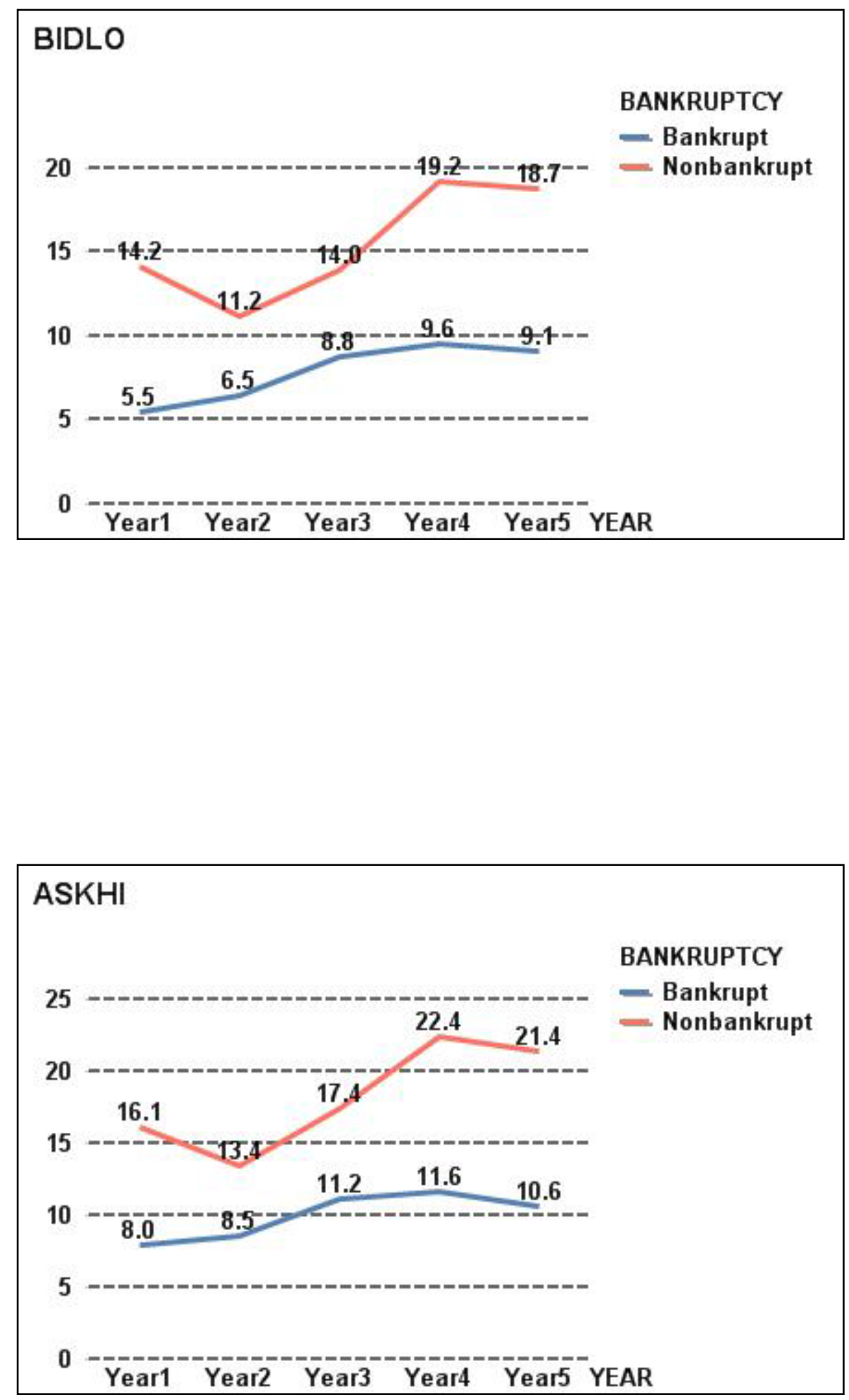

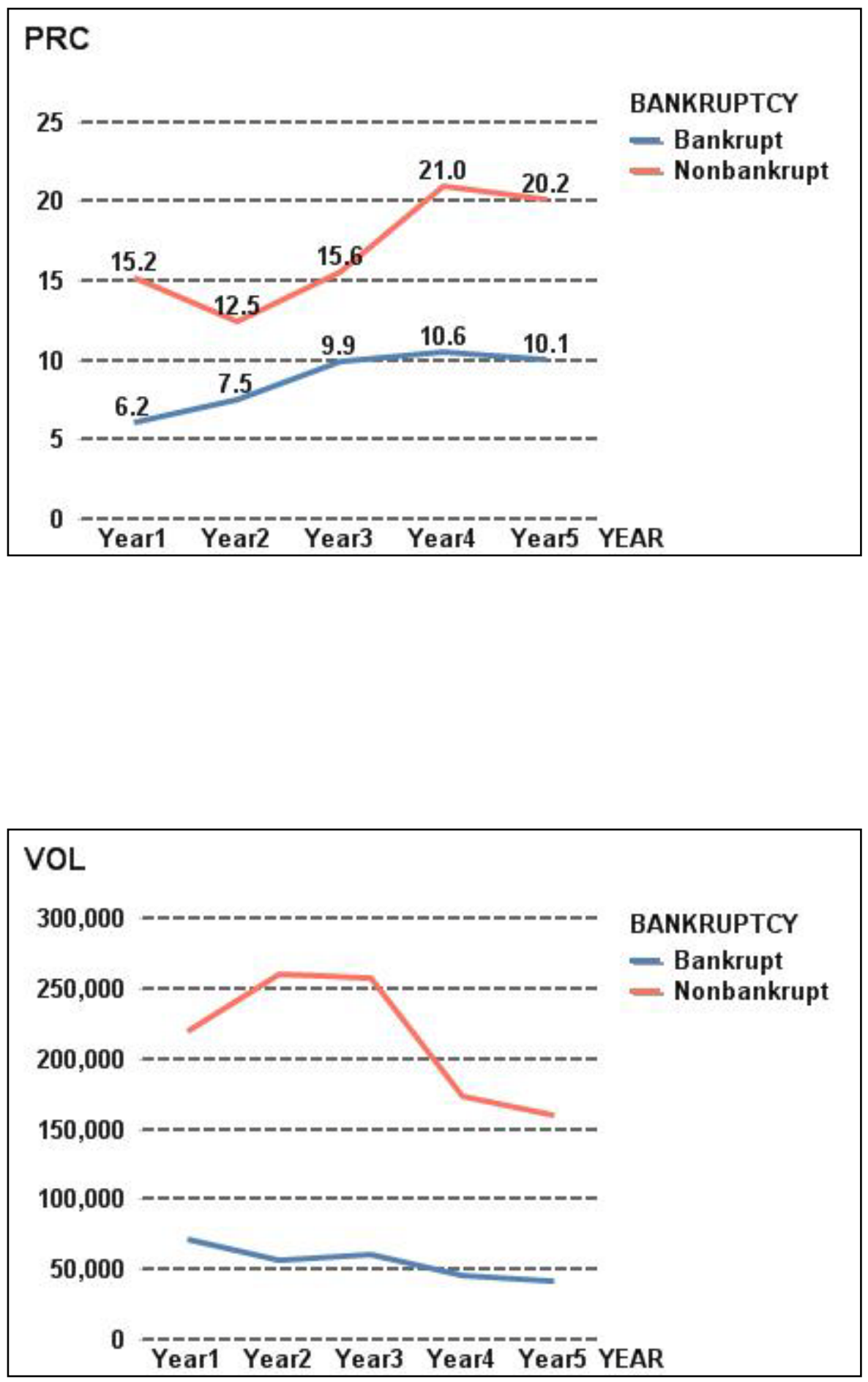

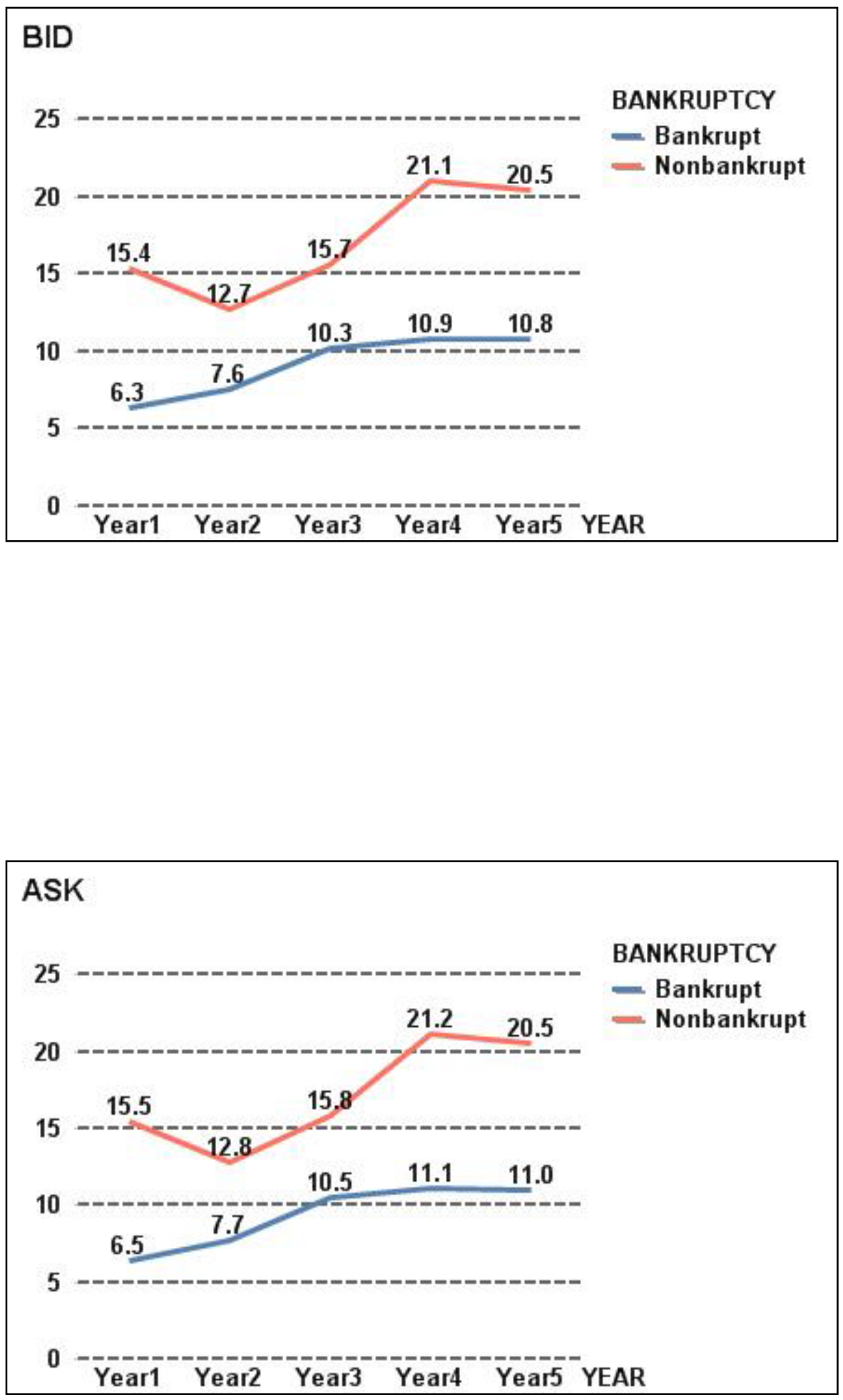

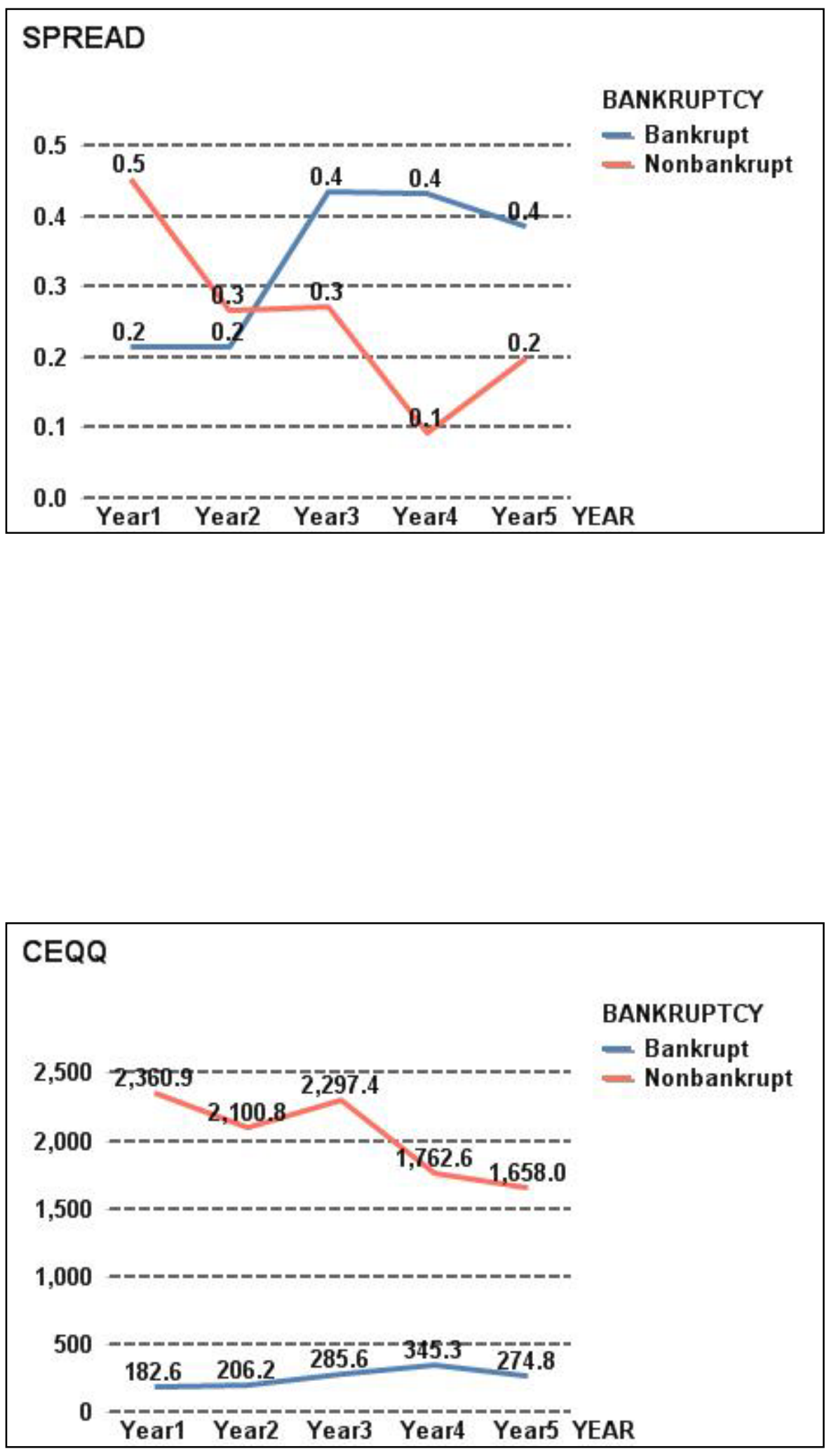

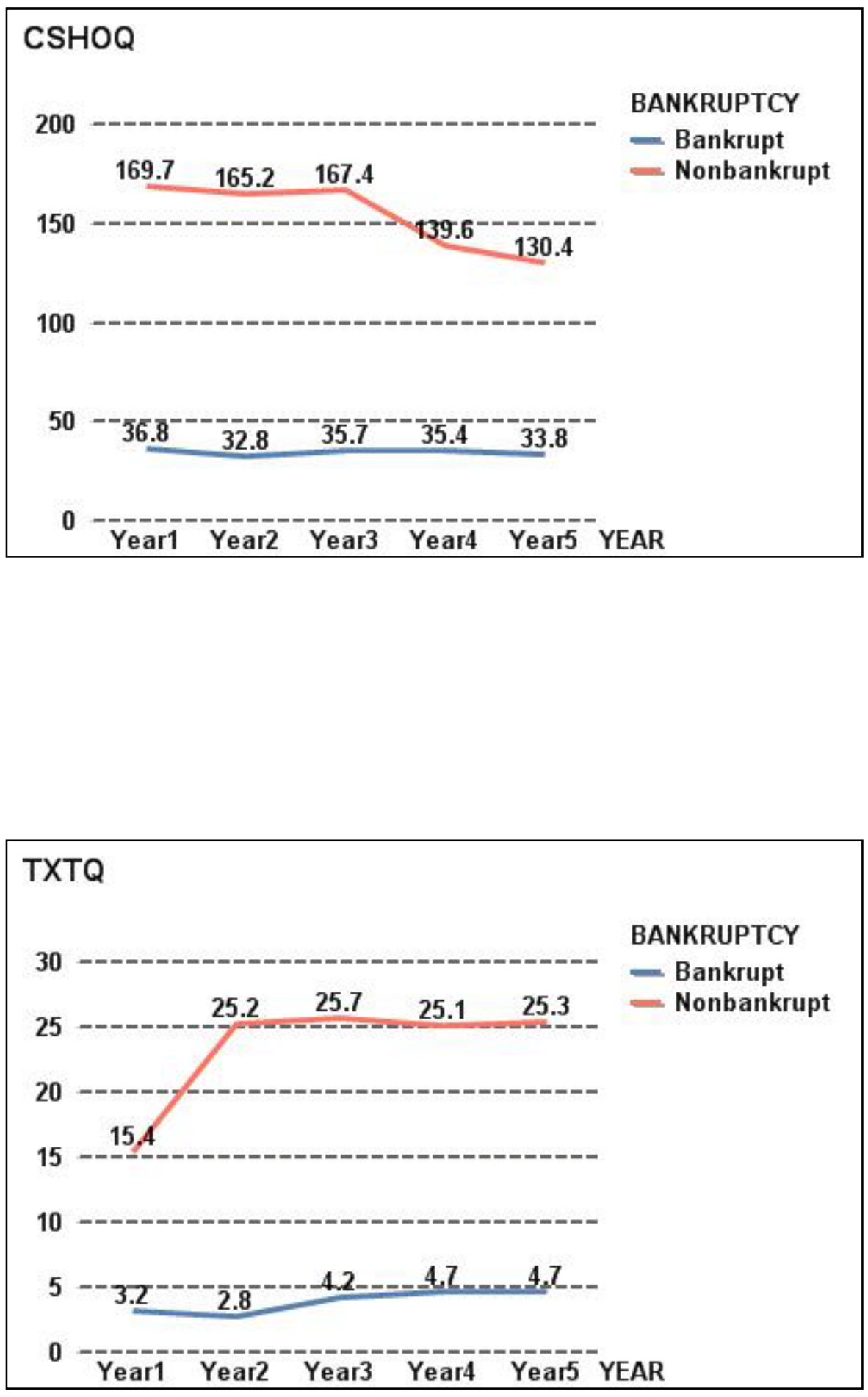

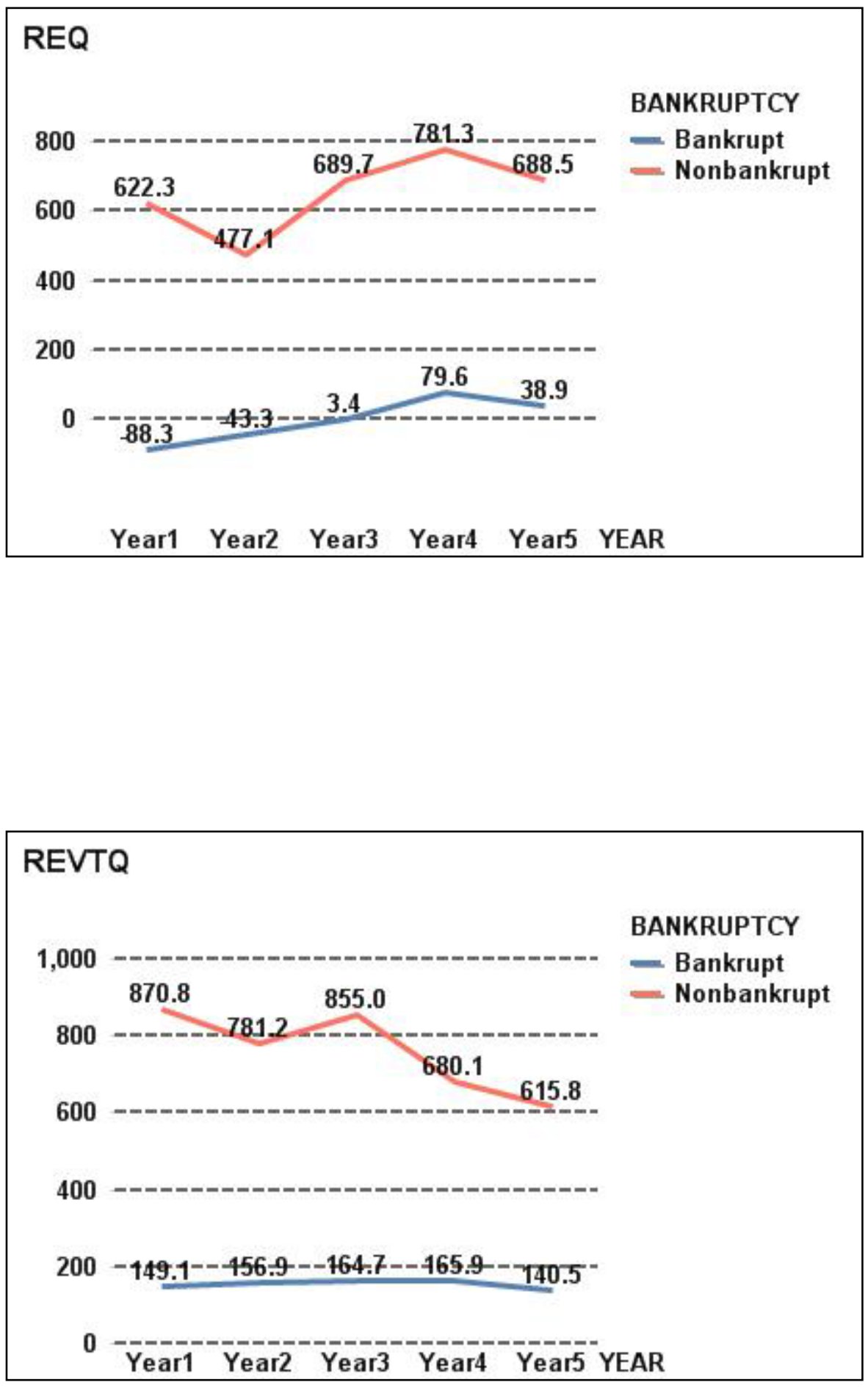

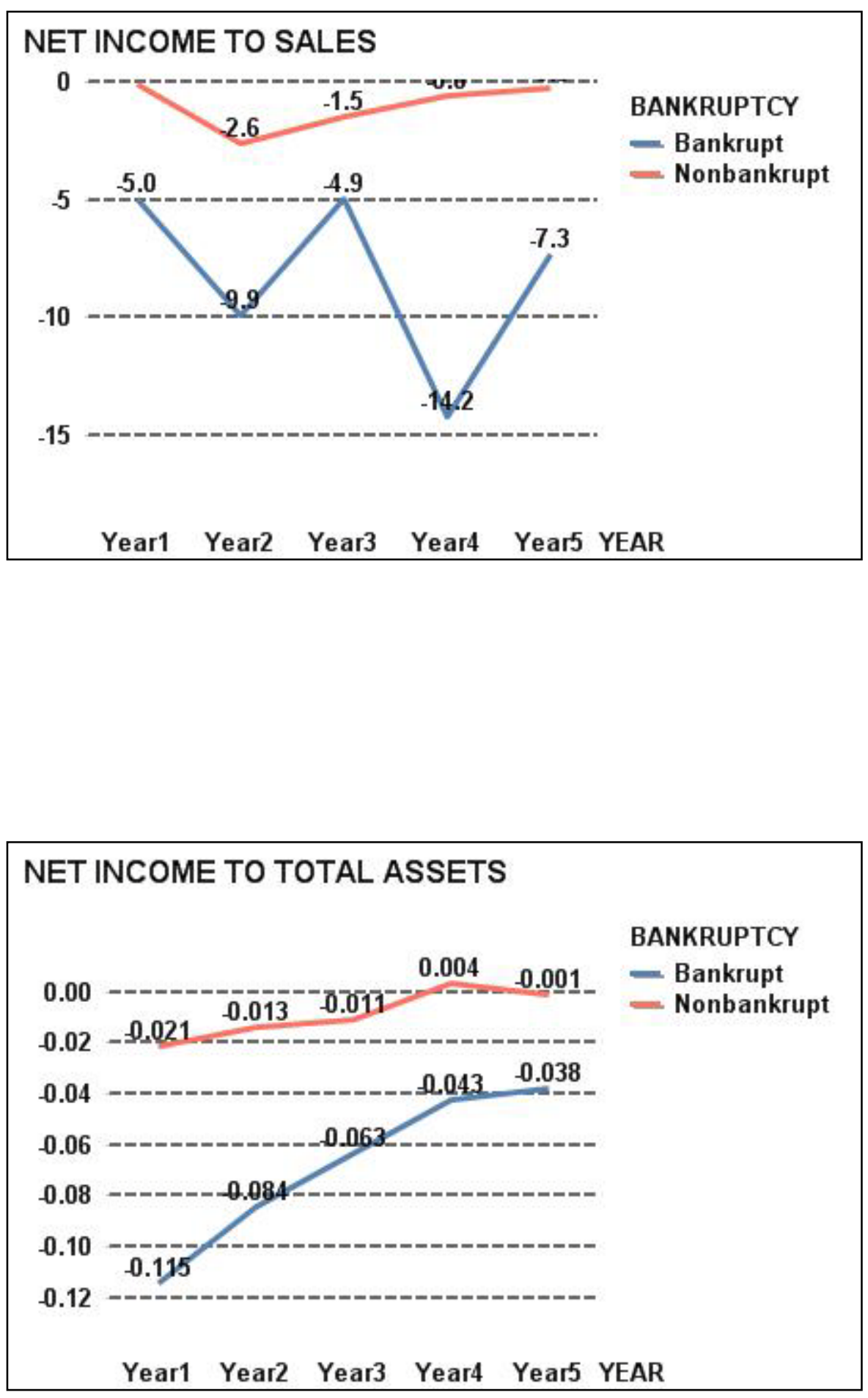


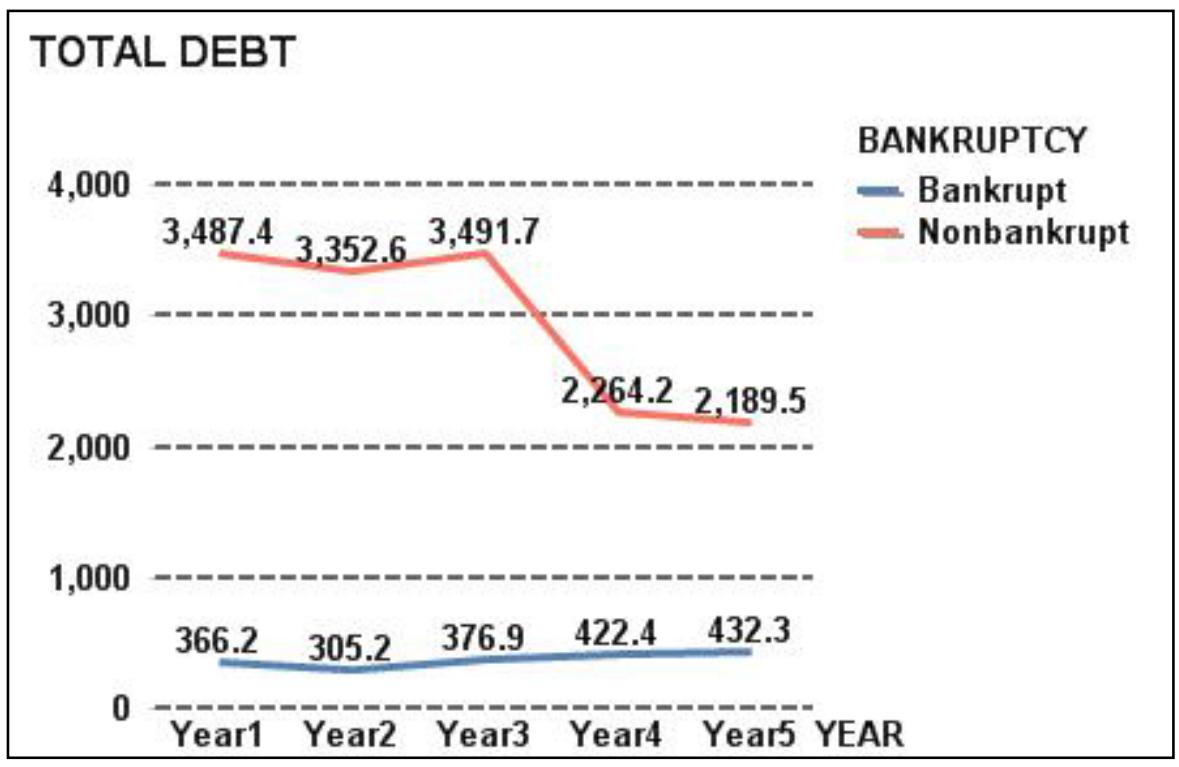

NET INCOME TO TOTAL DEBT

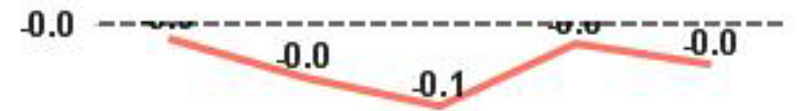

BANKRUPTCY

- Bankrupt

$-0.1$

- Nonbankrupt

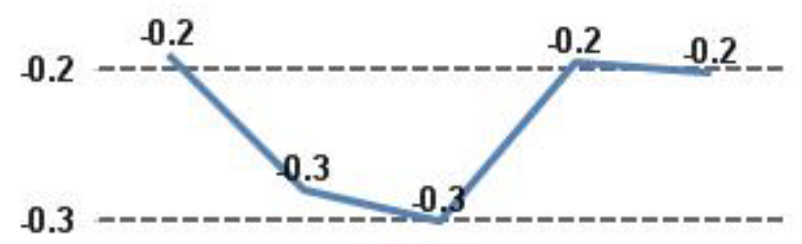

Year1 Year2 Year3 Year4 Year5 YEAR 

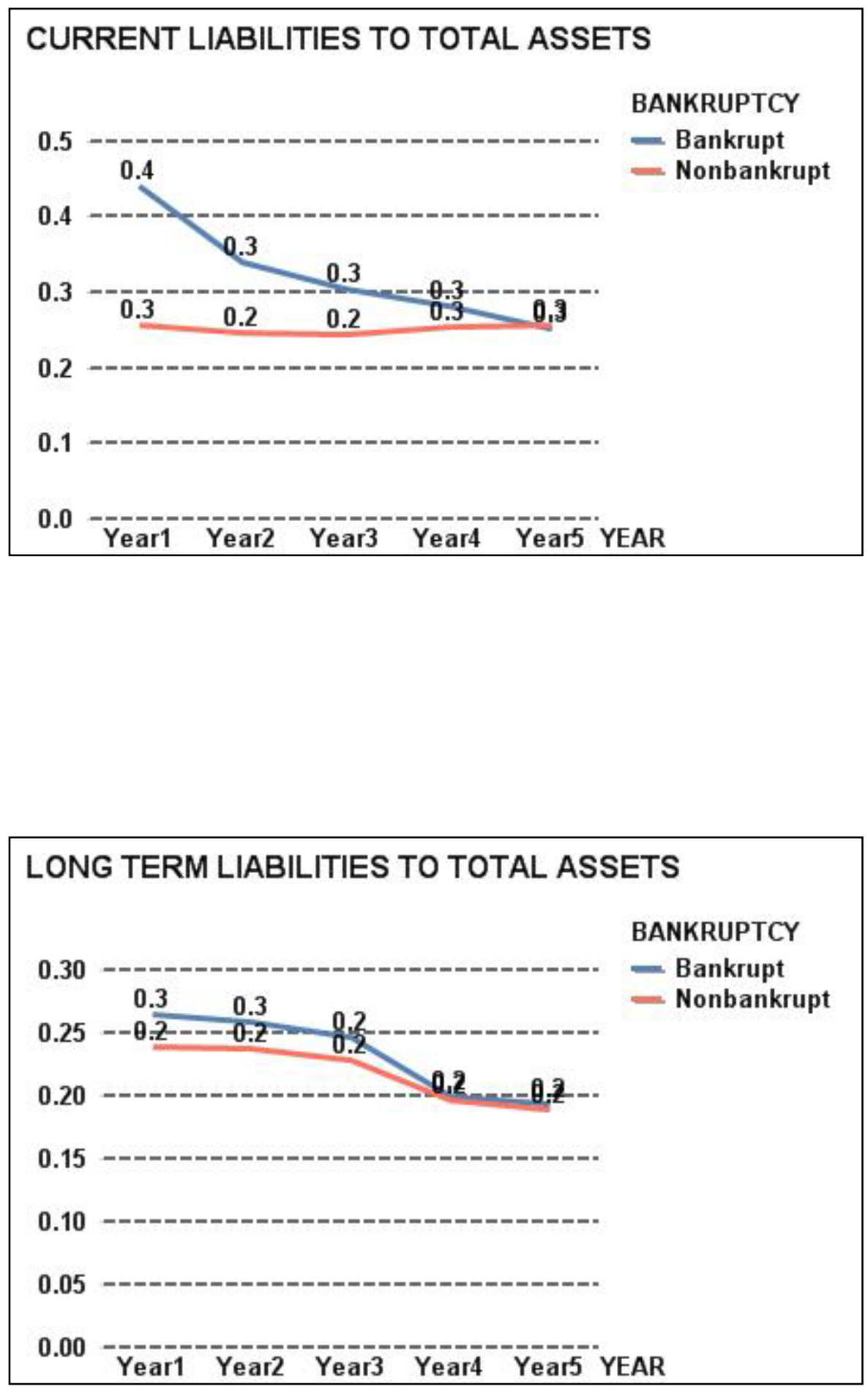

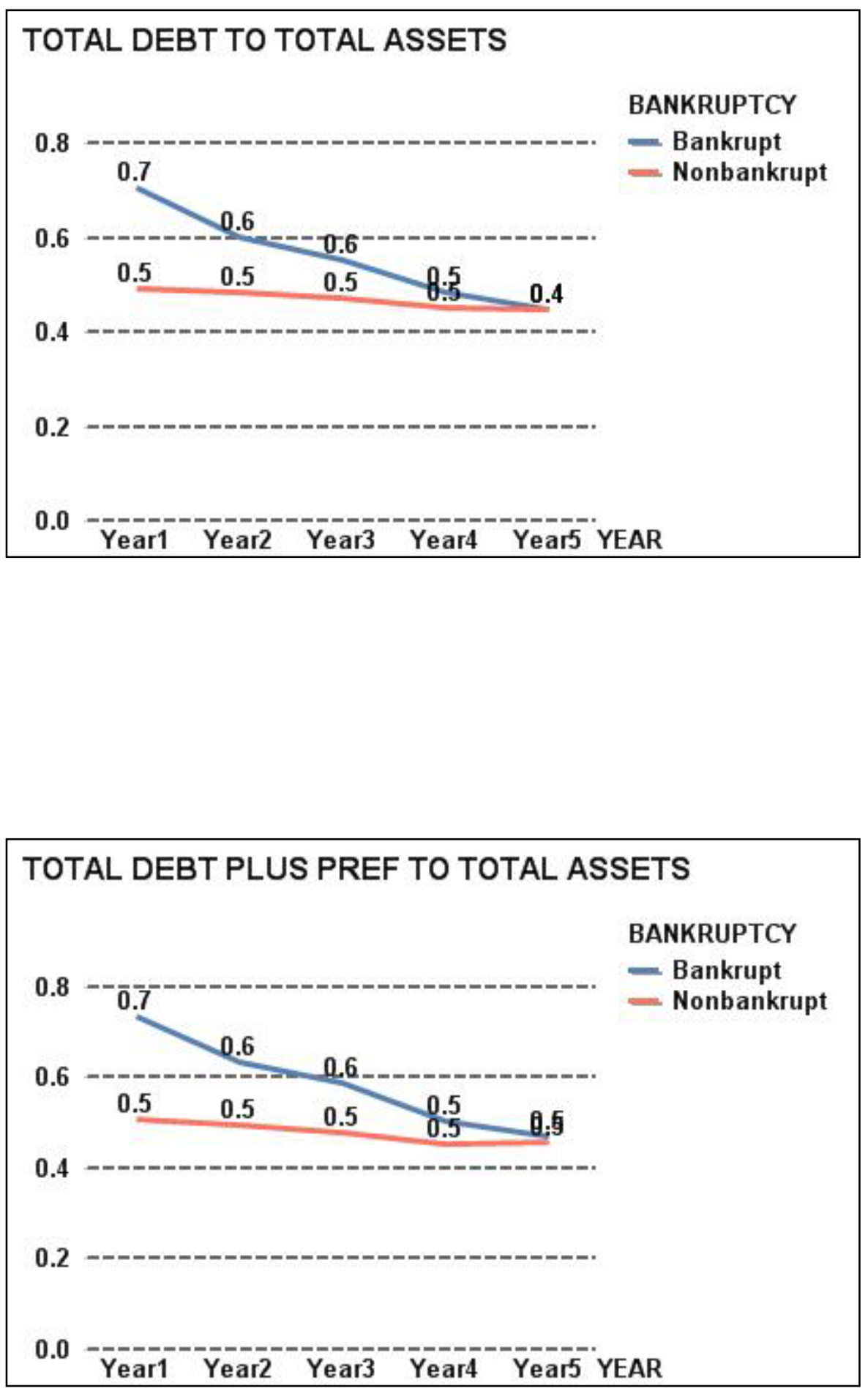

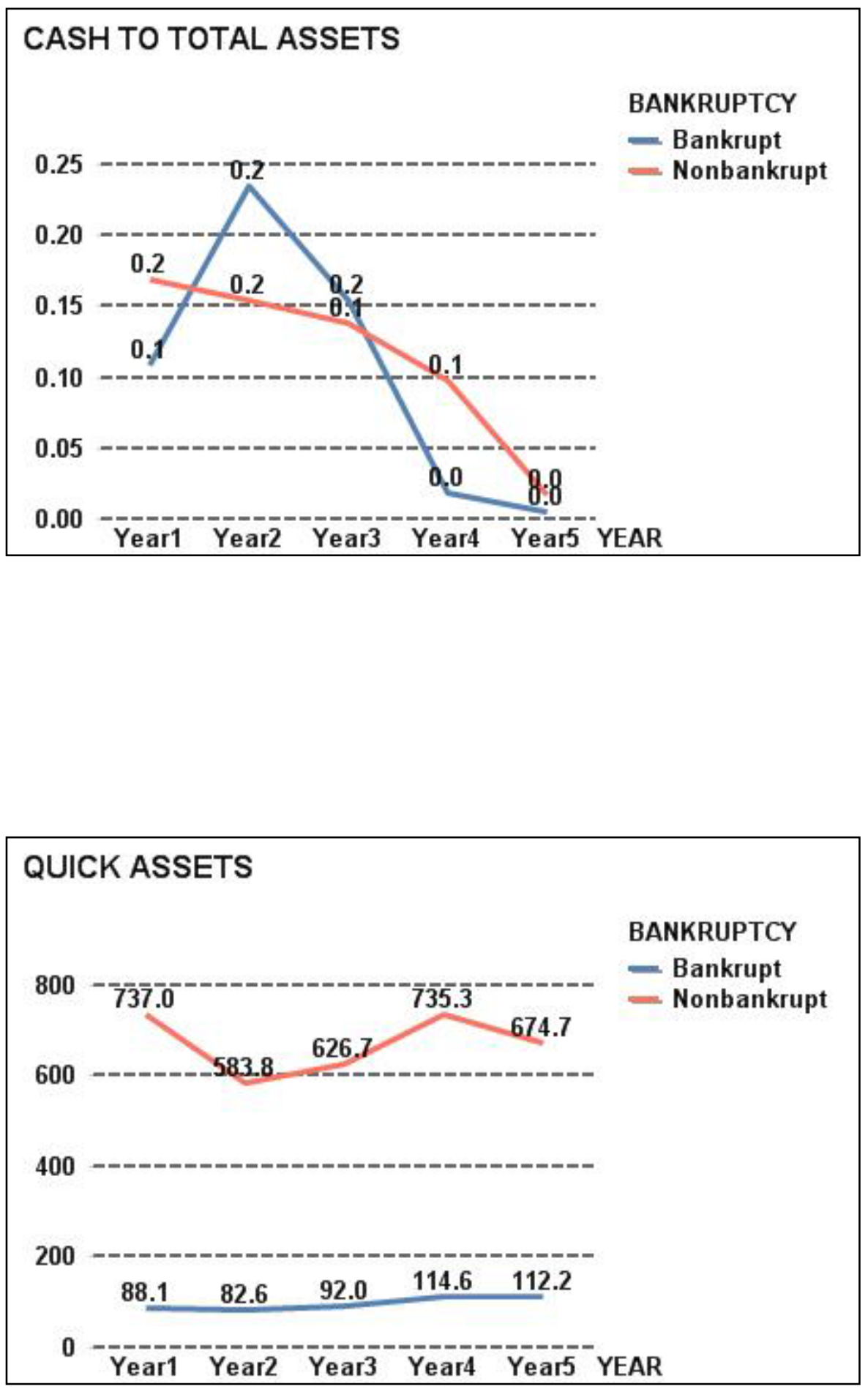

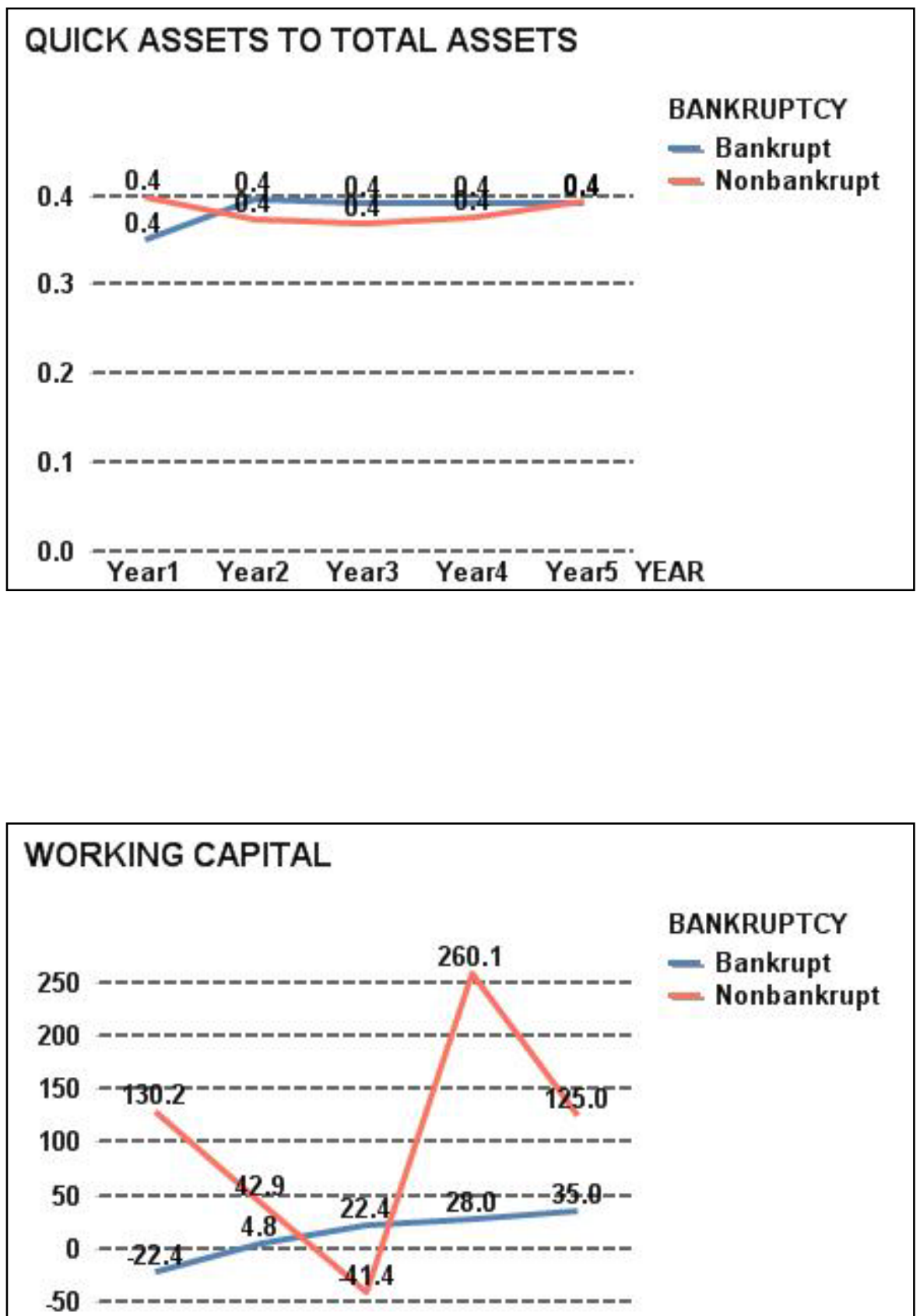

Year1 Year2 Year3 Year4 Year5 YEAR 

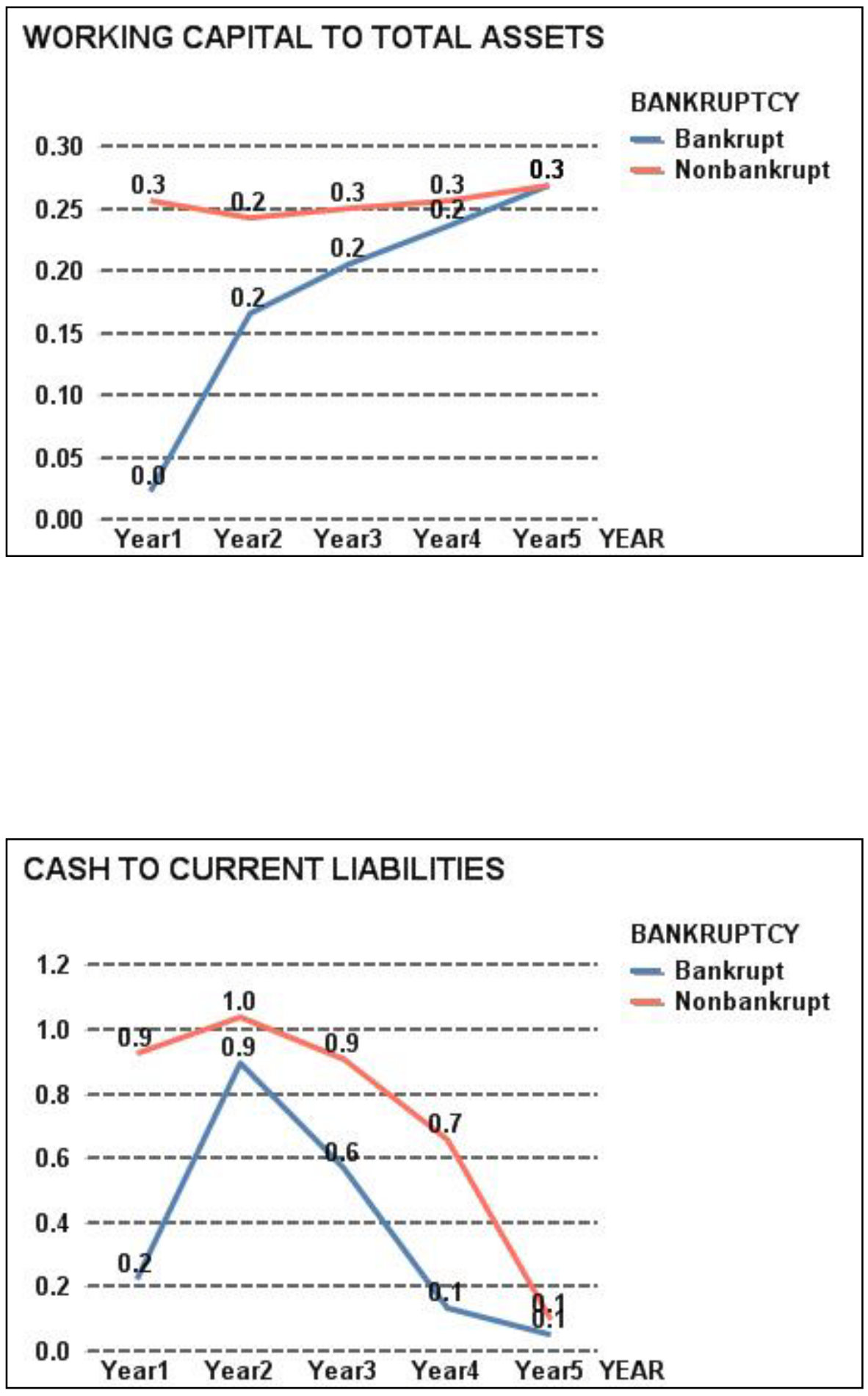

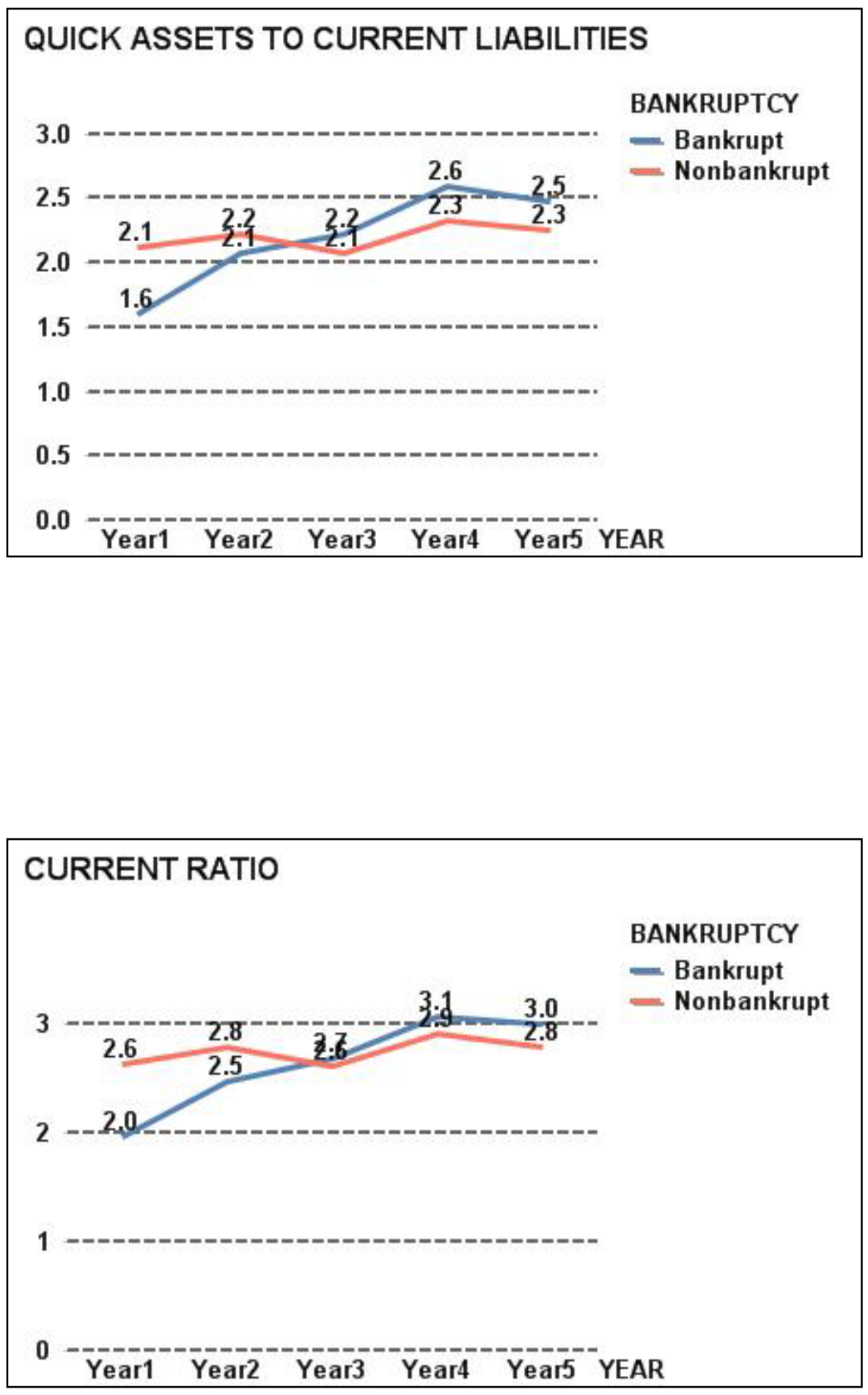

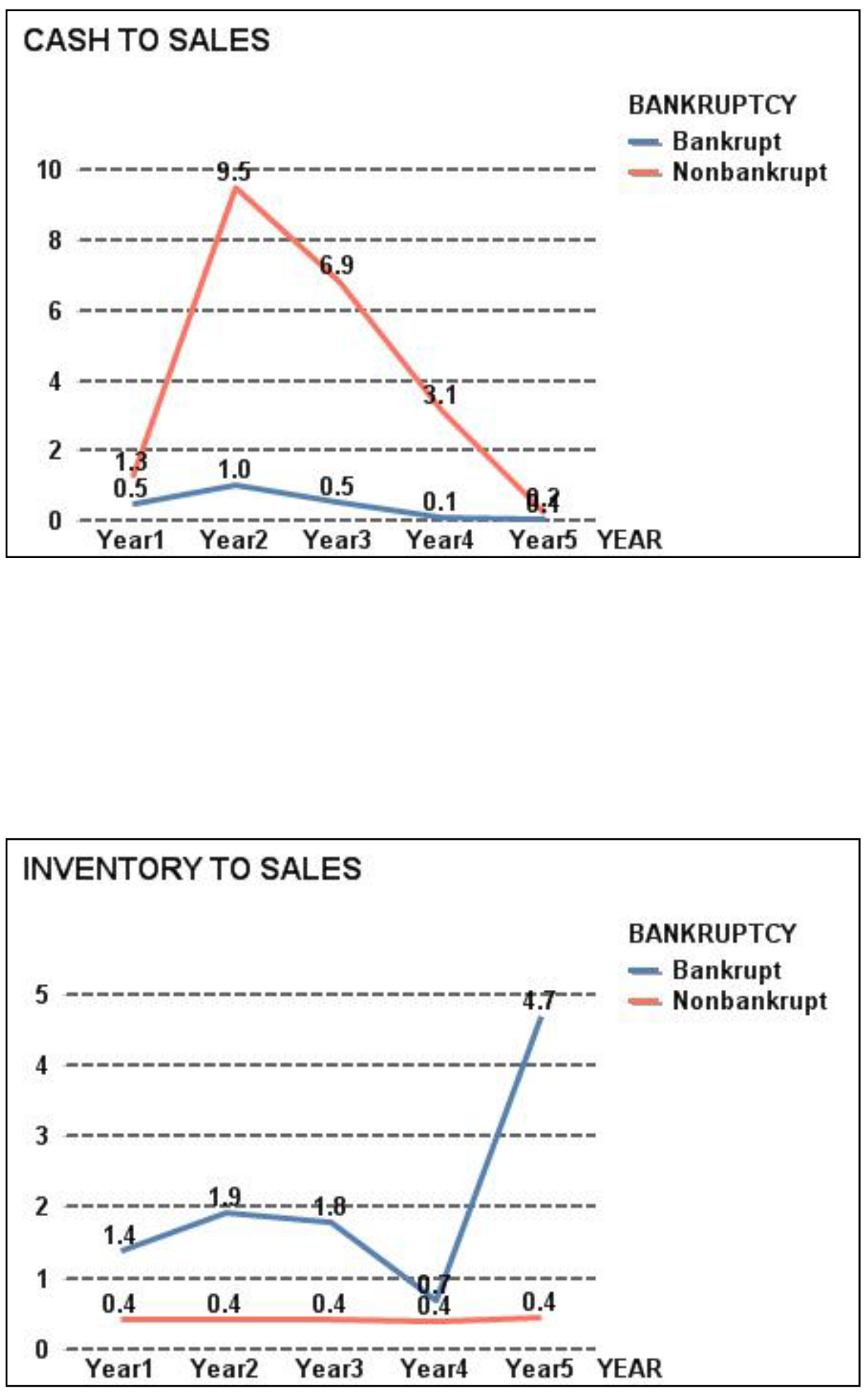

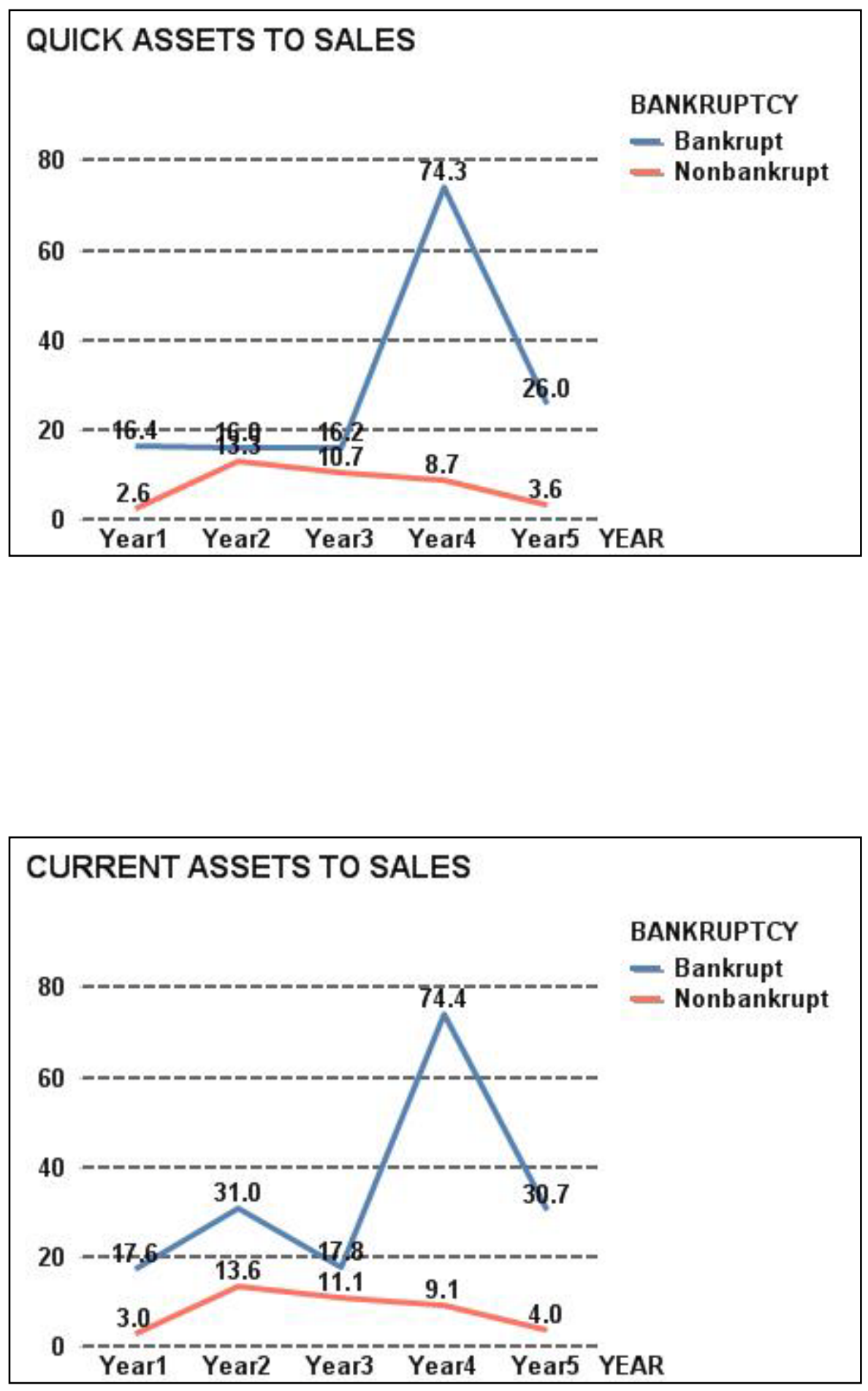

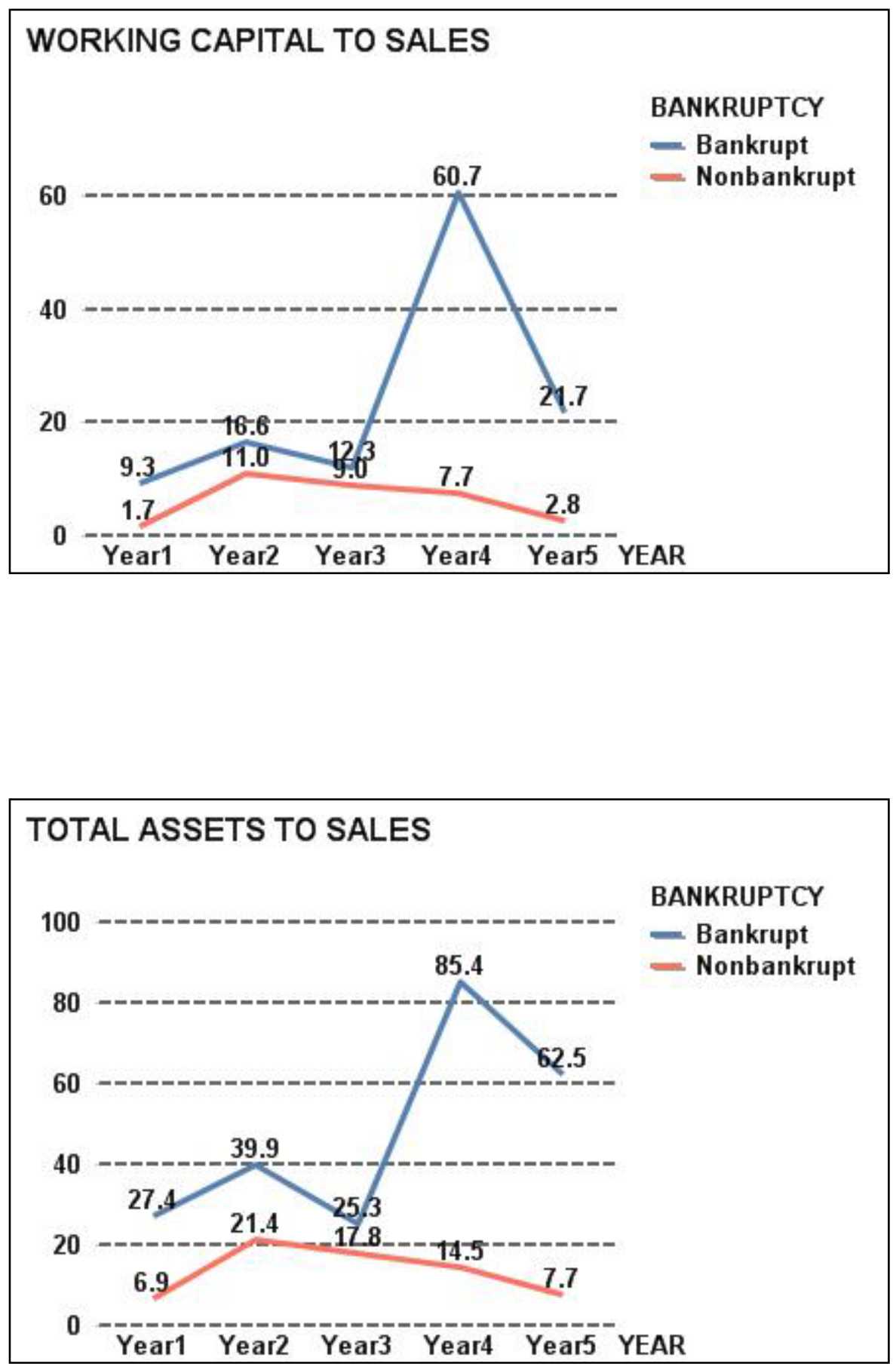

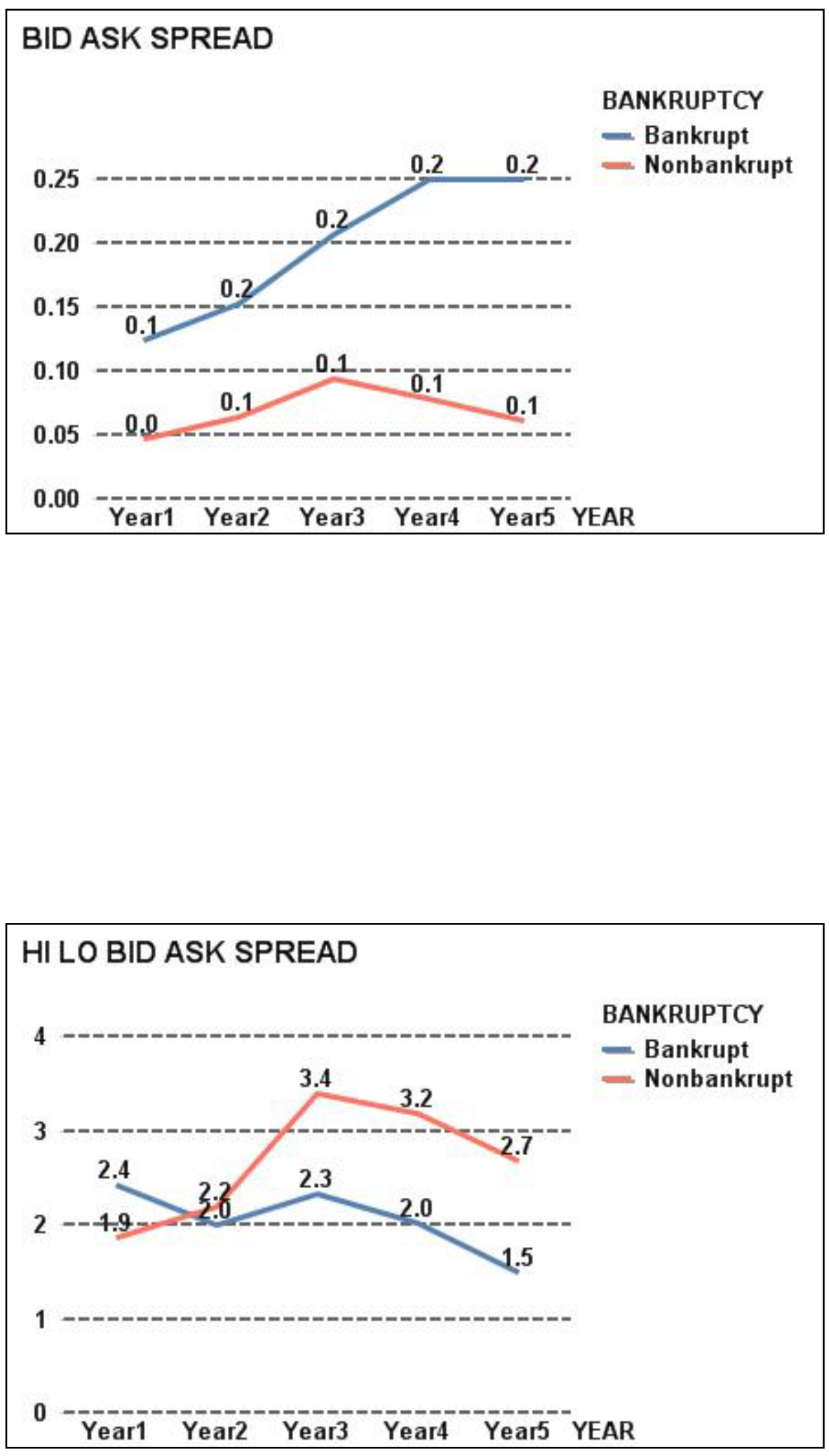

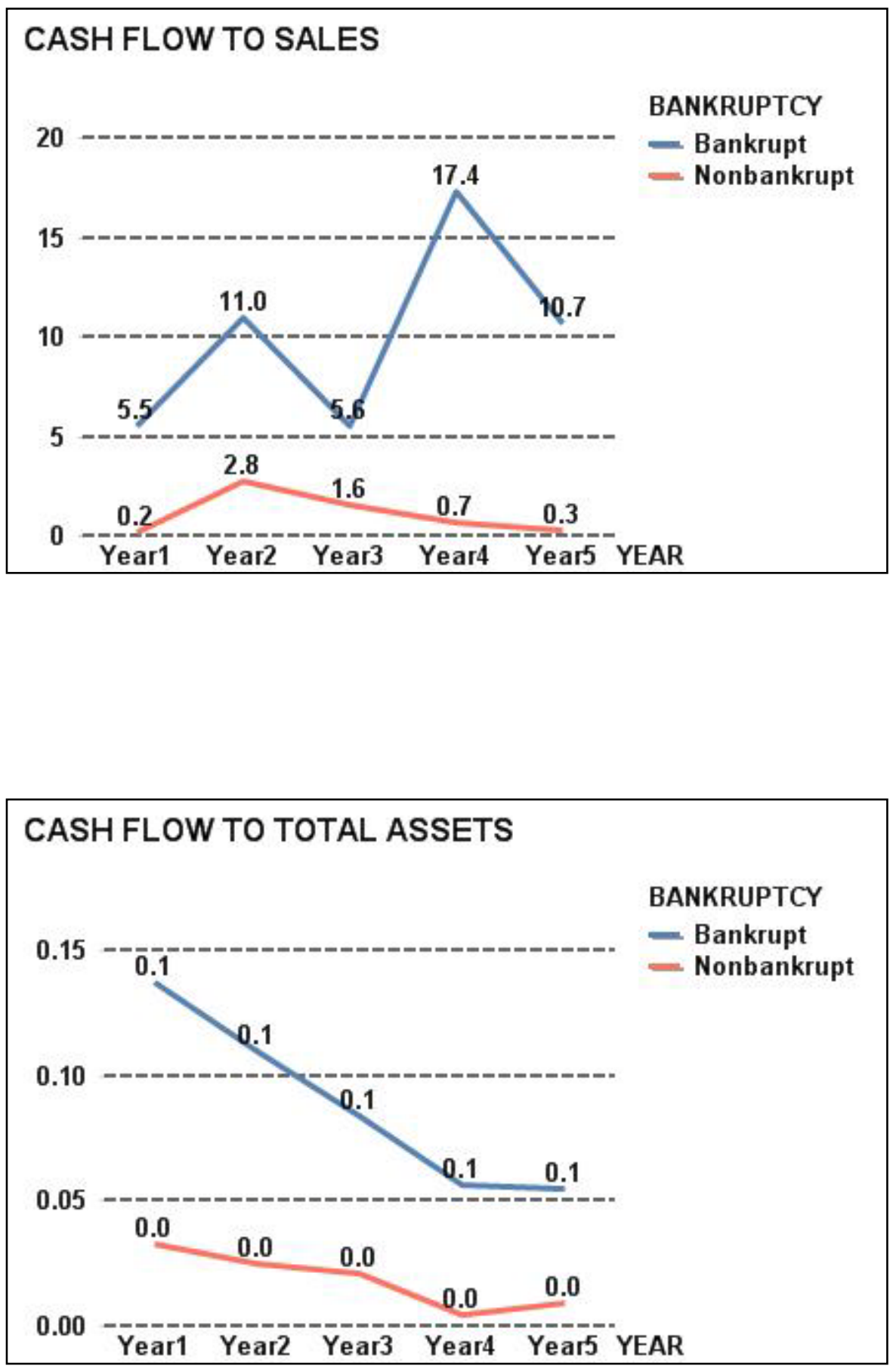

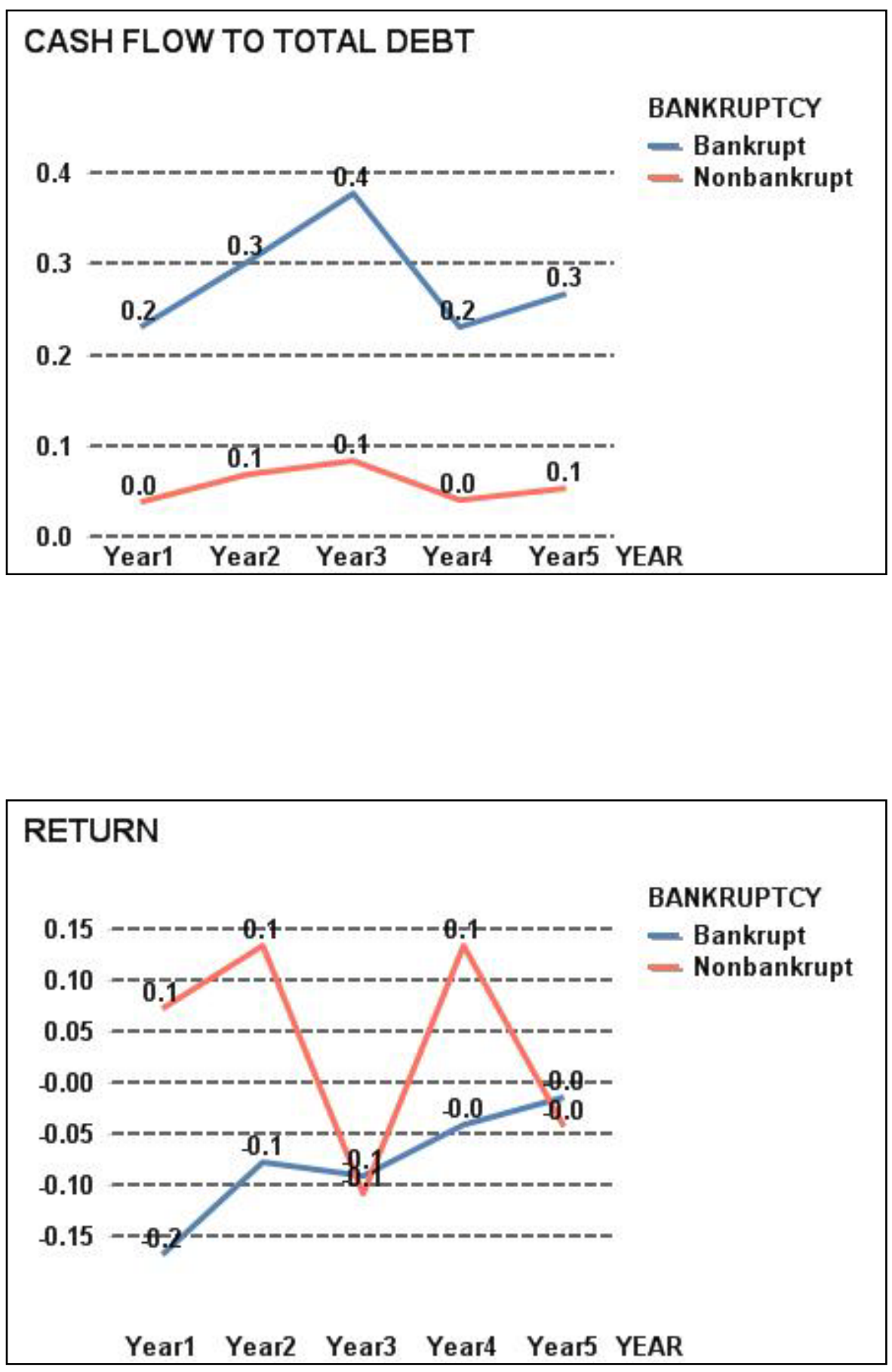

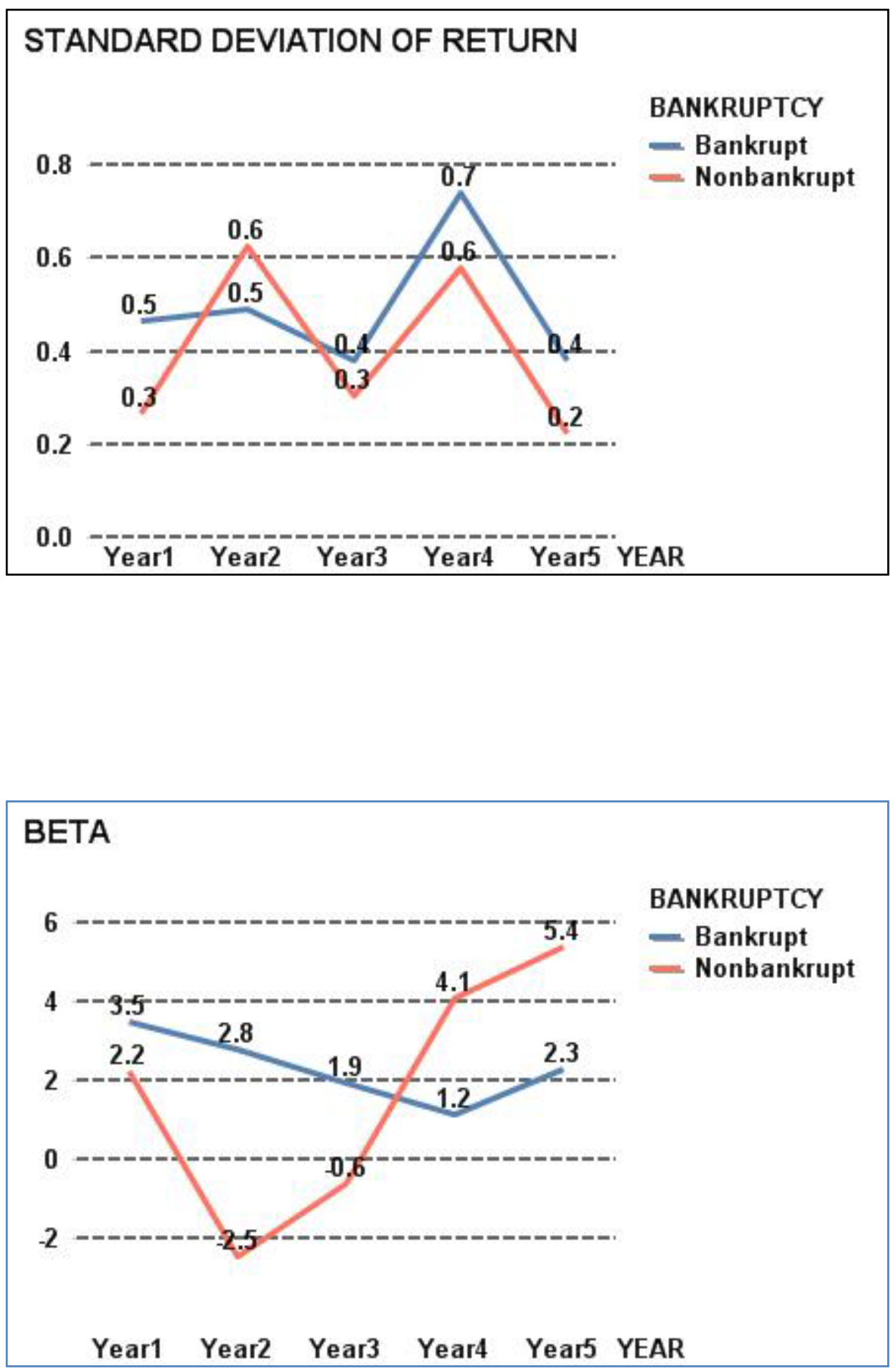

When compared to previous studies, cash flow plays a much smaller role in this study. While there is a clear difference between the cash flow ratios of the two samples, there is not much of a trend. Net income to total assets tells a much different story. Due to 
the crisis, net incomes are low and on the decline for both samples. However, the trend is much steeper for the bankrupt firms. Net income to total debt is much more flat.

Even though total debt does not fluctuate too much, current liabilities do. This is due to the fact that firms take on more short-term debt in distress to try to survive. Current liabilities to total assets are relatively stable for non-bankrupt firms, those for bankrupt firms increase 33\% from five years before bankruptcy to one year before. Longterm liabilities to total assets are more stable for both samples. Total debt to total assets and total debt plus preferred stock to total assets increase $60-75 \%$ leading up to bankruptcy, but those for non-bankrupt firms are stable. Cash to total assets increase for both samples, which is at first surprising for bankrupt firms; this is mainly due to the decline of total assets. Furthermore, working capital to total assets significantly declines when approaching bankruptcy, demonstrating that current assets other than cash decreased, and/or current liabilities increased. This is further highlighted through the cash to current liabilities ratio. Also, both quick assets and all current assets decline as current liabilities rise, as is expected. Inventories decline mostly 5 years prior to bankruptcy, and then stay relatively flat. These findings are consistent with the belief that firms ramp up short-term risks trying to find a last minute solution to the deterioration.

While the trend analysis serves an explanatory purpose, it is not a predictive analysis. To do so, a dichotomous classification test is first applied. A clear difference between this study and prior studies is that the misclassifications found using our sample are much higher than those found in the literature. This is mainly due to the fact that many firms, whether the firms went bankrupt or not, suffered some distress due to the financial crisis. Therefore, any one variable or ratio alone will be less able to predict 
which firm will go bankrupt and which firm will not. This will make the multivariate analysis in the coming chapters even more important.

Since the results are fairly similar between procedure 1 and 2 , the results discussed in the following paragraphs will be specifically about procedure 2 . This is more accurately a predictive test since the cutoff point is derived from one sample and then used to predict bankrupt or non-bankrupt firms in the other sample.

We begin again with the market and microstructure variables. Volume seems to have less predictive power as bankruptcy looms. The crisis led to heavy trading in all securities, so this makes volume a less discriminatory variable. While there may be more information in volume during normal periods, it is difficult to use during turmoil. Price, however, performs better, and improves in accuracy as bankruptcy approaches. The same occurs with the bid-ask spread and returns. Beta performs poorly and is erratic, but the standard deviation performs as well as price does. Overall, the market variables that are best at correctly classifying firms are prices, bid-ask spreads, and standard deviation. However, the variable with the most long-term accuracy (five years before bankruptcy) is the bid ask spread, with some misclassifications in the low $20 \%$. This is consistent with our hypothesis, that the bid-ask spread, which is set by market makers, is a leading indicator since a lot of information not found in the accounting books or by retail investors is found on the trading floor.

Moving on to accounting ratios, the most accurate group is the cash flow group. While the accuracy is not monotonic, the misclassifications mostly range from the mid $20 \%$ to the mid $30 \%$. Cash flow to total assets and cash flow to total debt correctly classify about $75 \%$ of the firms even five years before bankruptcy. This is interesting, 
especially since we later find that the cash flow variables are not part of the set of best predictors in the multivariate frameworks.

The net income ratios also perform well, but are less accurate and more erratic than the cash flow or market variables. The inaccuracy mostly ranges from the high $20 \%$ to $40 \%$. The net income to sales ratio misclassifies $25 \%$ to $33 \%$ of the firms.

Surprisingly, the debt ratios are poor classifiers. This seems to go against the idea that firms leverage themselves as financial distress occurs in order to survive. However, one key characteristic of all firms during the recent financial crisis was high leverage. Therefore, it is much more difficult to use debt as a discriminating variable in our sample. The same seems to occur with assets; this is clearly seen through the accounting identity. Working capital performs well by itself, meaning that the relationship between current assets and current liabilities is important; unfortunately, the same is not found for the current ratio.

While the results of the dichotomous test lead to predictions, they lack in one important area. Clearly, a loan officer or investor would prefer incorrectly predicting that a future non-bankrupt will go bankrupt (Type II error) to predicting that a future bankrupt firm will not go bankrupt (Type I error). One way to display these different errors is through a contingency table. Since we have already seen that certain variables or ratios perform substantially better than others, we will focus on those better performing variables and ratios. 
Table 2

Dichotomous classification Test Results for Ratios

This table presents the dichotomous classification test by classifying firms as either bankrupt or nonbankrupt by using a cutoff point for each variable or ratio that minimizes the misclassification rate. Procedure 1 classifies firms in each sample by using a cutoff derived from the same sample. Procedure 2 classifies firms in each sample by using a cutoff derived from the other sample. Year 1 is one year before bankruptcy and year 5 is five years before bankruptcy.

\section{SHROUT}

\begin{tabular}{lllllll}
\hline Procedure & Sample & \multicolumn{5}{c}{ \%Mis-classifications } \\
\cline { 3 - 7 } & & Year1 & Year2 & Year3 & Year4 & Year5 \\
\hline Procedure 1 & Sample1 & 40.16 & 39.34 & 37.72 & 35.92 & 40.45 \\
& Sample2 & 42.52 & 39.17 & 35.24 & 30.43 & 34.18 \\
\hline Procedure 2 & Sample1 & 40.16 & 37.70 & 36.84 & 37.86 & 39.33 \\
& Sample2 & 43.31 & 39.17 & 35.24 & 30.43 & 34.18 \\
\hline
\end{tabular}

PRC

\begin{tabular}{lllllll}
\hline Procedure & Sample & \multicolumn{5}{c}{ \%Mis-classifications } \\
\cline { 3 - 7 } & & Year1 & Year2 & Year3 & Year4 & Year5 \\
\hline Procedure 1 & Sample1 & 32.80 & 39.67 & 37.72 & 35.92 & 40.45 \\
& Sample2 & 29.13 & 35.83 & 37.14 & 35.87 & 32.91 \\
\hline Procedure 2 & Sample1 & 32.80 & 38.84 & 41.23 & 34.95 & 40.45 \\
& Sample2 & 29.92 & 38.33 & 39.05 & 34.78 & 34.18 \\
\hline
\end{tabular}

VOL

\begin{tabular}{lllllll}
\hline Procedure & Sample & \multicolumn{5}{c}{ \%Mis-classifications } \\
\cline { 3 - 7 } & & Year1 & Year2 & Year3 & Year4 & Year5 \\
\cline { 3 - 7 } & & & & & 34.95 & 38.20 \\
\hline Procedure 1 & Sample1 & 41.73 & 38.52 & 37.72 & 36.96 & 32.91 \\
& Sample2 & 40.16 & 39.17 & 36.19 & 36.96 \\
\hline
\end{tabular}




\begin{tabular}{lllllll}
\hline Procedure 2 & Sample1 & 40.94 & 37.70 & 36.84 & 33.98 & 37.08 \\
& Sample2 & 43.31 & 37.50 & 36.19 & 35.87 & 32.91 \\
\hline
\end{tabular}

SPREAD

\begin{tabular}{llccccc}
\hline Procedure & Sample & \multicolumn{5}{c}{ \%Mis-classifications } \\
\cline { 3 - 7 } & & Year1 & Year2 & Year3 & Year4 & Year5 \\
\hline Procedure 1 & Sample1 & 100.00 & 42.86 & 28.57 & 20.00 & 33.33 \\
& Sample2 & 57.14 & 60.00 & 33.33 & 66.67 & 33.33 \\
\hline Procedure 2 & Sample1 & 100.00 & 42.86 & 28.57 & 0.00 & 33.33 \\
& Sample2 & 42.86 & 80.00 & 66.67 & 66.67 & 66.67 \\
\hline
\end{tabular}

NET INCOME TO SALES

\begin{tabular}{lllllll}
\hline Procedure & Sample & \multicolumn{5}{c}{ \%Mis-classifications } \\
\cline { 3 - 7 } & & Year1 & Year2 & Year3 & Year4 & Year5 \\
\hline Procedure 1 & Sample1 & 34.68 & 35.83 & 49.11 & 43.00 & 40.23 \\
& Sample2 & 24.17 & 28.45 & 32.35 & 33.33 & 28.57 \\
\hline Procedure 2 & Sample1 & 36.29 & 34.17 & 45.54 & 40.00 & 40.23 \\
& Sample2 & 25.00 & 26.72 & 31.37 & 32.22 & 29.87 \\
\hline
\end{tabular}

NET INCOME TO TOTAL ASSETS

\begin{tabular}{lllllll}
\hline Procedure & Sample & \multicolumn{5}{c}{ \%Mis-classifications } \\
\cline { 3 - 7 } & & Year1 & Year2 & Year3 & Year4 & Year5 \\
\hline Procedure 1 & Sample1 & 33.59 & 34.71 & 44.74 & 38.83 & 40.45 \\
& Sample2 & 26.19 & 29.17 & 31.43 & 33.70 & 29.11 \\
\hline Procedure 2 & Sample1 & 36.72 & 33.88 & 45.61 & 40.78 & 40.45 \\
& Sample2 & 26.98 & 26.67 & 30.48 & 31.52 & 29.11 \\
\hline
\end{tabular}


TOTAL DEBT

\begin{tabular}{lllllll}
\hline Procedure & Sample & \multicolumn{5}{c}{ \%Mis-classifications } \\
\cline { 3 - 7 } & & Year1 & Year2 & Year3 & Year4 & Year5 \\
\hline Procedure 1 & Sample1 & 64.00 & 61.86 & 63.06 & 64.00 & 67.44 \\
& Sample2 & 54.40 & 58.82 & 61.54 & 63.74 & 62.82 \\
\hline Procedure 2 & Sample1 & 64.00 & 61.86 & 63.06 & 61.00 & 69.77 \\
& Sample2 & 55.20 & 57.98 & 62.50 & 65.93 & 62.82 \\
\hline
\end{tabular}

NET INCOME TO TOTAL DEBT

\begin{tabular}{lllllll}
\hline Procedure & Sample & \multicolumn{5}{c}{ \%Mis-classifications } \\
\cline { 3 - 7 } & & Year1 & Year2 & Year3 & Year4 & Year5 \\
\hline Procedure 1 & Sample1 & 31.20 & 33.90 & 45.95 & 40.00 & 40.70 \\
& Sample2 & 28.00 & 28.57 & 31.73 & 32.97 & 32.05 \\
\hline Procedure 2 & Sample1 & 34.40 & 33.05 & 44.14 & 42.00 & 39.53 \\
& Sample2 & 29.60 & 27.73 & 31.73 & 31.87 & 29.49 \\
\hline
\end{tabular}

\section{CURRENT LIABILITIES TO TOTAL ASSETS}

\begin{tabular}{llccccc}
\hline Procedure & Sample & \multicolumn{5}{c}{ \%Mis-classifications } \\
\cline { 3 - 7 } & & Year1 & Year2 & Year3 & Year4 & Year5 \\
\hline Procedure 1 & Sample1 & 38.10 & 44.54 & 41.96 & 42.57 & 51.72 \\
& Sample2 & 40.48 & 45.00 & 46.67 & 42.39 & 50.63 \\
\hline Procedure 2 & Sample1 & 35.71 & 42.02 & 41.07 & 42.57 & 51.72 \\
& Sample2 & 39.68 & 45.83 & 46.67 & 40.22 & 50.63 \\
\hline
\end{tabular}


LONG TERM LIABILTIES TO TOTAL ASSETS

\begin{tabular}{llccccc}
\hline Procedure & Sample & \multicolumn{5}{c}{ \%Mis-classifications } \\
\cline { 3 - 7 } & & Year1 & Year2 & Year3 & Year4 & Year5 \\
\hline Procedure 1 & Sample1 & 49.60 & 50.00 & 49.55 & 53.00 & 46.51 \\
& Sample2 & 44.00 & 41.18 & 50.96 & 48.35 & 47.44 \\
\hline Procedure 2 & Sample1 & 50.40 & 53.39 & 53.15 & 57.00 & 52.33 \\
& Sample2 & 44.00 & 44.54 & 50.00 & 49.45 & 50.00 \\
\hline
\end{tabular}

TOTAL DEBT TO TOTAL ASSETS

\begin{tabular}{lllllll}
\hline Procedure & Sample & \multicolumn{5}{c}{ \%Mis-classifications } \\
\cline { 3 - 7 } & & Year1 & Year2 & Year3 & Year4 & Year5 \\
\hline Procedure 1 & Sample1 & 38.40 & 41.53 & 41.44 & 41.00 & 52.33 \\
& Sample2 & 32.00 & 38.66 & 44.23 & 42.86 & 46.15 \\
\hline Procedure 2 & Sample1 & 40.80 & 42.37 & 41.44 & 44.00 & 53.49 \\
& Sample2 & 32.80 & 42.02 & 41.35 & 41.76 & 46.15 \\
\hline
\end{tabular}

TOTAL DEBT PLUS PREF TO TOTAL ASSETS

\begin{tabular}{lllllll}
\hline Procedure & Sample & \multicolumn{5}{c}{ \%Mis-classifications } \\
\cline { 3 - 7 } & & Year1 & Year2 & Year3 & Year4 & Year5 \\
\hline Procedure 1 & Sample1 & 39.20 & 42.37 & 42.34 & 37.00 & 48.84 \\
& Sample2 & 31.45 & 37.82 & 39.42 & 37.36 & 44.87 \\
\hline Procedure 2 & Sample1 & 40.00 & 42.37 & 42.34 & 43.00 & 53.49 \\
& Sample2 & 31.45 & 40.34 & 42.31 & 42.86 & 41.03 \\
\hline
\end{tabular}




\section{CASH TO TOTAL ASSETS}

\begin{tabular}{llccccc}
\hline Procedure & Sample & \multicolumn{5}{c}{ \%Mis-classifications } \\
\cline { 3 - 7 } & & Year1 & Year2 & Year3 & Year4 & Year5 \\
\hline Procedure 1 & Sample1 & 42.11 & 46.30 & 50.00 & 50.00 & 66.67 \\
& Sample2 & 48.08 & 52.94 & 52.27 & 61.90 & 100.00 \\
\hline Procedure 2 & Sample1 & 59.65 & 57.41 & 66.00 & 65.22 & 66.67 \\
& Sample2 & 34.62 & 33.33 & 43.18 & 45.24 & 100.00 \\
\hline
\end{tabular}

QUICK ASSETS

\begin{tabular}{lllllll}
\hline Procedure & Sample & \multicolumn{5}{c}{ \%Mis-classifications } \\
\cline { 3 - 7 } & & Year1 & Year2 & Year3 & Year4 & Year5 \\
\hline Procedure 1 & Sample1 & 36.29 & 38.14 & 34.23 & 29.70 & 36.05 \\
& Sample2 & 25.40 & 30.00 & 28.57 & 21.74 & 29.11 \\
\hline Procedure 2 & Sample1 & 36.29 & 38.14 & 35.14 & 29.70 & 36.05 \\
& Sample2 & 25.40 & 30.00 & 28.57 & 21.74 & 29.11 \\
& & & & & & \\
\hline
\end{tabular}

QUICK ASSETS TO TOTAL ASSETS

\begin{tabular}{lllllll}
\hline Procedure & Sample & \multicolumn{5}{c}{ \%Mis-classifications } \\
\cline { 3 - 7 } & & Year1 & Year2 & Year3 & Year4 & Year5 \\
\cline { 3 - 7 } & & 51.61 & 52.54 & 55.86 & 49.50 & 52.33 \\
\hline Procedure 1 & Sample1 & 39.68 & 53.33 & 48.57 & 50.00 & 48.10 \\
& Sample2 & 50.00 & 50.85 & 54.05 & 50.50 & 50.00 \\
\hline Procedure 2 & Sample1 & 43.65 & 50.00 & 50.48 & 50.00 & 46.84 \\
& Sample2 & & & & & \\
& & & &
\end{tabular}


WORKING CAPITAL

\begin{tabular}{lllllll}
\hline Procedure & Sample & \multicolumn{5}{c}{ \%Mis-classifications } \\
\cline { 3 - 7 } & & Year1 & Year2 & Year3 & Year4 & Year5 \\
\cline { 3 - 7 } & & & & & & \\
\hline Procedure 1 & Sample1 & 35.71 & 39.50 & 35.71 & 35.64 & 34.48 \\
& Sample2 & 26.19 & 30.83 & 30.48 & 27.17 & 35.44 \\
\hline Procedure 2 & Sample1 & 35.71 & 39.50 & 34.82 & 35.64 & 34.48 \\
& Sample2 & 25.40 & 30.83 & 27.62 & 27.17 & 31.65 \\
\hline
\end{tabular}

WORKING CAPITAL TO TOTAL ASSETS

\begin{tabular}{lllllll}
\hline Procedure & Sample & \multicolumn{5}{c}{ \%Mis-classifications } \\
\cline { 3 - 7 } & & Year1 & Year2 & Year3 & Year4 & Year5 \\
\cline { 3 - 7 } & & & & & & \\
\hline Procedure 1 & Sample1 & 40.48 & 50.42 & 46.43 & 47.52 & 49.43 \\
& Sample2 & 31.75 & 46.67 & 48.57 & 48.91 & 49.37 \\
\hline Procedure 2 & Sample1 & 43.65 & 49.58 & 50.00 & 46.53 & 51.72 \\
& Sample2 & 34.92 & 43.33 & 46.67 & 47.83 & 48.10 \\
\hline
\end{tabular}

CASH TO CURRENT LIABILITIES

\begin{tabular}{lllllll}
\hline Procedure & Sample & \multicolumn{5}{c}{ \%Mis-classifications } \\
\cline { 3 - 6 } & & Year1 & Year2 & Year3 & Year4 & Year5 \\
\cline { 3 - 7 } & & & & & & \\
\hline Procedure 1 & Sample1 & 38.18 & 48.08 & 52.08 & 50.00 & 66.67 \\
& Sample2 & 38.46 & 52.94 & 50.00 & 57.14 & 100.00 \\
\hline Procedure 2 & Sample1 & 49.09 & 50.00 & 58.33 & 61.36 & 66.67 \\
& Sample2 & 36.54 & 33.33 & 45.45 & 45.24 & 100.00 \\
\hline
\end{tabular}


QUICK ASSETS TO CURRENT LIABILITIES

\begin{tabular}{lllllll}
\hline Procedure & Sample & \multicolumn{5}{c}{ \%Mis-classifications } \\
\cline { 3 - 7 } & & Year1 & Year2 & Year3 & Year4 & Year5 \\
\cline { 3 - 7 } & & & & & & \\
\hline Procedure 1 & Sample1 & 41.13 & 44.07 & 48.65 & 44.55 & 50.00 \\
& Sample2 & 35.71 & 43.33 & 46.67 & 44.57 & 50.63 \\
\hline Procedure 2 & Sample1 & 41.13 & 44.07 & 49.55 & 50.50 & 55.81 \\
& Sample2 & 33.33 & 42.50 & 43.81 & 41.30 & 49.37 \\
\hline
\end{tabular}

CURRENT RATIO

\begin{tabular}{llccccc}
\hline Procedure & Sample & \multicolumn{5}{c}{ \%Mis-classifications } \\
\cline { 3 - 7 } & & Year1 & Year2 & Year3 & Year4 & Year5 \\
\hline Procedure 1 & Sample1 & 38.89 & 42.02 & 44.64 & 44.55 & 50.57 \\
& Sample2 & 34.13 & 47.50 & 41.90 & 45.65 & 51.90 \\
\hline Procedure 2 & Sample1 & 38.89 & 42.02 & 46.43 & 44.55 & 48.28 \\
& Sample2 & 33.33 & 47.50 & 44.76 & 46.74 & 51.90 \\
\hline
\end{tabular}

CASH TO SALES

\begin{tabular}{llccccc}
\hline Procedure & Sample & \multicolumn{5}{c}{ \%Mis-classifications } \\
\cline { 3 - 7 } & & Year1 & Year2 & Year3 & Year4 & Year5 \\
\hline Procedure 1 & Sample1 & 42.86 & 43.40 & 48.98 & 52.17 & 66.67 \\
& Sample2 & 49.02 & 42.00 & 58.14 & 61.90 & 100.00 \\
\hline Procedure 2 & Sample1 & 46.43 & 52.83 & 55.10 & 54.35 & 66.67 \\
& Sample2 & 43.14 & 40.00 & 53.49 & 54.76 & 50.00 \\
\hline
\end{tabular}




\section{INVENTORY TO SALES}

\begin{tabular}{lllllll}
\hline Procedure & Sample & \multicolumn{5}{c}{ \%Mis-classifications } \\
\cline { 3 - 7 } & & Year1 & Year2 & Year3 & Year4 & Year5 \\
\hline Procedure 1 & Sample1 & 49.18 & 52.59 & 52.25 & 48.00 & 54.12 \\
& Sample2 & 50.00 & 47.41 & 52.94 & 48.89 & 49.35 \\
\hline Procedure 2 & Sample1 & 48.36 & 52.59 & 52.25 & 46.00 & 54.12 \\
& Sample2 & 50.83 & 48.28 & 53.92 & 50.00 & 50.65 \\
\hline
\end{tabular}

QUICK ASSETS TO SALES

\begin{tabular}{lllllll}
\hline Procedure & Sample & \multicolumn{5}{c}{ \%Mis-classifications } \\
\cline { 3 - 7 } & & Year1 & Year2 & Year3 & Year4 & Year5 \\
\hline Procedure 1 & Sample1 & 58.68 & 53.04 & 55.96 & 55.10 & 57.14 \\
& Sample2 & 53.33 & 50.86 & 51.96 & 55.56 & 50.65 \\
\hline Procedure 2 & Sample1 & 55.37 & 51.30 & 57.80 & 56.12 & 59.52 \\
& Sample2 & 51.67 & 54.31 & 51.96 & 47.78 & 44.16 \\
& & & & & & \\
\hline
\end{tabular}

\section{CURRENT ASSETS TO SALES}

\begin{tabular}{lllllll}
\hline Procedure & Sample & \multicolumn{5}{c}{ \%Mis-classifications } \\
\cline { 3 - 7 } & & Year1 & Year2 & Year3 & Year4 & Year5 \\
\hline Procedure 1 & Sample1 & 59.35 & 52.99 & 52.73 & 54.08 & 55.29 \\
& Sample2 & 53.33 & 56.03 & 51.96 & 53.33 & 50.65 \\
\hline Procedure 2 & Sample1 & 56.10 & 52.14 & 53.64 & 55.10 & 57.65 \\
& Sample2 & 52.50 & 52.59 & 50.98 & 51.11 & 50.65 \\
\hline
\end{tabular}




\section{WORKING CAPITAL TO SALES}

\begin{tabular}{lllllll}
\hline Procedure & Sample & \multicolumn{5}{c}{ \%Mis-classifications } \\
\cline { 3 - 7 } & & Year1 & Year2 & Year3 & Year4 & Year5 \\
\hline Procedure 1 & Sample1 & 39.84 & 46.15 & 43.64 & 44.90 & 54.12 \\
& Sample2 & 39.17 & 48.28 & 47.06 & 48.89 & 53.25 \\
\hline Procedure 2 & Sample1 & 43.90 & 47.01 & 51.82 & 54.08 & 57.65 \\
& Sample2 & 35.00 & 40.52 & 45.10 & 48.89 & 49.35 \\
\hline
\end{tabular}

TOTAL ASSETS TO SALES

\begin{tabular}{llccccc}
\hline Procedure & Sample & \multicolumn{5}{c}{ \%Mis-classifications } \\
\cline { 3 - 7 } & & Year1 & Year2 & Year3 & Year4 & Year5 \\
\hline Procedure 1 & Sample1 & 47.20 & 50.42 & 50.00 & 52.00 & 49.43 \\
& Sample2 & 47.50 & 50.86 & 46.08 & 51.11 & 48.05 \\
\hline Procedure 2 & Sample1 & 47.20 & 50.42 & 50.00 & 51.00 & 49.43 \\
& Sample2 & 46.67 & 49.14 & 46.08 & 51.11 & 48.05 \\
\hline
\end{tabular}

BID ASK SPREAD

\begin{tabular}{llccccc}
\hline Procedure & Sample & \multicolumn{5}{c}{ \%Mis-classifications } \\
\cline { 3 - 7 } & & Year1 & Year2 & Year3 & Year4 & Year5 \\
\hline Procedure 1 & Sample1 & 32.26 & 28.93 & 33.33 & 33.01 & 30.59 \\
& Sample2 & 30.40 & 24.37 & 35.58 & 24.18 & 19.74 \\
\hline Procedure 2 & Sample1 & 27.42 & 26.45 & 33.33 & 35.92 & 29.41 \\
& Sample2 & 36.00 & 29.41 & 37.50 & 23.08 & 22.37 \\
\hline
\end{tabular}


HI LO BID ASK SPREAD

\begin{tabular}{lllllll}
\hline Procedure & Sample & \multicolumn{5}{c}{ \%Mis-classifications } \\
\cline { 3 - 7 } & & Year1 & Year2 & Year3 & Year4 & Year5 \\
\cline { 3 - 7 } & & & & & 62.14 & 56.18 \\
\hline Procedure 1 & Sample1 & 55.91 & 58.20 & 64.04 & 53.26 & 60.76 \\
& Sample2 & 59.84 & 57.50 & 59.05 & 60.19 & 55.06 \\
\hline Procedure 2 & Sample1 & 57.48 & 59.02 & 60.53 & 48.91 & 53.16 \\
& Sample2 & 59.06 & 57.50 & 60.00 & & \\
& & & & &
\end{tabular}

\section{CASH FLOW TO SALES}

\begin{tabular}{lllllll}
\hline Procedure & Sample & \multicolumn{5}{c}{ \%Mis-classifications } \\
\cline { 3 - 7 } & & Year1 & Year2 & Year3 & Year4 & Year5 \\
\cline { 3 - 7 } & & & & & 38.46 & 35.53 \\
\hline Procedure 1 & Sample1 & 28.69 & 35.65 & 37.50 & 36.59 & 26.87 \\
& Sample2 & 28.57 & 31.48 & 39.36 & 38.46 & 38.16 \\
\hline Procedure 2 & Sample1 & 29.51 & 33.04 & 38.46 & 37.80 & 28.36 \\
& Sample2 & 27.73 & 30.56 & 40.43 & & \\
& & & &
\end{tabular}

\section{CASH FLOW TO TOTAL ASSETS}

\begin{tabular}{|c|c|c|c|c|c|c|}
\hline \multirow[t]{2}{*}{ Procedure } & \multirow[t]{2}{*}{ Sample } & \multicolumn{5}{|c|}{ \%Mis-classifications } \\
\hline & & Year1 & Year2 & Year3 & Year4 & Year5 \\
\hline \multirow[t]{2}{*}{ Procedure 1} & Sample1 & 27.42 & 30.17 & 40.00 & 34.78 & 36.36 \\
\hline & Sample2 & 27.42 & 29.09 & 38.14 & 32.94 & 28.57 \\
\hline \multirow[t]{2}{*}{ Procedure 2} & Sample1 & 29.84 & 31.03 & 38.10 & 33.70 & 33.77 \\
\hline & Sample2 & 29.84 & 27.27 & 40.21 & 32.94 & 24.29 \\
\hline
\end{tabular}




\section{CASH FLOW TO TOTAL DEBT}

\begin{tabular}{lllllll}
\hline Procedure & Sample & \multicolumn{5}{c}{ \%Mis-classifications } \\
\cline { 3 - 7 } & & Year1 & Year2 & Year3 & Year4 & Year5 \\
\cline { 3 - 7 } & & & & & & \\
\hline Procedure 1 & Sample1 & 31.71 & 33.04 & 40.38 & 40.66 & 40.79 \\
& Sample2 & 29.75 & 29.91 & 36.17 & 34.15 & 29.85 \\
\hline Procedure 2 & Sample1 & 27.64 & 32.17 & 39.42 & 35.16 & 38.16 \\
& Sample2 & 28.10 & 30.84 & 36.17 & 31.71 & 23.88 \\
\hline
\end{tabular}

RETURN

\begin{tabular}{lllllll}
\hline Procedure & Sample & \multicolumn{5}{c}{ \%Mis-classifications } \\
\cline { 3 - 7 } & & Year1 & Year2 & Year3 & Year4 & Year5 \\
\cline { 3 - 7 } & & 72.36 & 67.50 & 41.28 & 55.43 & 45.45 \\
\hline Procedure 1 & Sample1 & 74.17 & 72.57 & 39.39 & 47.67 & 49.35 \\
& Sample2 & 72.36 & 68.33 & 41.28 & 55.43 & 45.45 \\
& Sample1 & 74.17 & 72.57 & 38.38 & 47.67 & 48.05 \\
& Sample2 & & & & & \\
\end{tabular}

STANDARD DEVIATION OF RETURN

\begin{tabular}{lllllll}
\hline Procedure & Sample & \multicolumn{5}{c}{ \%Mis-classifications } \\
\cline { 3 - 7 } & & Year1 & Year2 & Year3 & Year4 & Year5 \\
\cline { 3 - 7 } & & 36.73 & 57.14 & 40.66 & 46.15 & 36.00 \\
\hline Procedure 1 & Sample1 & 41.05 & 47.42 & 40.23 & 34.88 & 40.91 \\
& Sample2 & 34.69 & 53.57 & 43.96 & 46.15 & 40.00 \\
\hline Procedure 2 & Sample1 & 41.05 & 44.33 & 36.78 & 34.88 & 40.91 \\
& Sample2 & & & & & \\
& & & & &
\end{tabular}


BETA

\begin{tabular}{lllllll}
\hline Procedure & Sample & \multicolumn{5}{c}{ \%Mis-classifications } \\
\cline { 3 - 7 } & & Year1 & Year2 & Year3 & Year4 & Year5 \\
\cline { 3 - 7 } & & & & & & \\
\hline Procedure 1 & Sample1 & 56.47 & 26.83 & 32.43 & 60.61 & 63.64 \\
& Sample2 & 57.14 & 34.07 & 28.57 & 41.94 & 45.90 \\
\hline Procedure 2 & Sample1 & 58.82 & 26.83 & 35.14 & 48.48 & 61.82 \\
& Sample2 & 51.65 & 34.07 & 27.27 & 41.94 & 44.26 \\
\hline
\end{tabular}

The best classifying market variables according to the dichotomous test are price, bid-ask spread, and standard deviation. One year before failure, price leads to a $20 \%$ Type I error versus a 44\% type II error, whereas five years before failure it leads to a $36 \%$ Type I error versus a 32\% Type II error. For the bid-ask spread, one year before failure there is a $52 \%$ Type I error versus a $15 \%$ Type II error, but five years before failure it leads to an 18\% Type I error versus a 37\% Type II error. Lastly, the standard deviation predictions have a Type I error of $31 \%$ versus a Type II error of $38 \%$ in year one, and Type I error of $38 \%$ versus a Type II error of $11 \%$ in year five. One key difference with these results and those found previously in the literature is that Type I errors are sometimes lower than Type II errors using this sample. The prior literature consistently found that it was easier to correctly classify non-bankrupt firms than bankrupt firms. While this is not a definitive finding, it does show that market variables are better at correctly classifying firms that under distress, which is of utmost importance. This is consistent with our hypothesis that market variables are good long-term predictors 
of bankruptcy since market variables take into account future events, making them forward-looking variables.

Accounting ratios perform relatively well, but a clear pattern persists. Cash flow to total assets provides a Type I error of $15 \%$ versus a Type II error of $47 \%$ in year one, and a Type I error of $36 \%$ versus a Type II error of $33 \%$ in year five. Net income to total asset leads to a Type I error of $22 \%$ versus a Type II error of $52 \%$ in year one, and a Type I error of $46 \%$ versus a Type II error of $37 \%$ in year five. Net income to sales produce a Type I error of $20 \%$ versus a Type II error of $31 \%$ on year before bankruptcy, and Type I error of $51 \%$ versus a Type II error of $15 \%$ five years before bankruptcy. For working capital to total assets, the Type I and Type II errors in year one are $34 \%$ versus $54 \%$, and $49 \%$ versus $54 \%$ in year five, respectively. For the most part, Type I errors are smaller than Type II errors one year before failure, whereas Type I errors are larger than Type II errors five years before failure. This validates the idea that accounting ratios are backward-looking. By the time accounting ratios begin to correctly signal that firms are under distress, bankruptcy is imminent. This does not mean that these ratios are not important in the predictive process; it just means that there is more to the story. This finding, along with the above mentioned finding that market variables have overall lower Type I errors, are important findings. Any bankruptcy prediction model and/or research should include both accounting ratios and market variables to capture both short-term and long-term information. 
Table 3

Contingency Table Results for Classification Tests of Ratios

This table presents the contingency tables of classifying firms as either bankrupt or nonbankrupt by using a cutoff point for each variable or ratio that minimizes the misclassification rate. Procedure 2 classifies firms in each sample by using a cutoff derived from the other sample. Year 1 is one year before bankruptcy and year 5 is five years before bankruptcy.

SHROUT - Year1

\begin{tabular}{lcccrr}
\hline \multirow{2}{*}{ Procedure } & \multirow{2}{*}{ Sample } & Predicted & Bankrupt & Nonbankrupt & \multirow{2}{*}{ Total } \\
\cline { 3 - 5 } & & Bankrupt & 37 & 24 & 61 \\
& Sample1 & Nonbankrupt & 27 & 39 & 66 \\
& & 64 & 63 & 127 \\
\hline & Total & \% Mis classifications $=40.15$ & \\
\hline & Sample2 & Bankrupt & 38 & 20 & 58 \\
& Nonbankrupt & 35 & 34 & 69 \\
& & Total & 73 & 54 & 127 \\
\hline & & \% Mis classifications $=43.30$ & \\
\hline
\end{tabular}

SHROUT - Year 4

\begin{tabular}{|c|c|c|c|c|c|}
\hline \multirow[b]{2}{*}{ Procedure } & \multirow[b]{2}{*}{ Sample } & \multirow[b]{2}{*}{ Predicted } & \multicolumn{2}{|c|}{ Actual } & \multirow[b]{2}{*}{ Total } \\
\hline & & & Bankrupt & Nonbankrupt & \\
\hline \multirow[t]{8}{*}{ Procedure 2} & Sample1 & Bankrupt & 30 & 25 & 55 \\
\hline & & Nonbankrupt & 14 & 34 & 48 \\
\hline & & Total & 44 & 59 & 103 \\
\hline & & \multicolumn{4}{|c|}{$\%$ Mis classifications $=37.86$} \\
\hline & Sample2 & Bankrupt & 31 & 18 & 49 \\
\hline & & Nonbankrupt & 10 & 33 & 43 \\
\hline & & Total & 41 & 51 & 92 \\
\hline & & \multicolumn{4}{|c|}{$\%$ Mis classifications $=30.43$} \\
\hline
\end{tabular}


SHROUT - Year 5

\begin{tabular}{llcrrr}
\hline \multirow{2}{*}{ Procedure } & & & \multicolumn{2}{c}{ Actual } & \\
\cline { 3 - 4 } Procedure 2 & Sample & Predicted & Bankrupt & Nonbankrupt & Total \\
& & Bankrupt & 24 & 22 & 46 \\
& Nonbankrupt & 13 & 30 & 43 \\
& Total & 37 & 52 & 89 \\
\hline & Sample2 & Bankrupt & \% Mis classifications $=39.32$ & 40 \\
& & 23 & 17 & 39 \\
& & Nonbankrupt & 10 & 29 & 79 \\
\hline & Total & 33 & 46 & \\
\hline
\end{tabular}

PRC- Year1

\begin{tabular}{|c|c|c|c|c|c|}
\hline \multirow[b]{2}{*}{ Procedure } & \multirow[b]{2}{*}{ Sample } & \multirow[b]{2}{*}{ Predicted } & \multicolumn{2}{|c|}{ Actual } & \multirow[b]{2}{*}{ Total } \\
\hline & & & Bankrupt & Nonbankrupt & \\
\hline \multirow[t]{7}{*}{ Procedure 2} & Sample1 & Bankrupt & 47 & 25 & 72 \\
\hline & & Nonbankrupt & 16 & 37 & 53 \\
\hline & & Total & 63 & 62 & 125 \\
\hline & & \multicolumn{4}{|c|}{$\%$ Mis classifications $=32.8$} \\
\hline & Sample2 & Bankrupt & 59 & 24 & 83 \\
\hline & & Nonbankrupt & 14 & 30 & 44 \\
\hline & & Total & 73 & 54 & 127 \\
\hline
\end{tabular}

$\%$ Mis classifications $=29.92$

PRC - Year 4

\begin{tabular}{|c|c|c|c|c|c|}
\hline \multirow[b]{2}{*}{ Procedure } & \multirow[b]{2}{*}{ Sample } & \multirow[b]{2}{*}{ Predicted } & \multicolumn{2}{|c|}{ Actual } & \multirow[b]{2}{*}{ Total } \\
\hline & & & Bankrupt & Nonbankrupt & \\
\hline \multirow[t]{7}{*}{ Procedure 2} & Sample1 & Bankrupt & 22 & 14 & 36 \\
\hline & & Nonbankrupt & 22 & 45 & 67 \\
\hline & & Total & 44 & 59 & 103 \\
\hline & & \multicolumn{4}{|c|}{$\%$ Mis classifications $=34.95$} \\
\hline & Sample2 & Bankrupt & 26 & 17 & 43 \\
\hline & & Nonbankrupt & 15 & 34 & 49 \\
\hline & & Total & 41 & 51 & 92 \\
\hline
\end{tabular}


PRC- Year 5

\begin{tabular}{|c|c|c|c|c|c|}
\hline \multirow[b]{2}{*}{ Procedure } & \multirow[b]{2}{*}{ Sample } & \multirow[b]{2}{*}{ Predicted } & \multicolumn{2}{|c|}{ Actual } & \multirow[b]{2}{*}{ Total } \\
\hline & & & Bankrupt & Nonbankrupt & \\
\hline \multirow[t]{10}{*}{ Procedure 2} & Sample1 & Bankrupt & 15 & 14 & 29 \\
\hline & & Nonbankrupt & 22 & 38 & 60 \\
\hline & & Total & 37 & 52 & 89 \\
\hline & & \multicolumn{4}{|c|}{$\%$ Mis classifications $=40.44$} \\
\hline & Sample2 & Bankrupt & 21 & 15 & 36 \\
\hline & & Nonbankrupt & 12 & 31 & 43 \\
\hline & & Total & 33 & 46 & 79 \\
\hline & & \multicolumn{4}{|c|}{$\%$ Mis classifications $=34.17$} \\
\hline & \multicolumn{5}{|c|}{ VOL - Year1 } \\
\hline & \multirow[b]{2}{*}{ Sample } & \multirow[b]{2}{*}{ Predicted } & \multicolumn{2}{|c|}{ Actual } & \multirow[b]{2}{*}{ Total } \\
\hline Procedure & & & Bankrupt & Nonbankrupt & \\
\hline \multirow[t]{8}{*}{ Procedure 2} & Sample1 & Bankrupt & 38 & 26 & 64 \\
\hline & & Nonbankrupt & 26 & 37 & 63 \\
\hline & & Total & 64 & 63 & 127 \\
\hline & & \multicolumn{4}{|c|}{$\%$ Mis classifications $=40.94$} \\
\hline & Sample2 & Bankrupt & 40 & 22 & 62 \\
\hline & & Nonbankrupt & 33 & 32 & 65 \\
\hline & & Total & 73 & 54 & 127 \\
\hline & & \multicolumn{4}{|c|}{$\%$ Mis classifications $=43.30$} \\
\hline
\end{tabular}

\begin{tabular}{|c|c|c|c|c|c|}
\hline \multirow[b]{3}{*}{ Procedure } & \multicolumn{5}{|c|}{ VOL - Year 4} \\
\hline & \multirow[b]{2}{*}{ Sample } & \multirow[b]{2}{*}{ Predicted } & \multicolumn{2}{|c|}{ Actual } & \multirow[b]{2}{*}{ Total } \\
\hline & & & Bankrupt & Nonbankrupt & \\
\hline \multirow[t]{8}{*}{ Procedure 2} & Sample1 & Bankrupt & 27 & 18 & 45 \\
\hline & & Nonbankrupt & 17 & 41 & 58 \\
\hline & & Total & 44 & 59 & 103 \\
\hline & & \multicolumn{4}{|c|}{$\%$ Mis classifications $=33.98$} \\
\hline & Sample2 & Bankrupt & 31 & 23 & 54 \\
\hline & & Nonbankrupt & 10 & 28 & 38 \\
\hline & & Total & 41 & 51 & 92 \\
\hline & & & $\%$ Mis class & cations $=35.86$ & \\
\hline
\end{tabular}




\begin{tabular}{|c|c|c|c|c|c|}
\hline \multirow[b]{3}{*}{ Procedure } & \multicolumn{5}{|c|}{ VOL - Year 5} \\
\hline & & & & tual & \\
\hline & Sample & Predicted & Bankrupt & Nonbankrupt & Total \\
\hline \multirow[t]{7}{*}{ Procedure 2} & Sample1 & Bankrupt & 27 & 23 & 50 \\
\hline & & Nonbankrupt & 10 & 29 & 39 \\
\hline & & Total & 37 & 52 & 89 \\
\hline & & \multicolumn{4}{|c|}{$\%$ Mis classifications $=37.07$} \\
\hline & Sample2 & Bankrupt & 25 & 18 & 43 \\
\hline & & Nonbankrupt & 8 & 28 & 36 \\
\hline & & Total & 33 & 46 & 79 \\
\hline
\end{tabular}

$\%$ Mis classifications $=32.91$

NET INCOME TO SALES- Year1

\begin{tabular}{lccrrr}
\hline \multirow{2}{*}{ Procedure } & \multirow{2}{*}{ Sample } & Predicted & Bankrupt & Nonbankrupt & \multirow{2}{*}{ Total } \\
\cline { 3 - 5 } & & Bankrupt & 50 & 31 & 81 \\
\hline Procedure 2 & Sample1 & Nonbankrupt & 14 & 29 & 43 \\
& & 64 & 60 & 124 \\
\hline & Total & \% Mis classifications $=36.29$ & \\
\hline & Sample2 & Bankrupt & 54 & 16 & 70 \\
& & Nonbankrupt & 14 & 36 & 50 \\
& & Total & 68 & 52 & 120 \\
\hline & & \% Mis classifications $=25.0$ & \\
\hline
\end{tabular}

NET INCOME TO SALES - Year 4

\begin{tabular}{llcrrrr}
\hline & & \multicolumn{2}{c}{ Actual } & & \\
\cline { 3 - 4 } Procedure & Sample & Predicted & Bankrupt & Nonbankrupt & & Total \\
\hline Procedure 2 & Sample1 & Bankrupt & 25 & 22 & 47 \\
& & Nonbankrupt & 18 & 35 & 53 \\
& Total & 43 & 57 & 100 \\
\hline & & \% Mis classifications $=30.0$ & \\
\hline & Sample2 & Bankrupt & 20 & 10 & 30 \\
& Nonbankrupt & 19 & 41 & 60 \\
& & Total & 39 & 51 & 90 \\
\hline
\end{tabular}


NET INCOME TO SALES - Year 5

\begin{tabular}{llcrrrr}
\hline & & \multicolumn{2}{c}{ Actual } & & \\
\cline { 3 - 4 } Procedure & Sample & Predicted & Bankrupt & Nonbankrupt & & Total \\
\hline Procedure 2 & Sample1 & Bankrupt & 20 & 18 & 38 \\
& & Nonbankrupt & 17 & 32 & 49 \\
& Total & 37 & 50 & 87 \\
\hline & & \% Mis classifications $=40.22$ & \\
\hline & Sample2 & Bankrupt & 15 & 7 & 22 \\
& Nonbankrupt & 16 & 39 & 55 \\
& & Total & 31 & 46 & 77 \\
\hline
\end{tabular}

NET INCOME TO TOTAL ASSETS- Year1

\begin{tabular}{lccrrr}
\hline \multirow{2}{*}{ Procedure } & \multirow{2}{*}{ Sample } & Predicted & Bankrupt & Nonbankrupt & \multirow{2}{*}{ Total } \\
\cline { 3 - 4 } Procedure 2 & Sample1 & Bankrupt & 51 & 33 & 84 \\
& & Nonbankrupt & 14 & 30 & 44 \\
& Total & 65 & 63 & 128 \\
\hline & & \% Mis classifications $=36.71$ & \\
\hline & Sample2 & Bankrupt & 57 & 19 & 76 \\
& & Nonbankrupt & 15 & 35 & 50 \\
& Total & 72 & 54 & 126 \\
\hline
\end{tabular}

NET INCOME TO TOTAL ASSETS - Year 4

\begin{tabular}{|c|c|c|c|c|c|}
\hline \multirow[b]{2}{*}{ Procedure } & \multirow[b]{2}{*}{ Sample } & \multirow[b]{2}{*}{ Predicted } & \multicolumn{2}{|c|}{ Actual } & \multirow[b]{2}{*}{ Total } \\
\hline & & & Bankrupt & Nonbankrupt & \\
\hline \multirow[t]{8}{*}{ Procedure 2} & Sample1 & Bankrupt & 26 & 24 & 50 \\
\hline & & Nonbankrupt & 18 & 35 & 53 \\
\hline & & Total & 44 & 59 & 103 \\
\hline & & \multicolumn{4}{|c|}{$\%$ Mis classifications $=40.77$} \\
\hline & Sample2 & Bankrupt & 22 & 10 & 32 \\
\hline & & Nonbankrupt & 19 & 41 & 60 \\
\hline & & Total & 41 & 51 & 92 \\
\hline & & \multicolumn{4}{|c|}{$\%$ Mis classifications $=31.52$} \\
\hline
\end{tabular}


NET INCOME TO TOTAL ASSETS - Year 5

\begin{tabular}{|c|c|c|c|c|c|}
\hline \multirow[b]{2}{*}{ Procedure } & \multirow[b]{2}{*}{ Sample } & \multirow[b]{2}{*}{ Predicted } & \multicolumn{2}{|c|}{ Actual } & \multirow[b]{2}{*}{ Total } \\
\hline & & & Bankrupt & Nonbankrupt & \\
\hline \multirow[t]{8}{*}{ Procedure 2} & Sample1 & Bankrupt & 20 & 19 & 39 \\
\hline & & Nonbankrupt & 17 & 33 & 50 \\
\hline & & Total & 37 & 52 & 89 \\
\hline & & \multicolumn{4}{|c|}{$\%$ Mis classifications $=40.44$} \\
\hline & Sample2 & Bankrupt & 16 & 6 & 22 \\
\hline & & Nonbankrupt & 17 & 40 & 57 \\
\hline & & Total & 33 & 46 & 79 \\
\hline & & \multicolumn{4}{|c|}{$\%$ Mis classifications $=29.11$} \\
\hline
\end{tabular}

NET INCOME TO TOTAL DEBT- Year1

\begin{tabular}{|c|c|c|c|c|c|}
\hline \multirow[b]{2}{*}{ Procedure } & \multirow{2}{*}{ Sample } & \multirow[b]{2}{*}{ Predicted } & \multicolumn{2}{|c|}{ Actual } & \multirow[b]{2}{*}{ Total } \\
\hline & & & Bankrupt & Nonbankrupt & \\
\hline \multirow[t]{8}{*}{ Procedure 2} & Sample1 & Bankrupt & 51 & 30 & 81 \\
\hline & & Nonbankrupt & 13 & 31 & 44 \\
\hline & & Total & 64 & 61 & 125 \\
\hline & & \multicolumn{4}{|c|}{$\%$ Mis classifications $=34.4$} \\
\hline & Sample2 & Bankrupt & 54 & 19 & 73 \\
\hline & & Nonbankrupt & 18 & 34 & 52 \\
\hline & & Total & 72 & 53 & 125 \\
\hline & & & $\%$ Mis clas & ications $=29.6$ & \\
\hline
\end{tabular}

NET INCOME TO TOTAL DEBT - Year 4

\begin{tabular}{lccccr}
\hline & & \multicolumn{2}{c}{ Actual } & \\
\cline { 3 - 4 } Procedure & Sample & Predicted & Bankrupt & Nonbankrupt & Total \\
\hline Procedure 2 & Sample1 & Bankrupt & 24 & 23 & 47 \\
& & Nonbankrupt & 19 & 34 & 53 \\
& Total & 43 & 57 & 100 \\
\hline & & \% Mis classifications $=42.0$ & \\
\hline & Sample2 & Bankrupt & 22 & 10 & 32 \\
& & Nonbankrupt & 19 & 40 & 59 \\
& & Total & 41 & 50 & 91 \\
\hline & & \% Mis classifications $=31.86$ & \\
\hline
\end{tabular}


NET INCOME TO TOTAL DEBT - Year 5

\begin{tabular}{llcrrrr}
\hline & & \multicolumn{2}{c}{ Actual } & & \\
\cline { 3 - 4 } Procedure & Sample & Predicted & Bankrupt & Nonbankrupt & & Total \\
\hline Procedure 2 & Sample1 & Bankrupt & 20 & 18 & 38 \\
& & Nonbankrupt & 16 & 32 & 48 \\
& Total & 36 & 50 & 86 \\
\hline & & \% Mis classifications $=39.53$ & \\
\hline & Sample2 & Bankrupt & 16 & 6 & 22 \\
& Nonbankrupt & 17 & 39 & 56 \\
& & Total & 33 & 45 & 78 \\
\hline
\end{tabular}

\section{CASH TO TOTAL ASSETS- Year1}

\begin{tabular}{|c|c|c|c|c|c|}
\hline \multirow[b]{2}{*}{ Procedure } & \multirow[b]{2}{*}{ Sample } & \multirow[b]{2}{*}{ Predicted } & \multicolumn{2}{|c|}{ Actual } & \multirow[b]{2}{*}{ Total } \\
\hline & & & Bankrupt & Nonbankrupt & \\
\hline \multirow[t]{7}{*}{ Procedure 2} & Sample1 & Bankrupt & 4 & 33 & 37 \\
\hline & & Nonbankrupt & 1 & 19 & 20 \\
\hline & & Total & 5 & 52 & 57 \\
\hline & & \multicolumn{4}{|c|}{$\%$ Mis classifications $=59.64$} \\
\hline & Sample2 & Bankrupt & 0 & 15 & 15 \\
\hline & & Nonbankrupt & 3 & 34 & 37 \\
\hline & & Total & 3 & 49 & 52 \\
\hline
\end{tabular}

CASH TO TOTAL ASSETS - Year 4

\begin{tabular}{|c|c|c|c|c|c|}
\hline \multirow[b]{2}{*}{ Procedure } & \multirow[b]{2}{*}{ Sample } & \multirow[b]{2}{*}{ Predicted } & \multicolumn{2}{|c|}{ Actual } & \multirow[b]{2}{*}{ Total } \\
\hline & & & Bankrupt & Nonbankrupt & \\
\hline \multirow[t]{8}{*}{ Procedure 2} & Sample1 & Bankrupt & 1 & 30 & 31 \\
\hline & & Nonbankrupt & 0 & 15 & 15 \\
\hline & & Total & 1 & 45 & 46 \\
\hline & & \multicolumn{4}{|c|}{$\%$ Mis classifications $=65.21$} \\
\hline & Sample2 & Bankrupt & & 19 & 19 \\
\hline & & Nonbankrupt & & 23 & 23 \\
\hline & & Total & & 42 & 42 \\
\hline & & \multicolumn{4}{|c|}{$\%$ Mis classifications $=45.23$} \\
\hline
\end{tabular}


CASH TO TOTAL ASSETS - Year 5

\begin{tabular}{|c|c|c|c|c|c|}
\hline \multirow[b]{2}{*}{ Procedure } & \multirow[b]{2}{*}{ Sample } & \multirow[b]{2}{*}{ Predicted } & \multicolumn{2}{|c|}{ Actual } & \multirow[b]{2}{*}{ Total } \\
\hline & & & Bankrupt & Nonbankrupt & \\
\hline \multirow[t]{7}{*}{ Procedure 2} & Sample1 & Bankrupt & 1 & 2 & 3 \\
\hline & & Nonbankrupt & & & \\
\hline & & Total & 1 & 2 & 3 \\
\hline & & \multicolumn{4}{|c|}{$\%$ Mis classifications $=66.67$} \\
\hline & Sample2 & Bankrupt & & 2 & 2 \\
\hline & & Nonbankrupt & & & \\
\hline & & Total & & 2 & 2 \\
\hline
\end{tabular}

QUICK ASSETS- Year1

\begin{tabular}{|c|c|c|c|c|c|}
\hline \multirow[b]{2}{*}{ Procedure } & \multirow[b]{2}{*}{ Sample } & \multirow[b]{2}{*}{ Predicted } & \multicolumn{2}{|c|}{ Actual } & \multirow[b]{2}{*}{ Total } \\
\hline & & & Bankrupt & Nonbankrupt & \\
\hline \multirow[t]{7}{*}{ Procedure 2} & Sample1 & Bankrupt & 42 & 23 & 65 \\
\hline & & Nonbankrupt & 22 & 37 & 59 \\
\hline & & Total & 64 & 60 & 124 \\
\hline & & \multicolumn{4}{|c|}{$\%$ Mis classifications $=36.29$} \\
\hline & Sample2 & Bankrupt & 53 & 13 & 66 \\
\hline & & Nonbankrupt & 19 & 41 & 60 \\
\hline & & Total & 72 & 54 & 126 \\
\hline
\end{tabular}

$\%$ Mis classifications $=25.39$

QUICK ASSETS - Year 4

\begin{tabular}{llcrrrr}
\hline & & \multicolumn{2}{c}{ Actual } & & \\
\cline { 3 - 4 } Procedure & Sample & Predicted & Bankrupt & Nonbankrupt & & Total \\
\hline Procedure 2 & Sample1 & Bankrupt & 30 & 16 & 46 \\
& & Nonbankrupt & 14 & 41 & 55 \\
& Total & 44 & 57 & 101 \\
\hline & & \% Mis classifications $=29.70$ & \\
\hline & Sample2 & Bankrupt & 32 & 11 & 43 \\
& Nonbankrupt & 9 & 40 & 49 \\
& & Total & 41 & 51 & 92 \\
\hline
\end{tabular}


QUICK ASSETS - Year 5

\begin{tabular}{|c|c|c|c|c|c|}
\hline \multirow[b]{2}{*}{ Procedure } & \multirow[b]{2}{*}{ Sample } & \multirow[b]{2}{*}{ Predicted } & \multicolumn{2}{|c|}{ Actual } & \multirow[b]{2}{*}{ Total } \\
\hline & & & Bankrupt & Nonbankrupt & \\
\hline \multirow[t]{8}{*}{ Procedure 2} & Sample1 & Bankrupt & 27 & 21 & 48 \\
\hline & & Nonbankrupt & 10 & 28 & 38 \\
\hline & & Total & 37 & 49 & 86 \\
\hline & & \multicolumn{4}{|c|}{$\%$ Mis classifications $=36.04$} \\
\hline & Sample2 & Bankrupt & 26 & 16 & 42 \\
\hline & & Nonbankrupt & 7 & 30 & 37 \\
\hline & & Total & 33 & 46 & 79 \\
\hline & & \multicolumn{4}{|c|}{$\%$ Mis classifications $=29.11$} \\
\hline
\end{tabular}

QUICK ASSETS TO TOTAL ASSETS- Year1

\begin{tabular}{|c|c|c|c|c|c|}
\hline \multirow[b]{2}{*}{ Procedure } & \multirow[b]{2}{*}{ Sample } & \multirow[b]{2}{*}{ Predicted } & \multicolumn{2}{|c|}{ Actual } & \multirow[b]{2}{*}{ Total } \\
\hline & & & Bankrupt & Nonbankrupt & \\
\hline \multirow[t]{7}{*}{ Procedure 2} & Sample1 & Bankrupt & 39 & 37 & 76 \\
\hline & & Nonbankrupt & 25 & 23 & 48 \\
\hline & & Total & 64 & 60 & 124 \\
\hline & & \multicolumn{4}{|c|}{$\%$ Mis classifications $=50.0$} \\
\hline & Sample2 & Bankrupt & 37 & 20 & 57 \\
\hline & & Nonbankrupt & 35 & 34 & 69 \\
\hline & & Total & 72 & 54 & 126 \\
\hline
\end{tabular}

QUICK ASSETS TO TOTAL ASSETS - Year 4

\begin{tabular}{lccrrrr}
\hline & & \multicolumn{2}{c}{ Actual } & & \\
\cline { 3 - 4 } Procedure & Sample & Predicted & Bankrupt & Nonbankrupt & & Total \\
\hline Procedure 2 & Sample1 & Bankrupt & 27 & 34 & 61 \\
& & Nonbankrupt & 17 & 23 & 40 \\
& Total & 44 & 57 & 101 \\
\hline & & \% Mis classifications $=50.49$ & \\
\hline & Sample2 & Bankrupt & 17 & 22 & 39 \\
& Nonbankrupt & 24 & 29 & 53 \\
& & Total & 41 & 51 & \\
\hline & & \% Mis classifications $=50.0$ & \\
\hline
\end{tabular}


QUICK ASSETS TO TOTAL ASSETS - Year 5

\begin{tabular}{llcrrr}
\hline \multirow{2}{*}{ Procedure } & & & \multicolumn{2}{c}{ Actual } & \\
\cline { 3 - 4 } Procedure 2 & Sample & Predicted & Bankrupt & Nonbankrupt & Total \\
& & Bankrupt & 22 & 28 & 50 \\
& & Nonbankrupt & 15 & 21 & 36 \\
& Total & 37 & 49 & 86 \\
\hline & Sample2 & Bankrupt & \% Mis classifications $=50.0$ & 30 \\
& & 13 & 17 & 49 \\
& & Nonbankrupt & 20 & 29 & 79 \\
\hline & & Total & 33 & 46 & \\
\hline
\end{tabular}

QUICK ASSETS TO SALES- Year1

\begin{tabular}{|c|c|c|c|c|c|}
\hline \multirow[b]{2}{*}{ Procedure } & \multirow[b]{2}{*}{ Sample } & \multirow[b]{2}{*}{ Predicted } & \multicolumn{2}{|c|}{ Actual } & \multirow[b]{2}{*}{ Total } \\
\hline & & & Bankrupt & Nonbankrupt & \\
\hline \multirow[t]{8}{*}{ Procedure 2} & Sample1 & Bankrupt & 29 & 33 & 62 \\
\hline & & Nonbankrupt & 34 & 25 & 59 \\
\hline & & Total & 63 & 58 & 121 \\
\hline & & \multicolumn{4}{|c|}{$\%$ Mis classifications $=52.89$} \\
\hline & Sample2 & Bankrupt & 23 & 17 & 40 \\
\hline & & Nonbankrupt & 45 & 35 & 80 \\
\hline & & Total & 68 & 52 & 120 \\
\hline & & \multicolumn{4}{|c|}{$\%$ Mis classifications $=51.67$} \\
\hline
\end{tabular}

QUICK ASSETS TO SALES - Year 4

\begin{tabular}{|c|c|c|c|c|c|}
\hline \multirow[b]{2}{*}{ Procedure } & \multirow[b]{2}{*}{ Sample } & \multirow[b]{2}{*}{ Predicted } & \multicolumn{2}{|c|}{ Actual } & \multirow[b]{2}{*}{ Total } \\
\hline & & & Bankrupt & Nonbankrupt & \\
\hline \multirow[t]{8}{*}{ Procedure 2} & Sample1 & Bankrupt & 24 & 36 & 60 \\
\hline & & Nonbankrupt & 19 & 19 & 38 \\
\hline & & Total & 43 & 55 & 98 \\
\hline & & \multicolumn{4}{|c|}{$\%$ Mis classifications $=56.12$} \\
\hline & Sample2 & Bankrupt & 17 & 21 & 38 \\
\hline & & Nonbankrupt & 22 & 30 & 52 \\
\hline & & Total & 39 & 51 & 90 \\
\hline & & \multicolumn{4}{|c|}{$\%$ Mis classifications $=47.78$} \\
\hline
\end{tabular}


QUICK ASSETS TO SALES - Year 5

\begin{tabular}{|c|c|c|c|c|c|}
\hline \multirow[b]{2}{*}{ Procedure } & \multirow[b]{2}{*}{ Sample } & \multirow[b]{2}{*}{ Predicted } & \multicolumn{2}{|c|}{ Actual } & \multirow[b]{2}{*}{ Total } \\
\hline & & & Bankrupt & Nonbankrupt & \\
\hline \multirow[t]{8}{*}{ Procedure 2} & Sample1 & Bankrupt & 18 & 31 & 49 \\
\hline & & Nonbankrupt & 19 & 16 & 35 \\
\hline & & Total & 37 & 47 & 84 \\
\hline & & \multicolumn{4}{|c|}{$\%$ Mis classifications $=59.52$} \\
\hline & Sample2 & Bankrupt & 14 & 17 & 31 \\
\hline & & Nonbankrupt & 17 & 29 & 46 \\
\hline & & Total & 31 & 46 & 77 \\
\hline & & \multicolumn{4}{|c|}{$\%$ Mis classifications $=44.15$} \\
\hline
\end{tabular}

WORKING CAPITAL- Year1

\begin{tabular}{lcccrr}
\hline \multirow{2}{*}{ Procedure } & \multirow{2}{*}{ Sample } & Predicted & Bankrupt & Nonbankrupt & \multirow{2}{*}{ Total } \\
\cline { 3 - 5 } & & Bankrupt & 46 & 26 & 72 \\
& Sample1 & & 19 & 35 & 54 \\
& & Nonbankrupt & 65 & 61 & 126 \\
\hline & Total & \multicolumn{2}{c}{ \% Mis classifications $=35.71$} & \\
\hline & Sample2 & Bankrupt & 54 & 14 & 68 \\
& & Nonbankrupt & 18 & 40 & 58 \\
& & Total & 72 & 54 & 126 \\
\hline
\end{tabular}

WORKING CAPITAL - Year 4

\begin{tabular}{|c|c|c|c|c|c|}
\hline \multirow[b]{2}{*}{ Procedure } & \multirow[b]{2}{*}{ Sample } & \multirow[b]{2}{*}{ Predicted } & \multicolumn{2}{|c|}{ Actual } & \multirow[b]{2}{*}{ Total } \\
\hline & & & Bankrupt & Nonbankrupt & \\
\hline \multirow[t]{8}{*}{ Procedure 2} & Sample1 & Bankrupt & 26 & 18 & 44 \\
\hline & & Nonbankrupt & 18 & 39 & 57 \\
\hline & & Total & 44 & 57 & 101 \\
\hline & & \multicolumn{4}{|c|}{$\%$ Mis classifications $=35.64$} \\
\hline & Sample2 & Bankrupt & 25 & 9 & 34 \\
\hline & & Nonbankrupt & 16 & 42 & 58 \\
\hline & & Total & 41 & 51 & 92 \\
\hline & & \multicolumn{4}{|c|}{$\%$ Mis classifications $=27.17$} \\
\hline
\end{tabular}


WORKING CAPITAL - Year 5

\begin{tabular}{|c|c|c|c|c|c|}
\hline \multirow[b]{2}{*}{ Procedure } & \multirow[b]{2}{*}{ Sample } & \multirow[b]{2}{*}{ Predicted } & \multicolumn{2}{|c|}{ Actual } & \multirow[b]{2}{*}{ Total } \\
\hline & & & Bankrupt & Nonbankrupt & \\
\hline \multirow[t]{7}{*}{ Procedure 2} & Sample1 & Bankrupt & 24 & 17 & 41 \\
\hline & & Nonbankrupt & 13 & 33 & 46 \\
\hline & & Total & 37 & 50 & 87 \\
\hline & & \multicolumn{4}{|c|}{$\%$ Mis classifications $=34.48$} \\
\hline & Sample2 & Bankrupt & 22 & 14 & 36 \\
\hline & & Nonbankrupt & 11 & 32 & 43 \\
\hline & & Total & 33 & 46 & 79 \\
\hline
\end{tabular}

WORKING CAPITAL TO TOTAL ASSETS- Year1

\begin{tabular}{lccrrrr}
\hline \multirow{2}{*}{ Procedure } & \multirow{2}{*}{ Sample } & Predicted & Bankrupt & Nonbankrupt & & \multirow{2}{*}{ Total } \\
\cline { 3 - 4 } & & Sample1 & Bankrupt & 43 & 33 & 76 \\
& Nonbankrupt & 22 & 28 & 50 \\
& Total & 65 & 61 & 126 \\
\hline & & \% Mis classifications $=43.65$ & \\
\hline & Sample2 & Bankrupt & 47 & 19 & 66 \\
& Nonbankrupt & 25 & 35 & 60 \\
& & Total & 72 & 54 & 126 \\
\hline
\end{tabular}

$\%$ Mis classifications $=34.92$

WORKING CAPITAL TO TOTAL ASSETS - Year 4

\begin{tabular}{|c|c|c|c|c|c|}
\hline \multirow[b]{2}{*}{ Procedure } & \multirow[b]{2}{*}{ Sample } & \multirow[b]{2}{*}{ Predicted } & \multicolumn{2}{|c|}{ Actual } & \multirow[b]{2}{*}{ Total } \\
\hline & & & Bankrupt & Nonbankrupt & \\
\hline \multirow[t]{8}{*}{ Procedure 2} & Sample1 & Bankrupt & 24 & 27 & 51 \\
\hline & & Nonbankrupt & 20 & 30 & 50 \\
\hline & & Total & 44 & 57 & 101 \\
\hline & & \multicolumn{4}{|c|}{$\%$ Mis classifications $=46.53$} \\
\hline & Sample2 & Bankrupt & 14 & 17 & 31 \\
\hline & & Nonbankrupt & 27 & 34 & 61 \\
\hline & & Total & 41 & 51 & 92 \\
\hline & & \multicolumn{4}{|c|}{$\%$ Mis classifications $=47.82$} \\
\hline
\end{tabular}


WORKING CAPITAL TO TOTAL ASSETS - Year 5

\begin{tabular}{|c|c|c|c|c|c|}
\hline \multirow[b]{2}{*}{ Procedure } & \multirow[b]{2}{*}{ Sample } & \multirow[b]{2}{*}{ Predicted } & \multicolumn{2}{|c|}{ Actual } & \multirow[b]{2}{*}{ Total } \\
\hline & & & Bankrupt & Nonbankrupt & \\
\hline \multirow[t]{7}{*}{ Procedure 2} & Sample1 & Bankrupt & 19 & 27 & 46 \\
\hline & & Nonbankrupt & 18 & 23 & 41 \\
\hline & & Total & 37 & 50 & 87 \\
\hline & & \multicolumn{4}{|c|}{$\%$ Mis classifications $=51.72$} \\
\hline & Sample2 & Bankrupt & 14 & 19 & 33 \\
\hline & & Nonbankrupt & 19 & 27 & 46 \\
\hline & & Total & 33 & 46 & 79 \\
\hline
\end{tabular}

WORKING CAPITAL TO SALES- Year1

\begin{tabular}{|c|c|c|c|c|c|}
\hline \multirow[b]{2}{*}{ Procedure } & \multirow[b]{2}{*}{ Sample } & \multirow[b]{2}{*}{ Predicted } & \multicolumn{2}{|c|}{ Actual } & \multirow[b]{2}{*}{ Total } \\
\hline & & & Bankrupt & Nonbankrupt & \\
\hline \multirow[t]{8}{*}{ Procedure 2} & Sample1 & Bankrupt & 42 & 32 & 74 \\
\hline & & Nonbankrupt & 22 & 27 & 49 \\
\hline & & Total & 64 & 59 & 123 \\
\hline & & \multicolumn{4}{|c|}{$\%$ Mis classifications $=43.90$} \\
\hline & Sample2 & Bankrupt & 40 & 14 & 54 \\
\hline & & Nonbankrupt & 28 & 38 & 66 \\
\hline & & Total & 68 & 52 & 120 \\
\hline & & & $\%$ Mis clas & ications $=35.0$ & \\
\hline
\end{tabular}

WORKING CAPITAL TO SALES - Year 4

\begin{tabular}{|c|c|c|c|c|c|}
\hline \multirow[b]{2}{*}{ Procedure } & \multirow[b]{2}{*}{ Sample } & \multirow[b]{2}{*}{ Predicted } & \multicolumn{2}{|c|}{ Actual } & \multirow[b]{2}{*}{ Total } \\
\hline & & & Bankrupt & Nonbankrupt & \\
\hline \multirow[t]{7}{*}{ Procedure 2} & Sample1 & Bankrupt & 26 & 36 & 62 \\
\hline & & Nonbankrupt & 17 & 19 & 36 \\
\hline & & Total & 43 & 55 & 98 \\
\hline & & \multicolumn{4}{|c|}{$\%$ Mis classifications $=54.08$} \\
\hline & Sample2 & Bankrupt & 14 & 19 & 33 \\
\hline & & Nonbankrupt & 25 & 32 & 57 \\
\hline & & Total & 39 & 51 & 90 \\
\hline
\end{tabular}


WORKING CAPITAL TO SALES - Year 5

\begin{tabular}{llcrrrr}
\hline & & \multicolumn{2}{c}{ Actual } & & \\
\cline { 3 - 4 } Procedure & Sample & Predicted & Bankrupt & Nonbankrupt & & Total \\
\hline Procedure 2 & Sample1 & Bankrupt & 20 & 32 & 52 \\
& & Nonbankrupt & 17 & 16 & 33 \\
& Total & 37 & 48 & 85 \\
\hline & & \% Mis classifications $=57.64$ & \\
\hline & Sample2 & Bankrupt & 10 & 17 & 27 \\
& Nonbankrupt & 21 & 29 & 50 \\
& & Total & 31 & 46 & 77 \\
\hline
\end{tabular}

CASH TO CURRENT LIABILITIES- Year1

\begin{tabular}{lccrrrr}
\hline \multirow{2}{*}{ Procedure } & \multirow{2}{*}{ Sample } & Predicted & Bankrupt & Nonbankrupt & & \multirow{2}{*}{ Total } \\
\cline { 3 - 5 } & & Sample1 & Bankrupt & 4 & 26 & 30 \\
& Nonbankrupt & 1 & 24 & 25 \\
& Total & 5 & 50 & 55 \\
\hline & & \% Mis classifications $=49.09$ & \\
\hline & Sample2 & Bankrupt & 2 & 18 & 20 \\
& Nonbankrupt & 1 & 31 & 32 \\
& Total & 3 & 49 & 52 \\
\hline
\end{tabular}

$\%$ Mis classifications $=36.53$

CASH TO CURRENT LIABILITIES - Year 4

\begin{tabular}{|c|c|c|c|c|c|}
\hline \multirow[b]{2}{*}{ Procedure } & \multirow[b]{2}{*}{ Sample } & \multirow[b]{2}{*}{ Predicted } & \multicolumn{2}{|c|}{ Actual } & \multirow[b]{2}{*}{ Total } \\
\hline & & & Bankrupt & Nonbankrupt & \\
\hline \multirow[t]{8}{*}{ Procedure 2} & Sample1 & Bankrupt & 1 & 27 & 28 \\
\hline & & Nonbankrupt & 0 & 16 & 16 \\
\hline & & Total & 1 & 43 & 44 \\
\hline & & \multicolumn{4}{|c|}{$\%$ Mis classifications $=61.36$} \\
\hline & Sample2 & Bankrupt & & 19 & 19 \\
\hline & & Nonbankrupt & & 23 & 23 \\
\hline & & Total & & 42 & 42 \\
\hline & & \multicolumn{4}{|c|}{$\%$ Mis classifications $=54.76$} \\
\hline
\end{tabular}


CASH TO CURRENT LIABILITIES - Year 5

\begin{tabular}{|c|c|c|c|c|c|}
\hline \multirow[b]{2}{*}{ Procedure } & \multirow[b]{2}{*}{ Sample } & \multirow[b]{2}{*}{ Predicted } & \multicolumn{2}{|c|}{ Actual } & \multirow[b]{2}{*}{ Total } \\
\hline & & & Bankrupt & Nonbankrupt & \\
\hline \multirow[t]{8}{*}{ Procedure 2} & Sample1 & Bankrupt & 1 & 2 & 3 \\
\hline & & Nonbankrupt & & & \\
\hline & & Total & 1 & 2 & 3 \\
\hline & & \multicolumn{4}{|c|}{$\%$ Mis classifications $=66.67$} \\
\hline & Sample2 & Bankrupt & & 2 & 2 \\
\hline & & Nonbankrupt & & & \\
\hline & & Total & & 2 & 2 \\
\hline & & \multicolumn{4}{|c|}{$\%$ Mis classifications $=100.0$} \\
\hline
\end{tabular}

QUICK ASSETS TO CURRENT LIABILITIES- Year1

\begin{tabular}{lcccrr}
\hline \multirow{2}{*}{ Procedure } & \multirow{2}{*}{ Sample } & Predicted & Bankrupt & Nonbankrupt & \multirow{2}{*}{ Total } \\
\cline { 3 - 5 } & & Bankrupt & 43 & 30 & 73 \\
\hline Procedure 2 & Sample1 & Nonbankrupt & 21 & 30 & 51 \\
& & 64 & 60 & 124 \\
\hline & Total & \% Mis classifications $=41.12$ & \\
\hline & Sample2 & Bankrupt & 46 & 16 & 62 \\
& Nonbankrupt & 26 & 38 & 64 \\
& Total & 72 & 54 & 126 \\
\hline & & \% Mis classifications $=33.33$ & \\
\hline
\end{tabular}

QUICK ASSETS TO CURRENT LIABILITIES - Year 4

\begin{tabular}{|c|c|c|c|c|c|}
\hline \multirow[b]{2}{*}{ Procedure } & \multirow[b]{2}{*}{ Sample } & \multirow[b]{2}{*}{ Predicted } & \multicolumn{2}{|c|}{ Actual } & \multirow[b]{2}{*}{ Total } \\
\hline & & & Bankrupt & Nonbankrupt & \\
\hline \multirow[t]{8}{*}{ Procedure 2} & Sample1 & Bankrupt & 26 & 33 & 59 \\
\hline & & Nonbankrupt & 18 & 24 & 42 \\
\hline & & Total & 44 & 57 & 101 \\
\hline & & \multicolumn{4}{|c|}{$\%$ Mis classifications $=50.49$} \\
\hline & Sample2 & Bankrupt & 17 & 14 & 31 \\
\hline & & Nonbankrupt & 24 & 37 & 61 \\
\hline & & Total & 41 & 51 & 92 \\
\hline & & \multicolumn{4}{|c|}{$\%$ Mis classifications $=41.3$} \\
\hline
\end{tabular}


QUICK ASSETS TO CURRENT LIABILITIES - Year 5

\begin{tabular}{llcrrrr}
\hline \multirow{2}{*}{ Procedure } & & & \multicolumn{2}{c}{ Actual } & & \\
\cline { 3 - 4 } Procedure 2 & Sample & Predicted & Bankrupt & Nonbankrupt & & Total \\
& & Bankrupt & 18 & 29 & 47 \\
& Nonbankrupt & 19 & 20 & 39 \\
& Total & 37 & 49 & 86 \\
\hline & & \% Mis classifications $=55.81$ & \\
\hline & Sample2 & Bankrupt & 12 & 18 & 30 \\
& Nonbankrupt & 21 & 28 & 49 \\
& Total & 33 & 46 & 79 \\
\hline
\end{tabular}

$\%$ Mis classifications $=49.36$

\begin{tabular}{lccrrr}
\multicolumn{5}{c}{ CURRENT RATIO- Year1 } \\
\hline \multirow{2}{*}{ Procedure } & \multirow{2}{*}{ Sample } & Predicted & Bankrupt & Nonbankrupt & \multirow{2}{*}{ Total } \\
\cline { 3 - 4 } & Sample1 & Bankrupt & 42 & 26 & 68 \\
& & Nonbankrupt & 23 & 35 & 58 \\
& Total & 65 & 61 & 126 \\
\hline & & \% Mis classifications $=38.89$ & \\
\hline & Sample2 2 & Bankrupt & 52 & 22 & 74 \\
& & Nonbankrupt & 20 & 32 & 52 \\
& & Total & 72 & 54 & 126 \\
\hline
\end{tabular}

CURRENT RATIO - Year 4

\begin{tabular}{|c|c|c|c|c|c|}
\hline \multirow[b]{2}{*}{ Procedure } & \multirow[b]{2}{*}{ Sample } & \multirow[b]{2}{*}{ Predicted } & \multicolumn{2}{|c|}{ Actual } & \multirow[b]{2}{*}{ Total } \\
\hline & & & Bankrupt & Nonbankrupt & \\
\hline \multirow[t]{8}{*}{ Procedure 2} & Sample1 & Bankrupt & 23 & 24 & 47 \\
\hline & & Nonbankrupt & 21 & 33 & 54 \\
\hline & & Total & 44 & 57 & 101 \\
\hline & & \multicolumn{4}{|c|}{$\%$ Mis classifications $=44.55$} \\
\hline & Sample2 & Bankrupt & 19 & 21 & 40 \\
\hline & & Nonbankrupt & 22 & 30 & 52 \\
\hline & & Total & 41 & 51 & 92 \\
\hline & & \multicolumn{4}{|c|}{$\%$ Mis classifications $=46.73$} \\
\hline
\end{tabular}




\section{CURRENT RATIO - Year 5}

\begin{tabular}{llcrrr}
\hline & & \multicolumn{2}{c}{ Actual } & \\
\cline { 3 - 4 } Procedure & Sample & Predicted & Bankrupt & Nonbankrupt & Total \\
\hline Procedure 2 & Sample1 & Bankrupt & 19 & 24 & 43 \\
& & 18 & 26 & 44 \\
& Nonbankrupt & 37 & 50 & 87 \\
\hline & Total & \% Mis classifications = 48.27 & 38 \\
& & & 15 & 23 & 41 \\
& Sample2 & Bankrupt & 18 & 23 & 79 \\
\hline & Nonbankrupt & 33 & 46 &
\end{tabular}

\section{CASH TO SALES- Year1}

\begin{tabular}{|c|c|c|c|c|c|}
\hline \multirow[b]{2}{*}{ Procedure } & \multirow[b]{2}{*}{ Sample } & \multirow[b]{2}{*}{ Predicted } & \multicolumn{2}{|c|}{ Actual } & \multirow[b]{2}{*}{ Total } \\
\hline & & & Bankrupt & Nonbankrupt & \\
\hline \multirow[t]{7}{*}{ Procedure 2} & Sample1 & Bankrupt & 4 & 25 & 29 \\
\hline & & Nonbankrupt & 1 & 26 & 27 \\
\hline & & Total & 5 & 51 & 56 \\
\hline & & \multicolumn{4}{|c|}{$\%$ Mis classifications $=46.42$} \\
\hline & Sample2 & Bankrupt & 0 & 20 & 20 \\
\hline & & Nonbankrupt & 2 & 29 & 31 \\
\hline & & Total & 2 & 49 & 51 \\
\hline
\end{tabular}

CASH TO SALES - Year 4

\begin{tabular}{llcrrr}
\hline & & \multicolumn{2}{c}{ Actual } & \\
\cline { 3 - 4 } Procedure & Sample & Predicted & Bankrupt & Nonbankrupt & Total \\
\hline Procedure 2 & Sample1 & Bankrupt & 1 & 25 & 26 \\
& & 0 & 20 & 20 \\
& Nonbankrupt & 1 & 45 & 46 \\
\hline & Total & \% Mis classifications $=54.34$ & 23 \\
& Sample2 & Bankrupt & & 19 & 19 \\
& & Nonbankrupt & & 42 & 42 \\
\hline & & Total & \% Mis classifications $=54.76$ & \\
\hline
\end{tabular}


CASH TO SALES - Year 5

\begin{tabular}{|c|c|c|c|c|c|}
\hline \multirow[b]{2}{*}{ Procedure } & \multirow[b]{2}{*}{ Sample } & \multirow[b]{2}{*}{ Predicted } & \multicolumn{2}{|c|}{ Actual } & \multirow[b]{2}{*}{ Total } \\
\hline & & & Bankrupt & Nonbankrupt & \\
\hline \multirow[t]{8}{*}{ Procedure 2} & Sample1 & Bankrupt & 1 & 2 & . \\
\hline & & Nonbankrupt & & & \\
\hline & & Total & 1 & 2 & 3 \\
\hline & & \multicolumn{4}{|c|}{$\%$ Mis classifications $=66.67$} \\
\hline & Sample2 & Bankrupt & & 1 & 1 \\
\hline & & Nonbankrupt & & 1 & 1 \\
\hline & & Total & & 2 & 2 \\
\hline & & \multicolumn{4}{|c|}{$\%$ Mis classifications $=50.0$} \\
\hline
\end{tabular}

CURRENT ASSETS TO SALES- Year1

\begin{tabular}{lccrrr}
\hline \multirow{2}{*}{ Procedure } & \multirow{2}{*}{ Sample } & Predicted & Bankrupt & Nonbankrupt & \\
\cline { 3 - 5 } & & Bankrupt & 31 & 36 & Total \\
\hline Procedure 2 & Sample1 & Nonbankrupt & 33 & 23 & 67 \\
& & 64 & 59 & 56 \\
& & Total & \% Mis classifications $=56.09$ & 123 \\
\hline & Sample2 & Bankrupt & 22 & 17 & 39 \\
& & Nonbankrupt & 46 & 35 & 81 \\
& & Total & 68 & 52 & 120 \\
\hline & & \% Mis classifications $=52.5$ & \\
\hline
\end{tabular}

CURRENT ASSETS TO SALES - Year 4

\begin{tabular}{|c|c|c|c|c|c|}
\hline \multirow[b]{2}{*}{ Procedure } & \multirow[b]{2}{*}{ Sample } & \multirow[b]{2}{*}{ Predicted } & \multicolumn{2}{|c|}{ Actual } & \multirow[b]{2}{*}{ Total } \\
\hline & & & Bankrupt & Nonbankrupt & \\
\hline \multirow[t]{8}{*}{ Procedure 2} & Sample1 & Bankrupt & 26 & 37 & 63 \\
\hline & & Nonbankrupt & 17 & 18 & 35 \\
\hline & & Total & 43 & 55 & 98 \\
\hline & & \multicolumn{4}{|c|}{$\%$ Mis classifications $=55.10$} \\
\hline & Sample2 & Bankrupt & 14 & 21 & 35 \\
\hline & & Nonbankrupt & 25 & 30 & 55 \\
\hline & & Total & 39 & 51 & 90 \\
\hline & & & $\%$ Mis class & cations $=51.11$ & \\
\hline
\end{tabular}


CURRENT ASSETS TO SALES - Year 5

\begin{tabular}{lccrrr}
\hline & & \multicolumn{2}{c}{ Actual } & \\
\cline { 3 - 4 } Procedure & Sample & Predicted & Bankrupt & Nonbankrupt & Total \\
\hline Procedure 2 & Sample1 & Bankrupt & 21 & 33 & 54 \\
& & Nonbankrupt & 16 & 15 & 31 \\
& Total & 37 & 48 & 85 \\
\hline & & \% Mis classifications $=57.64$ & \\
\hline & Sample2 & Bankrupt & 11 & 19 & 30 \\
& Nonbankrupt & 20 & 27 & 47 \\
& Total & 31 & 46 & 77 \\
\hline
\end{tabular}

\begin{tabular}{|c|c|c|c|c|c|}
\hline \multirow[b]{2}{*}{ Procedure } & \multirow[b]{2}{*}{ Sample } & \multirow[b]{2}{*}{ Predicted } & \multicolumn{2}{|c|}{ Actual } & \multirow[b]{2}{*}{ Total } \\
\hline & & & Bankrupt & Nonbankrupt & \\
\hline \multirow[t]{8}{*}{ Procedure 2} & Sample1 & Bankrupt & 0 & 2 & 2 \\
\hline & & Nonbankrupt & 4 & 0 & 4 \\
\hline & & Total & 4 & 2 & 6 \\
\hline & & \multicolumn{4}{|c|}{$\%$ Mis classifications $=100.0$} \\
\hline & Sample2 & Bankrupt & 3 & 0 & 3 \\
\hline & & Nonbankrupt & 3 & 1 & 4 \\
\hline & & Total & 6 & 1 & 7 \\
\hline & & \multicolumn{4}{|c|}{$\%$ Mis classifications $=42.85$} \\
\hline
\end{tabular}

SPREAD - Year 4

\begin{tabular}{lcccrr}
\hline & & \multicolumn{2}{c}{ Actual } & \\
\cline { 3 - 4 } Procedure & Sample & Predicted & Bankrupt & Nonbankrupt & Total \\
\hline Procedure 2 & Sample1 & Bankrupt & 4 & 0 & 4 \\
& Nonbankrupt & 0 & 1 & 1 \\
& Total & 4 & 1 & 5 \\
\hline & & \% Mis classifications $=0$ & 1 \\
& Sample2 & Bankrupt & 1 & 2 \\
& Nonbankrupt & 2 & 3 \\
\hline & Total & 3 & \\
\hline
\end{tabular}


SPREAD - Year 5

\begin{tabular}{llcrrr}
\hline & & \multicolumn{2}{c}{ Actual } & \\
\cline { 3 - 4 } Procedure & Sample & Predicted & Bankrupt & Nonbankrupt & Total \\
\hline Procedure 2 & Sample1 & Bankrupt & 3 & 1 & 4 \\
& & Nonbankrupt & 1 & 1 & 2 \\
& & Total & 4 & 2 & 6 \\
\hline & & \% Mis classifications $=33.33$ & 1 \\
& Sample2 & Bankrupt & 1 & 0 & 5 \\
& Nonbankrupt & 4 & 1 & 6 \\
\hline & Total & 5 & 1 & \\
\hline
\end{tabular}

TOTAL DEBT- Year1

\begin{tabular}{lccrrr}
\hline \multirow{2}{*}{ Procedure } & \multirow{2}{*}{ Sample } & Predicted & Bankrupt & Nonbankrupt & Total \\
\cline { 3 - 5 } & Sample1 & Bankrupt & 29 & 45 & 74 \\
& Nonbankrupt & 35 & 16 & 51 \\
& Total & 64 & 61 & 125 \\
\hline & & \% Mis classifications $=64.0$ & \\
\hline & Sample2 & Bankrupt & 33 & 30 & 63 \\
& Nonbankrupt & 39 & 23 & 62 \\
& & Total & 72 & 53 & 125 \\
\hline & & \% Mis classifications $=55.2$ & \\
\hline
\end{tabular}

TOTAL DEBT - Year 4

\begin{tabular}{llcrrr}
\hline & & \multicolumn{2}{c}{ Actual } & \\
\cline { 3 - 4 } Procedure & Sample & Predicted & Bankrupt & Nonbankrupt & Total \\
\hline Procedure 2 & Sample1 & Bankrupt & 19 & 37 & 56 \\
& & Nonbankrupt & 24 & 20 & 44 \\
& Total & 43 & 57 & 100 \\
\hline & & \% Mis classifications $=61.0$ & \\
\hline & Sample2 & Bankrupt & 11 & 30 & 41 \\
& & Nonbankrupt & 30 & 20 & 50 \\
& Total & 41 & 50 & 91 \\
\hline & & \% Mis classifications $=65.93$ & \\
\hline
\end{tabular}


TOTAL DEBT - Year 5

\begin{tabular}{llcrrr}
\hline & & \multicolumn{2}{c}{ Actual } & \\
\cline { 3 - 4 } Procedure & Sample & Predicted & Bankrupt & Nonbankrupt & Total \\
\hline Procedure 2 & Sample1 & Bankrupt & 10 & 34 & 44 \\
& & Nonbankrupt & 26 & 16 & 42 \\
& Total & 36 & 50 & 86 \\
\hline & & \% Mis classifications $=69.76$ & \\
\hline & Sample2 & Bankrupt & 9 & 25 & 34 \\
& Nonbankrupt & 24 & 20 & 44 \\
& Total & 33 & 45 & 78 \\
\hline
\end{tabular}

CURRENT LIABILITIES TO TOTAL ASSETS- Year1

\begin{tabular}{lccrrr}
\hline \multirow{2}{*}{ Procedure } & \multirow{2}{*}{ Sample } & Predicted & Bankrupt & Nonbankrupt & Total \\
\cline { 3 - 5 } & & Bankrupt & 47 & 27 & 74 \\
Procedure 2 & Sample1 & Nonbankrupt & 18 & 34 & 52 \\
& & 65 & 61 & 126 \\
\hline & Total & \% Mis classifications $=35.71$ & \\
\hline & Sample2 & Bankrupt & 44 & 22 & 66 \\
& Nonbankrupt & 28 & 32 & 60 \\
& & Total & 72 & 54 & 126 \\
\hline & & \% Mis classifications $=39.68$ & \\
\hline
\end{tabular}

CURRENT LIABILITIES TO TOTAL ASSETS - Year 4

\begin{tabular}{llcrrr}
\hline & & \multicolumn{2}{c}{ Actual } & \\
\cline { 3 - 4 } Procedure & Sample & Predicted & Bankrupt & Nonbankrupt & Total \\
\hline Procedure 2 & Sample1 & Bankrupt & 26 & 25 & 51 \\
& & Nonbankrupt & 18 & 32 & 50 \\
& Total & 44 & 57 & 101 \\
\hline & & \% Mis classifications $=42.57$ & \\
\hline & Sample2 & Bankrupt & 23 & 19 & 42 \\
& Nonbankrupt & 18 & 32 & 50 \\
& Total & 41 & 51 & 92 \\
\hline
\end{tabular}

$\%$ Mis classifications $=40.21$ 
CURRENT LIABILITIES TO TOTAL ASSETS - Year 5

\begin{tabular}{lccrrr}
\hline & & \multicolumn{2}{c}{ Actual } & \\
\cline { 3 - 4 } Procedure & Sample & Predicted & Bankrupt & Nonbankrupt & Total \\
\hline Procedure 2 & Sample1 & Bankrupt & 16 & 24 & 40 \\
& & Nonbankrupt & 21 & 26 & 47 \\
& & Total & 37 & 50 & 87 \\
\hline & Sample2 & Bankrupt & 14 & 21 & 35 \\
& & Nonbankrupt & 19 & 25 & 44 \\
& & Total & 33 & 46 & 79 \\
\hline & & $\%$ Mis classifications $=51.72$ &
\end{tabular}

LONGTERM LIABILITIES TO TOTAL ASSETS- Year1

\begin{tabular}{|c|c|c|c|c|c|}
\hline \multirow[b]{2}{*}{ Procedure } & \multirow[b]{2}{*}{ Sample } & \multirow[b]{2}{*}{ Predicted } & \multicolumn{2}{|c|}{ Actual } & \multirow[b]{2}{*}{ Tota } \\
\hline & & & Bankrupt & Nonbankrupt & \\
\hline \multirow[t]{8}{*}{ Procedure 2} & Sample1 & Bankrupt & 38 & 37 & 75 \\
\hline & & Nonbankrupt & 26 & 24 & 50 \\
\hline & & Total & 64 & 61 & 125 \\
\hline & & \multicolumn{4}{|c|}{$\%$ Mis classifications $=50.4$} \\
\hline & Sample2 & Bankrupt & 40 & 23 & 63 \\
\hline & & Nonbankrupt & 32 & 30 & 62 \\
\hline & & Total & 72 & 53 & 125 \\
\hline & & \multicolumn{4}{|c|}{$\%$ Mis classifications $=44.0$} \\
\hline
\end{tabular}

LONGTERM LIABILITIES TO TOTAL ASSETS - Year 4

\begin{tabular}{lccrrr}
\hline \multirow{2}{*}{ Procedure } & & \multicolumn{2}{c}{ Actual } & \\
\cline { 3 - 4 } Procedure 2 & Sample & Predicted & Bankrupt & Nonbankrupt & Total \\
\hline & & Bankrupt & 18 & 32 & 50 \\
& Nonbankrupt & 25 & 25 & 50 \\
& Total & 43 & 57 & 100 \\
\hline & Sample2 & Bankrupt & \% Mis classifications $=57.0$ & 42 \\
& & 19 & 23 & 49 \\
& & Nonbankrupt & 22 & 27 & 91 \\
\hline
\end{tabular}


LONGTERM LIABILITIES TO TOTAL ASSETS - Year 5

\begin{tabular}{llcrrr}
\hline \multirow{2}{*}{ Procedure } & & & \multicolumn{2}{c}{ Actual } & \\
\cline { 3 - 4 } Procedure 2 & Sample & Sample1 & Bankrupt & 19 & Total \\
\cline { 3 - 4 } & & Nonbankrupt & 17 & 28 & 47 \\
& & 36 & 22 & 39 \\
\hline & Total & \% Mis classifications $=52.32$ & 56 \\
\hline & & 11 & 17 & 28 \\
& & Bankrupt & 22 & 28 & 50 \\
& & Nonbankrupt & 33 & 45 & 78 \\
\hline
\end{tabular}

TOTAL DEBT TO TOTAL ASSETS- Year1

\begin{tabular}{|c|c|c|c|c|c|}
\hline \multirow[b]{2}{*}{ Procedure } & \multirow[b]{2}{*}{ Sample } & \multirow[b]{2}{*}{ Predicted } & \multicolumn{2}{|c|}{ Actual } & \multirow[b]{2}{*}{ Tota } \\
\hline & & & Bankrupt & Nonbankrupt & \\
\hline \multirow[t]{8}{*}{ Procedure 2} & Sample1 & Bankrupt & 45 & 32 & 77 \\
\hline & & Nonbankrupt & 19 & 29 & 48 \\
\hline & & Total & 64 & 61 & 125 \\
\hline & & \multicolumn{4}{|c|}{$\%$ Mis classifications $=40.8$} \\
\hline & Sample2 & Bankrupt & 47 & 16 & 63 \\
\hline & & Nonbankrupt & 25 & 37 & 62 \\
\hline & & Total & 72 & 53 & 125 \\
\hline & & \multicolumn{4}{|c|}{$\%$ Mis classifications $=32.8$} \\
\hline
\end{tabular}

TOTAL DEBT TO TOTAL ASSETS - Year 4

\begin{tabular}{|c|c|c|c|c|c|}
\hline \multirow[b]{2}{*}{ Procedure } & \multirow[b]{2}{*}{ Sample } & \multirow[b]{2}{*}{ Predicted } & \multicolumn{2}{|c|}{ Actual } & \multirow[b]{2}{*}{ Tota } \\
\hline & & & Bankrupt & Nonbankrupt & \\
\hline \multirow[t]{8}{*}{ Procedure 2} & Sample1 & Bankrupt & 25 & 26 & 51 \\
\hline & & Nonbankrupt & 18 & 31 & 49 \\
\hline & & Total & 43 & 57 & 100 \\
\hline & & \multicolumn{4}{|c|}{$\%$ Mis classifications $=44.0$} \\
\hline & Sample2 & Bankrupt & 18 & 15 & 33 \\
\hline & & Nonbankrupt & 23 & 35 & 58 \\
\hline & & Total & 41 & 50 & 91 \\
\hline & & \multicolumn{4}{|c|}{$\%$ Mis classifications $=52.74$} \\
\hline
\end{tabular}


TOTAL DEBT TO TOTAL ASSETS - Year 5

\begin{tabular}{lccccr}
\hline & & \multicolumn{2}{c}{ Actual } & \\
\cline { 3 - 4 } Procedure & Sample & Predicted & Bankrupt & Nonbankrupt & Total \\
\hline Procedure 2 & Sample1 & Bankrupt & 15 & 25 & 40 \\
& & Nonbankrupt & 21 & 25 & 46 \\
& Total & 36 & 50 & 86 \\
\hline & & \% Mis classifications $=53.48$ & \\
\hline & Sample2 & Bankrupt & 13 & 16 & 29 \\
& & Nonbankrupt & 20 & 29 & 49 \\
& & Total & 33 & 45 & 78 \\
\hline
\end{tabular}

TOTAL DEBT PLUS PREF TO TOTAL ASSETS- Year1

\begin{tabular}{|c|c|c|c|c|c|}
\hline \multirow[b]{2}{*}{ Procedure } & \multirow[b]{2}{*}{ Sample } & \multirow[b]{2}{*}{ Predicted } & \multicolumn{2}{|c|}{ Actual } & \multirow[b]{2}{*}{ Tota } \\
\hline & & & Bankrupt & Nonbankrupt & \\
\hline \multirow[t]{7}{*}{ Procedure 2} & Sample1 & Bankrupt & 46 & 32 & 78 \\
\hline & & Nonbankrupt & 18 & 29 & 47 \\
\hline & & Total & 64 & 61 & 125 \\
\hline & & \multicolumn{4}{|c|}{$\%$ Mis classifications $=40.0$} \\
\hline & Sample2 & Bankrupt & 48 & 15 & 63 \\
\hline & & Nonbankrupt & 24 & 37 & 61 \\
\hline & & Total & 72 & 52 & 124 \\
\hline
\end{tabular}

$\%$ Mis classifications $=31.45$

TOTAL DEBT PLUS PREF TO TOTAL ASSETS - Year 4

\begin{tabular}{lccrrr}
\hline & & \multicolumn{2}{c}{ Actual } & \\
\cline { 3 - 4 } Procedure & Sample & Predicted & Bankrupt & Nonbankrupt & Total \\
\hline Procedure 2 & Sample1 & Bankrupt & 26 & 26 & 52 \\
& & Nonbankrupt & 17 & 31 & 48 \\
& Total & 43 & 57 & 100 \\
\hline & & $\%$ Mis classifications $=43.0$ & \\
\hline & Sample2 & Bankrupt & 17 & 15 & 32 \\
& & Nonbankrupt & 24 & 35 & 59 \\
& & Total & 41 & 50 & 91 \\
\hline
\end{tabular}


TOTAL DEBT PLUS PREF TO TOTAL ASSETS - Year 5

\begin{tabular}{lccccr}
\hline & & \multicolumn{2}{c}{ Actual } & \\
\cline { 3 - 4 } Procedure & Sample & Predicted & Bankrupt & Nonbankrupt & Total \\
\hline Procedure 2 & Sample1 & Bankrupt & 15 & 25 & 40 \\
& & Nonbankrupt & 21 & 25 & 46 \\
& Total & 36 & 50 & 86 \\
\hline & & \% Mis classifications $=53.48$ & \\
\hline & Sample2 & Bankrupt & 15 & 14 & 29 \\
& Nonbankrupt & 18 & 31 & 49 \\
& Total & 33 & 45 & 78 \\
\hline & & \% Mis classifications $=41.02$ &
\end{tabular}

INVENTORY TO SALES- Year1

\begin{tabular}{lcccrr}
\hline \multirow{2}{*}{ Procedure } & \multirow{2}{*}{ Sample } & Predicted & Bankrupt & Nonbankrupt & \\
\cline { 3 - 4 } & Sample1 & Bankrupt & 32 & 28 & Total \\
\hline & Nonbankrupt & 31 & 31 & 60 \\
& Total & 63 & 59 & 62 \\
& & \% Mis classifications $=52.67$ & 122 \\
\hline & Sample2 & Bankrupt & 34 & 27 & 61 \\
& Nonbankrupt & 34 & 25 & 59 \\
& & Total & 68 & 52 & 120 \\
\hline
\end{tabular}

$\%$ Mis classifications $=50.83$

\section{INVENTORY TO SALES - Year 4}

\begin{tabular}{llcrrr}
\hline & & \multicolumn{2}{c}{ Actual } & \\
\cline { 3 - 4 } Procedure & Sample & Predicted & Bankrupt & Nonbankrupt & Total \\
\hline Procedure 2 & Sample1 & Bankrupt & 22 & 25 & 47 \\
& & Nonbankrupt & 21 & 32 & 53 \\
& Total & 43 & 57 & 100 \\
\hline & & \% Mis classifications = 46.0 & \\
\hline & Sample2 & Bankrupt & 21 & 27 & 48 \\
& & Nonbankrupt & 18 & 24 & 42 \\
& & Total & 39 & 51 & 90 \\
\hline
\end{tabular}


INVENTORY TO SALES - Year 5

\begin{tabular}{lcccrr}
\hline & & \multicolumn{2}{c}{ Actual } & \\
\cline { 3 - 4 } Procedure & Sample & Predicted & Bankrupt & Nonbankrupt & Total \\
\hline Procedure 2 & Sample1 & Bankrupt & 19 & 28 & 47 \\
& & Nonbankrupt & 18 & 20 & 38 \\
& Total & 37 & 48 & 85 \\
\hline & & \% Mis classifications $=54.11$ & \\
\hline & Sample2 & Bankrupt & 16 & 24 & 40 \\
& Nonbankrupt & 15 & 22 & 37 \\
& Total & 31 & 46 & 77 \\
\hline & & \% Mis classifications $=50.64$ &
\end{tabular}

TOTAL ASSETS TO SALES- Year1

\begin{tabular}{|c|c|c|c|c|c|}
\hline \multirow[b]{2}{*}{ Procedure } & \multirow[b]{2}{*}{ Sample } & \multirow[b]{2}{*}{ Predicted } & \multicolumn{2}{|c|}{ Actual } & \multirow[b]{2}{*}{ Tota } \\
\hline & & & Bankrupt & Nonbankrupt & \\
\hline \multirow[t]{7}{*}{ Procedure 2} & Sample1 & Bankrupt & 33 & 28 & 61 \\
\hline & & Nonbankrupt & 31 & 33 & 64 \\
\hline & & Total & 64 & 61 & 125 \\
\hline & & \multicolumn{4}{|c|}{$\%$ Mis classifications $=47.2$} \\
\hline & Sample2 & Bankrupt & 41 & 29 & 70 \\
\hline & & Nonbankrupt & 27 & 23 & 50 \\
\hline & & Total & 68 & 52 & 120 \\
\hline
\end{tabular}

$\%$ Mis classifications $=46.67$

TOTAL ASSETS TO SALES - Year 4

\begin{tabular}{lccccr}
\hline & & \multicolumn{2}{c}{ Actual } & \\
\cline { 3 - 4 } Procedure & Sample & Predicted & Bankrupt & Nonbankrupt & Total \\
\hline Procedure 2 & Sample1 & Bankrupt & 19 & 27 & 46 \\
& & Nonbankrupt & 24 & 30 & 54 \\
& Total & 43 & 57 & 100 \\
\hline & & $\%$ Mis classifications $=51.0$ & 41 \\
& Sample2 & Bankrupt & 17 & 24 & 49 \\
& & Nonbankrupt & 22 & 27 & 90 \\
\hline & Total & 39 & 51 & \\
\hline
\end{tabular}


TOTAL ASSETS TO SALES - Year 5

\begin{tabular}{lccccr}
\hline & & \multicolumn{2}{c}{ Actual } & \\
\cline { 3 - 4 } Procedure & Sample & Predicted & Bankrupt & Nonbankrupt & Total \\
\hline Procedure 2 & Sample1 & Bankrupt & 18 & 24 & 42 \\
& & 19 & 26 & 45 \\
& & Nonbankrupt & 37 & 50 & 87 \\
\hline & Total & \% Mis classifications $=49.42$ & 36 \\
& & & 15 & 21 & 41 \\
& Sample2 & Bankrupt & 16 & 25 & 77 \\
\hline & Nonbankrupt & 31 & 46 &
\end{tabular}

BID ASK SPREAD- Year1

\begin{tabular}{lccrrr}
\hline \multirow{2}{*}{ Procedure } & \multirow{2}{*}{ Sample } & Predicted & Bankrupt & Nonbankrupt & Total \\
\cline { 3 - 5 } & & Bankrupt & 39 & 11 & 50 \\
& Sample1 & Nonbankrupt & 23 & 51 & 74 \\
& & 62 & 62 & 124 \\
\hline & Total & \% Mis classifications = 27.41 & \\
\hline & Sample2 & Bankrupt & 34 & 8 & 42 \\
& Nonbankrupt & 37 & 46 & 83 \\
& Total & 71 & 54 & 125 \\
\hline & & \% Mis classifications $=36.0$ & \\
\hline
\end{tabular}

BID ASK SPREAD - Year 4

\begin{tabular}{lccrrr}
\hline & & \multicolumn{2}{c}{ Actual } & \\
\cline { 3 - 4 } Procedure & Sample & Predicted & Bankrupt & Nonbankrupt & Total \\
\hline Procedure 2 & Sample1 & Bankrupt & 37 & 30 & 67 \\
& & Nonbankrupt & 7 & 29 & 36 \\
& & Total & 44 & 59 & 103 \\
\hline & & \% Mis classifications $=35.92$ & \\
\hline & Sample2 & Bankrupt & 34 & 15 & 49 \\
& & Nonbankrupt & 6 & 36 & 42 \\
& & Total & 40 & 51 & 91 \\
\hline & & \% Mis classifications $=20.37$ & \\
\hline
\end{tabular}


BID ASK SPREAD - Year 5

\begin{tabular}{lccrrr}
\hline & & \multicolumn{2}{c}{ Actual } & \\
\cline { 3 - 4 } Procedure & Sample & Predicted & Bankrupt & Nonbankrupt & Total \\
\hline Procedure 2 & Sample1 & Bankrupt & 28 & 19 & 47 \\
& & Nonbankrupt & 6 & 32 & 38 \\
& & Total & 34 & 51 & 85 \\
\hline & & \% Mis classifications $=29.41$ & \\
\hline & Sample2 & Bankrupt & 24 & 11 & 35 \\
& & Nonbankrupt & 6 & 35 & 41 \\
& & Total & 30 & 46 & 76 \\
\hline
\end{tabular}

HI LO BID ASK SPREAD- Year1

\begin{tabular}{lccrrr}
\hline \multirow{2}{*}{ Procedure } & \multirow{2}{*}{ Sample } & Predicted & Bankrupt & Nonbankrupt & Total \\
\cline { 3 - 5 } & & Bankrupt & 24 & 33 & 57 \\
& Sample1 & Nonbankrupt & 40 & 30 & 70 \\
& & 64 & 63 & 127 \\
\hline & Total & \% Mis classifications $=57.48$ & \\
\hline & Sample2 & Bankrupt & 22 & 24 & 46 \\
& & Nonbankrupt & 51 & 30 & 81 \\
& & Total & 73 & 54 & 127 \\
\hline & & \% Mis classifications $=59.05$ & \\
\hline
\end{tabular}

HI LO BID ASK SPREAD - Year 4

\begin{tabular}{llcrrr}
\hline & & \multicolumn{2}{c}{ Actual } & \\
\cline { 3 - 4 } Procedure & Sample & Predicted & Bankrupt & Nonbankrupt & Total \\
\hline Procedure 2 & Sample1 & Bankrupt & 24 & 42 & 66 \\
& & Nonbankrupt & 20 & 17 & 37 \\
& & 44 & 59 & 103 \\
\hline & Total & & \% Mis classifications $=60.19$ & \\
\hline & Sample2 & Bankrupt & 22 & 26 & 48 \\
& & Nonbankrupt & 19 & 25 & 44 \\
& & Total & 41 & 51 & 92 \\
\hline & & \% Mis classifications $=48.91$ &
\end{tabular}


HI LO BID ASK SPREAD - Year 5

\begin{tabular}{lccrrr}
\hline & & \multicolumn{2}{c}{ Actual } & \\
\cline { 3 - 4 } Procedure & Sample & Predicted & Bankrupt & Nonbankrupt & Total \\
\hline Procedure 2 & Sample1 & Bankrupt & 22 & 34 & 56 \\
& & Nonbankrupt & 15 & 18 & 33 \\
& Total & 37 & 52 & 89 \\
\hline & & \% Mis classifications $=55.05$ & \\
\hline & Sample2 & Bankrupt & 10 & 19 & 29 \\
& Nonbankrupt & 23 & 27 & 50 \\
& Total & 33 & 46 & 79 \\
\hline
\end{tabular}

\section{CASHFLOW TO SALES- Year1}

\begin{tabular}{|c|c|c|c|c|c|}
\hline \multirow[b]{2}{*}{ Procedure } & \multirow[b]{2}{*}{ Sample } & \multirow[b]{2}{*}{ Predicted } & \multicolumn{2}{|c|}{ Actual } & \multirow[b]{2}{*}{ Total } \\
\hline & & & Bankrupt & Nonbankrupt & \\
\hline \multirow[t]{7}{*}{ Procedure 2} & Sample1 & Bankrupt & 58 & 28 & 86 \\
\hline & & Nonbankrupt & 8 & 28 & 36 \\
\hline & & Total & 66 & 56 & 122 \\
\hline & & \multicolumn{4}{|c|}{$\%$ Mis classifications $=29.5$} \\
\hline & Sample2 & Bankrupt & 44 & 15 & 59 \\
\hline & & Nonbankrupt & 18 & 42 & 60 \\
\hline & & Total & 62 & 57 & 119 \\
\hline
\end{tabular}

$\%$ Mis classifications $=27.73$

\section{CASHFLOW TO SALES - Year 4}

\begin{tabular}{llcrrr}
\hline & & \multicolumn{2}{c}{ Actual } & \\
\cline { 3 - 4 } Procedure & Sample & Predicted & Bankrupt & Nonbankrupt & Total \\
\hline Procedure 2 & Sample1 & Bankrupt & 23 & 21 & 44 \\
& & Nonbankrupt & 14 & 33 & 47 \\
& Total & 37 & 54 & 91 \\
\hline & & \% Mis classifications $=38.46$ & \\
\hline & Sample2 & Bankrupt & 11 & 13 & 24 \\
& & Nonbankrupt & 18 & 40 & 58 \\
& & Total & 29 & 53 & 82 \\
\hline & & \% Mis classifications $=37.80$ & \\
\hline
\end{tabular}




\section{CASHFLOW TO SALES - Year 5}

\begin{tabular}{lccrrr}
\hline & & \multicolumn{2}{c}{ Actual } & \\
\cline { 3 - 4 } Procedure & Sample & Predicted & Bankrupt & Nonbankrupt & Total \\
\hline Procedure 2 & Sample1 & Bankrupt & 19 & 20 & 39 \\
& & Nonbankrupt & 9 & 28 & 37 \\
& Total & 28 & 48 & 76 \\
\hline & & \% Mis classifications = 38.15 & \\
\hline & Sample2 & Bankrupt & 8 & 7 & 15 \\
& & Nonbankrupt & 12 & 40 & 52 \\
& & Total & 20 & 47 & 67 \\
\hline & & \% Mis classifications $=28.35$ & \\
\hline
\end{tabular}

CASHFLOW TO TOTAL ASSETS- Year1

\begin{tabular}{lcccrr}
\hline \multirow{2}{*}{ Procedure } & \multirow{2}{*}{ Sample } & Predicted & Bankrupt & Nonbankrupt & \\
\cline { 3 - 4 } & & Bankrupt & 57 & 27 & Total \\
\hline Procedure 2 & Sample1 & Nonbankrupt & 10 & 30 & 84 \\
& & 67 & 57 & 40 \\
& & Total & \% Mis classifications $=29.83$ & 124 \\
\hline & & 49 & 21 & 70 \\
\hline & Sample2 & Bankrupt & 16 & 38 & 54 \\
& & Nonbankrupt & 65 & 59 & 124 \\
\hline & Total & \multicolumn{2}{c}{ \% Mis classifications $=29.83$} &
\end{tabular}

CASHFLOW TO TOTAL ASSETS - Year 4

\begin{tabular}{lccrrr}
\hline & & \multicolumn{2}{c}{ Actual } & \\
\cline { 3 - 4 } Procedure & Sample & Predicted & Bankrupt & Nonbankrupt & Total \\
\hline Procedure 2 & Sample1 & Bankrupt & 25 & 19 & 44 \\
& & Nonbankrupt & 12 & 36 & 48 \\
& & Total & 37 & 55 & 92 \\
\hline & & \% Mis classifications $=33.69$ & \\
\hline & Sample2 & Bankrupt & 14 & 11 & 25 \\
& & Nonbankrupt & 17 & 43 & 60 \\
& & Total & 31 & 54 & 85 \\
\hline
\end{tabular}


CASHFLOW TO TOTAL ASSETS - Year 5

\begin{tabular}{lccrrr}
\hline & & \multicolumn{2}{c}{ Actual } & \\
\cline { 3 - 4 } Procedure & Sample & Predicted & Bankrupt & Nonbankrupt & Total \\
\hline Procedure 2 & Sample1 & Bankrupt & 18 & 16 & 34 \\
& & Nonbankrupt & 10 & 33 & 43 \\
& Total & 28 & 49 & 77 \\
\hline & & \% Mis classifications $=33.76$ & 17 \\
& Sample2 & Bankrupt & 11 & 6 & 53 \\
& Nonbankrupt & 11 & 42 & 70 \\
\hline & Total & 22 & 48 & \\
\hline
\end{tabular}

CASHFLOW TO TOTAL DEBT- Year1

\begin{tabular}{lccrrr}
\hline \multirow{2}{*}{ Procedure } & \multirow{2}{*}{ Sample } & Predicted & Bankrupt & Nonbankrupt & \\
\cline { 3 - 5 } & & Bankrupt & 58 & 25 & Total \\
\hline Procedure 2 & Sample1 & Bonbankrupt & 9 & 31 & 83 \\
& & 67 & 56 & 40 \\
& & Total & \% Mis classifications $=27.64$ & 123 \\
\hline & Sample2 & Bankrupt & 49 & 19 & 68 \\
& & Nonbankrupt & 15 & 38 & 53 \\
& & Total & 64 & 57 & 121 \\
\hline & & \% Mis classifications $=28.09$ & \\
\hline
\end{tabular}

CASHFLOW TO TOTAL DEBT - Year 4

\begin{tabular}{|c|c|c|c|c|c|}
\hline \multirow[b]{2}{*}{ Procedure } & \multirow[b]{2}{*}{ Sample } & \multirow[b]{2}{*}{ Predicted } & \multicolumn{2}{|c|}{ Actual } & \multirow[b]{2}{*}{ Tota } \\
\hline & & & Bankrupt & Nonbankrupt & \\
\hline \multirow[t]{7}{*}{ Procedure 2} & Sample1 & Bankrupt & 24 & 19 & 43 \\
\hline & & Nonbankrupt & 13 & 35 & 48 \\
\hline & & Total & 37 & 54 & 91 \\
\hline & & \multicolumn{4}{|c|}{$\%$ Mis classifications $=35.16$} \\
\hline & Sample2 & Bankrupt & 15 & 11 & 26 \\
\hline & & Nonbankrupt & 15 & 41 & 56 \\
\hline & & Total & 30 & 52 & 82 \\
\hline
\end{tabular}


CASHFLOW TO TOTAL DEBT - Year 5

\begin{tabular}{lcccrr}
\hline & & \multicolumn{2}{c}{ Actual } & \\
\cline { 3 - 4 } Procedure & Sample & Predicted & Bankrupt & Nonbankrupt & Total \\
\hline Procedure 2 & Sample1 & Bankrupt & 17 & 18 & 35 \\
& & Nonbankrupt & 11 & 30 & 41 \\
& & Total & 28 & 48 & 76 \\
\hline & & \% Mis classifications = 38.15 & \\
\hline & Sample2 & Bankrupt & 11 & 6 & 17 \\
& & Nonbankrupt & 10 & 40 & 50 \\
& & Total & 21 & 46 & 67 \\
\hline
\end{tabular}

RETURN- Year1

\begin{tabular}{|c|c|c|c|c|c|}
\hline \multirow[b]{2}{*}{ Procedure } & \multirow[b]{2}{*}{ Sample } & \multirow[b]{2}{*}{ Predicted } & \multicolumn{2}{|c|}{ Actual } & \multirow[b]{2}{*}{ Tota } \\
\hline & & & Bankrupt & Nonbankrupt & \\
\hline \multirow[t]{7}{*}{ Procedure 2} & Sample1 & Bankrupt & 20 & 42 & 62 \\
\hline & & Nonbankrupt & 47 & 14 & 61 \\
\hline & & Total & 67 & 56 & 123 \\
\hline & & \multicolumn{4}{|c|}{$\%$ Mis classifications $=72.35$} \\
\hline & Sample2 & Bankrupt & 21 & 48 & 69 \\
\hline & & Nonbankrupt & 41 & 10 & 51 \\
\hline & & Total & 62 & 58 & 120 \\
\hline
\end{tabular}

RETURN - Year 4

\begin{tabular}{lccrrr}
\hline & & \multicolumn{2}{c}{ Actual } & \\
\cline { 3 - 4 } Procedure & Sample & Predicted & Bankrupt & Nonbankrupt & Total \\
\hline Procedure 2 & Sample1 & Bankrupt & 23 & 32 & 55 \\
& & Nonbankrupt & 19 & 18 & 37 \\
& & Total & 42 & 50 & 92 \\
\hline & & \% Mis classifications $=55.43$ & \\
\hline & Sample2 & Bankrupt & 22 & 27 & 49 \\
& & Nonbankrupt & 14 & 23 & 37 \\
\hline & Total & 36 & 50 & 86 \\
\hline
\end{tabular}


RETURN - Year 5

\begin{tabular}{lcccrr}
\hline & & \multicolumn{2}{c}{ Actual } & \\
\cline { 3 - 4 } Procedure & Sample & Predicted & Bankrupt & Nonbankrupt & Total \\
\hline Procedure 2 & Sample1 & Bankrupt & 18 & 24 & 42 \\
& & Nonbankrupt & 11 & 24 & 35 \\
& & Total & 29 & 48 & 77 \\
\hline & & \% Mis classifications = 45.45 & \\
\hline & Sample2 & Bankrupt & 17 & 24 & 41 \\
& & Nonbankrupt & 13 & 23 & 36 \\
& & Total & 30 & 47 & 77 \\
\hline
\end{tabular}

STANDARD DEVIATION OF RETURN- Year1

\begin{tabular}{lccrrr}
\hline \multirow{2}{*}{ Procedure } & \multirow{2}{*}{ Sample } & Predicted & \multicolumn{2}{c}{ Actual } & \\
\cline { 3 - 4 } & & Bankrupt & Nonbankrupt & Total \\
\hline Procedure 2 & Sample1 & Bankrupt & 31 & 20 & 51 \\
& & Nonbankrupt & 14 & 33 & 47 \\
& Total & 45 & 53 & 98 \\
\hline & & \% Mis classifications $=34.69$ & \\
\hline & Sample2 & Bankrupt & 22 & 17 & 39 \\
& & Nonbankrupt & 22 & 34 & 56 \\
& & Total & 44 & 51 & 95 \\
\hline & & \% Mis classifications $=41.05$ &
\end{tabular}

STANDARD DEVIATION OF RETURN - Year 4

\begin{tabular}{lccrrr}
\hline & & \multicolumn{2}{c}{ Actual } & \\
\cline { 3 - 4 } Procedure & Sample & Predicted & Bankrupt & Nonbankrupt & Total \\
\hline Procedure 2 & Sample1 & Bankrupt & 22 & 8 & 30 \\
& & Nonbankrupt & 16 & 6 & 22 \\
& Total & 38 & 14 & 52 \\
\hline & & \% Mis classifications $=46.15$ & \\
\hline & Sample2 & Bankrupt & 20 & 5 & 25 \\
& & Nonbankrupt & 10 & 8 & 18 \\
& & Total & 30 & 13 & 43 \\
\hline
\end{tabular}


STANDARD DEVIATION OF RETURN - Year 5

\begin{tabular}{llcrrr}
\hline & & \multicolumn{2}{c}{ Actual } & \\
\cline { 3 - 4 } Procedure & Sample & Predicted & Bankrupt & Nonbankrupt & Total \\
\hline Procedure 2 & Sample1 & Bankrupt & 10 & 4 & 14 \\
& & Nonbankrupt & 6 & 5 & 11 \\
& & 16 & 9 & 25 \\
\hline & & Total & \% Mis classifications $=40.0$ & 6 \\
& Sample2 & Bankrupt & 5 & 1 & 16 \\
& & Nonbankrupt & 8 & 8 & 22 \\
\hline & Total & 13 & 9 &
\end{tabular}

BETA- Year1

\begin{tabular}{lccrrr}
\hline \multirow{2}{*}{ Procedure } & \multirow{2}{*}{ Sample } & Predicted & Bankrupt & Nonbankrupt & \\
\cline { 3 - 4 } & & Bankrupt & 25 & 33 & Total \\
\hline Procedure 2 & Sample1 & Nonbankrupt & 17 & 10 & 58 \\
& & 42 & 43 & 27 \\
& & Total & \% Mis classifications $=58.82$ & 85 \\
\hline & Sample2 & Bankrupt & 20 & 29 & 49 \\
& & Nonbankrupt & 18 & 24 & 42 \\
& & Total & 38 & 53 & 91 \\
\hline
\end{tabular}

$\%$ Mis classifications $=51.64$

BETA - Year 4

\begin{tabular}{llcrrr}
\hline & & \multicolumn{2}{c}{ Actual } & \\
\cline { 3 - 4 } Procedure & Sample & Predicted & Bankrupt & Nonbankrupt & Total \\
\hline Procedure 2 & Sample1 & Bankrupt & 17 & 5 & 22 \\
& & Nonbankrupt & 11 & 0 & 11 \\
& & 28 & 5 & 33 \\
\hline & Total & \% Mis classifications $=48.48$ & \\
\hline & Sample2 & Bankrupt & 16 & 5 & 21 \\
& Nonbankrupt & 8 & 2 & 10 \\
& & Total & 24 & 7 & 31 \\
\hline & & \% Mis classifications $=41.93$ & \\
\hline
\end{tabular}


BETA - Year 5

\begin{tabular}{lccccr}
\hline & & \multicolumn{2}{c}{ Actual } & \\
\cline { 3 - 4 } Procedure & Sample & Predicted & Bankrupt & Nonbankrupt & Total \\
\hline Procedure 2 & Sample1 & Bankrupt & 10 & 24 & 34 \\
& & Nonbankrupt & 10 & 11 & 21 \\
& Total & 20 & 35 & 55 \\
\hline & & \% Mis classifications $=61.81$ & 35 \\
& Sample2 & Bankrupt & 12 & 23 & 26 \\
& & Nonbankrupt & 4 & 22 & 61 \\
\hline & Total & 16 & 45 & \\
\hline
\end{tabular}




\subsection{Summary and Conclusions}

The literature on bankruptcy prediction has focused on utilizing accounting ratios, backward-looking variables. While these have provided decent predictive power, they do not tell the whole story. To add to the literature, we have included market and microstructure variables in our analysis. These variables are forward-looking since they are derived from discounted estimates of the future. Therefore, any type of predictive process should employ variables that are focused on the future.

We find that the best performing predictors are price, standard deviation, and bidask spread. The market correctly signals that the future of a distressed firm is grim. However, accounting ratios still have explanatory power, namely those ratios that include working capital, net income, and current liabilities. Cash flow plays a less important role in correctly classifying distressed firms than is found in the prior literature. Therefore, our most important findings are that, while accounting ratios are still important to bankruptcy prediction, market variables need to be included for more accuracy.

The univariate analysis is a starting point in understanding how the different underlying variables behave prior to bankruptcy. However, a firm is not just one puzzle piece, but rather a sum of all of the pieces. While many of the pieces alone might not signal distress, together a very differ story is painted. Hence, we will now move on to multivariate analysis. Certain variables that did not play important roles in the univariate analysis might actually be extremely important when looking at the picture as a whole. This is where we begin the next chapter. 


\section{CHAPTER 3: MULTIVARIATE DISCIMINANT ANALYSIS}

\subsection{Introduction}

Bankruptcy prediction has been thoroughly investigated in the literature, especially with financial ratios as predictors. The main models used in bankruptcy prediction have been discriminant analysis and logit regression. The assumption of multivariate normality of the ratios used in these models is an important one. Any significant deviation from normality will put into question any conclusions made with the models. Karels and Prakash (1987) study the financial ratios used in previous studies. The preliminary results demonstrate statistical significance of multivariate skewness and kurtosis for the ratios used in the prior studies. A set of ratios that best conforms to multivariate normality is selected and used for prediction. However, most of the ratios used are accounting ratios, while only a couple are market variables. Following the results found in essay one, a set of variables will be selected that best conforms to multivariate normality. One set will contain only accounting ratios, another will contain only market variables, and the last will contain a mixture of the two. While market variables have been previously included in bankruptcy prediction, the assumptions underlying these models have not been verified. Furthermore, microstructure variables in a study of this kind have not been included.

This study attempts to describe and distinguish these two groups. The remainder of this paper is organized as follows: Section 3.2 reviews the previous literature associated with bankruptcy prediction and multivariate discriminant analysis. Section 3.3 discusses the data used in this study. Section 3.4 describes the methodology. Section 3.5 discusses the results, and Section 3.6 summarizes and concludes. 


\subsection{Literature Review}

The literature of bankruptcy prediction, and especially those applying multivariate discriminant analyses, is vast. The focus of most studies is the usefulness of accounting ratios in discriminating between bankrupt and non-bankrupt firms. The genesis of this methodology in bankruptcy prediction can be traced back to Altman (1968).

Altman (1968) extends the univariate analysis used for bankruptcy prediction. Employing twenty-two ratios that have been used in the prior literature, Altman finds that five ratios are best at discriminating between bankrupt and non-bankrupt firms. Even though some of these ratios performed poorly in a univariate setting, they still boosted the discriminating power of the function. The ratios are Working Capital/Total Assets, Retained Earnings/Total Assets, Earnings Before Interest and Taxes/Total Assets, Market Value of Equity/Book Value of Total Debt, and Sales/Total Assets. This analysis results in correctly classifying $94 \%$ of the bankrupt firms in the original sample, and $95 \%$ of the firms in the bankrupt and non-bankrupt samples.

Deakin (1972) extends the research done by Beaver (1968) and Altman (1968), and his results support those found in the prior literature. Blum (1974) performs a similar analysis, finding $94 \%$ accuracy one year before failure, $80 \%$ accuracy two years before failure, and 70\% accuracy three to five years before failure. Most important, Type II errors occur less than Type I errors one year before bankruptcy. In agreement with Beaver (1968), Cash Flow/Total Debt is found to be the best predictor. Interestingly, a market variable included in his analysis does not enhance predictability.

Moyer (1977) applies Altman's (1968) methodology and concludes that the model does not perform as well out-of-sample, and that predictive accuracy is modest when 
larger firms are included in the analysis. Re-estimating the model parameters, Moyer finds that two of the discriminating variables can be eliminated leading to better explanatory power.

Ketz (1978) tests the hypothesis that price-level variables are better at correctly classifying failed and non-failed firms than are historical accounting ratios. The $\mathrm{R}^{2}$, overall error rates, and error rates of classifying non-failed firms are equivalent using both methods, but the price-level variables show lower error rates in misclassifying failed firms. Norton and Smith (1979) perform a similar study, but find that the two different sets of variables perform relatively equally, meaning that price-level variables do not improve the predictability of bankruptcy prediction models.

Booth (1983) employs a decomposition measure to predict financial failure and discriminate between failed and non-failed firms. The decomposition measures are total assets, total liabilities, total equities, and total balance sheet, and these measures represent the change in the balance sheet from year to year. The findings do not support the inclusion of decomposition measures in bankruptcy prediction.

Hennaway and Morris (1983) develop multivariate discriminant models each year, one to five years before bankruptcy, and also incorporate macro-level and industrylevel variables/indicators. The main finding is that the models perform well one to five years before failure, which is important since earlier predictions are desirable.

Frydman et al. (1985) focus on the issues with discriminant analysis, along with other parametric models, namely the violations of the underlying assumptions. While their non-parametric model outperforms the more traditional parametric models, the discriminant analysis model still performs well. 
Gombola et al. (1987) focus on the ability of Cash Flow from Operations to predict financial deterioration. Previous studies find this to be an important variable in bankruptcy prediction. Their main finding is that the Cash Flow variables' predictive ability declines over time, going from a significant to an insignificant discriminatory variable. However, Aziz et al. (1988) find that Cash Flow based models perform well in relation to the traditional models, especially three or more years prior to bankruptcy.

McGurr and DeVaney (1998) study the financial ratios and cash flow items of bankrupt and non-bankrupt retail firms. They conclude that there are three apparent biases: industry bias (different ratio levels for companies in different industries), population bias (changing population over time in Compustat, leading to a bias in older studies), and time bias (the effect of recessionary and expansionary periods on different industries). Yang et al. (1999) compare MDA to newer, more data-intensive techniques, and find that MDA still performs better in bankruptcy prediction. However, Dimitras et al. (1999) find that using rough sets to avoid some of the limiting assumptions underlying MDA provides better predictive results. Brockman and Turtle (2003) apply an options framework to bankruptcy prediction and find that this outperforms Z-scores found through MDA.

\subsection{Data}

The list of bankrupt firms was obtained from bankruptcydata.com. The list includes companies the filed for bankruptcy from January 1995 to December 2010. The subsample of non-bankrupt firms comes from the entire database of Compustat, consisting of firms that did not file for bankruptcy during our sample period. The 
accounting ratios for all firms, bankrupt and non-bankrupt, are obtained from Compustat. The market variables for these firms were obtained from CRSP.

\subsection{Methodology}

As is common in the bankruptcy prediction literature, the non-bankrupt firms are selected in such a way so that firm size does not severely affect the results. Ex-ante, successful firms are expected to be larger than failing firms. Furthermore, firm success rates are highly influenced by their industry. For example, when the tech bubble was growing, any firm with a dotcom in its name benefited heavily. To mitigate this issue, it is common to select firms in such a way that size and industry factors do not distort the results.

The procedure is two-fold. First, a bankrupt firm is selected. Second, a nonbankrupt firm within the same industry with asset size closest to the bankrupt firm is selected. These two firms (the one bankrupt and the one non-bankrupt) are then stored and removed from the continuing procedure. A second bankrupt firm is selected, and the selection process is done with the remaining non-bankrupt firms. This is done for each bankrupt firm, so that in the end there are an equal number of bankrupt and non-bankrupt firms.

Before beginning the MDA, it is important to check whether or not the underlying assumptions are upheld (notably the normality assumptions and the equality of the dispersion matrices). We begin by studying the individual distribution of each ratio. To test for univariate normality, we employ the Shapiro-Wilk W test. The procedure is as follows:

$\mathrm{H}_{0}$ : The parent population is normal. 
$\mathrm{H}_{1}$ : The parent population is not normal.

The procedure is as follows:

1. Let $\mathrm{FV}_{\mathrm{ij}}$ be the $\mathrm{i}^{\text {th }}$ financial variable for the $\mathrm{j}^{\text {th }}$ company $(\mathrm{i}=1,2, \ldots, \mathrm{k}$;

$\mathrm{j}=1,2, \ldots, \mathrm{n})$, where $\mathrm{FV}_{\text {in }}$ and $\mathrm{FV}_{\mathrm{il}}$ are the largest and smallest ratios over all the companies in the sample.

2. Arrange the ratios in decreasing order:

a. $\mathrm{FV}_{\mathrm{i} 1} \leq \mathrm{FV}_{\mathrm{i} 2} \leq \ldots \leq \mathrm{FV}_{\text {in }}$

3. Set $m=n / 2$ if $n$ is even, $(n-1) / 2$ otherwise.

4. Calculate:

a. $b_{i}=a_{n}\left(F V_{i n}-F V_{i 1}\right)+\cdots+a_{n-m+1}\left(F V_{i, n-m+1}-F V_{i m}\right)$

b. $a_{i}$ can be found in Hahn and Shapiro (1970).

5. Calculate:

a. $S_{i}^{2}=\frac{1}{n} \sum_{j=1}^{n}\left(F V_{i j}-F V_{i} b a r\right)$

6. Calculate the W-statistic:

a. $\quad W_{i}=\frac{b_{i}^{2}}{s_{i}^{2}}$ for each ratio $(\mathrm{i}=1,2, \ldots, \mathrm{k})$.

Small values for $\mathrm{W}_{\mathrm{i}}$ will indicate non-normality. Due to the fact that financial variables tend to more often be lognormally distributed, the same procedure will be done to the logarithm of the ratios.

Next, since an important assumption of the MDA is multivariate normality, we will test to check whether or not the set of ratios selected are multivariate normal. To do so, we employ Maridia's test of multivariate normality, which tests skewness and kurtosis 
statistics. As a robustness check, the Henze-Zirkler T test is also used. The Mardia test is as follows:

Let $\mathrm{V}$ be a vector of $\mathrm{p}$ financial variables with $\mathrm{V}_{\mathrm{r}}$ as the $\mathrm{r}^{\text {th }}$ element of the vector, $\mu$ as the unknown mean vector, and $\sum$ as the covariance-variance matrix. The test then depends on an augmentation of the univariate measures of skewness and kurtosis. The steps are as follows:

Skewness:

1. Calculate the p- sample means:

a. $\quad V_{r} b a r=\frac{1}{n} \sum_{i=1}^{n} V_{r}^{i}$

b. For any two attributes $V_{r}$ and $V_{r}^{\prime}$, calculate the sum of squares:

$$
\text { i. } S_{r r^{\prime}}=\frac{1}{n} \sum_{i=1}^{n}\left(V_{r}^{i}-V_{r} b a r\right)\left(V_{r^{\prime}}^{i}-V_{r}, b a r\right)
$$

c. For any three attributes $V_{r}, V_{q}$, and $V_{y}$, calculate:

$$
\text { i. } M_{r q y}=\frac{1}{n} \sum_{i=1}^{n}\left(V_{r}^{i}-V_{r} b a r\right)\left(V_{q}^{i}-V_{q} b a r\right)\left(V_{y}^{i}-V_{y} b a r\right)
$$

2. Calculate the multivariate measure of skewness:

a. $\quad b_{1, p}=\sum_{r, q, y} \sum_{r^{\prime} q^{\prime} y^{\prime}} S_{r r^{\prime}} S_{q q^{\prime}} S_{y y^{\prime}} M_{r q y} M_{r^{\prime} q^{\prime} y^{\prime}}$

i. where $S_{r r^{\prime}}=S_{r r^{\prime}}^{-1}$.

3. Under the null hypothesis $H_{0}: \beta_{1, p}=0$, the test statistic $A=1 / 6 n b_{1, p}$ will follow a chi-squared distribution with $\mathrm{p}(\mathrm{p}+1)(\mathrm{p}+2) / 6$ degrees of freedom.

Kurtosis:

1. Calculate:

$$
\left.b_{2, p}=\frac{1}{n} \sum_{i=1}^{n}\left[\left(V_{r}^{i}-V_{r} b a r\right) S_{r q}\left(V_{q}^{i}-V_{q} b a r\right)\right]^{2}=\frac{1}{n} \sum_{i=1}^{n}\left(V_{i}-\text { Vbar }\right)^{\prime} S^{-1}\left(V_{i}-\text { Vbar }\right)\right]^{2}
$$


i. where $V_{i}=\left(V_{1 i}, V_{2 i}, \ldots, V_{p i}\right), i=1,2, \ldots, n$ is the vector of the $\mathrm{i}^{\text {th }}$ measure on each of the p-attributes, Vbar is the vector of sample means for the p-sample, and $S^{-1}$ is the inverse of the sample variance-covariance matrix.

2. Under the null hypothesis $H_{0}: \beta_{2, p}=p(p+2)$, the test statistic $B=$ $\frac{b_{2, p}-\beta_{2, p}}{\left[\frac{8 p(p+2)}{n}\right]^{1 / 2}}$ will be a $\mathrm{N}(0,1)$ variate.

Finally, since equality of the dispersion matrix is another important assumption underlying MDA, we use Box M Test for the equality of the variance-covariance matrix.

To test for multivariate normality, we must choose sets of variables. First, we will test for multivariate normality for all accounting ratios. Second, we will do so for all market variables (this will be done four different ways, substituting different measures of the bid-ask spread). Third, we will do so for the three accounting ratios and three market variables that had the highest $\mathrm{W}$ statistic from the above mentioned univariate normality test; this is also done for the logarithm of the ratios/variables. Finally, the same procedure is done for the six variables (three accounting ratios and three market variables) that showed the highest predictive power from the univariate analysis performed in the previous chapter.

While certain types of MDA are better suited for certain data than others, our purpose is to comprehensively study bankruptcy prediction. Therefore, we will not limit ourselves to one model specification. When the underlying assumptions that are mentioned above are satisfied, then linear MDA is appropriate. While this is a possibility, it is highly unlikely. Quadratic MDA is one possible solution to this problem; it is useful 
when the equality of the dispersion matrices is rejected. Furthermore, when the data does not prove to come from a normally distributed population (or any specified distribution), the nonparametric MDA is another solution. Given these outcomes, we will apply the analysis using the three different MDA methods.

Finally, to test that actual predictive ability of the MDA, we perform an out-ofsample test. Since we found the nonparametric MDA to perform best at correctly classifying bankrupt firms, also use it in the out-of-sample test. Using the ratios and variables from 5 years up until 2 years before bankruptcy, the nonparametric MDA model is created. Then, using this model, the predictive ability of the model is test one year before bankruptcy.

\subsection{Empirical Results}

We begin with the univariate normality test results (Table I). The W-statistic is used. For all the ratios, whether those of bankrupt or non-bankrupt firms, the null is rejected (i.e. the results indicate a departure from normality); all ratio statistics have $p$ values of less (and much less in most cases) than 1\%. After taking the logarithm of the ratios, the results only change for the spread variable. However, this must be taken with caution; the dataset for the spread variable is much smaller than that of the other ratios/variables. When looking at other measures of the spread, the variables are still found to be non-normal.

While univariate normality is not met, the underlying assumption for MDA requires multivariate normality. Even though the ratios and variables are not univariate normal, this does not necessarily mean that a set of the ratios are not multivariate normal. 
Therefore, we test for multivariate normality for the different sets of variables mentioned above.

Table 4

Univariate normality results for Ratios : Bankrupt firms

\begin{tabular}{|c|c|c|c|}
\hline RATIO & $\mathrm{N}$ & $\begin{array}{c}\mathrm{W} \\
\text { STATISTIC }\end{array}$ & P VALUE \\
\hline SHROUT & 1339 & 0.467422 & $<0.0001$ \\
\hline PRC & 1331 & 0.718935 & $<0.0001$ \\
\hline VOL & 1339 & 0.45501 & $<0.0001$ \\
\hline SPREAD & 53 & 0.840866 & $<0.0001$ \\
\hline NET INCOME TO SALES & 1267 & 0.057279 & $<0.0001$ \\
\hline NET INCOME TO TOTAL ASSETS & 1327 & 0.480268 & $<0.0001$ \\
\hline TOTAL DEBT & 1313 & 0.260369 & $<0.0001$ \\
\hline NET INCOME TO TOTAL DEBT & 1310 & 0.289402 & $<0.0001$ \\
\hline $\begin{array}{l}\text { CURRENT LIABILITIES TO TOTAL } \\
\text { ASSETS }\end{array}$ & 1329 & 0.813787 & $<0.0001$ \\
\hline $\begin{array}{l}\text { LONG TERM LIABILITIES TO TOTAL } \\
\text { ASSETS }\end{array}$ & 1313 & 0.828406 & $<0.0001$ \\
\hline TOTAL DEBT TO TOTAL ASSETS & 1313 & 0.919367 & $<0.0001$ \\
\hline $\begin{array}{l}\text { TOTAL DEBT PLUS PREF TO TOTAL } \\
\text { ASSETS }\end{array}$ & 1310 & 0.85664 & $<0.0001$ \\
\hline CASH TO TOTAL ASSETS & 52 & 0.794427 & $<0.0001$ \\
\hline QUICK ASSETS TO TOTAL ASSETS & 1315 & 0.942621 & $<0.0001$ \\
\hline WORKING CAPITAL TO TOTAL ASSETS & 1329 & 0.954237 & $<0.0001$ \\
\hline CASH TO CURRENT LIABILITIES & 52 & 0.77012 & $<0.0001$ \\
\hline $\begin{array}{l}\text { QUICK ASSETS TO CURRENT } \\
\text { LIABILITIES }\end{array}$ & 1315 & 0.50031 & $<0.0001$ \\
\hline CURRENT RATIO & 1329 & 0.519753 & $<0.0001$ \\
\hline CASH TO SALES & 46 & 0.738928 & $<0.0001$ \\
\hline INVENTORY TO SALES & 1248 & 0.044135 & $<0.0001$ \\
\hline QUICK ASSETS TO SALES & 1248 & 0.034549 & $<0.0001$ \\
\hline
\end{tabular}




\begin{tabular}{lccc} 
CURRENT ASSETS TO SALES & 1262 & 0.042619 & $<0.0001$ \\
WORKING CAPITAL TO SALES & 1262 & 0.040176 & $<0.0001$ \\
TOTAL ASSETS TO SALES & 1263 & 0.053942 & $<0.0001$ \\
BID ASK SPREAD & 1297 & 0.802743 & $<0.0001$ \\
HI LO BID ASK SPREAD & 1339 & 0.274931 & $<0.0001$ \\
STANDARD DEVIATION OF RETURN & 1116 & 0.4026 & $<0.0001$ \\
BETA & 892 & 0.378702 & $<0.0001$ \\
\hline
\end{tabular}

Univariate normality results for Logarithmic Ratios : Bankrupt firms

\begin{tabular}{|c|c|c|c|}
\hline RATIO & $\mathrm{N}$ & $\begin{array}{c}\mathrm{W} \\
\text { STATISTIC }\end{array}$ & P VALUE \\
\hline SHROUT & 1339 & 0.972232 & $<0.0001$ \\
\hline PRC & 1278 & 0.981476 & $<0.0001$ \\
\hline VOL & 1337 & 0.993966 & $<0.0001$ \\
\hline SPREAD & 53 & 0.94208 & 0.0125 \\
\hline NET INCOME TO SALES & 493 & 0.970445 & $<0.0001$ \\
\hline NET INCOME TO TOTAL ASSETS & 497 & 0.969024 & $<0.0001$ \\
\hline TOTAL DEBT & 1313 & 0.975077 & $<0.0001$ \\
\hline NET INCOME TO TOTAL DEBT & 482 & 0.98526 & $<0.0001$ \\
\hline $\begin{array}{l}\text { CURRENT LIABILITIES TO TOTAL } \\
\text { ASSETS }\end{array}$ & 1329 & 0.989039 & $<0.0001$ \\
\hline $\begin{array}{l}\text { LONG TERM LIABILITIES TO TOTAL } \\
\text { ASSETS }\end{array}$ & 1198 & 0.909605 & $<0.0001$ \\
\hline TOTAL DEBT TO TOTAL ASSETS & 1313 & 0.914667 & $<0.0001$ \\
\hline $\begin{array}{l}\text { TOTAL DEBT PLUS PREF TO TOTAL } \\
\text { ASSETS }\end{array}$ & 1310 & 0.933872 & $<0.0001$ \\
\hline CASH TO TOTAL ASSETS & 52 & 0.895725 & 0.0003 \\
\hline QUICK ASSETS TO TOTAL ASSETS & 1315 & 0.949774 & $<0.0001$ \\
\hline WORKING CAPITAL TO TOTAL ASSETS & 943 & 0.841992 & $<0.0001$ \\
\hline CASH TO CURRENT LIABILITIES & 52 & 0.94103 & 0.0123 \\
\hline
\end{tabular}




\begin{tabular}{lccc} 
QUICK ASSETS TO CURRENT & 1315 & 0.995243 & 0.0004 \\
LIABILITIES & & & \\
CURRENT RATIO & 1329 & 0.993424 & $<0.0001$ \\
CASH TO SALES & 46 & 0.91722 & 0.0030 \\
INVENTORY TO SALES & 945 & 0.945348 & $<0.0001$ \\
QUICK ASSETS TO SALES & 1248 & 0.927727 & $<0.0001$ \\
CURRENT ASSETS TO SALES & 1262 & 0.884118 & $<0.0001$ \\
WORKING CAPITAL TO SALES & 901 & 0.95849 & $<0.0001$ \\
TOTAL ASSETS TO SALES & 1263 & 0.858276 & $<0.0001$ \\
BID ASK SPREAD & 1269 & 0.96145 & $<0.0001$ \\
HI LO BID ASK SPREAD & 1283 & 0.992995 & $<0.0001$ \\
STANDARD DEVIATION OF RETURN & 1116 & 0.972684 & $<0.0001$ \\
BETA & 588 & 0.960947 & $<0.0001$ \\
\hline
\end{tabular}

Univariate normality results for Ratios : Nonbankrupt firms

\begin{tabular}{lccc}
\hline RATIO & $\mathrm{N}$ & $\begin{array}{c}\mathrm{W} \\
\text { STATISTIC }\end{array}$ & P VALUE \\
\hline SHROUT & & & \\
PRC & 1611 & 0.205651 & $<0.0001$ \\
VOL & 1601 & 0.865639 & $<0.0001$ \\
SPREAD & 26 & 0.33087 & $<0.0001$ \\
NET INCOME TO SALES & 1559 & 0.051582 & $<0.0001$ \\
NET INCOME TO TOTAL ASSETS & 1584 & 0.234626 & $<0.0001$ \\
TOTAL DEBT & 1541 & 0.175537 & $<0.0001$ \\
NET INCOME TO TOTAL DEBT & 1540 & 0.571895 & $<0.0001$ \\
CURRENT LIABILITIES TO TOTAL & 1558 & 0.505346 & $<0.0001$ \\
ASSETS & & & \\
LONG TERM LIABILITIES TO TOTAL & 1541 & 0.843893 & $<0.0001$ \\
ASSETS & & &
\end{tabular}




\begin{tabular}{|c|c|c|c|}
\hline TOTAL DEBT TO TOTAL ASSETS & 1541 & 0.727685 & $<0.0001$ \\
\hline $\begin{array}{l}\text { TOTAL DEBT PLUS PREF TO TOTAL } \\
\text { ASSETS }\end{array}$ & 1540 & 0.64565 & $<0.0001$ \\
\hline CASH TO TOTAL ASSETS & 1175 & 0.799459 & $<0.0001$ \\
\hline QUICK ASSETS TO TOTAL ASSETS & 1540 & 0.955474 & $<0.0001$ \\
\hline WORKING CAPITAL TO TOTAL ASSETS & 1558 & 0.749972 & $<0.0001$ \\
\hline CASH TO CURRENT LIABILITIES & 1152 & 0.548243 & $<0.0001$ \\
\hline $\begin{array}{l}\text { QUICK ASSETS TO CURRENT } \\
\text { LIABILITIES }\end{array}$ & 1540 & 0.570288 & $<0.0001$ \\
\hline CURRENT RATIO & 1558 & 0.636071 & $<0.0001$ \\
\hline CASH TO SALES & 1165 & 0.067674 & $<0.0001$ \\
\hline INVENTORY TO SALES & 1529 & 0.43067 & $<0.0001$ \\
\hline QUICK ASSETS TO SALES & 1511 & 0.0645 & $<0.0001$ \\
\hline CURRENT ASSETS TO SALES & 1529 & 0.064764 & $<0.0001$ \\
\hline WORKING CAPITAL TO SALES & 1529 & 0.066057 & $<0.0001$ \\
\hline TOTAL ASSETS TO SALES & 1558 & 0.073278 & $<0.0001$ \\
\hline BID ASK SPREAD & 1597 & 0.418527 & $<0.0001$ \\
\hline HI LO BID ASK SPREAD & 1605 & 0.534956 & $<0.0001$ \\
\hline STANDARD DEVIATION OF RETURN & 1337 & 0.149911 & $<0.0001$ \\
\hline BETA & 1287 & 0.527272 & $<0.0001$ \\
\hline
\end{tabular}

Univariate normality results for Logarithmic Ratios : Nonbankrupt firms

\begin{tabular}{|c|c|c|c|}
\hline RATIO & $\mathrm{N}$ & $\begin{array}{c}\text { W } \\
\text { STATISTIC }\end{array}$ & P VALUE \\
\hline SHROUT & 1611 & 0.960442 & $<0.0001$ \\
\hline PRC & 1575 & 0.955702 & $<0.0001$ \\
\hline VOL & 1605 & 0.990826 & $<0.0001$ \\
\hline SPREAD & 26 & 0.950027 & 0.2322 \\
\hline
\end{tabular}




\begin{tabular}{|c|c|c|c|}
\hline NET INCOME TO SALES & 1052 & 0.954629 & $<0.0001$ \\
\hline NET INCOME TO TOTAL ASSETS & 1054 & 0.94683 & $<0.0001$ \\
\hline TOTAL DEBT & 1541 & 0.971175 & $<0.0001$ \\
\hline NET INCOME TO TOTAL DEBT & 1030 & 0.976557 & $<0.0001$ \\
\hline $\begin{array}{l}\text { CURRENT LIABILITIES TO TOTAL } \\
\text { ASSETS }\end{array}$ & 1558 & 0.934419 & $<0.0001$ \\
\hline $\begin{array}{l}\text { LONG TERM LIABILITIES TO TOTAL } \\
\text { ASSETS }\end{array}$ & 1469 & 0.897339 & $<0.0001$ \\
\hline TOTAL DEBT TO TOTAL ASSETS & 1541 & 0.955337 & $<0.0001$ \\
\hline $\begin{array}{l}\text { TOTAL DEBT PLUS PREF TO TOTAL } \\
\text { ASSETS }\end{array}$ & 1540 & 0.956655 & $<0.0001$ \\
\hline CASH TO TOTAL ASSETS & 1161 & 0.953687 & $<0.0001$ \\
\hline QUICK ASSETS TO TOTAL ASSETS & 1540 & 0.934988 & $<0.0001$ \\
\hline WORKING CAPITAL TO TOTAL ASSETS & 1334 & 0.860201 & $<0.0001$ \\
\hline CASH TO CURRENT LIABILITIES & 1138 & 0.976883 & $<0.0001$ \\
\hline $\begin{array}{l}\text { QUICK ASSETS TO CURRENT } \\
\text { LIABILITIES }\end{array}$ & 1540 & 0.9697 & $<0.0001$ \\
\hline CURRENT RATIO & 1558 & 0.967229 & $<0.0001$ \\
\hline CASH TO SALES & 1151 & 0.963218 & $<0.0001$ \\
\hline INVENTORY TO SALES & 1204 & 0.93087 & $<0.0001$ \\
\hline QUICK ASSETS TO SALES & 1511 & 0.870741 & $<0.0001$ \\
\hline CURRENT ASSETS TO SALES & 1529 & 0.833411 & $<0.0001$ \\
\hline WORKING CAPITAL TO SALES & 1312 & 0.927458 & $<0.0001$ \\
\hline TOTAL ASSETS TO SALES & 1558 & 0.874383 & $<0.0001$ \\
\hline BID ASK SPREAD & 1577 & 0.910491 & $<0.0001$ \\
\hline HI LO BID ASK SPREAD & 1578 & 0.990328 & $<0.0001$ \\
\hline STANDARD DEVIATION OF RETURN & 1337 & 0.958347 & $<0.0001$ \\
\hline BETA & 612 & 0.979232 & $<0.0001$ \\
\hline
\end{tabular}


As seen in Table 5, for the most part, all variables and ratios, whether for bankrupt or nonbankrupt firms, display results indicating that these samples are multivariate nonnormal. The null is rejected for almost all sets of variables. This has been documented in the literature [Karels and Prakash (1987)] as a major problem with interpreting the results of other MDA results in the past. Multivariate normality is an important assumption underpinning these types of models.

Furthermore, the equality of the variance-covariance matrix is another important assumption. It is often violated. We find similar results (Table 6). While certain subgroups display equality of the dispersion matrices (null not rejected), these results must be taken with caution; the subgroups that have equal dispersion matrices suffer from small sample bias. When looking at the larger subgroups (i.e. all of the market variables, and the two subgroups of the top three market variables and accounting ratios from the univariate analysis in Chapter 2), it is evident that the Variance-Covariance matrices are not equivalent. Therefore, linear MDA is not appropriate. Quadratic MDA has been used as a solution the issue of non-equal dispersion matrices. However, we also have to deal with the fact that the variables are not multivariate normal. Since our purpose is a comprehensive study of bankruptcy prediction, we will employ linear, quadratic, and nonparametric MDA, and then compare the results of each.

Since accounting ratios alone in bankruptcy prediction have been exhaustively used in the prior literature, we will begin by looking at the market variables, and then the mix of the two. This is the crux of the analysis. The analysis is performed for years one through five before bankruptcy, but we will focus on year one and year five. The market 
variables used are shares outstanding, price, volume, and two different measures of the bid-ask spread.

Table 5

Multivariate Normality Results for Ratios : Bankrupt firms Accounting variables

\begin{tabular}{lcc}
\hline Test & Statistic & P value \\
\hline Mardia Skewness & 1459 & $<.0001$ \\
Mardia Kurtosis & 1.89 & 0.0582 \\
Henze-Zirkler T & 47.19 & $<.0001$ \\
\hline & \multicolumn{2}{c}{ Market variables } \\
\hline Test & Statistic & P value \\
\hline Mardia Skewness & 73699 & $<.0001$ \\
Mardia Kurtosis & 1069 & $<.0001$ \\
Henze-Zirkler T & 107.5 & $<.0001$ \\
\hline
\end{tabular}

Market variables without spread and hi lo bid ask spread

\begin{tabular}{lcc}
\hline$=$ Test & Statistic & P value \\
\hline Mardia Skewness & 19073 & $<.0001$ \\
Mardia Kurtosis & 377.3 & $<.0001$ \\
Henze-Zirkler T & 65.33 & $<.0001$
\end{tabular}

Market variables without spread and bid ask spread

\begin{tabular}{lcc}
\hline Test & Statistic & P value \\
\hline Mardia Skewness & 75729 & $<.0001$ \\
Mardia Kurtosis & 1309 & $<.0001$ \\
Henze-Zirkler T & 73.90 & $<.0001$ \\
\hline
\end{tabular}

Market variables without bid ask spread and hi lo bid ask spread

\begin{tabular}{lcc}
\hline Test & Statistic & P value \\
\hline Mardia Skewness & 296.8 & $<.0001$ \\
Mardia Kurtosis & 15.78 & $<.0001$ \\
Henze-Zirkler T & 14.28 & $<.0001$ \\
\hline
\end{tabular}


Top 3 Account and Market variables

\begin{tabular}{lcc}
\hline Test & Statistic & P value \\
\hline Mardia Skewness & 8470 & $<.0001$ \\
Mardia Kurtosis & 117.6 & $<.0001$ \\
Henze-Zirkler T & 88.27 & $<.0001$ \\
\hline
\end{tabular}

Top 3 account and market logarithmic variables

\begin{tabular}{lcc}
\hline Test & Statistic & P value \\
\hline Mardia Skewness & 74521 & $<.0001$ \\
Mardia Kurtosis & 897.8 & $<.0001$ \\
Henze-Zirkler T & 135.8 & $<.0001$ \\
\hline
\end{tabular}

Variables (Price, Standard deviation, bid ask spread, net income to sales, working capital to total assets and current liabilities to total assets )

\begin{tabular}{lcc}
\hline Test & Statistic & P value \\
\hline Mardia Skewness & 93575 & $<.0001$ \\
Mardia Kurtosis & 1026 & $<.0001$ \\
Henze-Zirkler T & 104.2 & $<.0001$ \\
\hline
\end{tabular}

Variables (Price, Standard deviation, hi lo bid ask spread, net income to sales, working capital to total assets and current liabilities to total assets )

\begin{tabular}{lcc}
\hline Test & Statistic & P value \\
\hline Mardia Skewness & $134 \mathrm{E} 3$ & $<.0001$ \\
Mardia Kurtosis & 1517 & $<.0001$ \\
Henze-Zirkler T & 123.7 & $<.0001$ \\
\hline
\end{tabular}


Multivariate Normality Results for Ratios : Non bankrupt firms Accounting variables

\begin{tabular}{lcc}
\hline Test & Statistic & P value \\
\hline Mardia Skewness & $729 \mathrm{E} 3$ & $<.0001$ \\
Mardia Kurtosis & 3166 & $<.0001$ \\
Henze-Zirkler T & 4597 & $<.0001$ \\
\hline \multicolumn{2}{c}{ Market variables } \\
\hline Test & Statistic & P value \\
\hline Mardia Skewness & 45305 & $<.0001$ \\
Mardia Kurtosis & 791.3 & $<.0001$ \\
Henze-Zirkler T & 119.8 & $<.0001$
\end{tabular}

Market variables without spread and hi lo bid ask spread

\begin{tabular}{lcc}
\hline Test & Statistic & P value \\
\hline Mardia Skewness & 42249 & $<.0001$ \\
Mardia Kurtosis & 674.8 & $<.0001$ \\
Henze-Zirkler T & 74.18 & $<.0001$ \\
\hline
\end{tabular}

Market variables without spread and bid ask spread

\begin{tabular}{lcc}
\hline Test & Statistic & P value \\
\hline Mardia Skewness & 29502 & $<.0001$ \\
Mardia Kurtosis & 653.8 & $<.0001$ \\
Henze-Zirkler T & 76.50 & $<.0001$ \\
\hline
\end{tabular}

Market variables without bid ask spread and hi lo bid ask spread

\begin{tabular}{lcc}
\hline Test & Statistic & P value \\
\hline Mardia Skewness & 45.83 & 0.0008 \\
Mardia Kurtosis & 1.28 & 0.2010 \\
Henze-Zirkler T & 3.17 & 0.0015 \\
\hline
\end{tabular}


Top 3 Account and Market variables

\begin{tabular}{lcc}
\hline Test & Statistic & P value \\
\hline Mardia Skewness & 27625 & $<.0001$ \\
Mardia Kurtosis & 408.0 & $<.0001$ \\
Henze-Zirkler T & 94.18 & $<.0001$ \\
& Top 3 Account and Market logarithmic variables \\
\hline Test & Statistic & P value \\
\hline Mardia Skewness & 34570 & $<.0001$ \\
Mardia Kurtosis & 482.8 & $<.0001$ \\
Henze-Zirkler T & 165.0 & $<.0001$ \\
\hline
\end{tabular}

Variables (Price, Standard deviation, bid ask spread, net income to sales, working capital to total assets and current liabilities to total assets )

\begin{tabular}{lcc}
\hline Test & Statistic & P value \\
\hline Mardia Skewness & $169 \mathrm{E} 3$ & $<.0001$ \\
Mardia Kurtosis & 1674 & $<.0001$ \\
Henze-Zirkler T & 131.1 & $<.0001$ \\
\hline
\end{tabular}

Variables (Price, Standard deviation, hi lo bid ask spread, net income to sales, working capital to total assets and current liabilities to total assets )

\begin{tabular}{lcc}
\hline Test & Statistic & P value \\
\hline Mardia Skewness & $157 \mathrm{E} 3$ & $<.0001$ \\
Mardia Kurtosis & 1706 & $<.0001$ \\
Henze-Zirkler T & 131.5 & $<.0001$ \\
\hline
\end{tabular}


For the linear MDA, one year before bankruptcy, $16 \%$ of actual bankrupt firms are erroneously labeled as non-bankrupt, whereas $38 \%$ of non-bankrupt firms are erroneously labeled as bankrupt. Five years before bankruptcy the error rates are $28 \%$ and $10 \%$, respectively. Interestingly, the misclassification rate for bankrupt firms decreases as bankruptcy looms, but the opposite occurs for nonbankrupt firms. For the quadratic MDA, one year before bankruptcy, $10 \%$ of actual bankrupt firms are erroneously labeled as non-bankrupt, whereas $57 \%$ of non-bankrupt firms are erroneously labeled as bankrupt. Five years before bankruptcy the error rates are $8 \%$ and $61 \%$, respectively. Here, both misclassification rates decrease as bankruptcy looms. For the nonparametric MDA, one year before bankruptcy, $12 \%$ of actual bankrupt firms are erroneously labeled as non-bankrupt, whereas $15 \%$ of non-bankrupt firms are erroneously labeled as bankrupt. Five years before bankruptcy the error rates are $25 \%$ and $3 \%$, respectively. These results are similar, but lower in magnitude, to the linear MDA.

For the set of only market variables, the quadratic MDA performs the best at correctly classifying bankrupt firms, whereas the nonparametric MDA performs best at correctly classifying nonbankrupt firms. Overall, the total error rates are lowest for the nonparametric MDA (misclassification rates for bankrupt as well as those of nonbankrupt firms). While this form of MDA has not been widely used throughout the literature, it is consistent and a continuation of prior research. As noted earlier, the assumptions underlying the parametric models are almost always violated. Therefore, it should come as no surprise that this (nonparametric) version of the model performs well.

The next two sets of variables used consist of those variables that performed best in the univariate analysis. The first set of these two contains price, standard deviation, 
bid-ask spread, net income to total sales, working capital to total assets, and current liabilities to total assets. For the linear MDA, one year before bankruptcy, $30 \%$ of actual bankrupt firms are erroneously labeled as non-bankrupt, whereas $12 \%$ of non-bankrupt firms are erroneously labeled as bankrupt. Five years before bankruptcy the error rates are $22 \%$ and $13 \%$, respectively. While the misclassification rates of the bankrupt firms slightly worsen as bankruptcy looms, those of nonbankrupt firms stay relatively flat. For the quadratic MDA, one year before bankruptcy, $45 \%$ of actual bankrupt firms are erroneously labeled as non-bankrupt, whereas $8 \%$ of non-bankrupt

Table 6

Results of Box's M Test for Equality of Variance-Covariance Matrix Accounting variables

\begin{tabular}{llccc}
\hline Year & Bankruptcy & $\mathrm{N}$ & Chi-square Statistic & P value \\
\hline Year 1 & Bankrupt & 6 & 0.000000 & 1.0000 \\
& Nonbankrupt & 95 & & \\
Year 2 & Bankrupt & 6 & 0.000000 & 1.0000 \\
& Nonbankrupt & 93 & & \\
Year 3 & Bankrupt & 2 & 0.000000 & 1.0000 \\
& Nonbankrupt & 86 & & - \\
Year 4 & Bankrupt & - & - & - \\
& Nonbankrupt & & - & \\
Year 5 & Bankrupt & - & & \\
& Nonbankrupt & & & \\
\hline
\end{tabular}

Market variables

\begin{tabular}{lllcc}
\hline Year & Bankruptcy & $\mathrm{N}$ & Chi-square Statistic & P value \\
\hline Year 1 & Bankrupt & 133 & 967.451325 & $<.0001$ \\
& Nonbankrupt & 116 & & \\
Year 2 & Bankrupt & 128 & 607.058492 & $<.0001$ \\
& Nonbankrupt & 112 & &
\end{tabular}




\begin{tabular}{llccc} 
Year 3 & Bankrupt & 107 & 515.281454 & $<.0001$ \\
& Nonbankrupt & 111 & & \\
Year 4 & Bankrupt & 84 & 567.979735 & $<.0001$ \\
& Nonbankrupt & 110 & & \\
Year 5 & Bankrupt & 64 & 316.579924 & $<.0001$ \\
& Nonbankrupt & 97 & & \\
\hline
\end{tabular}

Market variables without spread and hi lo bid ask spread

\begin{tabular}{llccc}
\hline Year & Bankruptcy & $\mathrm{N}$ & Chi-square Statistic & P value \\
\hline Year 1 & Bankrupt & 133 & 629.701533 & $<.0001$ \\
& Nonbankrupt & 116 & & \\
Year 2 & Bankrupt & 128 & 547.342903 & $<.0001$ \\
& Nonbankrupt & 112 & & \\
Year 3 & Bankrupt & 107 & 504.123756 & $<.0001$ \\
& Nonbankrupt & 111 & & $<.0001$ \\
Year 4 & Bankrupt & 84 & 469.823469 & \\
& Nonbankrupt & 110 & & $<.0001$ \\
Year 5 & Bankrupt & 64 & 311.466705 & \\
& Nonbankrupt & 97 & & \\
\hline
\end{tabular}

Market variables without spread and bid ask spread

\begin{tabular}{llccc}
\hline Year & Bankruptcy & $\mathrm{N}$ & Chi-square Statistic & P value \\
\hline Year 1 & Bankrupt & 136 & 935.473575 & $<.0001$ \\
& Nonbankrupt & 116 & & \\
Year 2 & Bankrupt & 129 & 584.366113 & $<.0001$ \\
& Nonbankrupt & 112 & & \\
Year 3 & Bankrupt & 108 & 510.771170 & $<.0001$ \\
& Nonbankrupt & 111 & &
\end{tabular}




\begin{tabular}{llccc} 
Year 4 & Bankrupt & 85 & 507.031076 & $<.0001$ \\
& Nonbankrupt & 110 & & \\
Year 5 & Bankrupt & 70 & 247.083392 & $<.0001$ \\
& Nonbankrupt & 98 & & \\
\hline
\end{tabular}

Market variables without bid ask spread and hi lo bid ask spread

\begin{tabular}{llccc}
\hline Year & Bankruptcy & N & Chi-square Statistic & P value \\
\hline Year 1 & Bankrupt & 10 & 21.306626 & 0.0191 \\
& Nonbankrupt & 3 & & \\
Year 2 & Bankrupt & 6 & 15.350371 & 0.1198 \\
& Nonbankrupt & 6 & & \\
Year 3 & Bankrupt & 7 & 15.637599 & 0.1105 \\
& Nonbankrupt & 3 & & - \\
Year 4 & Bankrupt & 7 & & \\
& Nonbankrupt & 1 & 19.382668 & 0.0357 \\
Year 5 & Bankrupt & 9 & & \\
& Nonbankrupt & 3 & & \\
\hline
\end{tabular}

Top 3 Account and Market variables

\begin{tabular}{llccc}
\hline Year & Bankruptcy & N & Chi-square Statistic & P value \\
\hline Year 1 & Bankrupt & 7 & 45.947752 & 0.0013 \\
& Nonbankrupt & 97 & & \\
Year 2 & Bankrupt & 7 & 45.432227 & 0.0015 \\
& Nonbankrupt & 93 & & \\
Year 3 & Bankrupt & 3 & 0.000000 & 1.0000 \\
& Nonbankrupt & 87 & - & - \\
Year 4 & Bankrupt & - & - & - \\
& Nonbankrupt & & & \\
Year 5 & Bankrupt & - & & \\
& Nonbankrupt & & & \\
\hline
\end{tabular}


Top 3 Account and Market logarithmic variables

\begin{tabular}{llccc}
\hline Year & Bankruptcy & N & Chi-square Statistic & P value \\
\hline Year 1 & Bankrupt & 4 & 43.532931 & 0.0027 \\
& Nonbankrupt & 78 & & \\
Year 2 & Bankrupt & 3 & 0.000000 & 1.0000 \\
& Nonbankrupt & 77 & & - \\
Year 3 & Bankrupt & 1 & - & - \\
& Nonbankrupt & 74 & - & - \\
Year 4 & Bankrupt & - & - & \\
& Nonbankrupt & & & \\
Year 5 & Bankrupt & - & & \\
& Nonbankrupt & & & \\
\hline
\end{tabular}

Variables (Price, Standard deviation, bid ask spread, net income to sales, working capital to total assets and current liabilities to total assets )

\begin{tabular}{llccc}
\hline Year & Bankruptcy & N & Chi-square Statistic & P value \\
\hline Year 1 & Bankrupt & 85 & 898.519782 & $<.0001$ \\
& Nonbankrupt & 99 & & \\
Year 2 & Bankrupt & 95 & 445.264189 & $<.0001$ \\
& Nonbankrupt & 106 & & \\
Year 3 & Bankrupt & 74 & 173.135756 & $<.0001$ \\
& Nonbankrupt & 99 & & $<.0001$ \\
Year 4 & Bankrupt & 66 & 391.112753 & \\
& Nonbankrupt & 24 & & $<.0001$ \\
Year 5 & Bankrupt & 27 & 177.245746 & \\
& Nonbankrupt & 16 & & \\
\hline
\end{tabular}


Variables (Price, Standard deviation, hi lo bid ask spread, net income to sales, working capital to total assets and current liabilities to total assets )

\begin{tabular}{llccc}
\hline Year & Bankruptcy & N & Chi-square Statistic & P value \\
\hline Year 1 & Bankrupt & 86 & 1159.435684 & $<.0001$ \\
& Nonbankrupt & 99 & & \\
Year 2 & Bankrupt & 95 & 435.487169 & $<.0001$ \\
& Nonbankrupt & 106 & & \\
Year 3 & Bankrupt & 75 & 182.030581 & $<.0001$ \\
& Nonbankrupt & 99 & & $<.0001$ \\
Year 4 & Bankrupt & 66 & 380.104350 & \\
& Nonbankrupt & 24 & & $<.0001$ \\
Year 5 & Bankrupt & 29 & 163.480053 & \\
& Nonbankrupt & 16 & & \\
\hline
\end{tabular}


firms are erroneously labeled as bankrupt. Five years before bankruptcy the error rates are $33 \%$ and $0 \%$, respectively. The misclassification rates for bankrupt firms are surprisingly high. For the nonparametric MDA, one year before bankruptcy, $20 \%$ of actual bankrupt firms are erroneously labeled as non-bankrupt, whereas $10 \%$ of nonbankrupt firms are erroneously labeled as bankrupt. Five years before bankruptcy the error rates are $11 \%$ and $25 \%$, respectively.

For this first set of mixed accounting ratios and market variables, the nonparametric MDA is most accurate at classifying bankrupt firms as such, but this set is better at correctly classifying nonbankrupt firms with the use of the quadratic MDA. Unfortunately, the quadratic MDA has very high misclassification rates for bankrupt firms. Therefore, again, overall accuracy is mostly best with the nonparametric MDA, and is consistent with the violations of the underlying assumptions tested above.

The second set of these two contains price, standard deviation, high-low bid-ask spread, net income to total sales, working capital to total assets, and current liabilities to total assets. For the linear MDA, one year before bankruptcy, $28 \%$ of actual bankrupt firms are erroneously labeled as non-bankrupt, whereas $14 \%$ of non-bankrupt firms are erroneously labeled as bankrupt. Five years before bankruptcy the error rates are $22 \%$ and $13 \%$, respectively. This is similar to the first 'mixed' set. For the quadratic MDA, one year before bankruptcy, $54 \%$ of actual bankrupt firms are erroneously labeled as nonbankrupt, whereas $7 \%$ of non-bankrupt firms are erroneously labeled as bankrupt. Five years before bankruptcy the error rates are $59 \%$ and $0 \%$, respectively. This is also consistent with the first 'mixed' set, but the misclassification rates for bankrupt firms are even higher. For the nonparametric MDA, one year before bankruptcy, $24 \%$ of actual 
bankrupt firms are erroneously labeled as non-bankrupt, whereas $9 \%$ of non-bankrupt firms are erroneously labeled as bankrupt. Five years before bankruptcy the error rates are $21 \%$ and $31 \%$, respectively.

For this last set of accounting ratios and market variables, the nonparametric MDA slightly outperforms the linear MDA at correctly classifying bankrupt firms, whereas the

Table 7

Results of Linear Discriminant Analysis : Accounting variables

YEAR 1

\begin{tabular}{lrlr}
\hline Observations & 101 DF Total & 100 \\
Variables & 17 DF Within Classes & 99 \\
Classes & 2 DF Between Classes & 1 \\
\hline
\end{tabular}

\begin{tabular}{|c|c|c|c|c|c|}
\hline \multicolumn{6}{|c|}{ Class Level Information } \\
\hline BANKRUPTCY & $\begin{array}{l}\text { Variable } \\
\text { Name }\end{array}$ & Frequency & Weight & Proportion & $\begin{array}{r}\text { Prior } \\
\text { Probability }\end{array}$ \\
\hline Bankrupt & Bankrupt & 6 & 6.0000 & 0.059406 & 0.500000 \\
\hline Nonbankrupt & Nonbankrupt & 95 & 95.0000 & 0.940594 & 0.500000 \\
\hline
\end{tabular}

\begin{tabular}{rr}
\hline Pooled Covariance Matrix Information \\
\hline $\begin{array}{r}\text { Natural Log of the } \\
\text { Matrix Rank }\end{array}$ & $\begin{array}{r}\text { Determinant of the } \\
\text { Covariance Matrix }\end{array}$ \\
\hline 17 & -22.67893 \\
\hline
\end{tabular}

Generalized Squared Distance to BANKRUPTCY

From

BANKRUPTCY Bankrupt Nonbankrupt

\begin{tabular}{lll}
\hline Bankrupt & 0 & 11.07153
\end{tabular}

Nonbankrupt $\quad 11.07153 \quad 0$


LINEAR DISCRIMINANT FUNCTION

\begin{tabular}{lrr}
\hline Variable & Bankrupt & Nonbankrupt \\
\hline Constant & -23.89413 & -11.26707 \\
M_NETINCOMETOSALES & 4.75443 & 1.30017 \\
M_NETINCOMETOTOTALASSETS & -0.52603 & 20.53297 \\
M_TOTALDEBT & 0.0000126 & 0.0000354 \\
M_NETINCOMETOTOTALDEBT & 2.04585 & -0.23351 \\
M_CURLIABTOTOTASSET & 83.15026 & 54.41938 \\
M_LTLIABTOTOTASSET & 81.27229 & 45.39088 \\
M_TOTDEBTPLUSPREFTOTOTASSET & -54.09291 & -28.20442 \\
M_WCTOTOTALASSETS & 14.38336 & 15.48818 \\
M_QASSETSTOCURLIABILITIES & 5.48194 & 4.43071 \\
M_CURRENTRATIO & 0.79798 & 0.12866 \\
M_INVENTORYTOSALES & 6.26052 & 3.77308 \\
M_QUICKASSETSTOSALES & 2.67253 & -0.27784 \\
M_WORKINGCAPITALTOSALES & -7.14631 & -3.34170 \\
M_TOTALASSETSTOSALES & 0.27541 & 0.43231 \\
M_CASHTOTOTALASSETS & 8.50860 & 4.37690 \\
M_CASHTOCURLIABILITIES & -6.49114 & -4.81007 \\
M_CASHTOSALES & 5.16078 & 4.11512 \\
\hline
\end{tabular}




\section{CLASSIFICATION SUMMARY}

\begin{tabular}{lrrr}
\hline \multicolumn{4}{c}{ Number of Observations and Percent Classified into BANKRUPTCY } \\
\hline From & Bankrupt & Nonbankrupt & Total \\
BANKRUPTCY & 3 & 3 & 6 \\
Bankrupt & 50.00 & 50.00 & 100.00 \\
& 3 & 92 & 95 \\
Nonbankrupt & 3.16 & 96.84 & 100.00 \\
& 6.94 & 94.06 & 101 \\
Total & 0.5 & 0.5 & 100.00 \\
\hline Priors & & & \\
\end{tabular}

\begin{tabular}{lrrr}
\hline \multicolumn{3}{c}{ Error Count Estimates for BANKRUPTCY } \\
\hline & Bankrupt & Nonbankrupt & Total \\
\cline { 2 - 4 } Rate & 0.5000 & 0.0316 & 0.2658 \\
Priors & 0.5000 & 0.5000 & \\
\hline
\end{tabular}

Results of Linear Discriminant Analysis : Market variables

YEAR 1

\begin{tabular}{lrr}
\hline Observations & 249 DF Total & 248 \\
Variables & 5 DF Within Classes & 247 \\
Classes & 2 DF Between Classes & 1 \\
\hline
\end{tabular}

\begin{tabular}{|c|c|c|c|c|c|}
\hline \multicolumn{6}{|c|}{ Class Level Information } \\
\hline BANKRUPTCY & $\begin{array}{l}\text { Variable } \\
\text { Name }\end{array}$ & Frequency & Weight & Proportion & $\begin{array}{r}\text { Prior } \\
\text { Probability }\end{array}$ \\
\hline Bankrupt & Bankrupt & 133 & 133.0000 & 0.534137 & 0.500000 \\
\hline Nonbankrupt & Nonbankrupt & 116 & 116.0000 & 0.465863 & 0.500000 \\
\hline
\end{tabular}




\begin{tabular}{rr}
\hline Pooled Covariance Matrix Information \\
\hline $\begin{array}{r}\text { Covariance } \\
\text { Matrix Rank }\end{array}$ & $\begin{array}{r}\text { Natural Log of the } \\
\text { Covariance Matrix }\end{array}$ \\
\hline 5 & 54.25902
\end{tabular}

\begin{tabular}{lrr}
\multicolumn{3}{l}{ Generalized Squared Distance to BANKRUPTCY } \\
\hline From & & \\
BANKRUPTCY & Bankrupt & Nonbankrupt \\
\hline Bankrupt & 0 & 1.10199 \\
Nonbankrupt & 1.10199 & 0 \\
\hline
\end{tabular}




\section{LINEAR DISCRIMINANT FUNCTION}

\section{Linear Discriminant Function for BANKRUPTCY}

\begin{tabular}{lcc}
\hline Variable & Bankrupt & Nonbankrupt \\
Constant & -0.70287 & -1.04106 \\
M_SHROUT & $-1.1535 \mathrm{E}-6$ & $-1.5762 \mathrm{E}-6$ \\
M_PRC & 0.04253 & 0.12219 \\
M_VOL & $1.37506 \mathrm{E}-6$ & $1.99419 \mathrm{E}-6$ \\
M_BIDASKSPREAD & 8.49887 & 4.35015 \\
M_HILOBIDASKSPREAD & 0.01103 & -0.06242 \\
\hline
\end{tabular}

\section{CLASSIFICATION SUMMARY}

\begin{tabular}{lrrr}
\hline \multicolumn{3}{c}{ Number of Observations and Percent Classified into BANKRUPTCY } \\
\hline From & & & \\
BANKRUPTCY & Bankrupt & Nonbankrupt & Total \\
\hline Bankrupt & 112 & 21 & 133 \\
& 84.21 & 15.79 & 100.00 \\
Nonbankrupt & 44 & 72 & 116 \\
& 37.93 & 62.07 & 100.00 \\
\hline Total & 156 & 93 & 249 \\
& 62.65 & 37.35 & 100.00 \\
\hline Priors & 0.5 & 0.5 & \\
& & & \\
\hline
\end{tabular}

\begin{tabular}{lrrr}
\hline \multicolumn{3}{c}{ Error Count Estimates for BANKRUPTCY } \\
\hline & Bankrupt & Nonbankrupt & Total \\
\hline Rate & 0.1579 & 0.3793 & 0.2686 \\
Priors & 0.5000 & 0.5000 & \\
\hline
\end{tabular}

YEAR 4

\begin{tabular}{lrr}
\hline Observations & 194 DF Total & 193 \\
Variables & 5 DF Within Classes & 192 \\
Classes & 2 DF Between Classes & 1 \\
\hline
\end{tabular}




\begin{tabular}{|c|c|c|c|c|c|}
\hline \multicolumn{6}{|c|}{ Class Level Information } \\
\hline BANKRUPTCY & $\begin{array}{l}\text { Variable } \\
\text { Name }\end{array}$ & Frequency & Weight & Proportion & $\begin{array}{r}\text { Prior } \\
\text { Probability }\end{array}$ \\
\hline Bankrupt & Bankrupt & 84 & 84.0000 & 0.432990 & 0.500000 \\
\hline Nonbankrupt & Nonbankrupt & 110 & 110.0000 & 0.567010 & 0.500000 \\
\hline
\end{tabular}

\begin{tabular}{rr}
\hline Pooled Covariance Matrix Information \\
\hline $\begin{array}{r}\text { Natural Log of the } \\
\text { Matrix Rank }\end{array}$ & $\begin{array}{r}\text { Determinant of the } \\
\text { Covariance Matrix }\end{array}$ \\
\hline 5 & 53.44970 \\
\hline
\end{tabular}

Generalized Squared Distance to BANKRUPTCY

From

BANKRUPTCY Bankrupt Nonbankrupt

\begin{tabular}{lrr}
\hline Bankrupt & 0 & 2.23491 \\
Nonbankrupt & 2.23491 & 0 \\
\hline
\end{tabular}

\section{LINEAR DISCRIMINANT FUNCTION}

Linear Discriminant Function for BANKRUPTCY

\begin{tabular}{lrr}
\hline Variable & Bankrupt & Nonbankrupt \\
\hline Constant & -1.81313 & -1.10490 \\
M_SHROUT & $-8.6769 \mathrm{E}-7$ & $-6.0896 \mathrm{E}-7$ \\
M_PRC & 0.03938 & 0.08833 \\
M_VOL & $1.12428 \mathrm{E}-6$ & $8.52787 \mathrm{E}-7$ \\
M_BIDASKSPREAD & 12.12005 & 3.11058 \\
M_HILOBIDASKSPREAD & 0.02012 & 0.04323 \\
\hline
\end{tabular}




\section{CLASSIFICATION SUMMARY}

\begin{tabular}{lrrr}
\hline \multicolumn{3}{c}{ Number of Observations and Percent Classified into BANKRUPTCY } \\
\hline From & & & \\
BANKRUPTCY & Bankrupt & Nonbankrupt & Total \\
\hline Bankrupt & 61 & 23 & 84 \\
& 72.62 & 27.38 & 100.00 \\
Nonbankrupt & 11 & 99 & 110 \\
& 10.00 & 90.00 & 100.00 \\
\hline Total & 72 & 122 & 194 \\
& 37.11 & 62.89 & 100.00 \\
\hline Priors & 0.5 & 0.5 & \\
\end{tabular}

\begin{tabular}{lrrr}
\hline \multicolumn{3}{c}{ Error Count Estimates for BANKRUPTCY } \\
\hline & Bankrupt & Nonbankrupt & Total \\
\hline Rate & 0.2738 & 0.1000 & 0.1869 \\
Priors & 0.5000 & 0.5000 & \\
\hline
\end{tabular}

YEAR 5

\begin{tabular}{lrlr}
\hline Observations & 161 DF Total & 160 \\
Variables & 5 DF Within Classes & 159 \\
Classes & 2 & DF Between Classes & 1 \\
\hline
\end{tabular}

\begin{tabular}{|c|c|c|c|c|c|}
\hline \multicolumn{6}{|c|}{ Class Level Information } \\
\hline BANKRUPTCY & $\begin{array}{l}\text { Variable } \\
\text { Name }\end{array}$ & Frequency & Weight & Proportion & $\begin{array}{r}\text { Prior } \\
\text { Probability }\end{array}$ \\
\hline Bankrupt & Bankrupt & 64 & 64.0000 & 0.397516 & 0.500000 \\
\hline Nonbankrupt & Nonbankrupt & 97 & 97.0000 & 0.602484 & 0.500000 \\
\hline
\end{tabular}

\begin{tabular}{rr}
\hline Pooled Covariance Matrix Information \\
\hline $\begin{array}{r}\text { Novariance } \\
\text { Matrix Rank }\end{array}$ & $\begin{array}{r}\text { Determinant of the } \\
\text { Covariance Matrix }\end{array}$ \\
\hline 5 & 51.76772 \\
\hline
\end{tabular}




\begin{tabular}{lrr}
\hline \multicolumn{3}{l}{ Generalized Squared Distance to BANKRUPTCY } \\
\hline From & & \\
BANKRUPTCY & Bankrupt & Nonbankrupt \\
\hline Bankrupt & 0 & 2.47216 \\
Nonbankrupt & 2.47216 & 0 \\
\hline
\end{tabular}

LINEAR DISCRIMINANT FUNCTION

\begin{tabular}{lrr}
\hline \multicolumn{3}{c}{ Linear Discriminant Function for BANKRUPTCY } \\
\hline Variable & Bankrupt & Nonbankrupt \\
\hline Constant & -2.04668 & -1.02227 \\
M_SHROUT & $3.84133 \mathrm{E}-8$ & $2.49029 \mathrm{E}-7$ \\
M_PRC & 0.03473 & 0.06832 \\
M_VOL & $3.69855 \mathrm{E}-7$ & $3.78623 \mathrm{E}-7$ \\
M_BIDASKSPREAD & 13.64273 & 3.33147 \\
M_HILOBIDASKSPREAD & 0.08978 & 0.13395 \\
\hline
\end{tabular}

\section{CLASSIFICATION SUMMARY}

Number of Observations and Percent Classified into BANKRUPTCY

\begin{tabular}{lrrr}
\hline From & & & \\
BANKRUPTCY & Bankrupt & Nonbankrupt & Total \\
\hline Bankrupt & 46 & 18 & 64 \\
& 71.88 & 28.13 & 100.00 \\
Nonbankrupt & 10 & 87 & 97 \\
& 10.31 & 89.69 & 100.00 \\
\hline Total & 56 & 105 & 161 \\
& 34.78 & 65.22 & 100.00 \\
\hline Priors & 0.5 & 0.5 & \\
& & & \\
\hline
\end{tabular}




\begin{tabular}{lrrr}
\hline \multicolumn{3}{c}{ Error Count Estimates for BANKRUPTCY } \\
\hline & Bankrupt & Nonbankrupt & Total \\
Rate & 0.2813 & 0.1031 & 0.1922 \\
Priors & 0.5000 & 0.5000 & \\
\hline
\end{tabular}

Results of Linear Discriminant Analysis : Market variables without spread and hi lo bid ask spread

YEAR 1

\begin{tabular}{lrlr}
\hline Observations & 249 DF Total & 248 \\
Variables & 4 DF Within Classes & 247 \\
Classes & 2 DF Between Classes & 1 \\
\hline
\end{tabular}




\begin{tabular}{|c|c|c|c|c|c|}
\hline \multicolumn{6}{|c|}{ Class Level Information } \\
\hline BANKRUPTCY & $\begin{array}{l}\text { Variable } \\
\text { Name }\end{array}$ & Frequency & Weight & Proportion & $\begin{array}{r}\text { Prior } \\
\text { Probability }\end{array}$ \\
\hline Bankrupt & Bankrupt & 133 & 133.0000 & 0.534137 & 0.500000 \\
\hline Nonbankrupt & Nonbankrupt & 116 & 116.0000 & 0.465863 & 0.500000 \\
\hline
\end{tabular}

\begin{tabular}{rr}
\hline Pooled Covariance & Matrix Information \\
\hline $\begin{array}{r}\text { Covariance } \\
\text { Matrix Rank }\end{array}$ & $\begin{array}{r}\text { Natural Log of the } \\
\text { Determinant of the } \\
\text { Covariance Matrix }\end{array}$ \\
\hline 4 & 50.68621
\end{tabular}

\begin{tabular}{lrr}
\hline \multicolumn{2}{l}{ Generalized Squared Distance to BANKRUPTCY } \\
\hline From & & \\
BANKRUPTCY & Bankrupt & Nonbankrupt \\
\hline Bankrupt & 0 & 0.90985 \\
Nonbankrupt & 0.90985 & 0 \\
\hline
\end{tabular}

LINEAR DISCRIMINANT FUNCTION

Linear Discriminant Function for BANKRUPTCY

\begin{tabular}{lrr}
\hline Variable & Bankrupt & Nonbankrupt \\
\hline Constant & -0.70070 & -0.97167 \\
M_SHROUT & $-1.1779 \mathrm{E}-6$ & $-1.4379 \mathrm{E}-6$ \\
M_PRC & 0.04544 & 0.10574 \\
M_VOL & $1.38777 \mathrm{E}-6$ & $1.92228 \mathrm{E}-6$ \\
M_BIDASKSPREAD & 8.55784 & 4.01632 \\
\hline
\end{tabular}




\section{CLASSIFICATION SUMMARY}

\begin{tabular}{lrrr}
\hline \multicolumn{2}{c}{ Number of Observations and Percent Classified into BANKRUPTCY } \\
\hline From & & & \\
BANKRUPTCY & Bankrupt & Nonbankrupt & Total \\
\hline Bankrupt & 110 & 23 & 133 \\
& 82.71 & 17.29 & 100.00 \\
Nonbankrupt & 45 & 71 & 116 \\
& 38.79 & 61.21 & 100.00 \\
\hline Total & 155 & 94 & 249 \\
& 62.25 & 37.75 & 100.00 \\
\hline Priors & 0.5 & 0.5 & \\
& & & \\
\hline
\end{tabular}

\begin{tabular}{lrrr}
\hline \multicolumn{3}{c}{ Error Count Estimates for BANKRUPTCY } \\
\hline & Bankrupt & Nonbankrupt & Total \\
\hline Rate & 0.1729 & 0.3879 & 0.2804 \\
Priors & 0.5000 & 0.5000 & \\
\hline
\end{tabular}

YEAR 4

\begin{tabular}{lrr}
\hline Observations & 194 DF Total & 193 \\
Variables & 4 DF Within Classes & 192 \\
Classes & 2 DF Between Classes & 1 \\
\hline
\end{tabular}

\begin{tabular}{|c|c|c|c|c|c|}
\hline \multicolumn{6}{|c|}{ Class Level Information } \\
\hline BANKRUPTCY & $\begin{array}{l}\text { Variable } \\
\text { Name }\end{array}$ & Frequency & Weight & Proportion & $\begin{array}{r}\text { Prior } \\
\text { Probability }\end{array}$ \\
\hline Bankrupt & Bankrupt & 84 & 84.0000 & 0.432990 & 0.500000 \\
\hline Nonbankrupt & Nonbankrupt & 110 & 110.0000 & 0.567010 & 0.500000 \\
\hline
\end{tabular}

\begin{tabular}{rr}
\hline Pooled Covariance Matrix Information \\
\hline $\begin{array}{r}\text { Novariance } \\
\text { Matrix Rank }\end{array}$ & $\begin{array}{r}\text { Determinant of the } \\
\text { Covariance Matrix }\end{array}$ \\
\hline 4 & 50.74589 \\
\hline
\end{tabular}




\begin{tabular}{lrr}
\hline \multicolumn{3}{l}{ Generalized Squared Distance to BANKRUPTCY } \\
\hline From & Bankrupt & Nonbankrupt \\
BANKRUPTCY & 0 & 2.22693 \\
\hline Bankrupt & 2.22693 & 0 \\
Nonbankrupt & \\
\hline
\end{tabular}

\section{LINEAR DISCRIMINANT FUNCTION}

\begin{tabular}{lrr}
\hline \multicolumn{3}{c}{ Linear Discriminant } \\
\hline Variable & Bankrupt & Nonbankrupt \\
\hline Constant & -1.81011 & -1.09094 \\
M_SHROUT & $-8.7659 \mathrm{E}-7$ & $-6.2809 \mathrm{E}-7$ \\
M_PRC & 0.04186 & 0.09366 \\
M_VOL & $1.12116 \mathrm{E}-6$ & $8.46076 \mathrm{E}-7$ \\
M_BIDASKSPREAD & 12.15603 & 3.18789 \\
\hline
\end{tabular}

\section{CLASSIFICATION SUMMARY}

\begin{tabular}{lrrr}
\hline \multicolumn{2}{c}{ Number of Observations and Percent Classified into BANKRUPTCY } \\
\hline From & & & Total \\
BANKRUPTCY & Bankrupt & Nonbankrupt & 84 \\
\hline Bankrupt & 61 & 23 & 100.00 \\
& 72.62 & 27.38 & 110 \\
Nonbankrupt & 11 & 99 & 100.00 \\
\hline Total & 10.00 & 90.00 & 194 \\
& 72 & 122 & 100.00 \\
\hline Priors & 37.11 & 62.89 & \\
& 0.5 & 0.5 & \\
\hline
\end{tabular}

\begin{tabular}{lrrr}
\hline \multicolumn{3}{c}{ Error Count Estimates for BANKRUPTCY } \\
\hline & Bankrupt & Nonbankrupt & Total \\
\hline Rate & 0.2738 & 0.1000 & 0.1869 \\
Priors & 0.5000 & 0.5000 & \\
\hline
\end{tabular}

YEAR 5 


\begin{tabular}{lrlr}
\hline Observations & 161 DF Total & 160 \\
Variables & 4 DF Within Classes & 159 \\
Classes & 2 DF Between Classes & 1 \\
\hline
\end{tabular}

\begin{tabular}{|c|c|c|c|c|c|}
\hline \multicolumn{6}{|c|}{ Class Level Information } \\
\hline BANKRUPTCY & $\begin{array}{l}\text { Variable } \\
\text { Name }\end{array}$ & Frequency & Weight & Proportion & $\begin{array}{r}\text { Prior } \\
\text { Probability }\end{array}$ \\
\hline Bankrupt & Bankrupt & 64 & 64.0000 & 0.397516 & 0.500000 \\
\hline Nonbankrupt & Nonbankrupt & 97 & 97.0000 & 0.602484 & 0.500000 \\
\hline
\end{tabular}

\begin{tabular}{rr}
\hline Pooled Covariance Matrix Information \\
\hline $\begin{array}{r}\text { Natural Log of the } \\
\text { Matrix Rank }\end{array}$ & $\begin{array}{r}\text { Determinant of the } \\
\text { Covariance Matrix }\end{array}$ \\
\hline 4 & 50.22446 \\
\hline
\end{tabular}

\begin{tabular}{lrr}
\hline \multicolumn{2}{l}{ Generalized Squared Distance to BANKRUPTCY } \\
\hline From & & \\
BANKRUPTCY & Bankrupt & Nonbankrupt \\
\hline Bankrupt & 0 & 2.46303 \\
Nonbankrupt & 2.46303 & 0 \\
\hline
\end{tabular}

\section{LINEAR DISCRIMINANT FUNCTION}

\begin{tabular}{|c|c|c|}
\hline \multicolumn{3}{|c|}{ Linear Discriminant Function for BANKRUPTCY } \\
\hline Variable & Bankrupt & Nonbankrupt \\
\hline Constant & -2.02782 & -0.98029 \\
\hline M_SHROUT & $-5.2201 \mathrm{E}-7$ & $-5.8711 \mathrm{E}-7$ \\
\hline M_PRC & 0.04399 & 0.08213 \\
\hline M_VOL & $8.31508 \mathrm{E}-7$ & $1.06741 \mathrm{E}-6$ \\
\hline M_BIDASKSPREAD & 13.69023 & 3.40235 \\
\hline
\end{tabular}




\section{CLASSIFICATION SUMMARY}

\begin{tabular}{lrrr}
\hline \multicolumn{2}{c}{ Number of Observations and Percent Classified into BANKRUPTCY } \\
\hline From & & & \\
BANKRUPTCY & Bankrupt & Nonbankrupt & Total \\
\hline Bankrupt & 46 & 18 & 64 \\
& 71.88 & 28.13 & 100.00 \\
Nonbankrupt & 10 & 87 & 97 \\
& 10.31 & 89.69 & 100.00 \\
\hline Total & 56 & 105 & 161 \\
& 34.78 & 65.22 & 100.00 \\
\hline Priors & 0.5 & 0.5 & \\
& & & \\
\hline
\end{tabular}

\begin{tabular}{lrrr}
\hline \multicolumn{3}{c}{ Error Count Estimates for BANKRUPTCY } \\
\hline & Bankrupt & Nonbankrupt & Total \\
\hline Rate & 0.2813 & 0.1031 & 0.1922 \\
Priors & 0.5000 & 0.5000 & \\
\hline
\end{tabular}

Results of Linear Discriminant Analysis : Market variables without spread and bid ask spread YEAR 1

\begin{tabular}{lrlr}
\hline Observations & 252 DF Total & 251 \\
Variables & 4 DF Within Classes & 250 \\
Classes & 2 DF Between Classes & 1 \\
\hline
\end{tabular}

\begin{tabular}{|c|c|c|c|c|c|}
\hline \multicolumn{6}{|c|}{ Class Level Information } \\
\hline BANKRUPTCY & $\begin{array}{l}\text { Variable } \\
\text { Name }\end{array}$ & Frequency & Weight & Proportion & $\begin{array}{r}\text { Prior } \\
\text { Probability }\end{array}$ \\
\hline Bankrupt & Bankrupt & 136 & 136.0000 & 0.539683 & 0.500000 \\
\hline Nonbankrupt & Nonbankrupt & 116 & 116.0000 & 0.460317 & 0.500000 \\
\hline
\end{tabular}




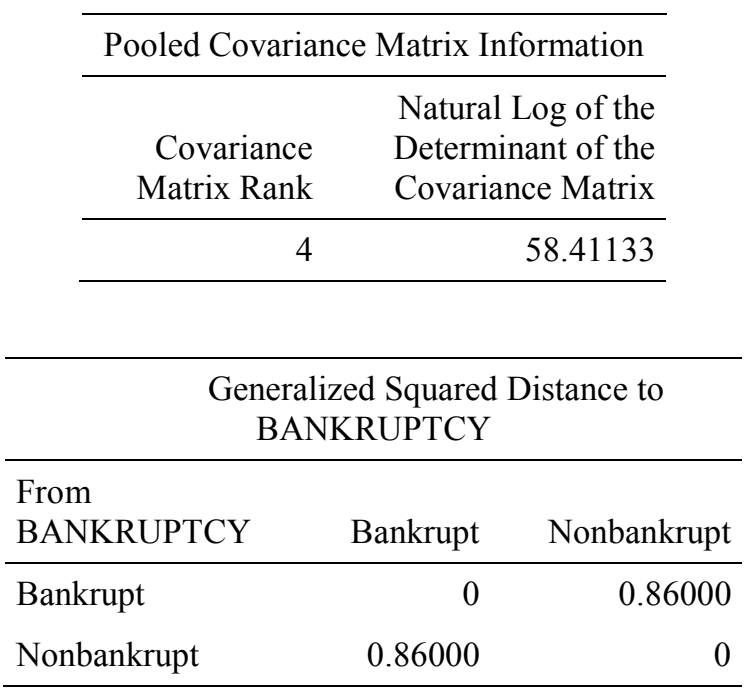

\section{LINEAR DISCRIMINANT FUNCTION}

\section{Linear Discriminant Function for BANKRUPTCY}

\begin{tabular}{lrr}
\hline Variable & Bankrupt & Nonbankrupt \\
\hline Constant & -0.15620 & -0.90788 \\
M_SHROUT & $-6.0381 \mathrm{E}-7$ & $-1.3142 \mathrm{E}-6$ \\
M_PRC & 0.03592 & 0.12008 \\
M_VOL & $6.70847 \mathrm{E}-7$ & $1.65622 \mathrm{E}-6$ \\
M_HILOBIDASKSPREAD & 0.02972 & -0.05339 \\
\hline
\end{tabular}

\section{CLASSIFICATION SUMMARY}

\begin{tabular}{lrrr}
\hline \multicolumn{3}{c}{ Number of Observations and Percent Classified into BANKRUPTCY } \\
\hline From & & & \\
BANKRUPTCY & Bankrupt & Nonbankrupt & Total \\
\hline Bankrupt & 115 & 21 & 136 \\
& 84.56 & 15.44 & 100.00 \\
Nonbankrupt & 53 & 63 & 116 \\
& 45.69 & 54.31 & 100.00 \\
\hline Total & 168 & 84 & 252 \\
& 66.67 & 33.33 & 100.00 \\
\hline Priors & 0.5 & 0.5 & \\
& & & \\
\hline
\end{tabular}




\begin{tabular}{lrrr}
\hline \multicolumn{3}{c}{ Error Count Estimates for BANKRUPTCY } \\
\hline & Bankrupt & Nonbankrupt & Total \\
\hline Rate & 0.1544 & 0.4569 & 0.3057 \\
Priors & 0.5000 & 0.5000 & \\
\hline
\end{tabular}

YEAR 4

\begin{tabular}{lrrr}
\hline Observations & 195 DF Total & 194 \\
Variables & 4 DF Within Classes & 193 \\
Classes & 2 DF Between Classes & 1 \\
\hline
\end{tabular}

\begin{tabular}{|c|c|c|c|c|c|}
\hline \multicolumn{6}{|c|}{ Class Level Information } \\
\hline BANKRUPTCY & $\begin{array}{l}\text { Variable } \\
\text { Name }\end{array}$ & Frequency & Weight & Proportion & $\begin{array}{r}\text { Prior } \\
\text { Probability }\end{array}$ \\
\hline Bankrupt & Bankrupt & 85 & 85.0000 & 0.435897 & 0.500000 \\
\hline Nonbankrupt & Nonbankrupt & 110 & 110.0000 & 0.564103 & 0.500000 \\
\hline
\end{tabular}

\begin{tabular}{rr}
\hline Pooled Covariance Matrix Information \\
\hline $\begin{array}{r}\text { Natural Log of the } \\
\text { Matrix Rank }\end{array}$ & $\begin{array}{r}\text { Determinant of the } \\
\text { Covariance Matrix }\end{array}$ \\
\hline 4 & 57.29326 \\
\hline
\end{tabular}

\begin{tabular}{lrr}
\hline \multicolumn{2}{l}{ Generalized Squared Distance to BANKRUPTCY } \\
\hline From & & \\
BANKRUPTCY & Bankrupt & Nonbankrupt \\
\hline Bankrupt & 0 & 0.53979 \\
Nonbankrupt & 0.53979 & 0 \\
\hline
\end{tabular}


LINEAR DISCRIMINANT FUNCTION

\begin{tabular}{|c|c|c|}
\hline \multicolumn{3}{|c|}{ Linear Discriminant Function for BANKRUPTCY } \\
\hline Variable & Bankrupt & Nonbankrupt \\
\hline Constant & -0.25703 & -1.00358 \\
\hline M_SHROUT & $3.21477 \mathrm{E}-7$ & $-3.079 \mathrm{E}-7$ \\
\hline M_PRC & 0.04342 & 0.08958 \\
\hline M_VOL & $-5.4745 \mathrm{E}-7$ & 4.30144E-7 \\
\hline M_HILOBIDASKSPREAD & 0.05049 & 0.05113 \\
\hline
\end{tabular}

\section{CLASSIFICATION SUMMARY}

Number of Observations and Percent Classified into BANKRUPTCY

\begin{tabular}{lrrr}
\hline From & Bankrupt & Nonbankrupt & Total \\
\hline Bankrupt & 67 & 18 & 85 \\
& 78.82 & 21.18 & 100.00 \\
Nonbankrupt & 58 & 52 & 110 \\
& 52.73 & 47.27 & 100.00 \\
\hline Total & 125 & 70 & 195 \\
& 64.10 & 35.90 & 100.00 \\
\hline Priors & 0.5 & 0.5 &
\end{tabular}

\begin{tabular}{lrrr}
\hline \multicolumn{3}{c}{ Error Count Estimates for BANKRUPTCY } \\
\hline & Bankrupt & Nonbankrupt & Total \\
\hline Rate & 0.2118 & 0.5273 & 0.3695 \\
Priors & 0.5000 & 0.5000 & \\
\hline
\end{tabular}

YEAR 5

\begin{tabular}{lrr}
\hline Observations & 168 DF Total & 167 \\
Variables & 4 DF Within Classes & 166 \\
Classes & 2 DF Between Classes & 1 \\
\hline
\end{tabular}




\begin{tabular}{|c|c|c|c|c|c|}
\hline \multicolumn{6}{|c|}{ Class Level Information } \\
\hline BANKRUPTCY & $\begin{array}{l}\text { Variable } \\
\text { Name }\end{array}$ & Frequency & Weight & Proportion & $\begin{array}{r}\text { Prior } \\
\text { Probability }\end{array}$ \\
\hline Bankrupt & Bankrupt & 70 & 70.0000 & 0.416667 & 0.500000 \\
\hline Nonbankrupt & Nonbankrupt & 98 & 98.0000 & 0.583333 & 0.500000 \\
\hline
\end{tabular}

\begin{tabular}{rr}
\hline Pooled Covariance Matrix Information \\
\hline $\begin{array}{r}\text { Natural Log of the } \\
\text { Matrix Rank }\end{array}$ & $\begin{array}{r}\text { Determinant of the } \\
\text { Covariance Matrix }\end{array}$ \\
\hline 4 & 55.60270
\end{tabular}

\begin{tabular}{lrr}
\hline \multicolumn{2}{l}{ Generalized Squared Distance to BANKRUPTCY } \\
\hline From & & \\
BANKRUPTCY & Bankrupt & Nonbankrupt \\
\hline Bankrupt & 0 & 0.48330 \\
Nonbankrupt & 0.48330 & 0 \\
\hline
\end{tabular}

LINEAR DISCRIMINANT FUNCTION

Linear Discriminant Function for BANKRUPTCY

\begin{tabular}{lrr}
\hline Variable & Bankrupt & Nonbankrupt \\
\hline Constant & -0.23238 & -0.89786 \\
M_SHROUT & $9.80841 \mathrm{E}-7$ & $4.47579 \mathrm{E}-7$ \\
M_PRC & 0.03036 & 0.06769 \\
M_VOL & $-9.1498 \mathrm{E}-7$ & $1.15496 \mathrm{E}-7$ \\
M_HILOBIDASKSPREAD & 0.11001 & 0.13359 \\
\hline
\end{tabular}




\section{CLASSIFICATION SUMMARY}

\begin{tabular}{lrrr}
\hline \multicolumn{2}{c}{ Number of Observations and Percent Classified into BANKRUPTCY } \\
\hline From & & & \\
BANKRUPTCY & Bankrupt & Nonbankrupt & Total \\
\hline Bankrupt & 55 & 15 & 70 \\
& 78.57 & 21.43 & 100.00 \\
Nonbankrupt & 45 & 53 & 98 \\
& 45.92 & 54.08 & 100.00 \\
\hline Total & 100 & 68 & 168 \\
& 59.52 & 40.48 & \\
\hline Priors & 0.5 & 0.5 & \\
& & & \\
\hline
\end{tabular}

\begin{tabular}{lrrr}
\hline \multicolumn{3}{c}{ Error Count Estimates for BANKRUPTCY } \\
\hline & Bankrupt & Nonbankrupt & Total \\
\hline Rate & 0.2143 & 0.4592 & 0.3367 \\
Priors & 0.5000 & 0.5000 & \\
\hline
\end{tabular}


Results of Linear Discriminant Analysis : Market variables without bid ask spread and hi lo bid ask spread YEAR 1

\begin{tabular}{lrlr}
\hline Observations & 13 DF Total & 12 \\
Variables & 4 DF Within Classes & 11 \\
Classes & 2 & DF Between Classes & 1 \\
\hline
\end{tabular}

\begin{tabular}{|c|c|c|c|c|c|}
\hline \multicolumn{6}{|c|}{ Class Level Information } \\
\hline BANKRUPTCY & $\begin{array}{l}\text { Variable } \\
\text { Name }\end{array}$ & Frequency & Weight & Proportion & $\begin{array}{r}\text { Prior } \\
\text { Probability }\end{array}$ \\
\hline Bankrupt & Bankrupt & 10 & 10.0000 & 0.769231 & 0.500000 \\
\hline Nonbankrupt & Nonbankrupt & 3 & 3.0000 & 0.230769 & 0.500000 \\
\hline
\end{tabular}

\begin{tabular}{rr}
\hline Pooled Covariance Matrix Information \\
\hline $\begin{array}{r}\text { Covariance } \\
\text { Matrix Rank }\end{array}$ & $\begin{array}{r}\text { Natural Log of the } \\
\text { Determinant of the } \\
\text { Covariance Matrix }\end{array}$ \\
\hline 4 & 32.02790
\end{tabular}

\begin{tabular}{lrr}
\hline \multicolumn{2}{l}{ Generalized Squared Distance to BANKRUPTCY } \\
\hline From & & \\
BANKRUPTCY & Bankrupt & Nonbankrupt \\
\hline Bankrupt & 0 & 4.38366 \\
Nonbankrupt & 4.38366 & 0 \\
\hline
\end{tabular}




\section{LINEAR DISCRIMINANT FUNCTION}

\begin{tabular}{lrr}
\hline \multicolumn{3}{c}{ Linear Discriminant Function for } \\
BANKRUPTCY \\
\hline Variable & Bankrupt & Nonbankrupt \\
\hline Constant & -2.76775 & -2.96839 \\
M_SHROUT & 0.0004948 & 0.0002658 \\
M_PRC & 0.11450 & 0.09712 \\
M_VOL & 0.0005243 & -0.0002326 \\
M_SPREAD & 3.30951 & 9.65757 \\
\hline
\end{tabular}

\section{CLASSIFICATION SUMMARY}

\begin{tabular}{lrrr}
\hline \multicolumn{2}{c}{ Number of Observations and Percent Classified into BANKRUPTCY } \\
\hline From & & & \\
BANKRUPTCY & Bankrupt & Nonbankrupt & Total \\
\hline Bankrupt & 9 & 1 & 10 \\
& 90.00 & 10.00 & 100.00 \\
Nonbankrupt & 0 & 3 & 3 \\
& 0.00 & 100.00 & 100.00 \\
\hline Total & 9 & 4 & 13 \\
& 69.23 & 30.77 & \\
\hline Priors & 0.5 & 0.5 & \\
& & &
\end{tabular}

\begin{tabular}{lrrr}
\hline \multicolumn{3}{c}{ Error Count Estimates for BANKRUPTCY } \\
\hline & Bankrupt & Nonbankrupt & Total \\
\hline Rate & 0.1000 & 0.0000 & 0.0500 \\
Priors & 0.5000 & 0.5000 & \\
\hline
\end{tabular}

YEAR 4

\begin{tabular}{lll}
\hline Observations & 8 DF Total & 7 \\
Variables & 4 DF Within Classes & 6 \\
Classes & 2 DF Between Classes & 1 \\
\hline
\end{tabular}




\begin{tabular}{|c|c|c|c|c|c|}
\hline \multicolumn{6}{|c|}{ Class Level Information } \\
\hline BANKRUPTCY & $\begin{array}{l}\text { Variable } \\
\text { Name }\end{array}$ & Frequency & Weight & Proportion & $\begin{array}{r}\text { Prior } \\
\text { Probability }\end{array}$ \\
\hline Bankrupt & Bankrupt & 7 & 7.0000 & 0.875000 & 0.500000 \\
\hline Nonbankrupt & Nonbankrupt & 1 & 1.0000 & 0.125000 & 0.500000 \\
\hline
\end{tabular}

\begin{tabular}{rr}
\hline Pooled Covariance Matrix Information \\
\hline $\begin{array}{r}\text { Novariance } \\
\text { Matrix Rank }\end{array}$ & $\begin{array}{r}\text { Determinant of the } \\
\text { Covariance Matrix }\end{array}$ \\
\hline 4 & 32.64361 \\
\hline
\end{tabular}

Generalized Squared Distance to BANKRUPTCY

From

BANKRUPTCY Bankrupt Nonbankrupt

\begin{tabular}{lll}
\hline Bankrupt & 0 & 20.01507
\end{tabular}

$\begin{array}{lll}\text { Nonbankrupt } & 20.01507 & 0\end{array}$

\section{LINEAR DISCRIMINANT FUNCTION}

\begin{tabular}{lrr}
\hline \multicolumn{3}{c}{ Linear Discriminant Function for } \\
BANKRUPTCY \\
\hline Variable & Bankrupt & Nonbankrupt \\
\hline Constant & -15.70441 & -0.73522 \\
M_SHROUT & 0.00193 & 0.0003658 \\
M_PRC & -6.69821 & -1.27927 \\
M_VOL & -0.0009417 & -0.0001405 \\
M_SPREAD & 29.72955 & 6.22165 \\
\hline
\end{tabular}




\section{CLASSIFICATION SUMMARY}

\begin{tabular}{lrrr}
\hline \multicolumn{2}{c}{ Number of Observations and Percent Classified into BANKRUPTCY } \\
\hline From & & & Total \\
BANKRUPTCY & Bankrupt & Nonbankrupt & 7 \\
\hline Bankrupt & 7 & 0 & 100.00 \\
& 100.00 & 0.00 & 1 \\
Nonbankrupt & 0 & 1 & 100.00 \\
\hline Total & 0.00 & 100.00 & 8 \\
& 7 & 1 & 100.00 \\
\hline Priors & 87.50 & 12.50 & \\
& 0.5 & 0.5 & \\
\hline
\end{tabular}

\begin{tabular}{lrrr}
\hline \multicolumn{3}{c}{ Error Count Estimates for BANKRUPTCY } \\
\hline & Bankrupt & Nonbankrupt & Total \\
\hline Rate & 0.0000 & 0.0000 & 0.0000 \\
Priors & 0.5000 & 0.5000 & \\
\hline
\end{tabular}

YEAR 5

\begin{tabular}{lrrr}
\hline Observations & 12 DF Total & 11 \\
Variables & 4 & DF Within Classes & 10 \\
Classes & 2 & DF Between Classes & 1 \\
\hline
\end{tabular}

\begin{tabular}{|c|c|c|c|c|c|}
\hline \multicolumn{6}{|c|}{ Class Level Information } \\
\hline BANKRUPTCY & $\begin{array}{l}\text { Variable } \\
\text { Name }\end{array}$ & Frequency & Weight & Proportion & $\begin{array}{r}\text { Prior } \\
\text { Probability }\end{array}$ \\
\hline Bankrupt & Bankrupt & 9 & 9.0000 & 0.750000 & 0.500000 \\
\hline Nonbankrupt & Nonbankrupt & 3 & 3.0000 & 0.250000 & 0.500000 \\
\hline
\end{tabular}

\begin{tabular}{rr}
\hline Pooled Covariance Matrix Information \\
\hline $\begin{array}{r}\text { Covariance } \\
\text { Matrix Rank }\end{array}$ & $\begin{array}{r}\text { Natural Log of the } \\
\text { Covariance Matrix }\end{array}$ \\
\hline 4 & 35.50994 \\
\hline
\end{tabular}




\begin{tabular}{lrr}
\hline \multicolumn{3}{l}{ Generalized Squared Distance to BANKRUPTCY } \\
\hline From & & \\
BANKRUPTCY & Bankrupt & Nonbankrupt \\
\hline Bankrupt & 0 & 1.97567 \\
Nonbankrupt & 1.97567 & 0 \\
\hline
\end{tabular}

LINEAR DISCRIMINANT FUNCTION

\begin{tabular}{lrr}
\hline \multicolumn{3}{c}{ Linear Discriminant Function for } \\
BANKRUPTCY \\
\hline Variable & Bankrupt & Nonbankrupt \\
\hline Constant & -3.34527 & -0.90619 \\
M_SHROUT & 0.0000820 & 0.0000611 \\
M_PRC & -0.13147 & -0.02655 \\
M_VOL & 0.0001999 & 0.0000167 \\
M_SPREAD & 10.97710 & 6.06596 \\
\hline
\end{tabular}

\section{CLASSIFICATION SUMMARY}

\begin{tabular}{lrrr}
\hline \multicolumn{2}{c}{ Number of Observations and Percent Classified into BANKRUPTCY } \\
\hline From & & & \\
BANKRUPTCY & Bankrupt & Nonbankrupt & Total \\
\hline Bankrupt & 6 & 3 & 9 \\
& 66.67 & 33.33 & 100.00 \\
Nonbankrupt & 1 & 2 & 3 \\
& 33.33 & 66.67 & 100.00 \\
\hline Total & 7 & 5 & 12 \\
& 58.33 & 41.67 & 100.00 \\
\hline Priors & 0.5 & 0.5 & \\
& & & \\
\hline
\end{tabular}

\begin{tabular}{lrrr}
\hline \multicolumn{3}{c}{ Error Count Estimates for BANKRUPTCY } \\
\hline & Bankrupt & Nonbankrupt & Total \\
\hline Rate & 0.3333 & 0.3333 & 0.3333 \\
Priors & 0.5000 & 0.5000 & \\
\hline
\end{tabular}


Results of Linear Discriminant Analysis : Top 3 Account and Market variables

YEAR 1

\begin{tabular}{lrr}
\hline Observations & 104 DF Total & 103 \\
Variables & 6 DF Within Classes & 102 \\
Classes & 2 DF Between Classes & 1 \\
\hline
\end{tabular}

\begin{tabular}{|c|c|c|c|c|c|}
\hline \multicolumn{6}{|c|}{ Class Level Information } \\
\hline BANKRUPTCY & $\begin{array}{l}\text { Variable } \\
\text { Name }\end{array}$ & Frequency & Weight & Proportion & $\begin{array}{r}\text { Prior } \\
\text { Probability }\end{array}$ \\
\hline Bankrupt & Bankrupt & 7 & 7.0000 & 0.067308 & 0.500000 \\
\hline Nonbankrupt & Nonbankrupt & 97 & 97.0000 & 0.932692 & 0.500000 \\
\hline
\end{tabular}

\begin{tabular}{rr}
\hline Pooled Covariance Matrix Information \\
\hline $\begin{array}{r}\text { Covariance } \\
\text { Matrix Rank }\end{array}$ & $\begin{array}{r}\text { Natural Log of the } \\
\text { Determinant of the } \\
\text { Covariance Matrix }\end{array}$ \\
\hline 6 & -10.80012
\end{tabular}

\begin{tabular}{lrr}
\hline \multicolumn{2}{l}{ Generalized Squared Distance to BANKRUPTCY } \\
\hline From & & \\
BANKRUPTCY & Bankrupt & Nonbankrupt \\
\hline Bankrupt & 0 & 1.21252 \\
Nonbankrupt & 1.21252 & 0 \\
\hline
\end{tabular}


LINEAR DISCRIMINANT FUNCTION

\begin{tabular}{lrr}
\hline Variable & Bankrupt & Nonbankrupt \\
\hline Constant & -6.55211 & -5.22930 \\
\hline M_QUICKASSETSTOTOTALASSTS & 16.80650 & 15.92397 \\
M_LTLIABTOTOTASSET & 12.56471 & 10.39807 \\
M_CASHTOTOTALASSETS & -2.63099 & -3.59411 \\
M_PRC & -0.01314 & 0.09108 \\
M_HILOBIDASKSPREAD & 0.87001 & 0.12567 \\
M_BIDASKSPREAD & 11.05879 & 13.52051 \\
\hline
\end{tabular}

\section{CLASSIFICATION SUMMARY}

Number of Observations and Percent Classified into BANKRUPTCY

\begin{tabular}{lrrr}
\hline From & & & \\
BANKRUPTCY & Bankrupt & Nonbankrupt & Total \\
\hline Bankrupt & 6 & 1 & 7 \\
& 85.71 & 14.29 & 100.00 \\
Nonbankrupt & 23 & 74 & 97 \\
& 23.71 & 76.29 & 100.00 \\
\hline Total & 29 & 75 & 104 \\
& 27.88 & 72.12 & 100.00 \\
\hline Priors & 0.5 & 0.5 & \\
& & & \\
\hline
\end{tabular}

\begin{tabular}{lrrr}
\hline \multicolumn{3}{c}{ Error Count Estimates for BANKRUPTCY } \\
\hline & Bankrupt & Nonbankrupt & Total \\
\hline Rate & 0.1429 & 0.2371 & 0.1900 \\
Priors & 0.5000 & 0.5000 & \\
\hline
\end{tabular}

YEAR 2

\begin{tabular}{lrr}
\hline Observations & 100 DF Total & 99 \\
Variables & 6 DF Within Classes & 98 \\
Classes & 2 DF Between Classes & 1 \\
\hline
\end{tabular}




\begin{tabular}{|c|c|c|c|c|c|}
\hline \multicolumn{6}{|c|}{ Class Level Information } \\
\hline BANKRUPTCY & $\begin{array}{l}\text { Variable } \\
\text { Name }\end{array}$ & Frequency & Weight & Proportion & $\begin{array}{r}\text { Prior } \\
\text { Probability }\end{array}$ \\
\hline Bankrupt & Bankrupt & 7 & 7.0000 & 0.070000 & 0.500000 \\
\hline Nonbankrupt & Nonbankrupt & 93 & 93.0000 & 0.930000 & 0.500000 \\
\hline
\end{tabular}

\begin{tabular}{rr} 
Pooled Covariance Matrix Information \\
\hline $\begin{array}{r}\text { Natural Log of the } \\
\text { Covariance } \\
\text { Matrix Rank }\end{array}$ & $\begin{array}{r}\text { Determinant of the } \\
\text { Covariance Matrix }\end{array}$ \\
\hline 6 & -9.97322
\end{tabular}

Generalized Squared Distance to BANKRUPTCY

From

BANKRUPTCY Bankrupt Nonbankrupt

\begin{tabular}{lrr}
\hline Bankrupt & 0 & 1.58188 \\
Nonbankrupt & 1.58188 & 0 \\
\hline
\end{tabular}

LINEAR DISCRIMINANT FUNCTION

\begin{tabular}{lrr}
\hline Variable & Bankrupt & Nonbankrupt \\
\hline Constant & -13.06377 & -8.34462 \\
M_QUICKASSETSTOTOTALASSTS & 31.54882 & 26.14597 \\
M_LTLIABTOTOTASSET & 28.69393 & 21.37375 \\
M_CASHTOTOTALASSETS & -3.57459 & -4.92930 \\
M_PRC & 0.13754 & 0.14330 \\
M_HILOBIDASKSPREAD & -0.17835 & -0.16421 \\
M_BIDASKSPREAD & 12.93141 & 13.30320 \\
\hline
\end{tabular}




\section{CLASSIFICATION SUMMARY}

\begin{tabular}{lrrr}
\hline \multicolumn{2}{c}{ Number of Observations and Percent Classified into BANKRUPTCY } \\
\hline From & & & Total \\
BANKRUPTCY & Bankrupt & Nonbankrupt & 7 \\
\hline Bankrupt & 6 & 1 & 100.00 \\
& 85.71 & 14.29 & 93 \\
Nonbankrupt & 23 & 70 & 100.00 \\
& 24.73 & 75.27 & 100 \\
Total & 29 & 71 & 100.00 \\
& 29.00 & 71.00 & \\
\hline Priors & 0.5 & 0.5 & \\
& & &
\end{tabular}

\begin{tabular}{lrrr}
\hline \multicolumn{3}{c}{ Error Count Estimates for BANKRUPTCY } \\
\hline & Bankrupt & Nonbankrupt & Total \\
\hline Rate & 0.1429 & 0.2473 & 0.1951 \\
Priors & 0.5000 & 0.5000 & \\
\hline
\end{tabular}

YEAR 3

\begin{tabular}{lrr}
\hline Observations & 90 DF Total & 89 \\
Variables & 6 DF Within Classes & 88 \\
Classes & 2 DF Between Classes & 1 \\
\hline
\end{tabular}

\begin{tabular}{|c|c|c|c|c|c|}
\hline \multicolumn{6}{|c|}{ Class Level Information } \\
\hline BANKRUPTCY & $\begin{array}{l}\text { Variable } \\
\text { Name }\end{array}$ & Frequency & Weight & Proportion & $\begin{array}{r}\text { Prior } \\
\text { Probability }\end{array}$ \\
\hline Bankrupt & Bankrupt & 3 & 3.0000 & 0.033333 & 0.500000 \\
\hline Nonbankrupt & Nonbankrupt & 87 & 87.0000 & 0.966667 & 0.500000 \\
\hline
\end{tabular}

\begin{tabular}{rr}
\hline Pooled Covariance Matrix Information \\
\hline $\begin{array}{r}\text { Covariance } \\
\text { Matrix Rank }\end{array}$ & $\begin{array}{r}\text { Natural Log of the } \\
\text { Covariance Matrix }\end{array}$ \\
\hline 6 & -7.30000 \\
\hline
\end{tabular}




\begin{tabular}{lrr}
\hline \multicolumn{3}{l}{ Generalized Squared Distance to BANKRUPTCY } \\
\hline From & & \\
BANKRUPTCY & Bankrupt & Nonbankrupt \\
\hline Bankrupt & 0 & 3.38909 \\
Nonbankrupt & 3.38909 & 0 \\
\hline
\end{tabular}

LINEAR DISCRIMINANT FUNCTION

\begin{tabular}{lrr}
\hline Variable & Bankrupt & Nonbankrupt \\
\hline Constant & -13.59752 & -8.21522 \\
M_QUICKASSETSTOTOTALASSTS & 34.81509 & 24.38655 \\
M_LTLIABTOTOTASSET & 24.11595 & 20.88755 \\
M_CASHTOTOTALASSETS & -2.53731 & -0.90059 \\
M_PRC & 0.06785 & 0.10697 \\
M_HILOBIDASKSPREAD & 0.09159 & 0.05053 \\
M_BIDASKSPREAD & 4.85112 & 7.29986 \\
\hline
\end{tabular}

\section{CLASSIFICATION SUMMARY}

\begin{tabular}{lrrr}
\hline \multicolumn{2}{c}{ Number of Observations and Percent Classified into BANKRUPTCY } \\
\hline From & & & \\
BANKRUPTCY & Bankrupt & Nonbankrupt & Total \\
\hline Bankrupt & 3 & 0 & 3 \\
& 100.00 & 0.00 & 100.00 \\
Nonbankrupt & 19 & 68 & 87 \\
& 21.84 & 78.16 & 100.00 \\
\hline Total & 22 & 68 & 90 \\
& 24.44 & 75.56 & 100.00 \\
\hline Priors & 0.5 & 0.5 & \\
& & & \\
\hline
\end{tabular}

\begin{tabular}{lrrr}
\hline \multicolumn{3}{c}{ Error Count Estimates for BANKRUPTCY } \\
\hline & Bankrupt & Nonbankrupt & Total \\
\hline Rate & 0.0000 & 0.2184 & 0.1092 \\
Priors & 0.5000 & 0.5000 & \\
\hline
\end{tabular}


Results of Linear Discriminant Analysis : Top 3 Account and Market logarithmic variables

YEAR 1

\begin{tabular}{lrlr}
\hline Observations & 82 DF Total & 81 \\
Variables & 6 DF Within Classes & 80 \\
Classes & 2 & DF Between Classes & 1 \\
\hline
\end{tabular}

\begin{tabular}{|c|c|c|c|c|c|}
\hline \multicolumn{6}{|c|}{ Class Level Information } \\
\hline BANKRUPTCY & $\begin{array}{l}\text { Variable } \\
\text { Name }\end{array}$ & Frequency & Weight & Proportion & $\begin{array}{r}\text { Prior } \\
\text { Probability }\end{array}$ \\
\hline Bankrupt & Bankrupt & 4 & 4.0000 & 0.048780 & 0.500000 \\
\hline Nonbankrupt & Nonbankrupt & 78 & 78.0000 & 0.951220 & 0.500000 \\
\hline
\end{tabular}

\begin{tabular}{rr}
\hline Pooled Covariance Matrix Information \\
\hline $\begin{array}{r}\text { Covariance } \\
\text { Matrix Rank }\end{array}$ & $\begin{array}{r}\text { Natural Log of the } \\
\text { Determinant of the } \\
\text { Covariance Matrix }\end{array}$ \\
\hline 6 & 0.84296 \\
\hline
\end{tabular}

\begin{tabular}{lrr}
\hline \multicolumn{2}{l}{ Generalized Squared Distance to BANKRUPTCY } \\
\hline From & & \\
BANKRUPTCY & Bankrupt & Nonbankrupt \\
\hline Bankrupt & 0 & 2.63756 \\
Nonbankrupt & 2.63756 & 0 \\
\hline
\end{tabular}


LINEAR DISCRIMINANT FUNCTION

\begin{tabular}{lcr}
\hline \multicolumn{3}{c}{ Linear Discriminant Function for BANKRUPTCY } \\
\hline Variable & Bankrupt & Nonbankrupt \\
\hline Constant & -84.13757 & -74.82504 \\
M_LOG_CASHTOCURLIABILITIES & -2.20271 & -1.35251 \\
M_LOG_NETINCOMETOTOTALDEBT & -8.35535 & -7.97391 \\
M_LOG_TOTALDEBT & -10.21895 & -9.89800 \\
M_LOG_VOL & -0.84229 & -1.79058 \\
M_LOG_HILOBIDASKSPREAD & 12.69352 & 12.24994 \\
M_LOG_SHROUT & 17.63940 & 17.90549 \\
\hline
\end{tabular}

\section{CLASSIFICATION SUMMARY}

\begin{tabular}{lrrr}
\hline \multicolumn{2}{c}{ Number of Observations and Percent Classified into BANKRUPTCY } \\
\hline From & & & Total \\
BANKRUPTCY & Bankrupt & Nonbankrupt & 4 \\
\hline Bankrupt & 3 & 1 & 100.00 \\
& 75.00 & 25.00 & 78 \\
Nonbankrupt & 17 & 61 & 100.00 \\
& 21.79 & 78.21 & 82 \\
Total & 20 & 62 & 100.00 \\
\hline Priors & 24.39 & 75.61 & \\
& 0.5 & 0.5 & \\
\hline
\end{tabular}

\begin{tabular}{lrrr}
\hline \multicolumn{3}{c}{ Error Count Estimates for BANKRUPTCY } \\
\hline & Bankrupt & Nonbankrupt & Total \\
\hline Rate & 0.2500 & 0.2179 & 0.2340 \\
Priors & 0.5000 & 0.5000 & \\
\hline
\end{tabular}


YEAR 2

\begin{tabular}{lrlr}
\hline Observations & 80 DF Total & 79 \\
Variables & 6 DF Within Classes & 78 \\
Classes & 2 DF Between Classes & 1 \\
\hline
\end{tabular}

\begin{tabular}{|c|c|c|c|c|c|}
\hline \multicolumn{6}{|c|}{ Class Level Information } \\
\hline BANKRUPTCY & $\begin{array}{l}\text { Variable } \\
\text { Name }\end{array}$ & Frequency & Weight & Proportion & $\begin{array}{r}\text { Prior } \\
\text { Probability }\end{array}$ \\
\hline Bankrupt & Bankrupt & 3 & 3.0000 & 0.037500 & 0.500000 \\
\hline Nonbankrupt & Nonbankrupt & 77 & 77.0000 & 0.962500 & 0.500000 \\
\hline
\end{tabular}

\begin{tabular}{rr}
\hline Pooled Covariance Matrix Information \\
\hline $\begin{array}{r}\text { Covariance } \\
\text { Matrix Rank }\end{array}$ & $\begin{array}{r}\text { Natural Log of the } \\
\text { Covarinant of the } \\
\text { Covance Matrix }\end{array}$ \\
\hline 6 & 0.82818 \\
\hline
\end{tabular}

\begin{tabular}{lrr}
\hline \multicolumn{2}{l}{ Generalized Squared Distance to BANKRUPTCY } \\
\hline From & & \\
BANKRUPTCY & Bankrupt & Nonbankrupt \\
\hline Bankrupt & 0 & 1.45415 \\
Nonbankrupt & 1.45415 & 0 \\
\hline
\end{tabular}

\section{LINEAR DISCRIMINANT FUNCTION}

\begin{tabular}{lrr}
\hline \multicolumn{3}{c}{ Linear Discriminant Function for BANKRUPTCY } \\
\hline Variable & Bankrupt & Nonbankrupt \\
\hline Constant & -73.35527 & -63.42261 \\
M_LOG_CASHTOCURLIABILITIES & -2.31427 & -1.66690 \\
M_LOG_NETINCOMETOTOTALDEBT & -5.89715 & -6.04658 \\
M_LOG_TOTALDEBT & -8.59159 & -8.24209 \\
M_LOG_VOL & -2.35394 & -2.30403 \\
M_LOG_HILOBIDASKSPREAD & 5.57258 & 5.72041 \\
M_LOG_SHROUT & 17.39879 & 16.29230 \\
\hline
\end{tabular}




\section{CLASSIFICATION SUMMARY}

\begin{tabular}{lrrr}
\hline \multicolumn{3}{c}{ Number of Observations and Percent Classified into BANKRUPTCY } \\
\hline From & & & \\
BANKRUPTCY & Bankrupt & Nonbankrupt & Total \\
\hline Bankrupt & 2 & 1 & 3 \\
& 66.67 & 33.33 & 100.00 \\
Nonbankrupt & 18 & 59 & 77 \\
& 23.38 & 76.62 & 100.00 \\
\hline Total & 20 & 60 & 80 \\
& 25.00 & 75.00 & 100.00 \\
\hline Priors & 0.5 & 0.5 & \\
& & &
\end{tabular}

\begin{tabular}{lrrr}
\hline \multicolumn{3}{c}{ Error Count Estimates for BANKRUPTCY } \\
\hline & Bankrupt & Nonbankrupt & Total \\
\hline Rate & 0.3333 & 0.2338 & 0.2835 \\
Priors & 0.5000 & 0.5000 & \\
\hline
\end{tabular}

YEAR 3

\begin{tabular}{lrrr}
\hline Observations & 75 DF Total & 74 \\
Variables & 6 DF Within Classes & 73 \\
Classes & 2 & DF Between Classes & 1 \\
\hline
\end{tabular}

\begin{tabular}{|c|c|c|c|c|c|}
\hline \multicolumn{6}{|c|}{ Class Level Information } \\
\hline BANKRUPTCY & $\begin{array}{l}\text { Variable } \\
\text { Name }\end{array}$ & Frequency & Weight & Proportion & $\begin{array}{r}\text { Prior } \\
\text { Probability }\end{array}$ \\
\hline Bankrupt & Bankrupt & 1 & 1.0000 & 0.013333 & 0.500000 \\
\hline Nonbankrupt & Nonbankrupt & 74 & 74.0000 & 0.986667 & 0.500000 \\
\hline
\end{tabular}

\begin{tabular}{rr}
\hline Pooled Covariance Matrix Information \\
\hline $\begin{array}{r}\text { Covariance } \\
\text { Matrix Rank }\end{array}$ & $\begin{array}{r}\text { Natural Log of the } \\
\text { Determinant of the } \\
\text { Covariance Matrix }\end{array}$ \\
\hline 6 & 0.46670 \\
\hline
\end{tabular}




\begin{tabular}{lrr}
\hline \multicolumn{3}{l}{ Generalized Squared Distance to BANKRUPTCY } \\
\hline From & & \\
BANKRUPTCY & Bankrupt & Nonbankrupt \\
\hline Bankrupt & 0 & 3.47549 \\
Nonbankrupt & 3.47549 & 0 \\
\hline
\end{tabular}

LINEAR DISCRIMINANT FUNCTION

\begin{tabular}{lrr}
\hline \multicolumn{3}{c}{ Linear Discriminant Function for BANKRUPTCY } \\
\hline Variable & Bankrupt & Nonbankrupt \\
\hline Constant & -89.44037 & -76.37517 \\
M_LOG_CASHTOCURLIABILITIES & -0.75524 & -1.40711 \\
M_LOG_NETINCOMETOTOTALDEBT & -11.56473 & -9.85061 \\
M_LOG_TOTALDEBT & -12.35136 & -10.75579 \\
M_LOG_VOL & -0.15926 & -0.67424 \\
M_LOG_HILOBIDASKSPREAD & 10.23674 & 9.33632 \\
M_LOG_SHROUT & 17.53023 & 16.70143 \\
\hline
\end{tabular}

\section{CLASSIFICATION SUMMARY}

\begin{tabular}{lrrr}
\hline \multicolumn{2}{c}{ Number of Observations and Percent Classified into BANKRUPTCY } \\
\hline From & & & Total \\
BANKRUPTCY & Bankrupt & Nonbankrupt & 1 \\
\hline Bankrupt & 1 & 0 & 100.00 \\
& 100.00 & 0.00 & 74 \\
Nonbankrupt & 11 & 63 & 100.00 \\
& 14.86 & 85.14 & 75 \\
Total & 12 & 63 & 100.00 \\
& 16.00 & 84.00 & \\
\hline Priors & 0.5 & 0.5 & \\
& & &
\end{tabular}

\begin{tabular}{lrrr}
\multicolumn{4}{c}{ Error Count Estimates for BANKRUPTCY } \\
\hline & Bankrupt & Nonbankrupt & Total \\
\hline Rate & 0.0000 & 0.1486 & 0.0743 \\
Priors & 0.5000 & 0.5000 & \\
\hline
\end{tabular}


Results of Linear Discriminant Analysis : Variables (Price, Standard deviation, bid ask spread, net income to sales, working capital to total assets and current liabilities to total assets )

YEAR 1

\begin{tabular}{lrr}
\hline Observations & 184 DF Total & 183 \\
Variables & 6 DF Within Classes & 182 \\
Classes & 2 DF Between Classes & 1 \\
\hline
\end{tabular}

\begin{tabular}{|c|c|c|c|c|c|}
\hline \multicolumn{6}{|c|}{ Class Level Information } \\
\hline BANKRUPTCY & $\begin{array}{l}\text { Variable } \\
\text { Name }\end{array}$ & Frequency & Weight & Proportion & $\begin{array}{r}\text { Prior } \\
\text { Probability }\end{array}$ \\
\hline Bankrupt & Bankrupt & 85 & 85.0000 & 0.461957 & 0.500000 \\
\hline Nonbankrupt & Nonbankrupt & 99 & 99.0000 & 0.538043 & 0.500000 \\
\hline
\end{tabular}

\begin{tabular}{rr}
\hline Pooled Covariance Matrix Information \\
\hline $\begin{array}{r}\text { Covariance } \\
\text { Matrix Rank }\end{array}$ & $\begin{array}{r}\text { Natural Log of the } \\
\text { Covariance Matrix }\end{array}$ \\
\hline 6 & -1.60984
\end{tabular}

\begin{tabular}{lrr}
\hline \multicolumn{2}{l}{ Generalized Squared Distance to BANKRUPTCY } \\
\hline From & & \\
BANKRUPTCY & Bankrupt & Nonbankrupt \\
\hline Bankrupt & 0 & 1.61073 \\
Nonbankrupt & 1.61073 & 0 \\
\hline
\end{tabular}


LINEAR DISCRIMINANT FUNCTION

\begin{tabular}{lrr}
\hline Variable & Bankrupt & Nonbankrupt \\
\hline Constant & -4.32807 & -3.80474 \\
\hline M_PRC & 0.11810 & 0.15330 \\
M_SDRETURN & 2.41645 & 2.05412 \\
M_BIDASKSPREAD & 9.73147 & 3.22090 \\
M_NETINCOMETOSALES & -0.02259 & 0.01054 \\
M_WCTOTOTALASSETS & 5.41778 & 7.32059 \\
M_CURLIABTOTOTASSET & 12.11498 & 10.67717 \\
\hline
\end{tabular}

\section{CLASSIFICATION SUMMARY}

Number of Observations and Percent Classified into BANKRUPTCY

\begin{tabular}{lrrr}
\hline From & & & \\
BANKRUPTCY & Bankrupt & Nonbankrupt & Total \\
\hline Bankrupt & 59 & 26 & 85 \\
& 69.41 & 30.59 & 100.00 \\
Nonbankrupt & 12 & 87 & 99 \\
& 12.12 & 87.88 & 100.00 \\
\hline Total & 71 & 113 & 184 \\
& 38.59 & 61.41 & 100.00 \\
\hline Priors & 0.5 & 0.5 & \\
& & & \\
\hline
\end{tabular}

\begin{tabular}{lrrr}
\hline \multicolumn{3}{c}{ Error Count Estimates for BANKRUPTCY } \\
\hline & Bankrupt & Nonbankrupt & Total \\
\hline Rate & 0.3059 & 0.1212 & 0.2135 \\
Priors & 0.5000 & 0.5000 & \\
\hline & & & \\
\hline Observations & 90 & DF Total & 89 \\
Variables & 6 & DF Within Classes & 88 \\
Classes & 2 & DF Between Classes & 1 \\
\hline
\end{tabular}




\begin{tabular}{|c|c|c|c|c|c|}
\hline \multicolumn{6}{|c|}{ Class Level Information } \\
\hline BANKRUPTCY & $\begin{array}{l}\text { Variable } \\
\text { Name }\end{array}$ & Frequency & Weight & Proportion & $\begin{array}{r}\text { Prior } \\
\text { Probability }\end{array}$ \\
\hline Bankrupt & Bankrupt & 66 & 66.0000 & 0.733333 & 0.500000 \\
\hline Nonbankrupt & Nonbankrupt & 24 & 24.0000 & 0.266667 & 0.500000 \\
\hline
\end{tabular}

\begin{tabular}{rr}
\hline Pooled Covariance Matrix Information \\
\hline $\begin{array}{r}\text { Natural Log of the } \\
\text { Matrix Rank }\end{array}$ & $\begin{array}{r}\text { Determinant of the } \\
\text { Covariance Matrix }\end{array}$ \\
\hline 6 & 7.08780 \\
\hline
\end{tabular}

\begin{tabular}{lrr}
\hline \multicolumn{2}{l}{ Generalized Squared Distance to BANKRUPTCY } \\
\hline From & & \\
BANKRUPTCY & Bankrupt & Nonbankrupt \\
\hline Bankrupt & 0 & 1.74309 \\
Nonbankrupt & 1.74309 & 0 \\
\hline
\end{tabular}

LINEAR DISCRIMINANT FUNCTION

\begin{tabular}{lcc}
\hline Variable & Bankrupt & Nonbankrupt \\
\hline Constant & -3.93720 & -4.10002 \\
M_PRC & 0.08345 & 0.13114 \\
M_SDRETURN & 0.79504 & 0.53044 \\
M_BIDASKSPREAD & 6.29447 & -0.26534 \\
M_NETINCOMETOSALES & -0.0006198 & 0.0003090 \\
M_WCTOTOTALASSETS & 6.21393 & 6.30264 \\
M_CURLIABTOTOTASSET & 11.70673 & 14.19433 \\
\hline
\end{tabular}

\section{CLASSIFICATION SUMMARY}




\begin{tabular}{lrrr}
\hline \multicolumn{2}{c}{ Number of Observations and Percent Classified into BANKRUPTCY } \\
\hline From & & & \\
BANKRUPTCY & Bankrupt & Nonbankrupt & Total \\
\hline Bankrupt & 50 & 16 & 66 \\
& 75.76 & 24.24 & 100.00 \\
Nonbankrupt & 4 & 20 & 24 \\
& 16.67 & 83.33 & 100.00 \\
\hline Total & 54 & 36 & 90 \\
& 60.00 & 40.00 & 100.00 \\
\hline Priors & 0.5 & 0.5 & \\
& & &
\end{tabular}

\begin{tabular}{lrrr}
\hline \multicolumn{3}{c}{ Error Count Estimates for BANKRUPTCY } \\
\hline & Bankrupt & Nonbankrupt & Total \\
\hline Rate & 0.2424 & 0.1667 & 0.2045 \\
Priors & 0.5000 & 0.5000 & \\
\hline
\end{tabular}

YEAR 5

\begin{tabular}{lrlr}
\hline Observations & 43 DF Total & 42 \\
Variables & 6 DF Within Classes & 41 \\
Classes & 2 DF Between Classes & 1 \\
\hline
\end{tabular}

Class Level Information

\begin{tabular}{|c|c|c|c|c|c|}
\hline BANKRUPTCY & $\begin{array}{l}\text { Variable } \\
\text { Name }\end{array}$ & Frequency & Weight & Proportion & $\begin{array}{r}\text { Prior } \\
\text { Probability }\end{array}$ \\
\hline Bankrupt & Bankrupt & 27 & 27.0000 & 0.627907 & 0.500000 \\
\hline Nonbankrupt & Nonbankrupt & 16 & 16.0000 & 0.372093 & 0.500000 \\
\hline
\end{tabular}

\begin{tabular}{rr}
\hline Pooled Covariance Matrix Information \\
\hline $\begin{array}{r}\text { Covariance } \\
\text { Matrix Rank }\end{array}$ & $\begin{array}{r}\text { Natural Log of the } \\
\text { Determinant of the } \\
\text { Covariance Matrix }\end{array}$ \\
\hline 6 & -0.52399 \\
\hline
\end{tabular}




\begin{tabular}{lrr}
\hline \multicolumn{3}{l}{ Generalized Squared Distance to BANKRUPTCY } \\
\hline From & & \\
BANKRUPTCY & Bankrupt & Nonbankrupt \\
\hline Bankrupt & 0 & 1.38511 \\
Nonbankrupt & 1.38511 & 0 \\
\hline
\end{tabular}

LINEAR DISCRIMINANT FUNCTION

\begin{tabular}{lrr}
\hline Variable & Bankrupt & Nonbankrupt \\
\hline Constant & -4.57820 & -3.57903 \\
M_PRC & 0.06467 & 0.09664 \\
M_SDRETURN & 2.45660 & 1.90797 \\
M_BIDASKSPREAD & 5.62832 & 1.17144 \\
M_NETINCOMETOSALES & -0.01887 & -0.00846 \\
M_WCTOTOTALASSETS & 6.82650 & 5.81797 \\
M_CURLIABTOTOTASSET & 15.37149 & 14.10884 \\
\hline
\end{tabular}

\section{CLASSIFICATION SUMMARY}

\begin{tabular}{lrrr}
\hline \multicolumn{3}{c}{ Number of Observations and Percent Classified into BANKRUPTCY } \\
\hline From & & & \\
BANKRUPTCY & Bankrupt & Nonbankrupt & Total \\
\hline Bankrupt & 21 & 6 & 27 \\
& 77.78 & 22.22 & 100.00 \\
Nonbankrupt & 2 & 14 & 16 \\
& 12.50 & 87.50 & 100.00 \\
\hline Total & 23 & 20 & 43 \\
& 53.49 & 46.51 & 100.00 \\
\hline Priors & 0.5 & 0.5 & \\
& & & \\
\hline
\end{tabular}

\begin{tabular}{lrrr}
\hline \multicolumn{3}{c}{ Error Count Estimates for BANKRUPTCY } \\
\hline & Bankrupt & Nonbankrupt & Total \\
\hline Rate & 0.2222 & 0.1250 & 0.1736 \\
Priors & 0.5000 & 0.5000 & \\
\hline
\end{tabular}


Results of Linear Discriminant Analysis : Variables (Price, Standard deviation, hi lo bid ask spread, net income to sales, working capital to total assets and current liabilities to total assets )

YEAR 1

\begin{tabular}{lrr}
\hline Observations & 185 DF Total & 184 \\
Variables & 6 DF Within Classes & 183 \\
Classes & 2 DF Between Classes & 1 \\
\hline
\end{tabular}

\begin{tabular}{|c|c|c|c|c|c|}
\hline \multicolumn{6}{|c|}{ Class Level Information } \\
\hline BANKRUPTCY & $\begin{array}{l}\text { Variable } \\
\text { Name }\end{array}$ & Frequency & Weight & Proportion & $\begin{array}{r}\text { Prior } \\
\text { Probability }\end{array}$ \\
\hline Bankrupt & Bankrupt & 86 & 86.0000 & 0.464865 & 0.500000 \\
\hline Nonbankrupt & Nonbankrupt & 99 & 99.0000 & 0.535135 & 0.500000 \\
\hline
\end{tabular}

\begin{tabular}{rr}
\hline Pooled Covariance Matrix Information \\
$\begin{array}{rr}\text { Covariance } \\
\text { Matrix Rank }\end{array}$ & $\begin{array}{r}\text { Natural Log of the } \\
\text { Coterminant of the } \\
\text { Covariance Matrix }\end{array}$ \\
\hline 6 & 6.60198 \\
\hline
\end{tabular}

\begin{tabular}{lrr}
\hline \multicolumn{2}{l}{ Generalized Squared Distance to BANKRUPTCY } \\
\hline From & & \\
BANKRUPTCY & Bankrupt & Nonbankrupt \\
\hline Bankrupt & 0 & 1.40346 \\
Nonbankrupt & 1.40346 & 0 \\
\hline
\end{tabular}


LINEAR DISCRIMINANT FUNCTION

\begin{tabular}{lrr}
\hline Variable & Bankrupt & Nonbankrupt \\
\hline Constant & -3.78217 & -3.81762 \\
M_PRC & 0.10704 & 0.16872 \\
M_SDRETURN & 2.74784 & 2.11682 \\
M_HILOBIDASKSPREAD & 0.02652 & -0.05729 \\
M_NETINCOMETOSALES & -0.01368 & 0.01312 \\
M_WCTOTOTALASSETS & 5.86099 & 7.52057 \\
M_CURLIABTOTOTASSET & 11.99349 & 10.62886 \\
\hline
\end{tabular}

\section{CLASSIFICATION SUMMARY}

\begin{tabular}{lrrr}
\hline \multicolumn{2}{c}{ Number of Observations and Percent Classified into BANKRUPTCY } \\
\hline From & & & \\
BANKRUPTCY & Bankrupt & Nonbankrupt & Total \\
\hline Bankrupt & 62 & 24 & 86 \\
& 72.09 & 27.91 & 100.00 \\
Nonbankrupt & 14 & 85 & 99 \\
& 14.14 & 85.86 & 100.00 \\
\hline Total & 76 & 109 & 185 \\
& 41.08 & 58.92 & 100.00 \\
\hline Priors & 0.5 & 0.5 & \\
& & & \\
\hline
\end{tabular}

\begin{tabular}{lrrr}
\hline \multicolumn{3}{c}{ Error Count Estimates for BANKRUPTCY } \\
\hline & Bankrupt & Nonbankrupt & Total \\
\hline Rate & 0.2791 & 0.1414 & 0.2102 \\
Priors & 0.5000 & 0.5000 & \\
\hline
\end{tabular}

YEAR 4

\begin{tabular}{lrrr}
\hline Observations & 90 DF Total & 89 \\
Variables & 6 DF Within Classes & 88 \\
Classes & 2 DF Between Classes & 1 \\
\hline
\end{tabular}




\begin{tabular}{|c|c|c|c|c|c|}
\hline \multicolumn{6}{|c|}{ Class Level Information } \\
\hline BANKRUPTCY & $\begin{array}{l}\text { Variable } \\
\text { Name }\end{array}$ & Frequency & Weight & Proportion & $\begin{array}{r}\text { Prior } \\
\text { Probability }\end{array}$ \\
\hline Bankrupt & Bankrupt & 66 & 66.0000 & 0.733333 & 0.500000 \\
\hline Nonbankrupt & Nonbankrupt & 24 & 24.0000 & 0.266667 & 0.500000 \\
\hline
\end{tabular}

\begin{tabular}{rr}
\hline Pooled Covariance Matrix Information \\
\hline $\begin{array}{r}\text { Covariance } \\
\text { Matrix Rank }\end{array}$ & $\begin{array}{r}\text { Deteral Log of the } \\
\text { Covariance Matrix }\end{array}$ \\
\hline 6 & 11.72874
\end{tabular}

\begin{tabular}{lrr}
\hline \multicolumn{3}{l}{ Generalized Squared Distance to BANKRUPTCY } \\
\hline From & & \\
BANKRUPTCY & Bankrupt & Nonbankrupt \\
\hline Bankrupt & 0 & 0.58867 \\
Nonbankrupt & 0.58867 & 0 \\
\hline
\end{tabular}

LINEAR DISCRIMINANT FUNCTION

\begin{tabular}{lrr}
\hline Variable & Bankrupt & Nonbankrupt \\
\hline Constant & -3.44353 & -4.29162 \\
M_PRC & 0.11406 & 0.18214 \\
M_SDRETURN & 0.71053 & 0.59407 \\
M_HILOBIDASKSPREAD & -0.21427 & -0.36226 \\
M_NETINCOMETOSALES & 0.0000734 & 0.0004625 \\
M_WCTOTOTALASSETS & 7.17306 & 7.08585 \\
M_CURLIABTOTOTASSET & 13.96813 & 14.83277 \\
\hline
\end{tabular}




\section{CLASSIFICATION SUMMARY}

\begin{tabular}{lrrr}
\hline \multicolumn{2}{c}{ Number of Observations and Percent Classified into BANKRUPTCY } \\
\hline From & & & \\
BANKRUPTCY & Bankrupt & Nonbankrupt & Total \\
\hline Bankrupt & 54 & 12 & 66 \\
& 81.82 & 18.18 & 100.00 \\
Nonbankrupt & 15 & 9 & 24 \\
& 62.50 & 37.50 & 100.00 \\
\hline Total & 69 & 21 & 90 \\
& 76.67 & 23.33 & 100.00 \\
\hline Priors & 0.5 & 0.5 & \\
& & & \\
\hline
\end{tabular}

\begin{tabular}{lrrr}
\hline \multicolumn{3}{c}{ Error Count Estimates for BANKRUPTCY } \\
\hline & Bankrupt & Nonbankrupt & Total \\
\hline Rate & 0.1818 & 0.6250 & 0.4034 \\
Priors & 0.5000 & 0.5000 & \\
\hline
\end{tabular}

YEAR 5

\begin{tabular}{lrr}
\hline Observations & 45 DF Total & 44 \\
Variables & 6 DF Within Classes & 43 \\
Classes & 2 DF Between Classes & 1 \\
\hline
\end{tabular}

\begin{tabular}{|c|c|c|c|c|c|}
\hline \multicolumn{6}{|c|}{ Class Level Information } \\
\hline BANKRUPTCY & $\begin{array}{l}\text { Variable } \\
\text { Name }\end{array}$ & Frequency & Weight & Proportion & $\begin{array}{r}\text { Prior } \\
\text { Probability }\end{array}$ \\
\hline Bankrupt & Bankrupt & 29 & 29.0000 & 0.644444 & 0.500000 \\
\hline Nonbankrupt & Nonbankrupt & 16 & 16.0000 & 0.355556 & 0.500000 \\
\hline
\end{tabular}

\begin{tabular}{rr}
\hline Pooled Covariance Matrix Information \\
\hline $\begin{array}{r}\text { Covariance } \\
\text { Matrix Rank }\end{array}$ & $\begin{array}{r}\text { Natural Log of the } \\
\text { Covariance Matrix }\end{array}$ \\
\hline 6 & 3.77731 \\
\hline
\end{tabular}




\begin{tabular}{lrr}
\hline \multicolumn{3}{l}{ Generalized Squared Distance to BANKRUPTCY } \\
\hline From & & \\
BANKRUPTCY & Bankrupt & Nonbankrupt \\
\hline Bankrupt & 0 & 0.64545 \\
Nonbankrupt & 0.64545 & 0 \\
\hline
\end{tabular}

LINEAR DISCRIMINANT FUNCTION

\begin{tabular}{lrr}
\hline Variable & Bankrupt & Nonbankrupt \\
\hline Constant & -3.86992 & -3.76312 \\
M_PRC & 0.02450 & 0.06279 \\
M_SDRETURN & 2.72330 & 2.02694 \\
M_HILOBIDASKSPREAD & 0.49479 & 0.49539 \\
M_NETINCOMETOSALES & -0.01455 & -0.00591 \\
M_WCTOTOTALASSETS & 5.12025 & 5.03768 \\
M_CURLIABTOTOTASSET & 16.80802 & 14.95241 \\
\hline
\end{tabular}

\section{CLASSIFICATION SUMMARY}

\begin{tabular}{lrrr}
\hline \multicolumn{3}{c}{ Number of Observations and Percent Classified into BANKRUPTCY } \\
\hline From & & & \\
BANKRUPTCY & Bankrupt & Nonbankrupt & Total \\
\hline Bankrupt & 20 & 9 & 29 \\
& 68.97 & 31.03 & 100.00 \\
Nonbankrupt & 7 & 9 & 16 \\
& 43.75 & 56.25 & 100.00 \\
\hline Total & 27 & 18 & 45 \\
& 60.00 & 40.00 & 100.00 \\
\hline Priors & 0.5 & 0.5 & \\
& & & \\
\hline
\end{tabular}

\begin{tabular}{lrrr}
\hline \multicolumn{3}{c}{ Error Count Estimates for BANKRUPTCY } \\
\hline & Bankrupt & Nonbankrupt & Total \\
\hline Rate & 0.3103 & 0.4375 & 0.3739 \\
Priors & 0.5000 & 0.5000 & \\
\hline
\end{tabular}


quadratic MDA does so for nonbankrupt firms. For overall accuracy, the nonparametric MDA slightly outperforms the linear MDA, consistent with the previously used sets of variables.

We must highlight the two most interesting findings. First, overall accuracy in classifying bankrupt firms (minimizing Type I error) is found through the use of market variables alone. This is important since it is much more costly to incorrectly classify an actual bankrupt firm than it is to do so with an actual nonbankrupt firm. This strikes a divergence from the previous literature. Most research has highlighted the value of adding market variables to bankruptcy prediction models, but concludes that accounting ratios are still important in bankruptcy prediction. Our results lead us to conclude that forward-looking market variables alone, without backward-looking accounting ratios, are sufficient to accurately forecast bankruptcy. Notably, by adding price, standard deviation of returns, and the bid-ask spread to the model, the model outperforms a model of just accounting ratios. This ties together a vast array of literature. The behavior of price, standard deviation of returns, and, recently, the bid-ask spread, has been documented to contain information. Therefore, it is promising that these variables show discriminatory power.

For correctly classifying nonbankrupt firms, which is of less importance than doing so with bankrupt firms, the mix of accounting ratios and market variables are better predictors than just the market variables. An explanation for this is the fact that the accounting ratios are not deteriorating, and this pattern alone may be able to demonstrate that these firms are not falling into distress. During non-financial crisis periods, the 
findings will probably be stronger. While market variables are generally noisier variables, the stability of accounting ratios is consistent with a firm that is not under distress. This highlights why it is still important to include accounting ratios in any bankruptcy prediction framework or model. They still contain important information, and while correctly classifying bankrupt firms is more pertinent to investors and loan officers, it is still important to lend and invest in firms that will not deteriorate.

The second important finding is the accuracy of the nonparametric MDA. While much research concludes that the assumptions underlying the linear MDA are violated, most researchers still employ parametric models. The improvement in technology and programming languages allows us to use a bevy of models, so we conclude that there is little use in still using the parametric models. While correctly classifying bankrupt firms is more important than doing so with nonbankrupt firms, overall accuracy is still desirable. An investor can be led to not optimally allocate her resources by avoiding investments in certain firms that are incorrectly classified as probable bankrupt firms. The nonparametric model provides the overall accuracy desired. While this has been avoided due to the tradeoff between accuracy and model complexity, this is no longer a reason to avoid these models. This will be further highlighted in the next chapter on neural networks.

Lastly, an out-of-sample nonparametric MDA is performed. We choose to use the nonparametric MDA because it has shown the highest overall accuracy. Using the ratios and variables from five years to two years before bankruptcy, the nonparametric model is estimated. Then, predictions are made as to whether firms are bankrupt or nonbankrupt one year before bankruptcy. While the misclassification rates are important, a prediction 
model should perform well using a hold-out sample, a sample not used in the estimation of the model. Since the data for one year before bankruptcy is not used in estimating the model, this will allow us to see how well the model performs at actually predicting bankruptcy.

After estimating the model using only the market variables, the model misclassifies/predicts $29 \%$ of the bankrupt firms and $17 \%$ of the nonbankrupt firms. For an out-of-sample prediction, the model is fairly accurate. However, higher classification rates are desirable in terms of the bankrupt firms. The cost of misclassifying bankrupt firms is much higher than that of doing so with nonbankrupt firms. Therefore, the misclassification rates should ideally be equal or lower than those for nonbankrupt firms. Using the current model, more than one in four bankrupt firms are incorrectly labeled. Furthermore, even though the mix of accounting ratios and market variables (price, standard deviation of price, bid-ask spread, net income to sales, working capital to total assets, and current liabilities to total assets) performed very well using the in-sample procedure, the error rates are higher using the out-of-sample procedure. The misclassification rates are $38 \%$ for the bankrupt firms and $15 \%$ for the nonbankrupt firms. When the bid-ask spread is replaced by the high-low bid-ask spread, the error rate for the bankrupt firms slightly improves (31\%), but that for the nonbankrupt firms substantially deteriorates (37\%). While the bankrupt misclassification rate is lower, the nonbankrupt misclassification rate is much higher. The decrease in the bankrupt misclassication rate is not high enough to justify using the high-low bid-ask spread.

Overall, MDA still performs relatively well in bankruptcy prediction. However, as has been noted in the past, the stringent underlying assumptions cause issues that are 
difficult to correct. The nonparametric MDA is an improvement, but more technical models are needed. This has led to the use of neural networks, which we discuss in Chapter 4.

Furthermore, the out-of-sample model estimated with only market variables shows much higher predictive power than that of the model estimated with market variables and accounting ratios. While this deviates from prior findings, it is an important addition to literature. This alone highlights the need to use forward-looking variables in any predictive framework. However, one caveat is the sample period we use. Much has been documented about the accounting ratios of firms over the past couple of decades, namely off-balance sheet transactions. This, mixed with the fact that a financial crisis loomed during our sample period (not the off-balance sheet transactions and the financial crisis are mutually exclusive), makes it more difficult for the accounting ratios to discriminate between firms. More evidence is needed during expansionary and normal market cycles.

Table 8

Results of Quadratic Discriminant Analysis : Accounting variables

YEAR 1

\begin{tabular}{lrlr}
\hline Observations & 101 & DF Total & 100 \\
Variables & 17 & DF Within Classes & 99 \\
Classes & 2 & DF Between Classes & 1 \\
\hline
\end{tabular}

\begin{tabular}{|c|c|c|c|c|c|}
\hline \multicolumn{6}{|c|}{ Class Level Information } \\
\hline BANKRUPTCY & $\begin{array}{l}\text { Variable } \\
\text { Name }\end{array}$ & Frequency & Weight & Proportion & $\begin{array}{r}\text { Prior } \\
\text { Probability }\end{array}$ \\
\hline Bankrupt & Bankrupt & 6 & 6.0000 & 0.059406 & 0.500000 \\
\hline Nonbankrupt & Nonbankrupt & 95 & 95.0000 & 0.940594 & 0.500000 \\
\hline
\end{tabular}




\begin{tabular}{lrr}
\hline \multicolumn{3}{c}{ Within Covariance Matrix Information } \\
\hline BANKRUPTCY & $\begin{array}{r}\text { Covariance } \\
\text { Matrix Rank }\end{array}$ & $\begin{array}{r}\text { Natural Log of the } \\
\text { Determinant of the } \\
\text { Covariance Matrix }\end{array}$ \\
\hline Bankrupt & 5 & -187.89108 \\
Nonbankrupt & 17 & -25.49897 \\
\hline
\end{tabular}

\begin{tabular}{lrr}
\hline \multicolumn{2}{c}{ Generalized Squared Distance to BANKRUPTCY } \\
\hline From & Bankrupt & Nonbankrupt \\
BANKRUPTCY & -187.89108 & 11.83408 \\
\hline Bankrupt & 11266946 & -25.49897 \\
\hline
\end{tabular}

\section{CLASSIFICATION SUMMARY}

\begin{tabular}{lrrr}
\hline \multicolumn{4}{c}{ Number of Observations and Percent Classified into } \\
BANKRUPTCY \\
\hline From & Bankrupt & Nonbankrupt & Total \\
BANKRUPTCY & 6 & 0 & 6 \\
\hline Bankrupt & 100.00 & 0.00 & 100.00 \\
& 0 & 95 & 95 \\
Nonbankrupt & 0.00 & 100.00 & 100.00 \\
\hline Total & 6 & 95 & 101 \\
& 5.94 & 94.06 & 100.00 \\
\hline Priors & 0.5 & 0.5 & \\
& & & \\
\hline
\end{tabular}




\begin{tabular}{lrrr}
\hline \multicolumn{3}{c}{ Error Count Estimates for BANKRUPTCY } \\
\hline & Bankrupt & Nonbankrupt & Total \\
\hline Rate & 0.0000 & 0.0000 & 0.0000 \\
Priors & 0.5000 & 0.5000 & \\
\hline
\end{tabular}

YEAR 2

\begin{tabular}{lrlr}
\hline Observations & 99 & DF Total & 98 \\
Variables & 17 & DF Within Classes & 97 \\
Classes & 2 & DF Between Classes & 1 \\
\hline
\end{tabular}

\begin{tabular}{|c|c|c|c|c|c|}
\hline \multicolumn{6}{|c|}{ Class Level Information } \\
\hline BANKRUPTCY & $\begin{array}{l}\text { Variable } \\
\text { Name }\end{array}$ & Frequency & Weight & Proportion & $\begin{array}{r}\text { Prior } \\
\text { Probability }\end{array}$ \\
\hline Bankrupt & Bankrupt & 6 & 6.0000 & 0.060606 & 0.500000 \\
\hline Nonbankrupt & Nonbankrupt & 93 & 93.0000 & 0.939394 & 0.500000 \\
\hline
\end{tabular}

\begin{tabular}{lrr}
\hline \multicolumn{3}{c}{ Within Covariance Matrix Information } \\
\hline BANKRUPTCY & $\begin{array}{r}\text { Covariance } \\
\text { Matrix Rank }\end{array}$ & $\begin{array}{r}\text { Natural Log of the } \\
\text { Determinant of the } \\
\text { Covariance Matrix }\end{array}$ \\
\hline Bankrupt & 5 & -173.21001 \\
Nonbankrupt & 17 & -10.03209 \\
\hline
\end{tabular}

\begin{tabular}{lrr}
\hline \multicolumn{2}{c}{ Generalized Squared Distance to BANKRUPTCY } \\
\hline From & Bankrupt & Nonbankrupt \\
\hline BANKRUPTCY & -173.21001 & -6.67155 \\
Bankrupt & 15873260 & -10.03209 \\
\hline
\end{tabular}




\section{CLASSIFICATION SUMMARY}

\begin{tabular}{lrrr}
\hline \multicolumn{3}{c}{$\begin{array}{c}\text { Number of Observations and Percent Classified into } \\
\text { BANKRUPTCY }\end{array}$} \\
\hline From & Bankrupt & Nonbankrupt & Total \\
BANKRUPTCY & 6 & 0 & 6 \\
Bankrupt & 100.00 & 0.00 & 100.00 \\
& 0 & 93 & 93 \\
Nonbankrupt & 0.00 & 100.00 & 100.00 \\
\hline Total & 6 & 93 & 99 \\
& 6.06 & 93.94 & 100.00 \\
\hline Priors & 0.5 & 0.5 & \\
& & &
\end{tabular}

\begin{tabular}{lrrr}
\hline \multicolumn{3}{c}{ Error Count Estimates for BANKRUPTCY } \\
\hline & Bankrupt & Nonbankrupt & Total \\
\hline Rate & 0.0000 & 0.0000 & 0.0000 \\
Priors & 0.5000 & 0.5000 & \\
\hline
\end{tabular}

YEAR 3

\begin{tabular}{lrlr}
\hline Observations & 88 DF Total & 87 \\
Variables & 17 & DF Within Classes & 86 \\
Classes & 2 & DF Between Classes & 1 \\
\hline
\end{tabular}

\begin{tabular}{|c|c|c|c|c|c|}
\hline \multicolumn{6}{|c|}{ Class Level Information } \\
\hline BANKRUPTCY & $\begin{array}{l}\text { Variable } \\
\text { Name }\end{array}$ & Frequency & Weight & Proportion & $\begin{array}{r}\text { Prior } \\
\text { Probability }\end{array}$ \\
\hline Bankrupt & Bankrupt & 2 & 2.0000 & 0.022727 & 0.500000 \\
\hline Nonbankrupt & Nonbankrupt & 86 & 86.0000 & 0.977273 & 0.500000 \\
\hline
\end{tabular}




\begin{tabular}{lrr}
\hline \multicolumn{3}{c}{ Within Covariance Matrix Information } \\
\hline BANKRUPTCY & $\begin{array}{r}\text { Covariance } \\
\text { Matrix Rank }\end{array}$ & $\begin{array}{r}\text { Natural Log of the } \\
\text { Determinant of the } \\
\text { Covariance Matrix }\end{array}$ \\
\hline Bankrupt & 1 & -238.93864 \\
Nonbankrupt & 17 & -8.66762 \\
\hline
\end{tabular}

\begin{tabular}{lrr}
\hline \multicolumn{2}{c}{ Generalized Squared Distance to BANKRUPTCY } \\
\hline From & Bankrupt & Nonbankrupt \\
BANKRUPTCY & -238.93864 & 0.71480 \\
\hline Bankrupt & 103908349 & -8.66762 \\
\hline
\end{tabular}

\section{CLASSIFICATION SUMMARY}

\begin{tabular}{lrrr}
\hline \multicolumn{4}{c}{ Number of Observations and Percent Classified into } \\
\hline BANKRUPTCY \\
\hline From & & & Total \\
\hline BANKRUPTCY & Bankrupt & Nonbankrupt & 2 \\
& 2 & 0 & 100.00 \\
Nonkrupt & 100.00 & 0.00 & 86 \\
& 0 & 86 & 100.00 \\
\hline Total & 0.00 & 100.00 & 88 \\
& 2 & 86 & 100.00 \\
\hline Priors & 2.27 & 97.73 & \\
& 0.5 & 0.5 & \\
\hline
\end{tabular}

\begin{tabular}{lrrr}
\hline \multicolumn{4}{c}{ Error Count Estimates for BANKRUPTCY } \\
\hline & Bankrupt & Nonbankrupt & Total \\
\hline Rate & 0.0000 & 0.0000 & 0.0000 \\
Priors & 0.5000 & 0.5000 & \\
\hline
\end{tabular}


Results of Quadratic Discriminant Analysis : Market variables

YEAR 1

\begin{tabular}{lrlr}
\hline Observations & 249 DF Total & 248 \\
Variables & 5 DF Within Classes & 247 \\
Classes & 2 DF Between Classes & 1 \\
\hline
\end{tabular}

\begin{tabular}{|c|c|c|c|c|c|}
\hline \multicolumn{6}{|c|}{ Class Level Information } \\
\hline BANKRUPTCY & $\begin{array}{l}\text { Variable } \\
\text { Name }\end{array}$ & Frequency & Weight & Proportion & $\begin{array}{r}\text { Prior } \\
\text { Probability }\end{array}$ \\
\hline Bankrupt & Bankrupt & 133 & 133.0000 & 0.534137 & 0.500000 \\
\hline Nonbankrupt & Nonbankrupt & 116 & 116.0000 & 0.465863 & 0.500000 \\
\hline
\end{tabular}

\begin{tabular}{lrr}
\hline \multicolumn{3}{c}{ Within Covariance Matrix Information } \\
\hline BANKRUPTCY & $\begin{array}{r}\text { Covariance } \\
\text { Matrix Rank }\end{array}$ & $\begin{array}{r}\text { Natural Log of the } \\
\text { Determinant of the } \\
\text { Covariance Matrix }\end{array}$ \\
\hline Bankrupt & 5 & 48.91501 \\
Nonbankrupt & 5 & 51.79354 \\
\hline
\end{tabular}

\begin{tabular}{lrr}
\hline \multicolumn{2}{l}{ Generalized Squared Distance to BANKRUPTCY } \\
\hline From & & \\
BANKRUPTCY & Bankrupt & Nonbankrupt \\
\hline Bankrupt & 48.91501 & 54.55474 \\
Nonbankrupt & 52.55099 & 51.79354 \\
\hline
\end{tabular}




\section{CLASSIFICATION SUMMARY}

Number of Observations and Percent Classified into BANKRUPTCY

\begin{tabular}{lrrr}
\hline From & Bankrupt & Nonbankrupt & Total \\
BANKRUPTCY & 119 & 14 & 133 \\
Bankrupt & 89.47 & 10.53 & 100.00 \\
& 67 & 49 & 116 \\
Nonbankrupt & 57.76 & 42.24 & 100.00 \\
\hline Total & 186 & 63 & 249 \\
& 74.70 & 25.30 & 100.00 \\
\hline Priors & 0.5 & 0.5 & \\
\hline
\end{tabular}

\begin{tabular}{lrrr}
\hline \multicolumn{3}{c}{ Error Count Estimates for BANKRUPTCY } \\
\hline & Bankrupt & Nonbankrupt & Total \\
\hline Rate & 0.1053 & 0.5776 & 0.3414 \\
Priors & 0.5000 & 0.5000 & \\
\hline
\end{tabular}

YEAR 4

\begin{tabular}{lrr}
\hline Observations & 194 DF Total & 193 \\
Variables & 5 DF Within Classes & 192 \\
Classes & 2 DF Between Classes & 1 \\
\hline
\end{tabular}

\begin{tabular}{|c|c|c|c|c|c|}
\hline \multicolumn{6}{|c|}{ Class Level Information } \\
\hline BANKRUPTCY & $\begin{array}{l}\text { Variable } \\
\text { Name }\end{array}$ & Frequency & Weight & Proportion & $\begin{array}{r}\text { Prior } \\
\text { Probability }\end{array}$ \\
\hline Bankrupt & Bankrupt & 84 & 84.0000 & 0.432990 & 0.500000 \\
\hline Nonbankrupt & Nonbankrupt & 110 & 110.0000 & 0.567010 & 0.500000 \\
\hline
\end{tabular}




\begin{tabular}{lrr}
\hline \multicolumn{3}{c}{ Within Covariance Matrix Information } \\
\hline BANKRUPTCY & $\begin{array}{r}\text { Covariance } \\
\text { Matrix Rank }\end{array}$ & $\begin{array}{r}\text { Natural Log of the } \\
\text { Determinant of the } \\
\text { Covariance Matrix }\end{array}$ \\
\hline Bankrupt & 5 & 45.28909 \\
Nonbankrupt & 5 & 54.30022 \\
\hline
\end{tabular}

\begin{tabular}{lrr}
\hline \multicolumn{3}{l}{ Generalized Squared Distance to BANKRUPTCY } \\
\hline From & & \\
BANKRUPTCY & Bankrupt & Nonbankrupt \\
\hline Bankrupt & 45.28909 & 59.38781 \\
Nonbankrupt & 48.90719 & 54.30022 \\
\hline
\end{tabular}

\section{CLASSIFICATION SUMMARY}

Number of Observations and Percent Classified into BANKRUPTCY

\begin{tabular}{lrrr}
\hline From & Bankrupt & Nonbankrupt & Total \\
BANKRUPTCY & 78 & 6 & 84 \\
Bankrupt & 92.86 & 7.14 & 100.00 \\
& 72 & 38 & 110 \\
Nonbankrupt & 65.45 & 34.55 & 100.00 \\
\hline Total & 150 & 44 & 194 \\
& 77.32 & 22.68 & 100.00 \\
\hline Priors & 0.5 & 0.5 & \\
\hline
\end{tabular}

\begin{tabular}{lrrr}
\hline \multicolumn{4}{c}{ Error Count Estimates for BANKRUPTCY } \\
\hline & Bankrupt & Nonbankrupt & Total \\
\hline Rate & 0.0714 & 0.6545 & 0.3630 \\
Priors & 0.5000 & 0.5000 & \\
\hline
\end{tabular}


YEAR 5

\begin{tabular}{lrr}
\hline Observations & 161 DF Total & 160 \\
Variables & 5 DF Within Classes & 159 \\
Classes & 2 DF Between Classes & 1 \\
\hline
\end{tabular}

\begin{tabular}{|c|c|c|c|c|c|}
\hline \multicolumn{6}{|c|}{ Class Level Information } \\
\hline BANKRUPTCY & $\begin{array}{l}\text { Variable } \\
\text { Name }\end{array}$ & Frequency & Weight & Proportion & $\begin{array}{r}\text { Prior } \\
\text { Probability }\end{array}$ \\
\hline Bankrupt & Bankrupt & 64 & 64.0000 & 0.397516 & 0.500000 \\
\hline Nonbankrupt & Nonbankrupt & 97 & 97.0000 & 0.602484 & 0.500000 \\
\hline
\end{tabular}

\begin{tabular}{lrr}
\hline \multicolumn{3}{c}{ Within Covariance Matrix Information } \\
\hline BANKRUPTCY & $\begin{array}{r}\text { Covariance } \\
\text { Matrix Rank }\end{array}$ & $\begin{array}{r}\text { Natural Log of the } \\
\text { Determinant of the } \\
\text { Covariance Matrix }\end{array}$ \\
\hline Bankrupt & 5 & 46.92654 \\
Nonbankrupt & 5 & 51.52546 \\
\hline
\end{tabular}

\begin{tabular}{lrr}
\hline \multicolumn{2}{l}{ Generalized Squared Distance to BANKRUPTCY } \\
\hline From & & \\
BANKRUPTCY & Bankrupt & Nonbankrupt \\
\hline Bankrupt & 46.92654 & 60.74987 \\
Nonbankrupt & 49.99313 & 51.52546 \\
\hline
\end{tabular}




\section{CLASSIFICATION SUMMARY}

Number of Observations and Percent Classified into BANKRUPTCY

\begin{tabular}{lrrr}
\hline From & & & \\
BANKRUPTCY & Bankrupt & Nonbankrupt & Total \\
\hline Bankrupt & 59 & 5 & 64 \\
& 92.19 & 7.81 & 100.00 \\
Nonbankrupt & 59 & 38 & 97 \\
& 60.82 & 39.18 & 100.00 \\
\hline Total & 118 & 43 & 161 \\
& 73.29 & 26.71 & 100.00 \\
\hline Priors & 0.5 & 0.5 & \\
\hline
\end{tabular}

\begin{tabular}{lrrr}
\multicolumn{4}{c}{ Error Count Estimates for BANKRUPTCY } \\
\hline & Bankrupt & Nonbankrupt & Total \\
\hline Rate & 0.0781 & 0.6082 & 0.3432 \\
Priors & 0.5000 & 0.5000 & \\
\hline
\end{tabular}


Results of Quadratic Discriminant Analysis : Market variables without spread and hi lo bid ask spread

YEAR 1

\begin{tabular}{lrlr}
\hline Observations & 249 & DF Total & 248 \\
Variables & 4 DF Within Classes & 247 \\
Classes & 2 DF Between Classes & 1 \\
\hline
\end{tabular}

\begin{tabular}{|c|c|c|c|c|c|}
\hline \multicolumn{6}{|c|}{ Class Level Information } \\
\hline BANKRUPTCY & $\begin{array}{l}\text { Variable } \\
\text { Name }\end{array}$ & Frequency & Weight & Proportion & $\begin{array}{r}\text { Prior } \\
\text { Probability }\end{array}$ \\
\hline Bankrupt & Bankrupt & 133 & 133.0000 & 0.534137 & 0.500000 \\
\hline Nonbankrupt & Nonbankrupt & 116 & 116.0000 & 0.465863 & 0.500000 \\
\hline
\end{tabular}

\begin{tabular}{lrr}
\hline \multicolumn{3}{c}{ Within Covariance Matrix Information } \\
\hline BANKRUPTCY & $\begin{array}{r}\text { Covariance } \\
\text { Matrix Rank }\end{array}$ & $\begin{array}{r}\text { Natural Log of the } \\
\text { Determinant of the } \\
\text { Covariance Matrix }\end{array}$ \\
\hline Bankrupt & 4 & 45.00183 \\
Nonbankrupt & 4 & 51.63759 \\
\hline
\end{tabular}

\begin{tabular}{lrr}
\hline \multicolumn{2}{l}{ Generalized Squared Distance to BANKRUPTCY } \\
\hline From & & \\
BANKRUPTCY & Bankrupt & Nonbankrupt \\
\hline Bankrupt & 45.00183 & 52.61127 \\
Nonbankrupt & 48.38619 & 51.63759 \\
\hline
\end{tabular}




\section{CLASSIFICATION SUMMARY}

\begin{tabular}{lrrr}
\hline \multicolumn{3}{c}{ Number of Observations and Percent Classified into BANKRUPTCY } \\
\hline From & & & \\
BANKRUPTCY & Bankrupt & Nonbankrupt & Total \\
\hline Bankrupt & 122 & 11 & 133 \\
& 91.73 & 8.27 & 100.00 \\
Nonbankrupt & 83 & 33 & 116 \\
& 71.55 & 28.45 & 100.00 \\
\hline Total & 205 & 44 & 249 \\
& 82.33 & 17.67 & 100.00 \\
\hline Priors & 0.5 & 0.5 & \\
\end{tabular}

\begin{tabular}{lrrr}
\hline \multicolumn{3}{c}{ Error Count Estimates for BANKRUPTCY } \\
\hline & Bankrupt & Nonbankrupt & Total \\
\hline Rate & 0.0827 & 0.7155 & 0.3991 \\
Priors & 0.5000 & 0.5000 & \\
\hline
\end{tabular}

YEAR 4

\begin{tabular}{|c|c|c|}
\hline Observations & 194 DF Total & 193 \\
\hline Variables & 4 DF Within Classes & 192 \\
\hline Classes & 2 DF Between Classes & 1 \\
\hline
\end{tabular}

\begin{tabular}{|c|c|c|c|c|c|}
\hline \multicolumn{6}{|c|}{ Class Level Information } \\
\hline BANKRUPTCY & $\begin{array}{l}\text { Variable } \\
\text { Name }\end{array}$ & Frequency & Weight & Proportion & $\begin{array}{r}\text { Prior } \\
\text { Probability }\end{array}$ \\
\hline Bankrupt & Bankrupt & 84 & 84.0000 & 0.432990 & 0.500000 \\
\hline Nonbankrupt & Nonbankrupt & 110 & 110.0000 & 0.567010 & 0.500000 \\
\hline
\end{tabular}




\begin{tabular}{lrr}
\hline \multicolumn{3}{c}{ Within Covariance Matrix Information } \\
\hline BANKRUPTCY & $\begin{array}{r}\text { Covariance } \\
\text { Matrix Rank }\end{array}$ & $\begin{array}{r}\text { Natural Log of the } \\
\text { Determinant of the } \\
\text { Covariance Matrix }\end{array}$ \\
\hline Bankrupt & 4 & 44.44756 \\
Nonbankrupt & 4 & 51.13029 \\
\hline
\end{tabular}

\begin{tabular}{lcr}
\hline \multicolumn{2}{l}{ Generalized Squared Distance to BANKRUPTCY } \\
\hline From & & \\
BANKRUPTCY & Bankrupt & Nonbankrupt \\
\hline Bankrupt & 44.44756 & 56.17319 \\
Nonbankrupt & 47.95322 & 51.13029 \\
\hline
\end{tabular}

\section{CLASSIFICATION SUMMARY}

\begin{tabular}{lrrr}
\hline \multicolumn{4}{c}{ Number of Observations and Percent Classified into } \\
\hline Brom & BanKRUPTCY & Total \\
BANKRUPTCY & 78 & Nonbankrupt & 84 \\
\hline Bankrupt & 92.86 & 7.14 & 100.00 \\
& 73 & 37 & 110 \\
Nonbankrupt & 66.36 & 33.64 & 100.00 \\
\hline Total & 151 & 43 & 194 \\
& 77.84 & 22.16 & 100.00 \\
\hline Priors & 0.5 & 0.5 & \\
& & & \\
\hline
\end{tabular}

Error Count Estimates for BANKRUPTCY

\begin{tabular}{lrrr} 
& Bankrupt & Nonbankrupt & Total \\
\hline Rate & 0.0714 & 0.6636 & 0.3675 \\
Priors & 0.5000 & 0.5000 & \\
\hline
\end{tabular}


YEAR 5

\begin{tabular}{lrr}
\hline Observations & 161 DF Total & 160 \\
Variables & 4 DF Within Classes & 159 \\
Classes & 2 DF Between Classes & 1 \\
\hline
\end{tabular}

\begin{tabular}{|c|c|c|c|c|c|}
\hline \multicolumn{6}{|c|}{ Class Level Information } \\
\hline BANKRUPTCY & $\begin{array}{l}\text { Variable } \\
\text { Name }\end{array}$ & Frequency & Weight & Proportion & $\begin{array}{r}\text { Prior } \\
\text { Probability }\end{array}$ \\
\hline Bankrupt & Bankrupt & 64 & 64.0000 & 0.397516 & 0.500000 \\
\hline Nonbankrupt & Nonbankrupt & 97 & 97.0000 & 0.602484 & 0.500000 \\
\hline
\end{tabular}

\begin{tabular}{lrr}
\hline \multicolumn{3}{c}{ Within Covariance Matrix Information } \\
\hline BANKRUPTCY & $\begin{array}{r}\text { Covariance } \\
\text { Matrix Rank }\end{array}$ & $\begin{array}{r}\text { Natural Log of the } \\
\text { Determinant of the } \\
\text { Covariance Matrix }\end{array}$ \\
\hline Bankrupt & 4 & 45.68770 \\
Nonbankrupt & 4 & 49.86151 \\
\hline
\end{tabular}

\begin{tabular}{lrr}
\hline \multicolumn{3}{c}{$\begin{array}{c}\text { Generalized Squared Distance to } \\
\text { BANKRUPTCY }\end{array}$} \\
\hline From & Bankrupt & Nonbankrupt \\
BANKRUPTCY & 45.68770 & 58.80715 \\
\hline Bankrupt & 48.73746 & 49.86151 \\
\hline
\end{tabular}




\section{CLASSIFICATION SUMMARY}

Number of Observations and Percent Classified into BANKRUPTCY

\begin{tabular}{lrrr}
\hline From & & & \\
BANKRUPTCY & Bankrupt & Nonbankrupt & Total \\
\hline Bankrupt & 59 & 5 & 64 \\
& 92.19 & 7.81 & 100.00 \\
Nonbankrupt & 61 & 36 & 97 \\
& 62.89 & 37.11 & 100.00 \\
\hline Total & 120 & 41 & 161 \\
& 74.53 & 25.47 & 100.00 \\
\hline Priors & 0.5 & 0.5 & \\
\hline
\end{tabular}

\begin{tabular}{lrrr}
\multicolumn{4}{c}{ Error Count Estimates for BANKRUPTCY } \\
\hline & Bankrupt & Nonbankrupt & Total \\
\hline Rate & 0.0781 & 0.6289 & 0.3535 \\
Priors & 0.5000 & 0.5000 & \\
\hline
\end{tabular}


Results of Quadratic Discriminant Analysis : Market variables without spread and bid ask spread

YEAR 1

\begin{tabular}{lrlr}
\hline Observations & 252 DF Total & 251 \\
Variables & 4 DF Within Classes & 250 \\
Classes & 2 & DF Between Classes & 1 \\
\hline
\end{tabular}

\begin{tabular}{|c|c|c|c|c|c|}
\hline \multicolumn{6}{|c|}{ Class Level Information } \\
\hline BANKRUPTCY & $\begin{array}{l}\text { Variable } \\
\text { Name }\end{array}$ & Frequency & Weight & Proportion & $\begin{array}{r}\text { Prior } \\
\text { Probability }\end{array}$ \\
\hline Bankrupt & Bankrupt & 136 & 136.0000 & 0.539683 & 0.500000 \\
\hline Nonbankrupt & Nonbankrupt & 116 & 116.0000 & 0.460317 & 0.500000 \\
\hline
\end{tabular}

\begin{tabular}{lrr}
\hline \multicolumn{3}{c}{ Within Covariance Matrix Information } \\
\hline BANKRUPTCY & $\begin{array}{r}\text { Covariance } \\
\text { Matrix Rank }\end{array}$ & $\begin{array}{r}\text { Natural Log of the } \\
\text { Determinant of the } \\
\text { Covariance Matrix }\end{array}$ \\
\hline Bankrupt & 4 & 52.72158 \\
Nonbankrupt & 4 & 56.81245 \\
\hline
\end{tabular}

\begin{tabular}{lrr}
\hline \multicolumn{3}{l}{ Generalized Squared Distance to BANKRUPTCY } \\
\hline From & & \\
BANKRUPTCY & Bankrupt & Nonbankrupt \\
\hline Bankrupt & 52.72158 & 59.26423 \\
Nonbankrupt & 56.34264 & 56.81245 \\
\hline
\end{tabular}




\section{CLASSIFICATION SUMMARY}

Number of Observations and Percent Classified into BANKRUPTCY

\begin{tabular}{lrrr}
\hline From & Bankrupt & Nonbankrupt & Total \\
BANKRUPTCY & 124 & 12 & 136 \\
Bankrupt & 91.18 & 8.82 & 100.00 \\
Nonbankrupt & 75 & 41 & 116 \\
& 64.66 & 35.34 & 100.00 \\
\hline Total & 199 & 53 & 252 \\
& 78.97 & 21.03 & 100.00 \\
\hline Priors & 0.5 & 0.5 & \\
\hline
\end{tabular}

\begin{tabular}{lrrr}
\hline \multicolumn{3}{c}{ Error Count Estimates for BANKRUPTCY } \\
\hline & Bankrupt & Nonbankrupt & Total \\
\hline Rate & 0.0882 & 0.6466 & 0.3674 \\
Priors & 0.5000 & 0.5000 & \\
\hline
\end{tabular}

YEAR 4

\begin{tabular}{lrr}
\hline Observations & 195 DF Total & 194 \\
Variables & 4 DF Within Classes & 193 \\
Classes & 2 DF Between Classes & 1 \\
\hline
\end{tabular}

\begin{tabular}{|c|c|c|c|c|c|}
\hline \multicolumn{6}{|c|}{ Class Level Information } \\
\hline BANKRUPTCY & $\begin{array}{l}\text { Variable } \\
\text { Name }\end{array}$ & Frequency & Weight & Proportion & $\begin{array}{r}\text { Prior } \\
\text { Probability }\end{array}$ \\
\hline Bankrupt & Bankrupt & 85 & 85.0000 & 0.435897 & 0.500000 \\
\hline Nonbankrupt & Nonbankrupt & 110 & 110.0000 & 0.564103 & 0.500000 \\
\hline
\end{tabular}




\begin{tabular}{lrr}
\hline \multicolumn{3}{c}{ Within Covariance Matrix Information } \\
\hline BANKRUPTCY & $\begin{array}{r}\text { Covariance } \\
\text { Matrix Rank }\end{array}$ & $\begin{array}{r}\text { Natural Log of the } \\
\text { Determinant of the } \\
\text { Covariance Matrix }\end{array}$ \\
\hline Bankrupt & 4 & 48.72453 \\
Nonbankrupt & 4 & 59.13656 \\
\hline
\end{tabular}

\begin{tabular}{lcr}
\hline \multicolumn{2}{l}{ Generalized Squared Distance to BANKRUPTCY } \\
\hline From & & \\
BANKRUPTCY & Bankrupt & Nonbankrupt \\
\hline Bankrupt & 48.72453 & 59.51742 \\
Nonbankrupt & 52.30193 & 59.13656 \\
\hline
\end{tabular}

\section{CLASSIFICATION SUMMARY}

\begin{tabular}{lrrr}
\hline \multicolumn{4}{c}{ Number of Observations and Percent Classified into } \\
\hline BANKRUPTCY \\
BANKRUPTCY & Bankrupt & Nonbankrupt & Total \\
\hline Bankrupt & 80 & 5 & 85 \\
& 94.12 & 5.88 & 100.00 \\
Nonbankrupt & 77 & 33 & 110 \\
& 70.00 & 30.00 & 100.00 \\
\hline Total & 157 & 38 & 195 \\
& 80.51 & 19.49 & 100.00 \\
\hline Priors & 0.5 & 0.5 & \\
& & &
\end{tabular}

\begin{tabular}{lrrr}
\hline \multicolumn{4}{c}{ Error Count Estimates for BANKRUPTCY } \\
\hline & Bankrupt & Nonbankrupt & Total \\
\hline Rate & 0.0588 & 0.7000 & 0.3794 \\
Priors & 0.5000 & 0.5000 & \\
\hline
\end{tabular}


YEAR 5

\begin{tabular}{lrr}
\hline Observations & 168 DF Total & 167 \\
Variables & 4 DF Within Classes & 166 \\
Classes & 2 DF Between Classes & 1 \\
\hline
\end{tabular}

\begin{tabular}{|c|c|c|c|c|c|}
\hline \multicolumn{6}{|c|}{ Class Level Information } \\
\hline BANKRUPTCY & $\begin{array}{l}\text { Variable } \\
\text { Name }\end{array}$ & Frequency & Weight & Proportion & $\begin{array}{r}\text { Prior } \\
\text { Probability }\end{array}$ \\
\hline Bankrupt & Bankrupt & 70 & 70.0000 & 0.416667 & 0.500000 \\
\hline Nonbankrupt & Nonbankrupt & 98 & 98.0000 & 0.583333 & 0.500000 \\
\hline
\end{tabular}

\begin{tabular}{lrr}
\hline \multicolumn{3}{c}{ Within Covariance Matrix Information } \\
\hline BANKRUPTCY & $\begin{array}{r}\text { Covariance } \\
\text { Matrix Rank }\end{array}$ & $\begin{array}{r}\text { Natural Log of the } \\
\text { Determinant of the } \\
\text { Covariance Matrix }\end{array}$ \\
\hline Bankrupt & 4 & 50.05742 \\
Nonbankrupt & 4 & 56.92958 \\
\hline
\end{tabular}

\begin{tabular}{lrr}
\hline \multicolumn{2}{l}{ Generalized Squared Distance to BANKRUPTCY } \\
\hline From & & \\
BANKRUPTCY & Bankrupt & Nonbankrupt \\
\hline Bankrupt & 50.05742 & 57.29045 \\
Nonbankrupt & 53.08211 & 56.92958 \\
\hline
\end{tabular}




\section{CLASSIFICATION SUMMARY}

Number of Observations and Percent Classified into BANKRUPTCY

\begin{tabular}{lrrr}
\hline From & & & \\
BANKRUPTCY & Bankrupt & Nonbankrupt & Total \\
\hline Bankrupt & 65 & 5 & 70 \\
& 92.86 & 7.14 & 100.00 \\
Nonbankrupt & 74 & 24 & 98 \\
& 75.51 & 24.49 & 100.00 \\
\hline Total & 139 & 29 & 168 \\
& 82.74 & 17.26 & 100.00 \\
\hline Priors & 0.5 & 0.5 & \\
\hline
\end{tabular}

\begin{tabular}{lrrr}
\multicolumn{4}{c}{ Error Count Estimates for BANKRUPTCY } \\
\hline & Bankrupt & Nonbankrupt & Total \\
\hline Rate & 0.0714 & 0.7551 & 0.4133 \\
Priors & 0.5000 & 0.5000 & \\
\hline
\end{tabular}


Results of Quadratic Discriminant Analysis : Market variables without bid ask spread and hi lo bid ask spread

YEAR 1

\begin{tabular}{lrrr}
\hline Observations & 13 DF Total & 12 \\
Variables & 4 DF Within Classes & 11 \\
Classes & 2 DF Between Classes & 1 \\
\hline
\end{tabular}

\begin{tabular}{|c|c|c|c|c|c|}
\hline \multicolumn{6}{|c|}{ Class Level Information } \\
\hline BANKRUPTCY & $\begin{array}{l}\text { Variable } \\
\text { Name }\end{array}$ & Frequency & Weight & Proportion & $\begin{array}{r}\text { Prior } \\
\text { Probability }\end{array}$ \\
\hline Bankrupt & Bankrupt & 10 & 10.0000 & 0.769231 & 0.500000 \\
\hline Nonbankrupt & Nonbankrupt & 3 & 3.0000 & 0.230769 & 0.500000 \\
\hline
\end{tabular}

\begin{tabular}{lrr}
\hline \multicolumn{3}{c}{ Within Covariance Matrix Information } \\
\hline BANKRUPTCY & $\begin{array}{r}\text { Covariance } \\
\text { Matrix Rank }\end{array}$ & $\begin{array}{r}\text { Natural Log of the } \\
\text { Determinant of the } \\
\text { Covariance Matrix }\end{array}$ \\
\hline Bankrupt & 4 & 29.90733 \\
Nonbankrupt & 2 & -0.30956 \\
\hline
\end{tabular}

\begin{tabular}{lrr}
\hline \multicolumn{2}{l}{ Generalized Squared Distance to BANKRUPTCY } \\
\hline From & & \\
BANKRUPTCY & Bankrupt & Nonbankrupt \\
\hline Bankrupt & 29.90733 & 91487822 \\
Nonbankrupt & 34.53467 & -0.30956 \\
\hline
\end{tabular}




\section{CLASSIFICATION SUMMARY}

Number of Observations and Percent Classified into BANKRUPTCY

\begin{tabular}{lrrr}
\hline From & Bankrupt & Nonbankrupt & Total \\
BANKRUPTCY & 10 & 0 & 10 \\
Bankrupt & 100.00 & 0.00 & 100.00 \\
& 0 & 3 & 3 \\
Nonbankrupt & 0.00 & 100.00 & 100.00 \\
\hline Total & 10 & 3 & 13 \\
& 76.92 & 23.08 & 100.00 \\
\hline Priors & 0.5 & 0.5 & \\
\hline
\end{tabular}

\begin{tabular}{lrrr}
\hline \multicolumn{3}{c}{ Error Count Estimates for BANKRUPTCY } \\
\hline & Bankrupt & Nonbankrupt & Total \\
\hline Rate & 0.0000 & 0.0000 & 0.0000 \\
Priors & 0.5000 & 0.5000 & \\
\hline
\end{tabular}

YEAR 5

\begin{tabular}{lrlr}
\hline Observations & 12 DF Total & 11 \\
Variables & 4 DF Within Classes & 10 \\
Classes & 2 DF Between Classes & 1 \\
\hline
\end{tabular}

\begin{tabular}{|c|c|c|c|c|c|}
\hline \multicolumn{6}{|c|}{ Class Level Information } \\
\hline BANKRUPTCY & $\begin{array}{l}\text { Variable } \\
\text { Name }\end{array}$ & Frequency & Weight & Proportion & $\begin{array}{r}\text { Prior } \\
\text { Probability }\end{array}$ \\
\hline Bankrupt & Bankrupt & 9 & 9.0000 & 0.750000 & 0.500000 \\
\hline Nonbankrupt & Nonbankrupt & 3 & 3.0000 & 0.250000 & 0.500000 \\
\hline
\end{tabular}




\begin{tabular}{lrr}
\hline \multicolumn{3}{c}{ Within Covariance Matrix Information } \\
\hline BANKRUPTCY & $\begin{array}{r}\text { Covariance } \\
\text { Matrix Rank }\end{array}$ & $\begin{array}{r}\text { Natural Log of the } \\
\text { Determinant of the } \\
\text { Covariance Matrix }\end{array}$ \\
\hline Bankrupt & 4 & 36.17780 \\
Nonbankrupt & 2 & -6.31841 \\
\hline
\end{tabular}

\begin{tabular}{lrr}
\hline \multicolumn{3}{l}{ Generalized Squared Distance to BANKRUPTCY } \\
\hline From & & \\
BANKRUPTCY & Bankrupt & Nonbankrupt \\
\hline Bankrupt & 36.17780 & 387580929 \\
Nonbankrupt & 37.93887 & -6.31841 \\
\hline
\end{tabular}

\section{CLASSIFICATION SUMMARY}

\begin{tabular}{lrrr}
\hline \multicolumn{4}{c}{ Number of Observations and Percent Classified into } \\
\hline BANKRUPTCY \\
Brom & Bankrupt & Nonbankrupt & Total \\
\hline Bankrupt & 9 & 0 & 9 \\
& 100.00 & 0.00 & 100.00 \\
Nonbankrupt & 0 & 3 & 3 \\
& 0.00 & 100.00 & 100.00 \\
\hline Total & 9 & 3 & 12 \\
& 75.00 & 25.00 & 100.00 \\
\hline Priors & 0.5 & 0.5 & \\
& & &
\end{tabular}

\begin{tabular}{lrrr}
\hline \multicolumn{4}{c}{ Error Count Estimates for BANKRUPTCY } \\
\hline & Bankrupt & Nonbankrupt & Total \\
\hline Rate & 0.0000 & 0.0000 & 0.0000 \\
Priors & 0.5000 & 0.5000 & \\
\hline
\end{tabular}


Results of Quadratic Discriminant Analysis : Top 3 Account and Market variables

YEAR 1

\begin{tabular}{lrr}
\hline Observations & 104 DF Total & 103 \\
Variables & 6 DF Within Classes & 102 \\
Classes & 2 DF Between Classes & 1 \\
\hline
\end{tabular}

\begin{tabular}{|c|c|c|c|c|c|}
\hline \multicolumn{6}{|c|}{ Class Level Information } \\
\hline BANKRUPTCY & $\begin{array}{l}\text { Variable } \\
\text { Name }\end{array}$ & Frequency & Weight & Proportion & $\begin{array}{r}\text { Prior } \\
\text { Probability }\end{array}$ \\
\hline Bankrupt & Bankrupt & 7 & 7.0000 & 0.067308 & 0.500000 \\
\hline Nonbankrupt & Nonbankrupt & 97 & 97.0000 & 0.932692 & 0.500000 \\
\hline
\end{tabular}

\begin{tabular}{lrr}
\hline \multicolumn{3}{c}{ Within Covariance Matrix Information } \\
\hline BANKRUPTCY & $\begin{array}{r}\text { Covariance } \\
\text { Matrix Rank }\end{array}$ & $\begin{array}{r}\text { Natural Log of the } \\
\text { Determinant of the } \\
\text { Covariance Matrix }\end{array}$ \\
\hline Bankrupt & 6 & -22.70273 \\
Nonbankrupt & 6 & -10.79765 \\
\hline
\end{tabular}

\begin{tabular}{lrr}
\hline \multicolumn{2}{l}{ Generalized Squared Distance to BANKRUPTCY } \\
\hline From & & \\
BANKRUPTCY & Bankrupt & Nonbankrupt \\
\hline Bankrupt & -22.70273 & -9.60572 \\
Nonbankrupt & 80.62950 & -10.79765 \\
\hline
\end{tabular}




\section{CLASSIFICATION SUMMARY}

Number of Observations and Percent Classified into BANKRUPTCY

\begin{tabular}{lrrr}
\hline From & Bankrupt & Nonbankrupt & Total \\
BANKRUPTCY & 7 & 0 & 7 \\
Bankrupt & 100.00 & 0.00 & 100.00 \\
Nonbankrupt & 5 & 92 & 97 \\
& 5.15 & 94.85 & 100.00 \\
\hline Total & 12 & 92 & 104 \\
& 11.54 & 88.46 & 100.00 \\
\hline Priors & 0.5 & 0.5 & \\
\hline
\end{tabular}

\begin{tabular}{lrrr}
\hline \multicolumn{4}{c}{ Error Count Estimates for BANKRUPTCY } \\
\hline & Bankrupt & Nonbankrupt & Total \\
\hline Rate & 0.0000 & 0.0515 & 0.0258 \\
Priors & 0.5000 & 0.5000 & \\
\hline
\end{tabular}

YEAR 2

\begin{tabular}{lrr}
\hline Observations & 100 DF Total & 99 \\
Variables & 6 DF Within Classes & 98 \\
Classes & 2 DF Between Classes & 1 \\
\hline
\end{tabular}

\begin{tabular}{|c|c|c|c|c|c|}
\hline \multicolumn{6}{|c|}{ Class Level Information } \\
\hline BANKRUPTCY & $\begin{array}{l}\text { Variable } \\
\text { Name }\end{array}$ & Frequency & Weight & Proportion & $\begin{array}{r}\text { Prior } \\
\text { Probability }\end{array}$ \\
\hline Bankrupt & Bankrupt & 7 & 7.0000 & 0.070000 & 0.500000 \\
\hline Nonbankrupt & Nonbankrupt & 93 & 93.0000 & 0.930000 & 0.500000 \\
\hline
\end{tabular}




\begin{tabular}{lrr}
\hline \multicolumn{3}{c}{ Within Covariance Matrix Information } \\
\hline BANKRUPTCY & $\begin{array}{r}\text { Covariance } \\
\text { Matrix Rank }\end{array}$ & $\begin{array}{r}\text { Natural Log of the } \\
\text { Determinant of the } \\
\text { Covariance Matrix }\end{array}$ \\
\hline Bankrupt & 6 & -21.56348 \\
Nonbankrupt & 6 & -9.98246 \\
\hline
\end{tabular}

\begin{tabular}{lcr}
\hline \multicolumn{2}{l}{ Generalized Squared Distance to BANKRUPTCY } \\
\hline From & & \\
BANKRUPTCY & Bankrupt & Nonbankrupt \\
\hline Bankrupt & -21.56348 & -8.36049 \\
Nonbankrupt & 806.37144 & -9.98246 \\
\hline
\end{tabular}

\section{CLASSIFICATION SUMMARY}

\begin{tabular}{lrrr}
\hline \multicolumn{4}{c}{ Number of Observations and Percent Classified into } \\
\hline BANKRUPTCY \\
Brom & Bankrupt & Nonbankrupt & Total \\
\hline Bankrupt & 7 & 0 & 7 \\
& 100.00 & 0.00 & 100.00 \\
Nonbankrupt & 7 & 86 & 93 \\
& 7.53 & 92.47 & 100.00 \\
\hline Total & 14 & 86 & 100 \\
& 14.00 & 86.00 & 100.00 \\
\hline Priors & 0.5 & 0.5 & \\
& & &
\end{tabular}

\begin{tabular}{lrrr}
\hline \multicolumn{4}{c}{ Error Count Estimates for BANKRUPTCY } \\
\hline & Bankrupt & Nonbankrupt & Total \\
\hline Rate & 0.0000 & 0.0753 & 0.0376 \\
Priors & 0.5000 & 0.5000 & \\
\hline
\end{tabular}


YEAR 3

\begin{tabular}{lrlr}
\hline Observations & 90 DF Total & 89 \\
Variables & 6 DF Within Classes & 88 \\
Classes & 2 & DF Between Classes & 1 \\
\hline
\end{tabular}

\begin{tabular}{|c|c|c|c|c|c|}
\hline \multicolumn{6}{|c|}{ Class Level Information } \\
\hline BANKRUPTCY & $\begin{array}{l}\text { Variable } \\
\text { Name }\end{array}$ & Frequency & Weight & Proportion & $\begin{array}{r}\text { Prior } \\
\text { Probability }\end{array}$ \\
\hline Bankrupt & Bankrupt & 3 & 3.0000 & 0.033333 & 0.500000 \\
\hline Nonbankrupt & Nonbankrupt & 87 & 87.0000 & 0.966667 & 0.500000 \\
\hline
\end{tabular}

\begin{tabular}{lrr}
\hline \multicolumn{3}{c}{ Within Covariance Matrix Information } \\
\hline BANKRUPTCY & $\begin{array}{r}\text { Covariance } \\
\text { Matrix Rank }\end{array}$ & $\begin{array}{r}\text { Natural Log of the } \\
\text { Determinant of the } \\
\text { Covariance Matrix }\end{array}$ \\
\hline Bankrupt & 2 & -83.35910 \\
Nonbankrupt & 6 & -7.25899 \\
\hline
\end{tabular}

\begin{tabular}{lrr}
\hline \multicolumn{2}{c}{ Generalized Squared Distance to BANKRUPTCY } \\
\hline From & Bankrupt & Nonbankrupt \\
BANKRUPTCY & -83.35910 & -3.89454 \\
\hline Bankrupt & 753748767 & -7.25899 \\
\hline
\end{tabular}




\section{CLASSIFICATION SUMMARY}

Number of Observations and Percent Classified into BANKRUPTCY

\begin{tabular}{lrrr}
\hline From & Bankrupt & Nonbankrupt & Total \\
BANKRUPTCY & 3 & 0 & 3 \\
Bankrupt & 100.00 & 0.00 & 100.00 \\
& 0 & 87 & 87 \\
Nonbankrupt & 0.00 & 100.00 & 100.00 \\
\hline Total & 3 & 87 & 90 \\
& 3.33 & 96.67 & 100.00 \\
\hline Priors & 0.5 & 0.5 & \\
\hline
\end{tabular}

\begin{tabular}{lrrr}
\multicolumn{4}{c}{ Error Count Estimates for BANKRUPTCY } \\
\hline & Bankrupt & Nonbankrupt & Total \\
\hline Rate & 0.0000 & 0.0000 & 0.0000 \\
Priors & 0.5000 & 0.5000 & \\
\hline
\end{tabular}


Results of Quadratic Discriminant Analysis : Top 3 Account and Market logarithmic variables

YEAR 1

\begin{tabular}{lrlr}
\hline Observations & 82 & DF Total & 81 \\
Variables & 6 DF Within Classes & 80 \\
Classes & 2 & DF Between Classes & 1 \\
\hline
\end{tabular}

\begin{tabular}{|c|c|c|c|c|c|}
\hline \multicolumn{6}{|c|}{ Class Level Information } \\
\hline BANKRUPTCY & $\begin{array}{l}\text { Variable } \\
\text { Name }\end{array}$ & Frequency & Weight & Proportion & $\begin{array}{r}\text { Prior } \\
\text { Probability }\end{array}$ \\
\hline Bankrupt & Bankrupt & 4 & 4.0000 & 0.048780 & 0.500000 \\
\hline Nonbankrupt & Nonbankrupt & 78 & 78.0000 & 0.951220 & 0.500000 \\
\hline
\end{tabular}

\begin{tabular}{lrr}
\hline \multicolumn{3}{c}{ Within Covariance Matrix Information } \\
\hline BANKRUPTCY & $\begin{array}{r}\text { Covariance } \\
\text { Matrix Rank }\end{array}$ & $\begin{array}{r}\text { Natural Log of the } \\
\text { Determinant of the } \\
\text { Covariance Matrix }\end{array}$ \\
\hline Bankrupt & 3 & -50.22638 \\
Nonbankrupt & 6 & 0.90059 \\
\hline
\end{tabular}

\begin{tabular}{lrr}
\hline \multicolumn{2}{c}{ Generalized Squared Distance to BANKRUPTCY } \\
\hline From & Bankrupt & Nonbankrupt \\
BANKRUPTCY & -50.22638 & 3.51367 \\
\hline Bankrupt & 153457811 & 0.90059 \\
\hline
\end{tabular}




\section{CLASSIFICATION SUMMARY}

Number of Observations and Percent Classified into BANKRUPTCY

\begin{tabular}{lrrr}
\hline From & Bankrupt & Nonbankrupt & Total \\
BANKRUPTCY & 4 & 0 & 4 \\
Bankrupt & 100.00 & 0.00 & 100.00 \\
Nonbankrupt & 0 & 78 & 78 \\
& 0.00 & 100.00 & 100.00 \\
\hline Total & 4 & 78 & 82 \\
& 4.88 & 95.12 & 100.00 \\
\hline Priors & 0.5 & 0.5 & \\
\hline
\end{tabular}

\begin{tabular}{lrrr}
\hline \multicolumn{3}{c}{ Error Count Estimates for BANKRUPTCY } \\
\hline & Bankrupt & Nonbankrupt & Total \\
\hline Rate & 0.0000 & 0.0000 & 0.0000 \\
Priors & 0.5000 & 0.5000 & \\
\hline
\end{tabular}

YEAR 2

\begin{tabular}{lrlr}
\hline Observations & 80 DF Total & 79 \\
Variables & 6 DF Within Classes & 78 \\
Classes & 2 & DF Between Classes & 1 \\
\hline
\end{tabular}

\begin{tabular}{|c|c|c|c|c|c|}
\hline \multicolumn{6}{|c|}{ Class Level Information } \\
\hline BANKRUPTCY & $\begin{array}{l}\text { Variable } \\
\text { Name }\end{array}$ & Frequency & Weight & Proportion & $\begin{array}{r}\text { Prior } \\
\text { Probability }\end{array}$ \\
\hline Bankrupt & Bankrupt & 3 & 3.0000 & 0.037500 & 0.500000 \\
\hline Nonbankrupt & Nonbankrupt & 77 & 77.0000 & 0.962500 & 0.500000 \\
\hline
\end{tabular}




\begin{tabular}{lrr}
\hline \multicolumn{3}{c}{ Within Covariance Matrix Information } \\
\hline BANKRUPTCY & $\begin{array}{r}\text { Covariance } \\
\text { Matrix Rank }\end{array}$ & $\begin{array}{r}\text { Natural Log of the } \\
\text { Determinant of the } \\
\text { Covariance Matrix }\end{array}$ \\
\hline Bankrupt & 2 & -60.33946 \\
Nonbankrupt & 6 & 0.83121 \\
\hline
\end{tabular}

\begin{tabular}{lrr}
\hline \multicolumn{3}{c}{$\begin{array}{c}\text { Generalized Squared Distance to } \\
\text { BANKRUPTCY }\end{array}$} \\
\hline $\begin{array}{lrr}\text { From } \\
\text { BANKRUPTCY }\end{array}$ & Bankrupt & Nonbankrupt \\
\hline Bankrupt & -60.33946 & 2.33795 \\
Nonbankrupt & 6967642 & 0.83121 \\
\hline
\end{tabular}

\section{CLASSIFICATION SUMMARY}

\begin{tabular}{lrrr}
\hline \multicolumn{4}{c}{ Number of Observations and Percent Classified into } \\
BANKRUPTCY \\
\hline From & Bankrupt & Nonbankrupt & Total \\
BANKRUPTCY & 3 & 0 & 3 \\
\hline Bankrupt & 100.00 & 0.00 & 100.00 \\
& 0 & 77 & 77 \\
Nonbankrupt & 0.00 & 100.00 & 100.00 \\
\hline Total & 3 & 77 & 80 \\
& 3.75 & 96.25 & 100.00 \\
\hline Priors & 0.5 & 0.5 & \\
& & &
\end{tabular}

\begin{tabular}{lrrr}
\hline \multicolumn{4}{c}{ Error Count Estimates for BANKRUPTCY } \\
\hline & Bankrupt & Nonbankrupt & Total \\
\hline Rate & 0.0000 & 0.0000 & 0.0000 \\
Priors & 0.5000 & 0.5000 & \\
\hline
\end{tabular}


Results of Quadratic Discriminant Analysis : Variables (Price, Standard deviation, bid ask spread, net income to sales, working capital to total assets and current liabilities to total assets )

YEAR 1

\begin{tabular}{lrr}
\hline Observations & 184 DF Total & 183 \\
Variables & 6 DF Within Classes & 182 \\
Classes & 2 DF Between Classes & 1 \\
\hline
\end{tabular}

\begin{tabular}{|c|c|c|c|c|c|}
\hline \multicolumn{6}{|c|}{ Class Level Information } \\
\hline BANKRUPTCY & $\begin{array}{l}\text { Variable } \\
\text { Name }\end{array}$ & Frequency & Weight & Proportion & $\begin{array}{r}\text { Prior } \\
\text { Probability }\end{array}$ \\
\hline Bankrupt & Bankrupt & 85 & 85.0000 & 0.461957 & 0.500000 \\
\hline Nonbankrupt & Nonbankrupt & 99 & 99.0000 & 0.538043 & 0.500000 \\
\hline
\end{tabular}

\begin{tabular}{lrr}
\hline \multicolumn{3}{c}{ Within Covariance Matrix Information } \\
\hline BANKRUPTCY & $\begin{array}{r}\text { Covariance } \\
\text { Matrix Rank }\end{array}$ & $\begin{array}{r}\text { Natural Log of the } \\
\text { Determinant of the } \\
\text { Covariance Matrix }\end{array}$ \\
\hline Bankrupt & 6 & 0.08497 \\
Nonbankrupt & 6 & -12.56568 \\
\hline
\end{tabular}

\begin{tabular}{lrr}
\hline \multicolumn{2}{l}{ Generalized Squared Distance to BANKRUPTCY } \\
\hline From & Bankrupt & Nonbankrupt \\
BANKRUPTCY & 0.08497 & 517.44508 \\
Bankrupt & 1.46675 & -12.56568 \\
\hline
\end{tabular}




\section{CLASSIFICATION SUMMARY}

Number of Observations and Percent Classified into BANKRUPTCY

\begin{tabular}{lrrr}
\hline From & Bankrupt & Nonbankrupt & Total \\
BANKRUPTCY & 46 & 39 & 85 \\
Bankrupt & 54.12 & 45.88 & 100.00 \\
& 8 & 91 & 99 \\
Nonbankrupt & 8.08 & 91.92 & 100.00 \\
\hline Total & 54 & 130 & 184 \\
& 29.35 & 70.65 & 100.00 \\
\hline Priors & 0.5 & 0.5 & \\
\hline
\end{tabular}

\begin{tabular}{lrrr}
\hline \multicolumn{3}{c}{ Error Count Estimates for BANKRUPTCY } \\
\hline & Bankrupt & Nonbankrupt & Total \\
\hline Rate & 0.4588 & 0.0808 & 0.2698 \\
Priors & 0.5000 & 0.5000 & \\
\hline
\end{tabular}

YEAR 2

\begin{tabular}{lrrr}
\hline Observations & 201 DF Total & 200 \\
Variables & 6 DF Within Classes & 199 \\
Classes & 2 DF Between Classes & 1 \\
\hline
\end{tabular}

\begin{tabular}{|c|c|c|c|c|c|}
\hline \multicolumn{6}{|c|}{ Class Level Information } \\
\hline BANKRUPTCY & $\begin{array}{l}\text { Variable } \\
\text { Name }\end{array}$ & Frequency & Weight & Proportion & $\begin{array}{r}\text { Prior } \\
\text { Probability }\end{array}$ \\
\hline Bankrupt & Bankrupt & 95 & 95.0000 & 0.472637 & 0.500000 \\
\hline Nonbankrupt & Nonbankrupt & 106 & 106.0000 & 0.527363 & 0.500000 \\
\hline
\end{tabular}




\begin{tabular}{lrr}
\hline \multicolumn{3}{c}{ Within Covariance Matrix Information } \\
\hline BANKRUPTCY & $\begin{array}{r}\text { Covariance } \\
\text { Matrix Rank }\end{array}$ & $\begin{array}{r}\text { Natural Log of the } \\
\text { Determinant of the } \\
\text { Covariance Matrix }\end{array}$ \\
\hline Bankrupt & 6 & 3.55063 \\
Nonbankrupt & 6 & 1.58352 \\
\hline
\end{tabular}

\begin{tabular}{lrr}
\hline \multicolumn{3}{l}{ Generalized Squared Distance to BANKRUPTCY } \\
\hline From & & \\
BANKRUPTCY & Bankrupt & Nonbankrupt \\
\hline Bankrupt & 3.55063 & 3.52813 \\
Nonbankrupt & 4.87329 & 1.58352 \\
\hline
\end{tabular}

\section{CLASSIFICATION SUMMARY}

\begin{tabular}{lrrr}
\hline \multicolumn{4}{c}{ Number of Observations and Percent Classified into } \\
\hline BANKRUPTCY \\
From & Bankrupt & Nonbankrupt & Total \\
\hline Bankrupt & 33 & 62 & 95 \\
& 34.74 & 65.26 & 100.00 \\
Nonbankrupt & 11 & 95 & 106 \\
& 10.38 & 89.62 & 100.00 \\
\hline Total & 44 & 157 & 201 \\
& 21.89 & 78.11 & 100.00 \\
\hline Priors & 0.5 & 0.5 & \\
& & &
\end{tabular}

\begin{tabular}{lrrr}
\hline \multicolumn{4}{c}{ Error Count Estimates for BANKRUPTCY } \\
\hline & Bankrupt & Nonbankrupt & Total \\
\hline Rate & 0.6526 & 0.1038 & 0.3782 \\
Priors & 0.5000 & 0.5000 & \\
\hline
\end{tabular}


YEAR 3

\begin{tabular}{lrr}
\hline Observations & 173 DF Total & 172 \\
Variables & 6 DF Within Classes & 171 \\
Classes & 2 DF Between Classes & 1 \\
\hline
\end{tabular}

\begin{tabular}{|c|c|c|c|c|c|}
\hline \multicolumn{6}{|c|}{ Class Level Information } \\
\hline BANKRUPTCY & $\begin{array}{l}\text { Variable } \\
\text { Name }\end{array}$ & Frequency & Weight & Proportion & $\begin{array}{r}\text { Prior } \\
\text { Probability }\end{array}$ \\
\hline Bankrupt & Bankrupt & 74 & 74.0000 & 0.427746 & 0.500000 \\
\hline Nonbankrupt & Nonbankrupt & 99 & 99.0000 & 0.572254 & 0.500000 \\
\hline
\end{tabular}

\begin{tabular}{lrr}
\hline \multicolumn{3}{c}{ Within Covariance Matrix Information } \\
\hline BANKRUPTCY & $\begin{array}{r}\text { Covariance } \\
\text { Matrix Rank }\end{array}$ & $\begin{array}{r}\text { Natural Log of the } \\
\text { Determinant of the } \\
\text { Covariance Matrix }\end{array}$ \\
\hline Bankrupt & 6 & 0.30543 \\
Nonbankrupt & 6 & -3.09270 \\
\hline
\end{tabular}

\begin{tabular}{lrr}
\hline \multicolumn{2}{l}{ Generalized Squared Distance to BANKRUPTCY } \\
\hline From & Bankrupt & Nonbankrupt \\
\hline BANKRUPTCY & 0.30543 & -1.46368 \\
Bankrupt & 1.21219 & -3.09270 \\
\hline
\end{tabular}




\section{CLASSIFICATION SUMMARY}

Number of Observations and Percent Classified into BANKRUPTCY

\begin{tabular}{lrrr}
\hline From & & & \\
BANKRUPTCY & Bankrupt & Nonbankrupt & Total \\
\hline Bankrupt & 26 & 48 & 74 \\
& 35.14 & 64.86 & 100.00 \\
Nonbankrupt & 9 & 90 & 99 \\
& 9.09 & 90.91 & 100.00 \\
\hline Total & 35 & 138 & 173 \\
& 20.23 & 79.77 & 100.00 \\
\hline Priors & 0.5 & 0.5 & \\
\hline
\end{tabular}

\begin{tabular}{lrrr}
\hline \multicolumn{3}{c}{ Error Count Estimates for BANKRUPTCY } \\
\hline & Bankrupt & Nonbankrupt & Total \\
\hline Rate & 0.6486 & 0.0909 & 0.3698 \\
Priors & 0.5000 & 0.5000 & \\
\hline
\end{tabular}

YEAR 4

\begin{tabular}{lrlr}
\hline Observations & 90 DF Total & 89 \\
Variables & 6 DF Within Classes & 88 \\
Classes & 2 & DF Between Classes & 1 \\
\hline
\end{tabular}

\begin{tabular}{|c|c|c|c|c|c|}
\hline \multicolumn{6}{|c|}{ Class Level Information } \\
\hline BANKRUPTCY & $\begin{array}{l}\text { Variable } \\
\text { Name }\end{array}$ & Frequency & Weight & Proportion & $\begin{array}{r}\text { Prior } \\
\text { Probability }\end{array}$ \\
\hline Bankrupt & Bankrupt & 66 & 66.0000 & 0.733333 & 0.500000 \\
\hline Nonbankrupt & Nonbankrupt & 24 & 24.0000 & 0.266667 & 0.500000 \\
\hline
\end{tabular}




\begin{tabular}{lrr}
\hline \multicolumn{3}{c}{ Within Covariance Matrix Information } \\
\hline BANKRUPTCY & $\begin{array}{r}\text { Covariance } \\
\text { Matrix Rank }\end{array}$ & $\begin{array}{r}\text { Natural Log of the } \\
\text { Determinant of the } \\
\text { Covariance Matrix }\end{array}$ \\
\hline Bankrupt & 6 & 7.45623 \\
Nonbankrupt & 6 & -12.86147 \\
\hline
\end{tabular}

\begin{tabular}{lrr}
\hline \multicolumn{3}{l}{ Generalized Squared Distance to BANKRUPTCY } \\
\hline From & & \\
BANKRUPTCY & Bankrupt & Nonbankrupt \\
\hline Bankrupt & 7.45623 & 292901 \\
Nonbankrupt & 9.10716 & -12.86147 \\
\hline
\end{tabular}

\section{CLASSIFICATION SUMMARY}

\begin{tabular}{lrrr}
\hline \multicolumn{4}{c}{ Number of Observations and Percent Classified into } \\
\hline BANKRUPTCY \\
BANKRUPTCY & Bankrupt & Nonbankrupt & Total \\
\hline Bankrupt & 29 & 37 & 66 \\
& 43.94 & 56.06 & 100.00 \\
Nonbankrupt & 0 & 24 & 24 \\
& 0.00 & 100.00 & 100.00 \\
\hline Total & 29 & 61 & 90 \\
& 32.22 & 67.78 & 100.00 \\
\hline Priors & 0.5 & 0.5 & \\
& & &
\end{tabular}

\begin{tabular}{lrrr}
\hline \multicolumn{4}{c}{ Error Count Estimates for BANKRUPTCY } \\
\hline & Bankrupt & Nonbankrupt & Total \\
\hline Rate & 0.5606 & 0.0000 & 0.2803 \\
Priors & 0.5000 & 0.5000 & \\
\hline
\end{tabular}


YEAR 5

\begin{tabular}{lrrr}
\hline Observations & 43 DF Total & 42 \\
Variables & 6 DF Within Classes & 41 \\
Classes & 2 DF Between Classes & 1 \\
\hline
\end{tabular}

\begin{tabular}{|c|c|c|c|c|c|}
\hline \multicolumn{6}{|c|}{ Class Level Information } \\
\hline BANKRUPTCY & $\begin{array}{l}\text { Variable } \\
\text { Name }\end{array}$ & Frequency & Weight & Proportion & $\begin{array}{r}\text { Prior } \\
\text { Probability }\end{array}$ \\
\hline Bankrupt & Bankrupt & 27 & 27.0000 & 0.627907 & 0.500000 \\
\hline Nonbankrupt & Nonbankrupt & 16 & 16.0000 & 0.372093 & 0.500000 \\
\hline
\end{tabular}

\begin{tabular}{lrr}
\hline \multicolumn{3}{c}{ Within Covariance Matrix Information } \\
\hline BANKRUPTCY & $\begin{array}{r}\text { Covariance } \\
\text { Matrix Rank }\end{array}$ & $\begin{array}{r}\text { Natural Log of the } \\
\text { Determinant of the } \\
\text { Covariance Matrix }\end{array}$ \\
\hline Bankrupt & 6 & 0.52974 \\
Nonbankrupt & 6 & -16.60573 \\
\hline
\end{tabular}

\begin{tabular}{lrr}
\hline \multicolumn{2}{l}{ Generalized Squared Distance to BANKRUPTCY } \\
\hline From & & \\
BANKRUPTCY & Bankrupt & Nonbankrupt \\
\hline Bankrupt & 0.52974 & 14699 \\
Nonbankrupt & 1.71635 & -16.60573 \\
\hline
\end{tabular}




\section{CLASSIFICATION SUMMARY}

Number of Observations and Percent Classified into BANKRUPTCY

\begin{tabular}{lrrr}
\hline From & & & \\
BANKRUPTCY & Bankrupt & Nonbankrupt & Total \\
\hline Bankrupt & 18 & 9 & 27 \\
& 66.67 & 33.33 & 100.00 \\
Nonbankrupt & 0 & 16 & 16 \\
& 0.00 & 100.00 & 100.00 \\
\hline Total & 18 & 25 & 43 \\
& 41.86 & 58.14 & 100.00 \\
\hline Priors & 0.5 & 0.5 & \\
\hline
\end{tabular}

\begin{tabular}{lrrr}
\multicolumn{4}{c}{ Error Count Estimates for BANKRUPTCY } \\
\hline & Bankrupt & Nonbankrupt & Total \\
\hline Rate & 0.3333 & 0.0000 & 0.1667 \\
Priors & 0.5000 & 0.5000 & \\
\hline
\end{tabular}


Results of Quadratic Discriminant Analysis : Variables (Price, Standard deviation, hi lo bid ask spread, net income to sales, working capital to total assets and current liabilities to total assets )

YEAR 1

\begin{tabular}{lrrr}
\hline Observations & 185 DF Total & 184 \\
Variables & 6 DF Within Classes & 183 \\
Classes & 2 & DF Between Classes & 1 \\
\hline
\end{tabular}

\begin{tabular}{|c|c|c|c|c|c|}
\hline \multicolumn{6}{|c|}{ Class Level Information } \\
\hline BANKRUPTCY & $\begin{array}{l}\text { Variable } \\
\text { Name }\end{array}$ & Frequency & Weight & Proportion & $\begin{array}{r}\text { Prior } \\
\text { Probability }\end{array}$ \\
\hline Bankrupt & Bankrupt & 86 & 86.0000 & 0.464865 & 0.500000 \\
\hline Nonbankrupt & Nonbankrupt & 99 & 99.0000 & 0.535135 & 0.500000 \\
\hline
\end{tabular}

\begin{tabular}{lrr}
\hline \multicolumn{3}{c}{ Within Covariance Matrix Information } \\
\hline BANKRUPTCY & $\begin{array}{r}\text { Covariance } \\
\text { Matrix Rank }\end{array}$ & $\begin{array}{r}\text { Natural Log of the } \\
\text { Determinant of the } \\
\text { Covariance Matrix }\end{array}$ \\
\hline Bankrupt & 6 & 8.41196 \\
Nonbankrupt & 6 & -7.22763 \\
\hline
\end{tabular}

\begin{tabular}{lrr}
\hline \multicolumn{3}{l}{ Generalized Squared Distance to BANKRUPTCY } \\
\hline From & & \\
BANKRUPTCY & Bankrupt & Nonbankrupt \\
\hline Bankrupt & 8.41196 & 508.07273 \\
Nonbankrupt & 9.82853 & -7.22763 \\
\hline
\end{tabular}




\section{CLASSIFICATION SUMMARY}

Number of Observations and Percent Classified into BANKRUPTCY

\begin{tabular}{lrrr}
\hline From & & & \\
BANKRUPTCY & Bankrupt & Nonbankrupt & Total \\
\hline Bankrupt & 39 & 47 & 86 \\
& 45.35 & 54.65 & 100.00 \\
Nonbankrupt & 7 & 92 & 99 \\
& 7.07 & 92.93 & 100.00 \\
\hline Total & 46 & 139 & 185 \\
& 24.86 & 75.14 & 100.00 \\
\hline Priors & 0.5 & 0.5 & \\
\hline
\end{tabular}

\begin{tabular}{lrrr}
\hline \multicolumn{3}{c}{ Error Count Estimates for BANKRUPTCY } \\
\hline & Bankrupt & Nonbankrupt & Total \\
\hline Rate & 0.5465 & 0.0707 & 0.3086 \\
Priors & 0.5000 & 0.5000 & \\
\hline
\end{tabular}

YEAR 2

\begin{tabular}{lrlr}
\hline Observations & 201 & DF Total & 200 \\
Variables & 6 DF Within Classes & 199 \\
Classes & 2 & DF Between Classes & 1 \\
\hline
\end{tabular}

\begin{tabular}{|c|c|c|c|c|c|}
\hline \multicolumn{6}{|c|}{ Class Level Information } \\
\hline BANKRUPTCY & $\begin{array}{l}\text { Variable } \\
\text { Name }\end{array}$ & Frequency & Weight & Proportion & $\begin{array}{r}\text { Prior } \\
\text { Probability }\end{array}$ \\
\hline Bankrupt & Bankrupt & 95 & 95.0000 & 0.472637 & 0.500000 \\
\hline Nonbankrupt & Nonbankrupt & 106 & 106.0000 & 0.527363 & 0.500000 \\
\hline
\end{tabular}




\begin{tabular}{lrr}
\hline \multicolumn{3}{c}{ Within Covariance Matrix Information } \\
\hline BANKRUPTCY & $\begin{array}{r}\text { Covariance } \\
\text { Matrix Rank }\end{array}$ & $\begin{array}{r}\text { Natural Log of the } \\
\text { Determinant of the } \\
\text { Covariance Matrix }\end{array}$ \\
\hline Bankrupt & 6 & 8.34547 \\
Nonbankrupt & 6 & 6.98046 \\
\hline
\end{tabular}

\begin{tabular}{lrr}
\hline \multicolumn{3}{l}{ Generalized Squared Distance to BANKRUPTCY } \\
\hline From & & \\
BANKRUPTCY & Bankrupt & Nonbankrupt \\
\hline Bankrupt & 8.34547 & 8.48245 \\
Nonbankrupt & 9.37163 & 6.98046 \\
\hline
\end{tabular}

\section{CLASSIFICATION SUMMARY}

\begin{tabular}{lrrr}
\hline \multicolumn{4}{c}{ Number of Observations and Percent Classified into } \\
\hline BANKRUPTCY \\
BANKRUPTCY & Bankrupt & Nonbankrupt & Total \\
\hline Bankrupt & 26 & 69 & 95 \\
& 27.37 & 72.63 & 100.00 \\
Nonbankrupt & 6 & 100 & 106 \\
& 5.66 & 94.34 & 100.00 \\
\hline Total & 32 & 169 & 201 \\
& 15.92 & 84.08 & 100.00 \\
\hline Priors & 0.5 & 0.5 & \\
& & &
\end{tabular}

\begin{tabular}{lrrr}
\hline \multicolumn{4}{c}{ Error Count Estimates for BANKRUPTCY } \\
\hline & Bankrupt & Nonbankrupt & Total \\
\hline Rate & 0.7263 & 0.0566 & 0.3915 \\
Priors & 0.5000 & 0.5000 & \\
\hline
\end{tabular}


YEAR 3

\begin{tabular}{lrr}
\hline Observations & 174 DF Total & 173 \\
Variables & 6 DF Within Classes & 172 \\
Classes & 2 DF Between Classes & 1 \\
\hline
\end{tabular}

\begin{tabular}{|c|c|c|c|c|c|}
\hline \multicolumn{6}{|c|}{ Class Level Information } \\
\hline BANKRUPTCY & $\begin{array}{l}\text { Variable } \\
\text { Name }\end{array}$ & Frequency & Weight & Proportion & $\begin{array}{r}\text { Prior } \\
\text { Probability }\end{array}$ \\
\hline Bankrupt & Bankrupt & 75 & 75.0000 & 0.431034 & 0.500000 \\
\hline Nonbankrupt & Nonbankrupt & 99 & 99.0000 & 0.568966 & 0.500000 \\
\hline
\end{tabular}

\begin{tabular}{lrr}
\hline \multicolumn{3}{c}{ Within Covariance Matrix Information } \\
\hline BANKRUPTCY & $\begin{array}{r}\text { Covariance } \\
\text { Matrix Rank }\end{array}$ & $\begin{array}{r}\text { Natural Log of the } \\
\text { Determinant of the } \\
\text { Covariance Matrix }\end{array}$ \\
\hline Bankrupt & 6 & 6.58269 \\
Nonbankrupt & 6 & 2.51630 \\
\hline
\end{tabular}

\begin{tabular}{lrr}
\hline \multicolumn{2}{l}{ Generalized Squared Distance to BANKRUPTCY } \\
\hline From & Bankrupt & Nonbankrupt \\
BANKRUPTCY & 6.58269 & 3.52036 \\
\hline Bankrupt & 6.94238 & 2.51630 \\
\hline
\end{tabular}




\section{CLASSIFICATION SUMMARY}

Number of Observations and Percent Classified into BANKRUPTCY

\begin{tabular}{lrrr}
\hline From & & & \\
BANKRUPTCY & Bankrupt & Nonbankrupt & Total \\
\hline Bankrupt & 21 & 54 & 75 \\
& 28.00 & 72.00 & 100.00 \\
Nonbankrupt & 7 & 92 & 99 \\
& 7.07 & 92.93 & 100.00 \\
\hline Total & 28 & 146 & 174 \\
& 16.09 & 83.91 & 100.00 \\
\hline Priors & 0.5 & 0.5 & \\
\hline
\end{tabular}

\begin{tabular}{lrrr}
\hline \multicolumn{3}{c}{ Error Count Estimates for BANKRUPTCY } \\
\hline & Bankrupt & Nonbankrupt & Total \\
\hline Rate & 0.7200 & 0.0707 & 0.3954 \\
Priors & 0.5000 & 0.5000 & \\
\hline
\end{tabular}

YEAR 4

\begin{tabular}{lrlr}
\hline Observations & 90 DF Total & 89 \\
Variables & 6 DF Within Classes & 88 \\
Classes & 2 & DF Between Classes & 1 \\
\hline
\end{tabular}

\begin{tabular}{|c|c|c|c|c|c|}
\hline \multicolumn{6}{|c|}{ Class Level Information } \\
\hline BANKRUPTCY & $\begin{array}{l}\text { Variable } \\
\text { Name }\end{array}$ & Frequency & Weight & Proportion & $\begin{array}{r}\text { Prior } \\
\text { Probability }\end{array}$ \\
\hline Bankrupt & Bankrupt & 66 & 66.0000 & 0.733333 & 0.500000 \\
\hline Nonbankrupt & Nonbankrupt & 24 & 24.0000 & 0.266667 & 0.500000 \\
\hline
\end{tabular}




\begin{tabular}{lrr}
\hline \multicolumn{3}{c}{ Within Covariance Matrix Information } \\
\hline BANKRUPTCY & $\begin{array}{r}\text { Covariance } \\
\text { Matrix Rank }\end{array}$ & $\begin{array}{r}\text { Natural Log of the } \\
\text { Determinant of the } \\
\text { Covariance Matrix }\end{array}$ \\
\hline Bankrupt & 6 & 11.88973 \\
Nonbankrupt & 6 & -7.10209 \\
\hline
\end{tabular}

\begin{tabular}{lrr}
\hline \multicolumn{3}{l}{ Generalized Squared Distance to BANKRUPTCY } \\
\hline From & & \\
BANKRUPTCY & Bankrupt & Nonbankrupt \\
\hline Bankrupt & 11.88973 & 251943 \\
Nonbankrupt & 12.70240 & -7.10209 \\
\hline
\end{tabular}

\section{CLASSIFICATION SUMMARY}

\begin{tabular}{lrrr}
\hline \multicolumn{4}{c}{ Number of Observations and Percent Classified into } \\
\hline BANKRUPTCY & Total \\
BANKRUPTCY & Bankrupt & Nonbankrupt & 66 \\
\hline Bankrupt & 21 & 45 & 100.00 \\
& 31.82 & 68.18 & 24 \\
Nonbankrupt & 0 & 24 & 100.00 \\
& 0.00 & 100.00 & 90 \\
Total & 21 & 69 & 100.00 \\
\hline Priors & 23.33 & 76.67 & \\
& 0.5 & 0.5 & \\
\hline
\end{tabular}

\begin{tabular}{lrrr}
\hline \multicolumn{4}{c}{ Error Count Estimates for BANKRUPTCY } \\
\hline & Bankrupt & Nonbankrupt & Total \\
\hline Rate & 0.6818 & 0.0000 & 0.3409 \\
Priors & 0.5000 & 0.5000 & \\
\hline
\end{tabular}


YEAR 5

\begin{tabular}{lrr}
\hline Observations & 45 DF Total & 44 \\
Variables & 6 DF Within Classes & 43 \\
Classes & 2 DF Between Classes & 1 \\
\hline
\end{tabular}

\begin{tabular}{|c|c|c|c|c|c|}
\hline \multicolumn{6}{|c|}{ Class Level Information } \\
\hline BANKRUPTCY & $\begin{array}{l}\text { Variable } \\
\text { Name }\end{array}$ & Frequency & Weight & Proportion & $\begin{array}{r}\text { Prior } \\
\text { Probability }\end{array}$ \\
\hline Bankrupt & Bankrupt & 29 & 29.0000 & 0.644444 & 0.500000 \\
\hline Nonbankrupt & Nonbankrupt & 16 & 16.0000 & 0.355556 & 0.500000 \\
\hline
\end{tabular}

\begin{tabular}{lrr}
\hline \multicolumn{3}{c}{ Within Covariance Matrix Information } \\
\hline BANKRUPTCY & $\begin{array}{r}\text { Covariance } \\
\text { Matrix Rank }\end{array}$ & $\begin{array}{r}\text { Natural Log of the } \\
\text { Determinant of the } \\
\text { Covariance Matrix }\end{array}$ \\
Bankrupt & 6 & 4.66785 \\
Nonbankrupt & 6 & -10.97919 \\
\hline
\end{tabular}

\begin{tabular}{lrr}
\hline \multicolumn{2}{l}{ Generalized Squared Distance to BANKRUPTCY } \\
\hline From & Bankrupt & Nonbankrupt \\
BANKRUPTCY & 4.66785 & 13174 \\
\hline Bankrupt & 5.37322 & -10.97919 \\
\hline
\end{tabular}




\section{CLASSIFICATION SUMMARY}

Number of Observations and Percent Classified into BANKRUPTCY

\begin{tabular}{lrrr}
\hline From & & & \\
BANKRUPTCY & Bankrupt & Nonbankrupt & Total \\
\hline Bankrupt & 12 & 17 & 29 \\
& 41.38 & 58.62 & 100.00 \\
Nonbankrupt & 0 & 16 & 16 \\
& 0.00 & 100.00 & 100.00 \\
\hline Total & 12 & 33 & 45 \\
& 26.67 & 73.33 & 100.00 \\
\hline Priors & 0.5 & 0.5 & \\
\hline
\end{tabular}

\begin{tabular}{lrrr}
\multicolumn{4}{c}{ Error Count Estimates for BANKRUPTCY } \\
\hline & Bankrupt & Nonbankrupt & Total \\
\hline Rate & 0.5862 & 0.0000 & 0.2931 \\
Priors & 0.5000 & 0.5000 & \\
\hline
\end{tabular}


Table 9

Results of Non-parametric Discriminant Analysis : Accounting variables

YEAR 1

\begin{tabular}{lrlr}
\hline Observations & 101 DF Total & 100 \\
Variables & 17 DF Within Classes & 99 \\
Classes & 2 DF Between Classes & 1 \\
\hline
\end{tabular}

\begin{tabular}{llrrrr}
\hline \multicolumn{5}{c}{ Class Level Information } \\
\hline BANKRUPTCY & $\begin{array}{l}\text { Variable } \\
\text { Name }\end{array}$ & Frequency & Weight & Proportion & $\begin{array}{c}\text { Prior } \\
\text { Probability }\end{array}$ \\
\hline Bankrupt & Bankrupt & 6 & 6.0000 & 0.059406 & 0.500000 \\
Nonbankrupt & Nonbankrupt & 95 & 95.0000 & 0.940594 & 0.500000 \\
\hline
\end{tabular}

\section{CLASSIFICATION SUMMARY}

\begin{tabular}{lrrr}
\hline \multicolumn{4}{c}{ Number of Observations and Percent Classified into } \\
BANKRUPTCY \\
\hline From & Bankrupt & Nonbankrupt & Total \\
BANKRUPTCY & 6 & 0 & 6 \\
\hline Bankrupt & 100.00 & 0.00 & 100.00 \\
& 4 & 91 & 95 \\
Nonbankrupt & 4.21 & 95.79 & 100.00 \\
\hline Total & 10 & 91 & 101 \\
& 9.90 & 90.10 & 100.00 \\
\hline Priors & 0.5 & 0.5 & \\
\hline
\end{tabular}

\begin{tabular}{lrrr}
\hline \multicolumn{4}{c}{ Error Count Estimates for BANKRUPTCY } \\
\hline & Bankrupt & Nonbankrupt & Total \\
\hline Rate & 0.0000 & 0.0421 & 0.0211 \\
Priors & 0.5000 & 0.5000 & \\
\hline
\end{tabular}


YEAR 2

\begin{tabular}{lrlr}
\hline Observations & 99 & DF Total & 98 \\
Variables & 17 DF Within Classes & 97 \\
Classes & 2 & DF Between Classes & 1 \\
\hline
\end{tabular}

\begin{tabular}{|c|c|c|c|c|c|}
\hline \multicolumn{6}{|c|}{ Class Level Information } \\
\hline BANKRUPTCY & $\begin{array}{l}\text { Variable } \\
\text { Name }\end{array}$ & Frequency & Weight & Proportion & $\begin{array}{r}\text { Prior } \\
\text { Probability }\end{array}$ \\
\hline Bankrupt & Bankrupt & 6 & 6.0000 & 0.060606 & 0.500000 \\
\hline Nonbankrupt & Nonbankrupt & 93 & 93.0000 & 0.939394 & 0.500000 \\
\hline
\end{tabular}

\section{CLASSIFICATION SUMMARY}

\begin{tabular}{lrrr}
\hline \multicolumn{4}{c}{ Number of Observations and Percent Classified into } \\
\hline BANKRUPTCY \\
Brom & & & Total \\
\hline BankRUPTCY & Bankrupt & Nonbankrupt & 6 \\
& 6 & 0 & 100.00 \\
Nonbankrupt & 100.00 & 0.00 & 93 \\
& 12 & 81 & 100.00 \\
\hline Total & 12.90 & 87.10 & 99 \\
& 18 & 81 & 100.00 \\
\hline Priors & 18.18 & 81.82 & \\
& 0.5 & 0.5 & \\
\hline
\end{tabular}

\begin{tabular}{lrrr}
\hline \multicolumn{3}{c}{ Error Count Estimates for BANKRUPTCY } \\
& Bankrupt & Nonbankrupt & Total \\
Rate & 0.0000 & 0.1290 & 0.0645 \\
Priors & 0.5000 & 0.5000 & \\
\hline
\end{tabular}


YEAR 3

\begin{tabular}{lrlr}
\hline Observations & 88 & DF Total & 87 \\
Variables & 17 & DF Within Classes & 86 \\
Classes & 2 & DF Between Classes & 1 \\
\hline
\end{tabular}

\begin{tabular}{|c|c|c|c|c|c|}
\hline \multicolumn{6}{|c|}{ Class Level Information } \\
\hline BANKRUPTCY & $\begin{array}{l}\text { Variable } \\
\text { Name }\end{array}$ & Frequency & Weight & Proportion & $\begin{array}{r}\text { Prior } \\
\text { Probability }\end{array}$ \\
\hline Bankrupt & Bankrupt & 2 & 2.0000 & 0.022727 & 0.500000 \\
\hline Nonbankrupt & Nonbankrupt & 86 & 86.0000 & 0.977273 & 0.500000 \\
\hline
\end{tabular}

\section{CLASSIFICATION SUMMARY}

\begin{tabular}{lrrr}
\hline \multicolumn{2}{c}{ Number of Observations and Percent Classified into BANKRUPTCY } \\
\hline From & & & Total \\
BANKRUPTCY & Bankrupt & Nonbankrupt & 2 \\
\hline Bankrupt & 2 & 0 & 100.00 \\
& 100.00 & 0.00 & 86 \\
Nonbankrupt & 5 & 81 & 100.00 \\
\hline Total & 5.81 & 94.19 & 88 \\
& 7 & 81 & 100.00 \\
\hline Priors & 7.95 & 92.05 & \\
& 0.5 & 0.5 & \\
\hline
\end{tabular}

\begin{tabular}{lrrr}
\multicolumn{4}{c}{ Error Count Estimates for BANKRUPTCY } \\
& Bankrupt & Nonbankrupt & Total \\
Rate & 0.0000 & 0.0581 & 0.0291 \\
Priors & 0.5000 & 0.5000 & \\
\hline
\end{tabular}


Results of Non-parametric Discriminant Analysis : Market variables

YEAR 1

\begin{tabular}{lrlr}
\hline Observations & 249 DF Total & 248 \\
Variables & 5 DF Within Classes & 247 \\
Classes & 2 DF Between Classes & 1 \\
\hline
\end{tabular}

Class Level Information

\begin{tabular}{llrrrr}
\hline & Variable & Frequency & Weight & Proportion & $\begin{array}{r}\text { Prior } \\
\text { Probability }\end{array}$ \\
\hline BANKRUPTCY & Name & 133 & 133.0000 & 0.534137 & 0.500000 \\
Nonbankrupt & Bankrupt & 116 & 116.0000 & 0.465863 & 0.500000 \\
\hline
\end{tabular}

\section{CLASSIFICATION SUMMARY}

\begin{tabular}{lrrr}
\hline \multicolumn{4}{c}{ Number of Observations and Percent Classified into BANKRUPTCY } \\
\hline From & & & \\
BANKRUPTCY & Bankrupt & Nonbankrupt & Total \\
\hline Bankrupt & 117 & 16 & 133 \\
& 87.97 & 12.03 & 100.00 \\
Nonbankrupt & 17 & 99 & 116 \\
& 14.66 & 85.34 & 100.00 \\
\hline Total & 134 & 115 & 249 \\
& 53.82 & 46.18 & 100.00 \\
\hline Priors & 0.5 & 0.5 & \\
\hline
\end{tabular}

\begin{tabular}{lrrr}
\hline \multicolumn{3}{c}{ Error Count Estimates for BANKRUPTCY } \\
\hline & Bankrupt & Nonbankrupt & Total \\
\hline Rate & 0.1203 & 0.1466 & 0.1334 \\
Priors & 0.5000 & 0.5000 & \\
\hline
\end{tabular}


YEAR 2

\begin{tabular}{lrlr}
\hline Observations & 240 DF Total & 239 \\
Variables & 5 DF Within Classes & 238 \\
Classes & 2 DF Between Classes & 1 \\
\hline
\end{tabular}

\begin{tabular}{|c|c|c|c|c|c|}
\hline \multicolumn{6}{|c|}{ Class Level Information } \\
\hline BANKRUPTCY & $\begin{array}{l}\text { Variable } \\
\text { Name }\end{array}$ & Frequency & Weight & Proportion & $\begin{array}{r}\text { Prior } \\
\text { Probability }\end{array}$ \\
\hline Bankrupt & Bankrupt & 128 & 128.0000 & 0.533333 & 0.500000 \\
\hline Nonbankrupt & Nonbankrupt & 112 & 112.0000 & 0.466667 & 0.500000 \\
\hline
\end{tabular}

\section{CLASSIFICATION SUMMARY}

Number of Observations and Percent Classified into BANKRUPTCY

\begin{tabular}{lrrr}
\hline From & & & \\
BANKRUPTCY & Bankrupt & Nonbankrupt & Total \\
\hline Bankrupt & 108 & 20 & 128 \\
& 84.38 & 15.63 & 100.00 \\
Nonbankrupt & 17 & 95 & 112 \\
& 15.18 & 84.82 & 100.00 \\
\hline Total & 125 & 115 & 240 \\
& 52.08 & 47.92 & 100.00 \\
\hline Priors & 0.5 & 0.5 & \\
& & & \\
\hline
\end{tabular}

\begin{tabular}{lrrr}
\hline \multicolumn{3}{c}{ Error Count Estimates for BANKRUPTCY } \\
\hline & Bankrupt & Nonbankrupt & Total \\
\hline Rate & 0.1563 & 0.1518 & 0.1540 \\
Priors & 0.5000 & 0.5000 & \\
\hline
\end{tabular}


YEAR 3

\begin{tabular}{lrlr}
\hline Observations & 218 DF Total & 217 \\
Variables & 5 DF Within Classes & 216 \\
Classes & 2 DF Between Classes & 1 \\
\hline
\end{tabular}

\begin{tabular}{|c|c|c|c|c|c|}
\hline \multicolumn{6}{|c|}{ Class Level Information } \\
\hline BANKRUPTCY & $\begin{array}{l}\text { Variable } \\
\text { Name }\end{array}$ & Frequency & Weight & Proportion & $\begin{array}{r}\text { Prior } \\
\text { Probability }\end{array}$ \\
\hline Bankrupt & Bankrupt & 107 & 107.0000 & 0.490826 & 0.500000 \\
\hline Nonbankrupt & Nonbankrupt & 111 & 111.0000 & 0.509174 & 0.500000 \\
\hline
\end{tabular}

\section{CLASSIFICATION SUMMARY}

Number of Observations and Percent Classified into BANKRUPTCY

\begin{tabular}{lrrr}
\hline From & & & \\
BANKRUPTCY & Bankrupt & Nonbankrupt & Total \\
\hline Bankrupt & 88 & 19 & 107 \\
& 82.24 & 17.76 & 100.00 \\
Nonbankrupt & 23 & 88 & 111 \\
& 20.72 & 79.28 & 100.00 \\
\hline Total & 111 & 107 & 218 \\
& 50.92 & 49.08 & 100.00 \\
\hline Priors & 0.5 & 0.5 & \\
& & & \\
\hline
\end{tabular}

\begin{tabular}{lrrr}
\hline \multicolumn{3}{c}{ Error Count Estimates for BANKRUPTCY } \\
\hline & Bankrupt & Nonbankrupt & Total \\
\hline Rate & 0.1776 & 0.2072 & 0.1924 \\
Priors & 0.5000 & 0.5000 & \\
\hline
\end{tabular}


YEAR 4

\begin{tabular}{lrr}
\hline Observations & 194 DF Total & 193 \\
Variables & 5 DF Within Classes & 192 \\
Classes & 2 DF Between Classes & 1 \\
\hline
\end{tabular}

\begin{tabular}{|c|c|c|c|c|c|}
\hline \multicolumn{6}{|c|}{ Class Level Information } \\
\hline BANKRUPTCY & $\begin{array}{l}\text { Variable } \\
\text { Name }\end{array}$ & Frequency & Weight & Proportion & $\begin{array}{r}\text { Prior } \\
\text { Probability }\end{array}$ \\
\hline Bankrupt & Bankrupt & 84 & 84.0000 & 0.432990 & 0.500000 \\
\hline Nonbankrupt & Nonbankrupt & 110 & 110.0000 & 0.567010 & 0.500000 \\
\hline
\end{tabular}

\section{CLASSIFICATION SUMMARY}

Number of Observations and Percent Classified into BANKRUPTCY

\begin{tabular}{lrrr}
\hline From & & & \\
BANKRUPTCY & Bankrupt & Nonbankrupt & Total \\
\hline Bankrupt & 70 & 14 & 84 \\
& 83.33 & 16.67 & 100.00 \\
Nonbankrupt & 14 & 96 & 110 \\
& 12.73 & 87.27 & 100.00 \\
\hline Total & 84 & 110 & 194 \\
& 43.30 & 56.70 & 100.00 \\
\hline Priors & 0.5 & 0.5 & \\
& & &
\end{tabular}

\begin{tabular}{lrrr}
\hline \multicolumn{3}{c}{ Error Count Estimates for BANKRUPTCY } \\
\hline & Bankrupt & Nonbankrupt & Total \\
\hline Rate & 0.1667 & 0.1273 & 0.1470 \\
Priors & 0.5000 & 0.5000 & \\
\hline
\end{tabular}


YEAR 5

\begin{tabular}{lrlr}
\hline Observations & 161 DF Total & 160 \\
Variables & 5 DF Within Classes & 159 \\
Classes & 2 DF Between Classes & 1 \\
\hline
\end{tabular}

\begin{tabular}{|c|c|c|c|c|c|}
\hline \multicolumn{6}{|c|}{ Class Level Information } \\
\hline BANKRUPTCY & $\begin{array}{l}\text { Variable } \\
\text { Name }\end{array}$ & Frequency & Weight & Proportion & $\begin{array}{r}\text { Prior } \\
\text { Probability }\end{array}$ \\
\hline Bankrupt & Bankrupt & 64 & 64.0000 & 0.397516 & 0.500000 \\
\hline Nonbankrupt & Nonbankrupt & 97 & 97.0000 & 0.602484 & 0.500000 \\
\hline
\end{tabular}

\section{CLASSIFICATION SUMMARY}

Number of Observations and Percent Classified into BANKRUPTCY

\begin{tabular}{lrrr}
\hline From & & & \\
BANKRUPTCY & Bankrupt & Nonbankrupt & Total \\
\hline Bankrupt & 48 & 16 & 64 \\
& 75.00 & 25.00 & 100.00 \\
Nonbankrupt & 3 & 94 & 97 \\
& 3.09 & 96.91 & 100.00 \\
\hline Total & 51 & 110 & 161 \\
& 31.68 & 68.32 & 100.00 \\
\hline Priors & 0.5 & 0.5 & \\
& & & \\
\hline
\end{tabular}

\begin{tabular}{lrrr}
\hline \multicolumn{3}{c}{ Error Count Estimates for BANKRUPTCY } \\
\hline & Bankrupt & Nonbankrupt & Total \\
\hline Rate & 0.2500 & 0.0309 & 0.1405 \\
Priors & 0.5000 & 0.5000 & \\
\hline
\end{tabular}


Results of Non-parametric Discriminant Analysis : Market variables without spread and hi lo bid ask spread

YEAR 1

\begin{tabular}{lrlr}
\hline Observations & 249 DF Total & 248 \\
Variables & 4 DF Within Classes & 247 \\
Classes & 2 DF Between Classes & 1 \\
\hline
\end{tabular}

\begin{tabular}{|c|c|c|c|c|c|}
\hline \multicolumn{6}{|c|}{ Class Level Information } \\
\hline BANKRUPTCY & $\begin{array}{l}\text { Variable } \\
\text { Name }\end{array}$ & Frequency & Weight & Proportion & $\begin{array}{r}\text { Prior } \\
\text { Probability }\end{array}$ \\
\hline Bankrupt & Bankrupt & 133 & 133.0000 & 0.534137 & 0.500000 \\
\hline Nonbankrupt & Nonbankrupt & 116 & 116.0000 & 0.465863 & 0.500000 \\
\hline
\end{tabular}

\section{CLASSIFICATION SUMMARY}

\begin{tabular}{lrrr}
\hline \multicolumn{3}{c}{ Number of Observations and Percent Classified into BANKRUPTCY } \\
\hline From & & & \\
BANKRUPTCY & Bankrupt & Nonbankrupt & Total \\
\hline Bankrupt & 114 & 19 & 133 \\
& 85.71 & 14.29 & 100.00 \\
Nonbankrupt & 20 & 96 & 116 \\
& 17.24 & 82.76 & 100.00 \\
\hline Total & 134 & 115 & 249 \\
& 53.82 & 46.18 & 100.00 \\
\hline Priors & 0.5 & 0.5 & \\
& & & \\
\hline
\end{tabular}

\begin{tabular}{lrrr}
\hline \multicolumn{3}{c}{ Error Count Estimates for BANKRUPTCY } \\
\hline & Bankrupt & Nonbankrupt & Total \\
\hline Rate & 0.1429 & 0.1724 & 0.1576 \\
Priors & 0.5000 & 0.5000 & \\
\hline
\end{tabular}


YEAR 2

\begin{tabular}{lrr}
\hline Observations & 240 DF Total & 239 \\
Variables & 4 DF Within Classes & 238 \\
Classes & 2 DF Between Classes & 1 \\
\hline
\end{tabular}

\begin{tabular}{|c|c|c|c|c|c|}
\hline \multicolumn{6}{|c|}{ Class Level Information } \\
\hline BANKRUPTCY & $\begin{array}{l}\text { Variable } \\
\text { Name }\end{array}$ & Frequency & Weight & Proportion & $\begin{array}{r}\text { Prior } \\
\text { Probability }\end{array}$ \\
\hline Bankrupt & Bankrupt & 128 & 128.0000 & 0.533333 & 0.500000 \\
\hline Nonbankrupt & Nonbankrupt & 112 & 112.0000 & 0.466667 & 0.500000 \\
\hline
\end{tabular}

\section{CLASSIFICATION SUMMARY}

Number of Observations and Percent Classified into BANKRUPTCY

\begin{tabular}{lrrr}
\hline From & & & \\
BANKRUPTCY & Bankrupt & Nonbankrupt & Total \\
\hline Bankrupt & 108 & 20 & 128 \\
& 84.38 & 15.63 & 100.00 \\
Nonbankrupt & 17 & 95 & 112 \\
& 15.18 & 84.82 & 100.00 \\
\hline Total & 125 & 115 & 240 \\
& 52.08 & 47.92 & 100.00 \\
\hline Priors & 0.5 & 0.5 & \\
& & & \\
\hline
\end{tabular}

\begin{tabular}{lrrr}
\hline \multicolumn{3}{c}{ Error Count Estimates for BANKRUPTCY } \\
\hline & Bankrupt & Nonbankrupt & Total \\
\hline Rate & 0.1563 & 0.1518 & 0.1540 \\
Priors & 0.5000 & 0.5000 & \\
\hline
\end{tabular}


YEAR 3

\begin{tabular}{lrlr}
\hline Observations & 218 DF Total & 217 \\
Variables & 4 DF Within Classes & 216 \\
Classes & 2 DF Between Classes & 1 \\
\hline
\end{tabular}

\begin{tabular}{|c|c|c|c|c|c|}
\hline \multicolumn{6}{|c|}{ Class Level Information } \\
\hline BANKRUPTCY & $\begin{array}{l}\text { Variable } \\
\text { Name }\end{array}$ & Frequency & Weight & Proportion & $\begin{array}{r}\text { Prior } \\
\text { Probability }\end{array}$ \\
\hline Bankrupt & Bankrupt & 107 & 107.0000 & 0.490826 & 0.500000 \\
\hline Nonbankrupt & Nonbankrupt & 111 & 111.0000 & 0.509174 & 0.500000 \\
\hline
\end{tabular}

\section{CLASSIFICATION SUMMARY}

Number of Observations and Percent Classified into BANKRUPTCY

\begin{tabular}{lrrr}
\hline From & & & \\
BANKRUPTCY & Bankrupt & Nonbankrupt & Total \\
\hline Bankrupt & 85 & 22 & 107 \\
& 79.44 & 20.56 & 100.00 \\
Nonbankrupt & 16 & 95 & 111 \\
& 14.41 & 85.59 & 100.00 \\
\hline Total & 101 & 117 & 218 \\
& 46.33 & 53.67 & 100.00 \\
\hline Priors & 0.5 & 0.5 & \\
& & & \\
\hline
\end{tabular}

\begin{tabular}{lrrr}
\hline \multicolumn{3}{c}{ Error Count Estimates for BANKRUPTCY } \\
\hline & Bankrupt & Nonbankrupt & Total \\
\hline Rate & 0.2056 & 0.1441 & 0.1749 \\
Priors & 0.5000 & 0.5000 & \\
\hline
\end{tabular}


YEAR 4

\begin{tabular}{lrr}
\hline Observations & 194 DF Total & 193 \\
Variables & 4 DF Within Classes & 192 \\
Classes & 2 DF Between Classes & 1 \\
\hline
\end{tabular}

\begin{tabular}{|c|c|c|c|c|c|}
\hline \multicolumn{6}{|c|}{ Class Level Information } \\
\hline BANKRUPTCY & $\begin{array}{l}\text { Variable } \\
\text { Name }\end{array}$ & Frequency & Weight & Proportion & $\begin{array}{r}\text { Prior } \\
\text { Probability }\end{array}$ \\
\hline Bankrupt & Bankrupt & 84 & 84.0000 & 0.432990 & 0.500000 \\
\hline Nonbankrupt & Nonbankrupt & 110 & 110.0000 & 0.567010 & 0.500000 \\
\hline
\end{tabular}

\section{CLASSIFICATION SUMMARY}

Number of Observations and Percent Classified into BANKRUPTCY

\begin{tabular}{lrrr}
\hline From & & & \\
BANKRUPTCY & Bankrupt & Nonbankrupt & Total \\
\hline Bankrupt & 70 & 14 & 84 \\
& 83.33 & 16.67 & 100.00 \\
Nonbankrupt & 14 & 96 & 110 \\
& 12.73 & 87.27 & 100.00 \\
\hline Total & 84 & 110 & 194 \\
& 43.30 & 56.70 & 100.00 \\
\hline Priors & 0.5 & 0.5 & \\
& & &
\end{tabular}

\begin{tabular}{lrrr}
\hline \multicolumn{3}{c}{ Error Count Estimates for BANKRUPTCY } \\
\hline & Bankrupt & Nonbankrupt & Total \\
\hline Rate & 0.1667 & 0.1273 & 0.1470 \\
Priors & 0.5000 & 0.5000 & \\
\hline
\end{tabular}


YEAR 5

\begin{tabular}{lrlr}
\hline Observations & 161 & DF Total & 160 \\
Variables & 4 DF Within Classes & 159 \\
Classes & 2 DF Between Classes & 1 \\
\hline
\end{tabular}

\begin{tabular}{|c|c|c|c|c|c|}
\hline \multicolumn{6}{|c|}{ Class Level Information } \\
\hline BANKRUPTCY & $\begin{array}{l}\text { Variable } \\
\text { Name }\end{array}$ & Frequency & Weight & Proportion & $\begin{array}{r}\text { Prior } \\
\text { Probability }\end{array}$ \\
\hline Bankrupt & Bankrupt & 64 & 64.0000 & 0.397516 & 0.500000 \\
\hline Nonbankrupt & Nonbankrupt & 97 & 97.0000 & 0.602484 & 0.500000 \\
\hline
\end{tabular}

\section{CLASSIFICATION SUMMARY}

Number of Observations and Percent Classified into BANKRUPTCY

\begin{tabular}{lrrr}
\hline From & & & \\
BANKRUPTCY & Bankrupt & Nonbankrupt & Total \\
\hline Bankrupt & 46 & 18 & 64 \\
& 71.88 & 28.13 & 100.00 \\
Nonbankrupt & 6 & 91 & 97 \\
& 6.19 & 93.81 & 100.00 \\
\hline Total & 52 & 109 & 161 \\
& 32.30 & 67.70 & 100.00 \\
\hline Priors & 0.5 & 0.5 & \\
& & & \\
\hline
\end{tabular}

\begin{tabular}{lrrr}
\hline \multicolumn{3}{c}{ Error Count Estimates for BANKRUPTCY } \\
\hline & Bankrupt & Nonbankrupt & Total \\
\hline Rate & 0.2813 & 0.0619 & 0.1716 \\
Priors & 0.5000 & 0.5000 & \\
\hline
\end{tabular}


Results of Non-parametric Discriminant Analysis : Market variables without spread and bid ask spread

YEAR 1

\begin{tabular}{lrlr}
\hline Observations & 252 DF Total & 251 \\
Variables & 4 DF Within Classes & 250 \\
Classes & 2 DF Between Classes & 1 \\
\hline
\end{tabular}

\begin{tabular}{|c|c|c|c|c|c|}
\hline \multicolumn{6}{|c|}{ Class Level Information } \\
\hline BANKRUPTCY & $\begin{array}{l}\text { Variable } \\
\text { Name }\end{array}$ & Frequency & Weight & Proportion & $\begin{array}{r}\text { Prior } \\
\text { Probability }\end{array}$ \\
\hline Bankrupt & Bankrupt & 136 & 136.0000 & 0.539683 & 0.500000 \\
\hline Nonbankrupt & Nonbankrupt & 116 & 116.0000 & 0.460317 & 0.500000 \\
\hline
\end{tabular}

\section{CLASSIFICATION SUMMARY}

\begin{tabular}{lrrr}
\hline \multicolumn{2}{c}{ Number of Observations and Percent Classified into BANKRUPTCY } \\
\hline From & & & \\
BANKRUPTCY & Bankrupt & Nonbankrupt & Total \\
\hline Bankrupt & 117 & 19 & 136 \\
& 86.03 & 13.97 & 100.00 \\
Nonbankrupt & 24 & 92 & 116 \\
& 20.69 & 79.31 & 100.00 \\
\hline Total & 141 & 111 & 252 \\
& 55.95 & 44.05 & 100.00 \\
\hline Priors & 0.5 & 0.5 & \\
\end{tabular}

\begin{tabular}{lrrr}
\hline \multicolumn{3}{c}{ Error Count Estimates for BANKRUPTCY } \\
\hline & Bankrupt & Nonbankrupt & Total \\
\hline Rate & 0.1397 & 0.2069 & 0.1733 \\
Priors & 0.5000 & 0.5000 & \\
\hline
\end{tabular}


YEAR 2

\begin{tabular}{lrlr}
\hline Observations & 241 & DF Total & 240 \\
Variables & 4 DF Within Classes & 239 \\
Classes & 2 DF Between Classes & 1 \\
\hline
\end{tabular}

\begin{tabular}{|c|c|c|c|c|c|}
\hline \multicolumn{6}{|c|}{ Class Level Information } \\
\hline BANKRUPTCY & $\begin{array}{l}\text { Variable } \\
\text { Name }\end{array}$ & Frequency & Weight & Proportion & $\begin{array}{r}\text { Prior } \\
\text { Probability }\end{array}$ \\
\hline Bankrupt & Bankrupt & 129 & 129.0000 & 0.535270 & 0.500000 \\
\hline Nonbankrupt & Nonbankrupt & 112 & 112.0000 & 0.464730 & 0.500000 \\
\hline
\end{tabular}

\section{CLASSIFICATION SUMMARY}

\begin{tabular}{lrrr}
\hline \multicolumn{4}{c}{ Number of Observations and Percent Classified into BANKRUPTCY } \\
\hline From & & & \\
BANKRUPTCY & Bankrupt & Nonbankrupt & Total \\
\hline Bankrupt & 106 & 23 & 129 \\
& 82.17 & 17.83 & 100.00 \\
Nonbankrupt & 40 & 72 & 112 \\
& 35.71 & 64.29 & 100.00 \\
\hline Total & 146 & 95 & 241 \\
& 60.58 & 39.42 & 100.00 \\
\hline Priors & 0.5 & 0.5 & \\
\hline
\end{tabular}

\begin{tabular}{lrrr}
\hline \multicolumn{3}{c}{ Error Count Estimates for BANKRUPTCY } \\
\hline & Bankrupt & Nonbankrupt & Total \\
\hline Rate & 0.1783 & 0.3571 & 0.2677 \\
Priors & 0.5000 & 0.5000 & \\
\hline
\end{tabular}


YEAR 3

\begin{tabular}{lrr}
\hline Observations & 219 DF Total & 218 \\
Variables & 4 DF Within Classes & 217 \\
Classes & 2 DF Between Classes & 1 \\
\hline
\end{tabular}

\begin{tabular}{|c|c|c|c|c|c|}
\hline \multicolumn{6}{|c|}{ Class Level Information } \\
\hline BANKRUPTCY & $\begin{array}{l}\text { Variable } \\
\text { Name }\end{array}$ & Frequency & Weight & Proportion & $\begin{array}{r}\text { Prior } \\
\text { Probability }\end{array}$ \\
\hline Bankrupt & Bankrupt & 108 & 108.0000 & 0.493151 & 0.500000 \\
\hline Nonbankrupt & Nonbankrupt & 111 & 111.0000 & 0.506849 & 0.500000 \\
\hline
\end{tabular}

\section{CLASSIFICATION SUMMARY}

\begin{tabular}{lrrr}
\hline \multicolumn{2}{c}{ Number of Observations and Percent Classified into BANKRUPTCY } \\
\hline From & & & Total \\
BANKRUPTCY & Bankrupt & Nonbankrupt & 108 \\
\hline Bankrupt & 87 & 21 & 100.00 \\
& 80.56 & 19.44 & 111 \\
Nonbankrupt & 26 & 85 & 100.00 \\
& 23.42 & 76.58 & 219 \\
\hline Total & 113 & 106 & 100.00 \\
\hline Priors & 51.60 & 48.40 & \\
& 0.5 & 0.5 & \\
\hline
\end{tabular}

\begin{tabular}{lrrr}
\hline \multicolumn{3}{c}{ Error Count Estimates for BANKRUPTCY } \\
\hline & Bankrupt & Nonbankrupt & Total \\
\hline Rate & 0.1944 & 0.2342 & 0.2143 \\
Priors & 0.5000 & 0.5000 & \\
\hline
\end{tabular}


YEAR 4

\begin{tabular}{lrr}
\hline Observations & 195 DF Total & 194 \\
Variables & 4 DF Within Classes & 193 \\
Classes & 2 DF Between Classes & 1 \\
\hline
\end{tabular}

\begin{tabular}{|c|c|c|c|c|c|}
\hline \multicolumn{6}{|c|}{ Class Level Information } \\
\hline BANKRUPTCY & $\begin{array}{l}\text { Variable } \\
\text { Name }\end{array}$ & Frequency & Weight & Proportion & $\begin{array}{r}\text { Prior } \\
\text { Probability }\end{array}$ \\
\hline Bankrupt & Bankrupt & 85 & 85.0000 & 0.435897 & 0.500000 \\
\hline Nonbankrupt & Nonbankrupt & 110 & 110.0000 & 0.564103 & 0.500000 \\
\hline
\end{tabular}

\section{CLASSIFICATION SUMMARY}

\begin{tabular}{lrrr}
\hline \multicolumn{2}{c}{ Number of Observations and Percent Classified into BANKRUPTCY } \\
\hline From & & & Total \\
BANKRUPTCY & Bankrupt & Nonbankrupt & 85 \\
\hline Bankrupt & 66 & 19 & 100.00 \\
& 77.65 & 22.35 & 110 \\
Nonbankrupt & 21 & 89 & 100.00 \\
\hline Total & 19.09 & 80.91 & 195 \\
& 87 & 108 & 100.00 \\
\hline Priors & 44.62 & 55.38 & \\
& 0.5 & 0.5 & \\
\hline
\end{tabular}

\begin{tabular}{lrrr}
\hline \multicolumn{3}{c}{ Error Count Estimates for BANKRUPTCY } \\
\hline & Bankrupt & Nonbankrupt & Total \\
\hline Rate & 0.2235 & 0.1909 & 0.2072 \\
Priors & 0.5000 & 0.5000 & \\
\hline
\end{tabular}


YEAR 5

\begin{tabular}{lrr}
\hline Observations & 168 DF Total & 167 \\
Variables & 4 DF Within Classes & 166 \\
Classes & 2 DF Between Classes & 1 \\
\hline
\end{tabular}

\begin{tabular}{|c|c|c|c|c|c|}
\hline \multicolumn{6}{|c|}{ Class Level Information } \\
\hline BANKRUPTCY & $\begin{array}{l}\text { Variable } \\
\text { Name }\end{array}$ & Frequency & Weight & Proportion & $\begin{array}{r}\text { Prior } \\
\text { Probability }\end{array}$ \\
\hline Bankrupt & Bankrupt & 70 & 70.0000 & 0.416667 & 0.500000 \\
\hline Nonbankrupt & Nonbankrupt & 98 & 98.0000 & 0.583333 & 0.500000 \\
\hline
\end{tabular}

\section{CLASSIFICATION SUMMARY}

\begin{tabular}{lrrr}
\hline \multicolumn{2}{c}{ Number of Observations and Percent Classified into BANKRUPTCY } \\
\hline From & & & \\
BANKRUPTCY & Bankrupt & Nonbankrupt & Total \\
\hline Bankrupt & 47 & 23 & 70 \\
& 67.14 & 32.86 & 100.00 \\
Nonbankrupt & 11 & 87 & 98 \\
& 11.22 & 88.78 & 100.00 \\
\hline Total & 58 & 110 & 168 \\
& 34.52 & 65.48 & 100.00 \\
\hline Priors & 0.5 & 0.5 & \\
& & &
\end{tabular}

\begin{tabular}{lrrr}
\hline \multicolumn{3}{c}{ Error Count Estimates for BANKRUPTCY } \\
\hline & Bankrupt & Nonbankrupt & Total \\
\hline Rate & 0.3286 & 0.1122 & 0.2204 \\
Priors & 0.5000 & 0.5000 & \\
\hline
\end{tabular}


Results of Non-parametric Discriminant Analysis : Market variables without bid ask spread and hi lo bid ask spread

YEAR 1

\begin{tabular}{lrr}
\hline Observations & 13 DF Total & 12 \\
Variables & 4 DF Within Classes & 11 \\
Classes & 2 DF Between Classes & 1 \\
\hline
\end{tabular}

\begin{tabular}{|c|c|c|c|c|c|}
\hline \multicolumn{6}{|c|}{ Class Level Information } \\
\hline BANKRUPTCY & $\begin{array}{l}\text { Variable } \\
\text { Name }\end{array}$ & Frequency & Weight & Proportion & $\begin{array}{r}\text { Prior } \\
\text { Probability }\end{array}$ \\
\hline Bankrupt & Bankrupt & 10 & 10.0000 & 0.769231 & 0.500000 \\
\hline Nonbankrupt & Nonbankrupt & 3 & 3.0000 & 0.230769 & 0.500000 \\
\hline
\end{tabular}

CLASSIFICATION SUMMARY

\begin{tabular}{lrrr}
\hline \multicolumn{3}{c}{ Number of Observations and Percent Classified into BANKRUPTCY } \\
\hline From & & & \\
BANKRUPTCY & Bankrupt & Nonbankrupt & Total \\
\hline Bankrupt & 8 & 2 & 10 \\
& 80.00 & 20.00 & 100.00 \\
Nonbankrupt & 0 & 3 & 3 \\
& 0.00 & 100.00 & 100.00 \\
\hline Total & 8 & 5 & 13 \\
& 61.54 & 38.46 & 100.00 \\
\hline Priors & 0.5 & 0.5 & \\
& & & \\
\hline
\end{tabular}

\begin{tabular}{lrrr}
\hline \multicolumn{3}{c}{ Error Count Estimates for BANKRUPTCY } \\
\hline & Bankrupt & Nonbankrupt & Total \\
\hline Rate & 0.2000 & 0.0000 & 0.1000 \\
Priors & 0.5000 & 0.5000 & \\
\hline
\end{tabular}


YEAR 2

\begin{tabular}{lrr}
\hline Observations & 12 DF Total & 11 \\
Variables & 4 DF Within Classes & 10 \\
Classes & 2 DF Between Classes & 1 \\
\hline
\end{tabular}

\begin{tabular}{|c|c|c|c|c|c|}
\hline \multicolumn{6}{|c|}{ Class Level Information } \\
\hline BANKRUPTCY & $\begin{array}{l}\text { Variable } \\
\text { Name }\end{array}$ & Frequency & Weight & Proportion & $\begin{array}{r}\text { Prior } \\
\text { Probability }\end{array}$ \\
\hline Bankrupt & Bankrupt & 6 & 6.0000 & 0.500000 & 0.500000 \\
\hline Nonbankrupt & Nonbankrupt & 6 & 6.0000 & 0.500000 & 0.500000 \\
\hline
\end{tabular}

\section{CLASSIFICATION SUMMARY}

Number of Observations and Percent Classified into BANKRUPTCY

\begin{tabular}{lrrr}
\hline From & & & \\
BANKRUPTCY & Bankrupt & Nonbankrupt & Total \\
\hline Bankrupt & 6 & 0 & 6 \\
& 100.00 & 0.00 & 100.00 \\
Nonbankrupt & 1 & 5 & 6 \\
& 16.67 & 83.33 & 100.00 \\
\hline Total & 7 & 5 & 12 \\
& 58.33 & 41.67 & 100.00 \\
\hline Priors & 0.5 & 0.5 & \\
& & &
\end{tabular}

\begin{tabular}{lrrr}
\hline \multicolumn{3}{c}{ Error Count Estimates for BANKRUPTCY } \\
\hline & Bankrupt & Nonbankrupt & Total \\
\hline Rate & 0.0000 & 0.1667 & 0.0833 \\
Priors & 0.5000 & 0.5000 & \\
\hline
\end{tabular}


YEAR 3

\begin{tabular}{lrll}
\hline Observations & 10 DF Total & 9 \\
Variables & 4 DF Within Classes & 8 \\
Classes & 2 DF Between Classes & 1 \\
\hline
\end{tabular}

\begin{tabular}{|c|c|c|c|c|c|}
\hline \multicolumn{6}{|c|}{ Class Level Information } \\
\hline BANKRUPTCY & $\begin{array}{l}\text { Variable } \\
\text { Name }\end{array}$ & Frequency & Weight & Proportion & $\begin{array}{r}\text { Prior } \\
\text { Probability }\end{array}$ \\
\hline Bankrupt & Bankrupt & 7 & 7.0000 & 0.700000 & 0.500000 \\
\hline Nonbankrupt & Nonbankrupt & 3 & 3.0000 & 0.300000 & 0.500000 \\
\hline
\end{tabular}

\section{CLASSIFICATION SUMMARY}

Number of Observations and Percent Classified into BANKRUPTCY

\begin{tabular}{lrrr}
\hline From & & & \\
BANKRUPTCY & Bankrupt & Nonbankrupt & Total \\
\hline Bankrupt & 6 & 1 & 7 \\
& 85.71 & 14.29 & 100.00 \\
Nonbankrupt & 0 & 3 & 3 \\
& 0.00 & 100.00 & 100.00 \\
\hline Total & 6 & 4 & 10 \\
& 60.00 & 40.00 & 100.00 \\
\hline Priors & 0.5 & 0.5 & \\
\hline
\end{tabular}

\begin{tabular}{lrrr}
\multicolumn{4}{c}{ Error Count Estimates for BANKRUPTCY } \\
\hline & Bankrupt & Nonbankrupt & Total \\
\hline Rate & 0.1429 & 0.0000 & 0.0714 \\
Priors & 0.5000 & 0.5000 & \\
\hline
\end{tabular}


YEAR 4

\begin{tabular}{lll}
\hline Observations & 8 DF Total & 7 \\
Variables & 4 DF Within Classes & 6 \\
Classes & 2 DF Between Classes & 1 \\
\hline
\end{tabular}

\begin{tabular}{|c|c|c|c|c|c|}
\hline \multicolumn{6}{|c|}{ Class Level Information } \\
\hline BANKRUPTCY & $\begin{array}{l}\text { Variable } \\
\text { Name }\end{array}$ & Frequency & Weight & Proportion & $\begin{array}{r}\text { Prior } \\
\text { Probability }\end{array}$ \\
\hline Bankrupt & Bankrupt & 7 & 7.0000 & 0.875000 & 0.500000 \\
\hline Nonbankrupt & Nonbankrupt & 1 & 1.0000 & 0.125000 & 0.500000 \\
\hline
\end{tabular}

\section{CLASSIFICATION SUMMARY}

Number of Observations and Percent Classified into BANKRUPTCY

\begin{tabular}{lrrr}
\hline From & & & \\
BANKRUPTCY & Bankrupt & Nonbankrupt & Total \\
\hline Bankrupt & 7 & 0 & 7 \\
& 100.00 & 0.00 & 100.00 \\
Nonbankrupt & 0 & 1 & 1 \\
& 0.00 & 100.00 & 100.00 \\
\hline Total & 7 & 1 & 8 \\
& 87.50 & 12.50 & 100.00 \\
\hline Priors & 0.5 & 0.5 & \\
\hline
\end{tabular}

\begin{tabular}{lrrr}
\multicolumn{4}{c}{ Error Count Estimates for BANKRUPTCY } \\
\hline & Bankrupt & Nonbankrupt & Total \\
\hline Rate & 0.0000 & 0.0000 & 0.0000 \\
Priors & 0.5000 & 0.5000 & \\
\hline
\end{tabular}


YEAR 5

\begin{tabular}{lrr}
\hline Observations & 12 DF Total & 11 \\
Variables & 4 DF Within Classes & 10 \\
Classes & 2 DF Between Classes & 1 \\
\hline
\end{tabular}

\begin{tabular}{|c|c|c|c|c|c|}
\hline \multicolumn{6}{|c|}{ Class Level Information } \\
\hline BANKRUPTCY & $\begin{array}{l}\text { Variable } \\
\text { Name }\end{array}$ & Frequency & Weight & Proportion & $\begin{array}{r}\text { Prior } \\
\text { Probability }\end{array}$ \\
\hline Bankrupt & Bankrupt & 9 & 9.0000 & 0.750000 & 0.500000 \\
\hline Nonbankrupt & Nonbankrupt & 3 & 3.0000 & 0.250000 & 0.500000 \\
\hline
\end{tabular}

\section{CLASSIFICATION SUMMARY}

Number of Observations and Percent Classified into BANKRUPTCY

\begin{tabular}{lrrr}
\hline From & & & \\
BANKRUPTCY & Bankrupt & Nonbankrupt & Total \\
\hline Bankrupt & 3 & 6 & 9 \\
& 33.33 & 66.67 & 100.00 \\
Nonbankrupt & 0 & 3 & 3 \\
& 0.00 & 100.00 & 100.00 \\
\hline Total & 3 & 9 & 12 \\
& 25.00 & 75.00 & 100.00 \\
\hline Priors & 0.5 & 0.5 & \\
& & & \\
\hline
\end{tabular}

\begin{tabular}{lrrr}
\hline \multicolumn{3}{c}{ Error Count Estimates for BANKRUPTCY } \\
\hline & Bankrupt & Nonbankrupt & Total \\
\hline Rate & 0.6667 & 0.0000 & 0.3333 \\
Priors & 0.5000 & 0.5000 & \\
\hline
\end{tabular}


Results of Non-parametric Discriminant Analysis : Top 3 Account and Market variables

YEAR 1

\begin{tabular}{lrr}
\hline Observations & 104 DF Total & 103 \\
Variables & 6 DF Within Classes & 102 \\
Classes & 2 DF Between Classes & 1 \\
\hline
\end{tabular}

\begin{tabular}{|c|c|c|c|c|c|}
\hline \multicolumn{6}{|c|}{ Class Level Information } \\
\hline BANKRUPTCY & $\begin{array}{l}\text { Variable } \\
\text { Name }\end{array}$ & Frequency & Weight & Proportion & $\begin{array}{r}\text { Prior } \\
\text { Probability }\end{array}$ \\
\hline Bankrupt & Bankrupt & 7 & 7.0000 & 0.067308 & 0.500000 \\
\hline Nonbankrupt & Nonbankrupt & 97 & 97.0000 & 0.932692 & 0.500000 \\
\hline
\end{tabular}

\section{CLASSIFICATION SUMMARY}

\begin{tabular}{lrrr}
\hline \multicolumn{2}{c}{ Number of Observations and Percent Classified into BANKRUPTCY } \\
\hline From & & & Total \\
BANKRUPTCY & Bankrupt & Nonbankrupt & 7 \\
\hline Bankrupt & 7 & 0 & 100.00 \\
& 100.00 & 0.00 & 97 \\
Nonbankrupt & 10 & 87 & 100.00 \\
& 10.31 & 89.69 & 104 \\
Total & 17 & 87 & 100.00 \\
\hline Priors & 16.35 & 83.65 & \\
& 0.5 & 0.5 & \\
\hline
\end{tabular}

\begin{tabular}{lrrr}
\hline \multicolumn{3}{c}{ Error Count Estimates for BANKRUPTCY } \\
\hline & Bankrupt & Nonbankrupt & Total \\
\hline Rate & 0.0000 & 0.1031 & 0.0515 \\
Priors & 0.5000 & 0.5000 & \\
\hline
\end{tabular}


YEAR 2

\begin{tabular}{lrr}
\hline Observations & 100 DF Total & 99 \\
Variables & 6 DF Within Classes & 98 \\
Classes & 2 DF Between Classes & 1 \\
\hline
\end{tabular}

\begin{tabular}{|c|c|c|c|c|c|}
\hline \multicolumn{6}{|c|}{ Class Level Information } \\
\hline BANKRUPTCY & $\begin{array}{l}\text { Variable } \\
\text { Name }\end{array}$ & Frequency & Weight & Proportion & $\begin{array}{r}\text { Prior } \\
\text { Probability }\end{array}$ \\
\hline Bankrupt & Bankrupt & 7 & 7.0000 & 0.070000 & 0.500000 \\
\hline Nonbankrupt & Nonbankrupt & 93 & 93.0000 & 0.930000 & 0.500000 \\
\hline
\end{tabular}

\section{CLASSIFICATION SUMMARY}

Number of Observations and Percent Classified into BANKRUPTCY

\begin{tabular}{lrrr}
\hline From & & & \\
BANKRUPTCY & Bankrupt & Nonbankrupt & Total \\
\hline Bankrupt & 7 & 0 & 7 \\
& 100.00 & 0.00 & 100.00 \\
Nonbankrupt & 8 & 85 & 93 \\
& 8.60 & 91.40 & 100.00 \\
\hline Total & 15 & 85 & 100 \\
& 15.00 & 85.00 & 100.00 \\
\hline Priors & 0.5 & 0.5 & \\
& & & \\
\hline
\end{tabular}

\begin{tabular}{lrrr}
\hline \multicolumn{3}{c}{ Error Count Estimates for BANKRUPTCY } \\
\hline & Bankrupt & Nonbankrupt & Total \\
\hline Rate & 0.0000 & 0.0860 & 0.0430 \\
Priors & 0.5000 & 0.5000 & \\
\hline
\end{tabular}


YEAR 3

\begin{tabular}{lrlr}
\hline Observations & 90 DF Total & 89 \\
Variables & 6 DF Within Classes & 88 \\
Classes & 2 & DF Between Classes & 1 \\
\hline
\end{tabular}

\begin{tabular}{|c|c|c|c|c|c|}
\hline \multicolumn{6}{|c|}{ Class Level Information } \\
\hline BANKRUPTCY & $\begin{array}{l}\text { Variable } \\
\text { Name }\end{array}$ & Frequency & Weight & Proportion & $\begin{array}{r}\text { Prior } \\
\text { Probability }\end{array}$ \\
\hline Bankrupt & Bankrupt & 3 & 3.0000 & 0.033333 & 0.500000 \\
\hline Nonbankrupt & Nonbankrupt & 87 & 87.0000 & 0.966667 & 0.500000 \\
\hline
\end{tabular}

\section{CLASSIFICATION SUMMARY}

\begin{tabular}{lrrr}
\hline \multicolumn{2}{c}{ Number of Observations and Percent Classified into BANKRUPTCY } \\
\hline From & & & Total \\
BANKRUPTCY & Bankrupt & Nonbankrupt & 3 \\
\hline Bankrupt & 3 & 0 & 100.00 \\
& 100.00 & 0.00 & 87 \\
Nonbankrupt & 8 & 79 & 100.00 \\
\hline Total & 9.20 & 90.80 & 90 \\
& 11 & 79 & 100.00 \\
\hline Priors & 12.22 & 87.78 & \\
& 0.5 & 0.5 & \\
\hline
\end{tabular}

\begin{tabular}{lrrr}
\hline \multicolumn{3}{c}{ Error Count Estimates for BANKRUPTCY } \\
\hline & Bankrupt & Nonbankrupt & Total \\
\hline Rate & 0.0000 & 0.0920 & 0.0460 \\
Priors & 0.5000 & 0.5000 & \\
\hline
\end{tabular}


Results of Non-parametric Discriminant Analysis : Top 3 Account and Market logarithmic variables YEAR 1

\begin{tabular}{lrlr}
\hline Observations & 82 & DF Total & 81 \\
Variables & 6 DF Within Classes & 80 \\
Classes & 2 & DF Between Classes & 1 \\
\hline
\end{tabular}

\begin{tabular}{|c|c|c|c|c|c|}
\hline \multicolumn{6}{|c|}{ Class Level Information } \\
\hline BANKRUPTCY & $\begin{array}{l}\text { Variable } \\
\text { Name }\end{array}$ & Frequency & Weight & Proportion & $\begin{array}{r}\text { Prior } \\
\text { Probability }\end{array}$ \\
\hline Bankrupt & Bankrupt & 4 & 4.0000 & 0.048780 & 0.500000 \\
\hline Nonbankrupt & Nonbankrupt & 78 & 78.0000 & 0.951220 & 0.500000 \\
\hline
\end{tabular}

\section{CLASSIFICATION SUMMARY}

\begin{tabular}{lrrr}
\hline \multicolumn{2}{c}{ Number of Observations and Percent Classified into BANKRUPTCY } \\
\hline From & & & Total \\
BANKRUPTCY & Bankrupt & Nonbankrupt & 4 \\
\hline Bankrupt & 4 & 0 & 100.00 \\
& 100.00 & 0.00 & 78 \\
Nonbankrupt & 6 & 72 & 100.00 \\
& 7.69 & 92.31 & 82 \\
Total & 10 & 72 & 100.00 \\
\hline Priors & 12.20 & 87.80 & \\
& 0.5 & 0.5 & \\
\hline
\end{tabular}

\begin{tabular}{lrrr}
\hline \multicolumn{3}{c}{ Error Count Estimates for BANKRUPTCY } \\
\hline & Bankrupt & Nonbankrupt & Total \\
\hline Rate & 0.0000 & 0.0769 & 0.0385 \\
Priors & 0.5000 & 0.5000 & \\
\hline
\end{tabular}


YEAR 2

\begin{tabular}{lrr}
\hline Observations & 80 DF Total & 79 \\
Variables & 6 DF Within Classes & 78 \\
Classes & 2 DF Between Classes & 1 \\
\hline
\end{tabular}

\begin{tabular}{|c|c|c|c|c|c|}
\hline \multicolumn{6}{|c|}{ Class Level Information } \\
\hline BANKRUPTCY & $\begin{array}{l}\text { Variable } \\
\text { Name }\end{array}$ & Frequency & Weight & Proportion & $\begin{array}{r}\text { Prior } \\
\text { Probability }\end{array}$ \\
\hline Bankrupt & Bankrupt & 3 & 3.0000 & 0.037500 & 0.500000 \\
\hline Nonbankrupt & Nonbankrupt & 77 & 77.0000 & 0.962500 & 0.500000 \\
\hline
\end{tabular}

\section{CLASSIFICATION SUMMARY}

\begin{tabular}{lrrr}
\hline \multicolumn{2}{c}{ Number of Observations and Percent Classified into BANKRUPTCY } \\
\hline From & & & Total \\
BANKRUPTCY & Bankrupt & Nonbankrupt & 3 \\
\hline Bankrupt & 3 & 0 & 100.00 \\
& 100.00 & 0.00 & 77 \\
Nonbankrupt & 5 & 72 & 100.00 \\
& 6.49 & 93.51 & 80 \\
Total & 8 & 72 & 100.00 \\
\hline Priors & 10.00 & 90.00 & \\
& 0.5 & 0.5 & \\
\hline
\end{tabular}

\begin{tabular}{lrrr}
\hline \multicolumn{3}{c}{ Error Count Estimates for BANKRUPTCY } \\
\hline & Bankrupt & Nonbankrupt & Total \\
\hline Rate & 0.0000 & 0.0649 & 0.0325 \\
Priors & 0.5000 & 0.5000 & \\
\hline
\end{tabular}


YEAR 3

\begin{tabular}{lrrr}
\hline Observations & 75 DF Total & 74 \\
Variables & 6 DF Within Classes & 73 \\
Classes & 2 DF Between Classes & 1 \\
\hline
\end{tabular}

\begin{tabular}{|c|c|c|c|c|c|}
\hline \multicolumn{6}{|c|}{ Class Level Information } \\
\hline BANKRUPTCY & $\begin{array}{l}\text { Variable } \\
\text { Name }\end{array}$ & Frequency & Weight & Proportion & $\begin{array}{r}\text { Prior } \\
\text { Probability }\end{array}$ \\
\hline Bankrupt & Bankrupt & 1 & 1.0000 & 0.013333 & 0.500000 \\
\hline Nonbankrupt & Nonbankrupt & 74 & 74.0000 & 0.986667 & 0.500000 \\
\hline
\end{tabular}

\section{CLASSIFICATION SUMMARY}

\begin{tabular}{lrrr}
\hline \multicolumn{2}{c}{ Number of Observations and Percent Classified into BANKRUPTCY } \\
\hline From & & & Total \\
BANKRUPTCY & Bankrupt & Nonbankrupt & 1 \\
\hline Bankrupt & 1 & 0 & 100.00 \\
& 100.00 & 0.00 & 74 \\
Nonbankrupt & 4 & 70 & 100.00 \\
& 5.41 & 94.59 & 75 \\
Total & 5 & 70 & 100.00 \\
\hline Priors & 6.67 & 93.33 & \\
\hline
\end{tabular}

\begin{tabular}{lrrr}
\hline \multicolumn{3}{c}{ Error Count Estimates for BANKRUPTCY } \\
\hline & Bankrupt & Nonbankrupt & Total \\
\hline Rate & 0.0000 & 0.0541 & 0.0270 \\
Priors & 0.5000 & 0.5000 & \\
\hline
\end{tabular}


Results of Non-parametric Discriminant Analysis : Variables (Price, Standard deviation, bid ask spread, net income to sales, working capital to total assets and current liabilities to total assets )

YEAR 1

\begin{tabular}{lrr}
\hline Observations & 184 DF Total & 183 \\
Variables & 6 DF Within Classes & 182 \\
Classes & 2 DF Between Classes & 1 \\
\hline
\end{tabular}

\begin{tabular}{|c|c|c|c|c|c|}
\hline \multicolumn{6}{|c|}{ Class Level Information } \\
\hline BANKRUPTCY & $\begin{array}{l}\text { Variable } \\
\text { Name }\end{array}$ & Frequency & Weight & Proportion & $\begin{array}{r}\text { Prior } \\
\text { Probability }\end{array}$ \\
\hline Bankrupt & Bankrupt & 85 & 85.0000 & 0.461957 & 0.500000 \\
\hline Nonbankrupt & Nonbankrupt & 99 & 99.0000 & 0.538043 & 0.500000 \\
\hline
\end{tabular}

\section{CLASSIFICATION SUMMARY}

\begin{tabular}{lrrr}
\hline \multicolumn{2}{c}{ Number of Observations and Percent Classified into BANKRUPTCY } \\
\hline From & & & Total \\
BANKRUPTCY & Bankrupt & Nonbankrupt & 85 \\
\hline Bankrupt & 68 & 17 & 100.00 \\
& 80.00 & 20.00 & 99 \\
Nonbankrupt & 10 & 89 & 100.00 \\
& 10.10 & 89.90 & 184 \\
\hline Total & 78 & 106 & 100.00 \\
\hline Priors & 42.39 & 57.61 & \\
& 0.5 & 0.5 & \\
\hline
\end{tabular}

\begin{tabular}{lrrr}
\hline \multicolumn{3}{c}{ Error Count Estimates for BANKRUPTCY } \\
\hline & Bankrupt & Nonbankrupt & Total \\
\hline Rate & 0.2000 & 0.1010 & 0.1505 \\
Priors & 0.5000 & 0.5000 & \\
\hline
\end{tabular}


YEAR 2

\begin{tabular}{lrr}
\hline Observations & 201 DF Total & 200 \\
Variables & 6 DF Within Classes & 199 \\
Classes & 2 DF Between Classes & 1 \\
\hline
\end{tabular}

\begin{tabular}{|c|c|c|c|c|c|}
\hline \multicolumn{6}{|c|}{ Class Level Information } \\
\hline BANKRUPTCY & $\begin{array}{l}\text { Variable } \\
\text { Name }\end{array}$ & Frequency & Weight & Proportion & $\begin{array}{r}\text { Prior } \\
\text { Probability }\end{array}$ \\
\hline Bankrupt & Bankrupt & 95 & 95.0000 & 0.472637 & 0.500000 \\
\hline Nonbankrupt & Nonbankrupt & 106 & 106.0000 & 0.527363 & 0.500000 \\
\hline
\end{tabular}

\section{CLASSIFICATION SUMMARY}

\begin{tabular}{lrrr}
\hline \multicolumn{2}{c}{ Number of Observations and Percent Classified into BANKRUPTCY } \\
\hline From & & & Total \\
BANKRUPTCY & Bankrupt & Nonbankrupt & 95 \\
\hline Bankrupt & 82 & 13 & 100.00 \\
& 86.32 & 13.68 & 106 \\
Nonbankrupt & 18 & 88 & 100.00 \\
\hline Total & 16.98 & 83.02 & 201 \\
& 100 & 101 & 100.00 \\
\hline Priors & 49.75 & 50.25 & \\
& 0.5 & 0.5 & \\
\hline
\end{tabular}

\begin{tabular}{lrrr}
\hline \multicolumn{3}{c}{ Error Count Estimates for BANKRUPTCY } \\
\hline & Bankrupt & Nonbankrupt & Total \\
\hline Rate & 0.1368 & 0.1698 & 0.1533 \\
Priors & 0.5000 & 0.5000 & \\
\hline
\end{tabular}


YEAR 3

\begin{tabular}{lrlr}
\hline Observations & 173 DF Total & 172 \\
Variables & 6 DF Within Classes & 171 \\
Classes & 2 DF Between Classes & 1 \\
\hline
\end{tabular}

\begin{tabular}{|c|c|c|c|c|c|}
\hline \multicolumn{6}{|c|}{ Class Level Information } \\
\hline BANKRUPTCY & $\begin{array}{l}\text { Variable } \\
\text { Name }\end{array}$ & Frequency & Weight & Proportion & $\begin{array}{r}\text { Prior } \\
\text { Probability }\end{array}$ \\
\hline Bankrupt & Bankrupt & 74 & 74.0000 & 0.427746 & 0.500000 \\
\hline Nonbankrupt & Nonbankrupt & 99 & 99.0000 & 0.572254 & 0.500000 \\
\hline
\end{tabular}

\section{CLASSIFICATION SUMMARY}

\begin{tabular}{lrrr}
\hline \multicolumn{2}{c}{ Number of Observations and Percent Classified into BANKRUPTCY } \\
\hline From & & & \\
BANKRUPTCY & Bankrupt & Nonbankrupt & Total \\
\hline Bankrupt & 55 & 19 & 74 \\
& 74.32 & 25.68 & 100.00 \\
Nonbankrupt & 9 & 90 & 99 \\
& 9.09 & 90.91 & 100.00 \\
\hline Total & 64 & 109 & 173 \\
& 36.99 & 63.01 & \\
\hline Priors & 0.5 & 0.5 & \\
& & & \\
\hline
\end{tabular}

\begin{tabular}{lrrr}
\hline \multicolumn{3}{c}{ Error Count Estimates for BANKRUPTCY } \\
\hline & Bankrupt & Nonbankrupt & Total \\
\hline Rate & 0.2568 & 0.0909 & 0.1738 \\
Priors & 0.5000 & 0.5000 & \\
\hline
\end{tabular}


YEAR 4

\begin{tabular}{lrrr}
\hline Observations & 90 DF Total & 89 \\
Variables & 6 DF Within Classes & 88 \\
Classes & 2 & DF Between Classes & 1 \\
\hline
\end{tabular}

\begin{tabular}{|c|c|c|c|c|c|}
\hline \multicolumn{6}{|c|}{ Class Level Information } \\
\hline BANKRUPTCY & $\begin{array}{l}\text { Variable } \\
\text { Name }\end{array}$ & Frequency & Weight & Proportion & $\begin{array}{r}\text { Prior } \\
\text { Probability }\end{array}$ \\
\hline Bankrupt & Bankrupt & 66 & 66.0000 & 0.733333 & 0.500000 \\
\hline Nonbankrupt & Nonbankrupt & 24 & 24.0000 & 0.266667 & 0.500000 \\
\hline
\end{tabular}

\section{CLASSIFICATION SUMMARY}

\begin{tabular}{lrrr}
\hline \multicolumn{2}{c}{ Number of Observations and Percent Classified into BANKRUPTCY } \\
\hline From & & & Total \\
BANKRUPTCY & Bankrupt & Nonbankrupt & 66 \\
\hline Bankrupt & 42 & 24 & 100.00 \\
& 63.64 & 36.36 & 24 \\
Nonbankrupt & 0 & 24 & 100.00 \\
& 0.00 & 100.00 & 90 \\
Total & 42 & 48 & 100.00 \\
\hline Priors & 46.67 & 53.33 & \\
& 0.5 & 0.5 & \\
\hline
\end{tabular}

\begin{tabular}{lrrr}
\hline \multicolumn{3}{c}{ Error Count Estimates for BANKRUPTCY } \\
\hline & Bankrupt & Nonbankrupt & Total \\
\hline Rate & 0.3636 & 0.0000 & 0.1818 \\
Priors & 0.5000 & 0.5000 & \\
\hline
\end{tabular}


YEAR 5

\begin{tabular}{lrrr}
\hline Observations & 43 DF Total & 42 \\
Variables & 6 DF Within Classes & 41 \\
Classes & 2 DF Between Classes & 1 \\
\hline
\end{tabular}

\begin{tabular}{|c|c|c|c|c|c|}
\hline \multicolumn{6}{|c|}{ Class Level Information } \\
\hline BANKRUPTCY & $\begin{array}{l}\text { Variable } \\
\text { Name }\end{array}$ & Frequency & Weight & Proportion & $\begin{array}{r}\text { Prior } \\
\text { Probability }\end{array}$ \\
\hline Bankrupt & Bankrupt & 27 & 27.0000 & 0.627907 & 0.500000 \\
\hline Nonbankrupt & Nonbankrupt & 16 & 16.0000 & 0.372093 & 0.500000 \\
\hline
\end{tabular}

\section{CLASSIFICATION SUMMARY}

\begin{tabular}{lrrr}
\hline \multicolumn{2}{c}{ Number of Observations and Percent Classified into BANKRUPTCY } \\
\hline From & & & Total \\
BANKRUPTCY & Bankrupt & Nonbankrupt & 27 \\
\hline Bankrupt & 24 & 3 & 100.00 \\
& 88.89 & 11.11 & 16 \\
Nonbankrupt & 4 & 12 & 100.00 \\
& 25.00 & 75.00 & 43 \\
Total & 28 & 15 & 100.00 \\
\hline Priors & 65.12 & 34.88 & \\
& 0.5 & 0.5 & \\
\hline
\end{tabular}

\begin{tabular}{lrrr}
\hline \multicolumn{3}{c}{ Error Count Estimates for BANKRUPTCY } \\
\hline & Bankrupt & Nonbankrupt & Total \\
\hline Rate & 0.1111 & 0.2500 & 0.1806 \\
Priors & 0.5000 & 0.5000 & \\
\hline
\end{tabular}


Results of Non-parametric Discriminant Analysis : Variables (Price, Standard deviation, hi lo bid ask spread, net income to sales, working capital to total assets and current liabilities to total assets )

YEAR 1

\begin{tabular}{lrr}
\hline Observations & 185 DF Total & 184 \\
Variables & 6 DF Within Classes & 183 \\
Classes & 2 DF Between Classes & 1 \\
\hline
\end{tabular}

\begin{tabular}{|c|c|c|c|c|c|}
\hline \multicolumn{6}{|c|}{ Class Level Information } \\
\hline BANKRUPTCY & $\begin{array}{l}\text { Variable } \\
\text { Name }\end{array}$ & Frequency & Weight & Proportion & $\begin{array}{r}\text { Prior } \\
\text { Probability }\end{array}$ \\
\hline Bankrupt & Bankrupt & 86 & 86.0000 & 0.464865 & 0.500000 \\
\hline Nonbankrupt & Nonbankrupt & 99 & 99.0000 & 0.535135 & 0.500000 \\
\hline
\end{tabular}

\section{CLASSIFICATION SUMMARY}

\begin{tabular}{lrrr}
\hline \multicolumn{2}{c}{ Number of Observations and Percent Classified into BANKRUPTCY } \\
\hline From & & & Total \\
BANKRUPTCY & Bankrupt & Nonbankrupt & 86 \\
\hline Bankrupt & 65 & 21 & 100.00 \\
& 75.58 & 24.42 & 99 \\
Nonbankrupt & 9 & 90 & 100.00 \\
& 9.09 & 90.91 & 185 \\
\hline Total & 74 & 111 & 100.00 \\
& 40.00 & 60.00 & \\
\hline Priors & 0.5 & 0.5 & \\
& & &
\end{tabular}

\begin{tabular}{lrrr}
\hline \multicolumn{3}{c}{ Error Count Estimates for BANKRUPTCY } \\
\hline & Bankrupt & Nonbankrupt & Total \\
\hline Rate & 0.2442 & 0.0909 & 0.1675 \\
Priors & 0.5000 & 0.5000 & \\
\hline
\end{tabular}


YEAR 2

\begin{tabular}{lrr}
\hline Observations & 201 DF Total & 200 \\
Variables & 6 DF Within Classes & 199 \\
Classes & 2 DF Between Classes & 1 \\
\hline
\end{tabular}

\begin{tabular}{|c|c|c|c|c|c|}
\hline \multicolumn{6}{|c|}{ Class Level Information } \\
\hline BANKRUPTCY & $\begin{array}{l}\text { Variable } \\
\text { Name }\end{array}$ & Frequency & Weight & Proportion & $\begin{array}{r}\text { Prior } \\
\text { Probability }\end{array}$ \\
\hline Bankrupt & Bankrupt & 95 & 95.0000 & 0.472637 & 0.500000 \\
\hline Nonbankrupt & Nonbankrupt & 106 & 106.0000 & 0.527363 & 0.500000 \\
\hline
\end{tabular}

\section{CLASSIFICATION SUMMARY}

\begin{tabular}{lrrr}
\hline \multicolumn{2}{c}{ Number of Observations and Percent Classified into BANKRUPTCY } \\
\hline From & & & Total \\
BANKRUPTCY & Bankrupt & Nonbankrupt & 95 \\
\hline Bankrupt & 72 & 23 & 100.00 \\
& 75.79 & 24.21 & 106 \\
Nonbankrupt & 18 & 88 & 100.00 \\
\hline Total & 16.98 & 83.02 & 201 \\
& 90 & 111 & 100.00 \\
\hline Priors & 44.78 & 55.22 & \\
& 0.5 & 0.5 & \\
\hline
\end{tabular}

\begin{tabular}{lrrr}
\hline \multicolumn{3}{c}{ Error Count Estimates for BANKRUPTCY } \\
\hline & Bankrupt & Nonbankrupt & Total \\
\hline Rate & 0.2421 & 0.1698 & 0.2060 \\
Priors & 0.5000 & 0.5000 & \\
\hline
\end{tabular}


YEAR 3

\begin{tabular}{lrr}
\hline Observations & 174 DF Total & 173 \\
Variables & 6 DF Within Classes & 172 \\
Classes & 2 DF Between Classes & 1 \\
\hline
\end{tabular}

\begin{tabular}{|c|c|c|c|c|c|}
\hline \multicolumn{6}{|c|}{ Class Level Information } \\
\hline BANKRUPTCY & $\begin{array}{l}\text { Variable } \\
\text { Name }\end{array}$ & Frequency & Weight & Proportion & $\begin{array}{r}\text { Prior } \\
\text { Probability }\end{array}$ \\
\hline Bankrupt & Bankrupt & 75 & 75.0000 & 0.431034 & 0.500000 \\
\hline Nonbankrupt & Nonbankrupt & 99 & 99.0000 & 0.568966 & 0.500000 \\
\hline
\end{tabular}

\section{CLASSIFICATION SUMMARY}

\begin{tabular}{lrrr}
\hline \multicolumn{2}{c}{ Number of Observations and Percent Classified into BANKRUPTCY } \\
\hline From & & & \\
BANKRUPTCY & Bankrupt & Nonbankrupt & Total \\
\hline Bankrupt & 43 & 32 & 75 \\
& 57.33 & 42.67 & 100.00 \\
Nonbankrupt & 10 & 89 & 99 \\
& 10.10 & 89.90 & 100.00 \\
\hline Total & 53 & 121 & 174 \\
& 30.46 & 69.54 & 100.00 \\
\hline Priors & 0.5 & 0.5 & \\
\end{tabular}

\begin{tabular}{lrrr}
\hline \multicolumn{3}{c}{ Error Count Estimates for BANKRUPTCY } \\
\hline & Bankrupt & Nonbankrupt & Total \\
\hline Rate & 0.4267 & 0.1010 & 0.2638 \\
Priors & 0.5000 & 0.5000 & \\
\hline
\end{tabular}


YEAR 4

\begin{tabular}{lrrr}
\hline Observations & 90 DF Total & 89 \\
Variables & 6 DF Within Classes & 88 \\
Classes & 2 & DF Between Classes & 1 \\
\hline
\end{tabular}

\begin{tabular}{|c|c|c|c|c|c|}
\hline \multicolumn{6}{|c|}{ Class Level Information } \\
\hline BANKRUPTCY & $\begin{array}{l}\text { Variable } \\
\text { Name }\end{array}$ & Frequency & Weight & Proportion & $\begin{array}{r}\text { Prior } \\
\text { Probability }\end{array}$ \\
\hline Bankrupt & Bankrupt & 66 & 66.0000 & 0.733333 & 0.500000 \\
\hline Nonbankrupt & Nonbankrupt & 24 & 24.0000 & 0.266667 & 0.500000 \\
\hline
\end{tabular}

\section{CLASSIFICATION SUMMARY}

\begin{tabular}{lrrr}
\hline \multicolumn{2}{c}{ Number of Observations and Percent Classified into BANKRUPTCY } \\
\hline From & & & \\
BANKRUPTCY & Bankrupt & Nonbankrupt & Total \\
\hline Bankrupt & 36 & 30 & 66 \\
& 54.55 & 45.45 & 100.00 \\
Nonbankrupt & 0 & 24 & 24 \\
& 0.00 & 100.00 & 100.00 \\
\hline Total & 36 & 54 & 90 \\
& 40.00 & 60.00 & 100.00 \\
\hline Priors & 0.5 & 0.5 & \\
& & &
\end{tabular}

\begin{tabular}{lrrr}
\hline \multicolumn{3}{c}{ Error Count Estimates for BANKRUPTCY } \\
\hline & Bankrupt & Nonbankrupt & Total \\
\hline Rate & 0.4545 & 0.0000 & 0.2273 \\
Priors & 0.5000 & 0.5000 & \\
\hline
\end{tabular}


YEAR 5

\begin{tabular}{|c|c|c|}
\hline Observations & 45 DF Total & 44 \\
\hline Variables & 6 DF Within Classes & 43 \\
\hline Classes & 2 DF Between Classes & 1 \\
\hline
\end{tabular}

\begin{tabular}{|c|c|c|c|c|c|}
\hline \multicolumn{6}{|c|}{ Class Level Information } \\
\hline BANKRUPTCY & $\begin{array}{l}\text { Variable } \\
\text { Name }\end{array}$ & Frequency & Weight & Proportion & $\begin{array}{r}\text { Prior } \\
\text { Probability }\end{array}$ \\
\hline Bankrupt & Bankrupt & 29 & 29.0000 & 0.644444 & 0.500000 \\
\hline Nonbankrupt & Nonbankrupt & 16 & 16.0000 & 0.355556 & 0.500000 \\
\hline
\end{tabular}

\section{CLASSIFICATION SUMMARY}

\begin{tabular}{lrrr}
\hline \multicolumn{2}{c}{ Number of Observations and Percent Classified into BANKRUPTCY } \\
\hline From & & & Total \\
BANKRUPTCY & Bankrupt & Nonbankrupt & 29 \\
\hline Bankrupt & 23 & 6 & 100.00 \\
& 79.31 & 20.69 & 16 \\
Nonbankrupt & 5 & 11 & 100.00 \\
& 31.25 & 68.75 & 45 \\
Total & 28 & 17 & 100.00 \\
\hline Priors & 62.22 & 37.78 & \\
\hline
\end{tabular}

\begin{tabular}{lrrr}
\hline \multicolumn{3}{c}{ Error Count Estimates for BANKRUPTCY } \\
\hline & Bankrupt & Nonbankrupt & Total \\
\hline Rate & 0.2069 & 0.3125 & 0.2597 \\
Priors & 0.5000 & 0.5000 & \\
\hline
\end{tabular}


Table 10

Non Parametric Discriminant analysis results for Out of sample validation : Accounting variables

\begin{tabular}{lrlr}
\hline Observations & 274 & DF Total & 273 \\
\hline Variables & 17 & DF Within Classes & 272 \\
Classes & 2 & DF Between Classes & 1 \\
\hline
\end{tabular}

\begin{tabular}{|c|c|c|c|c|c|}
\hline \multicolumn{6}{|c|}{ Class Level Information } \\
\hline BANKRUPTCY & $\begin{array}{l}\text { Variable } \\
\text { Name }\end{array}$ & Frequency & Weight & Proportion & $\begin{array}{r}\text { Prior } \\
\text { Probability }\end{array}$ \\
\hline Bankrupt & Bankrupt & 8 & 8.0000 & 0.029197 & 0.500000 \\
\hline Nonbankrupt & Nonbankrupt & 266 & 266.0000 & 0.970803 & 0.500000 \\
\hline
\end{tabular}

Classification summary

\begin{tabular}{lrrr}
\hline \multicolumn{2}{c}{ Number of Observations and Percent Classified into BANKRUPTCY } \\
\hline From & Bankrupt & Nonbankrupt & Total \\
BANKRUPTCY & 8 & 0 & 8 \\
\hline Bankrupt & 100.00 & 0.00 & 100.00 \\
& 8 & 258 & 266 \\
Nonbankrupt & 3.01 & 96.99 & 100.00 \\
& 16 & 258 & 274 \\
Total & 5.84 & 94.16 & 100.00 \\
\hline Priors & 0.5 & 0.5 & \\
\hline
\end{tabular}

\begin{tabular}{lrrr}
\hline \multicolumn{3}{c}{ Error Count Estimates for BANKRUPTCY } \\
\hline & Bankrupt & Nonbankrupt & Total \\
\hline Rate & 0.0000 & 0.0301 & 0.0150 \\
Priors & 0.5000 & 0.5000 & \\
\hline
\end{tabular}


Classification summary for Test Data

\begin{tabular}{lrrr}
\hline \multicolumn{2}{c}{ Number of Observations and Percent Classified into BANKRUPTCY } \\
\hline From & & & Total \\
BANKRUPTCY & Bankrupt & Nonbankrupt & 6 \\
\hline Bankrupt & 3 & 3 & 100.00 \\
& 50.00 & 50.00 & 95 \\
Nonbankrupt & 3 & 92 & 100.00 \\
& 3.16 & 96.84 & 101 \\
Total & 6 & 95 & 100.00 \\
& 5.94 & 94.06 & \\
\hline Priors & 0.5 & 0.5 & \\
& & &
\end{tabular}

\begin{tabular}{lrrr}
\multicolumn{4}{c}{ Error Count Estimates for BANKRUPTCY } \\
\hline & Bankrupt & Nonbankrupt & Total \\
\hline Rate & 0.5000 & 0.0316 & 0.2658 \\
Priors & 0.5000 & 0.5000 & \\
\hline
\end{tabular}


Non Parametric Discriminant analysis results for Out of sample validation :Market variables

\begin{tabular}{lrrr}
\hline Observations & 813 DF Total & 812 \\
\hline Variables & 5 & DF Within Classes & 811 \\
Classes & 2 & DF Between Classes & 1 \\
\hline
\end{tabular}

\begin{tabular}{|c|c|c|c|c|c|}
\hline \multicolumn{6}{|c|}{ Class Level Information } \\
\hline BANKRUPTCY & $\begin{array}{l}\text { Variable } \\
\text { Name }\end{array}$ & Frequency & Weight & Proportion & $\begin{array}{r}\text { Prior } \\
\text { Probability }\end{array}$ \\
\hline Bankrupt & Bankrupt & 383 & 383.0000 & 0.471095 & 0.500000 \\
\hline Nonbankrupt & Nonbankrupt & 430 & 430.0000 & 0.528905 & 0.500000 \\
\hline
\end{tabular}

Classification summary

\begin{tabular}{lrrr}
\hline \multicolumn{2}{c}{ Number of Observations and Percent Classified into BANKRUPTCY } \\
\hline From & & & \\
BANKRUPTCY & Bankrupt & Nonbankrupt & Total \\
\hline Bankrupt & 310 & 73 & 383 \\
& 80.94 & 19.06 & 100.00 \\
Nonbankrupt & 58 & 372 & 430 \\
& 13.49 & 86.51 & 100.00 \\
Total & 368 & 445 & 813 \\
& 45.26 & 54.74 & 100.00 \\
\hline Priors & 0.5 & 0.5 & \\
& & & \\
\hline
\end{tabular}

\begin{tabular}{lrrr}
\hline \multicolumn{3}{c}{ Error Count Estimates for BANKRUPTCY } \\
\hline & Bankrupt & Nonbankrupt & Total \\
\hline Rate & 0.1906 & 0.1349 & 0.1627 \\
Priors & 0.5000 & 0.5000 & \\
\hline
\end{tabular}


Classification summary for Test Data

\begin{tabular}{lrrr}
\hline \multicolumn{2}{c}{ Number of Observations and Percent Classified into BANKRUPTCY } \\
\hline From & & & \\
BANKRUPTCY & Bankrupt & Nonbankrupt & Total \\
\hline Bankrupt & 94 & 39 & 133 \\
& 70.68 & 29.32 & 100.00 \\
Nonbankrupt & 20 & 96 & 116 \\
& 17.24 & 82.76 & 100.00 \\
Total & 114 & 135 & 249 \\
& 45.78 & 54.22 & 100.00 \\
\hline Priors & 0.5 & 0.5 & \\
& & & \\
\hline
\end{tabular}

\begin{tabular}{lrrr}
\multicolumn{4}{c}{ Error Count Estimates for BANKRUPTCY } \\
\hline & Bankrupt & Nonbankrupt & Total \\
\hline Rate & 0.2932 & 0.1724 & 0.2328 \\
Priors & 0.5000 & 0.5000 & \\
\hline
\end{tabular}


Non Parametric Discriminant analysis results for Out of sample validation : Market variables without spread and hi lo bid ask spread

\begin{tabular}{lrrr}
\hline Observations & 813 DF Total & 812 \\
\hline Variables & 4 & DF Within Classes & 811 \\
Classes & 2 & DF Between Classes & 1 \\
\hline
\end{tabular}

\begin{tabular}{|c|c|c|c|c|c|}
\hline \multicolumn{6}{|c|}{ Class Level Information } \\
\hline BANKRUPTCY & $\begin{array}{l}\text { Variable } \\
\text { Name }\end{array}$ & Frequency & Weight & Proportion & $\begin{array}{r}\text { Prior } \\
\text { Probability }\end{array}$ \\
\hline Bankrupt & Bankrupt & 383 & 383.0000 & 0.471095 & 0.500000 \\
\hline Nonbankrupt & Nonbankrupt & 430 & 430.0000 & 0.528905 & 0.500000 \\
\hline
\end{tabular}

Classification summary

\begin{tabular}{lrrr}
\hline \multicolumn{2}{c}{ Number of Observations and Percent Classified into BANKRUPTCY } \\
\hline From & & & \\
BANKRUPTCY & Bankrupt & Nonbankrupt & Total \\
\hline Bankrupt & 318 & 65 & 383 \\
& 83.03 & 16.97 & 100.00 \\
Nonbankrupt & 55 & 375 & 430 \\
& 12.79 & 87.21 & 100.00 \\
Total & 373 & 440 & 813 \\
& 45.88 & 54.12 & 100.00 \\
\hline Priors & 0.5 & 0.5 & \\
& & & \\
\hline
\end{tabular}

\begin{tabular}{lrrr}
\multicolumn{4}{c}{ Error Count Estimates for BANKRUPTCY } \\
\hline & Bankrupt & Nonbankrupt & Total \\
\hline Rate & 0.1697 & 0.1279 & 0.1488 \\
Priors & 0.5000 & 0.5000 & \\
\hline
\end{tabular}


Classification summary for Test Data

\begin{tabular}{lrrr}
\hline \multicolumn{2}{c}{ Number of Observations and Percent Classified into BANKRUPTCY } \\
\hline From & & & \\
BANKRUPTCY & Bankrupt & Nonbankrupt & Total \\
\hline Bankrupt & 87 & 46 & 133 \\
& 65.41 & 34.59 & 100.00 \\
Nonbankrupt & 22 & 94 & 116 \\
& 18.97 & 81.03 & 100.00 \\
Total & 109 & 140 & 249 \\
& 43.78 & 56.22 & 100.00 \\
\hline Priors & 0.5 & 0.5 & \\
& & & \\
\hline
\end{tabular}

\begin{tabular}{lrrr}
\hline \multicolumn{3}{c}{ Error Count Estimates for BANKRUPTCY } \\
\hline & Bankrupt & Nonbankrupt & Total \\
\hline Rate & 0.3459 & 0.1897 & 0.2678 \\
Priors & 0.5000 & 0.5000 & \\
\hline
\end{tabular}


Non Parametric Discriminant analysis results for Out of sample validation : Market variables without spread and bid ask spread

\begin{tabular}{lrlr}
\hline Observations & 823 & DF Total & 822 \\
\hline Variables & 4 & DF Within Classes & 821 \\
Classes & 2 & DF Between Classes & 1 \\
\hline
\end{tabular}

\begin{tabular}{|c|c|c|c|c|c|}
\hline \multicolumn{6}{|c|}{ Class Level Information } \\
\hline BANKRUPTCY & $\begin{array}{l}\text { Variable } \\
\text { Name }\end{array}$ & Frequency & Weight & Proportion & $\begin{array}{r}\text { Prior } \\
\text { Probability }\end{array}$ \\
\hline Bankrupt & Bankrupt & 392 & 392.0000 & 0.476306 & 0.500000 \\
\hline Nonbankrupt & Nonbankrupt & 431 & 431.0000 & 0.523694 & 0.500000 \\
\hline
\end{tabular}

Classification summary

\begin{tabular}{lrrr}
\hline \multicolumn{2}{c}{ Number of Observations and Percent Classified into BANKRUPTCY } \\
\hline From & & & \\
BANKRUPTCY & Bankrupt & Nonbankrupt & Total \\
\hline Bankrupt & 316 & 76 & 100.00 \\
& 80.61 & 19.39 & 431 \\
Nonbankrupt & 78 & 353 & 100.00 \\
& 18.10 & 81.90 & 823 \\
Total & 394 & 429 & 100.00 \\
& 47.87 & 52.13 & \\
\hline Priors & 0.5 & 0.5 & \\
\end{tabular}

\begin{tabular}{lrrr}
\multicolumn{4}{c}{ Error Count Estimates for BANKRUPTCY } \\
\hline & Bankrupt & Nonbankrupt & Total \\
\hline Rate & 0.1939 & 0.1810 & 0.1874 \\
Priors & 0.5000 & 0.5000 & \\
\hline
\end{tabular}


Classification summary for Test Data

\begin{tabular}{lrrr}
\hline \multicolumn{2}{c}{ Number of Observations and Percent Classified into BANKRUPTCY } \\
\hline From & & & \\
BANKRUPTCY & Bankrupt & Nonbankrupt & Total \\
\hline Bankrupt & 90 & 46 & 136 \\
& 66.18 & 33.82 & 100.00 \\
Nonbankrupt & 49 & 67 & 116 \\
& 42.24 & 57.76 & 100.00 \\
Total & 139 & 113 & 252 \\
& 55.16 & 44.84 & 100.00 \\
\hline Priors & 0.5 & 0.5 & \\
& & & \\
\hline
\end{tabular}

\begin{tabular}{lrrr}
\hline \multicolumn{3}{c}{ Error Count Estimates for BANKRUPTCY } \\
\hline & Bankrupt & Nonbankrupt & Total \\
\hline Rate & 0.3382 & 0.4224 & 0.3803 \\
Priors & 0.5000 & 0.5000 & \\
\hline
\end{tabular}


Non Parametric Discriminant analysis results for Out of sample validation : Market variables without bid ask spread and hi lo bid ask spread

\begin{tabular}{lrlr}
\hline Observations & 42 & DF Total & 41 \\
\hline Variables & 4 & DF Within Classes & 40 \\
Classes & 2 & DF Between Classes & 1 \\
\hline
\end{tabular}

\begin{tabular}{|c|c|c|c|c|c|}
\hline \multicolumn{6}{|c|}{ Class Level Information } \\
\hline BANKRUPTCY & $\begin{array}{l}\text { Variable } \\
\text { Name }\end{array}$ & Frequency & Weight & Proportion & $\begin{array}{r}\text { Prior } \\
\text { Probability }\end{array}$ \\
\hline Bankrupt & Bankrupt & 29 & 29.0000 & 0.690476 & 0.500000 \\
\hline Nonbankrupt & Nonbankrupt & 13 & 13.0000 & 0.309524 & 0.500000 \\
\hline
\end{tabular}

Classification summary

\begin{tabular}{lrrr}
\hline \multicolumn{2}{c}{ Number of Observations and Percent Classified into BANKRUPTCY } \\
\hline From & & & Total \\
BANKRUPTCY & Bankrupt & Nonbankrupt & 29 \\
\hline Bankrupt & 13 & 16 & 100.00 \\
& 44.83 & 55.17 & 13 \\
Nonbankrupt & 0 & 13 & 100.00 \\
& 0.00 & 100.00 & 42 \\
Total & 13 & 29 & 100.00 \\
\hline Priors & 30.95 & 69.05 & \\
& 0.5 & 0.5 & \\
\hline
\end{tabular}

\begin{tabular}{lrrr}
\hline \multicolumn{3}{c}{ Error Count Estimates for BANKRUPTCY } \\
\hline & Bankrupt & Nonbankrupt & Total \\
\hline Rate & 0.5517 & 0.0000 & 0.2759 \\
Priors & 0.5000 & 0.5000 & \\
\hline
\end{tabular}


Classification summary for Test Data

\begin{tabular}{lrrr}
\hline \multicolumn{2}{c}{ Number of Observations and Percent Classified into BANKRUPTCY } \\
\hline From & & & Total \\
BANKRUPTCY & Bankrupt & Nonbankrupt & 10 \\
\hline Bankrupt & 1 & 9 & 100.00 \\
& 10.00 & 90.00 & 3 \\
Nonbankrupt & 1 & 2 & 100.00 \\
& 33.33 & 66.67 & 13 \\
Total & 2 & 11 & 100.00 \\
& 15.38 & 84.62 & \\
\hline Priors & 0.5 & 0.5 & \\
& & &
\end{tabular}

\begin{tabular}{lrrr}
\hline \multicolumn{3}{c}{ Error Count Estimates for BANKRUPTCY } \\
\hline & Bankrupt & Nonbankrupt & Total \\
\hline Rate & 0.9000 & 0.3333 & 0.6167 \\
Priors & 0.5000 & 0.5000 & \\
\hline
\end{tabular}


Non Parametric Discriminant analysis results for Out of sample validation : Top 3 Account and Market Ratios

\begin{tabular}{lrlr}
\hline Observations & 277 DF Total & 276 \\
Variables & 6 DF Within Classes & 275 \\
Classes & 2 DF Between Classes & 1 \\
\hline
\end{tabular}

\begin{tabular}{|c|c|c|c|c|c|}
\hline \multicolumn{6}{|c|}{ Class Level Information } \\
\hline BANKRUPTCY & $\begin{array}{l}\text { Variable } \\
\text { Name }\end{array}$ & Frequency & Weight & Proportion & $\begin{array}{r}\text { Prior } \\
\text { Probability }\end{array}$ \\
\hline Bankrupt & Bankrupt & 10 & 10.0000 & 0.036101 & 0.500000 \\
\hline Nonbankrupt & Nonbankrupt & 267 & 267.0000 & 0.963899 & 0.500000 \\
\hline
\end{tabular}

Classification summary

\begin{tabular}{lrrr}
\hline \multicolumn{2}{c}{ Number of Observations and Percent Classified into BANKRUPTCY } \\
\hline From & & & \\
BANKRUPTCY & Bankrupt & Nonbankrupt & Total \\
\hline Bankrupt & 10 & 0 & 10 \\
& 100.00 & 0.00 & 100.00 \\
Nonbankrupt & 12 & 255 & 267 \\
& 4.49 & 95.51 & 100.00 \\
\hline Total & 22 & 255 & 277 \\
& 7.94 & 92.06 & 100.00 \\
\hline Priors & 0.5 & 0.5 & \\
& & & \\
\hline
\end{tabular}

\begin{tabular}{lrrr}
\hline \multicolumn{3}{c}{ Error Count Estimates for BANKRUPTCY } \\
\hline & Bankrupt & Nonbankrupt & Total \\
\hline Rate & 0.0000 & 0.0449 & 0.0225 \\
Priors & 0.5000 & 0.5000 & \\
\hline
\end{tabular}


Classification summary for Test Data

\begin{tabular}{lrrr}
\hline \multicolumn{2}{c}{ Number of Observations and Percent Classified into BANKRUPTCY } \\
\hline From & & & \\
BANKRUPTCY & Bankrupt & Nonbankrupt & Total \\
\hline Bankrupt & 4 & 3 & 7 \\
& 57.14 & 42.86 & 100.00 \\
Nonbankrupt & 14 & 83 & 97 \\
& 14.43 & 85.57 & 100.00 \\
\hline Total & 18 & 86 & 104 \\
& 17.31 & 82.69 & 100.00 \\
\hline Priors & 0.5 & 0.5 & \\
& & & \\
\hline
\end{tabular}

\begin{tabular}{lrrr}
\hline \multicolumn{3}{c}{ Error Count Estimates for BANKRUPTCY } \\
\hline & Bankrupt & Nonbankrupt & Total \\
\hline Rate & 0.4286 & 0.1443 & 0.2865 \\
Priors & 0.5000 & 0.5000 & \\
\hline
\end{tabular}


Non Parametric Discriminant analysis results for Out of sample validation : Top 3 account and market logarithmic ratios

\begin{tabular}{lrlr}
\hline Observations & 218 DF Total & 217 \\
Variables & 6 DF Within Classes & 216 \\
Classes & 2 DF Between Classes & 1 \\
\hline
\end{tabular}

\begin{tabular}{|c|c|c|c|c|c|}
\hline \multicolumn{6}{|c|}{ Class Level Information } \\
\hline BANKRUPTCY & $\begin{array}{l}\text { Variable } \\
\text { Name }\end{array}$ & Frequency & Weight & Proportion & $\begin{array}{r}\text { Prior } \\
\text { Probability }\end{array}$ \\
\hline Bankrupt & Bankrupt & 4 & 4.0000 & 0.018349 & 0.500000 \\
\hline Nonbankrupt & Nonbankrupt & 214 & 214.0000 & 0.981651 & 0.500000 \\
\hline
\end{tabular}

Classification summary

\begin{tabular}{lrrr}
\hline \multicolumn{3}{c}{ Number of Observations and Percent Classified into BANKRUPTCY } \\
\hline From & & & Total \\
BANKRUPTCY & Bankrupt & Nonbankrupt & 4 \\
\hline Bankrupt & 4 & 0 & 100.00 \\
& 100.00 & 0.00 & 214 \\
Nonbankrupt & 7 & 207 & 100.00 \\
& 3.27 & 96.73 & 218 \\
\hline Total & 11 & 207 & 100.00 \\
& 5.05 & 94.95 & \\
\hline Priors & 0.5 & 0.5 & \\
\end{tabular}

\begin{tabular}{lrrr}
\hline \multicolumn{3}{c}{ Error Count Estimates for BANKRUPTCY } \\
\hline & Bankrupt & Nonbankrupt & Total \\
\hline Rate & 0.0000 & 0.0327 & 0.0164 \\
Priors & 0.5000 & 0.5000 & \\
\hline
\end{tabular}


Classification summary for Test Data

\begin{tabular}{lrrr}
\hline \multicolumn{2}{c}{ Number of Observations and Percent Classified into BANKRUPTCY } \\
\hline From & & & Total \\
BANKRUPTCY & Bankrupt & Nonbankrupt & 4 \\
\hline Bankrupt & 2 & 2 & 100.00 \\
& 50.00 & 50.00 & 78 \\
Nonbankrupt & 3 & 75 & 100.00 \\
& 3.85 & 96.15 & 82 \\
\hline Total & 5 & 77 & 100.00 \\
\hline Priors & 6.10 & 93.90 & \\
& 0.5 & 0.5 & \\
\hline
\end{tabular}

\begin{tabular}{lrrr}
\hline \multicolumn{4}{c}{ Error Count Estimates for BANKRUPTCY } \\
\hline & Bankrupt & Nonbankrupt & Total \\
\hline Rate & 0.5000 & 0.0385 & 0.2692 \\
Priors & 0.5000 & 0.5000 & \\
\hline
\end{tabular}


Non Parametric Discriminant analysis results for Out of sample validation : Variables (Price, Standard deviation, bid ask spread, net income to sales, working capital to total assets and current liabilities to total assets )

\begin{tabular}{lrlr}
\hline Observations & 507 DF Total & 506 \\
Variables & 6 DF Within Classes & 505 \\
Classes & 2 DF Between Classes & 1 \\
\hline
\end{tabular}

\begin{tabular}{|c|c|c|c|c|c|}
\hline \multicolumn{6}{|c|}{ Class Level Information } \\
\hline BANKRUPTCY & $\begin{array}{l}\text { Variable } \\
\text { Name }\end{array}$ & Frequency & Weight & Proportion & $\begin{array}{r}\text { Prior } \\
\text { Probability }\end{array}$ \\
\hline Bankrupt & Bankrupt & 262 & 262.0000 & 0.516765 & 0.500000 \\
\hline Nonbankrupt & Nonbankrupt & 245 & 245.0000 & 0.483235 & 0.500000 \\
\hline
\end{tabular}

Classification summary

\begin{tabular}{lrrr}
\hline \multicolumn{2}{c}{ Number of Observations and Percent Classified into BANKRUPTCY } \\
\hline From & & & \\
BANKRUPTCY & Bankrupt & Nonbankrupt & Total \\
\hline Bankrupt & 225 & 37 & 262 \\
& 85.88 & 14.12 & 100.00 \\
Nonbankrupt & 31 & 214 & 245 \\
& 12.65 & 87.35 & 100.00 \\
\hline Total & 256 & 251 & 507 \\
& 50.49 & 49.51 & 100.00 \\
\hline Priors & 0.5 & 0.5 & \\
& & &
\end{tabular}

\begin{tabular}{lrrr}
\hline \multicolumn{3}{c}{ Error Count Estimates for BANKRUPTCY } \\
\hline & Bankrupt & Nonbankrupt & Total \\
\hline Rate & 0.1412 & 0.1265 & 0.1339 \\
Priors & 0.5000 & 0.5000 & \\
\hline
\end{tabular}


Classification summary for Test Data

\begin{tabular}{lrrr}
\hline \multicolumn{2}{c}{ Number of Observations and Percent Classified into BANKRUPTCY } \\
\hline From & & & \\
BANKRUPTCY & Bankrupt & Nonbankrupt & Total \\
\hline Bankrupt & 53 & 32 & 85 \\
& 62.35 & 37.65 & 100.00 \\
Nonbankrupt & 15 & 84 & 99 \\
& 15.15 & 84.85 & 100.00 \\
\hline Total & 68 & 116 & 184 \\
& 36.96 & 63.04 & 100.00 \\
\hline Priors & 0.5 & 0.5 & \\
& & & \\
\hline
\end{tabular}

\begin{tabular}{lrrr}
\hline \multicolumn{3}{c}{ Error Count Estimates for BANKRUPTCY } \\
\hline & Bankrupt & Nonbankrupt & Total \\
\hline Rate & 0.3765 & 0.1515 & 0.2640 \\
Priors & 0.5000 & 0.5000 & \\
\hline
\end{tabular}


Non Parametric Discriminant analysis results for Out of sample validation : Variables (Price, Standard deviation, hi lo bid ask spread, net income to sales, working capital to total assets and current liabilities to total assets )

\begin{tabular}{lrr}
\hline Observations & 510 DF Total & 509 \\
Variables & 6 DF Within Classes & 508 \\
Classes & 2 DF Between Classes & 1 \\
\hline
\end{tabular}

\begin{tabular}{|c|c|c|c|c|c|}
\hline \multicolumn{6}{|c|}{ Class Level Information } \\
\hline BANKRUPTCY & $\begin{array}{l}\text { Variable } \\
\text { Name }\end{array}$ & Frequency & Weight & Proportion & $\begin{array}{r}\text { Prior } \\
\text { Probability }\end{array}$ \\
\hline Bankrupt & Bankrupt & 265 & 265.0000 & 0.519608 & 0.500000 \\
\hline Nonbankrupt & Nonbankrupt & 245 & 245.0000 & 0.480392 & 0.500000 \\
\hline
\end{tabular}

Classification summary

\begin{tabular}{lrrr}
\hline \multicolumn{2}{c}{ Number of Observations and Percent Classified into BANKRUPTCY } \\
\hline From & & & \\
BANKRUPTCY & Bankrupt & Nonbankrupt & Total \\
\hline Bankrupt & 206 & 59 & 265 \\
& 77.74 & 22.26 & 100.00 \\
Nonbankrupt & 48 & 197 & 245 \\
& 19.59 & 80.41 & 100.00 \\
\hline Total & 254 & 256 & 510 \\
& 49.80 & 50.20 & 100.00 \\
\hline Priors & 0.5 & 0.5 & \\
& & &
\end{tabular}

\begin{tabular}{lrrr}
\hline \multicolumn{3}{c}{ Error Count Estimates for BANKRUPTCY } \\
\hline & Bankrupt & Nonbankrupt & Total \\
\hline Rate & 0.2226 & 0.1959 & 0.2093 \\
Priors & 0.5000 & 0.5000 & \\
\hline
\end{tabular}


Classification summary for Test Data

\begin{tabular}{lrrr}
\hline \multicolumn{2}{c}{ Number of Observations and Percent Classified into BANKRUPTCY } \\
\hline From & & & \\
BANKRUPTCY & Bankrupt & Nonbankrupt & Total \\
\hline Bankrupt & 59 & 27 & 86 \\
& 68.60 & 31.40 & 100.00 \\
Nonbankrupt & 37 & 62 & 99 \\
& 37.37 & 62.63 & 100.00 \\
\hline Total & 96 & 89 & 185 \\
& 51.89 & 48.11 & 100.00 \\
\hline Priors & 0.5 & 0.5 & \\
& & & \\
\hline
\end{tabular}

\begin{tabular}{lrrr}
\hline \multicolumn{4}{c}{ Error Count Estimates for BANKRUPTCY } \\
\hline & Bankrupt & Nonbankrupt & Total \\
\hline Rate & 0.3140 & 0.3737 & 0.3438 \\
Priors & 0.5000 & 0.5000 & \\
\hline
\end{tabular}




\subsection{Summary and Conclusions}

Bankruptcy prediction research, especially that employing discriminant analysis, has been around for decades. The early research focuses on the ability of the linear MDA at correctly classifying firms as bankrupt or non-bankrupt. It has been shown that MDA does a good job (better than univariate analysis) at predicting bankruptcy. The subsequent literature focuses on the model specifications, testing the underlying assumptions of the models. It has been clearly documented that the underlying assumptions are often (if not always) violated. Furthermore, most early research employs accounting ratios, which are backward-looking, as the predictors of bankruptcy. Over time, the importance of market variables, which are forward-looking, has been documented. The consensus has been that a mix of accounting ratios and some market variables are best at predicting bankruptcy.

Through the use of linear, quadratic, and nonparametric MDA, along with using sets of only market variables and two different sets of a mix of accounting ratios and market variables, we have two main findings. First, market variables alone are best at correctly classifying bankrupt firms. This is consistent with the hypothesis that market variables should be better in a predictive model since they take into account future prospects, whereas accounting ratios are only a snapshot in time and are always reported after they have taken effect. This finding is consistent when performing an out-of-sample procedure. Second, the nonparametric MDA displays the highest overall accuracy at correctly classifying firms, no matter which set of variables is used. This is important because it allows us to predict bankruptcy without necessarily having to worry about the underlying assumptions. 


\section{CHAPTER 4: NEURAL NETWORKS}

\subsection{Introduction}

While bankruptcy prediction has been a very fruitful area of research for decades, it is still in its infancy in terms of accuracy. Most models that are used for bankruptcy prediction hinge on the assumption that the data independent and normally distributed. Even though it has been documented that many of the models used in previous studies are incompatible with the data, there still have not been many solutions. We have demonstrated in the previous chapter that the assumptions are violated for many variables, whether they are accounting ratios or market and microstructure variables. Therefore, traditional models, while somewhat accurate, are not the final solution.

There is always the trade-off between the complexity and accuracy of the model. However, with the improvement in technology, some of the more complicated models are much easier to use now. Therefore, settling for simpler models is less acceptable now. This has led to the application of neural networks in many areas, specifically in bankruptcy prediction.

The use of neural networks has been a positive turning point. Most relations between variables are much more complex than allowed by traditional models. Using this methodology, along with proper and broader variable selection, promising results shall follow. We will apply the neural network methodology, which has shown to be a more robust prediction methodology than older models to bankruptcy prediction, using both forward-looking variables (market and microstructure variables) and backward-looking variables (accounting ratios). While neural networks have been used previously, this will be the first study to use all of these variables. 
The most important findings are that the neural networks greatly outperform the traditional models. Furthermore, the neural network performs best five years before bankruptcy. In terms of prediction, this is an improvement when compared to the univariate analysis and the multivariate discriminant analysis. Five years before bankruptcy, the neural network using certain subsets of variables is able to correctly classify bankrupt $97 \%$ of the firms. A mix of market variables and accounting ratios leads to the highest classification rates. Namely, the market variables price, the standard deviation of the price, and the bid-ask spread, along with the accounting ratios net income to sales, working capital to total assets, and current liabilities to total assets are best at correctly classifying bankrupt firms and also show the lowest overall misclassification rates.

This study attempts to describe and distinguish these two groups. The remainder of this paper is organized as follows: Section 4.2 reviews the previous literature associated with bankruptcy univariate analysis. Section 4.3 discusses the data used in this study. Section 4.4 describes the methodology. Section 4.5 discusses the results, and Section 1.6 summarizes and concludes.

\subsection{Literature Review}

Salchenberger et al. (1992) study the ability of neural networks to predict the probability of failure of savings and loan associations, and compare the performance of neural networks with that of traditional models. They conclude that neural networks outperform the traditional models at correctly classifying firms as failed or nonfailed.

Following these results and the prior literature that has found that the assumptions underlying most traditional models are violated when studying bankruptcy 
prediction, Coats and Fant (1993) use neural networks to test whether or not this model can outperform Altman's traditional Z score model using the five same ratios as Altman. While the MDA performs better during the year of the going-concern opinion, the neural network performs better in the year leading up to it. Therefore, the neural network is more desirable since earlier prediction is always preferable to later prediction.

Boritz and Kennedy (1995) test different neural network models and also compare these models to the traditional bankruptcy prediction models. The predictive ability of the neural networks vary across different techniques, and the predictive power is highly sensitive to the set of predictors used and to sampling error. Leshno and Spector (1996) perform a similar study and confirm so of the previous findings. They also find that including financial data from periods outside of the bankruptcy period enhance the predictive ability of the model. Also, if an enhancement model is used, which makes the model very strong, then the model becomes too specific to the data used, rather than as a predictive model.

Jo et al. (1997) compare the accuracy of neural networks and multivariate discriminant analysis at predicting bankruptcy of Korean firms. Using different specifications and variables selection methods, they find that neural networks outperform the traditional multivariate discriminant analysis.

Yang et al. (1999) study different neural network models and also compare them to the traditional predictive models. Unlike the prior literature on bankruptcy prediction employing neural networks, they find that discriminant analysis outperformed the neural network models, especially at correctly classifying bankrupt firms. 


\subsection{Data}

The list of bankrupt firms was obtained from bankruptcydata.com. The list includes companies the filed for bankruptcy from January 1995 to December 2010. The subsample of non-bankrupt firms comes from the entire database of Compustat, consisting of firms that did not file for bankruptcy during our sample period. The accounting ratios for all firms, bankrupt and non-bankrupt, are obtained from Compustat. The market variables for these firms were obtained from CRSP.

\subsection{Methodology}

A neural network is a collection of elements that are connected by nodes. It is designed after the human brain. Unlike traditional models that require stringent assumptions, the neural network tries to find connections between the input and output variables, regardless the distribution of the variables. A weighted combination of the inputs is created, called NET. The output can be a weighted combination of the inputs or a nonlinear transformation of the NET. Two types of neural networks are used: multilayer perceptron and radial basis function networks. Like all neural networks, these types of neural networks make no assumptions about the underlying probability density functions.

The multi-layer perceptron consists of three or more layers: an input and output layer with one or more hidden layers. Each node in a layer connects with a specific weight to every node in the proceeding layer. This is followed by a learning process. The weights change every time a new piece of data is processed, and this is based on the amount of error in the output when compared to the expected result. This is done through backpropagation, which minimizes the objective function. This optimization process is 
most useful for neural networks that do not have any feedback. The radial basis functions are similar, but they are a more specialized activation function.

\subsection{Empirical Results}

Since the set of market variables and two subsets of accounting and market variables have proven to be the best in the previous chapters, we will focus on those in this chapter. We begin with the Multi-Layer Perceptron results, and then follow with the Radial basis functions.

Starting with the market variables, the multi-layer perceptron correctly classifies bankrupt firms $86 \%, 81 \%, 80 \%, 92 \%$, and $87 \%$ of the time in years one through five,

and $88 \%, 81 \%, 77 \%, 88 \%$, and $92 \%$ for nonbankrupt firms in years one through five. The classification rates are higher than those for traditional models, but more important, the model is better at classifying both bankrupt and non-bankrupt firms five years before bankruptcy than it is at classifying firms one year before bankruptcy. As a predictive model, this is desirable. The overall misclassification rates are $12.5 \%$ and $10 \%$ in years one and five, respectively.

This is promising on two fronts. First, as mentioned above, market variables are forward-looking variables. Therefore, in a predictive framework, the input variables should be those that contain information about the future. Accounting ratios are not useless, but they do contain mostly stale information. The above results validate this. Second, a less stringent yet more technical model is desirable because financial distress, and the path taken to get there, is not a simple, clear path. Univariate analysis and multivariate discriminant analysis are not poor statistical techniques for certain studies, 
but they lack the precision and breadth that the neural network allows. This is also evident in the following results

Table 11

Results of Multi Layer Perceptron : Accounting variables

YEAR 1

VARIABLE SUMMARY

\begin{tabular}{ccc}
\hline ROLE & LEVEL & COUNT \\
\hline INPUT & INTERVAL & 17 \\
TARGET & TARGET & 1 \\
\hline
\end{tabular}

FIT STATISTICS

\begin{tabular}{|c|c|c|}
\hline $\begin{array}{l}\text { FIT } \\
\text { STATISTIC }\end{array}$ & STATISTIC LABEL & $\begin{array}{l}\text { STATISTIC } \\
\text { VALUE }\end{array}$ \\
\hline _ DFT_ & Total Degrees of Freedom. & 255 \\
\hline _ DFE_ & Degrees of Freedom for Error. & 140 \\
\hline _DFM_ & Model Degrees of Freedom. & 115 \\
\hline $\mathrm{NW}_{-}$ & Number of Estimated Weights. & 115 \\
\hline $\mathrm{AIC}_{-}$ & Akaike's Information Criterion. & 239.105 \\
\hline SBC_ $_{-}$ & Schwarz's Bayesian Criterion. & 646.351 \\
\hline _ASE_ & Average Squared Error. & 0.003 \\
\hline MAX_ & Maximum Absolute Error. & 0.496 \\
\hline DIV_ & Divisor for ASE. & 510 \\
\hline NOBS_ & Sum of Frequencies. & 255 \\
\hline _RASE_ & Root Average Squared Error. & 0.059 \\
\hline SSE_ & Sum of Squared Errors. & 1.755 \\
\hline SSUMW & Sum of Case Weights Times Freq. & 510 \\
\hline _FPE_ & Final Prediction Error. & 0.009 \\
\hline MSE_ & Mean Squared Error. & 0.006 \\
\hline _RFPE_ & Root Final Prediction Error. & 0.095 \\
\hline _RMSE_ & Root Mean Squared Error. & 0.079 \\
\hline _AVERR_ & Average Error Function. & 0.018 \\
\hline _ERR_ & Error Function. & 9.105 \\
\hline${ }_{-} \mathrm{MISC}_{-}$ & Misclassification Rate. & 0 \\
\hline WRONG & Number of Wrong Classifications. & 0 \\
\hline
\end{tabular}


CLASSIFICATION SUMMARY

\begin{tabular}{lllccc}
\hline & & PERCENT & PERCENT & & \multicolumn{2}{c}{$\begin{array}{l}\text { PERCENT } \\
\text { OF } \\
\text { TARGET }\end{array}$} & PREDICT & TARGET & PFEDICT & COUNT & TOTAL \\
\hline BANKRUPT & BANKRUPT & 100 & 100 & 138 & 54.1176 \\
NONBANKRUPT & NONBANKRUPT & 100 & 100 & 117 & 45.8824 \\
\hline
\end{tabular}

YEAR 2

VARIABLE SUMMARY

\begin{tabular}{lll}
\hline ROLE & LEVEL & COUNT \\
\hline INPUT & INTERVAL & 17 \\
TARGET & TARGET & 1 \\
\hline
\end{tabular}

FIT STATISTICS

\begin{tabular}{|c|c|c|}
\hline $\begin{array}{l}\text { FIT } \\
\text { STATISTIC }\end{array}$ & STATISTIC LABEL & $\begin{array}{l}\text { STATISTIC } \\
\text { VALUE }\end{array}$ \\
\hline DFT_ $_{-}$ & Total Degrees of Freedom. & 242 \\
\hline _DFE_ & Degrees of Freedom for Error. & 127 \\
\hline _DFM_ & Model Degrees of Freedom. & 115 \\
\hline $\mathrm{NW}_{-}$ & Number of Estimated Weights. & 115 \\
\hline _AIC_ & Akaike's Information Criterion. & 233.523 \\
\hline${ }_{-} \mathrm{SBC}_{-}$ & Schwarz's Bayesian Criterion. & 634.751 \\
\hline $\mathrm{ASE}_{-}$ & Average Squared Error. & 0.002 \\
\hline _MAX_ & Maximum Absolute Error. & 0.476 \\
\hline DIV_ & Divisor for ASE. & 484 \\
\hline NOBS_ & Sum of Frequencies. & 242 \\
\hline _RASE_ & Root Average Squared Error. & 0.04 \\
\hline SSE_ & Sum of Squared Errors. & 0.792 \\
\hline SUMW_ & Sum of Case Weights Times Freq. & 484 \\
\hline _FPE_ & Final Prediction Error. & 0.005 \\
\hline $\mathrm{MSE}_{-}$ & Mean Squared Error. & 0.003 \\
\hline _RFPE_ & Root Final Prediction Error. & 0.068 \\
\hline _RMSE_ & Root Mean Squared Error. & 0.056 \\
\hline _AVERR_ & Average Error Function. & 0.007 \\
\hline _ERR_ & Error Function. & 3.523 \\
\hline${ }_{-}$MISC_ & Misclassification Rate. & 0 \\
\hline WRONG & Number of Wrong Classifications. & 0 \\
\hline
\end{tabular}


CLASSIFICATION SUMMARY

\begin{tabular}{lllccc}
\hline & & PERCENT & PERCENT & & \multicolumn{2}{c}{$\begin{array}{l}\text { PERCENT } \\
\text { OF } \\
\text { TARGET }\end{array}$} & PREDICT & TARGET & PFEDICT & COUNT & TOTAL \\
\hline BANKRUPT & BANKRUPT & 100 & 100 & 129 & 53.3058 \\
NONBANKRUPT & NONBANKRUPT & 100 & 100 & 113 & 46.6942 \\
\hline
\end{tabular}

YEAR 3

VARIABLE SUMMARY

\begin{tabular}{lll}
\hline ROLE & LEVEL & COUNT
\end{tabular}

\begin{tabular}{lll}
\hline INPUT & INTERVAL & 17
\end{tabular}

TARGET TARGET 1

FIT STATISTICS

\begin{tabular}{|c|c|c|}
\hline $\begin{array}{l}\text { FIT } \\
\text { STATISTIC } \\
\end{array}$ & STATISTIC LABEL & $\begin{array}{l}\text { STATISTIC } \\
\text { VALUE }\end{array}$ \\
\hline DFT_ $_{-}$ & Total Degrees of Freedom. & 219 \\
\hline DFE_ & Degrees of Freedom for Error. & 104 \\
\hline DFM & Model Degrees of Freedom. & 115 \\
\hline NW_ & Number of Estimated Weights. & 115 \\
\hline AIC_ & Akaike's Information Criterion. & 244.337 \\
\hline $\mathrm{SBC}_{-}$ & Schwarz's Bayesian Criterion. & 634.081 \\
\hline _ASE_ & Average Squared Error. & 0.006 \\
\hline MAX_ & Maximum Absolute Error. & 0.486 \\
\hline DIV_ & Divisor for ASE. & 438 \\
\hline _NOBS_ & Sum of Frequencies. & 219 \\
\hline _RASE_ & Root Average Squared Error. & 0.079 \\
\hline $\mathrm{SSE}_{-}$ & Sum of Squared Errors. & 2.699 \\
\hline _SUMW_ & Sum of Case Weights Times Freq. & 438 \\
\hline _FPE_ & Final Prediction Error. & 0.02 \\
\hline _MSE_ & Mean Squared Error. & 0.013 \\
\hline _RFPE_ & Root Final Prediction Error. & 0.141 \\
\hline _RMSE_ & Root Mean Squared Error. & 0.114 \\
\hline AVERR_ & Average Error Function. & 0.033 \\
\hline ERR_ & Error Function. & 14.337 \\
\hline _MISC_ & Misclassification Rate. & 0 \\
\hline WRONG & Number of Wrong Classifications. & 0 \\
\hline
\end{tabular}


CLASSIFICATION SUMMARY

\begin{tabular}{|c|c|c|c|c|c|}
\hline TARGET & PREDICT & $\begin{array}{l}\text { PERCENT } \\
\text { OF } \\
\text { TARGET }\end{array}$ & $\begin{array}{l}\text { PERCENT } \\
\text { OF } \\
\text { PREDICT }\end{array}$ & COUNT & $\begin{array}{l}\text { PERCENT } \\
\text { OF } \\
\text { TOTAL }\end{array}$ \\
\hline BANKRUPT & BANKRUPT & 100 & 100 & 108 & 49.3151 \\
\hline NONBANKRUPT & NONBANKRUPT & 100 & 100 & 111 & 50.6849 \\
\hline
\end{tabular}

YEAR 4

VARIABLE SUMMARY

\begin{tabular}{lll} 
ROLE & LEVEL & COUNT \\
\hline INPUT & INTERVAL & 17
\end{tabular}

TARGET TARGET 1

FIT STATISTICS

\begin{tabular}{|c|c|c|}
\hline $\begin{array}{l}\text { FIT } \\
\text { STATISTIC }\end{array}$ & STATISTIC LABEL & $\begin{array}{l}\text { STATISTIC } \\
\text { VALUE }\end{array}$ \\
\hline DFT $_{-}$ & Total Degrees of Freedom. & 195 \\
\hline _DFE_ & Degrees of Freedom for Error. & 80 \\
\hline _DFM_ & Model Degrees of Freedom. & 115 \\
\hline $\mathrm{NW}_{-}$ & Number of Estimated Weights. & 115 \\
\hline $\mathrm{AIC}_{-}$ & Akaike's Information Criterion. & 242.227 \\
\hline${ }_{-} \mathrm{SBC}_{-}$ & Schwarz's Bayesian Criterion. & 618.622 \\
\hline _ASE_ & Average Squared Error. & 0.006 \\
\hline _MAX_ & Maximum Absolute Error. & 0.465 \\
\hline _DIV_ & Divisor for ASE. & 390 \\
\hline NOBS_ & Sum of Frequencies. & 195 \\
\hline _RASE_ & Root Average Squared Error. & 0.078 \\
\hline $\mathrm{SSE}_{-}$ & Sum of Squared Errors. & 2.385 \\
\hline SUMW_ & Sum of Case Weights Times Freq. & 390 \\
\hline _FPE_ & Final Prediction Error. & 0.024 \\
\hline _MSE_ & Mean Squared Error. & 0.015 \\
\hline _RFPE_ & Root Final Prediction Error. & 0.154 \\
\hline _RMSE_ & Root Mean Squared Error. & 0.122 \\
\hline _AVERR_ & Average Error Function. & 0.031 \\
\hline _ERR_ & Error Function. & 12.227 \\
\hline _MISC_ & Misclassification Rate. & 0 \\
\hline WRONG & Number of Wrong Classifications. & 0 \\
\hline
\end{tabular}


CLASSIFICATION SUMMARY

\begin{tabular}{llcccc}
\hline & & $\begin{array}{l}\text { PERCENT } \\
\text { OF } \\
\text { TARGET }\end{array}$ & $\begin{array}{l}\text { PERCENT } \\
\text { OF } \\
\text { TARGET }\end{array}$ & $\begin{array}{l}\text { PERICT } \\
\text { COUNT }\end{array}$ & $\begin{array}{l}\text { OF } \\
\text { TOTAL }\end{array}$ \\
\hline BANKRUPT & BANKRUPT & 100 & 100 & 85 & 43.5897 \\
NONBANKRUPT & NONBANKRUPT & 100 & 100 & 110 & 56.4103 \\
\hline
\end{tabular}

YEAR 5

\begin{tabular}{lll}
\multicolumn{3}{c}{ VARIABLE SUMMARY } \\
\hline ROLE & LEVEL & COUNT \\
\hline INPUT & INTERVAL & 17 \\
TARGET & TARGET & 1 \\
\hline \multicolumn{3}{c}{ FIT STATISTICS }
\end{tabular}

\begin{tabular}{|c|c|c|}
\hline $\begin{array}{l}\text { FIT } \\
\text { STATISTIC }\end{array}$ & STATISTIC LABEL & $\begin{array}{l}\text { STATISTIC } \\
\text { VALUE }\end{array}$ \\
\hline DFT $_{-}$ & Total Degrees of Freedom. & 168 \\
\hline _DFE_ & Degrees of Freedom for Error. & 53 \\
\hline _DFM_ & Model Degrees of Freedom. & 115 \\
\hline $\mathrm{NW}_{-}$ & Number of Estimated Weights. & 115 \\
\hline $\mathrm{AIC}_{-}$ & Akaike's Information Criterion. & 238.324 \\
\hline _SBC$_{-}$ & Schwarz's Bayesian Criterion. & 597.58 \\
\hline _ASE_ & Average Squared Error. & 0.004 \\
\hline MAX_ & Maximum Absolute Error. & 0.373 \\
\hline DIV $_{-}$ & Divisor for ASE. & 336 \\
\hline NOBS_ & Sum of Frequencies. & 168 \\
\hline _RASE_ & Root Average Squared Error. & 0.065 \\
\hline _SSE_ & Sum of Squared Errors. & 1.422 \\
\hline SUMW_ & Sum of Case Weights Times Freq. & 336 \\
\hline _FPE_ & Final Prediction Error. & 0.023 \\
\hline $\mathrm{MSE}_{-}$ & Mean Squared Error. & 0.013 \\
\hline _RFPE_ & Root Final Prediction Error. & 0.15 \\
\hline _RMSE_ & Root Mean Squared Error. & 0.116 \\
\hline _AVERR_ & Average Error Function. & 0.025 \\
\hline ERR_ & Error Function. & 8.324 \\
\hline _MISC_ & Misclassification Rate. & 0 \\
\hline WRONG & Number of Wrong Classifications. & 0 \\
\hline
\end{tabular}




\section{CLASSIFICATION SUMMARY}

\begin{tabular}{llcccc}
\hline & & PERCENT & PERCENT & & \multicolumn{2}{l}{ PERCENT } \\
& & OF & OF \\
TARGET & PREDICT & TARGET & PREDICT & COUNT & TOTAL \\
\hline BANKRUPT & BANKRUPT & 100 & 100 & 70 & 41.6667 \\
NONBANKRUPT & NONBANKRUPT & 100 & 100 & 98 & 58.3333 \\
\hline
\end{tabular}

Results of Multi Layer Perceptron : Market variables

YEAR 1

VARIABLE SUMMARY

ROLE LEVEL COUNT

INPUT INTERVAL 5

TARGET TARGET 1

FIT STATISTICS

\begin{tabular}{|c|c|c|}
\hline $\begin{array}{l}\text { FIT } \\
\text { STATISTIC }\end{array}$ & STATISTIC LABEL & $\begin{array}{l}\text { STATISTIC } \\
\text { VALUE }\end{array}$ \\
\hline $\mathrm{DFT}_{-}$ & Total Degrees of Freedom. & 255 \\
\hline DFE_ & Degrees of Freedom for Error. & 212 \\
\hline DFM_ & Model Degrees of Freedom. & 43 \\
\hline $\mathrm{NW}_{-}$ & Number of Estimated Weights. & 43 \\
\hline _ $\mathrm{AIC}_{-}$ & Akaike's Information Criterion. & 254.472 \\
\hline $\mathrm{SBC}_{-}$ & Schwarz's Bayesian Criterion. & 406.746 \\
\hline _ASE_ & Average Squared Error. & 0.102 \\
\hline _MAX_ & Maximum Absolute Error. & 0.937 \\
\hline${ }_{-} \mathrm{DIV}$ & Divisor for ASE. & 510 \\
\hline _NOBS_ & Sum of Frequencies. & 255 \\
\hline _RASE_ & Root Average Squared Error. & 0.319 \\
\hline SSE_ & Sum of Squared Errors. & 51.802 \\
\hline _SUMW_ & Sum of Case Weights Times Freq. & 510 \\
\hline _FPE_ & Final Prediction Error. & 0.143 \\
\hline _MSE_ & Mean Squared Error. & 0.122 \\
\hline _RFPE_ & Root Final Prediction Error. & 0.378 \\
\hline _RMSE_ & Root Mean Squared Error. & 0.35 \\
\hline _AVERR_ & Average Error Function. & 0.33 \\
\hline ERR_ & Error Function. & 168.472 \\
\hline _MISC_ & Misclassification Rate. & 0.125 \\
\hline WRONG & Number of Wrong Classifications. & 32 \\
\hline
\end{tabular}


CLASSIFICATION SUMMARY

\begin{tabular}{llcccc}
\hline & & PERCENT & PERCENT & & \multicolumn{2}{l}{ PERCENT } \\
& & OF & OF & \\
TARGET & PREDICT & TARGET & PREDICT & COUNT & TOTAL \\
\hline BANKRUPT & BANKRUPT & 86.3014 & 91.3043 & 126 & 49.4118 \\
NONBANKRUPT & BANKRUPT & 13.6986 & 17.094 & 20 & 7.8431 \\
BANKRUPT & NONBANKRUPT & 11.0092 & 8.6957 & 12 & 4.7059 \\
NONBANKRUPT & NONBANKRUPT & 88.9908 & 82.906 & 97 & 38.0392 \\
\hline
\end{tabular}

YEAR 2

VARIABLE SUMMARY

\begin{tabular}{lll}
\hline ROLE & LEVEL \\
\hline
\end{tabular}

INPUT INTERVAL 5

TARGET TARGET 1

FIT STATISTICS

\begin{tabular}{|c|c|c|}
\hline $\begin{array}{l}\text { FIT } \\
\text { STATISTIC }\end{array}$ & STATISTIC LABEL & $\begin{array}{l}\text { STATISTIC } \\
\text { VALUE }\end{array}$ \\
\hline $\mathrm{DFT}_{-}$ & Total Degrees of Freedom. & 242 \\
\hline DFE_ & Degrees of Freedom for Error. & 199 \\
\hline DFM & Model Degrees of Freedom. & 43 \\
\hline NW_ & Number of Estimated Weights. & 43 \\
\hline _AIC_ & Akaike's Information Criterion. & 297.655 \\
\hline $\mathrm{SBC}_{-}$ & Schwarz's Bayesian Criterion. & 447.679 \\
\hline _ASE_ & Average Squared Error. & 0.139 \\
\hline MAX & Maximum Absolute Error. & 0.912 \\
\hline DIV & Divisor for ASE. & 484 \\
\hline _NOBS & Sum of Frequencies. & 242 \\
\hline _RASE_ & Root Average Squared Error. & 0.373 \\
\hline SSE_ & Sum of Squared Errors. & 67.439 \\
\hline SUMW_ & Sum of Case Weights Times Freq. & 484 \\
\hline FPE_ & Final Prediction Error. & 0.2 \\
\hline MSE & Mean Squared Error. & 0.169 \\
\hline
\end{tabular}




\begin{tabular}{|c|c|c|}
\hline RFPE_ & Root Final Prediction Error. & 0.447 \\
\hline _RMSE_ & Root Mean Squared Error. & 0.412 \\
\hline _AVERR_ & Average Error Function. & 0.437 \\
\hline ERR_ & Error Function. & 211.655 \\
\hline MISC$_{-}$ & Misclassification Rate. & 0.19 \\
\hline WRONG & Number of Wrong Classifications. & 46 \\
\hline
\end{tabular}

CLASSIFICATION SUMMARY

\begin{tabular}{llcccc}
\hline & & PERCENT & PERCENT & & \multicolumn{2}{l}{$\begin{array}{l}\text { PERCENT } \\
\text { OF }\end{array}$} \\
TARGET & PREDICT & TARGET & $\begin{array}{l}\text { OF } \\
\text { PREDICT }\end{array}$ & COUNT & TOTAL \\
\hline BANKRUPT & BANKRUPT & 81.203 & 83.7209 & 108 & 44.6281 \\
NONBANKRUPT & BANKRUPT & 18.797 & 22.1239 & 25 & 10.3306 \\
BANKRUPT & NONBANKRUPT & 19.2661 & 16.2791 & 21 & 8.6777 \\
NONBANKRUPT & NONBANKRUPT & 80.7339 & 77.8761 & 88 & 36.3636 \\
\hline
\end{tabular}

YEAR 3

VARIABLE SUMMARY

\begin{tabular}{lll}
\hline ROLE & LEVEL & COUNT \\
\hline INPUT & INTERVAL & 5
\end{tabular}

TARGET TARGET 1

FIT STATISTICS

\begin{tabular}{|c|c|c|}
\hline $\begin{array}{l}\text { FIT } \\
\text { STATISTIC }\end{array}$ & STATISTIC LABEL & $\begin{array}{l}\text { STATISTIC } \\
\text { VALUE }\end{array}$ \\
\hline DFT_ $_{-}$ & Total Degrees of Freedom. & 219 \\
\hline _DFE_ & Degrees of Freedom for Error. & 176 \\
\hline _DFM_ & Model Degrees of Freedom. & 43 \\
\hline $\mathrm{NW}_{-}$ & Number of Estimated Weights. & 43 \\
\hline $\mathrm{AIC}_{-}$ & Akaike's Information Criterion. & 287.3 \\
\hline${ }_{-} \mathrm{SBC}$ & Schwarz's Bayesian Criterion. & 433.03 \\
\hline ASE_ & Average Squared Error. & 0.153 \\
\hline _MAX_ & Maximum Absolute Error. & 0.923 \\
\hline DIV $_{-}$ & Divisor for ASE. & 438 \\
\hline NOBS & Sum of Frequencies. & 219 \\
\hline RASE_ & Root Average Squared Error. & 0.391 \\
\hline _SSE_ & Sum of Squared Errors. & 66.834 \\
\hline SUMW_ & Sum of Case Weights Times Freq. & 438 \\
\hline FPE & Final Prediction Error. & 0.227 \\
\hline
\end{tabular}




\begin{tabular}{llc}
\hline _MSE_ & Mean Squared Error. & 0.19 \\
${ }_{-}$RFPE_ & Root Final Prediction Error. & 0.477 \\
${ }_{-}$RMSE__ & Root Mean Squared Error. & 0.436 \\
${ }_{-}$AVERR_ & Average Error Function. & 0.46 \\
${ }_{-}$ERR_ & Error Function. & 201.3 \\
${ }_{\text {MISC }}{ }_{-}$ & Misclassification Rate. & 0.21 \\
\hline
\end{tabular}

CLASSIFICATION SUMMARY

\begin{tabular}{llcccc}
\hline & & PERCENT & PERCENT & & \multicolumn{2}{l}{$\begin{array}{l}\text { PERCENT } \\
\text { OF }\end{array}$} \\
TARGET & PREDICT & TARGET & $\begin{array}{l}\text { OF } \\
\text { PREDICT }\end{array}$ & COUNT & TOTAL \\
\hline BANKRUPT & BANKRUPT & 80.3922 & 75.9259 & 82 & 37.4429 \\
NONBANKRUPT & BANKRUPT & 19.6078 & 18.018 & 20 & 9.1324 \\
BANKRUPT & NONBANKRUPT & 22.2222 & 24.0741 & 26 & 11.8721 \\
NONBANKRUPT & NONBANKRUPT & 77.7778 & 81.982 & 91 & 41.5525 \\
\hline
\end{tabular}

YEAR 4

VARIABLE SUMMARY

\begin{tabular}{lll}
\hline ROLE & LEVEL & COUNT \\
\hline INPUT & INTERVAL & 5 \\
TARGET & TARGET & 1 \\
\hline
\end{tabular}

FIT STATISTICS

\begin{tabular}{|c|c|c|}
\hline $\begin{array}{l}\text { FIT } \\
\text { STATISTIC } \\
\end{array}$ & STATISTIC LABEL & $\begin{array}{l}\text { STATISTIC } \\
\text { VALUE }\end{array}$ \\
\hline DFT_ $_{-}$ & Total Degrees of Freedom. & 195 \\
\hline _DFE_ & Degrees of Freedom for Error. & 152 \\
\hline _DFM_ & Model Degrees of Freedom. & 43 \\
\hline $\mathrm{NW}_{-}$ & Number of Estimated Weights. & 43 \\
\hline _AIC_ & Akaike's Information Criterion. & 190.354 \\
\hline${ }_{-} \mathrm{SBC}_{-}$ & Schwarz's Bayesian Criterion. & 331.093 \\
\hline $\mathrm{ASE}_{-}$ & Average Squared Error. & 0.081 \\
\hline -MAX_ & Maximum Absolute Error. & 0.941 \\
\hline $\mathrm{DIV}_{-}$ & Divisor for ASE. & 390 \\
\hline _NOBS_ & Sum of Frequencies. & 195 \\
\hline _RASE_ & Root Average Squared Error. & 0.285 \\
\hline _SSE_ & Sum of Squared Errors. & 31.766 \\
\hline SUMW & Sum of Case Weights Times Freq. & 390 \\
\hline
\end{tabular}




\begin{tabular}{|c|c|c|}
\hline FPE_ & Final Prediction Error. & 0.128 \\
\hline MSE_ & Mean Squared Error. & 0.104 \\
\hline RFPE_ & Root Final Prediction Error. & 0.357 \\
\hline RMSE_ & Root Mean Squared Error. & 0.323 \\
\hline AVERR_ & Average Error Function. & 0.268 \\
\hline ERR_ & Error Function. & 104.354 \\
\hline MISC_ & Misclassification Rate. & 0.097 \\
\hline WRONG & Number of Wrong Classifications. & 19 \\
\hline
\end{tabular}

YEAR 5

VARIABLE SUMMARY

\begin{tabular}{lll}
\hline ROLE & LEVEL & COUNT \\
\hline INPUT & INTERVAL & 5
\end{tabular}

TARGET TARGET 1

FIT STATISTICS

\begin{tabular}{|c|c|c|}
\hline $\begin{array}{l}\text { FIT } \\
\text { STATISTIC }\end{array}$ & STATISTIC LABEL & $\begin{array}{l}\text { STATISTIC } \\
\text { VALUE }\end{array}$ \\
\hline DFT $_{-}$ & Total Degrees of Freedom. & 168 \\
\hline _DFE_ & Degrees of Freedom for Error. & 125 \\
\hline _DFM & Model Degrees of Freedom. & 43 \\
\hline $\mathrm{NW}_{-}$ & Number of Estimated Weights. & 43 \\
\hline $\mathrm{AIC}_{-}$ & Akaike's Information Criterion. & 186.053 \\
\hline $\mathrm{SBC}_{-}$ & Schwarz's Bayesian Criterion. & 320.384 \\
\hline $\mathrm{ASE}_{-}$ & Average Squared Error. & 0.092 \\
\hline _MAX_ & Maximum Absolute Error. & 0.954 \\
\hline DIV $_{-}$ & Divisor for ASE. & 336 \\
\hline NOBS_ & Sum of Frequencies. & 168 \\
\hline _RASE_ & Root Average Squared Error. & 0.303 \\
\hline SSE & Sum of Squared Errors. & 30.768 \\
\hline
\end{tabular}




\begin{tabular}{|c|c|c|}
\hline SUMW_ & Sum of Case Weights Times Freq. & 336 \\
\hline _FPE_ & Final Prediction Error. & 0.155 \\
\hline $\mathrm{MSE}_{-}$ & Mean Squared Error. & 0.123 \\
\hline RFPE_ & Root Final Prediction Error. & 0.393 \\
\hline RMSE_ & Root Mean Squared Error. & 0.351 \\
\hline _AVERR_ & Average Error Function. & 0.298 \\
\hline ERR_ & Error Function. & 100.053 \\
\hline _MISC_ & Misclassification Rate. & 0.101 \\
\hline WRONG_ & Number of Wrong Classifications. & 17 \\
\hline
\end{tabular}

\section{CLASSIFICATION SUMMARY}

\begin{tabular}{|c|c|c|c|c|c|}
\hline TARGET & PREDICT & $\begin{array}{l}\text { PERCENT } \\
\text { OF } \\
\text { TARGET }\end{array}$ & $\begin{array}{l}\text { PERCENT } \\
\text { OF } \\
\text { PREDICT }\end{array}$ & COUNT & $\begin{array}{l}\text { PERCENT } \\
\text { OF } \\
\text { TOTAL }\end{array}$ \\
\hline BANKRUPT & BANKRUPT & 87.3239 & 88.5714 & 62 & 36.9048 \\
\hline NONBANKRUPT & BANKRUPT & 12.6761 & 9.1837 & 9 & 5.3571 \\
\hline BANKRUPT & NONBANKRUPT & 8.2474 & 11.4286 & 8 & 4.7619 \\
\hline NONBANKRUPT & NONBANKRUPT & 91.7526 & 90.8163 & 89 & 52.9762 \\
\hline
\end{tabular}


Results of Multi Layer Perceptron : Market variables without spread and hi lo bid ask spread

YEAR 1

VARIABLE SUMMARY

\begin{tabular}{lll}
\hline ROLE & LEVEL & COUNT \\
\hline INPUT & INTERVAL & 4
\end{tabular}

TARGET TARGET 1

FIT STATISTICS

\begin{tabular}{|c|c|c|}
\hline $\begin{array}{l}\text { FIT } \\
\text { STATISTIC }\end{array}$ & STATISTIC LABEL & $\begin{array}{l}\text { STATISTIC } \\
\text { VALUE }\end{array}$ \\
\hline DFT_ $_{-}$ & Total Degrees of Freedom. & 255 \\
\hline _DFE_ & Degrees of Freedom for Error. & 218 \\
\hline _DFM_ & Model Degrees of Freedom. & 37 \\
\hline $\mathrm{NW}_{-}$ & Number of Estimated Weights. & 37 \\
\hline _AIC_ & Akaike's Information Criterion. & 296.65 \\
\hline $\mathrm{SBC}_{-}$ & Schwarz's Bayesian Criterion. & 427.676 \\
\hline ASE_ & Average Squared Error. & 0.141 \\
\hline -MAX_ & Maximum Absolute Error. & 0.959 \\
\hline DIV_ & Divisor for ASE. & 510 \\
\hline _NOBS_ & Sum of Frequencies. & 255 \\
\hline _RASE_ & Root Average Squared Error. & 0.376 \\
\hline _SSE_ & Sum of Squared Errors. & 72.028 \\
\hline SUMW_ & Sum of Case Weights Times Freq. & 510 \\
\hline $\mathrm{FPE}_{-}$ & Final Prediction Error. & 0.189 \\
\hline _MSE_ & Mean Squared Error. & 0.165 \\
\hline RFPE_ & Root Final Prediction Error. & 0.435 \\
\hline RMSE_ & Root Mean Squared Error. & 0.406 \\
\hline _AVERR_ & Average Error Function. & 0.437 \\
\hline _ERR_ & Error Function. & 222.65 \\
\hline _MISC_ & Misclassification Rate. & 0.196 \\
\hline WRONG & Number of Wrong Classifications. & 50 \\
\hline
\end{tabular}


CLASSIFICATION SUMMARY

\begin{tabular}{llccccc}
\hline & & PERCENT & PERCENT & & \multicolumn{2}{l}{ PERCENT } \\
& & OF & OF & \\
TARGET & PREDICT & TARGET & PREDICT & COUNT & TOTAL \\
\hline BANKRUPT & BANKRUPT & 83.8462 & 78.9855 & 109 & 42.7451 \\
NONBANKRUPT & BANKRUPT & 16.1538 & 17.9487 & 21 & 8.2353 \\
BANKRUPT & NONBANKRUPT & 23.2 & 21.0145 & 29 & 11.3725 \\
NONBANKRUPT & NONBANKRUPT & 76.8 & 82.0513 & 96 & 37.6471 \\
\hline
\end{tabular}

YEAR 2

VARIABLE SUMMARY

\begin{tabular}{lll}
\hline ROLE & LEVEL & COUNT \\
& & \\
\hline INPUT & INTERVAL & 4
\end{tabular}

TARGET TARGET 1

FIT STATISTICS

\begin{tabular}{|c|c|c|}
\hline $\begin{array}{l}\text { FIT } \\
\text { STATISTIC }\end{array}$ & STATISTIC LABEL & $\begin{array}{l}\text { STATISTIC } \\
\text { VALUE }\end{array}$ \\
\hline DFT_ $_{-}$ & Total Degrees of Freedom. & 242 \\
\hline _DFE_ & Degrees of Freedom for Error. & 205 \\
\hline _DFM_ & Model Degrees of Freedom. & 37 \\
\hline $\mathrm{NW}_{-}$ & Number of Estimated Weights. & 37 \\
\hline $\mathrm{AIC}_{-}$ & Akaike's Information Criterion. & 305.497 \\
\hline${ }_{-} \mathrm{SBC}$ & Schwarz's Bayesian Criterion. & 434.588 \\
\hline _ASE_ & Average Squared Error. & 0.155 \\
\hline MAX_ & Maximum Absolute Error. & 0.919 \\
\hline $\mathrm{DIV}_{-}$ & Divisor for ASE. & 484 \\
\hline NOBS_ & Sum of Frequencies. & 242 \\
\hline _RASE_ & Root Average Squared Error. & 0.394 \\
\hline SSE_ & Sum of Squared Errors. & 74.984 \\
\hline${ }_{-} \mathrm{SUMW}$ & Sum of Case Weights Times Freq. & 484 \\
\hline FPE_ & Final Prediction Error. & 0.211 \\
\hline _MSE_ & Mean Squared Error. & 0.183 \\
\hline RFPE_ & Root Final Prediction Error. & 0.459 \\
\hline _RMSE_ & Root Mean Squared Error. & 0.428 \\
\hline _AVERR_ & Average Error Function. & 0.478 \\
\hline ERR_ & Error Function. & 231.497 \\
\hline _MISC_ & Misclassification Rate. & 0.211 \\
\hline WRONG & Number of Wrong Classifications. & 51 \\
\hline
\end{tabular}


CLASSIFICATION SUMMARY

\begin{tabular}{llccccc}
\hline & & PERCENT & PERCENT & & \multicolumn{2}{l}{ PERCENT } \\
& & OF & OF & \\
TARGET & PREDICT & TARGET & PREDICT & COUNT & TOTAL \\
\hline BANKRUPT & BANKRUPT & 77.0833 & 86.0465 & 111 & 45.8678 \\
NONBANKRUPT & BANKRUPT & 22.9167 & 29.2035 & 33 & 13.6364 \\
BANKRUPT & NONBANKRUPT & 18.3673 & 13.9535 & 18 & 7.438 \\
NONBANKRUPT & NONBANKRUPT & 81.6327 & 70.7965 & 80 & 33.0579 \\
\hline
\end{tabular}

YEAR 3

VARIABLE SUMMARY

\begin{tabular}{lll}
\hline ROLE & LEVEL & COUNT \\
& & \\
\hline INPUT & INTERVAL & 4
\end{tabular}

TARGET TARGET 1

FIT STATISTICS

\begin{tabular}{|c|c|c|}
\hline $\begin{array}{l}\text { FIT } \\
\text { STATISTIC }\end{array}$ & STATISTIC LABEL & $\begin{array}{l}\text { STATISTIC } \\
\text { VALUE }\end{array}$ \\
\hline DFT $_{-}$ & Total Degrees of Freedom. & 219 \\
\hline DFE_ & Degrees of Freedom for Error. & 182 \\
\hline _DFM_ & Model Degrees of Freedom. & 37 \\
\hline $\mathrm{NW}_{-}$ & Number of Estimated Weights. & 37 \\
\hline $\mathrm{AIC}_{-}$ & Akaike's Information Criterion. & 281.888 \\
\hline SBC_ $_{-}$ & Schwarz's Bayesian Criterion. & 407.284 \\
\hline ASE_ & Average Squared Error. & 0.157 \\
\hline _MAX_ & Maximum Absolute Error. & 0.95 \\
\hline DIV_ $_{-}$ & Divisor for ASE. & 438 \\
\hline NOBS_ & Sum of Frequencies. & 219 \\
\hline RASE_ & Root Average Squared Error. & 0.396 \\
\hline SSE_ & Sum of Squared Errors. & 68.587 \\
\hline SUMW_ & Sum of Case Weights Times Freq. & 438 \\
\hline _FPE_ & Final Prediction Error. & 0.22 \\
\hline MSE_ & Mean Squared Error. & 0.188 \\
\hline RFPE_ & Root Final Prediction Error. & 0.469 \\
\hline _RMSE_ & Root Mean Squared Error. & 0.434 \\
\hline _AVERR_ & Average Error Function. & 0.475 \\
\hline _ERR_ & Error Function. & 207.888 \\
\hline _MISC_ & Misclassification Rate. & 0.219 \\
\hline WRONG & Number of Wrong Classifications. & 48 \\
\hline
\end{tabular}


CLASSIFICATION SUMMARY

\begin{tabular}{llcccc}
\hline & & PERCENT & PERCENT & & \multicolumn{2}{l}{ PERCENT } \\
& & OF & OF \\
TARGET & PREDICT & TARGET & PREDICT & COUNT & TOTAL \\
\hline BANKRUPT & BANKRUPT & 75.8621 & 81.4815 & 88 & 40.1826 \\
NONBANKRUPT & BANKRUPT & 24.1379 & 25.2252 & 28 & 12.7854 \\
BANKRUPT & NONBANKRUPT & 19.4175 & 18.5185 & 20 & 9.1324 \\
NONBANKRUPT & NONBANKRUPT & 80.5825 & 74.7748 & 83 & 37.8995 \\
\hline
\end{tabular}

YEAR 4

VARIABLE SUMMARY

\begin{tabular}{lll}
\hline ROLE & LEVEL & COUNT \\
& & \\
\hline INPUT & INTERVAL & 4
\end{tabular}

TARGET TARGET 1

FIT STATISTICS

\begin{tabular}{|c|c|c|}
\hline $\begin{array}{l}\text { FIT } \\
\text { STATISTIC }\end{array}$ & STATISTIC LABEL & $\begin{array}{l}\text { STATISTIC } \\
\text { VALUE }\end{array}$ \\
\hline DFT $_{-}$ & Total Degrees of Freedom. & 195 \\
\hline DFE & Degrees of Freedom for Error. & 158 \\
\hline _DFM_ & Model Degrees of Freedom. & 37 \\
\hline $\mathrm{NW}_{-}$ & Number of Estimated Weights. & 37 \\
\hline $\mathrm{AIC}_{-}$ & Akaike's Information Criterion. & 200.982 \\
\hline${ }_{-} \mathrm{SBC}_{-}$ & Schwarz's Bayesian Criterion. & 322.083 \\
\hline ASE_ & Average Squared Error. & 0.102 \\
\hline _MAX_ & Maximum Absolute Error. & 0.965 \\
\hline DIV_ $_{-}$ & Divisor for ASE. & 390 \\
\hline NOBS_ & Sum of Frequencies. & 195 \\
\hline RASE_ & Root Average Squared Error. & 0.319 \\
\hline SSE_ & Sum of Squared Errors. & 39.801 \\
\hline SUMW_ & Sum of Case Weights Times Freq. & 390 \\
\hline FPE_ & Final Prediction Error. & 0.15 \\
\hline _MSE_ & Mean Squared Error. & 0.126 \\
\hline RFPE_ & Root Final Prediction Error. & 0.387 \\
\hline _RMSE_ & Root Mean Squared Error. & 0.355 \\
\hline _AVERR_ & Average Error Function. & 0.326 \\
\hline _ERR_ & Error Function. & 126.982 \\
\hline _MISC_ & Misclassification Rate. & 0.128 \\
\hline WRONG & Number of Wrong Classifications. & 25 \\
\hline
\end{tabular}


CLASSIFICATION SUMMARY

\begin{tabular}{llcccc}
\hline & & PERCENT & PERCENT & & \multicolumn{2}{l}{ PERCENT } \\
& & OF & OF \\
TARGET & PREDICT & TARGET & PREDICT & COUNT & TOTAL \\
\hline BANKRUPT & BANKRUPT & 84.8837 & 85.8824 & 73 & 37.4359 \\
NONBANKRUPT & BANKRUPT & 15.1163 & 11.8182 & 13 & 6.6667 \\
BANKRUPT & NONBANKRUPT & 11.0092 & 14.1176 & 12 & 6.1538 \\
NONBANKRUPT & NONBANKRUPT & 88.9908 & 88.1818 & 97 & 49.7436 \\
\hline
\end{tabular}

YEAR 5

VARIABLE SUMMARY

\begin{tabular}{lll}
\hline ROLE & LEVEL & COUNT \\
& & \\
\hline INPUT & INTERVAL & 4
\end{tabular}

TARGET TARGET 1

FIT STATISTICS

\begin{tabular}{|c|c|c|}
\hline $\begin{array}{l}\text { FIT } \\
\text { STATISTIC }\end{array}$ & STATISTIC LABEL & $\begin{array}{l}\text { STATISTIC } \\
\text { VALUE }\end{array}$ \\
\hline DFT $_{-}$ & Total Degrees of Freedom. & 168 \\
\hline DFE_ & Degrees of Freedom for Error. & 131 \\
\hline _DFM_ & Model Degrees of Freedom. & 37 \\
\hline $\mathrm{NW}_{-}$ & Number of Estimated Weights. & 37 \\
\hline $\mathrm{AIC}_{-}$ & Akaike's Information Criterion. & 176.618 \\
\hline${ }_{-} \mathrm{SBC}_{-}$ & Schwarz's Bayesian Criterion. & 292.205 \\
\hline ASE_ & Average Squared Error. & 0.094 \\
\hline _MAX_ & Maximum Absolute Error. & 0.971 \\
\hline DIV_ $_{-}$ & Divisor for ASE. & 336 \\
\hline NOBS_ & Sum of Frequencies. & 168 \\
\hline RASE_ & Root Average Squared Error. & 0.307 \\
\hline SSE_ & Sum of Squared Errors. & 31.688 \\
\hline SUMW_ & Sum of Case Weights Times Freq. & 336 \\
\hline FPE_ & Final Prediction Error. & 0.148 \\
\hline _MSE_ & Mean Squared Error. & 0.121 \\
\hline RFPE_ & Root Final Prediction Error. & 0.384 \\
\hline _RMSE_ & Root Mean Squared Error. & 0.348 \\
\hline _AVERR_ & Average Error Function. & 0.305 \\
\hline ERR_ & Error Function. & 102.618 \\
\hline _MISC_ & Misclassification Rate. & 0.119 \\
\hline WRONG & Number of Wrong Classifications. & 20 \\
\hline
\end{tabular}


CLASSIFICATION SUMMARY

\begin{tabular}{llllll}
\hline & & PERCENT & PERCENT & & $\begin{array}{l}\text { PERCENT } \\
\text { OF }\end{array}$ \\
TARGET & PREDICT & TARGET & PREDICT & COUNT & TOTAL \\
\hline BANKRUPT & BANKRUPT & 84.7222 & 87.1429 & 61 & 36.3095 \\
NONBANKRUPT & BANKRUPT & 15.2778 & 11.2245 & 11 & 6.5476 \\
BANKRUPT & NONBANKRUPT & 9.375 & 12.8571 & 9 & 5.3571 \\
NONBANKRUPT & NONBANKRUPT & 90.625 & 88.7755 & 87 & 51.7857 \\
\hline
\end{tabular}


Results of Multi Layer Perceptron : Market variables without spread and bid ask spread

YEAR 1

VARIABLE SUMMARY

\begin{tabular}{lll}
\hline ROLE & LEVEL & COUNT \\
\hline INPUT & INTERVAL & 4
\end{tabular}

TARGET TARGET 1

FIT STATISTICS

\begin{tabular}{|c|c|c|}
\hline $\begin{array}{l}\text { FIT } \\
\text { STATISTIC }\end{array}$ & STATISTIC LABEL & $\begin{array}{l}\text { STATISTIC } \\
\text { VALUE }\end{array}$ \\
\hline DFT $_{-}$ & Total Degrees of Freedom. & 255 \\
\hline _DFE_ & Degrees of Freedom for Error. & 218 \\
\hline _DFM_ & Model Degrees of Freedom. & 37 \\
\hline $\mathrm{NW}_{-}$ & Number of Estimated Weights. & 37 \\
\hline $\mathrm{AIC}_{-}$ & Akaike's Information Criterion. & 293.559 \\
\hline${ }_{-} \mathrm{SBC}_{-}$ & Schwarz's Bayesian Criterion. & 424.586 \\
\hline _ASE_ & Average Squared Error. & 0.137 \\
\hline _MAX_ & Maximum Absolute Error. & 0.954 \\
\hline $\mathrm{DIV}_{-}$ & Divisor for ASE. & 510 \\
\hline NOBS_ & Sum of Frequencies. & 255 \\
\hline _RASE_ & Root Average Squared Error. & 0.37 \\
\hline $\mathrm{SSE}_{-}$ & Sum of Squared Errors. & 69.776 \\
\hline SUMW_ & Sum of Case Weights Times Freq. & 510 \\
\hline FPE_ & Final Prediction Error. & 0.183 \\
\hline -MSE_ & Mean Squared Error. & 0.16 \\
\hline _RFPE_ & Root Final Prediction Error. & 0.428 \\
\hline _RMSE_ & Root Mean Squared Error. & 0.4 \\
\hline _AVERR_ & Average Error Function. & 0.431 \\
\hline ERR_ & Error Function. & 219.559 \\
\hline _MISC_ & Misclassification Rate. & 0.196 \\
\hline _WRONG & Number of Wrong Classifications. & 50 \\
\hline
\end{tabular}


CLASSIFICATION SUMMARY

\begin{tabular}{|c|c|c|c|c|c|}
\hline TARGET & PREDICT & $\begin{array}{l}\text { PERCENT } \\
\text { OF } \\
\text { TARGET }\end{array}$ & $\begin{array}{l}\text { PERCENT } \\
\text { OF } \\
\text { PREDICT }\end{array}$ & COUNT & $\begin{array}{l}\text { PERCENT } \\
\text { OF } \\
\text { TOTAL }\end{array}$ \\
\hline BANKRUPT & BANKRUPT & 78.9474 & 86.9565 & 120 & 47.0588 \\
\hline NONBANKRUPT & BANKRUPT & 21.0526 & 27.3504 & 32 & 12.549 \\
\hline BANKRUPT & NONBANKRUPT & 17.4757 & 13.0435 & 18 & 7.0588 \\
\hline NONBANKRUPT & NONBANKRUPT & 82.5243 & 72.6496 & 85 & 33.3333 \\
\hline
\end{tabular}

YEAR 2

VARIABLE SUMMARY

\begin{tabular}{lll}
\hline ROLE & LEVEL & COUNT \\
& & \\
\hline INPUT & INTERVAL & 4
\end{tabular}

TARGET TARGET 1

FIT STATISTICS

\begin{tabular}{|c|c|c|}
\hline $\begin{array}{l}\text { FIT } \\
\text { STATISTIC }\end{array}$ & STATISTIC LABEL & $\begin{array}{l}\text { STATISTIC } \\
\text { VALUE }\end{array}$ \\
\hline DFT $_{-}$ & Total Degrees of Freedom. & 242 \\
\hline DFE_ & Degrees of Freedom for Error. & 205 \\
\hline _DFM_ & Model Degrees of Freedom. & 37 \\
\hline $\mathrm{NW}_{-}$ & Number of Estimated Weights. & 37 \\
\hline $\mathrm{AIC}_{-}$ & Akaike's Information Criterion. & 349.622 \\
\hline SBC_ $_{-}$ & Schwarz's Bayesian Criterion. & 478.712 \\
\hline ASE_ & Average Squared Error. & 0.195 \\
\hline _MAX_ & Maximum Absolute Error. & 0.854 \\
\hline DIV_ $_{-}$ & Divisor for ASE. & 484 \\
\hline NOBS_ & Sum of Frequencies. & 242 \\
\hline RASE_ & Root Average Squared Error. & 0.442 \\
\hline SSE_ & Sum of Squared Errors. & 94.617 \\
\hline SUMW_ & Sum of Case Weights Times Freq. & 484 \\
\hline _FPE_ & Final Prediction Error. & 0.266 \\
\hline MSE_ & Mean Squared Error. & 0.231 \\
\hline RFPE_ & Root Final Prediction Error. & 0.516 \\
\hline RMSE_ & Root Mean Squared Error. & 0.48 \\
\hline _AVERR_ & Average Error Function. & 0.569 \\
\hline _ERR_ & Error Function. & 275.622 \\
\hline _MISC_ & Misclassification Rate. & 0.298 \\
\hline WRONG & Number of Wrong Classifications. & 72 \\
\hline
\end{tabular}


CLASSIFICATION SUMMARY

\begin{tabular}{llcccc}
\hline & & PERCENT & PERCENT & & PERCENT \\
& & OF & OF & \\
TARGET & PREDICT & TARGET & PREDICT & COUNT & TOTAL \\
\hline BANKRUPT & BANKRUPT & 67.7019 & 84.4961 & 109 & 45.0413 \\
NONBANKRUPT & BANKRUPT & 32.2981 & 46.0177 & 52 & 21.4876 \\
BANKRUPT & NONBANKRUPT & 24.6914 & 15.5039 & 20 & 8.2645 \\
NONBANKRUPT & NONBANKRUPT & 75.3086 & 53.9823 & 61 & 25.2066 \\
\hline
\end{tabular}

YEAR 3

VARIABLE SUMMARY

\begin{tabular}{lll}
\hline ROLE & LEVEL & COUNT \\
& & \\
\hline INPUT & INTERVAL & 4
\end{tabular}

TARGET TARGET 1

FIT STATISTICS

\begin{tabular}{|c|c|c|}
\hline $\begin{array}{l}\text { FIT } \\
\text { STATISTIC }\end{array}$ & STATISTIC LABEL & $\begin{array}{l}\text { STATISTIC } \\
\text { VALUE }\end{array}$ \\
\hline DFT_ $_{-}$ & Total Degrees of Freedom. & 219 \\
\hline _DFE_ & Degrees of Freedom for Error. & 182 \\
\hline _DFM_ & Model Degrees of Freedom. & 37 \\
\hline $\mathrm{NW}_{-}$ & Number of Estimated Weights. & 37 \\
\hline _AIC_ & Akaike's Information Criterion. & 324.718 \\
\hline $\mathrm{SBC}_{-}$ & Schwarz's Bayesian Criterion. & 450.113 \\
\hline _ASE_ & Average Squared Error. & 0.197 \\
\hline _MAX_ & Maximum Absolute Error. & 0.803 \\
\hline $\mathrm{DIV}_{-}$ & Divisor for ASE. & 438 \\
\hline NOBS_ & Sum of Frequencies. & 219 \\
\hline _RASE_ & Root Average Squared Error. & 0.444 \\
\hline SSE_ & Sum of Squared Errors. & 86.423 \\
\hline${ }_{-} \mathrm{SUMW}$ & Sum of Case Weights Times Freq. & 438 \\
\hline FPE_ & Final Prediction Error. & 0.278 \\
\hline _MSE_ & Mean Squared Error. & 0.237 \\
\hline RFPE_ & Root Final Prediction Error. & 0.527 \\
\hline _RMSE_ & Root Mean Squared Error. & 0.487 \\
\hline _AVERR_ & Average Error Function. & 0.572 \\
\hline ERR_ & Error Function. & 250.718 \\
\hline _MISC_ & Misclassification Rate. & 0.297 \\
\hline WRONG & Number of Wrong Classifications. & 65 \\
\hline
\end{tabular}


CLASSIFICATION SUMMARY

\begin{tabular}{llccccc}
\hline & & PERCENT & PERCENT & & \multicolumn{2}{l}{$\begin{array}{l}\text { PERCENT } \\
\text { OF }\end{array}$} \\
TARGET & PREDICT & TARGET & $\begin{array}{l}\text { OF } \\
\text { PREDICT }\end{array}$ & COUNT & TOTAL \\
\hline BANKRUPT & BANKRUPT & 67.2 & 77.7778 & 84 & 38.3562 \\
NONBANKRUPT & BANKRUPT & 32.8 & 36.9369 & 41 & 18.7215 \\
BANKRUPT & NONBANKRUPT & 25.5319 & 22.2222 & 24 & 10.9589 \\
NONBANKRUPT & NONBANKRUPT & 74.4681 & 63.0631 & 70 & 31.9635 \\
\hline
\end{tabular}

YEAR 4

VARIABLE SUMMARY

\begin{tabular}{lll}
\hline ROLE & LEVEL & COUNT \\
& & \\
\hline INPUT & INTERVAL & 4
\end{tabular}

TARGET TARGET 1

FIT STATISTICS

\begin{tabular}{|c|c|c|}
\hline $\begin{array}{l}\text { FIT } \\
\text { STATISTIC }\end{array}$ & STATISTIC LABEL & $\begin{array}{l}\text { STATISTIC } \\
\text { VALUE }\end{array}$ \\
\hline DFT $_{-}$ & Total Degrees of Freedom. & 195 \\
\hline DFE_ & Degrees of Freedom for Error. & 158 \\
\hline _DFM_ & Model Degrees of Freedom. & 37 \\
\hline $\mathrm{NW}_{-}$ & Number of Estimated Weights. & 37 \\
\hline $\mathrm{AIC}_{-}$ & Akaike's Information Criterion. & 267.887 \\
\hline SBC_ $_{-}$ & Schwarz's Bayesian Criterion. & 388.988 \\
\hline ASE_ & Average Squared Error. & 0.169 \\
\hline _MAX_ & Maximum Absolute Error. & 0.902 \\
\hline DIV_ $_{-}$ & Divisor for ASE. & 390 \\
\hline NOBS_ & Sum of Frequencies. & 195 \\
\hline RASE_ & Root Average Squared Error. & 0.411 \\
\hline SSE_ & Sum of Squared Errors. & 65.74 \\
\hline SUMW_ & Sum of Case Weights Times Freq. & 390 \\
\hline FPE_ & Final Prediction Error. & 0.248 \\
\hline _MSE_ & Mean Squared Error. & 0.208 \\
\hline RFPE_ & Root Final Prediction Error. & 0.498 \\
\hline _RMSE_ & Root Mean Squared Error. & 0.456 \\
\hline _AVERR_ & Average Error Function. & 0.497 \\
\hline _ERR_ & Error Function. & 193.887 \\
\hline _MISC_ & Misclassification Rate. & 0.262 \\
\hline WRONG & Number of Wrong Classifications. & 51 \\
\hline
\end{tabular}


CLASSIFICATION SUMMARY

\begin{tabular}{llccccc}
\hline & & PERCENT & PERCENT & & \multicolumn{2}{l}{ PERCENT } \\
& & OF & OF \\
TARGET & PREDICT & TARGET & PREDICT & COUNT & TOTAL \\
\hline BANKRUPT & BANKRUPT & 67.7083 & 76.4706 & 65 & 33.3333 \\
NONBANKRUPT & BANKRUPT & 32.2917 & 28.1818 & 31 & 15.8974 \\
BANKRUPT & NONBANKRUPT & 20.202 & 23.5294 & 20 & 10.2564 \\
NONBANKRUPT & NONBANKRUPT & 79.798 & 71.8182 & 79 & 40.5128 \\
\hline
\end{tabular}

YEAR 5

VARIABLE SUMMARY

\begin{tabular}{lll}
\hline ROLE & LEVEL & COUNT \\
& & \\
\hline INPUT & INTERVAL & 4
\end{tabular}

TARGET TARGET 1

FIT STATISTICS

\begin{tabular}{|c|c|c|}
\hline $\begin{array}{l}\text { FIT } \\
\text { STATISTIC }\end{array}$ & STATISTIC LABEL & $\begin{array}{l}\text { STATISTIC } \\
\text { VALUE }\end{array}$ \\
\hline DFT $_{-}$ & Total Degrees of Freedom. & 168 \\
\hline DFE_ & Degrees of Freedom for Error. & 131 \\
\hline _DFM_ & Model Degrees of Freedom. & 37 \\
\hline $\mathrm{NW}_{-}$ & Number of Estimated Weights. & 37 \\
\hline $\mathrm{AIC}_{-}$ & Akaike's Information Criterion. & 229.214 \\
\hline SBC_ $_{-}$ & Schwarz's Bayesian Criterion. & 344.801 \\
\hline ASE_ & Average Squared Error. & 0.153 \\
\hline _MAX_ & Maximum Absolute Error. & 0.974 \\
\hline DIV_ $_{-}$ & Divisor for ASE. & 336 \\
\hline NOBS_ & Sum of Frequencies. & 168 \\
\hline RASE_ & Root Average Squared Error. & 0.391 \\
\hline SSE_ & Sum of Squared Errors. & 51.495 \\
\hline SUMW_ & Sum of Case Weights Times Freq. & 336 \\
\hline _FPE_ & Final Prediction Error. & 0.24 \\
\hline MSE_ & Mean Squared Error. & 0.197 \\
\hline RFPE_ & Root Final Prediction Error. & 0.49 \\
\hline RMSE_ & Root Mean Squared Error. & 0.443 \\
\hline _AVERR_ & Average Error Function. & 0.462 \\
\hline _ERR_ & Error Function. & 155.214 \\
\hline _MISC_ & Misclassification Rate. & 0.226 \\
\hline WRONG & Number of Wrong Classifications. & 38 \\
\hline
\end{tabular}


CLASSIFICATION SUMMARY

\begin{tabular}{|c|c|c|c|c|c|}
\hline TARGET & PREDICT & $\begin{array}{l}\text { PERCENT } \\
\text { OF } \\
\text { TARGET }\end{array}$ & $\begin{array}{l}\text { PERCENT } \\
\text { OF } \\
\text { PREDICT }\end{array}$ & COUNT & $\begin{array}{l}\text { PERCENT } \\
\text { OF } \\
\text { TOTAL }\end{array}$ \\
\hline BANKRUPT & BANKRUPT & 72.8571 & 72.8571 & 51 & 30.3571 \\
\hline NONBANKRUPT & BANKRUPT & 27.1429 & 19.3878 & 19 & 11.3095 \\
\hline BANKRUPT & NONBANKRUPT & 19.3878 & 27.1429 & 19 & 11.3095 \\
\hline NONBANKRUPT & NONBANKRUPT & 80.6122 & 80.6122 & 79 & 47.0238 \\
\hline
\end{tabular}


Results of Multi Layer Perceptron : Market variables without bid ask spread and hi lo bid ask spread

YEAR 1

VARIABLE SUMMARY

\begin{tabular}{lll}
\hline ROLE & LEVEL & COUNT \\
\hline INPUT & INTERVAL & 4
\end{tabular}

TARGET TARGET 1

FIT STATISTICS

\begin{tabular}{|c|c|c|}
\hline $\begin{array}{l}\text { FIT } \\
\text { STATISTIC }\end{array}$ & STATISTIC LABEL & $\begin{array}{l}\text { STATISTIC } \\
\text { VALUE }\end{array}$ \\
\hline DFT_ $_{-}$ & Total Degrees of Freedom. & 255 \\
\hline _DFE_ & Degrees of Freedom for Error. & 218 \\
\hline _DFM_ & Model Degrees of Freedom. & 37 \\
\hline $\mathrm{NW}_{-}$ & Number of Estimated Weights. & 37 \\
\hline _AIC_ & Akaike's Information Criterion. & 354.963 \\
\hline $\mathrm{SBC}_{-}$ & Schwarz's Bayesian Criterion. & 485.989 \\
\hline ASE_ & Average Squared Error. & 0.189 \\
\hline -MAX_ & Maximum Absolute Error. & 0.902 \\
\hline DIV_ & Divisor for ASE. & 510 \\
\hline _NOBS_ & Sum of Frequencies. & 255 \\
\hline _RASE_ & Root Average Squared Error. & 0.434 \\
\hline _SSE_ & Sum of Squared Errors. & 96.281 \\
\hline SUMW_ & Sum of Case Weights Times Freq. & 510 \\
\hline $\mathrm{FPE}_{-}$ & Final Prediction Error. & 0.253 \\
\hline _MSE_ & Mean Squared Error. & 0.221 \\
\hline RFPE_ & Root Final Prediction Error. & 0.503 \\
\hline RMSE_ & Root Mean Squared Error. & 0.47 \\
\hline _AVERR_ & Average Error Function. & 0.551 \\
\hline _ERR_ & Error Function. & 280.963 \\
\hline _MISC_ & Misclassification Rate. & 0.275 \\
\hline WRONG & Number of Wrong Classifications. & 70 \\
\hline
\end{tabular}


CLASSIFICATION SUMMARY

\begin{tabular}{|c|c|c|c|c|c|}
\hline TARGET & PREDICT & $\begin{array}{l}\text { PERCENT } \\
\text { OF } \\
\text { TARGET }\end{array}$ & $\begin{array}{l}\text { PERCENT } \\
\text { OF } \\
\text { PREDICT }\end{array}$ & COUNT & $\begin{array}{l}\text { PERCENT } \\
\text { OF } \\
\text { TOTAL }\end{array}$ \\
\hline BANKRUPT & BANKRUPT & 71.7949 & 81.1594 & 112 & 43.9216 \\
\hline NONBANKRUPT & BANKRUPT & 28.2051 & 37.6068 & 44 & 17.2549 \\
\hline BANKRUPT & NONBANKRUPT & 26.2626 & 18.8406 & 26 & 10.1961 \\
\hline NONBANKRUPT & NONBANKRUPT & 73.7374 & 62.3932 & 73 & 28.6275 \\
\hline
\end{tabular}

YEAR 2

VARIABLE SUMMARY

\begin{tabular}{lll}
\hline ROLE & LEVEL & COUNT \\
& & \\
\hline INPUT & INTERVAL & 4
\end{tabular}

TARGET TARGET 1

FIT STATISTICS

\begin{tabular}{|c|c|c|}
\hline $\begin{array}{l}\text { FIT } \\
\text { STATISTIC }\end{array}$ & STATISTIC LABEL & $\begin{array}{l}\text { STATISTIC } \\
\text { VALUE }\end{array}$ \\
\hline DFT $_{-}$ & Total Degrees of Freedom. & 242 \\
\hline DFE_ & Degrees of Freedom for Error. & 205 \\
\hline _DFM_ & Model Degrees of Freedom. & 37 \\
\hline $\mathrm{NW}_{-}$ & Number of Estimated Weights. & 37 \\
\hline $\mathrm{AIC}_{-}$ & Akaike's Information Criterion. & 360.782 \\
\hline SBC_ $_{-}$ & Schwarz's Bayesian Criterion. & 489.873 \\
\hline ASE_ & Average Squared Error. & 0.206 \\
\hline _MAX_ & Maximum Absolute Error. & 0.767 \\
\hline DIV_ $_{-}$ & Divisor for ASE. & 484 \\
\hline NOBS_ & Sum of Frequencies. & 242 \\
\hline RASE_ & Root Average Squared Error. & 0.454 \\
\hline SSE_ & Sum of Squared Errors. & 99.646 \\
\hline SUMW_ & Sum of Case Weights Times Freq. & 484 \\
\hline _FPE_ & Final Prediction Error. & 0.28 \\
\hline MSE_ & Mean Squared Error. & 0.243 \\
\hline RFPE_ & Root Final Prediction Error. & 0.529 \\
\hline _RMSE_ & Root Mean Squared Error. & 0.493 \\
\hline _AVERR_ & Average Error Function. & 0.593 \\
\hline _ERR_ & Error Function. & 286.782 \\
\hline MISC_ & Misclassification Rate. & 0.318 \\
\hline WRONG & Number of Wrong Classifications. & 77 \\
\hline
\end{tabular}


CLASSIFICATION SUMMARY

\begin{tabular}{llccccc}
\hline & & PERCENT & PERCENT & & PERCENT \\
& & OF & OF & \\
TARGET & PREDICT & TARGET & PREDICT & COUNT & TOTAL \\
\hline BANKRUPT & BANKRUPT & 67.5676 & 77.5194 & 100 & 41.3223 \\
NONBANKRUPT & BANKRUPT & 32.4324 & 42.4779 & 48 & 19.8347 \\
BANKRUPT & NONBANKRUPT & 30.8511 & 22.4806 & 29 & 11.9835 \\
NONBANKRUPT & NONBANKRUPT & 69.1489 & 57.5221 & 65 & 26.8595 \\
\hline
\end{tabular}

YEAR 3

VARIABLE SUMMARY

\begin{tabular}{lll}
\hline ROLE & LEVEL & COUNT \\
& & \\
\hline INPUT & INTERVAL & 4
\end{tabular}

TARGET TARGET 1

FIT STATISTICS

\begin{tabular}{|c|c|c|}
\hline $\begin{array}{l}\text { FIT } \\
\text { STATISTIC }\end{array}$ & STATISTIC LABEL & $\begin{array}{l}\text { STATISTIC } \\
\text { VALUE }\end{array}$ \\
\hline DFT $_{-}$ & Total Degrees of Freedom. & 219 \\
\hline DFE_ & Degrees of Freedom for Error. & 182 \\
\hline _DFM_ & Model Degrees of Freedom. & 37 \\
\hline $\mathrm{NW}_{-}$ & Number of Estimated Weights. & 37 \\
\hline $\mathrm{AIC}_{-}$ & Akaike's Information Criterion. & 323.336 \\
\hline SBC_ $_{-}$ & Schwarz's Bayesian Criterion. & 448.732 \\
\hline ASE_ & Average Squared Error. & 0.196 \\
\hline _MAX_ & Maximum Absolute Error. & 0.796 \\
\hline DIV_ $_{-}$ & Divisor for ASE. & 438 \\
\hline NOBS_ & Sum of Frequencies. & 219 \\
\hline RASE_ & Root Average Squared Error. & 0.442 \\
\hline SSE_ & Sum of Squared Errors. & 85.738 \\
\hline SUMW_ & Sum of Case Weights Times Freq. & 438 \\
\hline FPE_ & Final Prediction Error. & 0.275 \\
\hline _MSE_ & Mean Squared Error. & 0.236 \\
\hline RFPE_ & Root Final Prediction Error. & 0.525 \\
\hline _RMSE_ & Root Mean Squared Error. & 0.485 \\
\hline _AVERR_ & Average Error Function. & 0.569 \\
\hline ERR_ & Error Function. & 249.336 \\
\hline MISC_ & Misclassification Rate. & 0.279 \\
\hline WRONG & Number of Wrong Classifications. & 61 \\
\hline
\end{tabular}


CLASSIFICATION SUMMARY

\begin{tabular}{llcccc}
\hline & & PERCENT & PERCENT & & PERCENT \\
& & OF & OF & \\
TARGET & PREDICT & TARGET & PREDICT & COUNT & TOTAL \\
\hline BANKRUPT & BANKRUPT & 69.4215 & 77.7778 & 84 & 38.3562 \\
NONBANKRUPT & BANKRUPT & 30.5785 & 33.3333 & 37 & 16.895 \\
BANKRUPT & NONBANKRUPT & 24.4898 & 22.2222 & 24 & 10.9589 \\
NONBANKRUPT & NONBANKRUPT & 75.5102 & 66.6667 & 74 & 33.79 \\
\hline
\end{tabular}

YEAR 4

VARIABLE SUMMARY

\begin{tabular}{lll}
\hline ROLE & LEVEL & COUNT \\
& & \\
\hline INPUT & INTERVAL & 4
\end{tabular}

TARGET TARGET 1

FIT STATISTICS

\begin{tabular}{|c|c|c|}
\hline $\begin{array}{l}\text { FIT } \\
\text { STATISTIC }\end{array}$ & STATISTIC LABEL & $\begin{array}{l}\text { STATISTIC } \\
\text { VALUE }\end{array}$ \\
\hline DFT $_{-}$ & Total Degrees of Freedom. & 195 \\
\hline DFE_ & Degrees of Freedom for Error. & 158 \\
\hline _DFM_ & Model Degrees of Freedom. & 37 \\
\hline $\mathrm{NW}_{-}$ & Number of Estimated Weights. & 37 \\
\hline $\mathrm{AIC}_{-}$ & Akaike's Information Criterion. & 281.918 \\
\hline${ }_{-} \mathrm{SBC}_{-}$ & Schwarz's Bayesian Criterion. & 403.019 \\
\hline ASE_ & Average Squared Error. & 0.183 \\
\hline _MAX_ & Maximum Absolute Error. & 0.925 \\
\hline DIV_ $_{-}$ & Divisor for ASE. & 390 \\
\hline NOBS_ & Sum of Frequencies. & 195 \\
\hline RASE_ & Root Average Squared Error. & 0.428 \\
\hline SSE_ & Sum of Squared Errors. & 71.309 \\
\hline SUMW_ & Sum of Case Weights Times Freq. & 390 \\
\hline FPE_ & Final Prediction Error. & 0.268 \\
\hline _MSE_ & Mean Squared Error. & 0.226 \\
\hline RFPE_ & Root Final Prediction Error. & 0.518 \\
\hline _RMSE_ & Root Mean Squared Error. & 0.475 \\
\hline _AVERR_ & Average Error Function. & 0.533 \\
\hline _ERR_ & Error Function. & 207.918 \\
\hline _MISC_ & Misclassification Rate. & 0.262 \\
\hline WRONG & Number of Wrong Classifications. & 51 \\
\hline
\end{tabular}


CLASSIFICATION SUMMARY

\begin{tabular}{|c|c|c|c|c|c|}
\hline TARGET & PREDICT & $\begin{array}{l}\text { PERCENT } \\
\text { OF } \\
\text { TARGET }\end{array}$ & $\begin{array}{l}\text { PERCENT } \\
\text { OF } \\
\text { PREDICT }\end{array}$ & COUNT & $\begin{array}{l}\text { PERCENT } \\
\text { OF } \\
\text { TOTAL }\end{array}$ \\
\hline BANKRUPT & BANKRUPT & 68.4783 & 74.1176 & 63 & 32.3077 \\
\hline NONBANKRUPT & BANKRUPT & 31.5217 & 26.3636 & 29 & 14.8718 \\
\hline BANKRUPT & NONBANKRUPT & 21.3592 & 25.8824 & 22 & 11.2821 \\
\hline NONBANKRUPT & NONBANKRUPT & 78.6408 & 73.6364 & 81 & 41.5385 \\
\hline
\end{tabular}

YEAR 5

VARIABLE SUMMARY

\begin{tabular}{lll}
\hline ROLE & LEVEL & COUNT \\
& & \\
\hline INPUT & INTERVAL & 4
\end{tabular}

TARGET TARGET 1

FIT STATISTICS

\begin{tabular}{|c|c|c|}
\hline $\begin{array}{l}\text { FIT } \\
\text { STATISTIC }\end{array}$ & STATISTIC LABEL & $\begin{array}{l}\text { STATISTIC } \\
\text { VALUE }\end{array}$ \\
\hline DFT $_{-}$ & Total Degrees of Freedom. & 168 \\
\hline DFE_ & Degrees of Freedom for Error. & 131 \\
\hline _DFM_ & Model Degrees of Freedom. & 37 \\
\hline $\mathrm{NW}_{-}$ & Number of Estimated Weights. & 37 \\
\hline $\mathrm{AIC}_{-}$ & Akaike's Information Criterion. & 252.594 \\
\hline SBC_ $_{-}$ & Schwarz's Bayesian Criterion. & 368.181 \\
\hline ASE_ & Average Squared Error. & 0.182 \\
\hline _MAX_ & Maximum Absolute Error. & 0.932 \\
\hline DIV_ $_{-}$ & Divisor for ASE. & 336 \\
\hline NOBS_ & Sum of Frequencies. & 168 \\
\hline RASE_ & Root Average Squared Error. & 0.427 \\
\hline SSE_ & Sum of Squared Errors. & 61.217 \\
\hline SUMW_ & Sum of Case Weights Times Freq. & 336 \\
\hline FPE_ & Final Prediction Error. & 0.285 \\
\hline _MSE_ & Mean Squared Error. & 0.234 \\
\hline RFPE_ & Root Final Prediction Error. & 0.534 \\
\hline _RMSE_ & Root Mean Squared Error. & 0.483 \\
\hline _AVERR_ & Average Error Function. & 0.532 \\
\hline _ERR_ & Error Function. & 178.594 \\
\hline _MISC_ & Misclassification Rate. & 0.28 \\
\hline WRONG & Number of Wrong Classifications. & 47 \\
\hline
\end{tabular}


CLASSIFICATION SUMMARY

\begin{tabular}{llccccc}
\hline & & PERCENT & PERCENT & & \multicolumn{2}{c}{$\begin{array}{l}\text { PERCENT } \\
\text { OF }\end{array}$} \\
TARGET & PREDICT & TARGET & OF & PREDICT & COUNT & TOTAL \\
\hline BANKRUPT & BANKRUPT & 64.9351 & 71.4286 & 50 & 29.7619 \\
NONBANKRUPT & BANKRUPT & 35.0649 & 27.551 & 27 & 16.0714 \\
BANKRUPT & NONBANKRUPT & 21.978 & 28.5714 & 20 & 11.9048 \\
NONBANKRUPT & NONBANKRUPT & 78.022 & 72.449 & 71 & 42.2619 \\
\hline
\end{tabular}


Results of Multi Layer Perceptron : Top 3 Account and Market variables

YEAR 1

VARIABLE SUMMARY

\begin{tabular}{lll}
\hline ROLE & LEVEL & COUNT \\
\hline INPUT & INTERVAL & 6
\end{tabular}

TARGET TARGET 1

FIT STATISTICS

\begin{tabular}{|c|c|c|}
\hline $\begin{array}{l}\text { FIT } \\
\text { STATISTIC }\end{array}$ & STATISTIC LABEL & $\begin{array}{l}\text { STATISTIC } \\
\text { VALUE }\end{array}$ \\
\hline DFT_ $_{-}$ & Total Degrees of Freedom. & 255 \\
\hline _DFE_ & Degrees of Freedom for Error. & 206 \\
\hline _DFM_ & Model Degrees of Freedom. & 49 \\
\hline $\mathrm{NW}_{-}$ & Number of Estimated Weights. & 49 \\
\hline _ $\mathrm{AIC}_{-}$ & Akaike's Information Criterion. & 254.282 \\
\hline _SBC$_{-}$ & Schwarz's Bayesian Criterion. & 427.804 \\
\hline _ASE_ & Average Squared Error. & 0.094 \\
\hline _MAX_ & Maximum Absolute Error. & 0.947 \\
\hline DIV_ & Divisor for ASE. & 510 \\
\hline NOBS_ & Sum of Frequencies. & 255 \\
\hline _RASE_ & Root Average Squared Error. & 0.307 \\
\hline SSE_ $_{-}$ & Sum of Squared Errors. & 48.082 \\
\hline SUMW & Sum of Case Weights Times Freq. & 510 \\
\hline FPE_ & Final Prediction Error. & 0.139 \\
\hline _MSE_ & Mean Squared Error. & 0.117 \\
\hline _RFPE_ & Root Final Prediction Error. & 0.373 \\
\hline _RMSE_ & Root Mean Squared Error. & 0.342 \\
\hline _AVERR_ & Average Error Function. & 0.306 \\
\hline _ERR_ & Error Function. & 156.282 \\
\hline _MISC_ & Misclassification Rate. & 0.122 \\
\hline WRONG & Number of Wrong Classifications. & 31 \\
\hline
\end{tabular}


CLASSIFICATION SUMMARY

\begin{tabular}{|c|c|c|c|c|c|}
\hline TARGET & PREDICT & $\begin{array}{l}\text { PERCENT } \\
\text { OF } \\
\text { TARGET }\end{array}$ & $\begin{array}{l}\text { PERCENT } \\
\text { OF } \\
\text { PREDICT }\end{array}$ & COUNT & $\begin{array}{l}\text { PERCENT } \\
\text { OF } \\
\text { TOTAL }\end{array}$ \\
\hline BANKRUPT & BANKRUPT & 86.3946 & 92.029 & 127 & 49.8039 \\
\hline NONBANKRUPT & BANKRUPT & 13.6054 & 17.094 & 20 & 7.8431 \\
\hline BANKRUPT & NONBANKRUPT & 10.1852 & 7.971 & 11 & 4.3137 \\
\hline NONBANKRUPT & NONBANKRUPT & 89.8148 & 82.906 & 97 & 38.0392 \\
\hline
\end{tabular}

YEAR 2

VARIABLE SUMMARY

\begin{tabular}{lll}
\hline ROLE & LEVEL & COUNT \\
& & \\
\hline INPUT & INTERVAL & 6
\end{tabular}

TARGET TARGET 1

FIT STATISTICS

\begin{tabular}{|c|c|c|}
\hline $\begin{array}{l}\text { FIT } \\
\text { STATISTIC }\end{array}$ & STATISTIC LABEL & $\begin{array}{l}\text { STATISTIC } \\
\text { VALUE }\end{array}$ \\
\hline DFT_ $_{-}$ & Total Degrees of Freedom. & 242 \\
\hline _DFE_ & Degrees of Freedom for Error. & 193 \\
\hline _DFM_ & Model Degrees of Freedom. & 49 \\
\hline $\mathrm{NW}_{-}$ & Number of Estimated Weights. & 49 \\
\hline $\mathrm{AIC}_{-}$ & Akaike's Information Criterion. & 246.106 \\
\hline${ }_{-} \mathrm{SBC}$ & Schwarz's Bayesian Criterion. & 417.064 \\
\hline _ASE_ & Average Squared Error. & 0.094 \\
\hline MAX_ & Maximum Absolute Error. & 0.972 \\
\hline $\mathrm{DIV}_{-}$ & Divisor for ASE. & 484 \\
\hline NOBS_ & Sum of Frequencies. & 242 \\
\hline _RASE_ & Root Average Squared Error. & 0.307 \\
\hline SSE_ & Sum of Squared Errors. & 45.516 \\
\hline${ }_{-} \mathrm{SUMW}$ & Sum of Case Weights Times Freq. & 484 \\
\hline FPE_ & Final Prediction Error. & 0.142 \\
\hline _MSE_ & Mean Squared Error. & 0.118 \\
\hline RFPE_ & Root Final Prediction Error. & 0.377 \\
\hline _RMSE_ & Root Mean Squared Error. & 0.343 \\
\hline _AVERR_ & Average Error Function. & 0.306 \\
\hline ERR_ & Error Function. & 148.106 \\
\hline _MISC_ & Misclassification Rate. & 0.112 \\
\hline WRONG & Number of Wrong Classifications. & 27 \\
\hline
\end{tabular}




\section{CLASSIFICATION SUMMARY}

\begin{tabular}{llcccc}
\hline & & $\begin{array}{l}\text { PERCENT } \\
\text { OF }\end{array}$ & $\begin{array}{l}\text { PERCENT } \\
\text { OF }\end{array}$ & & $\begin{array}{l}\text { PERCENT } \\
\text { OF }\end{array}$ \\
TARGET & PREDICT & TARGET & PREDICT & COUNT & TOTAL \\
\hline BANKRUPT & BANKRUPT & 88.0597 & 91.4729 & 118 & 48.7603 \\
NONBANKRUPT & BANKRUPT & 11.9403 & 14.1593 & 16 & 6.6116 \\
BANKRUPT & NONBANKRUPT & 10.1852 & 8.5271 & 11 & 4.5455 \\
NONBANKRUPT & NONBANKRUPT & 89.8148 & 85.8407 & 97 & 40.0826 \\
\hline
\end{tabular}

YEAR 3

VARIABLE SUMMARY

\begin{tabular}{lll}
\hline ROLE & LEVEL & COUNT \\
& & \\
\hline INPUT & INTERVAL & 6
\end{tabular}

TARGET TARGET 1

FIT STATISTICS

\begin{tabular}{|c|c|c|}
\hline $\begin{array}{l}\text { FIT } \\
\text { STATISTIC }\end{array}$ & STATISTIC LABEL & $\begin{array}{l}\text { STATISTIC } \\
\text { VALUE }\end{array}$ \\
\hline DFT $_{-}$ & Total Degrees of Freedom. & 219 \\
\hline _DFE_ & Degrees of Freedom for Error. & 170 \\
\hline _DFM_ & Model Degrees of Freedom. & 49 \\
\hline $\mathrm{NW}_{-}$ & Number of Estimated Weights. & 49 \\
\hline $\mathrm{AIC}_{-}$ & Akaike's Information Criterion. & 232.603 \\
\hline $\mathrm{SBC}_{-}$ & Schwarz's Bayesian Criterion. & 398.667 \\
\hline _ASE_ & Average Squared Error. & 0.093 \\
\hline _MAX_ & Maximum Absolute Error. & 0.975 \\
\hline $\mathrm{DIV}_{-}$ & Divisor for ASE. & 438 \\
\hline NOBS_ & Sum of Frequencies. & 219 \\
\hline _RASE_ & Root Average Squared Error. & 0.305 \\
\hline $\mathrm{SSE}_{-}$ & Sum of Squared Errors. & 40.777 \\
\hline SUMW_ & Sum of Case Weights Times Freq. & 438 \\
\hline FPE_ & Final Prediction Error. & 0.147 \\
\hline MSE_ & Mean Squared Error. & 0.12 \\
\hline _RFPE_ & Root Final Prediction Error. & 0.383 \\
\hline RMSE_ & Root Mean Squared Error. & 0.346 \\
\hline _AVERR_ & Average Error Function. & 0.307 \\
\hline _ERR_ & Error Function. & 134.603 \\
\hline _MISC_ & Misclassification Rate. & 0.105 \\
\hline _WRONG & Number of Wrong Classifications. & 23 \\
\hline
\end{tabular}




\section{CLASSIFICATION SUMMARY}

\begin{tabular}{llcccc}
\hline & & PERCENT & PERCENT & & \multicolumn{2}{l}{ PERCENT } \\
OF & OF & & \\
TARGET & PREDICT & TARGET & PREDICT & COUNT & TOTAL \\
\hline BANKRUPT & BANKRUPT & 89.7196 & 88.8889 & 96 & 43.8356 \\
NONBANKRUPT & BANKRUPT & 10.2804 & 9.9099 & 11 & 5.0228 \\
BANKRUPT & NONBANKRUPT & 10.7143 & 11.1111 & 12 & 5.4795 \\
NONBANKRUPT & NONBANKRUPT & 89.2857 & 90.0901 & 100 & 45.6621 \\
\hline
\end{tabular}

YEAR 4

VARIABLE SUMMARY

\begin{tabular}{lll}
\hline ROLE & LEVEL & COUNT \\
& & \\
\hline INPUT & INTERVAL & 6
\end{tabular}

TARGET TARGET 1

FIT STATISTICS

\begin{tabular}{|c|c|c|}
\hline $\begin{array}{l}\text { FIT } \\
\text { STATISTIC }\end{array}$ & STATISTIC LABEL & $\begin{array}{l}\text { STATISTIC } \\
\text { VALUE }\end{array}$ \\
\hline DFT $_{-}$ & Total Degrees of Freedom. & 195 \\
\hline _DFE_ & Degrees of Freedom for Error. & 146 \\
\hline _DFM_ & Model Degrees of Freedom. & 49 \\
\hline $\mathrm{NW}_{-}$ & Number of Estimated Weights. & 49 \\
\hline $\mathrm{AIC}_{-}$ & Akaike's Information Criterion. & 168.74 \\
\hline $\mathrm{SBC}_{-}$ & Schwarz's Bayesian Criterion. & 329.117 \\
\hline _ASE_ & Average Squared Error. & 0.057 \\
\hline _MAX_ & Maximum Absolute Error. & 0.858 \\
\hline $\mathrm{DIV}_{-}$ & Divisor for ASE. & 390 \\
\hline NOBS_ & Sum of Frequencies. & 195 \\
\hline _RASE_ & Root Average Squared Error. & 0.239 \\
\hline $\mathrm{SSE}_{-}$ & Sum of Squared Errors. & 22.291 \\
\hline SUMW_ & Sum of Case Weights Times Freq. & 390 \\
\hline FPE_ & Final Prediction Error. & 0.096 \\
\hline MSE_ & Mean Squared Error. & 0.076 \\
\hline _RFPE_ & Root Final Prediction Error. & 0.309 \\
\hline RMSE_ & Root Mean Squared Error. & 0.276 \\
\hline _AVERR_ & Average Error Function. & 0.181 \\
\hline _ERR_ & Error Function. & 70.74 \\
\hline _MISC_ & Misclassification Rate. & 0.072 \\
\hline _WRONG & Number of Wrong Classifications. & 14 \\
\hline
\end{tabular}


CLASSIFICATION SUMMARY

\begin{tabular}{llcccc}
\hline & & PERCENT & PERCENT & & PERCENT \\
& & OF & OF & & OF \\
TARGET & PREDICT & TARGET & PREDICT & COUNT & TOTAL \\
\hline BANKRUPT & BANKRUPT & 93.8272 & 89.4118 & 76 & 38.9744 \\
NONBANKRUPT & BANKRUPT & 6.1728 & 4.5455 & 5 & 2.5641 \\
BANKRUPT & NONBANKRUPT & 7.8947 & 10.5882 & 9 & 4.6154 \\
NONBANKRUPT & NONBANKRUPT & 92.1053 & 95.4545 & 105 & 53.8462 \\
\hline
\end{tabular}

YEAR 5

VARIABLE SUMMARY

\begin{tabular}{lll}
\hline ROLE & LEVEL & COUNT \\
& & \\
\hline INPUT & INTERVAL & 6
\end{tabular}

TARGET TARGET 1

FIT STATISTICS

\begin{tabular}{|c|c|c|}
\hline $\begin{array}{l}\text { FIT } \\
\text { STATISTIC }\end{array}$ & STATISTIC LABEL & $\begin{array}{l}\text { STATISTIC } \\
\text { VALUE }\end{array}$ \\
\hline DFT $_{-}$ & Total Degrees of Freedom. & 168 \\
\hline DFE_ & Degrees of Freedom for Error. & 119 \\
\hline _DFM_ & Model Degrees of Freedom. & 49 \\
\hline $\mathrm{NW}_{-}$ & Number of Estimated Weights. & 49 \\
\hline $\mathrm{AIC}_{-}$ & Akaike's Information Criterion. & 169.834 \\
\hline${ }_{-} \mathrm{SBC}_{-}$ & Schwarz's Bayesian Criterion. & 322.908 \\
\hline ASE_ & Average Squared Error. & 0.066 \\
\hline _MAX_ & Maximum Absolute Error. & 0.941 \\
\hline DIV_ $_{-}$ & Divisor for ASE. & 336 \\
\hline NOBS_ & Sum of Frequencies. & 168 \\
\hline RASE_ & Root Average Squared Error. & 0.256 \\
\hline SSE_ & Sum of Squared Errors. & 22.103 \\
\hline SUMW_ & Sum of Case Weights Times Freq. & 336 \\
\hline FPE_ & Final Prediction Error. & 0.12 \\
\hline _MSE_ & Mean Squared Error. & 0.093 \\
\hline RFPE_ & Root Final Prediction Error. & 0.346 \\
\hline _RMSE_ & Root Mean Squared Error. & 0.305 \\
\hline _AVERR_ & Average Error Function. & 0.214 \\
\hline _ERR_ & Error Function. & 71.834 \\
\hline _MISC_ & Misclassification Rate. & 0.083 \\
\hline WRONG & Number of Wrong Classifications. & 14 \\
\hline
\end{tabular}


CLASSIFICATION SUMMARY

\begin{tabular}{llccccc}
\hline & & PERCENT & PERCENT & & PERCENT \\
OF & OF & & \\
TARGET & PREDICT & TARGET & PREDICT & COUNT & TOTAL \\
\hline BANKRUPT & BANKRUPT & 88.8889 & 91.4286 & 64 & 38.0952 \\
NONBANKRUPT & BANKRUPT & 11.1111 & 8.1633 & 8 & 4.7619 \\
BANKRUPT & NONBANKRUPT & 6.25 & 8.5714 & 6 & 3.5714 \\
NONBANKRUPT & NONBANKRUPT & 93.75 & 91.8367 & 90 & 53.5714 \\
\hline
\end{tabular}


Results of Multi Layer Perceptron : Top 3 Account and Market logarithmic variables

YEAR 1

VARIABLE SUMMARY

\begin{tabular}{lll}
\hline ROLE & LEVEL & COUNT \\
\hline INPUT & INTERVAL & 6
\end{tabular}

TARGET TARGET 1

FIT STATISTICS

\begin{tabular}{|c|c|c|}
\hline FIT STATISTIC & STATISTIC LABEL & $\begin{array}{l}\text { STATISTIC } \\
\text { VALUE }\end{array}$ \\
\hline DFT_ $_{-}$ & Total Degrees of Freedom. & 255 \\
\hline DFE_ $_{-}$ & Degrees of Freedom for Error. & 206 \\
\hline _DFM_ & Model Degrees of Freedom. & 49 \\
\hline $\mathrm{NW}_{-}$ & Number of Estimated Weights. & 49 \\
\hline $\mathrm{AIC}_{-}$ & Akaike's Information Criterion. & 286.941 \\
\hline${ }_{-} \mathrm{SBC}_{-}$ & Schwarz's Bayesian Criterion. & 460.463 \\
\hline ASE_ & Average Squared Error. & 0.113 \\
\hline _MAX_ & Maximum Absolute Error. & 0.972 \\
\hline DIV_ & Divisor for ASE. & 510 \\
\hline NOBS_ & Sum of Frequencies. & 255 \\
\hline _RASE_ & Root Average Squared Error. & 0.336 \\
\hline _SSE_ & Sum of Squared Errors. & 57.618 \\
\hline _SUMW_ & Sum of Case Weights Times Freq. & 510 \\
\hline _FPE_ & Final Prediction Error. & 0.167 \\
\hline _MSE_ & Mean Squared Error. & 0.14 \\
\hline _RFPE_ & Root Final Prediction Error. & 0.408 \\
\hline _RMSE_ & Root Mean Squared Error. & 0.374 \\
\hline _AVERR_ & Average Error Function. & 0.37 \\
\hline _ERR_ & Error Function. & 188.941 \\
\hline MISC_ $_{-}$ & Misclassification Rate. & 0.137 \\
\hline WRONG & Number of Wrong Classifications. & 35 \\
\hline
\end{tabular}


CLASSIFICATION SUMMARY

\begin{tabular}{llccccc}
\hline & & PERCENT & PERCENT & & \multicolumn{2}{l}{ PERCENT } \\
& & OF & OF & \\
TARGET & PREDICT & TARGET & PREDICT & COUNT & TOTAL \\
\hline BANKRUPT & BANKRUPT & 87.5912 & 86.9565 & 120 & 47.0588 \\
NONBANKRUPT & BANKRUPT & 12.4088 & 14.5299 & 17 & 6.6667 \\
BANKRUPT & NONBANKRUPT & 15.2542 & 13.0435 & 18 & 7.0588 \\
NONBANKRUPT & NONBANKRUPT & 84.7458 & 85.4701 & 100 & 39.2157 \\
\hline
\end{tabular}

YEAR 2

VARIABLE SUMMARY

\begin{tabular}{lll}
\hline ROLE & LEVEL & COUNT \\
& & \\
\hline INPUT & INTERVAL & 6
\end{tabular}

TARGET TARGET 1

FIT STATISTICS

\begin{tabular}{|c|c|c|}
\hline $\begin{array}{l}\text { FIT } \\
\text { STATISTIC }\end{array}$ & STATISTIC LABEL & $\begin{array}{l}\text { STATISTIC } \\
\text { VALUE }\end{array}$ \\
\hline DFT $_{-}$ & Total Degrees of Freedom. & 242 \\
\hline DFE_ & Degrees of Freedom for Error. & 193 \\
\hline _DFM_ & Model Degrees of Freedom. & 49 \\
\hline $\mathrm{NW}_{-}$ & Number of Estimated Weights. & 49 \\
\hline $\mathrm{AIC}_{-}$ & Akaike's Information Criterion. & 278.68 \\
\hline $\mathrm{SBC}_{-}$ & Schwarz's Bayesian Criterion. & 449.638 \\
\hline $\mathrm{ASE}_{-}$ & Average Squared Error. & 0.118 \\
\hline MAX_ & Maximum Absolute Error. & 0.964 \\
\hline DIV $_{-}$ & Divisor for ASE. & 484 \\
\hline NOBS_ & Sum of Frequencies. & 242 \\
\hline _RASE_ & Root Average Squared Error. & 0.344 \\
\hline SSE_ & Sum of Squared Errors. & 57.23 \\
\hline S SUMW & Sum of Case Weights Times Freq. & 484 \\
\hline FPE_ & Final Prediction Error. & 0.178 \\
\hline _MSE_ & Mean Squared Error. & 0.148 \\
\hline _RFPE_ & Root Final Prediction Error. & 0.422 \\
\hline _RMSE_ & Root Mean Squared Error. & 0.385 \\
\hline _AVERR_ & Average Error Function. & 0.373 \\
\hline ERR_ & Error Function. & 180.68 \\
\hline _MISC_ & Misclassification Rate. & 0.161 \\
\hline WRONG & Number of Wrong Classifications. & 39 \\
\hline
\end{tabular}


CLASSIFICATION SUMMARY

\begin{tabular}{llcccc}
\hline & & PERCENT & PERCENT & & PERCENT \\
& & OF & OF & \\
TARGET & PREDICT & TARGET & PREDICT & COUNT & TOTAL \\
\hline BANKRUPT & BANKRUPT & 84.0909 & 86.0465 & 111 & 45.8678 \\
NONBANKRUPT & BANKRUPT & 15.9091 & 18.5841 & 21 & 8.6777 \\
BANKRUPT & NONBANKRUPT & 16.3636 & 13.9535 & 18 & 7.438 \\
NONBANKRUPT & NONBANKRUPT & 83.6364 & 81.4159 & 92 & 38.0165 \\
\hline
\end{tabular}

YEAR 3

VARIABLE SUMMARY

\begin{tabular}{lll}
\hline ROLE & LEVEL & COUNT \\
& & \\
\hline INPUT & INTERVAL & 6
\end{tabular}

TARGET TARGET 1

FIT STATISTICS

\begin{tabular}{|c|c|c|}
\hline $\begin{array}{l}\text { FIT } \\
\text { STATISTIC }\end{array}$ & STATISTIC LABEL & $\begin{array}{l}\text { STATISTIC } \\
\text { VALUE }\end{array}$ \\
\hline DFT $_{-}$ & Total Degrees of Freedom. & 219 \\
\hline DFE_ & Degrees of Freedom for Error. & 170 \\
\hline _DFM_ & Model Degrees of Freedom. & 49 \\
\hline $\mathrm{NW}_{-}$ & Number of Estimated Weights. & 49 \\
\hline $\mathrm{AIC}_{-}$ & Akaike's Information Criterion. & 240.753 \\
\hline SBC_ $_{-}$ & Schwarz's Bayesian Criterion. & 406.818 \\
\hline ASE_ & Average Squared Error. & 0.101 \\
\hline _MAX_ & Maximum Absolute Error. & 0.975 \\
\hline DIV_ $_{-}$ & Divisor for ASE. & 438 \\
\hline NOBS_ & Sum of Frequencies. & 219 \\
\hline RASE_ & Root Average Squared Error. & 0.318 \\
\hline SSE_ & Sum of Squared Errors. & 44.213 \\
\hline SUMW_ & Sum of Case Weights Times Freq. & 438 \\
\hline _FPE_ & Final Prediction Error. & 0.159 \\
\hline MSE_ & Mean Squared Error. & 0.13 \\
\hline RFPE_ & Root Final Prediction Error. & 0.399 \\
\hline _RMSE_ & Root Mean Squared Error. & 0.361 \\
\hline _AVERR_ & Average Error Function. & 0.326 \\
\hline _ERR_ & Error Function. & 142.753 \\
\hline _MISC_ & Misclassification Rate. & 0.11 \\
\hline WRONG & Number of Wrong Classifications. & 24 \\
\hline
\end{tabular}




\section{CLASSIFICATION SUMMARY}

\begin{tabular}{llccccc}
\hline & & PERCENT & PERCENT & & \multicolumn{2}{l}{ PERCENT } \\
& & OF & OF \\
TARGET & PREDICT & TARGET & PREDICT & COUNT & TOTAL \\
\hline BANKRUPT & BANKRUPT & 88.1818 & 89.8148 & 97 & 44.2922 \\
NONBANKRUPT & BANKRUPT & 11.8182 & 11.7117 & 13 & 5.9361 \\
BANKRUPT & NONBANKRUPT & 10.0917 & 10.1852 & 11 & 5.0228 \\
NONBANKRUPT & NONBANKRUPT & 89.9083 & 88.2883 & 98 & 44.7489 \\
\hline
\end{tabular}

YEAR 4

VARIABLE SUMMARY

\begin{tabular}{lll}
\hline ROLE & LEVEL & COUNT \\
& & \\
\hline INPUT & INTERVAL & 6
\end{tabular}

TARGET TARGET 1

FIT STATISTICS

\begin{tabular}{|c|c|c|}
\hline $\begin{array}{l}\text { FIT } \\
\text { STATISTIC }\end{array}$ & STATISTIC LABEL & $\begin{array}{l}\text { STATISTIC } \\
\text { VALUE }\end{array}$ \\
\hline DFT $_{-}$ & Total Degrees of Freedom. & 195 \\
\hline _DFE_ & Degrees of Freedom for Error. & 146 \\
\hline _DFM_ & Model Degrees of Freedom. & 49 \\
\hline $\mathrm{NW}_{-}$ & Number of Estimated Weights. & 49 \\
\hline $\mathrm{AIC}_{-}$ & Akaike's Information Criterion. & 192.392 \\
\hline $\mathrm{SBC}_{-}$ & Schwarz's Bayesian Criterion. & 352.769 \\
\hline _ASE_ & Average Squared Error. & 0.077 \\
\hline _MAX_ & Maximum Absolute Error. & 0.981 \\
\hline $\mathrm{DIV}_{-}$ & Divisor for ASE. & 390 \\
\hline NOBS_ & Sum of Frequencies. & 195 \\
\hline _RASE_ & Root Average Squared Error. & 0.277 \\
\hline $\mathrm{SSE}_{-}$ & Sum of Squared Errors. & 29.947 \\
\hline SUMW_ & Sum of Case Weights Times Freq. & 390 \\
\hline FPE_ & Final Prediction Error. & 0.128 \\
\hline MSE_ & Mean Squared Error. & 0.103 \\
\hline _RFPE_ & Root Final Prediction Error. & 0.358 \\
\hline RMSE_ & Root Mean Squared Error. & 0.32 \\
\hline _AVERR_ & Average Error Function. & 0.242 \\
\hline _ERR_ & Error Function. & 94.392 \\
\hline _MISC_ & Misclassification Rate. & 0.103 \\
\hline _WRONG & Number of Wrong Classifications. & 20 \\
\hline
\end{tabular}




\section{CLASSIFICATION SUMMARY}

\begin{tabular}{llccccc}
\hline & & PERCENT & PERCENT & & PERCENT \\
& & OF & OF & \\
TARGET & PREDICT & TARGET & PREDICT & COUNT & TOTAL \\
\hline BANKRUPT & BANKRUPT & 88.2353 & 88.2353 & 75 & 38.4615 \\
NONBANKRUPT & BANKRUPT & 11.7647 & 9.0909 & 10 & 5.1282 \\
BANKRUPT & NONBANKRUPT & 9.0909 & 11.7647 & 10 & 5.1282 \\
NONBANKRUPT & NONBANKRUPT & 90.9091 & 90.9091 & 100 & 51.2821 \\
\hline
\end{tabular}

YEAR 5

VARIABLE SUMMARY

\begin{tabular}{lll}
\hline ROLE & LEVEL & COUNT \\
& & \\
\hline INPUT & INTERVAL & 6
\end{tabular}

TARGET TARGET 1

FIT STATISTICS

\begin{tabular}{|c|c|c|}
\hline $\begin{array}{l}\text { FIT } \\
\text { STATISTIC }\end{array}$ & STATISTIC LABEL & $\begin{array}{l}\text { STATISTIC } \\
\text { VALUE }\end{array}$ \\
\hline DFT $_{-}$ & Total Degrees of Freedom. & 168 \\
\hline _DFE_ & Degrees of Freedom for Error. & 119 \\
\hline _DFM_ & Model Degrees of Freedom. & 49 \\
\hline $\mathrm{NW}_{-}$ & Number of Estimated Weights. & 49 \\
\hline $\mathrm{AIC}_{-}$ & Akaike's Information Criterion. & 219.711 \\
\hline $\mathrm{SBC}_{-}$ & Schwarz's Bayesian Criterion. & 372.786 \\
\hline _ASE_ & Average Squared Error. & 0.113 \\
\hline _MAX_ & Maximum Absolute Error. & 0.916 \\
\hline $\mathrm{DIV}_{-}$ & Divisor for ASE. & 336 \\
\hline NOBS_ & Sum of Frequencies. & 168 \\
\hline _RASE_ & Root Average Squared Error. & 0.336 \\
\hline $\mathrm{SSE}_{-}$ & Sum of Squared Errors. & 37.897 \\
\hline SUMW_ & Sum of Case Weights Times Freq. & 336 \\
\hline FPE_ & Final Prediction Error. & 0.206 \\
\hline MSE_ & Mean Squared Error. & 0.159 \\
\hline _RFPE_ & Root Final Prediction Error. & 0.454 \\
\hline RMSE_ & Root Mean Squared Error. & 0.399 \\
\hline _AVERR_ & Average Error Function. & 0.362 \\
\hline ERR_ & Error Function. & 121.711 \\
\hline _MISC_ & Misclassification Rate. & 0.125 \\
\hline _WRONG & Number of Wrong Classifications. & 21 \\
\hline
\end{tabular}


CLASSIFICATION SUMMARY

\begin{tabular}{llccccc}
\hline & & PERCENT & PERCENT & & PERCENT \\
OF & OF & & \\
TARGET & PREDICT & TARGET & PREDICT & COUNT & TOTAL \\
\hline BANKRUPT & BANKRUPT & 90.1639 & 78.5714 & 55 & 32.7381 \\
NONBANKRUPT & BANKRUPT & 9.8361 & 6.1224 & 6 & 3.5714 \\
BANKRUPT & NONBANKRUPT & 14.0187 & 21.4286 & 15 & 8.9286 \\
NONBANKRUPT & NONBANKRUPT & 85.9813 & 93.8776 & 92 & 54.7619 \\
\hline
\end{tabular}


Results of Multi Layer Perceptron : Variables (Price, Standard deviation, bid ask spread, net income to sales, working capital to total assets and current liabilities to total assets )

YEAR 1

VARIABLE SUMMARY

\begin{tabular}{lll}
\hline ROLE & LEVEL & COUNT \\
\hline INPUT & INTERVAL & 6
\end{tabular}

TARGET TARGET 1

FIT STATISTICS

\begin{tabular}{|c|c|c|}
\hline $\begin{array}{l}\text { FIT } \\
\text { STATISTIC }\end{array}$ & STATISTIC LABEL & $\begin{array}{l}\text { STATISTIC } \\
\text { VALUE }\end{array}$ \\
\hline DFT_ $_{-}$ & Total Degrees of Freedom. & 255 \\
\hline _DFE_ & Degrees of Freedom for Error. & 206 \\
\hline _DFM_ & Model Degrees of Freedom. & 49 \\
\hline $\mathrm{NW}_{-}$ & Number of Estimated Weights. & 49 \\
\hline $\mathrm{AIC}_{-}$ & Akaike's Information Criterion. & 259.926 \\
\hline${ }_{-} \mathrm{SBC}_{-}$ & Schwarz's Bayesian Criterion. & 433.448 \\
\hline _ASE_ & Average Squared Error. & 0.096 \\
\hline _MAX_ & Maximum Absolute Error. & 0.968 \\
\hline DIV $_{-}$ & Divisor for ASE. & 510 \\
\hline NOBS & Sum of Frequencies. & 255 \\
\hline _RASE_ & Root Average Squared Error. & 0.31 \\
\hline $\mathrm{SSE}_{-}$ & Sum of Squared Errors. & 49.015 \\
\hline SUMW_ & Sum of Case Weights Times Freq. & 510 \\
\hline FPE_ & Final Prediction Error. & 0.142 \\
\hline _MSE_ & Mean Squared Error. & 0.119 \\
\hline _RFPE_ & Root Final Prediction Error. & 0.377 \\
\hline _RMSE_ & Root Mean Squared Error. & 0.345 \\
\hline _AVERR_ & Average Error Function. & 0.318 \\
\hline _ERR_ & Error Function. & 161.926 \\
\hline _MISC_ & Misclassification Rate. & 0.106 \\
\hline WRONG & Number of Wrong Classifications. & 27 \\
\hline
\end{tabular}


CLASSIFICATION SUMMARY

\begin{tabular}{llccccc}
\hline & & PERCENT & PERCENT & & \multicolumn{2}{l}{ PERCENT } \\
& & OF & OF & \\
TARGET & PREDICT & TARGET & PREDICT & COUNT & TOTAL \\
\hline BANKRUPT & BANKRUPT & 90.5109 & 89.8551 & 124 & 48.6275 \\
NONBANKRUPT & BANKRUPT & 9.4891 & 11.1111 & 13 & 5.098 \\
BANKRUPT & NONBANKRUPT & 11.8644 & 10.1449 & 14 & 5.4902 \\
NONBANKRUPT & NONBANKRUPT & 88.1356 & 88.8889 & 104 & 40.7843 \\
\hline
\end{tabular}

YEAR 2

VARIABLE SUMMARY

\begin{tabular}{lll}
\hline ROLE & LEVEL & COUNT \\
& & \\
\hline INPUT & INTERVAL & 6
\end{tabular}

TARGET TARGET 1

FIT STATISTICS

\begin{tabular}{|c|c|c|}
\hline $\begin{array}{l}\text { FIT } \\
\text { STATISTIC }\end{array}$ & STATISTIC LABEL & $\begin{array}{l}\text { STATISTIC } \\
\text { VALUE }\end{array}$ \\
\hline DFT $_{-}$ & Total Degrees of Freedom. & 242 \\
\hline DFE_ & Degrees of Freedom for Error. & 193 \\
\hline _DFM_ & Model Degrees of Freedom. & 49 \\
\hline $\mathrm{NW}_{-}$ & Number of Estimated Weights. & 49 \\
\hline $\mathrm{AIC}_{-}$ & Akaike's Information Criterion. & 280.076 \\
\hline${ }_{-} \mathrm{SBC}_{-}$ & Schwarz's Bayesian Criterion. & 451.034 \\
\hline ASE_ & Average Squared Error. & 0.123 \\
\hline _MAX_ & Maximum Absolute Error. & 0.896 \\
\hline DIV_ $_{-}$ & Divisor for ASE. & 484 \\
\hline NOBS_ & Sum of Frequencies. & 242 \\
\hline RASE_ & Root Average Squared Error. & 0.351 \\
\hline _SSE_ & Sum of Squared Errors. & 59.77 \\
\hline SUMW_ & Sum of Case Weights Times Freq. & 484 \\
\hline FPE_ & Final Prediction Error. & 0.186 \\
\hline _MSE_ & Mean Squared Error. & 0.155 \\
\hline RFPE_ & Root Final Prediction Error. & 0.432 \\
\hline _RMSE_ & Root Mean Squared Error. & 0.394 \\
\hline _AVERR_ & Average Error Function. & 0.376 \\
\hline ERR_ & Error Function. & 182.076 \\
\hline _MISC_ & Misclassification Rate. & 0.165 \\
\hline WRONG & Number of Wrong Classifications. & 40 \\
\hline
\end{tabular}


CLASSIFICATION SUMMARY

\begin{tabular}{llccccc}
\hline & & PERCENT & PERCENT & & \multicolumn{2}{l}{$\begin{array}{l}\text { PERCENT } \\
\text { OF }\end{array}$} \\
TARGET & PREDICT & TARGET & OF & PRDICT & COUNT & TOTAL \\
\hline BANKRUPT & BANKRUPT & 83.9695 & 85.2713 & 110 & 45.4545 \\
NONBANKRUPT & BANKRUPT & 16.0305 & 18.5841 & 21 & 8.6777 \\
BANKRUPT & NONBANKRUPT & 17.1171 & 14.7287 & 19 & 7.8512 \\
NONBANKRUPT & NONBANKRUPT & 82.8829 & 81.4159 & 92 & 38.0165 \\
\hline
\end{tabular}

YEAR 3

VARIABLE SUMMARY

\begin{tabular}{lll}
\hline ROLE & LEVEL & COUNT \\
& & \\
\hline INPUT & INTERVAL & 6
\end{tabular}

TARGET TARGET 1

FIT STATISTICS

\begin{tabular}{|c|c|c|}
\hline $\begin{array}{l}\text { FIT } \\
\text { STATISTIC }\end{array}$ & STATISTIC LABEL & $\begin{array}{l}\text { STATISTIC } \\
\text { VALUE }\end{array}$ \\
\hline DFT_ $_{-}$ & Total Degrees of Freedom. & 219 \\
\hline _DFE_ & Degrees of Freedom for Error. & 170 \\
\hline _DFM_ & Model Degrees of Freedom. & 49 \\
\hline $\mathrm{NW}_{-}$ & Number of Estimated Weights. & 49 \\
\hline $\mathrm{AIC}_{-}$ & Akaike's Information Criterion. & 250.47 \\
\hline $\mathrm{SBC}_{-}$ & Schwarz's Bayesian Criterion. & 416.535 \\
\hline _ASE_ & Average Squared Error. & 0.109 \\
\hline _MAX_ & Maximum Absolute Error. & 0.984 \\
\hline $\mathrm{DIV}_{-}$ & Divisor for ASE. & 438 \\
\hline NOBS_ & Sum of Frequencies. & 219 \\
\hline _RASE_ & Root Average Squared Error. & 0.331 \\
\hline SSE_ & Sum of Squared Errors. & 47.952 \\
\hline${ }_{-} \mathrm{SUMW}$ & Sum of Case Weights Times Freq. & 438 \\
\hline FPE_ & Final Prediction Error. & 0.173 \\
\hline _MSE_ & Mean Squared Error. & 0.141 \\
\hline RFPE_ & Root Final Prediction Error. & 0.415 \\
\hline _RMSE_ & Root Mean Squared Error. & 0.376 \\
\hline _AVERR_ & Average Error Function. & 0.348 \\
\hline ERR_ & Error Function. & 152.47 \\
\hline _MISC_ & Misclassification Rate. & 0.169 \\
\hline WRONG & Number of Wrong Classifications. & 37 \\
\hline
\end{tabular}


CLASSIFICATION SUMMARY

\begin{tabular}{llcccc}
\hline & & PERCENT & PERCENT & & \multicolumn{2}{c}{$\begin{array}{l}\text { PERCENT } \\
\text { OF } \\
\text { TARGET }\end{array}$} & PREDICT & TARGET & $\begin{array}{l}\text { OF } \\
\text { PREDICT }\end{array}$ & COUNT & TOTAL \\
\hline BANKRUPT & BANKRUPT & 81.4159 & 85.1852 & 92 & 42.0091 \\
NONBANKRUPT & BANKRUPT & 18.5841 & 18.9189 & 21 & 9.589 \\
BANKRUPT & NONBANKRUPT & 15.0943 & 14.8148 & 16 & 7.3059 \\
NONBANKRUPT & NONBANKRUPT & 84.9057 & 81.0811 & 90 & 41.0959 \\
\hline
\end{tabular}

YEAR 4

VARIABLE SUMMARY

\begin{tabular}{lll}
\hline ROLE & LEVEL & COUNT \\
& & \\
\hline INPUT & INTERVAL & 6
\end{tabular}

TARGET TARGET 1

FIT STATISTICS

\begin{tabular}{|c|c|c|}
\hline $\begin{array}{l}\text { FIT } \\
\text { STATISTIC }\end{array}$ & STATISTIC LABEL & $\begin{array}{l}\text { STATISTIC } \\
\text { VALUE }\end{array}$ \\
\hline DFT_ $_{-}$ & Total Degrees of Freedom. & 195 \\
\hline _DFE_ & Degrees of Freedom for Error. & 146 \\
\hline _DFM_ & Model Degrees of Freedom. & 49 \\
\hline $\mathrm{NW}_{-}$ & Number of Estimated Weights. & 49 \\
\hline $\mathrm{AIC}_{-}$ & Akaike's Information Criterion. & 179.296 \\
\hline $\mathrm{SBC}_{-}$ & Schwarz's Bayesian Criterion. & 339.673 \\
\hline _ASE_ & Average Squared Error. & 0.061 \\
\hline _MAX_ & Maximum Absolute Error. & 0.953 \\
\hline $\mathrm{DIV}_{-}$ & Divisor for ASE. & 390 \\
\hline NOBS_ & Sum of Frequencies. & 195 \\
\hline _RASE_ & Root Average Squared Error. & 0.248 \\
\hline SSE_ & Sum of Squared Errors. & 23.964 \\
\hline${ }_{-} \mathrm{SUMW}$ & Sum of Case Weights Times Freq. & 390 \\
\hline FPE_ & Final Prediction Error. & 0.103 \\
\hline _MSE_ & Mean Squared Error. & 0.082 \\
\hline RFPE_ & Root Final Prediction Error. & 0.32 \\
\hline _RMSE_ & Root Mean Squared Error. & 0.286 \\
\hline _AVERR_ & Average Error Function. & 0.208 \\
\hline ERR_ & Error Function. & 81.296 \\
\hline _MISC_ & Misclassification Rate. & 0.067 \\
\hline WRONG & Number of Wrong Classifications. & 13 \\
\hline
\end{tabular}


CLASSIFICATION SUMMARY

\begin{tabular}{llcccc}
\hline & & PERCENT & PERCENT & & PERCENT \\
& & OF & OF & & OF \\
TARGET & PREDICT & TARGET & PREDICT & COUNT & TOTAL \\
\hline BANKRUPT & BANKRUPT & 93.9024 & 90.5882 & 77 & 39.4872 \\
NONBANKRUPT & BANKRUPT & 6.0976 & 4.5455 & 5 & 2.5641 \\
BANKRUPT & NONBANKRUPT & 7.0796 & 9.4118 & 8 & 4.1026 \\
NONBANKRUPT & NONBANKRUPT & 92.9204 & 95.4545 & 105 & 53.8462 \\
\hline
\end{tabular}

YEAR 5

VARIABLE SUMMARY

\begin{tabular}{lll}
\hline ROLE & LEVEL & COUNT \\
& & \\
\hline INPUT & INTERVAL & 6
\end{tabular}

TARGET TARGET 1

FIT STATISTICS

\begin{tabular}{|c|c|c|}
\hline $\begin{array}{l}\text { FIT } \\
\text { STATISTIC }\end{array}$ & STATISTIC LABEL & $\begin{array}{l}\text { STATISTIC } \\
\text { VALUE }\end{array}$ \\
\hline DFT $_{-}$ & Total Degrees of Freedom. & 168 \\
\hline DFE_ & Degrees of Freedom for Error. & 119 \\
\hline _DFM_ & Model Degrees of Freedom. & 49 \\
\hline $\mathrm{NW}_{-}$ & Number of Estimated Weights. & 49 \\
\hline $\mathrm{AIC}_{-}$ & Akaike's Information Criterion. & 158.573 \\
\hline SBC_ $_{-}$ & Schwarz's Bayesian Criterion. & 311.647 \\
\hline ASE_ & Average Squared Error. & 0.051 \\
\hline _MAX_ & Maximum Absolute Error. & 0.973 \\
\hline DIV_ $_{-}$ & Divisor for ASE. & 336 \\
\hline NOBS_ & Sum of Frequencies. & 168 \\
\hline RASE_ & Root Average Squared Error. & 0.226 \\
\hline SSE_ & Sum of Squared Errors. & 17.199 \\
\hline SUMW_ & Sum of Case Weights Times Freq. & 336 \\
\hline _FPE_ & Final Prediction Error. & 0.093 \\
\hline MSE_ & Mean Squared Error. & 0.072 \\
\hline RFPE_ & Root Final Prediction Error. & 0.306 \\
\hline _RMSE_ & Root Mean Squared Error. & 0.269 \\
\hline _AVERR_ & Average Error Function. & 0.18 \\
\hline _ERR_ & Error Function. & 60.573 \\
\hline MISC_ & Misclassification Rate. & 0.048 \\
\hline WRONG & Number of Wrong Classifications. & 8 \\
\hline
\end{tabular}


CLASSIFICATION SUMMARY

\begin{tabular}{llcccc}
\hline & & PERCENT & PERCENT & & \multicolumn{2}{c}{ PERCENT } \\
& & OF & OF & \\
TARGET & PREDICT & TARGET & PREDICT & COUNT & TOTAL \\
\hline BANKRUPT & BANKRUPT & 94.2857 & 94.2857 & 66 & 39.2857 \\
NONBANKRUPT & BANKRUPT & 5.7143 & 4.0816 & 4 & 2.381 \\
BANKRUPT & NONBANKRUPT & 4.0816 & 5.7143 & 4 & 2.381 \\
NONBANKRUPT & NONBANKRUPT & 95.9184 & 95.9184 & 94 & 55.9524 \\
\hline
\end{tabular}


Results of Multi Layer Perceptron : Variables (Price, Standard deviation, hi lo bid ask spread, net income to sales, working capital to total assets and current liabilities to total assets )

YEAR 1

VARIABLE SUMMARY

\begin{tabular}{lll}
\hline ROLE & LEVEL & COUNT \\
\hline INPUT & INTERVAL & 6
\end{tabular}

TARGET TARGET 1

FIT STATISTICS

\begin{tabular}{|c|c|c|}
\hline $\begin{array}{l}\text { FIT } \\
\text { STATISTIC }\end{array}$ & STATISTIC LABEL & $\begin{array}{l}\text { STATISTIC } \\
\text { VALUE }\end{array}$ \\
\hline DFT $_{-}$ & Total Degrees of Freedom. & 255 \\
\hline _DFE_ & Degrees of Freedom for Error. & 206 \\
\hline _DFM_ & Model Degrees of Freedom. & 49 \\
\hline $\mathrm{NW}_{-}$ & Number of Estimated Weights. & 49 \\
\hline $\mathrm{AIC}_{-}$ & Akaike's Information Criterion. & 263.773 \\
\hline $\mathrm{SBC}_{-}$ & Schwarz's Bayesian Criterion. & 437.295 \\
\hline _ASE_ & Average Squared Error. & 0.097 \\
\hline _MAX_ & Maximum Absolute Error. & 0.991 \\
\hline $\mathrm{DIV}_{-}$ & Divisor for ASE. & 510 \\
\hline NOBS & Sum of Frequencies. & 255 \\
\hline _RASE_ & Root Average Squared Error. & 0.311 \\
\hline $\mathrm{SSE}_{-}$ & Sum of Squared Errors. & 49.443 \\
\hline SUMW_ & Sum of Case Weights Times Freq. & 510 \\
\hline FPE_ & Final Prediction Error. & 0.143 \\
\hline _MSE_ & Mean Squared Error. & 0.12 \\
\hline _RFPE_ & Root Final Prediction Error. & 0.378 \\
\hline _RMSE_ & Root Mean Squared Error. & 0.346 \\
\hline _AVERR_ & Average Error Function. & 0.325 \\
\hline _ERR_ & Error Function. & 165.773 \\
\hline _MISC_ & Misclassification Rate. & 0.118 \\
\hline WRONG & Number of Wrong Classifications. & 30 \\
\hline
\end{tabular}


CLASSIFICATION SUMMARY

\begin{tabular}{llccccc}
\hline & & PERCENT & PERCENT & & \multicolumn{2}{l}{ PERCENT } \\
& & OF & OF & & OF \\
TARGET & PREDICT & TARGET & PREDICT & COUNT & TOTAL \\
\hline BANKRUPT & BANKRUPT & 85.5263 & 94.2029 & 130 & 50.9804 \\
NONBANKRUPT & BANKRUPT & 14.4737 & 18.8034 & 22 & 8.6275 \\
BANKRUPT & NONBANKRUPT & 7.767 & 5.7971 & 8 & 3.1373 \\
NONBANKRUPT & NONBANKRUPT & 92.233 & 81.1966 & 95 & 37.2549 \\
\hline
\end{tabular}

YEAR 2

VARIABLE SUMMARY

\begin{tabular}{lll}
\hline ROLE & LEVEL & COUNT \\
& & \\
\hline INPUT & INTERVAL & 6
\end{tabular}

TARGET TARGET 1

FIT STATISTICS

\begin{tabular}{|c|c|c|}
\hline $\begin{array}{l}\text { FIT } \\
\text { STATISTIC }\end{array}$ & STATISTIC LABEL & $\begin{array}{l}\text { STATISTIC } \\
\text { VALUE }\end{array}$ \\
\hline DFT $_{-}$ & Total Degrees of Freedom. & 242 \\
\hline DFE_ & Degrees of Freedom for Error. & 193 \\
\hline _DFM_ & Model Degrees of Freedom. & 49 \\
\hline $\mathrm{NW}_{-}$ & Number of Estimated Weights. & 49 \\
\hline $\mathrm{AIC}_{-}$ & Akaike's Information Criterion. & 338.131 \\
\hline SBC_ $_{-}$ & Schwarz's Bayesian Criterion. & 509.089 \\
\hline ASE_ & Average Squared Error. & 0.164 \\
\hline _MAX_ & Maximum Absolute Error. & 0.96 \\
\hline DIV_ $_{-}$ & Divisor for ASE. & 484 \\
\hline NOBS_ & Sum of Frequencies. & 242 \\
\hline RASE_ & Root Average Squared Error. & 0.405 \\
\hline SSE_ & Sum of Squared Errors. & 79.539 \\
\hline SUMW_ & Sum of Case Weights Times Freq. & 484 \\
\hline FPE_ & Final Prediction Error. & 0.248 \\
\hline _MSE_ & Mean Squared Error. & 0.206 \\
\hline RFPE_ & Root Final Prediction Error. & 0.498 \\
\hline RMSE_ & Root Mean Squared Error. & 0.454 \\
\hline _AVERR_ & Average Error Function. & 0.496 \\
\hline ERR_ & Error Function. & 240.131 \\
\hline _MISC_ & Misclassification Rate. & 0.202 \\
\hline WRONG & Number of Wrong Classifications. & 49 \\
\hline
\end{tabular}


CLASSIFICATION SUMMARY

\begin{tabular}{llrrrr}
\hline & & \multicolumn{2}{l}{ PERCENT } & \multicolumn{1}{l}{ PERCENT } & \multicolumn{2}{l}{$\begin{array}{l}\text { PERCENT } \\
\text { OF }\end{array}$} \\
TARGET & PREDICT & TARGET & $\begin{array}{l}\text { OF } \\
\text { PREDICT }\end{array}$ & COUNT & \multicolumn{1}{l}{ TOTAL } \\
\hline BANKRUPT & BANKRUPT & 79.8507 & 82.9457 & 107 & 44.2149 \\
NONBANKRUPT & BANKRUPT & 20.1493 & 23.8938 & 27 & 11.157 \\
BANKRUPT & NONBANKRUPT & 20.3704 & 17.0543 & 22 & 9.0909 \\
NONBANKRUPT & NONBANKRUPT & 79.6296 & 76.1062 & 86 & 35.5372 \\
\hline
\end{tabular}

YEAR 3

VARIABLE SUMMARY

\begin{tabular}{lll}
\hline ROLE & LEVEL & COUNT \\
\hline INPUT & INTERVAL & 6
\end{tabular}

TARGET TARGET 1

FIT STATISTICS

\begin{tabular}{|c|c|c|}
\hline $\begin{array}{l}\text { FIT } \\
\text { STATISTIC }\end{array}$ & STATISTIC LABEL & $\begin{array}{l}\text { STATISTIC } \\
\text { VALUE }\end{array}$ \\
\hline DFT $_{-}$ & Total Degrees of Freedom. & 219 \\
\hline _DFE_ & Degrees of Freedom for Error. & 170 \\
\hline _DFM_ & Model Degrees of Freedom. & 49 \\
\hline $\mathrm{NW}_{-}$ & Number of Estimated Weights. & 49 \\
\hline $\mathrm{AIC}_{-}$ & Akaike's Information Criterion. & 283.966 \\
\hline $\mathrm{SBC}_{-}$ & Schwarz's Bayesian Criterion. & 450.03 \\
\hline _ASE_ & Average Squared Error. & 0.137 \\
\hline _MAX_ & Maximum Absolute Error. & 0.993 \\
\hline DIV $_{-}$ & Divisor for ASE. & 438 \\
\hline NOBS_ & Sum of Frequencies. & 219 \\
\hline _RASE_ & Root Average Squared Error. & 0.37 \\
\hline SSE_ & Sum of Squared Errors. & 59.808 \\
\hline SUMW_ & Sum of Case Weights Times Freq. & 438 \\
\hline -FPE_ & Final Prediction Error. & 0.215 \\
\hline MSE_ & Mean Squared Error. & 0.176 \\
\hline _RFPE_ & Root Final Prediction Error. & 0.464 \\
\hline _RMSE_ & Root Mean Squared Error. & 0.419 \\
\hline _AVERR_ & Average Error Function. & 0.425 \\
\hline ERR_ & Error Function. & 185.966 \\
\hline _MISC_ & Misclassification Rate. & 0.192 \\
\hline WRONG & Number of Wrong Classifications. & 42 \\
\hline
\end{tabular}


CLASSIFICATION SUMMARY

\begin{tabular}{llcccc}
\hline & & PERCENT & PERCENT & & PERCENT \\
& & OF & OF & \\
TARGET & PREDICT & TARGET & PREDICT & COUNT & TOTAL \\
\hline BANKRUPT & BANKRUPT & 79.4643 & 82.4074 & 89 & 40.6393 \\
NONBANKRUPT & BANKRUPT & 20.5357 & 20.7207 & 23 & 10.5023 \\
BANKRUPT & NONBANKRUPT & 17.757 & 17.5926 & 19 & 8.6758 \\
NONBANKRUPT & NONBANKRUPT & 82.243 & 79.2793 & 88 & 40.1826 \\
\hline
\end{tabular}

YEAR 4

VARIABLE SUMMARY

\begin{tabular}{lll}
\hline ROLE & LEVEL & COUNT \\
& & \\
\hline INPUT & INTERVAL & 6
\end{tabular}

TARGET TARGET 1

FIT STATISTICS

\begin{tabular}{|c|c|c|}
\hline $\begin{array}{l}\text { FIT } \\
\text { STATISTIC }\end{array}$ & STATISTIC LABEL & $\begin{array}{l}\text { STATISTIC } \\
\text { VALUE }\end{array}$ \\
\hline DFT $_{-}$ & Total Degrees of Freedom. & 195 \\
\hline DFE_ & Degrees of Freedom for Error. & 146 \\
\hline _DFM_ & Model Degrees of Freedom. & 49 \\
\hline $\mathrm{NW}_{-}$ & Number of Estimated Weights. & 49 \\
\hline $\mathrm{AIC}_{-}$ & Akaike's Information Criterion. & 246.888 \\
\hline${ }_{-} \mathrm{SBC}_{-}$ & Schwarz's Bayesian Criterion. & 407.265 \\
\hline ASE_ & Average Squared Error. & 0.121 \\
\hline _MAX_ & Maximum Absolute Error. & 0.863 \\
\hline DIV_ $_{-}$ & Divisor for ASE. & 390 \\
\hline NOBS_ & Sum of Frequencies. & 195 \\
\hline RASE_ & Root Average Squared Error. & 0.348 \\
\hline _SSE_ & Sum of Squared Errors. & 47.141 \\
\hline SUMW_ & Sum of Case Weights Times Freq. & 390 \\
\hline FPE_ & Final Prediction Error. & 0.202 \\
\hline _MSE_ & Mean Squared Error. & 0.161 \\
\hline RFPE_ & Root Final Prediction Error. & 0.449 \\
\hline _RMSE_ & Root Mean Squared Error. & 0.402 \\
\hline _AVERR_ & Average Error Function. & 0.382 \\
\hline _ERR_ & Error Function. & 148.888 \\
\hline _MISC_ & Misclassification Rate. & 0.123 \\
\hline WRONG & Number of Wrong Classifications. & 24 \\
\hline
\end{tabular}


CLASSIFICATION SUMMARY

\begin{tabular}{llcccc}
\hline & & PERCENT & PERCENT & & \multicolumn{2}{l}{ PERCENT } \\
& & OF & OF \\
TARGET & PREDICT & TARGET & PREDICT & COUNT & TOTAL \\
\hline BANKRUPT & BANKRUPT & 85.8824 & 85.8824 & 73 & 37.4359 \\
NONBANKRUPT & BANKRUPT & 14.1176 & 10.9091 & 12 & 6.1538 \\
BANKRUPT & NONBANKRUPT & 10.9091 & 14.1176 & 12 & 6.1538 \\
NONBANKRUPT & NONBANKRUPT & 89.0909 & 89.0909 & 98 & 50.2564 \\
\hline
\end{tabular}

YEAR 5

VARIABLE SUMMARY

\begin{tabular}{lll}
\hline ROLE & LEVEL & COUNT \\
& & \\
\hline INPUT & INTERVAL & 6
\end{tabular}

TARGET TARGET 1

FIT STATISTICS

\begin{tabular}{|c|c|c|}
\hline $\begin{array}{l}\text { FIT } \\
\text { STATISTIC }\end{array}$ & STATISTIC LABEL & $\begin{array}{l}\text { STATISTIC } \\
\text { VALUE }\end{array}$ \\
\hline DFT $_{-}$ & Total Degrees of Freedom. & 168 \\
\hline DFE_ & Degrees of Freedom for Error. & 119 \\
\hline _DFM_ & Model Degrees of Freedom. & 49 \\
\hline $\mathrm{NW}_{-}$ & Number of Estimated Weights. & 49 \\
\hline $\mathrm{AIC}_{-}$ & Akaike's Information Criterion. & 199.844 \\
\hline SBC_ $_{-}$ & Schwarz's Bayesian Criterion. & 352.918 \\
\hline ASE_ & Average Squared Error. & 0.094 \\
\hline _MAX_ & Maximum Absolute Error. & 0.966 \\
\hline DIV_ $_{-}$ & Divisor for ASE. & 336 \\
\hline NOBS_ & Sum of Frequencies. & 168 \\
\hline RASE_ & Root Average Squared Error. & 0.307 \\
\hline SSE_ & Sum of Squared Errors. & 31.619 \\
\hline SUMW_ & Sum of Case Weights Times Freq. & 336 \\
\hline FPE_ & Final Prediction Error. & 0.172 \\
\hline _MSE_ & Mean Squared Error. & 0.133 \\
\hline RFPE_ & Root Final Prediction Error. & 0.414 \\
\hline _RMSE_ & Root Mean Squared Error. & 0.364 \\
\hline _AVERR_ & Average Error Function. & 0.303 \\
\hline ERR_ & Error Function. & 101.844 \\
\hline _MISC_ & Misclassification Rate. & 0.125 \\
\hline WRONG & Number of Wrong Classifications. & 21 \\
\hline
\end{tabular}


CLASSIFICATION SUMMARY

\begin{tabular}{llccccc}
\hline & & PERCENT & PERCENT & & \multicolumn{2}{c}{ PERCENT } \\
& & OF & OF & \\
TARGET & PREDICT & TARGET & PREDICT & COUNT & TOTAL \\
\hline BANKRUPT & BANKRUPT & 82.6667 & 88.5714 & 62 & 36.9048 \\
NONBANKRUPT & BANKRUPT & 17.3333 & 13.2653 & 13 & 7.7381 \\
BANKRUPT & NONBANKRUPT & 8.6022 & 11.4286 & 8 & 4.7619 \\
NONBANKRUPT & NONBANKRUPT & 91.3978 & 86.7347 & 85 & 50.5952 \\
\hline
\end{tabular}


The next two sets of variables are those six variables that performed best in both the univariate analysis and the multivariate discriminant analysis. The two sets contain price, standard deviation, bid-ask spread, net income to sales, working capital to total assets, and current liabilities to total assets (the second set is the same as the first, but the bid-ask spread is measured by the high-low bid-ask spread).

For the first set, the classification rates for the bankrupt firms are $90 \%, 84 \%, 82 \%$, $94 \%$, and $94 \%$ in years one through five, and $88 \%, 83 \%, 85 \%, 93 \%$, and $96 \%$ in years one through five for the nonbankrupt firms. The overall misclassification rates are $10.6 \%$ and $5 \%$ in years one and five, respectively.

For the second set, bankrupt firms in years one through five, respectively, have the following classification rates: $86 \%, 80 \%, 79 \%, 85 \%$, and $83 \%$. The classification rates for nonbankrupt firms are $92 \%, 80 \%, 82 \%, 89 \%$, and $91 \%$ in years one through five. The misclassification rates ranges are around $12 \%$ in both years one and five. The high-low bid-ask spread allows the multi-layer perceptron to correctly classify the nonbankrupt firms better, but it does slightly the opposite for the bankrupt firms. Therefore, the high-low bid ask spread is less desirable than the end-of-day bid-ask spread since correctly classifying bankrupt firms is of higher importance.

It is important to note that by adding a few accounting ratios to the input variables along with price, standard deviation, and bid-ask spread, the model becomes more accurate than it is with only market variables. While market variables are forwardlooking and account ratios are backward-looking, accounting ratios still contain information. More importantly, the deterioration and pattern of the account ratios contain certain information that the market variables do not include. Accounting ratios are also 
much less noisy than the market variables, not as highly affected by human sentiment and market movements.

We now direct our attention to the radial basis functions. With the market variables as the inputs, the classification rates for the bankrupt firms are $80 \%, 77 \%, 76 \%$, $84 \%$, and $82 \%$, whereas those for nonbankrupt firms are $84 \%, 73 \%, 70 \%, 86 \%$, and $88 \%$, from years one to five. The overall misclassification rates are $18 \%$ and $15 \%$ in years one and five, respectively.

For the first set of mixed variables, the classification rates for the bankrupt firms are $83 \%, 75 \%, 81 \%, 90 \%$, and $97 \%$, whereas those for the nonbankrupt firms are $81 \%$, $82 \%, 71 \%, 89 \%$, and $91 \%$. The overall misclassification rates are $18 \%$ one year before bankruptcy versus $6.5 \%$ five years before bankruptcy. For the second set, the bankruptcy classification rates for years one through five are $88 \%, 69 \%, 72 \%, 80 \%$, and $88 \%$, while those of the nonbankrupt firms are $89 \%, 64 \%, 70 \%, 79 \%$, and $81 \%$. The misclassification rates, overall, are $11.4 \%$ and $17 \%$ in years one and five, respectively.

While the radial basis function still performs relatively well, the multi-layer perceptron has higher classification rates for all different input sets and years. This is likely due to the fact that the parameters of the multi-layer perceptron are non-linear, while those of the radial basis function are linear. As discussed earlier in this chapter and in previous chapter, the relations between the variables and the likelihood of bankruptcy are not linear. This is consistent with the findings in the literature and the previous chapter. 
Table 12

Results of Radial Basis Function Networks : Accounting variables

YEAR 1

\begin{tabular}{lll}
\multicolumn{3}{c}{ VARIABLE SUMMARY } \\
\hline ROLE & LEVEL & COUNT \\
\hline INPUT & INTERVAL & 17 \\
TARGET & TARGET & 1 \\
\hline
\end{tabular}

FIT STATISTICS

\begin{tabular}{|c|c|c|}
\hline $\begin{array}{l}\text { FIT } \\
\text { STATISTIC }\end{array}$ & STATISTIC LABEL & $\begin{array}{l}\text { STATISTIC } \\
\text { VALUE }\end{array}$ \\
\hline DFT $_{-}$ & Total Degrees of Freedom. & 255 \\
\hline _ DFE_ & Degrees of Freedom for Error. & 141 \\
\hline _DFM_ & Model Degrees of Freedom. & 114 \\
\hline $\mathrm{NW}_{-}$ & Number of Estimated Weights. & 114 \\
\hline $\mathrm{AIC}_{-}$ & Akaike's Information Criterion. & 385.235 \\
\hline $\mathrm{SBC}_{-}$ & Schwarz's Bayesian Criterion. & 788.939 \\
\hline _ASE_ & Average Squared Error. & 0.088 \\
\hline _MAX_ & Maximum Absolute Error. & 0.919 \\
\hline DIV_ & Divisor for ASE. & 510 \\
\hline NOBS_ & Sum of Frequencies. & 255 \\
\hline _RASE_ & Root Average Squared Error. & 0.297 \\
\hline _SSE_ & Sum of Squared Errors. & 45.05 \\
\hline SSUMW_ & Sum of Case Weights Times Freq. & 510 \\
\hline _FPE_ & Final Prediction Error. & 0.231 \\
\hline _MSE_ & Mean Squared Error. & 0.16 \\
\hline _RFPE_ & Root Final Prediction Error. & 0.481 \\
\hline _RMSE_ & Root Mean Squared Error. & 0.4 \\
\hline _AVERR_ & Average Error Function. & 0.308 \\
\hline _ERR_ & Error Function. & 157.235 \\
\hline _MISC_ & Misclassification Rate. & 0.098 \\
\hline WRONG & Number of Wrong Classifications. & 25 \\
\hline
\end{tabular}


CLASSIFICATION SUMMARY

\begin{tabular}{llcccc}
\hline & & PERCENT & PERCENT & & PERCENT \\
& & OF & OF & & OF \\
TARGET & PREDICT & TARGET & PREDICT & COUNT & TOTAL \\
\hline BANKRUPT & BANKRUPT & 87.4172 & 95.6522 & 132 & 51.7647 \\
NONBANKRUPT & BANKRUPT & 12.5828 & 16.2393 & 19 & 7.451 \\
BANKRUPT & NONBANKRUPT & 5.7692 & 4.3478 & 6 & 2.3529 \\
NONBANKRUPT & NONBANKRUPT & 94.2308 & 83.7607 & 98 & 38.4314 \\
\hline
\end{tabular}

YEAR 2

VARIABLE SUMMARY

\begin{tabular}{lll}
\hline ROLE & LEVEL & COUNT \\
\hline INPUT & INTERVAL & 17
\end{tabular}

TARGET TARGET 1

FIT STATISTICS

\begin{tabular}{|c|c|c|}
\hline $\begin{array}{l}\text { FIT } \\
\text { STATISTIC }\end{array}$ & STATISTIC LABEL & $\begin{array}{l}\text { STATISTIC } \\
\text { VALUE }\end{array}$ \\
\hline DFT_ $_{-}$ & Total Degrees of Freedom. & 242 \\
\hline _DFE_ & Degrees of Freedom for Error. & 128 \\
\hline _DFM_ & Model Degrees of Freedom. & 114 \\
\hline $\mathrm{NW}_{-}$ & Number of Estimated Weights. & 114 \\
\hline $\mathrm{AIC}_{-}$ & Akaike's Information Criterion. & 397.3 \\
\hline${ }_{-} \mathrm{SBC}$ & Schwarz's Bayesian Criterion. & 795.039 \\
\hline _ASE_ & Average Squared Error. & 0.101 \\
\hline MAX_ & Maximum Absolute Error. & 0.914 \\
\hline DIV & Divisor for ASE. & 484 \\
\hline NOBS_ & Sum of Frequencies. & 242 \\
\hline _RASE_ & Root Average Squared Error. & 0.318 \\
\hline $\mathrm{SSE}_{-}$ & Sum of Squared Errors. & 48.799 \\
\hline SUMW_ & Sum of Case Weights Times Freq. & 484 \\
\hline _FPE_ & Final Prediction Error. & 0.28 \\
\hline _MSE_ & Mean Squared Error. & 0.191 \\
\hline _RFPE_ & Root Final Prediction Error. & 0.53 \\
\hline _RMSE_ & Root Mean Squared Error. & 0.437 \\
\hline _AVERR_ & Average Error Function. & 0.35 \\
\hline ERR_ & Error Function. & 169.3 \\
\hline _MISC_ & Misclassification Rate. & 0.116 \\
\hline WRONG & Number of Wrong Classifications. & 28 \\
\hline
\end{tabular}


CLASSIFICATION SUMMARY

\begin{tabular}{llcccc}
\hline & & PERCENT & PERCENT & & PERCENT \\
& & OF & OF & \\
TARGET & PREDICT & TARGET & PREDICT & COUNT & TOTAL \\
\hline BANKRUPT & BANKRUPT & 87.4074 & 91.4729 & 118 & 48.7603 \\
NONBANKRUPT & BANKRUPT & 12.5926 & 15.0442 & 17 & 7.0248 \\
BANKRUPT & NONBANKRUPT & 10.2804 & 8.5271 & 11 & 4.5455 \\
NONBANKRUPT & NONBANKRUPT & 89.7196 & 84.9558 & 96 & 39.6694 \\
\hline
\end{tabular}

YEAR 3

VARIABLE SUMMARY

\begin{tabular}{lll}
\hline ROLE & LEVEL & COUNT \\
\hline INPUT & INTERVAL & 17
\end{tabular}

TARGET TARGET 1

FIT STATISTICS

\begin{tabular}{|c|c|c|}
\hline $\begin{array}{l}\text { FIT } \\
\text { STATISTIC }\end{array}$ & STATISTIC LABEL & $\begin{array}{l}\text { STATISTIC } \\
\text { VALUE }\end{array}$ \\
\hline DFT_ $_{-}$ & Total Degrees of Freedom. & 219 \\
\hline DFE & Degrees of Freedom for Error. & 105 \\
\hline _DFM_ & Model Degrees of Freedom. & 114 \\
\hline $\mathrm{NW}_{-}$ & Number of Estimated Weights. & 114 \\
\hline $\mathrm{AIC}_{-}$ & Akaike's Information Criterion. & 450.195 \\
\hline${ }_{-} \mathrm{SBC}$ & Schwarz's Bayesian Criterion. & 836.549 \\
\hline ASE_ & Average Squared Error. & 0.168 \\
\hline _MAX_ & Maximum Absolute Error. & 0.936 \\
\hline $\mathrm{DIV}_{-}$ & Divisor for ASE. & 438 \\
\hline _NOBS_ & Sum of Frequencies. & 219 \\
\hline RASE_ & Root Average Squared Error. & 0.41 \\
\hline _SSE_ & Sum of Squared Errors. & 73.669 \\
\hline SUMW_ & Sum of Case Weights Times Freq. & 438 \\
\hline _FPE_ & Final Prediction Error. & 0.533 \\
\hline _MSE_ & Mean Squared Error. & 0.351 \\
\hline _RFPE_ & Root Final Prediction Error. & 0.73 \\
\hline _RMSE_ & Root Mean Squared Error. & 0.592 \\
\hline AVERR_ & Average Error Function. & 0.507 \\
\hline ERR_ & Error Function. & 222.195 \\
\hline _MISC_ & Misclassification Rate. & 0.233 \\
\hline WRONG & Number of Wrong Classifications. & 51 \\
\hline
\end{tabular}


CLASSIFICATION SUMMARY

\begin{tabular}{llrrrr}
\hline & & PERCENT & \multicolumn{2}{l}{ PERCENT } & \multicolumn{2}{l}{ PERCENT } \\
& & OF & OF & \multicolumn{2}{l}{ OF } \\
TARGET & PREDICT & TARGET & PREDICT & COUNT & \multicolumn{1}{c}{ TOTAL } \\
\hline BANKRUPT & BANKRUPT & 70.2128 & 91.6667 & 99 & 45.2055 \\
NONBANKRUPT & BANKRUPT & 29.7872 & 37.8378 & 42 & 19.1781 \\
BANKRUPT & NONBANKRUPT & 11.5385 & 8.3333 & 9 & 4.1096 \\
NONBANKRUPT & NONBANKRUPT & 88.4615 & 62.1622 & 69 & 31.5068 \\
\hline
\end{tabular}

YEAR 4

VARIABLE SUMMARY

\begin{tabular}{lll}
\hline ROLE & LEVEL & COUNT \\
\hline INPUT & INTERVAL & 17
\end{tabular}

TARGET TARGET 1

FIT STATISTICS

\begin{tabular}{|c|c|c|}
\hline $\begin{array}{l}\text { FIT } \\
\text { STATISTIC }\end{array}$ & STATISTIC LABEL & $\begin{array}{l}\text { STATISTIC } \\
\text { VALUE }\end{array}$ \\
\hline DFT_ $_{-}$ & Total Degrees of Freedom. & 195 \\
\hline _DFE_ & Degrees of Freedom for Error. & 81 \\
\hline _DFM_ & Model Degrees of Freedom. & 114 \\
\hline $\mathrm{NW}_{-}$ & Number of Estimated Weights. & 114 \\
\hline AIC_ & Akaike's Information Criterion. & 412.793 \\
\hline $\mathrm{SBC}_{-}$ & Schwarz's Bayesian Criterion. & 785.914 \\
\hline ASE_ & Average Squared Error. & 0.158 \\
\hline MAX_ & Maximum Absolute Error. & 0.935 \\
\hline DIV_ & Divisor for ASE. & 390 \\
\hline NOBS_ & Sum of Frequencies. & 195 \\
\hline _RASE_ & Root Average Squared Error. & 0.398 \\
\hline _SSE_ & Sum of Squared Errors. & 61.695 \\
\hline _SUMW_ & Sum of Case Weights Times Freq. & 390 \\
\hline FPE_ & Final Prediction Error. & 0.603 \\
\hline _MSE_ & Mean Squared Error. & 0.381 \\
\hline _RFPE_ & Root Final Prediction Error. & 0.777 \\
\hline _RMSE_ & Root Mean Squared Error. & 0.617 \\
\hline _AVERR_ & Average Error Function. & 0.474 \\
\hline ERR_ & Error Function. & 184.793 \\
\hline MISC_$_{-}$ & Misclassification Rate. & 0.241 \\
\hline WRONG & Number of Wrong Classifications. & 47 \\
\hline
\end{tabular}


CLASSIFICATION SUMMARY

\begin{tabular}{llcccc}
\hline & & PERCENT & PERCENT & & PERCENT \\
& & OF & OF \\
TARGET & PREDICT & TARGET & PREDICT & COUNT & TOTAL \\
\hline BANKRUPT & BANKRUPT & 70.6522 & 76.4706 & 65 & 33.3333 \\
NONBANKRUPT & BANKRUPT & 29.3478 & 24.5455 & 27 & 13.8462 \\
BANKRUPT & NONBANKRUPT & 19.4175 & 23.5294 & 20 & 10.2564 \\
NONBANKRUPT & NONBANKRUPT & 80.5825 & 75.4545 & 83 & 42.5641 \\
\hline
\end{tabular}

YEAR 5

VARIABLE SUMMARY

\begin{tabular}{lll}
\hline ROLE & LEVEL & COUNT \\
\hline INPUT & INTERVAL & 17
\end{tabular}

TARGET TARGET 1

FIT STATISTICS

\begin{tabular}{|c|c|c|}
\hline $\begin{array}{l}\text { FIT } \\
\text { STATISTIC }\end{array}$ & STATISTIC LABEL & $\begin{array}{l}\text { STATISTIC } \\
\text { VALUE }\end{array}$ \\
\hline DFT_ $_{-}$ & Total Degrees of Freedom. & 168 \\
\hline DFE & Degrees of Freedom for Error. & 54 \\
\hline _DFM_ & Model Degrees of Freedom. & 114 \\
\hline $\mathrm{NW}_{-}$ & Number of Estimated Weights. & 114 \\
\hline $\mathrm{AIC}_{-}$ & Akaike's Information Criterion. & 428.477 \\
\hline${ }_{-} \mathrm{SBC}$ & Schwarz's Bayesian Criterion. & 784.609 \\
\hline ASE_ & Average Squared Error. & 0.204 \\
\hline _MAX_ & Maximum Absolute Error. & 0.778 \\
\hline $\mathrm{DIV}_{-}$ & Divisor for ASE. & 336 \\
\hline _NOBS_ & Sum of Frequencies. & 168 \\
\hline RASE_ & Root Average Squared Error. & 0.451 \\
\hline _SSE_ & Sum of Squared Errors. & 68.479 \\
\hline SUMW_ & Sum of Case Weights Times Freq. & 336 \\
\hline _FPE_ & Final Prediction Error. & 1.064 \\
\hline _MSE_ & Mean Squared Error. & 0.634 \\
\hline _RFPE_ & Root Final Prediction Error. & 1.032 \\
\hline _RMSE_ & Root Mean Squared Error. & 0.796 \\
\hline _AVERR_ & Average Error Function. & 0.597 \\
\hline ERR_ & Error Function. & 200.477 \\
\hline _MISC_ & Misclassification Rate. & 0.292 \\
\hline WRONG & Number of Wrong Classifications. & 49 \\
\hline
\end{tabular}


CLASSIFICATION SUMMARY

\begin{tabular}{|c|c|c|c|c|c|}
\hline TARGET & PREDICT & $\begin{array}{l}\text { PERCENT } \\
\text { OF } \\
\text { TARGET }\end{array}$ & $\begin{array}{l}\text { PERCENT } \\
\text { OF } \\
\text { PREDICT }\end{array}$ & COUNT & $\begin{array}{l}\text { PERCENT } \\
\text { OF } \\
\text { TOTAL }\end{array}$ \\
\hline BANKRUPT & BANKRUPT & 64.3836 & 67.1429 & 47 & 27.9762 \\
\hline NONBANKRUPT & BANKRUPT & 35.6164 & 26.5306 & 26 & 15.4762 \\
\hline BANKRUPT & NONBANKRUPT & 24.2105 & 32.8571 & 23 & 13.6905 \\
\hline NONBANKRUPT & NONBANKRUPT & 75.7895 & 73.4694 & 72 & 42.8571 \\
\hline
\end{tabular}


Results of Radial Basis Function Networks : Market variables

YEAR 1

VARIABLE SUMMARY

\begin{tabular}{lll}
\hline ROLE & LEVEL & COUNT \\
\hline INPUT & INTERVAL & 5
\end{tabular}

TARGET TARGET 1

FIT STATISTICS

\begin{tabular}{|c|c|c|}
\hline $\begin{array}{l}\text { FIT } \\
\text { STATISTIC }\end{array}$ & STATISTIC LABEL & $\begin{array}{l}\text { STATISTIC } \\
\text { VALUE }\end{array}$ \\
\hline $\mathrm{DFT}_{-}$ & Total Degrees of Freedom. & 255 \\
\hline DFE_ & Degrees of Freedom for Error. & 213 \\
\hline DFM_ & Model Degrees of Freedom. & 42 \\
\hline $\mathrm{NW}_{-}$ & Number of Estimated Weights. & 42 \\
\hline $\mathrm{AIC}_{-}$ & Akaike's Information Criterion. & 321.332 \\
\hline${ }_{-} \mathrm{SBC}$ & Schwarz's Bayesian Criterion. & 470.065 \\
\hline ASE_ & Average Squared Error. & 0.147 \\
\hline MAX_ & Maximum Absolute Error. & 0.881 \\
\hline DIV_ & Divisor for ASE. & 510 \\
\hline NOBS_ & Sum of Frequencies. & 255 \\
\hline _RASE_ & Root Average Squared Error. & 0.383 \\
\hline _SSE_ & Sum of Squared Errors. & 74.972 \\
\hline _SUMW_ & Sum of Case Weights Times Freq. & 510 \\
\hline _FPE_ & Final Prediction Error. & 0.205 \\
\hline _MSE_ & Mean Squared Error. & 0.176 \\
\hline _RFPE_ & Root Final Prediction Error. & 0.453 \\
\hline _RMSE_ & Root Mean Squared Error. & 0.42 \\
\hline _AVERR_ & Average Error Function. & 0.465 \\
\hline _ERR_ & Error Function. & 237.332 \\
\hline _MISC_ & Misclassification Rate. & 0.18 \\
\hline WRONG & Number of Wrong Classifications. & 46 \\
\hline
\end{tabular}


CLASSIFICATION SUMMARY

\begin{tabular}{llccccc}
\hline & & PERCENT & PERCENT & & \multicolumn{2}{l}{ PERCENT } \\
& & OF & OF & \\
TARGET & PREDICT & TARGET & PREDICT & COUNT & TOTAL \\
\hline BANKRUPT & BANKRUPT & 80.2632 & 88.4058 & 122 & 47.8431 \\
NONBANKRUPT & BANKRUPT & 19.7368 & 25.641 & 30 & 11.7647 \\
BANKRUPT & NONBANKRUPT & 15.534 & 11.5942 & 16 & 6.2745 \\
NONBANKRUPT & NONBANKRUPT & 84.466 & 74.359 & 87 & 34.1176 \\
\hline
\end{tabular}

YEAR 2

VARIABLE SUMMARY

\begin{tabular}{lll}
\hline ROLE & LEVEL & COUNT \\
\hline INPUT & INTERVAL & 5
\end{tabular}

TARGET TARGET 1

FIT STATISTICS

\begin{tabular}{|c|c|c|}
\hline $\begin{array}{l}\text { FIT } \\
\text { STATISTIC }\end{array}$ & STATISTIC LABEL & $\begin{array}{l}\text { STATISTIC } \\
\text { VALUE }\end{array}$ \\
\hline DFT_ $_{-}$ & Total Degrees of Freedom. & 242 \\
\hline DFE & Degrees of Freedom for Error. & 200 \\
\hline _DFM_ & Model Degrees of Freedom. & 42 \\
\hline $\mathrm{NW}_{-}$ & Number of Estimated Weights. & 42 \\
\hline $\mathrm{AIC}_{-}$ & Akaike's Information Criterion. & 353.263 \\
\hline${ }_{-} \mathrm{SBC}$ & Schwarz's Bayesian Criterion. & 499.798 \\
\hline ASE_ & Average Squared Error. & 0.185 \\
\hline _MAX_ & Maximum Absolute Error. & 0.834 \\
\hline $\mathrm{DIV}_{-}$ & Divisor for ASE. & 484 \\
\hline _NOBS_ & Sum of Frequencies. & 242 \\
\hline RASE_ & Root Average Squared Error. & 0.43 \\
\hline SSE_ & Sum of Squared Errors. & 89.692 \\
\hline SUMW_ & Sum of Case Weights Times Freq. & 484 \\
\hline _FPE_ & Final Prediction Error. & 0.263 \\
\hline _MSE_ & Mean Squared Error. & 0.224 \\
\hline _RFPE_ & Root Final Prediction Error. & 0.513 \\
\hline _RMSE_ & Root Mean Squared Error. & 0.474 \\
\hline _AVERR_ & Average Error Function. & 0.556 \\
\hline ERR_ & Error Function. & 269.263 \\
\hline _MISC_ & Misclassification Rate. & 0.244 \\
\hline WRONG & Number of Wrong Classifications. & 59 \\
\hline
\end{tabular}


CLASSIFICATION SUMMARY

\begin{tabular}{llccccc}
\hline & & PERCENT & PERCENT & & \multicolumn{2}{l}{$\begin{array}{l}\text { PERCENT } \\
\text { OF }\end{array}$} \\
TARGET & PREDICT & TARGET & OF & PRDICT & COUNT & TOTAL \\
\hline BANKRUPT & BANKRUPT & 77.3438 & 76.7442 & 99 & 40.9091 \\
NONBANKRUPT & BANKRUPT & 22.6563 & 25.6637 & 29 & 11.9835 \\
BANKRUPT & NONBANKRUPT & 26.3158 & 23.2558 & 30 & 12.3967 \\
NONBANKRUPT & NONBANKRUPT & 73.6842 & 74.3363 & 84 & 34.7107 \\
\hline
\end{tabular}

YEAR 3

VARIABLE SUMMARY

\begin{tabular}{lll}
\hline ROLE & LEVEL & COUNT \\
\hline INPUT & INTERVAL & 5
\end{tabular}

TARGET TARGET 1

FIT STATISTICS

\begin{tabular}{|c|c|c|}
\hline $\begin{array}{l}\text { FIT } \\
\text { STATISTIC }\end{array}$ & STATISTIC LABEL & $\begin{array}{l}\text { STATISTIC } \\
\text { VALUE }\end{array}$ \\
\hline DFT_ $_{-}$ & Total Degrees of Freedom. & 219 \\
\hline _DFE_ & Degrees of Freedom for Error. & 177 \\
\hline _DFM_ & Model Degrees of Freedom. & 42 \\
\hline $\mathrm{NW}_{-}$ & Number of Estimated Weights. & 42 \\
\hline $\mathrm{AIC}_{-}$ & Akaike's Information Criterion. & 330.372 \\
\hline${ }_{-} \mathrm{SBC}$ & Schwarz's Bayesian Criterion. & 472.713 \\
\hline _ASE_ & Average Squared Error. & 0.19 \\
\hline MAX_ & Maximum Absolute Error. & 0.872 \\
\hline DIV & Divisor for ASE. & 438 \\
\hline NOBS_ & Sum of Frequencies. & 219 \\
\hline _RASE_ & Root Average Squared Error. & 0.435 \\
\hline $\mathrm{SSE}_{-}$ & Sum of Squared Errors. & 83.046 \\
\hline SUMW_ & Sum of Case Weights Times Freq. & 438 \\
\hline _FPE_ & Final Prediction Error. & 0.28 \\
\hline _MSE_ & Mean Squared Error. & 0.235 \\
\hline _RFPE_ & Root Final Prediction Error. & 0.529 \\
\hline _RMSE_ & Root Mean Squared Error. & 0.484 \\
\hline _AVERR_ & Average Error Function. & 0.562 \\
\hline ERR_ & Error Function. & 246.372 \\
\hline _MISC_ & Misclassification Rate. & 0.269 \\
\hline WRONG & Number of Wrong Classifications. & 59 \\
\hline
\end{tabular}




\section{CLASSIFICATION SUMMARY}

\begin{tabular}{llccccc}
\hline & & PERCENT & PERCENT & & \multicolumn{2}{l}{ PERCENT } \\
& & OF & OF & \\
TARGET & PREDICT & TARGET & PREDICT & COUNT & TOTAL \\
\hline BANKRUPT & BANKRUPT & 77.5281 & 63.8889 & 69 & 31.5068 \\
NONBANKRUPT & BANKRUPT & 22.4719 & 18.018 & 20 & 9.1324 \\
BANKRUPT & NONBANKRUPT & 30 & 36.1111 & 39 & 17.8082 \\
NONBANKRUPT & NONBANKRUPT & 70 & 81.982 & 91 & 41.5525 \\
\hline
\end{tabular}

YEAR 4

VARIABLE SUMMARY

\begin{tabular}{lll}
\hline ROLE & LEVEL & COUNT \\
\hline INPUT & INTERVAL & 5
\end{tabular}

TARGET TARGET 1

FIT STATISTICS

\begin{tabular}{|c|c|c|}
\hline $\begin{array}{l}\text { FIT } \\
\text { STATISTIC }\end{array}$ & STATISTIC LABEL & $\begin{array}{l}\text { STATISTIC } \\
\text { VALUE }\end{array}$ \\
\hline DFT_ $_{-}$ & Total Degrees of Freedom. & 195 \\
\hline _DFE_ & Degrees of Freedom for Error. & 153 \\
\hline _DFM_ & Model Degrees of Freedom. & 42 \\
\hline $\mathrm{NW}_{-}$ & Number of Estimated Weights. & 42 \\
\hline $\mathrm{AIC}_{-}$ & Akaike's Information Criterion. & 237.763 \\
\hline${ }_{-} \mathrm{SBC}$ & Schwarz's Bayesian Criterion. & 375.229 \\
\hline _ASE_ & Average Squared Error. & 0.119 \\
\hline MAX_ & Maximum Absolute Error. & 0.916 \\
\hline DIV & Divisor for ASE. & 390 \\
\hline NOBS_ & Sum of Frequencies. & 195 \\
\hline _RASE_ & Root Average Squared Error. & 0.345 \\
\hline _SSE_ & Sum of Squared Errors. & 46.441 \\
\hline SUMW_ & Sum of Case Weights Times Freq. & 390 \\
\hline _FPE_ & Final Prediction Error. & 0.184 \\
\hline _MSE_ & Mean Squared Error. & 0.152 \\
\hline _RFPE_ & Root Final Prediction Error. & 0.429 \\
\hline _RMSE_ & Root Mean Squared Error. & 0.39 \\
\hline _AVERR_ & Average Error Function. & 0.394 \\
\hline _ERR_ & Error Function. & 153.763 \\
\hline _MISC_ & Misclassification Rate. & 0.149 \\
\hline WRONG & Number of Wrong Classifications. & 29 \\
\hline
\end{tabular}


CLASSIFICATION SUMMARY

\begin{tabular}{llccccc}
\hline & & PERCENT & PERCENT & & \multicolumn{2}{l}{ PERCENT } \\
& & OF & OF \\
TARGET & PREDICT & TARGET & PREDICT & COUNT & TOTAL \\
\hline BANKRUPT & BANKRUPT & 84.1463 & 81.1765 & 69 & 35.3846 \\
NONBANKRUPT & BANKRUPT & 15.8537 & 11.8182 & 13 & 6.6667 \\
BANKRUPT & NONBANKRUPT & 14.1593 & 18.8235 & 16 & 8.2051 \\
NONBANKRUPT & NONBANKRUPT & 85.8407 & 88.1818 & 97 & 49.7436 \\
\hline
\end{tabular}

YEAR 5

VARIABLE SUMMARY

\begin{tabular}{lll}
\hline ROLE & LEVEL & COUNT \\
\hline INPUT & INTERVAL & 5
\end{tabular}

TARGET TARGET 1

FIT STATISTICS

\begin{tabular}{|c|c|c|}
\hline $\begin{array}{l}\text { FIT } \\
\text { STATISTIC }\end{array}$ & STATISTIC LABEL & $\begin{array}{l}\text { STATISTIC } \\
\text { VALUE }\end{array}$ \\
\hline DFT_ $_{-}$ & Total Degrees of Freedom. & 168 \\
\hline _DFE_ & Degrees of Freedom for Error. & 126 \\
\hline _DFM_ & Model Degrees of Freedom. & 42 \\
\hline $\mathrm{NW}_{-}$ & Number of Estimated Weights. & 42 \\
\hline $\mathrm{AIC}_{-}$ & Akaike's Information Criterion. & 219.788 \\
\hline${ }_{-} \mathrm{SBC}$ & Schwarz's Bayesian Criterion. & 350.995 \\
\hline _ASE_ & Average Squared Error. & 0.122 \\
\hline MAX_ & Maximum Absolute Error. & 0.913 \\
\hline DIV & Divisor for ASE. & 336 \\
\hline NOBS_ & Sum of Frequencies. & 168 \\
\hline _RASE_ & Root Average Squared Error. & 0.349 \\
\hline _SSE_ & Sum of Squared Errors. & 40.892 \\
\hline SUMW_ & Sum of Case Weights Times Freq. & 336 \\
\hline _FPE_ & Final Prediction Error. & 0.203 \\
\hline _MSE_ & Mean Squared Error. & 0.162 \\
\hline _RFPE_ & Root Final Prediction Error. & 0.45 \\
\hline _RMSE_ & Root Mean Squared Error. & 0.403 \\
\hline _AVERR_ & Average Error Function. & 0.404 \\
\hline _ERR_ & Error Function. & 135.788 \\
\hline _MISC_ & Misclassification Rate. & 0.149 \\
\hline WRONG & Number of Wrong Classifications. & 25 \\
\hline
\end{tabular}


CLASSIFICATION SUMMARY

\begin{tabular}{llccccc}
\hline & & PERCENT & PERCENT & & \multicolumn{2}{c}{$\begin{array}{l}\text { PERCENT } \\
\text { OF }\end{array}$} \\
TARGET & PREDICT & TARGET & OF & PREDICT & COUNT & TOTAL \\
\hline BANKRUPT & BANKRUPT & 81.6901 & 82.8571 & 58 & 34.5238 \\
NONBANKRUPT & BANKRUPT & 18.3099 & 13.2653 & 13 & 7.7381 \\
BANKRUPT & NONBANKRUPT & 12.3711 & 17.1429 & 12 & 7.1429 \\
NONBANKRUPT & NONBANKRUPT & 87.6289 & 86.7347 & 85 & 50.5952 \\
\hline
\end{tabular}


Results of Radial Basis Function Networks : Market variables without spread and hi lo bid ask spread

YEAR 1

VARIABLE SUMMARY

\begin{tabular}{lll}
\hline ROLE & LEVEL & COUNT \\
\hline INPUT & INTERVAL & 4
\end{tabular}

TARGET TARGET 1

FIT STATISTICS

\begin{tabular}{|c|c|c|}
\hline $\begin{array}{l}\text { FIT } \\
\text { STATISTIC }\end{array}$ & STATISTIC LABEL & $\begin{array}{l}\text { STATISTIC } \\
\text { VALUE }\end{array}$ \\
\hline DFT $_{-}$ & Total Degrees of Freedom. & 255 \\
\hline _DFE_ & Degrees of Freedom for Error. & 219 \\
\hline _DFM_ & Model Degrees of Freedom. & 36 \\
\hline $\mathrm{NW}_{-}$ & Number of Estimated Weights. & 36 \\
\hline $\mathrm{AIC}_{-}$ & Akaike's Information Criterion. & 334.768 \\
\hline${ }_{-} \mathrm{SBC}_{-}$ & Schwarz's Bayesian Criterion. & 462.253 \\
\hline _ASE_ & Average Squared Error. & 0.169 \\
\hline _MAX_ & Maximum Absolute Error. & 0.879 \\
\hline $\mathrm{DIV}_{-}$ & Divisor for ASE. & 510 \\
\hline _NOBS_ & Sum of Frequencies. & 255 \\
\hline _RASE_ & Root Average Squared Error. & 0.411 \\
\hline $\mathrm{SSE}_{-}$ & Sum of Squared Errors. & 86.194 \\
\hline SUMW_ & Sum of Case Weights Times Freq. & 510 \\
\hline _FPE_ & Final Prediction Error. & 0.225 \\
\hline _MSE_ & Mean Squared Error. & 0.197 \\
\hline _RFPE_ & Root Final Prediction Error. & 0.474 \\
\hline _RMSE_ & Root Mean Squared Error. & 0.444 \\
\hline _AVERR_ & Average Error Function. & 0.515 \\
\hline _ERR_ & Error Function. & 262.768 \\
\hline _MISC_ & Misclassification Rate. & 0.259 \\
\hline WRONG & Number of Wrong Classifications. & 66 \\
\hline
\end{tabular}


CLASSIFICATION SUMMARY

\begin{tabular}{|c|c|c|c|c|c|}
\hline TARGET & PREDICT & $\begin{array}{l}\text { PERCENT } \\
\text { OF } \\
\text { TARGET }\end{array}$ & $\begin{array}{l}\text { PERCENT } \\
\text { OF } \\
\text { PREDICT }\end{array}$ & COUNT & $\begin{array}{l}\text { PERCENT } \\
\text { OF } \\
\text { TOTAL }\end{array}$ \\
\hline BANKRUPT & BANKRUPT & 74 & 80.4348 & 111 & 43.5294 \\
\hline NONBANKRUPT & BANKRUPT & 26 & 33.3333 & 39 & 15.2941 \\
\hline BANKRUPT & NONBANKRUPT & 25.7143 & 19.5652 & 27 & 10.5882 \\
\hline NONBANKRUPT & NONBANKRUPT & 74.2857 & 66.6667 & 78 & 30.5882 \\
\hline
\end{tabular}

YEAR 2

VARIABLE SUMMARY

\begin{tabular}{lll}
\hline ROLE & LEVEL & COUNT \\
\hline INPUT & INTERVAL & 4
\end{tabular}

TARGET TARGET 1

FIT STATISTICS

\begin{tabular}{|c|c|c|}
\hline $\begin{array}{l}\text { FIT } \\
\text { STATISTIC }\end{array}$ & STATISTIC LABEL & $\begin{array}{l}\text { STATISTIC } \\
\text { VALUE }\end{array}$ \\
\hline DFT_ $_{-}$ & Total Degrees of Freedom. & 242 \\
\hline DFE & Degrees of Freedom for Error. & 206 \\
\hline _DFM_ & Model Degrees of Freedom. & 36 \\
\hline $\mathrm{NW}_{-}$ & Number of Estimated Weights. & 36 \\
\hline $\mathrm{AIC}_{-}$ & Akaike's Information Criterion. & 314.49 \\
\hline${ }_{-} \mathrm{SBC}$ & Schwarz's Bayesian Criterion. & 440.092 \\
\hline ASE_ & Average Squared Error. & 0.162 \\
\hline _MAX_ & Maximum Absolute Error. & 0.89 \\
\hline $\mathrm{DIV}_{-}$ & Divisor for ASE. & 484 \\
\hline _NOBS_ & Sum of Frequencies. & 242 \\
\hline _RASE_ & Root Average Squared Error. & 0.403 \\
\hline _SSE_ & Sum of Squared Errors. & 78.621 \\
\hline SUMW_ & Sum of Case Weights Times Freq. & 484 \\
\hline _FPE_ & Final Prediction Error. & 0.219 \\
\hline _MSE_ & Mean Squared Error. & 0.191 \\
\hline _RFPE_ & Root Final Prediction Error. & 0.468 \\
\hline _RMSE_ & Root Mean Squared Error. & 0.437 \\
\hline _AVERR_ & Average Error Function. & 0.501 \\
\hline ERR_ & Error Function. & 242.49 \\
\hline _MISC_ & Misclassification Rate. & 0.231 \\
\hline WRONG & Number of Wrong Classifications. & 56 \\
\hline
\end{tabular}


CLASSIFICATION SUMMARY

\begin{tabular}{llcccc}
\hline & & PERCENT & PERCENT & & PERCENT \\
& & OF & OF & \\
TARGET & PREDICT & TARGET & PREDICT & COUNT & TOTAL \\
\hline BANKRUPT & BANKRUPT & 76.6423 & 81.3953 & 105 & 43.3884 \\
NONBANKRUPT & BANKRUPT & 23.3577 & 28.3186 & 32 & 13.2231 \\
BANKRUPT & NONBANKRUPT & 22.8571 & 18.6047 & 24 & 9.9174 \\
NONBANKRUPT & NONBANKRUPT & 77.1429 & 71.6814 & 81 & 33.4711 \\
\hline
\end{tabular}

YEAR 3

VARIABLE SUMMARY

\begin{tabular}{lll}
\hline ROLE & LEVEL & COUNT \\
\hline INPUT & INTERVAL & 4
\end{tabular}

TARGET TARGET 1

FIT STATISTICS

\begin{tabular}{|c|c|c|}
\hline $\begin{array}{l}\text { FIT } \\
\text { STATISTIC }\end{array}$ & STATISTIC LABEL & $\begin{array}{l}\text { STATISTIC } \\
\text { VALUE }\end{array}$ \\
\hline DFT_ $_{-}$ & Total Degrees of Freedom. & 219 \\
\hline DFE & Degrees of Freedom for Error. & 183 \\
\hline _DFM_ & Model Degrees of Freedom. & 36 \\
\hline $\mathrm{NW}_{-}$ & Number of Estimated Weights. & 36 \\
\hline $\mathrm{AIC}_{-}$ & Akaike's Information Criterion. & 309.794 \\
\hline${ }_{-} \mathrm{SBC}$ & Schwarz's Bayesian Criterion. & 431.801 \\
\hline ASE_ & Average Squared Error. & 0.182 \\
\hline _MAX_ & Maximum Absolute Error. & 0.92 \\
\hline $\mathrm{DIV}_{-}$ & Divisor for ASE. & 438 \\
\hline _NOBS_ & Sum of Frequencies. & 219 \\
\hline RASE_ & Root Average Squared Error. & 0.427 \\
\hline _SSE_ & Sum of Squared Errors. & 79.835 \\
\hline SUMW_ & Sum of Case Weights Times Freq. & 438 \\
\hline _FPE_ & Final Prediction Error. & 0.254 \\
\hline _MSE_ & Mean Squared Error. & 0.218 \\
\hline _RFPE_ & Root Final Prediction Error. & 0.504 \\
\hline _RMSE_ & Root Mean Squared Error. & 0.467 \\
\hline _AVERR_ & Average Error Function. & 0.543 \\
\hline ERR_ & Error Function. & 237.794 \\
\hline _MISC_ & Misclassification Rate. & 0.269 \\
\hline WRONG & Number of Wrong Classifications. & 59 \\
\hline
\end{tabular}


CLASSIFICATION SUMMARY

\begin{tabular}{llccccc}
\hline & & PERCENT & PERCENT & & \multicolumn{2}{c}{ PERCENT } \\
& & OF & OF \\
TARGET & PREDICT & TARGET & PREDICT & COUNT & TOTAL \\
\hline BANKRUPT & BANKRUPT & 76.9231 & 64.8148 & 70 & 31.9635 \\
NONBANKRUPT & BANKRUPT & 23.0769 & 18.9189 & 21 & 9.589 \\
BANKRUPT & NONBANKRUPT & 29.6875 & 35.1852 & 38 & 17.3516 \\
NONBANKRUPT & NONBANKRUPT & 70.3125 & 81.0811 & 90 & 41.0959 \\
\hline
\end{tabular}

YEAR 4

VARIABLE SUMMARY

\begin{tabular}{lll}
\hline ROLE & LEVEL & COUNT \\
\hline INPUT & INTERVAL & 4
\end{tabular}

TARGET TARGET 1

FIT STATISTICS

\begin{tabular}{|c|c|c|}
\hline $\begin{array}{l}\text { FIT } \\
\text { STATISTIC }\end{array}$ & STATISTIC LABEL & $\begin{array}{l}\text { STATISTIC } \\
\text { VALUE }\end{array}$ \\
\hline DFT_ $_{-}$ & Total Degrees of Freedom. & 195 \\
\hline DFE & Degrees of Freedom for Error. & 159 \\
\hline _DFM_ & Model Degrees of Freedom. & 36 \\
\hline $\mathrm{NW}_{-}$ & Number of Estimated Weights. & 36 \\
\hline $\mathrm{AIC}_{-}$ & Akaike's Information Criterion. & 220.204 \\
\hline${ }_{-} \mathrm{SBC}$ & Schwarz's Bayesian Criterion. & 338.032 \\
\hline ASE_ & Average Squared Error. & 0.115 \\
\hline _MAX_ & Maximum Absolute Error. & 0.936 \\
\hline $\mathrm{DIV}_{-}$ & Divisor for ASE. & 390 \\
\hline _NOBS_ & Sum of Frequencies. & 195 \\
\hline _RASE_ & Root Average Squared Error. & 0.339 \\
\hline _SSE_ & Sum of Squared Errors. & 44.913 \\
\hline SUMW_ & Sum of Case Weights Times Freq. & 390 \\
\hline _FPE_ & Final Prediction Error. & 0.167 \\
\hline _MSE_ & Mean Squared Error. & 0.141 \\
\hline _RFPE_ & Root Final Prediction Error. & 0.409 \\
\hline _RMSE_ & Root Mean Squared Error. & 0.376 \\
\hline _AVERR_ & Average Error Function. & 0.38 \\
\hline ERR_ & Error Function. & 148.204 \\
\hline _MISC_ & Misclassification Rate. & 0.154 \\
\hline WRONG & Number of Wrong Classifications. & 30 \\
\hline
\end{tabular}


CLASSIFICATION SUMMARY

\begin{tabular}{|c|c|c|c|c|c|}
\hline TARGET & PREDICT & $\begin{array}{l}\text { PERCENT } \\
\text { OF } \\
\text { TARGET }\end{array}$ & $\begin{array}{l}\text { PERCENT } \\
\text { OF } \\
\text { PREDICT }\end{array}$ & COUNT & $\begin{array}{l}\text { PERCENT } \\
\text { OF } \\
\text { TOTAL }\end{array}$ \\
\hline BANKRUPT & BANKRUPT & 83.1325 & 81.1765 & 69 & 35.3846 \\
\hline NONBANKRUPT & BANKRUPT & 16.8675 & 12.7273 & 14 & 7.1795 \\
\hline BANKRUPT & NONBANKRUPT & 14.2857 & 18.8235 & 16 & 8.2051 \\
\hline NONBANKRUPT & NONBANKRUPT & 85.7143 & 87.2727 & 96 & 49.2308 \\
\hline
\end{tabular}

YEAR 5

VARIABLE SUMMARY

\begin{tabular}{lll}
\hline ROLE & LEVEL & COUNT \\
\hline INPUT & INTERVAL & 4
\end{tabular}

TARGET TARGET 1

FIT STATISTICS

\begin{tabular}{|c|c|c|}
\hline $\begin{array}{l}\text { FIT } \\
\text { STATISTIC }\end{array}$ & STATISTIC LABEL & $\begin{array}{l}\text { STATISTIC } \\
\text { VALUE }\end{array}$ \\
\hline DFT_ $_{-}$ & Total Degrees of Freedom. & 168 \\
\hline _DFE_ & Degrees of Freedom for Error. & 132 \\
\hline _DFM_ & Model Degrees of Freedom. & 36 \\
\hline $\mathrm{NW}_{-}$ & Number of Estimated Weights. & 36 \\
\hline $\mathrm{AIC}_{-}$ & Akaike's Information Criterion. & 203.775 \\
\hline${ }_{-} \mathrm{SBC}$ & Schwarz's Bayesian Criterion. & 316.238 \\
\hline _ASE_ & Average Squared Error. & 0.118 \\
\hline MAX_ & Maximum Absolute Error. & 0.934 \\
\hline DIV & Divisor for ASE. & 336 \\
\hline NOBS_ & Sum of Frequencies. & 168 \\
\hline _RASE_ & Root Average Squared Error. & 0.344 \\
\hline _SSE_ & Sum of Squared Errors. & 39.754 \\
\hline SUMW_ & Sum of Case Weights Times Freq. & 336 \\
\hline _FPE_ & Final Prediction Error. & 0.183 \\
\hline _MSE_ & Mean Squared Error. & 0.151 \\
\hline _RFPE_ & Root Final Prediction Error. & 0.428 \\
\hline _RMSE_ & Root Mean Squared Error. & 0.388 \\
\hline _AVERR_ & Average Error Function. & 0.392 \\
\hline ERR_ & Error Function. & 131.775 \\
\hline _MISC_ & Misclassification Rate. & 0.137 \\
\hline WRONG & Number of Wrong Classifications. & 23 \\
\hline
\end{tabular}


CLASSIFICATION SUMMARY

\begin{tabular}{llccccc}
\hline & & PERCENT & PERCENT & & \multicolumn{2}{l}{$\begin{array}{l}\text { PERCENT } \\
\text { OF }\end{array}$} \\
TARGET & PREDICT & TARGET & $\begin{array}{l}\text { OF } \\
\text { PREDICT }\end{array}$ & COUNT & TOTAL \\
\hline BANKRUPT & BANKRUPT & 83.0986 & 84.2857 & 59 & 35.119 \\
NONBANKRUPT & BANKRUPT & 16.9014 & 12.2449 & 12 & 7.1429 \\
BANKRUPT & NONBANKRUPT & 11.3402 & 15.7143 & 11 & 6.5476 \\
NONBANKRUPT & NONBANKRUPT & 88.6598 & 87.7551 & 86 & 51.1905 \\
\hline
\end{tabular}


Results of Radial Basis Function Networks : Market variables without spread and bid ask spread

YEAR 1

VARIABLE SUMMARY

\begin{tabular}{lll}
\hline ROLE & LEVEL & COUNT \\
\hline INPUT & INTERVAL & 4
\end{tabular}

TARGET TARGET 1

FIT STATISTICS

\begin{tabular}{|c|c|c|}
\hline $\begin{array}{l}\text { FIT } \\
\text { STATISTIC }\end{array}$ & STATISTIC LABEL & $\begin{array}{l}\text { STATISTIC } \\
\text { VALUE }\end{array}$ \\
\hline DFT_ $_{-}$ & Total Degrees of Freedom. & 255 \\
\hline _DFE_ & Degrees of Freedom for Error. & 219 \\
\hline _DFM_ & Model Degrees of Freedom. & 36 \\
\hline $\mathrm{NW}_{-}$ & Number of Estimated Weights. & 36 \\
\hline _AIC_ & Akaike's Information Criterion. & 310.732 \\
\hline $\mathrm{SBC}_{-}$ & Schwarz's Bayesian Criterion. & 438.218 \\
\hline ASE_ & Average Squared Error. & 0.149 \\
\hline _MAX_ & Maximum Absolute Error. & 0.916 \\
\hline DIV_ & Divisor for ASE. & 510 \\
\hline _NOBS_ & Sum of Frequencies. & 255 \\
\hline _RASE_ & Root Average Squared Error. & 0.386 \\
\hline _SSE_ & Sum of Squared Errors. & 75.953 \\
\hline SUMW_ & Sum of Case Weights Times Freq. & 510 \\
\hline $\mathrm{FPE}_{-}$ & Final Prediction Error. & 0.198 \\
\hline _MSE_ & Mean Squared Error. & 0.173 \\
\hline RFPE_ & Root Final Prediction Error. & 0.445 \\
\hline RMSE_ & Root Mean Squared Error. & 0.416 \\
\hline _AVERR_ & Average Error Function. & 0.468 \\
\hline _ERR_ & Error Function. & 238.732 \\
\hline _MISC_ & Misclassification Rate. & 0.2 \\
\hline WRONG & Number of Wrong Classifications. & 51 \\
\hline
\end{tabular}


CLASSIFICATION SUMMARY

\begin{tabular}{llccccc}
\hline & & PERCENT & PERCENT & & \multicolumn{2}{l}{$\begin{array}{l}\text { PERCENT } \\
\text { OF }\end{array}$} \\
TARGET & PREDICT & TARGET & OF & PRDICT & COUNT & TOTAL \\
\hline BANKRUPT & BANKRUPT & 79.1946 & 85.5072 & 118 & 46.2745 \\
NONBANKRUPT & BANKRUPT & 20.8054 & 26.4957 & 31 & 12.1569 \\
BANKRUPT & NONBANKRUPT & 18.8679 & 14.4928 & 20 & 7.8431 \\
NONBANKRUPT & NONBANKRUPT & 81.1321 & 73.5043 & 86 & 33.7255 \\
\hline
\end{tabular}

YEAR 2

VARIABLE SUMMARY

\begin{tabular}{lll}
\hline ROLE & LEVEL & COUNT \\
\hline INPUT & INTERVAL & 4
\end{tabular}

TARGET TARGET 1

FIT STATISTICS

\begin{tabular}{|c|c|c|}
\hline $\begin{array}{l}\text { FIT } \\
\text { STATISTIC }\end{array}$ & STATISTIC LABEL & $\begin{array}{l}\text { STATISTIC } \\
\text { VALUE }\end{array}$ \\
\hline DFT_ $_{-}$ & Total Degrees of Freedom. & 242 \\
\hline _DFE_ & Degrees of Freedom for Error. & 206 \\
\hline _DFM_ & Model Degrees of Freedom. & 36 \\
\hline $\mathrm{NW}_{-}$ & Number of Estimated Weights. & 36 \\
\hline $\mathrm{AIC}_{-}$ & Akaike's Information Criterion. & 368.383 \\
\hline${ }_{-} \mathrm{SBC}$ & Schwarz's Bayesian Criterion. & 493.984 \\
\hline _ASE_ & Average Squared Error. & 0.212 \\
\hline MAX_ & Maximum Absolute Error. & 0.799 \\
\hline DIV & Divisor for ASE. & 484 \\
\hline NOBS_ & Sum of Frequencies. & 242 \\
\hline _RASE_ & Root Average Squared Error. & 0.461 \\
\hline $\mathrm{SSE}_{-}$ & Sum of Squared Errors. & 102.671 \\
\hline SUMW_ & Sum of Case Weights Times Freq. & 484 \\
\hline _FPE_ & Final Prediction Error. & 0.286 \\
\hline _MSE_ & Mean Squared Error. & 0.249 \\
\hline _RFPE_ & Root Final Prediction Error. & 0.535 \\
\hline _RMSE_ & Root Mean Squared Error. & 0.499 \\
\hline _AVERR_ & Average Error Function. & 0.612 \\
\hline _ERR_ & Error Function. & 296.383 \\
\hline _MISC_ & Misclassification Rate. & 0.326 \\
\hline WRONG & Number of Wrong Classifications. & 79 \\
\hline
\end{tabular}


CLASSIFICATION SUMMARY

\begin{tabular}{llcccc}
\hline & & PERCENT & PERCENT & & PERCENT \\
& & OF & OF & \\
TARGET & PREDICT & TARGET & PREDICT & COUNT & TOTAL \\
\hline BANKRUPT & BANKRUPT & 65.625 & 81.3953 & 105 & 43.3884 \\
NONBANKRUPT & BANKRUPT & 34.375 & 48.6726 & 55 & 22.7273 \\
BANKRUPT & NONBANKRUPT & 29.2683 & 18.6047 & 24 & 9.9174 \\
NONBANKRUPT & NONBANKRUPT & 70.7317 & 51.3274 & 58 & 23.9669 \\
\hline
\end{tabular}

YEAR 3

VARIABLE SUMMARY

\begin{tabular}{lll}
\hline ROLE & LEVEL & COUNT \\
\hline INPUT & INTERVAL & 4
\end{tabular}

TARGET TARGET 1

FIT STATISTICS

\begin{tabular}{|c|c|c|}
\hline $\begin{array}{l}\text { FIT } \\
\text { STATISTIC }\end{array}$ & STATISTIC LABEL & $\begin{array}{l}\text { STATISTIC } \\
\text { VALUE }\end{array}$ \\
\hline DFT_ $_{-}$ & Total Degrees of Freedom. & 219 \\
\hline DFE & Degrees of Freedom for Error. & 183 \\
\hline _DFM_ & Model Degrees of Freedom. & 36 \\
\hline $\mathrm{NW}_{-}$ & Number of Estimated Weights. & 36 \\
\hline $\mathrm{AIC}_{-}$ & Akaike's Information Criterion. & 335.846 \\
\hline${ }_{-} \mathrm{SBC}$ & Schwarz's Bayesian Criterion. & 457.853 \\
\hline ASE_ & Average Squared Error. & 0.208 \\
\hline _MAX_ & Maximum Absolute Error. & 0.807 \\
\hline $\mathrm{DIV}_{-}$ & Divisor for ASE. & 438 \\
\hline _NOBS_ & Sum of Frequencies. & 219 \\
\hline RASE_ & Root Average Squared Error. & 0.457 \\
\hline _SSE_ & Sum of Squared Errors. & 91.289 \\
\hline SUMW_ & Sum of Case Weights Times Freq. & 438 \\
\hline _FPE_ & Final Prediction Error. & 0.29 \\
\hline _MSE_ & Mean Squared Error. & 0.249 \\
\hline _RFPE_ & Root Final Prediction Error. & 0.539 \\
\hline _RMSE_ & Root Mean Squared Error. & 0.499 \\
\hline _AVERR_ & Average Error Function. & 0.602 \\
\hline ERR_ & Error Function. & 263.846 \\
\hline _MISC_ & Misclassification Rate. & 0.297 \\
\hline WRONG & Number of Wrong Classifications. & 65 \\
\hline
\end{tabular}


CLASSIFICATION SUMMARY

\begin{tabular}{llcccc}
\hline & & PERCENT & PERCENT & & PERCENT \\
& & OF & OF & \\
TARGET & PREDICT & TARGET & PREDICT & COUNT & TOTAL \\
\hline BANKRUPT & BANKRUPT & 66.4122 & 80.5556 & 87 & 39.726 \\
NONBANKRUPT & BANKRUPT & 33.5878 & 39.6396 & 44 & 20.0913 \\
BANKRUPT & NONBANKRUPT & 23.8636 & 19.4444 & 21 & 9.589 \\
NONBANKRUPT & NONBANKRUPT & 76.1364 & 60.3604 & 67 & 30.5936 \\
\hline
\end{tabular}

YEAR 4

VARIABLE SUMMARY

\begin{tabular}{lll}
\hline ROLE & LEVEL & COUNT \\
\hline INPUT & INTERVAL & 4
\end{tabular}

TARGET TARGET 1

FIT STATISTICS

\begin{tabular}{|c|c|c|}
\hline $\begin{array}{l}\text { FIT } \\
\text { STATISTIC }\end{array}$ & STATISTIC LABEL & $\begin{array}{l}\text { STATISTIC } \\
\text { VALUE }\end{array}$ \\
\hline DFT_ $_{-}$ & Total Degrees of Freedom. & 195 \\
\hline _DFE_ & Degrees of Freedom for Error. & 159 \\
\hline _DFM_ & Model Degrees of Freedom. & 36 \\
\hline $\mathrm{NW}_{-}$ & Number of Estimated Weights. & 36 \\
\hline $\mathrm{AIC}_{-}$ & Akaike's Information Criterion. & 289.662 \\
\hline${ }_{-} \mathrm{SBC}$ & Schwarz's Bayesian Criterion. & 407.49 \\
\hline _ASE_ & Average Squared Error. & 0.19 \\
\hline MAX_ & Maximum Absolute Error. & 0.925 \\
\hline DIV & Divisor for ASE. & 390 \\
\hline NOBS_ & Sum of Frequencies. & 195 \\
\hline _RASE_ & Root Average Squared Error. & 0.436 \\
\hline _SSE_ & Sum of Squared Errors. & 74.08 \\
\hline SUMW_ & Sum of Case Weights Times Freq. & 390 \\
\hline _FPE_ & Final Prediction Error. & 0.276 \\
\hline _MSE_ & Mean Squared Error. & 0.233 \\
\hline _RFPE_ & Root Final Prediction Error. & 0.525 \\
\hline _RMSE_ & Root Mean Squared Error. & 0.483 \\
\hline _AVERR_ & Average Error Function. & 0.558 \\
\hline ERR_ & Error Function. & 217.662 \\
\hline _MISC_ & Misclassification Rate. & 0.277 \\
\hline WRONG & Number of Wrong Classifications. & 54 \\
\hline
\end{tabular}


CLASSIFICATION SUMMARY

\begin{tabular}{llcccc}
\hline & & PERCENT & PERCENT & & PERCENT \\
OF & OF & & OF \\
TARGET & PREDICT & TARGET & PREDICT & COUNT & TOTAL \\
\hline BANKRUPT & BANKRUPT & 67.4157 & 70.5882 & 60 & 30.7692 \\
NONBANKRUPT & BANKRUPT & 32.5843 & 26.3636 & 29 & 14.8718 \\
BANKRUPT & NONBANKRUPT & 23.5849 & 29.4118 & 25 & 12.8205 \\
NONBANKRUPT & NONBANKRUPT & 76.4151 & 73.6364 & 81 & 41.5385 \\
\hline
\end{tabular}

YEAR 5

VARIABLE SUMMARY

\begin{tabular}{lll}
\hline ROLE & LEVEL & COUNT \\
\hline INPUT & INTERVAL & 4
\end{tabular}

TARGET TARGET 1

FIT STATISTICS

\begin{tabular}{|c|c|c|}
\hline $\begin{array}{l}\text { FIT } \\
\text { STATISTIC }\end{array}$ & STATISTIC LABEL & $\begin{array}{l}\text { STATISTIC } \\
\text { VALUE }\end{array}$ \\
\hline DFT_ $_{-}$ & Total Degrees of Freedom. & 168 \\
\hline DFE & Degrees of Freedom for Error. & 132 \\
\hline _DFM_ & Model Degrees of Freedom. & 36 \\
\hline $\mathrm{NW}_{-}$ & Number of Estimated Weights. & 36 \\
\hline $\mathrm{AIC}_{-}$ & Akaike's Information Criterion. & 267.413 \\
\hline${ }_{-} \mathrm{SBC}$ & Schwarz's Bayesian Criterion. & 379.876 \\
\hline ASE_ & Average Squared Error. & 0.199 \\
\hline _MAX_ & Maximum Absolute Error. & 0.877 \\
\hline $\mathrm{DIV}_{-}$ & Divisor for ASE. & 336 \\
\hline _NOBS_ & Sum of Frequencies. & 168 \\
\hline _RASE_ & Root Average Squared Error. & 0.446 \\
\hline _SSE_ & Sum of Squared Errors. & 66.699 \\
\hline SUMW_ & Sum of Case Weights Times Freq. & 336 \\
\hline _FPE_ & Final Prediction Error. & 0.307 \\
\hline _MSE_ & Mean Squared Error. & 0.253 \\
\hline _RFPE_ & Root Final Prediction Error. & 0.554 \\
\hline _RMSE_ & Root Mean Squared Error. & 0.503 \\
\hline _AVERR_ & Average Error Function. & 0.582 \\
\hline ERR_ & Error Function. & 195.413 \\
\hline _MISC_ & Misclassification Rate. & 0.292 \\
\hline WRONG & Number of Wrong Classifications. & 49 \\
\hline
\end{tabular}


CLASSIFICATION SUMMARY

\begin{tabular}{llccccc}
\hline & & PERCENT & PERCENT & & \multicolumn{2}{c}{$\begin{array}{l}\text { PERCENT } \\
\text { OF }\end{array}$} \\
TARGET & PREDICT & TARGET & OF & PREICT & COUNT & TOTAL \\
\hline BANKRUPT & BANKRUPT & 65.6716 & 62.8571 & 44 & 26.1905 \\
NONBANKRUPT & BANKRUPT & 34.3284 & 23.4694 & 23 & 13.6905 \\
BANKRUPT & NONBANKRUPT & 25.7426 & 37.1429 & 26 & 15.4762 \\
NONBANKRUPT & NONBANKRUPT & 74.2574 & 76.5306 & 75 & 44.6429 \\
\hline
\end{tabular}


Results of Radial Basis Function Networks : Market variables without bid ask spread and hi lo bid ask spread

YEAR 1

VARIABLE SUMMARY

\begin{tabular}{lll}
\hline ROLE & LEVEL & COUNT \\
\hline INPUT & INTERVAL & 4
\end{tabular}

TARGET TARGET 1

FIT STATISTICS

\begin{tabular}{|c|c|c|}
\hline $\begin{array}{l}\text { FIT } \\
\text { STATISTIC }\end{array}$ & STATISTIC LABEL & $\begin{array}{l}\text { STATISTIC } \\
\text { VALUE }\end{array}$ \\
\hline DFT $_{-}$ & Total Degrees of Freedom. & 255 \\
\hline _DFE_ & Degrees of Freedom for Error. & 219 \\
\hline _DFM_ & Model Degrees of Freedom. & 36 \\
\hline $\mathrm{NW}_{-}$ & Number of Estimated Weights. & 36 \\
\hline $\mathrm{AIC}_{-}$ & Akaike's Information Criterion. & 362.741 \\
\hline${ }_{-} \mathrm{SBC}_{-}$ & Schwarz's Bayesian Criterion. & 490.227 \\
\hline _ASE_ & Average Squared Error. & 0.194 \\
\hline _MAX_ & Maximum Absolute Error. & 0.888 \\
\hline $\mathrm{DIV}_{-}$ & Divisor for ASE. & 510 \\
\hline NOBS & Sum of Frequencies. & 255 \\
\hline _RASE_ & Root Average Squared Error. & 0.44 \\
\hline $\mathrm{SSE}_{-}$ & Sum of Squared Errors. & 98.93 \\
\hline SUMW_ & Sum of Case Weights Times Freq. & 510 \\
\hline FPE_ & Final Prediction Error. & 0.258 \\
\hline _MSE_ & Mean Squared Error. & 0.226 \\
\hline _RFPE_ & Root Final Prediction Error. & 0.508 \\
\hline _RMSE_ & Root Mean Squared Error. & 0.475 \\
\hline _AVERR_ & Average Error Function. & 0.57 \\
\hline _ERR_ & Error Function. & 290.741 \\
\hline _MISC_ & Misclassification Rate. & 0.294 \\
\hline WRONG & Number of Wrong Classifications. & 75 \\
\hline
\end{tabular}


CLASSIFICATION SUMMARY

\begin{tabular}{|c|c|c|c|c|c|}
\hline TARGET & PREDICT & $\begin{array}{l}\text { PERCENT } \\
\text { OF } \\
\text { TARGET }\end{array}$ & $\begin{array}{l}\text { PERCENT } \\
\text { OF } \\
\text { PREDICT }\end{array}$ & COUNT & $\begin{array}{l}\text { PERCENT } \\
\text { OF } \\
\text { TOTAL }\end{array}$ \\
\hline BANKRUPT & BANKRUPT & 76.0331 & 66.6667 & 92 & 36.0784 \\
\hline NONBANKRUPT & BANKRUPT & 23.9669 & 24.7863 & 29 & 11.3725 \\
\hline BANKRUPT & NONBANKRUPT & 34.3284 & 33.3333 & 46 & 18.0392 \\
\hline NONBANKRUPT & NONBANKRUPT & 65.6716 & 75.2137 & 88 & 34.5098 \\
\hline
\end{tabular}

YEAR 2

VARIABLE SUMMARY

\begin{tabular}{lll}
\hline ROLE & LEVEL & COUNT \\
\hline INPUT & INTERVAL & 4
\end{tabular}

TARGET TARGET 1

FIT STATISTICS

\begin{tabular}{|c|c|c|}
\hline $\begin{array}{l}\text { FIT } \\
\text { STATISTIC }\end{array}$ & STATISTIC LABEL & $\begin{array}{l}\text { STATISTIC } \\
\text { VALUE }\end{array}$ \\
\hline DFT_ $_{-}$ & Total Degrees of Freedom. & 242 \\
\hline _DFE_ & Degrees of Freedom for Error. & 206 \\
\hline _DFM_ & Model Degrees of Freedom. & 36 \\
\hline $\mathrm{NW}_{-}$ & Number of Estimated Weights. & 36 \\
\hline $\mathrm{AIC}_{-}$ & Akaike's Information Criterion. & 373.013 \\
\hline${ }_{-} \mathrm{SBC}$ & Schwarz's Bayesian Criterion. & 498.615 \\
\hline _ASE_ & Average Squared Error. & 0.216 \\
\hline MAX_ & Maximum Absolute Error. & 0.76 \\
\hline DIV & Divisor for ASE. & 484 \\
\hline NOBS_ & Sum of Frequencies. & 242 \\
\hline _RASE_ & Root Average Squared Error. & 0.465 \\
\hline $\mathrm{SSE}_{-}$ & Sum of Squared Errors. & 104.485 \\
\hline SUMW_ & Sum of Case Weights Times Freq. & 484 \\
\hline _FPE_ & Final Prediction Error. & 0.291 \\
\hline _MSE_ & Mean Squared Error. & 0.254 \\
\hline _RFPE_ & Root Final Prediction Error. & 0.54 \\
\hline _RMSE_ & Root Mean Squared Error. & 0.504 \\
\hline _AVERR_ & Average Error Function. & 0.622 \\
\hline ERR_ & Error Function. & 301.013 \\
\hline _MISC_ & Misclassification Rate. & 0.326 \\
\hline WRONG & Number of Wrong Classifications. & 79 \\
\hline
\end{tabular}


CLASSIFICATON SUMMARY

\begin{tabular}{|c|c|c|c|c|c|}
\hline TARGET & PREDICT & $\begin{array}{l}\text { PERCENT } \\
\text { OF } \\
\text { TARGET }\end{array}$ & $\begin{array}{l}\text { PERCENT } \\
\text { OF } \\
\text { PREDICT }\end{array}$ & COUNT & $\begin{array}{l}\text { PERCENT } \\
\text { OF } \\
\text { TOTAL }\end{array}$ \\
\hline BANKRUPT & BANKRUPT & 67.8571 & 73.6434 & 95 & 39.2562 \\
\hline NONBANKRUPT & BANKRUPT & 32.1429 & 39.823 & 45 & 18.595 \\
\hline BANKRUPT & NONBANKRUPT & 33.3333 & 26.3566 & 34 & 14.0496 \\
\hline NONBANKRUPT & NONBANKRUPT & 66.6667 & 60.177 & 68 & 28.0992 \\
\hline
\end{tabular}

YEAR 3

VARIABLE SUMMARY

\begin{tabular}{lll}
\hline ROLE & LEVEL & COUNT \\
\hline INPUT & INTERVAL & 4
\end{tabular}

TARGET TARGET 1

FIT STATISTICS

\begin{tabular}{|c|c|c|}
\hline $\begin{array}{l}\text { FIT } \\
\text { STATISTIC }\end{array}$ & STATISTIC LABEL & $\begin{array}{l}\text { STATISTIC } \\
\text { VALUE }\end{array}$ \\
\hline DFT_ $_{-}$ & Total Degrees of Freedom. & 219 \\
\hline _DFE_ & Degrees of Freedom for Error. & 183 \\
\hline _DFM_ & Model Degrees of Freedom. & 36 \\
\hline $\mathrm{NW}_{-}$ & Number of Estimated Weights. & 36 \\
\hline $\mathrm{AIC}_{-}$ & Akaike's Information Criterion. & 347.577 \\
\hline${ }_{-} \mathrm{SBC}$ & Schwarz's Bayesian Criterion. & 469.584 \\
\hline _ASE_ & Average Squared Error. & 0.219 \\
\hline MAX_ & Maximum Absolute Error. & 0.807 \\
\hline DIV & Divisor for ASE. & 438 \\
\hline NOBS_ & Sum of Frequencies. & 219 \\
\hline _RASE_ & Root Average Squared Error. & 0.468 \\
\hline _SSE_ & Sum of Squared Errors. & 95.907 \\
\hline SUMW_ & Sum of Case Weights Times Freq. & 438 \\
\hline _FPE_ & Final Prediction Error. & 0.305 \\
\hline _MSE_ & Mean Squared Error. & 0.262 \\
\hline _RFPE_ & Root Final Prediction Error. & 0.552 \\
\hline _RMSE_ & Root Mean Squared Error. & 0.512 \\
\hline _AVERR_ & Average Error Function. & 0.629 \\
\hline _ERR_ & Error Function. & 275.577 \\
\hline _MISC_ & Misclassification Rate. & 0.32 \\
\hline WRONG & Number of Wrong Classifications. & 70 \\
\hline
\end{tabular}


CLASSIFICATION SUMMARY

\begin{tabular}{llcccc}
\hline & & PERCENT & PERCENT & & PERCENT \\
& & OF & OF & \\
TARGET & PREDICT & TARGET & PREDICT & COUNT & TOTAL \\
\hline BANKRUPT & BANKRUPT & 66.1017 & 72.2222 & 78 & 35.6164 \\
NONBANKRUPT & BANKRUPT & 33.8983 & 36.036 & 40 & 18.2648 \\
BANKRUPT & NONBANKRUPT & 29.703 & 27.7778 & 30 & 13.6986 \\
NONBANKRUPT & NONBANKRUPT & 70.297 & 63.964 & 71 & 32.4201 \\
\hline
\end{tabular}

YEAR 4

VARIABLE SUMMARY

\begin{tabular}{lll}
\hline ROLE & LEVEL & COUNT \\
\hline INPUT & INTERVAL & 4 \\
TARGET & TARGET & 1 \\
\hline
\end{tabular}

FIT STATISTICS

\begin{tabular}{|c|c|c|}
\hline $\begin{array}{l}\text { FIT } \\
\text { STATISTIC }\end{array}$ & STATISTIC LABEL & $\begin{array}{l}\text { STATISTIC } \\
\text { VALUE }\end{array}$ \\
\hline DFT_ $_{-}$ & Total Degrees of Freedom. & 195 \\
\hline _DFE_ & Degrees of Freedom for Error. & 159 \\
\hline _DFM_ & Model Degrees of Freedom. & 36 \\
\hline $\mathrm{NW}_{-}$ & Number of Estimated Weights. & 36 \\
\hline $\mathrm{AIC}_{-}$ & Akaike's Information Criterion. & 293.73 \\
\hline${ }_{-} \mathrm{SBC}_{-}$ & Schwarz's Bayesian Criterion. & 411.558 \\
\hline _ASE_ & Average Squared Error. & 0.194 \\
\hline _MAX_ & Maximum Absolute Error. & 0.936 \\
\hline DIV_ $_{-}$ & Divisor for ASE. & 390 \\
\hline NOBS & Sum of Frequencies. & 195 \\
\hline _RASE_ & Root Average Squared Error. & 0.441 \\
\hline _SSE_ & Sum of Squared Errors. & 75.726 \\
\hline SUMW_ & Sum of Case Weights Times Freq. & 390 \\
\hline FPE_ & Final Prediction Error. & 0.282 \\
\hline _MSE_ & Mean Squared Error. & 0.238 \\
\hline _RFPE_ & Root Final Prediction Error. & 0.531 \\
\hline _RMSE_ & Root Mean Squared Error. & 0.488 \\
\hline _AVERR_ & Average Error Function. & 0.569 \\
\hline ERR & Error Function. & 221.73 \\
\hline
\end{tabular}




\begin{tabular}{|c|c|c|c|c|c|}
\hline${ }_{-}{ }_{\text {WRONG }}$ & \multicolumn{2}{|l|}{ Misclassification Rate. } & \multicolumn{2}{|c|}{0.277} & \\
\hline \multicolumn{6}{|c|}{ CLASSIFICATION SUMMARY } \\
\hline TARGET & PREDICT & $\begin{array}{l}\text { PERCENT } \\
\text { OF } \\
\text { TARGET }\end{array}$ & $\begin{array}{l}\text { PERCENT } \\
\text { OF } \\
\text { PREDICT }\end{array}$ & COUNT & $\begin{array}{l}\text { PERCENT } \\
\text { OF } \\
\text { TOTAL }\end{array}$ \\
\hline BANKRUPT & BANKRUPT & 69.1358 & 65.8824 & 56 & 28.7179 \\
\hline NONBANKRUPT & BANKRUPT & 30.8642 & 22.7273 & 25 & 12.8205 \\
\hline BANKRUPT & NONBANKRUPT & 25.4386 & 34.1176 & 29 & 14.8718 \\
\hline NONBANKRUPT & NONBANKRUPT & 74.5614 & 77.2727 & 85 & 43.5897 \\
\hline
\end{tabular}

YEAR 5

VARIABLE SUMMARY

\begin{tabular}{lll}
\hline ROLE & LEVEL & COUNT \\
\hline INPUT & INTERVAL & 4 \\
TARGET & TARGET & 1 \\
\hline
\end{tabular}

FIT STATISTICS

\begin{tabular}{|c|c|c|}
\hline $\begin{array}{l}\text { FIT } \\
\text { STATISTIC }\end{array}$ & STATISTIC LABEL & $\begin{array}{l}\text { STATISTIC } \\
\text { VALUE }\end{array}$ \\
\hline $\mathrm{DFT}_{-}$ & Total Degrees of Freedom. & 168 \\
\hline DFE_ & Degrees of Freedom for Error. & 132 \\
\hline _DFM_ & Model Degrees of Freedom. & 36 \\
\hline $\mathrm{NW}_{-}$ & Number of Estimated Weights. & 36 \\
\hline _AIC_ & Akaike's Information Criterion. & 275.095 \\
\hline${ }_{-} \mathrm{SBC}$ & Schwarz's Bayesian Criterion. & 387.558 \\
\hline _ASE_ & Average Squared Error. & 0.209 \\
\hline _MAX_ & Maximum Absolute Error. & 0.846 \\
\hline DIV $_{-}$ & Divisor for ASE. & 336 \\
\hline NOBS_ & Sum of Frequencies. & 168 \\
\hline _RASE_ & Root Average Squared Error. & 0.457 \\
\hline $\mathrm{SSE}_{-}$ & Sum of Squared Errors. & 70.293 \\
\hline SUMW_ & Sum of Case Weights Times Freq. & 336 \\
\hline _FPE_ & Final Prediction Error. & 0.323 \\
\hline MSE_ & Mean Squared Error. & 0.266 \\
\hline RFPE_ & Root Final Prediction Error. & 0.569 \\
\hline RMSE_ & Root Mean Squared Error. & 0.516 \\
\hline AVERR & Average Error Function. & 0.604 \\
\hline
\end{tabular}




\begin{tabular}{|c|c|c|c|c|c|}
\hline ERR_ & \multicolumn{2}{|l|}{ Error Function. } & \multicolumn{3}{|c|}{203.095} \\
\hline MISC_ & \multicolumn{2}{|l|}{ Misclassification Rate. } & \multicolumn{2}{|c|}{0.315} & \\
\hline WRONG & \multicolumn{2}{|c|}{ Number of Wrong Classifications. } & \multicolumn{2}{|c|}{53} & \\
\hline \multicolumn{6}{|c|}{ CLASSIFICATION SUMMARY } \\
\hline TARGET & PREDICT & $\begin{array}{l}\text { PERCENT } \\
\text { OF } \\
\text { TARGET }\end{array}$ & $\begin{array}{l}\text { PERCENT } \\
\text { OF } \\
\text { PREDICT }\end{array}$ & COUNT & $\begin{array}{l}\text { PERCENT } \\
\text { OF } \\
\text { TOTAL }\end{array}$ \\
\hline BANKRUPT & BANKRUPT & 61.9718 & 62.8571 & 44 & 26.1905 \\
\hline NONBANKRUPT & BANKRUPT & 38.0282 & 27.551 & 27 & 16.0714 \\
\hline BANKRUPT & NONBANKRUPT & 26.8041 & 37.1429 & 26 & 15.4762 \\
\hline NONBANKRUPT & NONBANKRUPT & 73.1959 & 72.449 & 71 & 42.2619 \\
\hline
\end{tabular}


Results of Radial Basis Function Networks : Top 3 Account and Market variables

YEAR 1

\begin{tabular}{lll}
\multicolumn{3}{c}{ VARIABLE SUMMARY } \\
\hline ROLE & LEVEL & COUNT \\
\hline INPUT & INTERVAL & 6 \\
TARGET & TARGET & 1 \\
\hline
\end{tabular}

FIT STATISTICS

\begin{tabular}{|c|c|c|}
\hline $\begin{array}{l}\text { FIT } \\
\text { STATISTIC }\end{array}$ & STATISTIC LABEL & $\begin{array}{l}\text { STATISTIC } \\
\text { VALUE }\end{array}$ \\
\hline $\mathrm{DFT}_{-}$ & Total Degrees of Freedom. & 255 \\
\hline _DFE_ & Degrees of Freedom for Error. & 207 \\
\hline _DFM_ & Model Degrees of Freedom. & 48 \\
\hline $\mathrm{NW}_{-}$ & Number of Estimated Weights. & 48 \\
\hline $\mathrm{AIC}_{-}$ & Akaike's Information Criterion. & 332.364 \\
\hline${ }_{-} \mathrm{SBC}_{-}$ & Schwarz's Bayesian Criterion. & 502.345 \\
\hline $\mathrm{ASE}_{-}$ & Average Squared Error. & 0.148 \\
\hline${ }_{-} \mathrm{MAX}_{-}$ & Maximum Absolute Error. & 0.891 \\
\hline DIV_ & Divisor for ASE. & 510 \\
\hline NOBS_ & Sum of Frequencies. & 255 \\
\hline RASE_ & Root Average Squared Error. & 0.385 \\
\hline _SSE_ & Sum of Squared Errors. & 75.428 \\
\hline SUMW_ & Sum of Case Weights Times Freq. & 510 \\
\hline $\mathrm{FPE}_{-}$ & Final Prediction Error. & 0.216 \\
\hline _MSE_ & Mean Squared Error. & 0.182 \\
\hline _RFPE_ & Root Final Prediction Error. & 0.465 \\
\hline _RMSE_ & Root Mean Squared Error. & 0.427 \\
\hline _AVERR_ & Average Error Function. & 0.463 \\
\hline _ERR_ & Error Function. & 236.364 \\
\hline _MISC_ & Misclassification Rate. & 0.216 \\
\hline WRONG & Number of Wrong Classifications. & 55 \\
\hline
\end{tabular}


CLASSIFICATION SUMMARY

\begin{tabular}{llccccc}
\hline & & PERCENT & PERCENT & & \multicolumn{2}{l}{ PERCENT } \\
& & OF & OF & \\
TARGET & PREDICT & TARGET & PREDICT & COUNT & TOTAL \\
\hline BANKRUPT & BANKRUPT & 74.8503 & 90.5797 & 125 & 49.0196 \\
NONBANKRUPT & BANKRUPT & 25.1497 & 35.8974 & 42 & 16.4706 \\
BANKRUPT & NONBANKRUPT & 14.7727 & 9.4203 & 13 & 5.098 \\
NONBANKRUPT & NONBANKRUPT & 85.2273 & 64.1026 & 75 & 29.4118 \\
\hline
\end{tabular}

YEAR 2

VARIABLE SUMMARY

\begin{tabular}{lll}
\hline ROLE & LEVEL & COUNT \\
\hline INPUT & INTERVAL & 6 \\
TARGET & TARGET & 1 \\
\hline
\end{tabular}

FIT STATISTICS

\begin{tabular}{|c|c|c|}
\hline $\begin{array}{l}\text { FIT } \\
\text { STATISTIC }\end{array}$ & STATISTIC LABEL & $\begin{array}{l}\text { STATISTIC } \\
\text { VALUE }\end{array}$ \\
\hline DFT_ $_{-}$ & Total Degrees of Freedom. & 242 \\
\hline _DFE_ & Degrees of Freedom for Error. & 194 \\
\hline _DFM_ & Model Degrees of Freedom. & 48 \\
\hline NW_ & Number of Estimated Weights. & 48 \\
\hline _AIC_ & Akaike's Information Criterion. & 319.177 \\
\hline${ }_{-} \mathrm{SBC}_{-}$ & Schwarz's Bayesian Criterion. & 486.646 \\
\hline _ASE_ & Average Squared Error. & 0.144 \\
\hline _MAX_ & Maximum Absolute Error. & 0.868 \\
\hline DIV_ $_{-}$ & Divisor for ASE. & 484 \\
\hline NOBS & Sum of Frequencies. & 242 \\
\hline _RASE_ & Root Average Squared Error. & 0.379 \\
\hline _SSE_ & Sum of Squared Errors. & 69.58 \\
\hline SUMW_ & Sum of Case Weights Times Freq. & 484 \\
\hline FPE_ & Final Prediction Error. & 0.215 \\
\hline _MSE_ & Mean Squared Error. & 0.179 \\
\hline _RFPE_ & Root Final Prediction Error. & 0.464 \\
\hline _RMSE_ & Root Mean Squared Error. & 0.423 \\
\hline _AVERR_ & Average Error Function. & 0.461 \\
\hline ERR & Error Function. & 223.177 \\
\hline
\end{tabular}




\begin{tabular}{|c|c|c|c|c|c|}
\hline $\begin{array}{l}{ }_{-} \mathrm{MISC}_{-} \\
\text {_WRONG }\end{array}$ & \multicolumn{2}{|c|}{$\begin{array}{l}\text { Misclassification Rate. } \\
\text { Number of Wrong Classifications. }\end{array}$} & IARY & $\begin{array}{l}169 \\
41 \\
\end{array}$ & \\
\hline TARGET & PREDICT & $\begin{array}{l}\text { PERCENT } \\
\text { OF } \\
\text { TARGET }\end{array}$ & $\begin{array}{l}\text { PERCENT } \\
\text { OF } \\
\text { PREDICT }\end{array}$ & COUNT & $\begin{array}{l}\text { PERCENT } \\
\text { OF } \\
\text { TOTAL }\end{array}$ \\
\hline BANKRUPT & BANKRUPT & 81.4286 & 88.3721 & 114 & 47.1074 \\
\hline NONBANKRUPT & BANKRUPT & 18.5714 & 23.0088 & 26 & 10.7438 \\
\hline BANKRUPT & NONBANKRUPT & 14.7059 & 11.6279 & 15 & 6.1983 \\
\hline NONBANKRUPT & NONBANKRUPT & 85.2941 & 76.9912 & 87 & 35.9504 \\
\hline
\end{tabular}

YEAR 3

VARIABLE SUMMARY

\begin{tabular}{lll}
\hline ROLE & LEVEL & COUNT \\
\hline INPUT & INTERVAL & 6 \\
TARGET & TARGET & 1 \\
\hline
\end{tabular}

FIT STATISTICS

\begin{tabular}{|c|c|c|}
\hline $\begin{array}{l}\text { FIT } \\
\text { STATISTIC }\end{array}$ & STATISTIC LABEL & $\begin{array}{l}\text { STATISTIC } \\
\text { VALUE }\end{array}$ \\
\hline DFT_ $_{-}$ & Total Degrees of Freedom. & 219 \\
\hline _DFE_ & Degrees of Freedom for Error. & 171 \\
\hline _DFM_ & Model Degrees of Freedom. & 48 \\
\hline $\mathrm{NW}_{-}$ & Number of Estimated Weights. & 48 \\
\hline $\mathrm{AIC}_{-}$ & Akaike's Information Criterion. & 302.845 \\
\hline${ }_{-} \mathrm{SBC}_{-}$ & Schwarz's Bayesian Criterion. & 465.52 \\
\hline _ASE_ & Average Squared Error. & 0.151 \\
\hline _MAX_ & Maximum Absolute Error. & 0.889 \\
\hline $\mathrm{DIV}_{-}$ & Divisor for ASE. & 438 \\
\hline _NOBS_ & Sum of Frequencies. & 219 \\
\hline _RASE_ & Root Average Squared Error. & 0.388 \\
\hline _SSE_ & Sum of Squared Errors. & 66.046 \\
\hline${ }_{-}$SUMW_ & Sum of Case Weights Times Freq. & 438 \\
\hline FPE_ & Final Prediction Error. & 0.235 \\
\hline MSE_ & Mean Squared Error. & 0.193 \\
\hline _RFPE_ & Root Final Prediction Error. & 0.485 \\
\hline _RMSE_ & Root Mean Squared Error. & 0.439 \\
\hline AVERR & Average Error Function. & 0.472 \\
\hline
\end{tabular}




\begin{tabular}{|c|c|c|c|c|c|}
\hline ERR & \multicolumn{2}{|l|}{ Error Function. } & \multicolumn{3}{|c|}{206.845} \\
\hline _ MISC_ & \multicolumn{2}{|l|}{ Misclassification Rate. } & \multicolumn{2}{|c|}{0.192} & \\
\hline WRONG & \multicolumn{2}{|c|}{ Number of Wrong Classifications. } & \multicolumn{2}{|r|}{42} & \\
\hline \multicolumn{6}{|c|}{ CLASSIFICATION SUMMARY } \\
\hline TARGET & PREDICT & $\begin{array}{l}\text { PERCENT } \\
\text { OF } \\
\text { TARGET }\end{array}$ & $\begin{array}{l}\text { PERCENT } \\
\text { OF } \\
\text { PREDICT }\end{array}$ & COUNT & $\begin{array}{l}\text { PERCENT } \\
\text { OF } \\
\text { TOTAL }\end{array}$ \\
\hline BANKRUPT & BANKRUPT & 79.4643 & 82.4074 & 89 & 40.6393 \\
\hline NONBANKRUPT & BANKRUPT & 20.5357 & 20.7207 & 23 & 10.5023 \\
\hline BANKRUPT & NONBANKRUPT & 17.757 & 17.5926 & 19 & 8.6758 \\
\hline NONBANKRUPT & NONBANKRUPT & 82.243 & 79.2793 & 88 & 40.1826 \\
\hline
\end{tabular}

YEAR 4

VARIABLE SUMMARY

\begin{tabular}{lll}
\hline ROLE & LEVEL & COUNT \\
\hline INPUT & INTERVAL & 6 \\
TARGET & TARGET & 1 \\
\hline
\end{tabular}

FIT STATISTICS

\begin{tabular}{|c|c|c|}
\hline $\begin{array}{l}\text { FIT } \\
\text { STATISTIC }\end{array}$ & STATISTIC LABEL & $\begin{array}{l}\text { STATISTIC } \\
\text { VALUE }\end{array}$ \\
\hline DFT_ $_{-}$ & Total Degrees of Freedom. & 195 \\
\hline _DFE_ & Degrees of Freedom for Error. & 147 \\
\hline _DFM_ & Model Degrees of Freedom. & 48 \\
\hline $\mathrm{NW}_{-}$ & Number of Estimated Weights. & 48 \\
\hline $\mathrm{AIC}_{-}$ & Akaike's Information Criterion. & 216.526 \\
\hline${ }_{-} \mathrm{SBC}$ & Schwarz's Bayesian Criterion. & 373.63 \\
\hline ASE_ & Average Squared Error. & 0.089 \\
\hline${ }_{-}$MAX_ & Maximum Absolute Error. & 0.955 \\
\hline DIV $_{-}$ & Divisor for ASE. & 390 \\
\hline _NOBS_ & Sum of Frequencies. & 195 \\
\hline _RASE_ & Root Average Squared Error. & 0.298 \\
\hline _SSE_ & Sum of Squared Errors. & 34.648 \\
\hline SUMW_ & Sum of Case Weights Times Freq. & 390 \\
\hline _FPE_ & Final Prediction Error. & 0.147 \\
\hline _MSE_ & Mean Squared Error. & 0.118 \\
\hline _RFPE_ & Root Final Prediction Error. & 0.383 \\
\hline RMSE & Root Mean Squared Error. & 0.343 \\
\hline
\end{tabular}




\begin{tabular}{|c|c|c|c|c|c|}
\hline _AVERR_ & \multicolumn{2}{|c|}{ Average Error Function. } & \multicolumn{3}{|c|}{0.309} \\
\hline ERR_ & \multicolumn{2}{|l|}{ Error Function. } & \multicolumn{2}{|c|}{120.526} & \\
\hline _MISC_ & \multicolumn{2}{|l|}{ Misclassification Rate. } & \multicolumn{2}{|c|}{0.103} & \\
\hline WRONG & \multicolumn{2}{|c|}{ Number of Wrong Classifications. } & \multicolumn{2}{|r|}{20} & \\
\hline \multicolumn{6}{|c|}{ CLASSIFICATION SUMMARY } \\
\hline TARGET & PREDICT & $\begin{array}{l}\text { PERCENT } \\
\text { OF } \\
\text { TARGET }\end{array}$ & $\begin{array}{l}\text { PERCENT } \\
\text { OF } \\
\text { PREDICT }\end{array}$ & COUNT & $\begin{array}{l}\text { PERCENT } \\
\text { OF } \\
\text { TOTAL }\end{array}$ \\
\hline BANKRUPT & BANKRUPT & 87.3563 & 89.4118 & 76 & 38.9744 \\
\hline NONBANKRUPT & BANKRUPT & 12.6437 & 10 & 11 & 5.641 \\
\hline BANKRUPT & NONBANKRUPT & 8.3333 & 10.5882 & 9 & 4.6154 \\
\hline NONBANKRUPT & NONBANKRUPT & 91.6667 & 90 & 99 & 50.7692 \\
\hline
\end{tabular}

YEAR 5

VARIABLE SUMMARY

\begin{tabular}{lll} 
ROLE & LEVEL & COUNT \\
\hline INPUT & INTERVAL & 6 \\
TARGET & TARGET & 1 \\
\hline
\end{tabular}

FIT STATISTICS

\begin{tabular}{|c|c|c|}
\hline $\begin{array}{l}\text { FIT } \\
\text { STATISTIC }\end{array}$ & STATISTIC LABEL & $\begin{array}{l}\text { STATISTIC } \\
\text { VALUE }\end{array}$ \\
\hline DFT_ $_{-}$ & Total Degrees of Freedom. & 168 \\
\hline _DFE_ & Degrees of Freedom for Error. & 120 \\
\hline _DFM_ & Model Degrees of Freedom. & 48 \\
\hline $\mathrm{NW}_{-}$ & Number of Estimated Weights. & 48 \\
\hline $\mathrm{AIC}_{-}$ & Akaike's Information Criterion. & 205.68 \\
\hline${ }_{-} \mathrm{SBC}_{-}$ & Schwarz's Bayesian Criterion. & 355.631 \\
\hline _ASE_ & Average Squared Error. & 0.097 \\
\hline _MAX_ & Maximum Absolute Error. & 0.954 \\
\hline $\mathrm{DIV}_{-}$ & Divisor for ASE. & 336 \\
\hline NOBS_ & Sum of Frequencies. & 168 \\
\hline _RASE_ & Root Average Squared Error. & 0.311 \\
\hline $\mathrm{SSE}_{-}$ & Sum of Squared Errors. & 32.574 \\
\hline SUMW_ & Sum of Case Weights Times Freq. & 336 \\
\hline _FPE_ & Final Prediction Error. & 0.175 \\
\hline MSE_ & Mean Squared Error. & 0.136 \\
\hline RFPE & Root Final Prediction Error. & 0.418 \\
\hline
\end{tabular}




\begin{tabular}{llc}
\hline _RMSE_ & Root Mean Squared Error. & 0.368 \\
_AVERR_ & Average Error Function. & 0.326 \\
ERR_ & Error Function. & 109.68 \\
${ }_{\text {MISC_}}$ & Misclassification Rate. & 0.119 \\
_WRONG_ & Number of Wrong Classifications. & 20 \\
\hline
\end{tabular}

CLASSIFICATION SUMMARY

\begin{tabular}{llcccc}
\hline & & PERCENT & PERCENT & & \multicolumn{2}{l}{$\begin{array}{l}\text { PERCENT } \\
\text { OF }\end{array}$} \\
TARGET & PREDICT & TARGET & $\begin{array}{l}\text { OF } \\
\text { PREDICT }\end{array}$ & COUNT & TOTAL \\
\hline BANKRUPT & BANKRUPT & 85.7143 & 85.7143 & 60 & 35.7143 \\
NONBANKRUPT & BANKRUPT & 14.2857 & 10.2041 & 10 & 5.9524 \\
BANKRUPT & NONBANKRUPT & 10.2041 & 14.2857 & 10 & 5.9524 \\
NONBANKRUPT & NONBANKRUPT & 89.7959 & 89.7959 & 88 & 52.381 \\
\hline
\end{tabular}


Results of Radial Basis Function Networks : Top 3 Account and Market logarithmic variables

YEAR 1

\begin{tabular}{lll}
\multicolumn{3}{c}{ VARIABLE SUMMARY } \\
\hline ROLE & LEVEL & COUNT \\
\hline INPUT & INTERVAL & 6 \\
TARGET & TARGET & 1 \\
\hline
\end{tabular}

FIT STATISTICS

\begin{tabular}{|c|c|c|}
\hline $\begin{array}{l}\text { FIT } \\
\text { STATISTIC }\end{array}$ & STATISTIC LABEL & $\begin{array}{l}\text { STATISTIC } \\
\text { VALUE }\end{array}$ \\
\hline $\mathrm{DFT}_{-}$ & Total Degrees of Freedom. & 255 \\
\hline DFE_ & Degrees of Freedom for Error. & 207 \\
\hline DFM_ & Model Degrees of Freedom. & 48 \\
\hline $\mathrm{NW}_{-}$ & Number of Estimated Weights. & 48 \\
\hline $\mathrm{AIC}_{-}$ & Akaike's Information Criterion. & 351.13 \\
\hline $\mathrm{SBC}_{-}$ & Schwarz's Bayesian Criterion. & 521.111 \\
\hline ASE_ & Average Squared Error. & 0.163 \\
\hline MAX_ & Maximum Absolute Error. & 0.884 \\
\hline DIV_ $_{-}$ & Divisor for ASE. & 510 \\
\hline _NOBS & Sum of Frequencies. & 255 \\
\hline _RASE_ & Root Average Squared Error. & 0.404 \\
\hline _SSE_ & Sum of Squared Errors. & 83.249 \\
\hline _SUMW_ & Sum of Case Weights Times Freq. & 510 \\
\hline FPE_ & Final Prediction Error. & 0.239 \\
\hline MSE_ & Mean Squared Error. & 0.201 \\
\hline _RFPE_ & Root Final Prediction Error. & 0.489 \\
\hline _RMSE_ & Root Mean Squared Error. & 0.448 \\
\hline _AVERR_ & Average Error Function. & 0.5 \\
\hline ERR_ & Error Function. & 255.13 \\
\hline _MISC_ & Misclassification Rate. & 0.216 \\
\hline WRONG & Number of Wrong Classifications. & 55 \\
\hline
\end{tabular}


CLASSIFICATION SUMMARY

\begin{tabular}{llccccc}
\hline & & PERCENT & PERCENT & & PERCENT \\
& & OF & OF & \\
TARGET & PREDICT & TARGET & PREDICT & COUNT & TOTAL \\
\hline BANKRUPT & BANKRUPT & 73.9884 & 92.7536 & 128 & 50.1961 \\
NONBANKRUPT & BANKRUPT & 26.0116 & 38.4615 & 45 & 17.6471 \\
BANKRUPT & NONBANKRUPT & 12.1951 & 7.2464 & 10 & 3.9216 \\
NONBANKRUPT & NONBANKRUPT & 87.8049 & 61.5385 & 72 & 28.2353 \\
\hline
\end{tabular}

YEAR 2

VARIABLE SUMMARY

\begin{tabular}{lll}
\hline ROLE & LEVEL & COUNT \\
\hline INPUT & INTERVAL & 6 \\
TARGET & TARGET & 1 \\
\hline
\end{tabular}

FIT STATISTICS

\begin{tabular}{|c|c|c|}
\hline $\begin{array}{l}\text { FIT } \\
\text { STATISTIC }\end{array}$ & STATISTIC LABEL & $\begin{array}{l}\text { STATISTIC } \\
\text { VALUE }\end{array}$ \\
\hline DFT_ $_{-}$ & Total Degrees of Freedom. & 242 \\
\hline _DFE_ & Degrees of Freedom for Error. & 194 \\
\hline _DFM_ & Model Degrees of Freedom. & 48 \\
\hline NW_ & Number of Estimated Weights. & 48 \\
\hline _AIC_ & Akaike's Information Criterion. & 356.335 \\
\hline${ }_{-} \mathrm{SBC}_{-}$ & Schwarz's Bayesian Criterion. & 523.804 \\
\hline _ASE_ & Average Squared Error. & 0.178 \\
\hline _MAX_ & Maximum Absolute Error. & 0.87 \\
\hline DIV_ $_{-}$ & Divisor for ASE. & 484 \\
\hline NOBS & Sum of Frequencies. & 242 \\
\hline _RASE_ & Root Average Squared Error. & 0.421 \\
\hline _SSE_ & Sum of Squared Errors. & 85.94 \\
\hline SUMW_ & Sum of Case Weights Times Freq. & 484 \\
\hline FPE_ & Final Prediction Error. & 0.265 \\
\hline _MSE_ & Mean Squared Error. & 0.221 \\
\hline _RFPE_ & Root Final Prediction Error. & 0.515 \\
\hline _RMSE_ & Root Mean Squared Error. & 0.471 \\
\hline _AVERR_ & Average Error Function. & 0.538 \\
\hline ERR_ & Error Function. & 260.335 \\
\hline
\end{tabular}




\begin{tabular}{llc}
\hline MISC__ & Misclassification Rate. & 0.236 \\
_WRONG__ & Number of Wrong Classifications. & 57 \\
\hline
\end{tabular}

CLASSIFICATION SUMMARY

\begin{tabular}{llcccc}
\hline & & PERCENT & PERCENT & & \multicolumn{2}{l}{ PERCENT } \\
OF & OF & OF & & OF \\
TARGET & PREDICT & TARGET & PREDICT & COUNT & TOTAL \\
\hline BANKRUPT & BANKRUPT & 77.2727 & 79.0698 & 102 & 42.1488 \\
NONBANKRUPT & BANKRUPT & 22.7273 & 26.5487 & 30 & 12.3967 \\
BANKRUPT & NONBANKRUPT & 24.5455 & 20.9302 & 27 & 11.157 \\
NONBANKRUPT & NONBANKRUPT & 75.4545 & 73.4513 & 83 & 34.2975 \\
\hline
\end{tabular}

YEAR 3

VARIABLE SUMMARY

\begin{tabular}{lll}
\hline ROLE & LEVEL & COUNT \\
\hline INPUT & INTERVAL & 6 \\
TARGET & TARGET & 1 \\
\hline
\end{tabular}

FIT STATISTICS

\begin{tabular}{|c|c|c|}
\hline $\begin{array}{l}\text { FIT } \\
\text { STATISTIC }\end{array}$ & STATISTIC LABEL & $\begin{array}{l}\text { STATISTIC } \\
\text { VALUE }\end{array}$ \\
\hline DFT $_{-}$ & Total Degrees of Freedom. & 219 \\
\hline _DFE_ & Degrees of Freedom for Error. & 171 \\
\hline _DFM_ & Model Degrees of Freedom. & 48 \\
\hline $\mathrm{NW}_{-}$ & Number of Estimated Weights. & 48 \\
\hline _AIC_ & Akaike's Information Criterion. & 319.649 \\
\hline $\mathrm{SBC}_{-}$ & Schwarz's Bayesian Criterion. & 482.325 \\
\hline _ASE_ & Average Squared Error. & 0.167 \\
\hline MAX_ & Maximum Absolute Error. & 0.914 \\
\hline $\mathrm{DIV}_{-}$ & Divisor for ASE. & 438 \\
\hline NOBS_ & Sum of Frequencies. & 219 \\
\hline _RASE_ & Root Average Squared Error. & 0.408 \\
\hline _SSE_ & Sum of Squared Errors. & 73.009 \\
\hline _SUMW_ & Sum of Case Weights Times Freq. & 438 \\
\hline _FPE_ & Final Prediction Error. & 0.26 \\
\hline MSE_ & Mean Squared Error. & 0.213 \\
\hline _RFPE_ & Root Final Prediction Error. & 0.51 \\
\hline RMSE_ & Root Mean Squared Error. & 0.462 \\
\hline
\end{tabular}




\begin{tabular}{|c|c|c|c|c|c|}
\hline \multirow{5}{*}{$\begin{array}{l}{ }_{-} \text {AVERR_- } \\
{ }_{-} \text {ERR_- } \\
{ }_{-} \mathrm{MISC}_{-} \\
\\
\end{array}$} & \multicolumn{3}{|c|}{ Average Error Function. } & \multicolumn{2}{|c|}{0.511} \\
\hline & \multicolumn{3}{|c|}{ Error Function. } & \multicolumn{2}{|c|}{223.649} \\
\hline & \multicolumn{3}{|c|}{ Misclassification Rate. } & \multicolumn{2}{|c|}{0.233} \\
\hline & \multicolumn{3}{|c|}{ Number of Wrong Classifications. } & \multicolumn{2}{|c|}{51} \\
\hline & \multicolumn{5}{|c|}{ CLASSIFICATION SUMMARY } \\
\hline TARGET & PREDICT & $\begin{array}{l}\text { PERCENT } \\
\text { OF } \\
\text { TARGET }\end{array}$ & $\begin{array}{l}\text { PERCENT } \\
\text { OF } \\
\text { PREDICT }\end{array}$ & COUNT & $\begin{array}{l}\text { PERCENT } \\
\text { OF } \\
\text { TOTAL }\end{array}$ \\
\hline BANKRUPT & BANKRUPT & 77.6699 & 74.0741 & 80 & 36.5297 \\
\hline NONBANKRUPT & BANKRUPT & 22.3301 & 20.7207 & 23 & 10.5023 \\
\hline BANKRUPT & NONBANKRUPT & 24.1379 & 25.9259 & 28 & 12.7854 \\
\hline NONBANKRUPT & NONBANKRUPT & 75.8621 & 79.2793 & 88 & 40.1826 \\
\hline
\end{tabular}

YEAR 4

VARIABLE SUMMARY

\begin{tabular}{lll}
\hline ROLE & LEVEL & COUNT \\
\hline INPUT & INTERVAL & 6 \\
TARGET & TARGET & 1 \\
\hline
\end{tabular}

FIT STATISTICS

\begin{tabular}{|c|c|c|}
\hline $\begin{array}{l}\text { FIT } \\
\text { STATISTIC }\end{array}$ & STATISTIC LABEL & $\begin{array}{l}\text { STATISTIC } \\
\text { VALUE }\end{array}$ \\
\hline DFT_ $_{-}$ & Total Degrees of Freedom. & 195 \\
\hline _DFE_ & Degrees of Freedom for Error. & 147 \\
\hline _DFM_ & Model Degrees of Freedom. & 48 \\
\hline $\mathrm{NW}_{-}$ & Number of Estimated Weights. & 48 \\
\hline AIC_ & Akaike's Information Criterion. & 254.967 \\
\hline $\mathrm{SBC}_{-}$ & Schwarz's Bayesian Criterion. & 412.07 \\
\hline _ASE_ & Average Squared Error. & 0.129 \\
\hline MAX_ & Maximum Absolute Error. & 0.876 \\
\hline DIV $_{-}$ & Divisor for ASE. & 390 \\
\hline NOBS_ & Sum of Frequencies. & 195 \\
\hline _RASE_ & Root Average Squared Error. & 0.359 \\
\hline _SSE_ & Sum of Squared Errors. & 50.317 \\
\hline SUMW_ & Sum of Case Weights Times Freq. & 390 \\
\hline _FPE_ & Final Prediction Error. & 0.213 \\
\hline _MSE_ & Mean Squared Error. & 0.171 \\
\hline RFPE & Root Final Prediction Error. & 0.462 \\
\hline
\end{tabular}




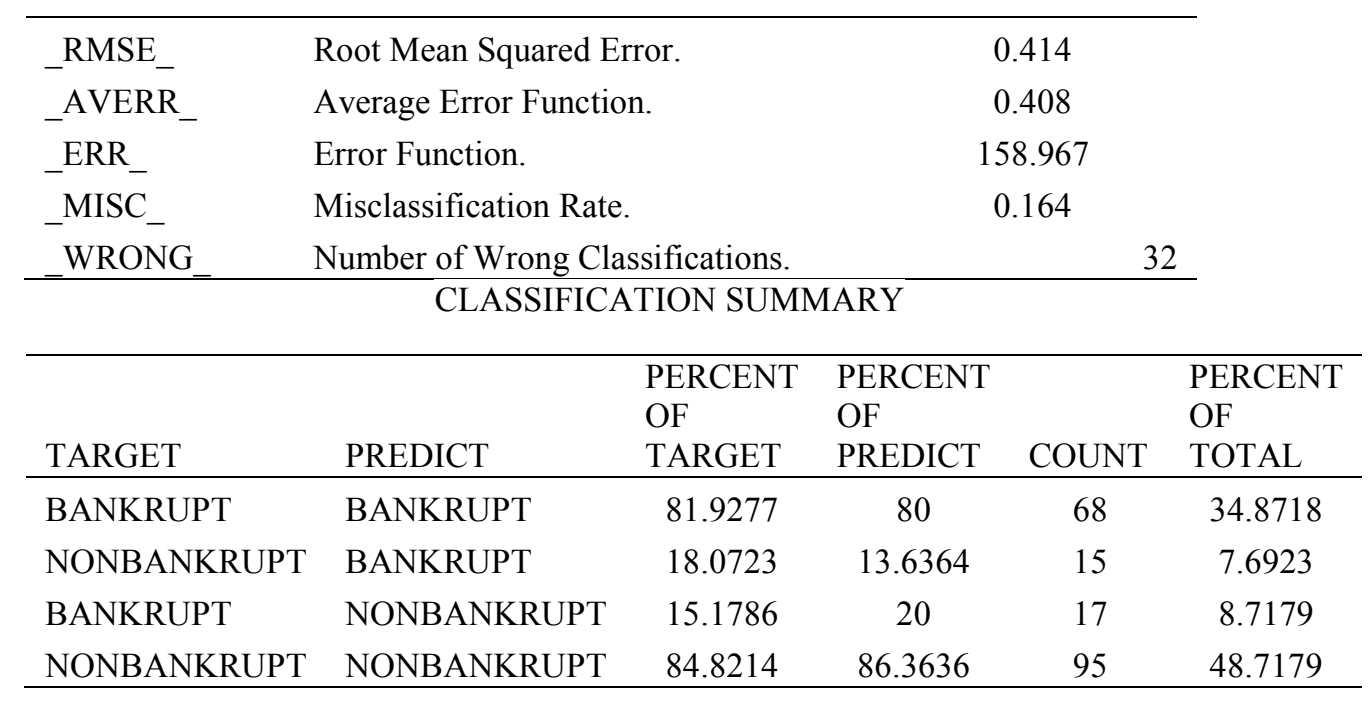

YEAR 5

VARIABLE SUMMARY

\begin{tabular}{lll}
\hline ROLE & LEVEL & COUNT \\
\hline INPUT & INTERVAL & 6 \\
TARGET & TARGET & 1 \\
\hline
\end{tabular}

FIT STATISTICS

\begin{tabular}{|c|c|c|}
\hline $\begin{array}{l}\text { FIT } \\
\text { STATISTIC }\end{array}$ & STATISTIC LABEL & $\begin{array}{l}\text { STATISTIC } \\
\text { VALUE }\end{array}$ \\
\hline DFT_ $_{-}$ & Total Degrees of Freedom. & 168 \\
\hline DFE_ & Degrees of Freedom for Error. & 120 \\
\hline _DFM_ & Model Degrees of Freedom. & 48 \\
\hline $\mathrm{NW}_{-}$ & Number of Estimated Weights. & 48 \\
\hline $\mathrm{AIC}_{-}$ & Akaike's Information Criterion. & 259.049 \\
\hline${ }_{-} \mathrm{SBC}$ & Schwarz's Bayesian Criterion. & 408.999 \\
\hline _ASE_ & Average Squared Error. & 0.16 \\
\hline MAX_ & Maximum Absolute Error. & 0.906 \\
\hline $\mathrm{DIV}_{-}$ & Divisor for ASE. & 336 \\
\hline _NOBS_ & Sum of Frequencies. & 168 \\
\hline _RASE_ & Root Average Squared Error. & 0.4 \\
\hline _SSE_ & Sum of Squared Errors. & 53.832 \\
\hline$\_$SUMW & Sum of Case Weights Times Freq. & 336 \\
\hline _FPE_ & Final Prediction Error. & 0.288 \\
\hline MSE & Mean Squared Error. & 0.224 \\
\hline
\end{tabular}




\begin{tabular}{|c|c|c|c|c|c|}
\hline _RFPE_ & \multicolumn{2}{|c|}{ Root Final Prediction Error. } & \multicolumn{2}{|c|}{0.537} & \\
\hline _RMSE_ & \multicolumn{2}{|c|}{ Root Mean Squared Error. } & \multicolumn{2}{|c|}{0.474} & \\
\hline _AVERR_ & \multicolumn{2}{|l|}{ Average Error Function. } & \multicolumn{2}{|c|}{0.485} & \\
\hline _ERR_ & \multicolumn{2}{|l|}{ Error Function. } & \multicolumn{2}{|c|}{163.049} & \\
\hline _MISC_ & \multicolumn{2}{|l|}{ Misclassification Rate. } & \multicolumn{2}{|c|}{0.25} & \\
\hline WRONG & \multicolumn{2}{|c|}{ Number of Wrong Classifications. } & \multicolumn{2}{|c|}{42} & \\
\hline \multicolumn{6}{|c|}{ CLASSIFICATION SUMMARY } \\
\hline TARGET & PREDICT & $\begin{array}{l}\text { PERCENT } \\
\text { OF } \\
\text { TARGET }\end{array}$ & $\begin{array}{l}\text { PERCENT } \\
\text { OF } \\
\text { PREDICT }\end{array}$ & COUNT & $\begin{array}{l}\text { PERCENT } \\
\text { OF } \\
\text { TOTAL }\end{array}$ \\
\hline BANKRUPT & BANKRUPT & 68.9189 & 72.8571 & 51 & 30.3571 \\
\hline NONBANKRUPT & BANKRUPT & 31.0811 & 23.4694 & 23 & 13.6905 \\
\hline BANKRUPT & NONBANKRUPT & 20.2128 & 27.1429 & 19 & 11.3095 \\
\hline NONBANKRUPT & NONBANKRUPT & 79.7872 & 76.5306 & 75 & 44.6429 \\
\hline
\end{tabular}


Results of Radial Basis Function Networks : Variables (Price, Standard deviation, bid ask spread, net income to sales, working capital to total assets and current liabilities to total assets )

YEAR 1

VARIABLE SUMMARY

\begin{tabular}{lll}
\hline ROLE & LEVEL & COUNT \\
\hline INPUT & INTERVAL & 6 \\
TARGET & TARGET & 1 \\
\hline
\end{tabular}

FIT STATISTICS

\begin{tabular}{|c|c|c|}
\hline $\begin{array}{l}\text { FIT } \\
\text { STATISTIC }\end{array}$ & STATISTIC LABEL & $\begin{array}{l}\text { STATISTIC } \\
\text { VALUE }\end{array}$ \\
\hline DFT_ $_{-}$ & Total Degrees of Freedom. & 255 \\
\hline DFE_ $_{-}$ & Degrees of Freedom for Error. & 207 \\
\hline _DFM_ & Model Degrees of Freedom. & 48 \\
\hline $\mathrm{NW}_{-}$ & Number of Estimated Weights. & 48 \\
\hline $\mathrm{AIC}_{-}$ & Akaike's Information Criterion. & 309.809 \\
\hline $\mathrm{SBC}_{-}$ & Schwarz's Bayesian Criterion. & 479.789 \\
\hline _ASE_ & Average Squared Error. & 0.13 \\
\hline -MAX_ & Maximum Absolute Error. & 0.927 \\
\hline $\mathrm{DIV}_{-}$ & Divisor for ASE. & 510 \\
\hline NOBS_ & Sum of Frequencies. & 255 \\
\hline _RASE_ & Root Average Squared Error. & 0.361 \\
\hline _SSE_ & Sum of Squared Errors. & 66.54 \\
\hline SUMW_ & Sum of Case Weights Times Freq. & 510 \\
\hline _FPE_ & Final Prediction Error. & 0.191 \\
\hline $\mathrm{MSE}_{-}$ & Mean Squared Error. & 0.161 \\
\hline _RFPE_ & Root Final Prediction Error. & 0.437 \\
\hline _RMSE_ & Root Mean Squared Error. & 0.401 \\
\hline _AVERR_ & Average Error Function. & 0.419 \\
\hline ERR_ & Error Function. & 213.809 \\
\hline _MISC_ & Misclassification Rate. & 0.176 \\
\hline WRONG & Number of Wrong Classifications. & 45 \\
\hline
\end{tabular}


CLASSIFICATION SUMMARY

\begin{tabular}{llcccc}
\hline & & PERCENT & PERCENT & & PERCENT \\
& & OF & OF & \\
TARGET & PREDICT & TARGET & PREDICT & COUNT & TOTAL \\
\hline BANKRUPT & BANKRUPT & 83.4532 & 84.058 & 116 & 45.4902 \\
NONBANKRUPT & BANKRUPT & 16.5468 & 19.6581 & 23 & 9.0196 \\
BANKRUPT & NONBANKRUPT & 18.9655 & 15.942 & 22 & 8.6275 \\
NONBANKRUPT & NONBANKRUPT & 81.0345 & 80.3419 & 94 & 36.8627 \\
\hline
\end{tabular}

YEAR 2

VARIABLE SUMMARY

\begin{tabular}{lll}
\hline ROLE & LEVEL & COUNT \\
\hline INPUT & INTERVAL & 6 \\
TARGET & TARGET & 1 \\
\hline
\end{tabular}

FIT STATISTICS

\begin{tabular}{|c|c|c|}
\hline $\begin{array}{l}\text { FIT } \\
\text { STATISTIC }\end{array}$ & STATISTIC LABEL & $\begin{array}{l}\text { STATISTIC } \\
\text { VALUE }\end{array}$ \\
\hline DFT_ $_{-}$ & Total Degrees of Freedom. & 242 \\
\hline _DFE_ & Degrees of Freedom for Error. & 194 \\
\hline _DFM_ & Model Degrees of Freedom. & 48 \\
\hline NW_ & Number of Estimated Weights. & 48 \\
\hline _AIC_ & Akaike's Information Criterion. & 335.255 \\
\hline${ }_{-} \mathrm{SBC}_{-}$ & Schwarz's Bayesian Criterion. & 502.724 \\
\hline _ASE_ & Average Squared Error. & 0.16 \\
\hline _MAX_ & Maximum Absolute Error. & 0.91 \\
\hline DIV_ $_{-}$ & Divisor for ASE. & 484 \\
\hline NOBS & Sum of Frequencies. & 242 \\
\hline _RASE_ & Root Average Squared Error. & 0.401 \\
\hline _SSE_ & Sum of Squared Errors. & 77.669 \\
\hline SUMW_ & Sum of Case Weights Times Freq. & 484 \\
\hline FPE_ & Final Prediction Error. & 0.24 \\
\hline _MSE_ & Mean Squared Error. & 0.2 \\
\hline _RFPE_ & Root Final Prediction Error. & 0.49 \\
\hline _RMSE_ & Root Mean Squared Error. & 0.447 \\
\hline _AVERR_ & Average Error Function. & 0.494 \\
\hline ERR_ & Error Function. & 239.255 \\
\hline
\end{tabular}




\begin{tabular}{llc}
\hline MISC__ & Misclassification Rate. & 0.223 \\
_WRONG__ & Number of Wrong Classifications. & 54 \\
\hline
\end{tabular}

CLASSIFICATION SUMMARY

\begin{tabular}{|c|c|c|c|c|c|}
\hline TARGET & PREDICT & $\begin{array}{l}\text { PERCENT } \\
\text { OF } \\
\text { TARGET }\end{array}$ & $\begin{array}{l}\text { PERCENT } \\
\text { OF } \\
\text { PREDICT }\end{array}$ & COUNT & $\begin{array}{l}\text { PERCENT } \\
\text { OF } \\
\text { TOTAL }\end{array}$ \\
\hline BANKRUPT & BANKRUPT & 74.8344 & 87.5969 & 113 & 46.6942 \\
\hline NONBANKRUPT & BANKRUPT & 25.1656 & 33.6283 & 38 & 15.7025 \\
\hline BANKRUPT & NONBANKRUPT & 17.5824 & 12.4031 & 16 & 6.6116 \\
\hline NONBANKRUPT & NONBANKRUPT & 82.4176 & 66.3717 & 75 & 30.9917 \\
\hline
\end{tabular}

YEAR 3

VARIABLE SUMMARY

\begin{tabular}{lll}
\hline ROLE & LEVEL & COUNT \\
\hline INPUT & INTERVAL & 6 \\
TARGET & TARGET & 1 \\
\hline
\end{tabular}

FIT STATISTICS

\begin{tabular}{|c|c|c|}
\hline $\begin{array}{l}\text { FIT } \\
\text { STATISTIC }\end{array}$ & STATISTIC LABEL & $\begin{array}{l}\text { STATISTIC } \\
\text { VALUE }\end{array}$ \\
\hline DFT $_{-}$ & Total Degrees of Freedom. & 219 \\
\hline _DFE_ & Degrees of Freedom for Error. & 171 \\
\hline _DFM_ & Model Degrees of Freedom. & 48 \\
\hline $\mathrm{NW}_{-}$ & Number of Estimated Weights. & 48 \\
\hline _AIC_ & Akaike's Information Criterion. & 307.717 \\
\hline $\mathrm{SBC}_{-}$ & Schwarz's Bayesian Criterion. & 470.393 \\
\hline _ASE_ & Average Squared Error. & 0.157 \\
\hline _MAX_ & Maximum Absolute Error. & 0.916 \\
\hline $\mathrm{DIV}_{-}$ & Divisor for ASE. & 438 \\
\hline NOBS_ & Sum of Frequencies. & 219 \\
\hline _RASE_ & Root Average Squared Error. & 0.397 \\
\hline _SSE_ & Sum of Squared Errors. & 68.92 \\
\hline _SUMW_ & Sum of Case Weights Times Freq. & 438 \\
\hline _FPE_ & Final Prediction Error. & 0.246 \\
\hline MSE_ & Mean Squared Error. & 0.202 \\
\hline _RFPE_ & Root Final Prediction Error. & 0.496 \\
\hline RMSE_ & Root Mean Squared Error. & 0.449 \\
\hline
\end{tabular}




\begin{tabular}{llc}
\hline _AVERR__ & Average Error Function. & 0.483 \\
_ERR__ & Error Function. & 211.717 \\
_MISC__ & Misclassification Rate. & 0.251 \\
_WRONG__ & Number of Wrong Classifications. & 55 \\
\hline
\end{tabular}

CLASSIFICATION SUMMARY

\begin{tabular}{llcccc}
\hline & & PERCENT & PERCENT & & PERCENT \\
& & OF & OF \\
TARGET & PREDICT & TARGET & PREDICT & COUNT & TOTAL \\
\hline BANKRUPT & BANKRUPT & 81.1765 & 63.8889 & 69 & 31.5068 \\
NONBANKRUPT & BANKRUPT & 18.8235 & 14.4144 & 16 & 7.3059 \\
BANKRUPT & NONBANKRUPT & 29.1045 & 36.1111 & 39 & 17.8082 \\
NONBANKRUPT & NONBANKRUPT & 70.8955 & 85.5856 & 95 & 43.379 \\
\hline
\end{tabular}

YEAR 4

VARIABLE SUMMARY

\begin{tabular}{lll}
\hline ROLE & LEVEL & COUNT \\
\hline INPUT & INTERVAL & 6 \\
TARGET & TARGET & 1 \\
\hline
\end{tabular}

FIT STATISTICS

\begin{tabular}{|c|c|c|}
\hline $\begin{array}{l}\text { FIT } \\
\text { STATISTIC }\end{array}$ & STATISTIC LABEL & $\begin{array}{l}\text { STATISTIC } \\
\text { VALUE }\end{array}$ \\
\hline DFT_ $_{-}$ & Total Degrees of Freedom. & 195 \\
\hline _DFE_ & Degrees of Freedom for Error. & 147 \\
\hline _DFM_ & Model Degrees of Freedom. & 48 \\
\hline $\mathrm{NW}_{-}$ & Number of Estimated Weights. & 48 \\
\hline AIC_ & Akaike's Information Criterion. & 217.585 \\
\hline SBC_ & Schwarz's Bayesian Criterion. & 374.689 \\
\hline $\mathrm{ASE}_{-}$ & Average Squared Error. & 0.092 \\
\hline -MAX_ & Maximum Absolute Error. & 0.944 \\
\hline DIV_ & Divisor for ASE. & 390 \\
\hline NOBS_ & Sum of Frequencies. & 195 \\
\hline RASE_ & Root Average Squared Error. & 0.303 \\
\hline _SSE_ & Sum of Squared Errors. & 35.847 \\
\hline SUMW & Sum of Case Weights Times Freq. & 390 \\
\hline _FPE_ & Final Prediction Error. & 0.152 \\
\hline MSE & Mean Squared Error. & 0.122 \\
\hline
\end{tabular}




\begin{tabular}{|c|c|c|}
\hline RFPE_ & Root Final Prediction Error. & 0.39 \\
\hline _RMSE_ & Root Mean Squared Error. & 0.349 \\
\hline _AVERR_ & Average Error Function. & 0.312 \\
\hline ERR_ & Error Function. & 121.585 \\
\hline MISC$_{-}$ & Misclassification Rate. & 0.108 \\
\hline WRONG & Number of Wrong Classifications. & 21 \\
\hline
\end{tabular}

CLASSIFICATION SUMMARY

\begin{tabular}{llcccc}
\hline & & PERCENT & PERCENT & & \multicolumn{2}{l}{ PERCENT } \\
OF & OF & OF & \\
TARGET & PREDICT & TARGET & PREDICT & COUNT & TOTAL \\
\hline BANKRUPT & BANKRUPT & 90 & 84.7059 & 72 & 36.9231 \\
NONBANKRUPT & BANKRUPT & 10 & 7.2727 & 8 & 4.1026 \\
BANKRUPT & NONBANKRUPT & 11.3043 & 15.2941 & 13 & 6.6667 \\
NONBANKRUPT & NONBANKRUPT & 88.6957 & 92.7273 & 102 & 52.3077 \\
\hline
\end{tabular}

YEAR 5

VARIABLE SUMMARY

\begin{tabular}{lll}
\hline ROLE & LEVEL & COUNT \\
\hline INPUT & INTERVAL & 6 \\
TARGET & TARGET & 1 \\
\hline
\end{tabular}

FIT STATISTICS

\begin{tabular}{|c|c|c|}
\hline $\begin{array}{l}\text { FIT } \\
\text { STATISTIC }\end{array}$ & STATISTIC LABEL & $\begin{array}{l}\text { STATISTIC } \\
\text { VALUE }\end{array}$ \\
\hline DFT_ $_{-}$ & Total Degrees of Freedom. & 168 \\
\hline _DFE_ & Degrees of Freedom for Error. & 120 \\
\hline _DFM_ & Model Degrees of Freedom. & 48 \\
\hline $\mathrm{NW}_{-}$ & Number of Estimated Weights. & 48 \\
\hline $\mathrm{AIC}_{-}$ & Akaike's Information Criterion. & 182.001 \\
\hline${ }_{-} \mathrm{SBC}$ & Schwarz's Bayesian Criterion. & 331.952 \\
\hline _ASE_ & Average Squared Error. & 0.065 \\
\hline MAX_ & Maximum Absolute Error. & 0.957 \\
\hline _DIV_ & Divisor for ASE. & 336 \\
\hline NOBS & Sum of Frequencies. & 168 \\
\hline _RASE_ & Root Average Squared Error. & 0.255 \\
\hline _SSE_ & Sum of Squared Errors. & 21.908 \\
\hline SUMW & Sum of Case Weights Times Freq. & 336 \\
\hline
\end{tabular}




\begin{tabular}{|c|c|c|}
\hline FPE_ & Final Prediction Error. & 0.117 \\
\hline MSE_ & Mean Squared Error. & 0.091 \\
\hline RFPE_ & Root Final Prediction Error. & 0.343 \\
\hline RMSE_ & Root Mean Squared Error. & 0.302 \\
\hline AVERR_ & Average Error Function. & 0.256 \\
\hline ERR_ & Error Function. & 86.001 \\
\hline MISC_ & Misclassification Rate. & 0.065 \\
\hline WRONG & Number of Wrong Classifications. & 11 \\
\hline
\end{tabular}

CLASSIFICATION SUMMARY

\begin{tabular}{llcccc}
\hline & & PERCENT & PERCENT & & \multicolumn{2}{c}{$\begin{array}{l}\text { PERCENT } \\
\text { OF }\end{array}$} \\
TARGET & PREDICT & TARGET & PFEDICT & COUNT & TOTAL \\
\hline BANKRUPT & BANKRUPT & 96.8254 & 87.1429 & 61 & 36.3095 \\
NONBANKRUPT & BANKRUPT & 3.1746 & 2.0408 & 2 & 1.1905 \\
BANKRUPT & NONBANKRUPT & 8.5714 & 12.8571 & 9 & 5.3571 \\
NONBANKRUPT & NONBANKRUPT & 91.4286 & 97.9592 & 96 & 57.1429 \\
\hline
\end{tabular}


Results of Radial Basis Function Networks : Variables (Price, Standard deviation, hi lo bid ask spread, net income to sales, working capital to total assets and current liabilities to total assets )

YEAR 1

VARIABLE SUMMARY

\begin{tabular}{lll}
\hline ROLE & LEVEL & COUNT \\
\hline INPUT & INTERVAL & 6 \\
TARGET & TARGET & 1 \\
\hline
\end{tabular}

FIT STATISTICS

\begin{tabular}{|c|c|c|}
\hline $\begin{array}{l}\text { FIT } \\
\text { STATISTIC }\end{array}$ & STATISTIC LABEL & $\begin{array}{l}\text { STATISTIC } \\
\text { VALUE }\end{array}$ \\
\hline DFT $_{-}$ & Total Degrees of Freedom. & 255 \\
\hline DFE_ & Degrees of Freedom for Error. & 207 \\
\hline _DFM_ & Model Degrees of Freedom. & 48 \\
\hline $\mathrm{NW}_{-}$ & Number of Estimated Weights. & 48 \\
\hline _AIC_ & Akaike's Information Criterion. & 288.321 \\
\hline $\mathrm{SBC}_{-}$ & Schwarz's Bayesian Criterion. & 458.302 \\
\hline $\mathrm{ASE}_{-}$ & Average Squared Error. & 0.109 \\
\hline _MAX_ & Maximum Absolute Error. & 0.922 \\
\hline DIV $_{-}$ & Divisor for ASE. & 510 \\
\hline NOBS_ & Sum of Frequencies. & 255 \\
\hline _RASE_ & Root Average Squared Error. & 0.33 \\
\hline SSE_ & Sum of Squared Errors. & 55.555 \\
\hline _SUMW_ & Sum of Case Weights Times Freq. & 510 \\
\hline FPE_ & Final Prediction Error. & 0.159 \\
\hline _MSE_ & Mean Squared Error. & 0.134 \\
\hline _RFPE_ & Root Final Prediction Error. & 0.399 \\
\hline _RMSE_ & Root Mean Squared Error. & 0.366 \\
\hline _AVERR_ & Average Error Function. & 0.377 \\
\hline ERR_ & Error Function. & 192.321 \\
\hline _MISC_ & Misclassification Rate. & 0.114 \\
\hline WRONG & Number of Wrong Classifications. & 29 \\
\hline
\end{tabular}


CLASSIFICATION SUMMARY

\begin{tabular}{llccccc}
\hline & & PERCENT & PERCENT & & \multicolumn{2}{l}{ PERCENT } \\
& & OF & OF & \\
TARGET & PREDICT & TARGET & PREDICT & COUNT & TOTAL \\
\hline BANKRUPT & BANKRUPT & 88.1119 & 91.3043 & 126 & 49.4118 \\
NONBANKRUPT & BANKRUPT & 11.8881 & 14.5299 & 17 & 6.6667 \\
BANKRUPT & NONBANKRUPT & 10.7143 & 8.6957 & 12 & 4.7059 \\
NONBANKRUPT & NONBANKRUPT & 89.2857 & 85.4701 & 100 & 39.2157 \\
\hline
\end{tabular}

YEAR 2

VARIABLE SUMMARY

\begin{tabular}{lll}
\hline ROLE & LEVEL & COUNT \\
\hline INPUT & INTERVAL & 6 \\
TARGET & TARGET & 1 \\
\hline
\end{tabular}

FIT STATISTICS

\begin{tabular}{|c|c|c|}
\hline $\begin{array}{l}\text { FIT } \\
\text { STATISTIC } \\
\end{array}$ & STATISTIC LABEL & $\begin{array}{l}\text { STATISTIC } \\
\text { VALUE } \\
\end{array}$ \\
\hline DFT_ $_{-}$ & Total Degrees of Freedom. & 242 \\
\hline _DFE_ & Degrees of Freedom for Error. & 194 \\
\hline _DFM_ & Model Degrees of Freedom. & 48 \\
\hline $\mathrm{NW}_{-}$ & Number of Estimated Weights. & 48 \\
\hline $\mathrm{AIC}_{-}$ & Akaike's Information Criterion. & 394.503 \\
\hline $\mathrm{SBC}_{-}$ & Schwarz's Bayesian Criterion. & 561.972 \\
\hline _ASE_ & Average Squared Error. & 0.214 \\
\hline MAX_ & Maximum Absolute Error. & 0.793 \\
\hline DIV $_{-}$ & Divisor for ASE. & 484 \\
\hline _NOBS_ & Sum of Frequencies. & 242 \\
\hline RASE_ & Root Average Squared Error. & 0.463 \\
\hline _SSE_ & Sum of Squared Errors. & 103.587 \\
\hline S SUMW & Sum of Case Weights Times Freq. & 484 \\
\hline _FPE_ & Final Prediction Error. & 0.32 \\
\hline $\mathrm{MSE}_{-}$ & Mean Squared Error. & 0.267 \\
\hline RFPE_ & Root Final Prediction Error. & 0.566 \\
\hline _RMSE_ & Root Mean Squared Error. & 0.517 \\
\hline _AVERR_ & Average Error Function. & 0.617 \\
\hline _ERR_ & Error Function. & 298.503 \\
\hline MISC & Misclassification Rate. & 0.331 \\
\hline
\end{tabular}




\begin{tabular}{lll}
\hline WRONG__ Number of Wrong Classifications. & 80 \\
\hline
\end{tabular}

CLASSIFICATION SUMMARY

\begin{tabular}{llcccc}
\hline & & $\begin{array}{l}\text { PERCENT } \\
\text { OF }\end{array}$ & $\begin{array}{l}\text { PERCENT } \\
\text { OF }\end{array}$ & & $\begin{array}{l}\text { PERCENT } \\
\text { OF }\end{array}$ \\
TARGET & PREDICT & TARGET & PREDICT & COUNT & TOTAL \\
\hline BANKRUPT & BANKRUPT & 69.2913 & 68.2171 & 88 & 36.3636 \\
NONBANKRUPT & BANKRUPT & 30.7087 & 34.5133 & 39 & 16.1157 \\
BANKRUPT & NONBANKRUPT & 35.6522 & 31.7829 & 41 & 16.9421 \\
NONBANKRUPT & NONBANKRUPT & 64.3478 & 65.4867 & 74 & 30.5785 \\
\hline
\end{tabular}

YEAR 3

VARIABLE SUMMARY

\begin{tabular}{lll}
\hline ROLE & LEVEL & COUNT \\
\hline INPUT & INTERVAL & 6 \\
TARGET & TARGET & 1 \\
\hline
\end{tabular}

FIT STATISTICS

\begin{tabular}{|c|c|c|}
\hline $\begin{array}{l}\text { FIT } \\
\text { STATISTIC }\end{array}$ & STATISTIC LABEL & $\begin{array}{l}\text { STATISTIC } \\
\text { VALUE }\end{array}$ \\
\hline DFT $_{-}$ & Total Degrees of Freedom. & 219 \\
\hline DFE_ & Degrees of Freedom for Error. & 171 \\
\hline _DFM_ & Model Degrees of Freedom. & 48 \\
\hline $\mathrm{NW}_{-}$ & Number of Estimated Weights. & 48 \\
\hline $\mathrm{AIC}_{-}$ & Akaike's Information Criterion. & 320.465 \\
\hline${ }_{-} \mathrm{SBC}_{-}$ & Schwarz's Bayesian Criterion. & 483.14 \\
\hline _ASE_ & Average Squared Error. & 0.175 \\
\hline _MAX_ & Maximum Absolute Error. & 0.805 \\
\hline $\mathrm{DIV}_{-}$ & Divisor for ASE. & 438 \\
\hline NOBS_ & Sum of Frequencies. & 219 \\
\hline RASE_ & Root Average Squared Error. & 0.418 \\
\hline _SSE_ & Sum of Squared Errors. & 76.519 \\
\hline SUMW_ & Sum of Case Weights Times Freq. & 438 \\
\hline FPE_ & Final Prediction Error. & 0.273 \\
\hline _MSE_ & Mean Squared Error. & 0.224 \\
\hline _RFPE_ & Root Final Prediction Error. & 0.522 \\
\hline _RMSE_ & Root Mean Squared Error. & 0.473 \\
\hline AVERR & Average Error Function. & 0.512 \\
\hline
\end{tabular}




\begin{tabular}{|c|c|c|c|c|c|}
\hline ERR_ & \multicolumn{2}{|l|}{ Error Function. } & \multicolumn{3}{|c|}{224.465} \\
\hline${ }_{-} \mathrm{MISC}_{-}$ & \multicolumn{2}{|l|}{ Misclassification Rate. } & \multicolumn{2}{|c|}{0.292} & \\
\hline WRONG & \multicolumn{2}{|c|}{ Number of Wrong Classifications. } & \multicolumn{2}{|c|}{64} & \\
\hline \multicolumn{6}{|c|}{ CLASSIFICATION SUMMARY } \\
\hline TARGET & PREDICT & $\begin{array}{l}\text { PERCENT } \\
\text { OF } \\
\text { TARGET }\end{array}$ & $\begin{array}{l}\text { PERCENT } \\
\text { OF } \\
\text { PREDICT }\end{array}$ & COUNT & $\begin{array}{l}\text { PERCENT } \\
\text { OF } \\
\text { TOTAL }\end{array}$ \\
\hline BANKRUPT & BANKRUPT & 72 & 66.6667 & 72 & 32.8767 \\
\hline NONBANKRUPT & BANKRUPT & 28 & 25.2252 & 28 & 12.7854 \\
\hline BANKRUPT & NONBANKRUPT & 30.2521 & 33.3333 & 36 & 16.4384 \\
\hline NONBANKRUPT & NONBANKRUPT & 69.7479 & 74.7748 & 83 & 37.8995 \\
\hline
\end{tabular}

YEAR 4

VARIABLE SUMMARY

\begin{tabular}{lll}
\hline ROLE & LEVEL & COUNT \\
\hline INPUT & INTERVAL & 6 \\
TARGET & TARGET & 1 \\
\hline
\end{tabular}

FIT STATISTICS

\begin{tabular}{|c|c|c|}
\hline $\begin{array}{l}\text { FIT } \\
\text { STATISTIC }\end{array}$ & STATISTIC LABEL & $\begin{array}{l}\text { STATISTIC } \\
\text { VALUE }\end{array}$ \\
\hline DFT_ $_{-}$ & Total Degrees of Freedom. & 195 \\
\hline _DFE_ & Degrees of Freedom for Error. & 147 \\
\hline _DFM_ & Model Degrees of Freedom. & 48 \\
\hline $\mathrm{NW}_{-}$ & Number of Estimated Weights. & 48 \\
\hline $\mathrm{AIC}_{-}$ & Akaike's Information Criterion. & 290.569 \\
\hline${ }_{-} \mathrm{SBC}$ & Schwarz's Bayesian Criterion. & 447.673 \\
\hline _ASE_ & Average Squared Error. & 0.161 \\
\hline _MAX_ & Maximum Absolute Error. & 0.905 \\
\hline _DIV_ & Divisor for ASE. & 390 \\
\hline _NOBS_ & Sum of Frequencies. & 195 \\
\hline _RASE_ & Root Average Squared Error. & 0.401 \\
\hline _SSE_ & Sum of Squared Errors. & 62.726 \\
\hline SUMW_ & Sum of Case Weights Times Freq. & 390 \\
\hline FPE_ & Final Prediction Error. & 0.266 \\
\hline _MSE_ & Mean Squared Error. & 0.213 \\
\hline _RFPE_ & Root Final Prediction Error. & 0.516 \\
\hline RMSE & Root Mean Squared Error. & 0.462 \\
\hline
\end{tabular}




\begin{tabular}{llcl}
\hline _AVERR__ & Average Error Function. & 0.499 & \\
${ }_{\text {ERR__ }}$ & Error Function. & 194.569 & \\
${ }_{\text {MISC__ }}$ & Misclassification Rate. & 0.205 & \\
_WRONG__ & Number of Wrong Classifications. & & 40 \\
\hline
\end{tabular}

CLASSIFICATION SUMMARY

\begin{tabular}{llcccc}
\hline & & PERCENT & PERCENT & & PERCENT \\
& & OF & OF \\
TARGET & PREDICT & TARGET & PREDICT & COUNT & TOTAL \\
\hline BANKRUPT & BANKRUPT & 80 & 70.5882 & 60 & 30.7692 \\
NONBANKRUPT & BANKRUPT & 20 & 13.6364 & 15 & 7.6923 \\
BANKRUPT & NONBANKRUPT & 20.8333 & 29.4118 & 25 & 12.8205 \\
NONBANKRUPT & NONBANKRUPT & 79.1667 & 86.3636 & 95 & 48.7179 \\
\hline
\end{tabular}

YEAR 5

VARIABLE SUMMARY

\begin{tabular}{lll}
\hline ROLE & LEVEL & COUNT \\
\hline INPUT & INTERVAL & 6 \\
TARGET & TARGET & 1 \\
\hline
\end{tabular}

FIT STATISTICS

\begin{tabular}{|c|c|c|}
\hline $\begin{array}{l}\text { FIT } \\
\text { STATISTIC }\end{array}$ & STATISTIC LABEL & $\begin{array}{l}\text { STATISTIC } \\
\text { VALUE }\end{array}$ \\
\hline DFT_ $_{-}$ & Total Degrees of Freedom. & 168 \\
\hline _DFE_ & Degrees of Freedom for Error. & 120 \\
\hline _DFM_ & Model Degrees of Freedom. & 48 \\
\hline $\mathrm{NW}_{-}$ & Number of Estimated Weights. & 48 \\
\hline AIC_ & Akaike's Information Criterion. & 228.562 \\
\hline SBC_ & Schwarz's Bayesian Criterion. & 378.513 \\
\hline $\mathrm{ASE}_{-}$ & Average Squared Error. & 0.123 \\
\hline -MAX_ & Maximum Absolute Error. & 0.952 \\
\hline DIV & Divisor for ASE. & 336 \\
\hline NOBS & Sum of Frequencies. & 168 \\
\hline RASE_ & Root Average Squared Error. & 0.351 \\
\hline _SSE_ & Sum of Squared Errors. & 41.454 \\
\hline SUMW_ & Sum of Case Weights Times Freq. & 336 \\
\hline _FPE_ & Final Prediction Error. & 0.222 \\
\hline MSE & Mean Squared Error. & 0.173 \\
\hline
\end{tabular}




\begin{tabular}{llc}
\hline _RFPE_ & Root Final Prediction Error. & 0.471 \\
${ }_{\text {RMSE_}}$ & Root Mean Squared Error. & 0.416 \\
${ }_{\text {_AVERR_ }}$ & Average Error Function. & 0.395 \\
${ }_{\text {ERR_- }}$ & Error Function. & 132.562 \\
_MISC_ & Misclassification Rate. & 0.167 \\
_WRONG_ & Number of Wrong Classifications. & 28 \\
\hline
\end{tabular}

CLASSIFICATION SUMMARY

\begin{tabular}{llcccc}
\hline & & PERCENT & PERCENT & & \multicolumn{2}{l}{$\begin{array}{l}\text { PERCENT } \\
\text { OF }\end{array}$} \\
TARGET & PREDICT & TARGET & $\begin{array}{l}\text { OF } \\
\text { PREDICT }\end{array}$ & COUNT & TOTAL \\
\hline BANKRUPT & BANKRUPT & 87.5 & 70 & 49 & 29.1667 \\
NONBANKRUPT & BANKRUPT & 12.5 & 7.1429 & 7 & 4.1667 \\
BANKRUPT & NONBANKRUPT & 18.75 & 30 & 21 & 12.5 \\
NONBANKRUPT & NONBANKRUPT & 81.25 & 92.8571 & 91 & 54.1667 \\
\hline
\end{tabular}


Table 13

MLP analysis results for Out of sample validation :Market variables

\begin{tabular}{ccc}
\multicolumn{3}{c}{ VARIABLE SUMMARY } \\
\hline ROLE & LEVEL & COUNT \\
\hline INPUT & INTERVAL & 6 \\
TARGET & TARGET & 1 \\
\hline
\end{tabular}

FIT STATISTICS

\begin{tabular}{|c|c|c|}
\hline $\begin{array}{l}\text { FIT } \\
\text { STATISTIC }\end{array}$ & STATISTIC LABEL & STATISTIC VALUE \\
\hline DFT $_{-}$ & Total Degrees of Freedom. & 824 \\
\hline _DFE_ & Degrees of Freedom for Error. & 781 \\
\hline DFM_ & Model Degrees of Freedom. & 43 \\
\hline $\mathrm{NW}_{-}$ & Number of Estimated Weights. & 43 \\
\hline $\mathrm{AIC}_{-}$ & Akaike's Information Criterion. & 822.02 \\
\hline${ }_{-} \mathrm{SBC}$ & Schwarz's Bayesian Criterion. & 1024.73 \\
\hline _ASE_ & Average Squared Error. & 0.14 \\
\hline MAX_ & Maximum Absolute Error. & 0.96 \\
\hline DIV $_{-}$ & Divisor for ASE. & 1648 \\
\hline NOBS_ & Sum of Frequencies. & 824 \\
\hline _RASE_ & Root Average Squared Error. & 0.38 \\
\hline SSE_ & Sum of Squared Errors. & 236.61 \\
\hline _SUMW_ & Sum of Case Weights Times Freq. & 1648 \\
\hline FPE_ & Final Prediction Error. & 0.16 \\
\hline MSE_ & Mean Squared Error. & 0.15 \\
\hline _RFPE_ & Root Final Prediction Error. & 0.4 \\
\hline _RMSE_ & Root Mean Squared Error. & 0.39 \\
\hline _AVERR_ & Average Error Function. & 0.45 \\
\hline ERR_ & Error Function. & 736.02 \\
\hline${ }_{-} \mathrm{MISC}_{-}$ & Misclassification Rate. & 0.2 \\
\hline WRONG & Number of Wrong Classifications. & 164 \\
\hline
\end{tabular}


CLASSIFICATION SUMMARY (YEAR 2 TO 5)

\begin{tabular}{llcccc}
\hline & & $\begin{array}{l}\text { PERCENT } \\
\text { OF }\end{array}$ & $\begin{array}{l}\text { PERCENT } \\
\text { OF }\end{array}$ & & $\begin{array}{l}\text { PERCENT } \\
\text { OF } \\
\text { TARGET }\end{array}$ \\
\hline BANKRUPT & PREDICT & TARGET & PREDICT & COUNT & TOTAL \\
NONBANKRUPT & BANKRUPT & 79.0816 & 79.0816 & 310 & 37.6214 \\
BANKRUPT & NONBANKRUPT & 18.9184 & 18.9815 & 82 & 9.9515 \\
NONBANKRUPT & NONBANKRUPT & 81.0185 & 20.9184 & 82 & 9.9515 \\
\hline
\end{tabular}

CLASSIFICATION SUMMARY FOR TEST DATA (YEAR 1)

\begin{tabular}{rrrr}
\hline \multirow{2}{*}{ Actual } & \multicolumn{2}{c}{ Predicted } & \multirow{2}{*}{ Total } \\
\cline { 2 - 3 } & Bankrupt & Nonbankrupt & \\
\hline Bankrupt & 96 & 42 & 138 \\
& 69.57 & 30.43 & \\
Nonbankrupt & 20 & 97 & 117 \\
& 17.09 & 82.91 & \\
\hline Total & 116 & 139 & 2 \\
\hline
\end{tabular}


MLP analysis results for Out of sample validation : Variables (Price, Standard deviation, bid ask spread, net income to sales, working capital to total assets and current liabilities to total assets )

\begin{tabular}{ccc}
\multicolumn{3}{c}{ VARIABLE SUMMARY } \\
\hline ROLE & LEVEL & COUNT \\
\hline INPUT & INTERVAL & 6 \\
TARGET & TARGET & 1 \\
\hline
\end{tabular}

FIT STATISTICS

\begin{tabular}{|c|c|c|}
\hline $\begin{array}{l}\text { FIT } \\
\text { STATISTIC }\end{array}$ & STATISTIC LABEL & $\begin{array}{l}\text { STATISTIC } \\
\text { VALUE }\end{array}$ \\
\hline DFT $_{-}$ & Total Degrees of Freedom. & 824 \\
\hline DFE_ & Degrees of Freedom for Error. & 775 \\
\hline _DFM_ & Model Degrees of Freedom. & 49 \\
\hline $\mathrm{NW}_{-}$ & Number of Estimated Weights. & 49 \\
\hline $\mathrm{AIC}_{-}$ & Akaike's Information Criterion. & 818.71 \\
\hline _SBC_ $_{-}$ & Schwarz's Bayesian Criterion. & 1049.7 \\
\hline _ASE_ & Average Squared Error. & 0.14 \\
\hline MAX_ & Maximum Absolute Error. & 0.96 \\
\hline DIV $_{-}$ & Divisor for ASE. & 1648 \\
\hline NOBS_ & Sum of Frequencies. & 824 \\
\hline _RASE_ & Root Average Squared Error. & 0.37 \\
\hline _SSE_ & Sum of Squared Errors. & 230.42 \\
\hline SUMW_ & Sum of Case Weights Times Freq. & 1648 \\
\hline _FPE_ & Final Prediction Error. & 0.16 \\
\hline _MSE_ & Mean Squared Error. & 0.15 \\
\hline _RFPE_ & Root Final Prediction Error. & 0.4 \\
\hline _RMSE_ & Root Mean Squared Error. & 0.39 \\
\hline _AVERR_ & Average Error Function. & 0.44 \\
\hline _ERR_ & Error Function. & 720.71 \\
\hline _MISC_ & Misclassification Rate. & 0.18 \\
\hline WRONG & Number of Wrong Classifications. & 151 \\
\hline
\end{tabular}




\section{CLASSIFICATION SUMMARY (YEAR 2 TO 5)}

\begin{tabular}{|c|c|c|c|c|c|}
\hline TARGET & PREDICT & $\begin{array}{l}\text { PERCENT } \\
\text { OF } \\
\text { TARGET }\end{array}$ & $\begin{array}{l}\text { PERCENT } \\
\text { OF } \\
\text { PREDICT }\end{array}$ & COUNT & $\begin{array}{l}\text { PERCENT } \\
\text { OF } \\
\text { TOTAL }\end{array}$ \\
\hline BANKRUPT & BANKRUPT & 81.6273 & 79.3367 & 311 & 37.7427 \\
\hline NONBANKRUPT & BANKRUPT & 18.3727 & 16.2037 & 70 & 8.4951 \\
\hline BANKRUPT & NONBANKRUPT & 18.2844 & 20.6633 & 81 & 9.8301 \\
\hline NONBANKRUPT & NONBANKRUPT & 81.7156 & 83.7963 & 362 & 43.932 \\
\hline
\end{tabular}

CLASSIFICATION SUMMARY FOR TEST DATA (YEAR 1)

\begin{tabular}{rrrr}
\hline \multirow{2}{*}{ Actual } & \multicolumn{2}{c}{ Predicted } & \multirow{2}{*}{ Total } \\
\cline { 2 - 3 } & Bankrupt & Nonbankrupt & \\
\hline Bankrupt & 94 & 44 & 138 \\
& 68.12 & 31.88 & \\
\hline Nonbankrupt & 20 & 97 & 117 \\
& 17.09 & 82.91 & \\
\hline Total & 114 & 141 & 255 \\
\hline
\end{tabular}




\subsection{Summary and Conclusions}

Traditional models have been extensively used in bankruptcy prediction for over four decades. However, over time, the underlying assumptions of these models have been called into question; many papers in the literature have shown that the distributional assumptions, along with other assumptions, are often violated. This has led to the use of more complex models, namely neural networks.

This has been a fruitful area of research, both because of the importance of early detection of financial distress and the improvement of technology. There is always a trade-off when deciding on using more complex models: practical efficiency versus precision. However, over time the complexity in using these models has subdued.

We test the predictive ability of two neural network models (multi-layer perceptron and radial basis function) on accounting ratios, market variables, and different

mixes of both. While market variables alone have high predictive power, we find that the best predictions in terms of both classifying bankrupt firms and overall precision are made with a mix of market variables and accounting ratios. The market variables included in this subset are price, standard deviation of price, and bid-ask spread, and the accounting ratios are net income to sales, working capital to total assets, and current liabilities to total assets. 


\section{CHAPTER 5: EVALUATION, COMPARISON OF MODELS, AND CONCLUSION}

\subsection{Evaluation and comparison of models}

Since the goal of this dissertation is to evaluate the predictive ability of different bankruptcy prediction models using different variables, in this chapter we compare the out-of-sample performance of different models, using different sets of variables. We focus on the set of market variables versus the mixed set of market variables and accounting ratios, which are price, standard deviation, bid-ask spread, net income to sales, working capital to total assets, and current liabilities to total assets.

The univariate analysis demonstrates that the best discriminating market variables are the price, standard deviation, and bid-ask spread, while the bid-ask spread is the best at discriminating in the long term. The cash flow ratios display misclassification rates of 20 to $30 \%$, and the net income ratios have misclassification rates of 20 to $40 \%$.

Specifically, net income to sales ratio shows $25-33 \%$ misclassification rates.

Using the discriminant analysis, the market variables misclassify $29 \%$ of bankrupt firms and $17 \%$ of nonbankrupt firms. The set, price, standard deviation, bid-ask spread, net income to sales, working capital to total assets, and current liabilities to total assets, misclassify $38 \%$ of the bankrupt firms and $15 \%$ of nonbankrupt firms.

Employing neural networks, namely the multi-layer perceptron, market variables correctly classify $70 \%$ of bankrupt firms and $83 \%$ of nonbankrupt firms. The set of six market variables and accounting ratios correctly classify $68 \%$ of bankrupt firms and $83 \%$ of nonbankrupt firms. 


\subsection{Conclusion}

This dissertation is a comprehensive study of bankruptcy prediction. Traditional approaches such as univariate analysis multivariate discriminant analysis are employed. From the univariate analysis in Chapter 2, market variables, such as price, standard deviation of return, and bid-ask spread, and certain accounting ratios, namely net income to sales, working capital to total assets, and current liabilities to total assets, show the highest ability to distinguish between bankrupt and nonbankrupt firms in a dichotomous classification test. However, since financial distress is a complex process, individual ratios and variables do not tell the whole story.

Multivariate discriminant analysis is employed in chapter 3. After testing for univariate and multivariate normality and finding that the variables and sets of variables are nonnormal, three different forms of discriminant analysis are used: linear, quadratic, and nonparametric analysis. Different combinations of variables and ratios are used in each discriminant analysis: all accounting ratios, all market variables, and different combinations of both. While market variables alone perform well, the combinations perform better at discriminating between bankrupt and nonbankrupt firms. The most important findings are that the nonparametric discriminant analysis is the most accurate and the most accurate set of variables consists of price, standard deviation of return, bidask spread, net income to sales, working capital to total assets, and current liabilities to total assets. This is important because the nonparametric discriminant analysis has not been heavily used in the literature, yet it is the most appropriate since the assumptions are often violated. Furthermore, the use of a combination of accounting ratios and market and 
microstructure variables shows the need for forward-looking variables in bankruptcy prediction. These findings indicate the need for more complex techniques.

Chapter 4 utilizes neural networks for bankruptcy prediction. Multi-layer perceptron and radial basis function are the two forms of neural networks employed. The use of neural networks has grown in the literature and it is more useful now that the technology needed is available. Multi-layer perceptron is the most accurate technique according to the results, which is consistent with non-linearly related data, and the combination of accounting ratios and market and microstructure variables is found to be the most accurate predictor. The misclassification rates, and more importantly, the ability of the model to correctly classify bankrupt firms, are higher than found using univariate analysis and multivariate discriminant analysis. 


\section{REFERENCES}

Altman, E. 1968. Financial ratios, discriminant analysis and the prediction of corporate bankruptcy. Journal of Finance 23: 589-609.

Aziz, A, Emanuel, D., and Lawson, G. 1988. Bankruptcy prediction - An investigation of cash flow based models. Journal of Management Studies 25: 5.

Beaver, W. 1966. Financial ratios as predictors of failure. Empirical Research in Accounting: Selected Studies, Supplement to Journal of Accounting Research 4.

Beaver, W. 1968. The information content of annual earnings announcements. Journal of Accounting Research 6: 67-92.

Blum, M. Failing company discriminant analysis. Journal of Accounting Research 12: 125.

Booth, P. 1983. Decomposition measures and the prediction of financial failure. Journal of Business Finance \& Accounting 10: 67-82.

Boritz, J. and Kennedy, D. 1995. Effectiveness of neural network types for prediction of business failure.

Brockman, P. and Turtle, H.J. 2003. A barrier option framework for corporate security valuation. Journal of Financial Economics 67: 511-529.

Casey, C.J. and Bartczak, N.J. 1984. Cash flow - it's not the bottom line. Harvard Business Review July-August: 61-66.

Coats, P. 1993. Recognizing financial distress patterns using a neural network tool. Financial Management 22: 142-155.

Deakin, E. 1972. A discriminant analysis of predictors of business failure. Journal of Accounting Research 10: 167-179.

Dimitras, A.I., Slowinski, R., Susmaga, R., and Zopounidis, C. 1999. Business failure prediction using rough sets. European Journal of Operational Research 114: 263-280.

Eisenbeis, R. 1977. Pitfalls in the application of discriminant analysis in business, finance, and economics. Journal of Finance 32: 875-900.

El Hennawy, R.H.A. and Morris, R.C. 1983. The significance of base year in developing failure prediction models. Journal of Business Finance and Accounting 10: 209-223. 
Frino, A., Jones, S., and Wong, J. 2007. Market Behaviour around Bankruptcy Announcements: Evidence from the Australian Stock Exchange. Account \& Finance 47: 713-730.

Frydman, H., Altman, E., and Kao, D. 1985. Introducing recursive partitioning for financial classification: the case of financial distress. The Journal of Finance 50: 269-291.

Gombola, M.J., Haskins, M.E., Ketz, J.E., and Williams, D.D. 1987. Cash flow in bankruptcy prediction. Financial Management Winter: 55-65.

Gonedes, NJ. 1973. Properties of Accounting Numbers: Models and Tests. Journal of Accounting Research 11:212-237.

Jardin, P. 2010. Predicting bankruptcy using neural networks and other classification methods: The influence of variable selection techniques on model accuracy. Neurocomputing 73: 2047-2060.

Jo, H., Han, I., and Lee, H. 1997. Bankruptcy prediction using case-based reasoning, neural networks, and discriminant analysis. Expert Systems with Applications 13: 97108.

Ketz, F. 1978. The effect of general price-level adjustments on the predictive ability of financial ratios. Journal of Accounting Research 16: 273-284.

Kothari, S.P. 2001. Capital markets research in accounting. Journal of Accounting and Economics 31: 105-231.

Leshno, M. and Spector, Y. 1996. Neural-network prediction analysis - the bankruptcy case. Neurocomputing 10: 125-147.

Lin, L. and Piesse, J. 2001. The identification of corporate distress: a conditional probability analysis approach. Documents, Department of Management, Birbeck, University of London, London.

McGurr, P.T. and DeVaney, S.A. 1998. Predicting business failure of retail firms: an analysis using mixed industry models. Journal of Business Research 43: 169-176.

Moyer, R.C. 1977. Forecasting financial failure: a re-examination. Financial Management Spring: 11-17.

Neophytou, R.C., Charitou, A., and Cahralambous, C. 2001. Predicting corporate failure: empirical evidence in the U.K. Discussion Paper No. 01-73, March, School of Management, University of Southampton, Southampton. 
Norton, C. and Smith, R. 1979. A comparison of general price level and historical cost financial statements in the prediction of bankruptcy. The Accounting Review 54: 72-87.

Ohlson, J. 1980. Financial ratios and the probabilistic prediction of bankruptcy. Journal of Accounting Research 18: 109-131.

Prakash, A \& Karels, G. 1987. Multivariate Normality and Forecasting of Business Bankruptcy. Journal of Business Finance \& Accounting 14: 573-593.

Salchenberger, L.M., Cinar, E.M., and Lash, N.A. 1992. Neural networks: a new tool for predicting thrift failures. Decision Sciences 23: 899-916.

Shumway, T. 2001. Forecasting bankruptcy more accurately: A simple hazard model. Journal of Business 74: 101-124.

Yang, Z. R., Platt, M. B., and Platt, H.D. 1999. Probabilistic neural networks in bankruptcy prediction. Journal of Business Research 44: 67-74.

Zavgren, C. 1983. The Prediction of Corporate Failure: The State of the Art. Journal of Accounting Literature 2: 1-38. 
VITA

GIOVANNI FERNANDEZ

August 18, 1985

Born, Miami Beach, Florida

2007

B.S., Finance

Florida International University

Miami, Florida

2007-2011

Graduate Teaching and

Research Assistant

Florida International University

Miami, Florida

\section{PUBLICATIONS AND PRESENTATIONS}

"Alpha: Empirical Evidence of Mutual Fund Performance under Different Economic Cycles and over Fund Objectives," Eastern Finance Association Meeting, Savannah, Georgia 2011. 